\title{
Costs of Storing and Transporting Hydrogen
}

Wade A. Amos

National Renewable Energy Laboratory

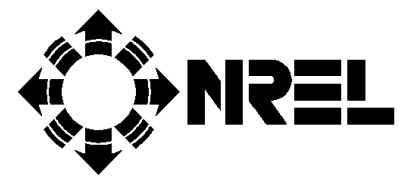

National Renewable Energy Laboratory 1617 Cole Boulevard

Golden, Colorado 80401-3393

A national laboratory of the U.S. Department of Energy Managed by Midwest Research Institute for the U.S. Department of Energy under contract No. DE-AC36-83CH10093 


\section{Costs of Storing and Transporting Hydrogen}

Wade A. Amos

National Renewable Energy Laboratory

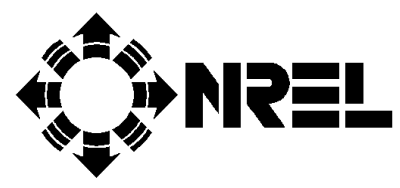

National Renewable Energy Laboratory 1617 Cole Boulevard

Golden, Colorado 80401-3393

A national laboratory of the U.S. Department of Energy Managed by Midwest Research Institute for the U.S. Department of Energy under contract No. DE-AC36-83CH10093

Prepared under Task No. HY914041

November 1998 


\section{NOTICE}

This report was prepared as an account of work sponsored by an agency of the United States government. Neither the United States government nor any agency thereof, nor any of their employees, makes any warranty, express or implied, or assumes any legal liability or responsibility for the accuracy, completeness, or usefulness of any information, apparatus, product, or process disclosed, or represents that its use would not infringe privately owned rights. Reference herein to any specific commercial product, process, or service by trade name, trademark, manufacturer, or otherwise does not necessarily constitute or imply its endorsement, recommendation, or favoring by the United States government or any agency thereof. The views and opinions of authors expressed herein do not necessarily state or reflect those of the United States government or any agency thereof.

Available to DOE and DOE contractors from:

Office of Scientific and Technical Information (OSTI)

P.O. Box 62

Oak Ridge, TN 37831

Prices available by calling 423-576-8401

Available to the public from:

National Technical Information Service (NTIS)

U.S. Department of Commerce

5285 Port Royal Road

Springfield, VA 22161

703-605-6000 or 800-553-6847

or

DOE Information Bridge

http://www.doe.gov/bridge/home.html 


\section{EXECUTIVE SUMMARY}

An analysis was performed to estimate the costs associated with storing and transporting hydrogen. These costs can be added to a hydrogen production cost to determine the total delivered cost of hydrogen.

Storage methods analyzed included compressed gas, liquid hydrogen, metal hydride, and underground storage. Major capital and operating costs were considered over a range of production rates and storage times. In all cases, underground storage was the cheapest method; liquid hydrogen has advantages over compressed gas for longer storage times.

For the transport of hydrogen, compressed gas, liquid hydrogen, metal hydride, and pipeline delivery were considered. Modes of transportation included truck and rail transport for the compressed gas and metal hydride. For liquid hydrogen, barge delivery was investigated as an option in addition to truck and rail. Transportation costs were estimated for a range of production rates and delivery distances. For large quantities of hydrogen, pipeline delivery was the cheapest option. For smaller quantities of hydrogen, liquid hydrogen had advantages over the other methods for longer delivery distances.

All cost assumptions and sample calculations are included in the report along with some background information on each storage method. The appendix contains sensitivity analyses and graphs showing important trends associated with hydrogen storage and transportation. 


\section{TABLE OF CONTENTS}

1.0 INTRODUCTION

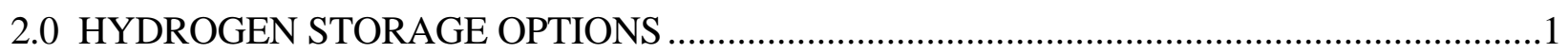

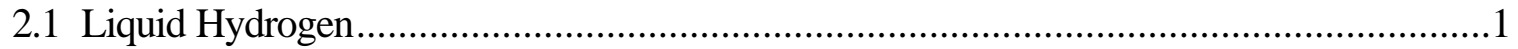

2.1.1 Liquefaction Processes...............................................................................

2.1.2 Ortho-to-Para Conversion ........................................................................6

2.1.3 Liquid Hydrogen Storage ........................................................................

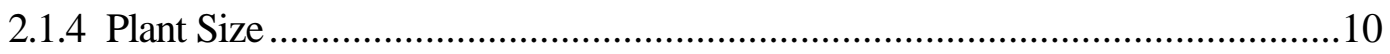

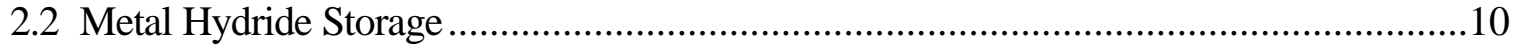

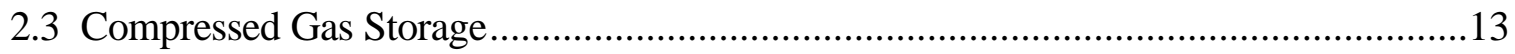

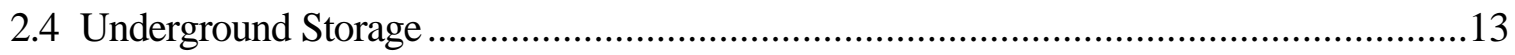

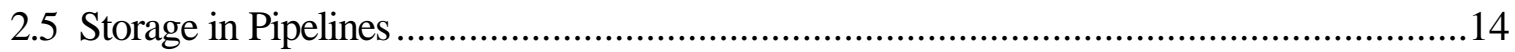

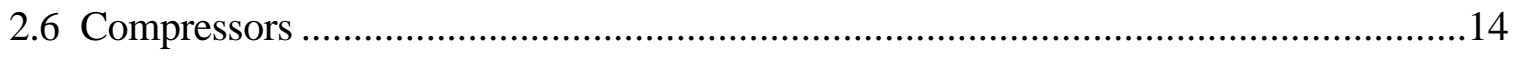

2.7 Expanders.............................................................................................................15

2.8 Developing Methods of Hydrogen Storage …………................................................15

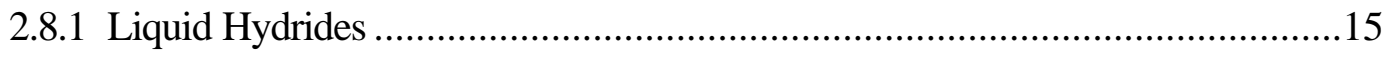

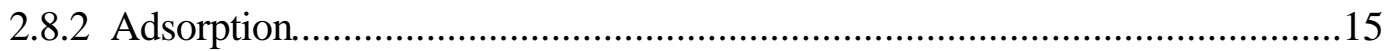

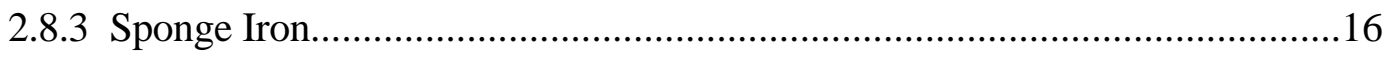

2.8.4 Glass Microspheres............................................................................16

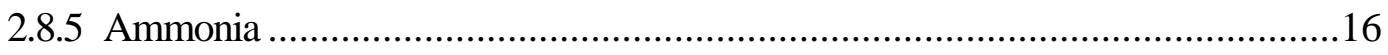

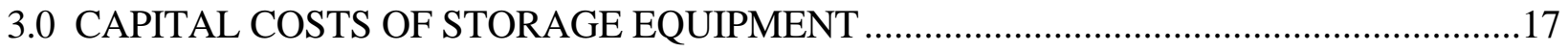

3.1 Compressor Capital Costs ....................................................................................17

3.2 Liquefaction Capital Costs......................................................................................17

3.3 Metal Hydride Capital Costs ....................................................................................18

3.4 Compressed Gas (Above-Ground) Capital Costs …………..........................................19

3.5 Liquid Hydrogen Vessel Capital Costs.........................................................................20

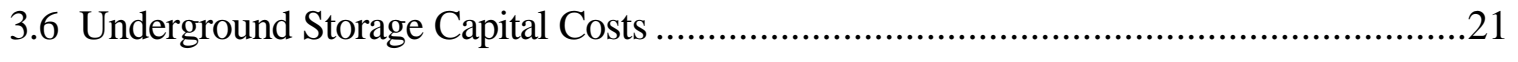

3.7 Pipeline Capital Costs ......................................................................................2

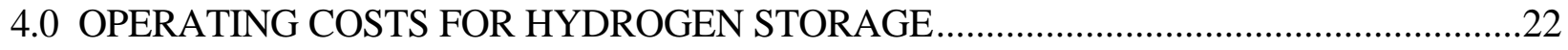

4.1 Compressed Gas Operating Costs..............................................................................22

4.2 Liquefaction Operating Costs ...............................................................................23

4.3 Metal Hydride Operating Costs.................................................................................24

4.4 Underground Compressed Gas Operating Costs...........................................................24

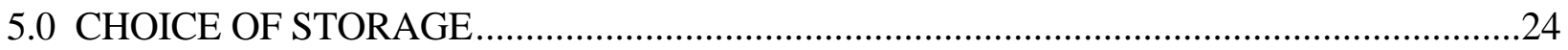

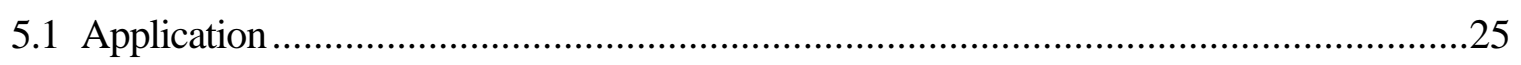

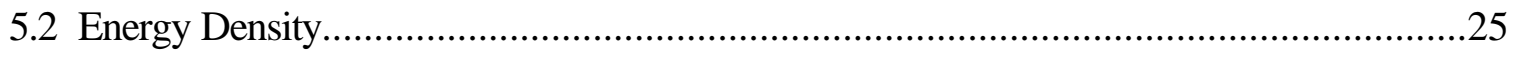

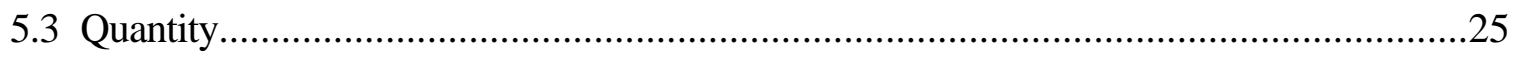

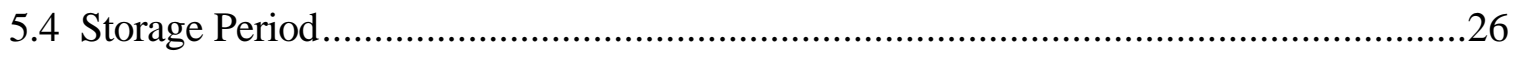


5.5 Energy Availability...............................................................................................2

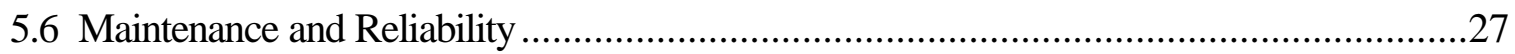

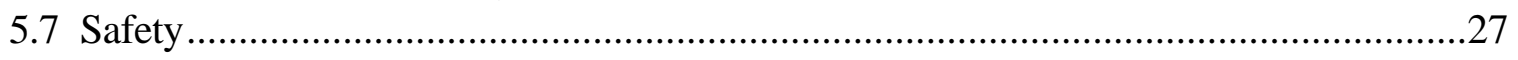

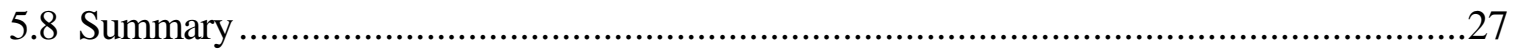

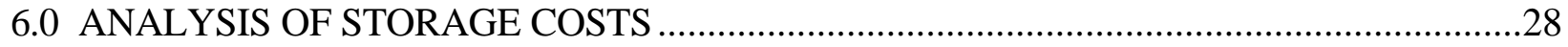

6.1 Cost Assumptions ..............................................................................................28

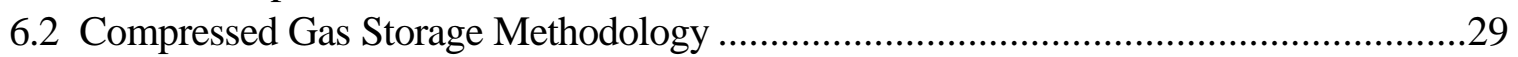

6.3 Liquid Hydrogen Storage Methodology ………………..................................................30

6.4 Metal Hydride Methodology .......................................................................................

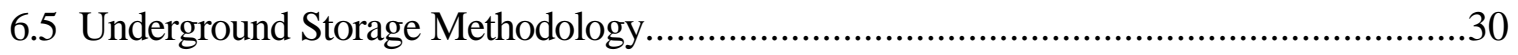

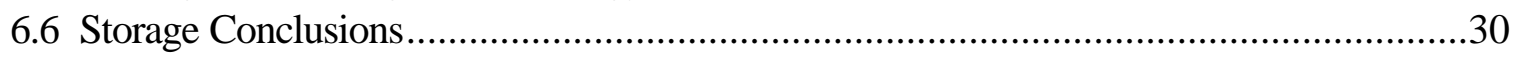

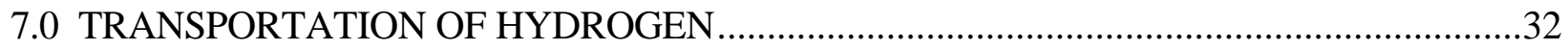

7.1 Compressed Gas Transport.........................................................................................

7.2 Liquid Hydrogen Transport ......................................................................................33

7.3 Metal Hydride Transport.........................................................................................

8.0 CAPITAL COSTS OF TRANSPORTATION EQUIPMENT ................................................34

8.1 Compressed Gas Transport Costs..............................................................................34

8.2 Compressed Gas Pipeline Costs................................................................................

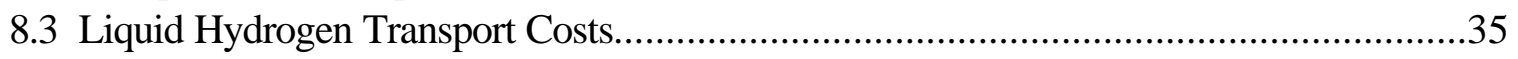

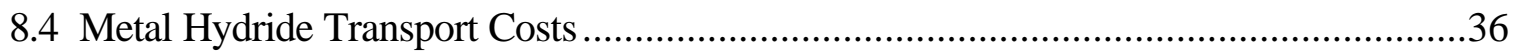

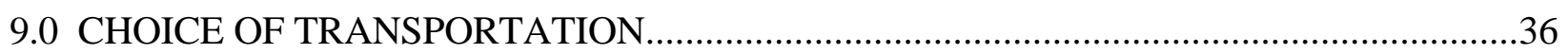

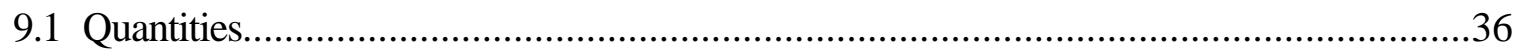

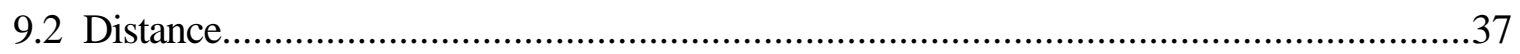

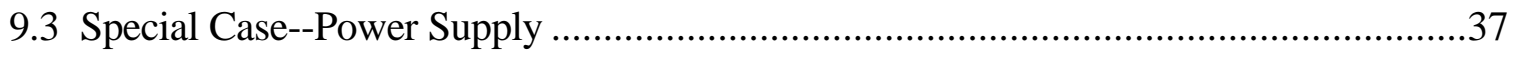

9.4 Futures in Hydrogen Transport ...............................................................................

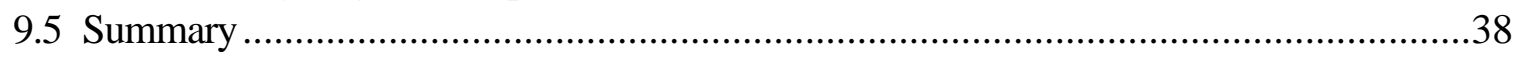

10.0 ANALYSIS OF THE COST TO TRANSPORT HYDROGEN …….....................................

10.1 Cost Assumptions for Hydrogen Transport ...................................................................39

10.2 Truck Transport Methodology ................................................................................

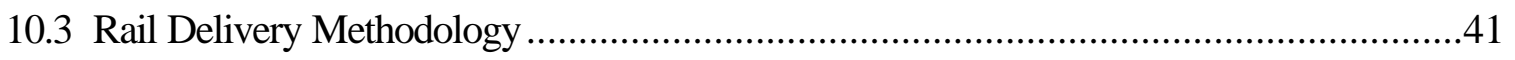

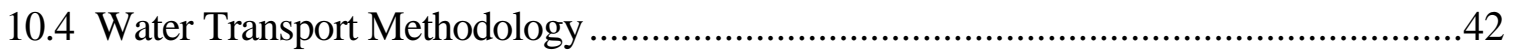

10.5 Pipeline Delivery Methodology ……….................................................................42

10.6 Transport Conclusions............................................................................................

11.0 COMBINED STORAGE AND TRANSPORTATION COSTS …….....................................44

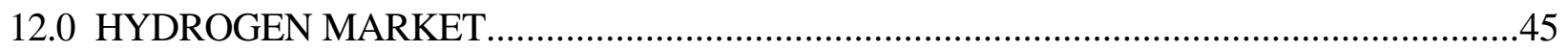

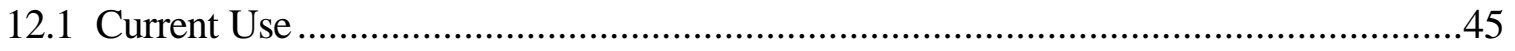


12.2 Projected Demand .46

12.3 Uses

12.4 Delivery Method 48

12.5 Current Prices.

REFERENCES AND PERTINENT LITERATURE .50

APPENDIX A - SAMPLE CALCULATIONS OF HYDROGEN STORAGE COSTS

APPENDIX B - SAMPLE CALCULATIONS OF HYDROGEN TRANSPORT COSTS

APPENDIX C - SAMPLE POWER REQUIREMENT CALCULATIONS

APPENDIX D - HYDROGEN STORAGE COSTS

APPENDIX E - HYDROGEN TRANSPORT COSTS

APPENDIX F - HYDROGEN STORAGE FIGURES

APPENDIX G - HYDROGEN TRANSPORTATION FIGURES

APPENDIX H - COMBINED STORAGE AND TRANSPORT COSTS 


\section{LIST OF FIGURES}

Figure 1 - Linde Liquefaction Process Flowsheet ...............................................................2

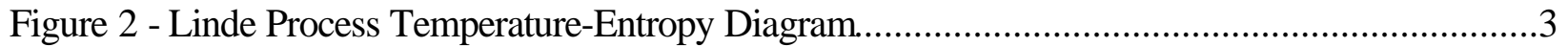

Figure 3 - Pre-Cooled Liquefaction Flowsheet..................................................................

Figure 4 - Pre-Cooled Liquefaction Temperature-Entropy Diagram............................................5

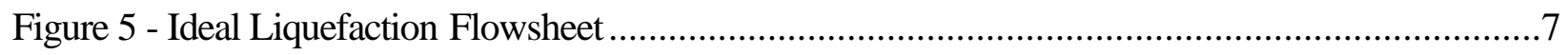

Figure 6 - Ideal Liquefaction Temperature-Entropy Diagram.....................................................8

Figure 7 - Metal Hydride Pressure Behavior ............................................................................... 12

Appendix F - Hydrogen Storage Figures

Appendix G - Hydrogen Transportation Figures

Appendix H - Combined Storage and Transportation Costs 


\section{LIST OF TABLES}

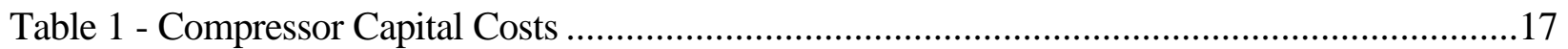

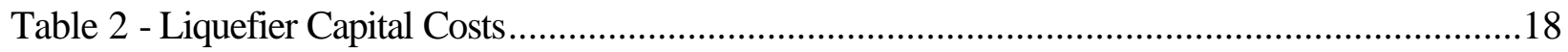

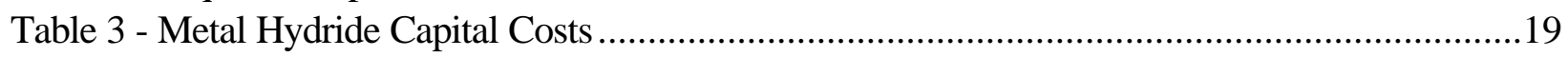

Table 4 - Compressed Hydrogen Pressure Vessel Capital Costs......................................................20

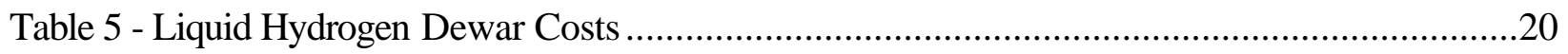

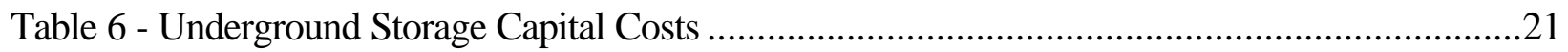

Table 7 - Compressed Gas Above-Ground Storage Total Costs.......................................................22

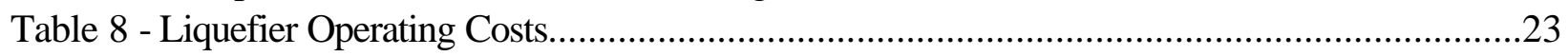

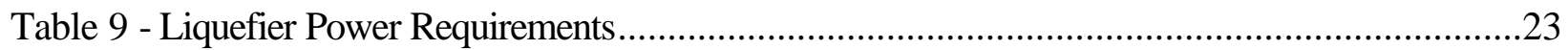

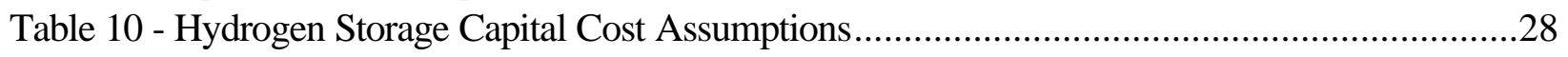

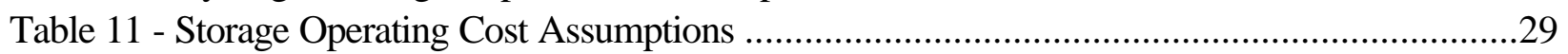

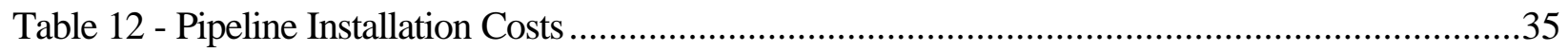

Table 13 - Hydrogen Transport Capital Cost Assumptions..............................................................39

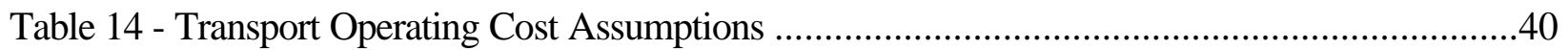

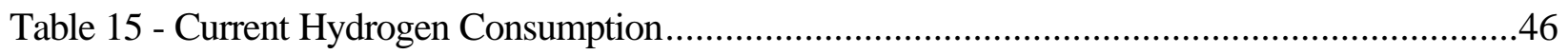

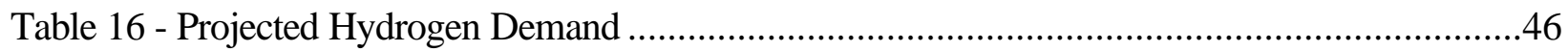

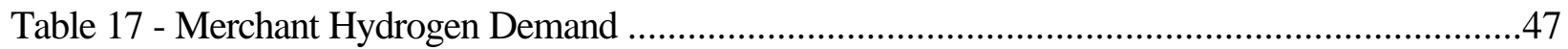

Table 18 - Projected Merchant Hydrogen Demand ...........................................................................4

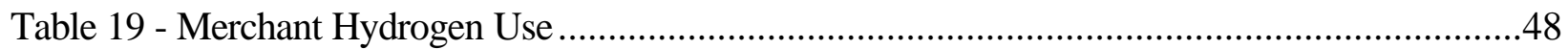

Table 20 - Industrial Hydrogen Use (Hart 1997)_..........................................................................4

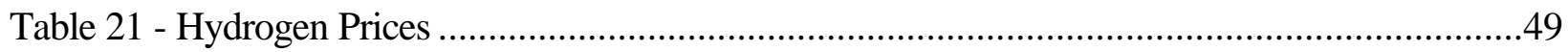

Appendix D - Hydrogen Storage Costs

Appendix E - Hydrogen Transport Costs 


\section{ABBREVIATIONS AND ACRONYMS}

$\begin{array}{llll}\mathrm{ADS} & \text { Alternative depreciation system } & \mathrm{m} & \text { Meter } \\ \mathrm{atm} & \text { Atmospheres (pressure) } & \mathrm{M} & \text { One thousand (1,000) } \\ \mathrm{Btu} & \text { British thermal unit } & \mathrm{MH}_{2} & \text { Metal hydride } \\ { }^{\circ} \mathrm{C} & \text { Degrees Celsius } & \mathrm{mi} & \text { Mile } \\ \mathrm{cal} & \text { Calorie } & \mathrm{MM} \text { Btu } & \text { One million Btu's } \\ \mathrm{d} & \text { Day } & \mathrm{mo} & \text { Month } \\ { }^{\circ} \mathrm{F} & \text { Degrees Fahrenheit } & \mathrm{MPa} & \text { Megapascal } \\ \mathrm{ft} & \text { Feet } & \mathrm{mpg} & \text { Miles per gallon } \\ \mathrm{gal} & \text { Gallon } & \mathrm{mph} & \text { Miles per hour } \\ \mathrm{GH} & & \mathrm{N} & \text { Newton } \\ \mathrm{GJ} & \text { Gaseous hydrogen } & \mathrm{Nm} & \text { Normal cubic meter } \\ \mathrm{gm} & \text { Gigajoule } & \mathrm{Pa} & \text { Pascal } \\ \mathrm{h} & \text { Hour } & \mathrm{psia} & \text { Pounds (force) per square inch } \\ \mathrm{H}{ }_{2} & \text { Hydrogen } & & \text { absolute pressure } \\ \mathrm{hp} & \text { Horsepower } & \mathrm{psig} & \text { Pounds (force) per square inch } \\ \mathrm{hr} & \text { Hour } & & \text { gauge pressure } \\ \mathrm{in} . & \text { Inch } & \mathrm{Q} & \text { Heat } \\ \mathrm{K} & \text { Degrees Kelvin } & \mathrm{s} & \text { Second } \\ \mathrm{kg} & \text { Kilogram } & \mathrm{scf} & \text { Standard cubic foot } \\ \mathrm{kJ} & \text { Kilojoule } & \mathrm{sec} & \text { Second } \\ \mathrm{km} & \text { Kilometer } & \text { ton } & \text { English ton (2,000 pounds) } \\ \mathrm{kW} & \text { Kilowatt } & \text { tonne } & \text { Metric ton (1,000 kilograms) } \\ \mathrm{kWh} & \text { Kilowatt-hour } & \text { tpd } & \text { Tons per day } \\ \mathrm{L} & \text { Liter } & \mathrm{Wc} & \text { Work (compression) } \\ \mathrm{lb} & \text { Pound } & \mathrm{We} & \text { Work (expansion) } \\ \mathrm{LH}{ }_{2} & \text { Liquid hydrogen } & \mathrm{yr} & \text { Year } \\ & & & \end{array}$




\subsection{INTRODUCTION}

The purpose of this report is to analyze the capital and operating costs associated with storing and transporting hydrogen. It mentions some future trends in hydrogen storage and transportation, but concentrates on current commercial processes. The storage techniques considered are liquid hydrogen, compressed gas, metal hydride, and underground storage. The modes of transportation examined are liquid hydrogen delivery by truck, rail, and barge; gaseous hydrogen delivery by truck, rail, and pipeline; and metal hydride delivery by truck and rail.

\subsection{HYDROGEN STORAGE OPTIONS}

The main options for storing hydrogen are as a compressed gas, as a liquid, or combined with a metal hydride. Underground storage is also considered, although it is just a special case of compressed gas storage. Each alternative has advantages and disadvantages. For example, liquid hydrogen has the highest storage density of any method, but it also requires an insulated storage container and an energyintensive liquefaction process.

\subsection{Liquid Hydrogen}

\subsubsection{Liquefaction Processes}

Liquefaction is done by cooling a gas to form a liquid. Liquefaction processes use a combination of compressors, heat exchangers, expansion engines, and throttle valves to achieve the desired cooling (Flynn 1992). The simplest liquefaction process is the Linde cycle or Joule-Thompson expansion cycle. In this process, the gas is compressed at ambient pressure, then cooled in a heat exchanger, before passing through a throttle valve where it undergoes an isenthalpic Joule-Thompson expansion, producing some liquid. This liquid is removed and the cool gas is returned to the compressor via the heat exchanger (Flynn 1992). A flowsheet of the Linde process is shown in Figure 1. The same process is represented on a temperature-entropy diagram in Figure 2.

The Linde cycle works for gases, such as nitrogen, that cool upon expansion at room temperature. Hydrogen, however, warms upon expansion at room temperature. In order for hydrogen gas to cool upon expansion, its temperature must be below its inversions temperature of $202 \mathrm{~K}\left(-95^{\circ} \mathrm{F}\right)$. To reach the inversion temperature, modern hydrogen liquefaction processes use liquid nitrogen pre-cooling to lower the temperature of the hydrogen gas to $78 \mathrm{~K}\left(-319^{\circ} \mathrm{F}\right)$ before the first expansion valve. The nitrogen gas is recovered and recycled in a continuous refrigeration loop (Flynn 1992; Timmerhaus and Flynn 1989). The pre-cooled Linde process is shown in Figure 3. Figure 4 is the associated temperature-entropy diagram for the process. 
Figure 1 - Linde Liquefaction Process Flowsheet

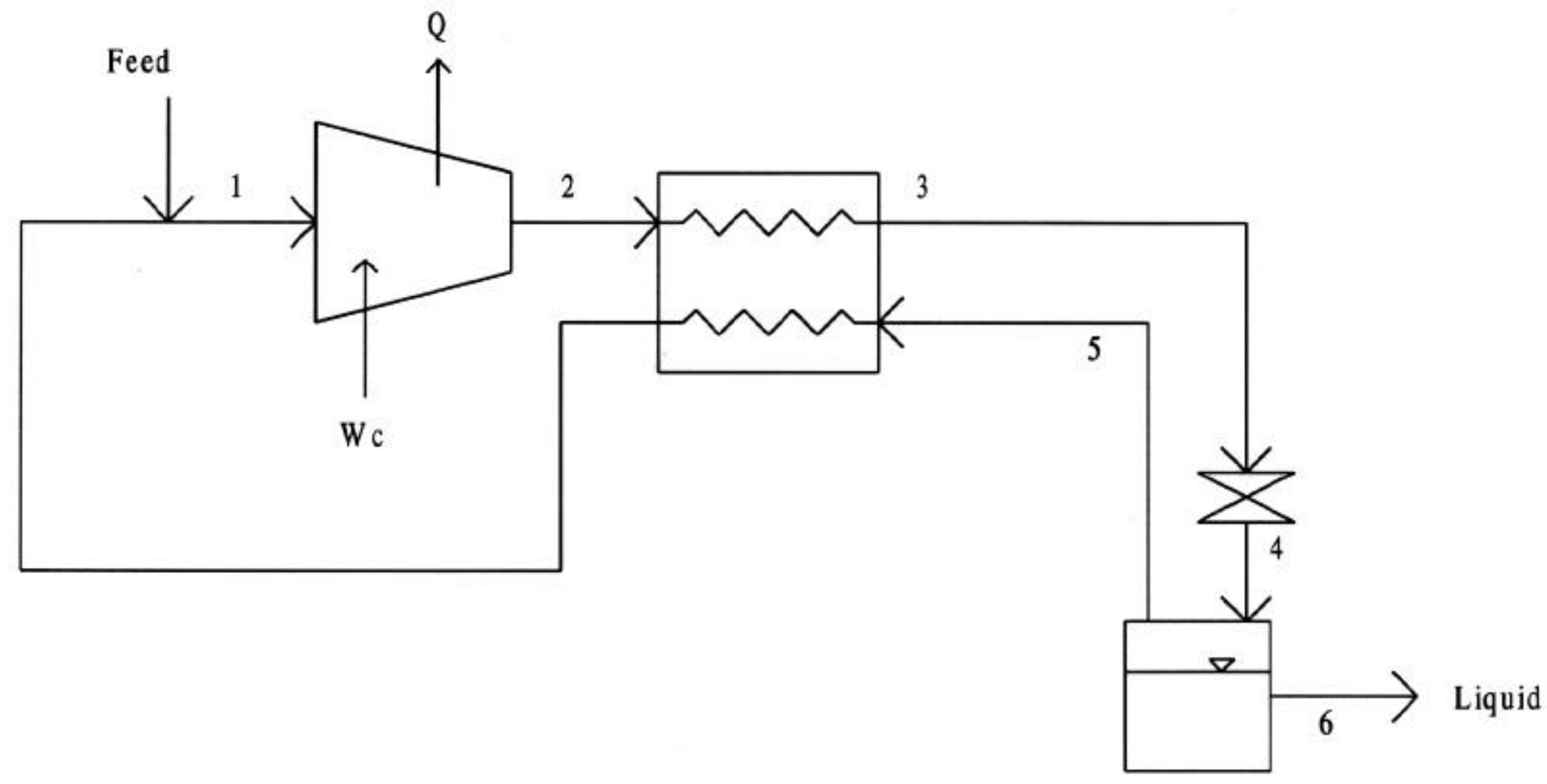


Figure 2 - Linde Process Temperature-Entropy Diagram

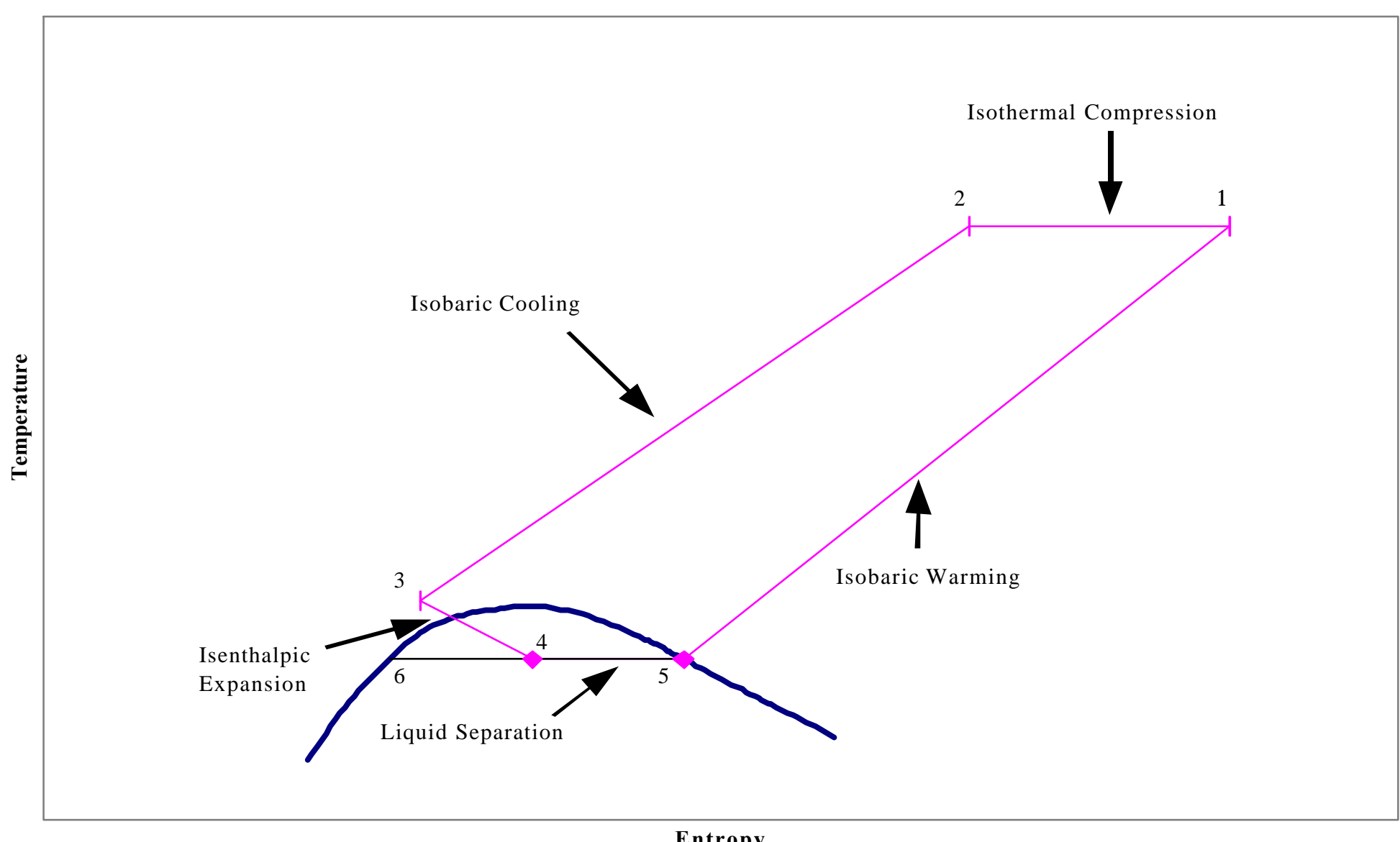

Entropy 
Figure 3 - Pre-Cooled Liquefaction Flowsheet

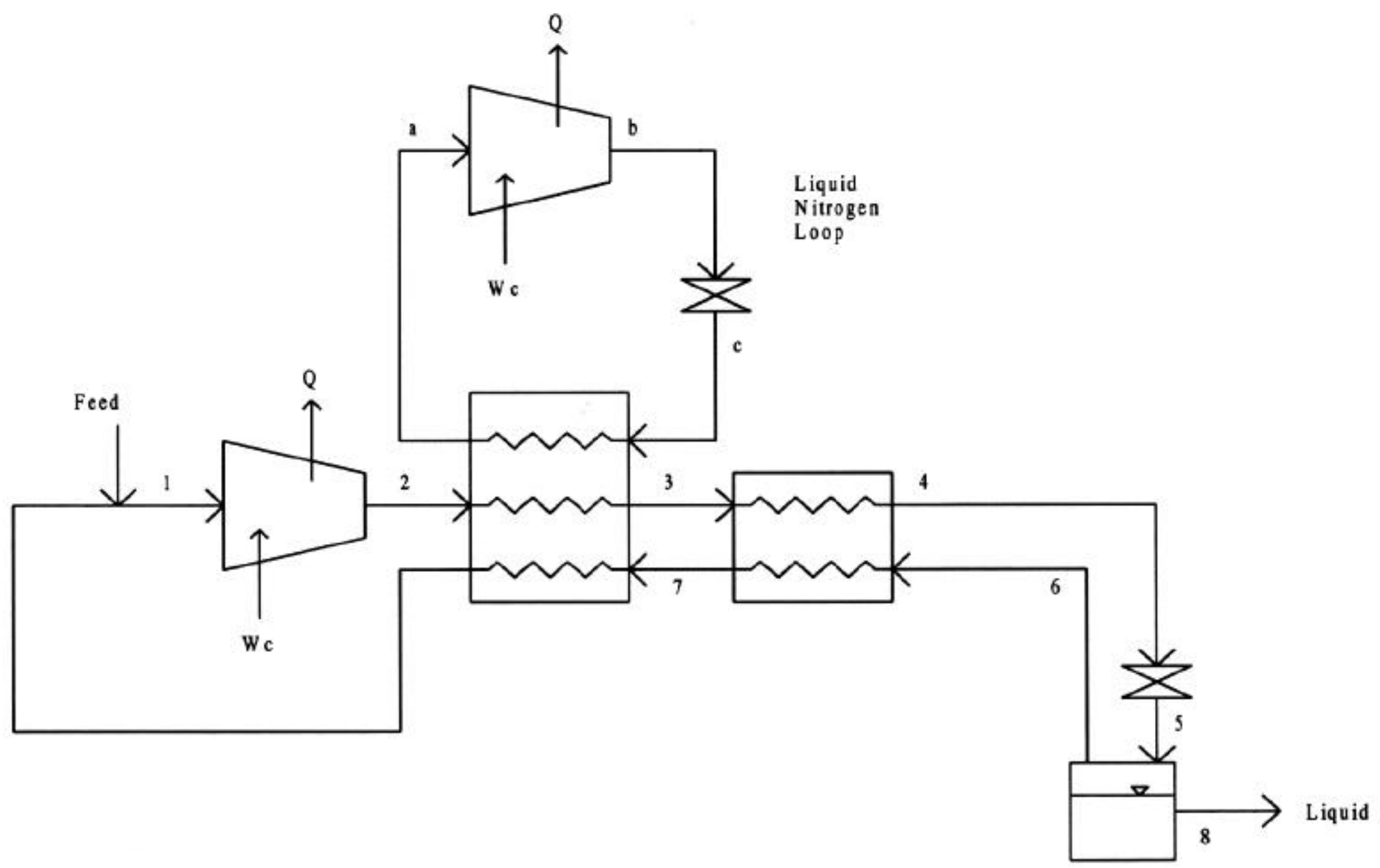


Figure 4 - Pre-Cooled Liquefaction Temperature-Entropy Diagram

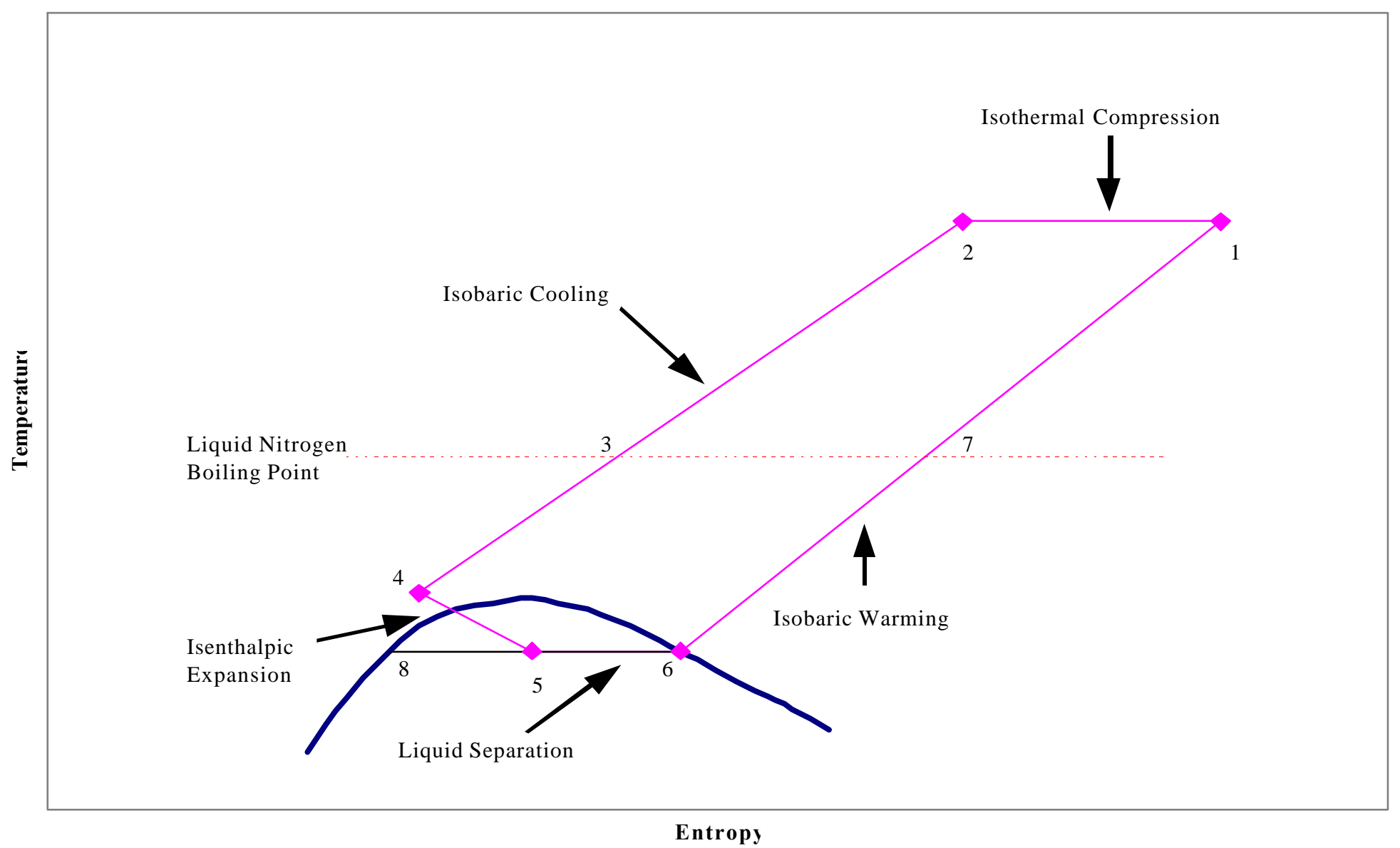


An alternative to the pre-cooled Linde process is to pass the high-pressure gas through an expansion engine. An expansion engine, or turbine, will always cool a gas, regardless of its inversion temperature (Flynn 1992). The theoretical process referred to as ideal liquefaction uses a reversible expansion to reduce the energy required for liquefaction. It consists of an isothermal compressor, followed by an isentropic expansion to cool the gas and produce a liquid. It is used as a theoretical basis for the amount of energy required for liquefaction, or ideal work of liquefaction, and is used to compare liquefaction processes (Timmerhaus and Flynn, 1989). In practice, an expansion engine can be used only to cool the gas stream, not to condense it because excessive liquid formation in the expansion engine would damage the turbine blades (Timmerhaus and Flynn 1989). Figure 5 is a flowsheet for an ideal liquefaction process; Figure 6 shows the process using a temperature-entropy diagram.

The ideal work of liquefaction for hydrogen is $3.228 \mathrm{kWh} / \mathrm{kg}(1.464 \mathrm{kWh} / \mathrm{lb})$. For comparison, the ideal work of liquefaction for nitrogen is only $0.207 \mathrm{kWh} / \mathrm{kg}(0.094 \mathrm{kWh} / \mathrm{lb})($ Timmerhaus and Flynn 1989). Appendix C contains sample work calculations for ideal liquefaction, the Linde process, and the nitrogen pre-cooled Linde process.

Other processes include the Dual-Pressure Linde Process, the Claude Cycle, the Dual-Pressure Claude Cycle, and the Haylandt Cycle. They are similar to the above processes, but use extra heat exchangers, multiple compressors, and expansion engines to reduce the energy required for liquefaction. This energy reduction is offset by higher capital costs (Timmerhaus and Flynn 1989).

\subsubsection{Ortho-to-Para Conversion}

Hydrogen molecules exist in two forms, para and ortho, depending on the electron configurations in the two individual hydrogen atoms (Noganow 1992). At hydrogen's boiling point of $20 \mathrm{~K}$ $\left(-423^{\circ} \mathrm{F}\right)$, the equilibrium concentration is almost all para-hydrogen, but at room temperature or higher, the equilibrium concentration is $25 \%$ para-hydrogen and $75 \%$ ortho-hydrogen (Noganow 1992; Encyclopedia of Chemical Technology 1991; Timmerhaus and Flynn 1989). The uncatalyzed conversion from ortho to para-hydrogen proceeds very slowly, so without a catalyzed conversion step, the hydrogen may be liquefied, but may still contain significant quantities of ortho-hydrogen. This orthohydrogen will eventually be converted into the para form in an exothermic reaction (Timmerhaus and Flynn, 1989).

This poses a problem because the transition from ortho to para-hydrogen releases a significant amount of heat $(527 \mathrm{~kJ} / \mathrm{kg}$ [227 Btu/lb]) (Noganow 1992). If ortho-hydrogen remains after liquefaction, this heat of transformation will slowly be released as the conversion proceeds, resulting in the evaporation of as much as $50 \%$ of the liquid hydrogen over about 10 days. This means long-term storage of hydrogen requires that the hydrogen be converted from its ortho form to its para form to minimize boil-off losses (Noganow 1992; Timmerhaus and Flynn 1989). 
Figure 5 - Ideal Liquefaction Flowsheet

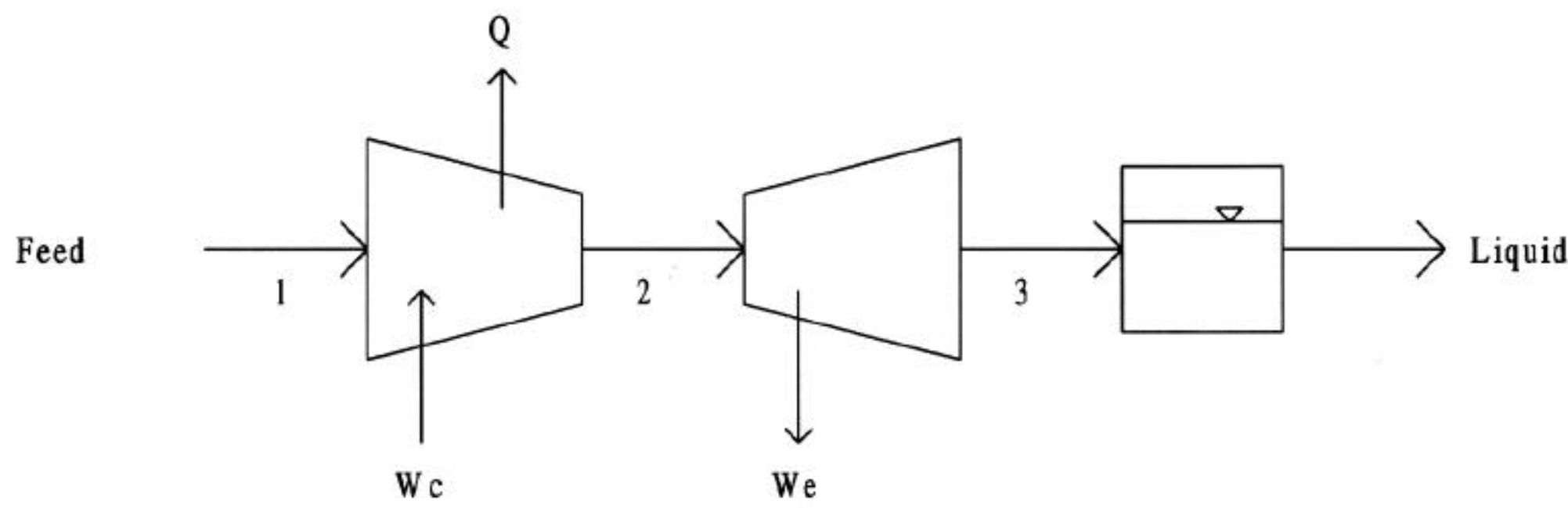


Figure 6 - Ideal Liquefaction Temperature-Entropy Diagram

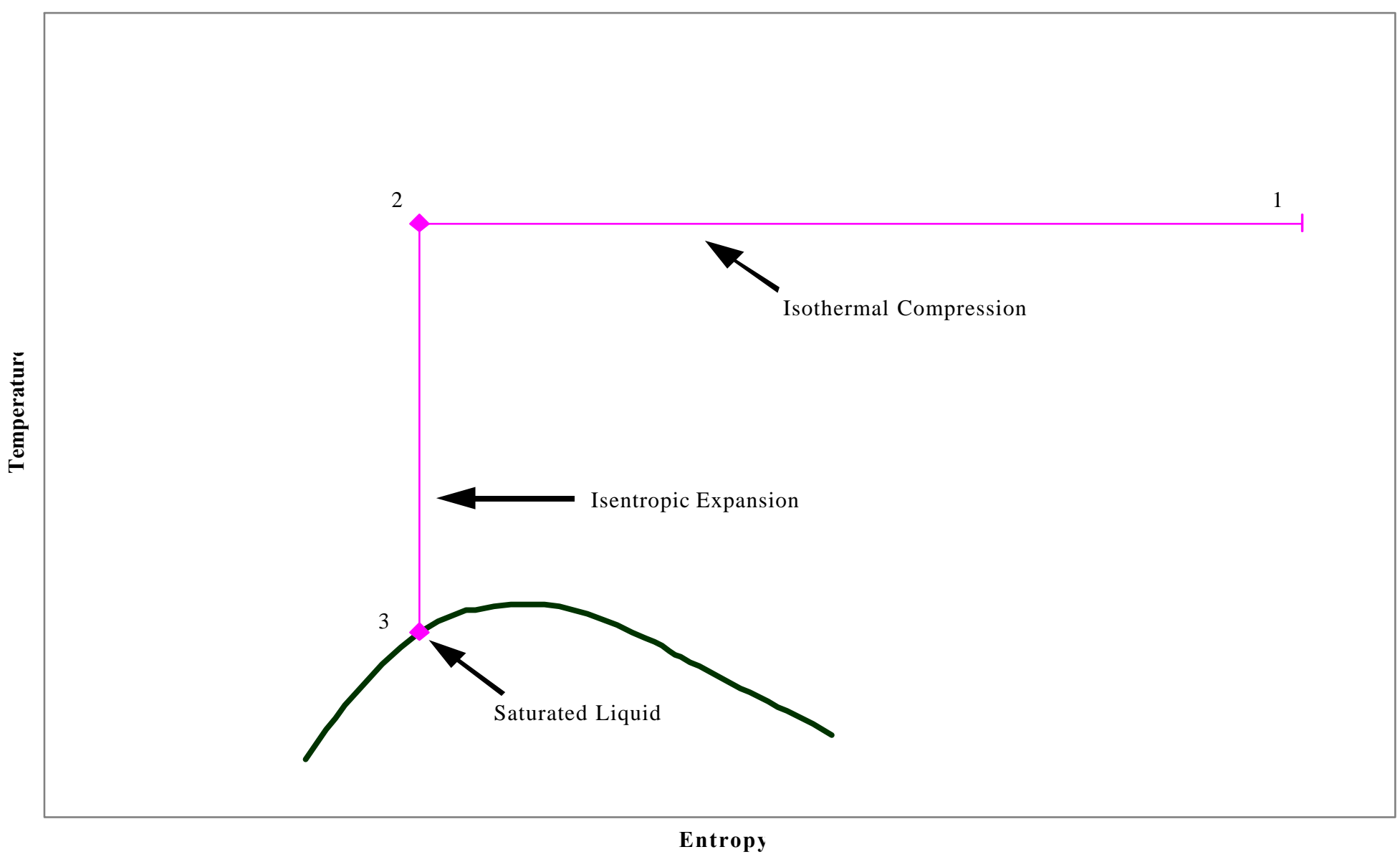


This can be accomplished using a number of catalysts including activated carbon, platinized asbestos, ferric oxide, rare earth metals, uranium compounds, chromic oxide, and some nickel compounds (Encyclopedia of Chemical Technology 1991; Timmerhaus and Flynn 1989). Activated charcoal is used most commonly, but ferric oxide is also an inexpensive alternative (Noganow 1992; Timmerhaus and Flynn 1989). The heat released in the conversion is usually removed by cooling the reaction with liquid nitrogen, then liquid hydrogen. Liquid nitrogen is used first because it requires less energy to liquefy than hydrogen, but still cools the hydrogen enough to achieve an equilibrium concentration of roughly $60 \%$ para-hydrogen (Timmerhaus and Flynn, 1989).

\subsubsection{Liquid Hydrogen Storage}

A major concern in liquid hydrogen storage is minimizing hydrogen losses from liquid boil-off. Because liquid hydrogen is stored as a cryogenic liquid that is at its boiling point, any heat transfer to the liquid causes some hydrogen to evaporate. The source of this heat can be ortho-to-para conversion, mixing or pumping energy, radiant heating, convection heating or conduction heating. Any evaporation will result in a net loss in system efficiency, because work went into liquefying the hydrogen, but there will be an even greater loss if the hydrogen is released to the atmosphere instead of being recovered.

The first step in avoiding boil-off losses is to perform an ortho-to-para conversion of the hydrogen during the liquefaction step to prevent any conversion and subsequent evaporation from occurring during storage. Another important step in preventing boil-off is to use insulated cryogenic containers.

Cryogenic containers, or dewars, are designed to minimize conductive, convective, and radiant heat transfer from the outer container wall to the liquid (Hart 1997). All cryogenic containers have a doublewall construction and the space between the walls is evacuated to nearly eliminate heat transfer from convection and conduction. To prevent radiant heat transfer, multiple layers (30-100) of reflective, low-emittance heat shielding--usually aluminized plastic Mylar--are put between the inner and outer walls of the vessel. A cheaper alternative to Mylar film is perlite (colloidal silica) placed between the vessel walls (Timmerhaus and Flynn 1989). Some large storage vessels have an additional outer wall with the space filled with liquid nitrogen. This reduces heat transfer by lowering the temperature difference driving the heat transfer (Huston 1984).

Most liquid hydrogen tanks are spherical, because this shape has the lowest surface area for heat transfer per unit volume (Hart 1997; Timmerhaus and Flynn 1989; Report to Congress 1995). As the diameter of the tank increases, the volume increases faster than the surface area, so a large tank will have proportionally less heat transfer area than a small tank, reducing boil-off. Cylindrical tanks are sometimes used because they are easier and cheaper to construct than spherical tanks and their volumeto-surface area ratio is almost the same (Timmerhaus and Flynn 1989). 
Liquid hydrogen storage vessels at customer sites typically have a capacity of 110-5,300 kg (23011,700 lb) (International Journal of Ambient Energy 1992; Report to Congress 1995; Zittel and Wurster 1996; Huston 1984; Taylor et al. 1986). NASA has the largest spherical tank in the world with a capacity of 228,000 kg (500,000 lb) of liquid hydrogen (International Journal of Ambient Energy 1992; Zittel and Wurster 1996; Taylor et al. 1986; Report to Congress 1995). Hydrogen liquefaction plants normally have about $115,000 \mathrm{~kg}(250,000 \mathrm{lb})$ of storage onsite (Report to Congress 1995). Single tanks can be constructed to hold as much as 900,000 kg (2,000,000 lb) of hydrogen (Report to Congress 1995).

Even with careful insulation, some hydrogen will evaporate. This hydrogen gas can be vented, allowed to build up pressure in the vessel, or captured and returned to the liquefaction process. If the liquid hydrogen is stored in a pressure vessel, the gas can be left to build up gradually until it reaches the design pressure, then some of the gas must be vented (Hart 1997). The length of time it takes for the gas pressure to reach the pressure limit is called the lock-up time. For processes that use gaseous hydrogen, if the storage time is shorter than the lock-up time, no hydrogen losses will occur--any gases produced can be drawn off first and used in the process instead of being vented to the atmosphere (Hart 1997).

Another option if the hydrogen is stored on the same site where it is liquefied is to pull the hydrogen gas out of the liquid hydrogen vessel and re-liquefy it. This way no hydrogen is lost, and because the hydrogen gas is still cold, it is easier to compress. In large transportation applications such as barges, the boil-off gas is being considered as transportation fuel--as the hydrogen gas boils off the liquid, it is recaptured and fed into the ship's boiler.

If the hydrogen cannot be recovered, it can be vented. Venting the hydrogen to the atmosphere poses little safety risk because it will quickly diffuse into the air.

\subsubsection{Plant Size}

Medium-sized liquefaction plants have production rates of 380-2,300 kg/h $(830-5,000 \mathrm{lb} / \mathrm{h})($ Zittel and Wurster 1996). Plants built during the past few years have been smaller (110-450 kg/h [250-1000 $\mathrm{lb} / \mathrm{h}]$ ) (Zittel and Wurster, 1996). One plant built in Germany during 1991 has a production rate of 170 $\mathrm{kg} / \mathrm{h}(370 \mathrm{lb} / \mathrm{h})$ (Zittel and Wurster 1996).

\subsection{Metal Hydride Storage}

Metal hydrides store hydrogen by chemically bonding the hydrogen to metal or metalloid elements and alloys (Noganow 1992). Hydrides are unique because some can adsorb hydrogen at or below atmospheric pressure, then release the hydrogen at significantly higher pressures when heated--the higher the temperature, the higher the pressure. There is a wide operating range of temperatures and pressures for hydrides depending on the alloy chosen (Ali and Sadhu 1994; Hydrogen Components, Inc. 1997). Each alloy has different performance characteristics, such as cycle life and heat of reaction. 
Figure 7 illustrates the temperature and pressure relationship for a typical hydride. When the hydrogen partial pressure is first increased, the hydrogen dissolves in the metal or alloy, then begins to bond to the metal. During the bonding period the equilibrium or plateau pressure remains constant from the time that $10 \%$ of the hydrogen has been stored until about $90 \%$ of the storage capacity is reached. After the $90 \%$ point, higher pressures are required to reach $100 \%$ of the hydride storage capacity (Worf 1992; Huston 1984). Heat released during hydride formation must be continuously removed to prevent the hydride from heating up. If the temperature is allowed to increase the equilibrium pressure will increase until no more bonding occurs. If hydrogen is being recovered from another gas, some hydrogen can be allowed to escape or blow off, taking away any contaminants that didn't bond to the hydride (Au et al. 1996).

To recover the hydrogen from the metal hydride, heat must be added to break the bonds between the hydrogen and the metal. Again, the higher the temperature, the higher the release pressure. Initially the pressure of the gas is high as any free hydrogen is released, then the pressure plateaus as the hydride bonds are broken. When only about $10 \%$ of the hydrogen remains the equilibrium pressure drops off (Worf 1992; Huston 1984). This last bit of hydrogen dissolved in the metal matrix is difficult to remove, and represents strongly bonded hydrogen that cannot be recovered in the normal charge/discharge cycle (Au et al. 1996).

Metal hydride beds can be configured similar to carbon adsorption columns. This results in a reaction front moving through the bed with a very high upstream concentration of hydrogen and a low residual concentration downstream of the reaction front. Using this configuration, it is easy to determine when the bed is completely charged because the outlet hydrogen concentration will suddenly increase. Using multiple columns allows semi-continuous charging and discharging of the hydrides (Au et al. 1996).

Hydrides store only about 2\%-6\% hydrogen by weight (Encyclopedia of Chemical Technology 1991; Hart 1997), but have high volumetric storage densities. The heats of reaction for hydrides can range from 9,300 to greater than $23,250 \mathrm{~kJ} / \mathrm{kg}(4,000-10,000 \mathrm{Btu} / \mathrm{lb})$ of hydrogen, and operating pressures can reach more than $10 \mathrm{MPa}(1,450 \mathrm{psig})$. Some hydride release temperatures can also be quite high-greater than $500^{\circ} \mathrm{C}\left(932^{\circ} \mathrm{F}\right)$ (Ali and Sadhu 1994; Hydrogen Components, Inc. 1997).

With this wide range in pressures and temperatures, the construction of the storage unit becomes a challenge. The vessel containing the hydride must be pressurized and contain sufficient heat exchange area to allow rapid heat transfer for charging and discharging the hydride (Encyclopedia of Chemical Technology 1991). The metal hydride alloy must also be structurally and thermally stable to withstand numerous charge/discharge cycles. Some hydrides can also be poisoned by carbon dioxide, sulfur compounds, or water (International Journal of Ambient Energy 1992). 
Figure 7 - Metal Hydride Pressure Behavior

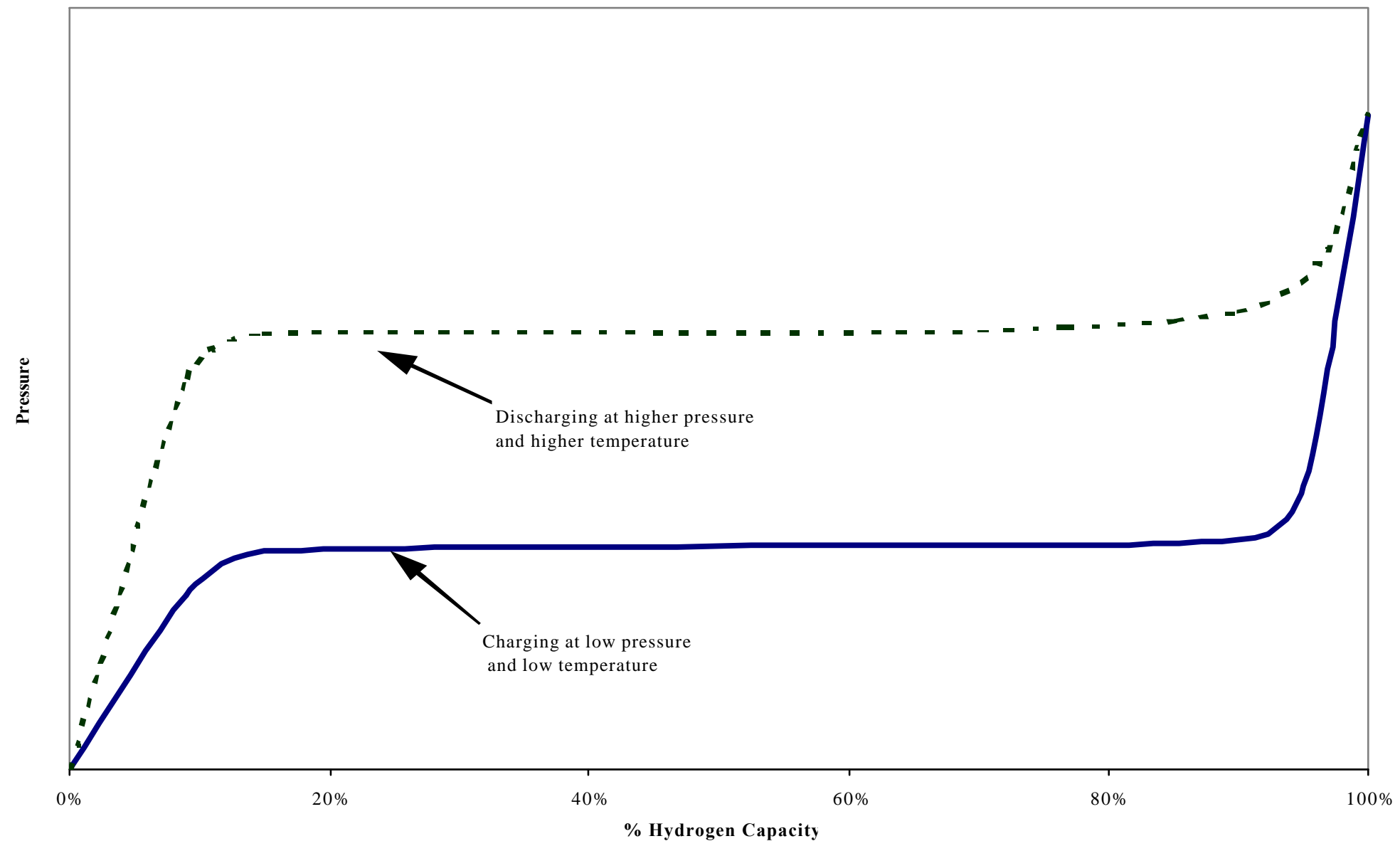


One industrial site has used a low-temperature metal hydride to successfully recover $18 \mathrm{~kg}$ (39 lb) of hydrogen in 4 hours from an ammonia waste steam containing $50 \%$ hydrogen. Cooling water was used for removing heat during absorption and warm water supplied the heat for desorption. One benefit of using a metal hydride in this application was the purification effect provided by the metal hydride. Even though the incoming hydrogen concentration was only $50 \%$, a brief purging or blowdown of the hydride vessel resulted in a $99.999 \%$ hydrogen purity with $76 \%$ hydrogen recovery (Au et al. 1996).

\subsection{Compressed Gas Storage}

Compressed gas storage of hydrogen is the simplest storage solution--the only equipment required is a compressor and a pressure vessel (Schwarz and Amonkwah 1993). The main problem with compressed gas storage is the low storage density, which depends on the storage pressure. Higher storage pressures result in higher capital and operating costs (Garrett 1989).

Low-pressure spherical tanks can hold as much as $1,300 \mathrm{~kg}(2,900 \mathrm{lb})$ of hydrogen at 1.2-1.6 MPa (1,700-2,300 psig) (Hart 1997). High-pressure storage vessels have maximum operating pressures of 20-30 MPa (2,900-4,350 psig) (Zittel and Wurster 1996). European countries tend to use lowpressure cylindrical tanks with a maximum operating pressure of $5 \mathrm{MPa}(725 \mathrm{psig}$ ) and storage capacities of 115-400 kg (255-800 lb) of hydrogen (Zittel and Wurster 1996).

One concern with large storage vessels (especially underground storage) is the cushion gas that remains in the "empty" vessel at the end of the discharge cycle. In small containers this may not be a concern, but in larger containers this may represent a large quantity of gas (Hart 1997; Taylor et al. 1986). One option is to use a liquid such as brine to fill the volume of the container and displace the remaining hydrogen gas (Taylor et al. 1986).

\subsection{Underground Storage}

Depending on the geology of an area, underground storage of hydrogen gas may be possible (Zittel and Wurster 1996). Underground storage of natural gas is common and underground storage of helium, which diffuses faster than hydrogen, has been practiced successfully in Texas (Hart 1997).

For underground storage of hydrogen, a large cavern or area of porous rock with an impermeable caprock above it is needed to contain the gas. A porous layer of rock saturated with water is an example of a good caprock layer. Other options include abandoned natural gas wells, solution mined salt caverns, and manmade caverns.

As mentioned with compressed gas containers, one consideration is the cushion gas that occupies the underground storage volume at the end of the discharge cycle (Hart 1997; Taylor et al. 1986). This can be as much as $50 \%$ of the working volume, or several hundred thousand kilograms 
(pounds) of gas. Some storage schemes pump brine into the area to displace the hydrogen, but this increases the operating and capital costs (Taylor et al. 1986; Zittel and Wurster 1996).

\subsection{Storage in Pipelines}

Piping systems are usually several miles long, and in some cases may be hundreds of miles long. Because of the great length, and therefore great volume, of these piping systems, a slight change in the operating pressure of a pipeline system can result in a large change in the amount of gas contained within the piping network. By making small changes in operating pressure, the pipeline can be used to handle fluctuations in supply and demand, avoiding the cost of onsite storage (Hart 1997; Report to Congress 1995).

\subsection{Compressors}

Compressed gas storage, liquefaction, underground storage, and pipelines all require compressors; only metal hydride storage does not, although a compressor may also be used for hydrides depending upon the hydride plateau pressure (Schwarz and Amonkwah 1993).

Hydrogen can be compressed using standard axial, radial or reciprocating piston-type compressors by making slight modifications of the seals to take into account the higher diffusivity of the hydrogen molecules (Hart 1997). Reciprocating compressors can be as large as 11,200 kW (15,000 hp) and can handle hydrogen flows of $890 \mathrm{~kg} / \mathrm{h}(1,950 \mathrm{lb} / \mathrm{h})$ at up to $25 \mathrm{MPa}(3,600 \mathrm{psig})$. They also work well with variable flows (Timmerhaus and Flynn 1989). Radial compressors are used for flows of 160$22,000 \mathrm{~kg} / \mathrm{h}(350-49,000 \mathrm{lb} / \mathrm{h})$ and axial compressors for $6,400-89,000 \mathrm{~kg} / \mathrm{h}(14,000-200,000 \mathrm{lb} / \mathrm{h})$ (Timmerhaus and Flynn 1989). One benefit of axial compressors is that several can be mounted on one common shaft, but they must be protected from surging by using a recycle and have an efficiency of only about 50\% (Timmerhaus and Flynn 1989).

The first stage in most multi-stage compressors normally reaches a couple of atmospheres of compression (0.3-0.4 MPa [45-60 psig]). In higher-pressure applications, 3-4 MPa (435-580 psig) of precompression is done before compressing the gas to $25-30 \mathrm{MPa}(3,600-4,400 \mathrm{psig}$ ) (Zittel and Wurster 1996).

A metal hydride can also be used for gas compression by adsorbing hydrogen at a low temperature and low pressure and then heating the hydride to a higher temperature to produce a higher pressure (Hydrogen Components, Inc. 1997). A series of hydrides that have increasing desorption temperatures can be used for compression so the adsorption heat of one hydride can be used for the desoprtion heat of another. Compression ratios greater than 20:1 are possible using hydrides, with final pressures of over $100 \mathrm{MPa}$ (14,700 psig) (Huston, 1984, Hydrogen Components, Inc. 1997). 


\subsection{Expanders}

Modern liquefaction processes and some compressed gas storage schemes use expansion engines to recover some of the energy in the compressed hydrogen gas. In liquefaction, expansion engines are used to cool the gas more efficiently than just throttling the gas in a Joule-Thompson expansion (Timmerhaus and Flynn 1989). In gas storage, expansion engines are sometimes used to produce work from the gas leaving a high-pressure storage container if the application requires only low pressure hydrogen.

Turboexpanders are usually used for large gas flows, but can range from 0.75 to $7,500 \mathrm{~kW}(1-10,000$ $\mathrm{hp}$ ), handling flows as high as $103,000 \mathrm{~kg} / \mathrm{h}(230,000 \mathrm{lb} / \mathrm{h})$ of hydrogen (Timmerhaus and Flynn 1989). Turboexpanders have efficiencies of $85 \%$ at full flow, but the efficiency can drop to $60 \%$ as the flow rate for a given turbine drops (Timmerhaus and Flynn 1989). Reciprocating expanders, which can be used for variable flows, have efficiencies of 75\%-85\% (Timmerhaus and Flynn 1989).

\subsection{Developing Methods of Hydrogen Storage}

Besides liquid, gaseous, metal hydride, and underground storage methods, several other methods of storing hydrogen are in various stages of development. Each has its own advantages and disadvantages.

\subsubsection{Liquid Hydrides}

Japan is looking at a scheme to produces hydrogen by electrolysis using hydropower in Canada, storing the hydrogen in the form of cyclohexane for transport to Japan, then regenerating the hydrogen to produce electricity. Because hydroelectric power is available at relatively low costs in Canada, this source of renewable energy can be used to produce hydrogen through electrolysis. The hydrogen then reacts with benzene to form cyclohexane. The hydrogen can be recovered using a catalyzed reaction with membrane separation (Chemical Engineering 1994).

This would allow the hydrogen to be transported across the ocean as a stable liquid, but the process does involve a toxic chemical (benzene) and requires complex recovery equipment. (T-Raissi and Sadhu 1994; Huston 1984). Hydrogen can also be converted into methanol, but again the toxicity of methanol is a concern (Chemical Engineering 1994; Huston 1984; Hart 1997; T-Raissi and Sadhu 1994).

\subsubsection{Adsorption}

Adsorption is a high density storage alternative compared to compressed gas, with a storage volume of about one-third that of compressed gas at $20 \mathrm{MPa}(2,900 \mathrm{psig})$. The mass of the storage media, however, becomes a factor because only $1 \%-10 \%$ of the storage system by weight is hydrogen. The weight of the storage media may be two to four times heavier than a 
comparable compressed gas system, including the vessel. Another issue with hydrogen adsorption is that under some circumstances, only $80 \%$ of the adsorbed hydrogen can be recovered from the storage media (Hart 1997).

Carbon adsorption has a relatively good storage density, but currently available systems require refrigeration and an insulated storage container to reach high storage densities. Carbon nanotube research may improve the outlook of using carbon adsorption by producing carbon with much higher surface areas per unit mass, allowing it to adsorb greater amounts of hydrogen at room temperature. Currently carbon can adsorb up to $4 \%$ hydrogen by weight, with a goal of reaching about $8 \%$ at room temperature with further research (Hart 1997; Schwarz and Amonkwah 1993; T-Raissi and Sadhu 1994; Report to Congress 1995).

\subsubsection{Sponge Iron}

Iron oxide reacts with hydrogen in an endothermic reaction at $1,230^{\circ} \mathrm{C}\left(2,240^{\circ} \mathrm{F}\right)$ to form iron and water. Later, the hydrogen can be recovered by reacting the iron with steam to again form iron oxide and hydrogen. The uncatalyzed reaction requires temperatures of $430^{\circ}-630^{\circ} \mathrm{C}\left(800^{\circ}-1,160^{\circ} \mathrm{F}\right)$, but with the appropriate catalyst, the reaction temperature can be reduced to $250^{\circ} \mathrm{C}\left(482^{\circ} \mathrm{F}\right)$. An added benefit of using sponge iron is that, unlike some competing storage methods, it is not poisoned by carbon monoxide, which is produced when reforming hydrocarbons to hydrogen (Hart 1997; T-Raissi and Sadhu 1994).

So far, sponge iron storage has been demonstrated on a laboratory scale only and is at least 3-5 years from commercialization, but it could have the advantages of high energy density and low storage cost (T-Raissi and Sadhu 1994; Zittel and Wurster 1996).

\subsubsection{Glass Microspheres}

Glass microspheres are small, hollow spheres 25-500 microns (0.001-0.020 in.) in diameter constructed of a glass that becomes permeable to hydrogen when heated to $200^{\circ}-400^{\circ} \mathrm{C}\left(392^{\circ}\right.$ $\left.752^{\circ} \mathrm{F}\right)$. Hydrogen gas enters the microspheres and becomes trapped when they are cooled to room temperature. The hydrogen can then be recovered by reheating the microspheres (Hart 1997; Report to Congress 1995).

\subsubsection{Ammonia}

Hydrogen can be reacted to form ammonia, which can be stored at $1.7 \mathrm{MPa}$ (250 psig). It can then be dissociated back into hydrogen and nitrogen over an iron oxide catalyst at $700^{\circ} \mathrm{C}\left(1,292^{\circ} \mathrm{F}\right)$ and 0.1 $\mathrm{MPa}(15 \mathrm{psig})$, consuming $7.9 \mathrm{kWh} / \mathrm{kg}(3.6 \mathrm{kWh} / \mathrm{lb})$ of electricity in the process. The ammonia gas provides a high storage density, but it is hazardous to handle and requires electricity to dissociate the ammonia back into hydrogen and nitrogen (Huston 1984). 


\subsection{CAPITAL COSTS OF STORAGE EQUIPMENT}

\subsection{Compressor Capital Costs}

Compressor costs are based on the amount of work done by the compressor, which depends on the inlet pressure, outlet pressure, and flow rate. Reciprocating compressors are most commonly used for hydrogen applications, but centrifugal compressors are also an option. Reciprocating compressors cost about 50\% more than a comparable centrifugal compressor, but have higher efficiencies (Timmerhaus and Flynn 1989). The capital costs of both types of compressors have a sizing exponent of 0.80 . High operating pressures also add to the cost of a compressor (Garrett 1985).

Table 1 gives some examples of compressor costs. The prices are $\$ 650-\$ 6,600 / \mathrm{kW}(\$ 440$ $\$ 4,900 / \mathrm{hp}$ ); the larger compressors are several times cheaper on a unit basis than smaller ones.

Table 1 - Compressor Capital Costs

\begin{tabular}{|r|r|r|r|r|l|}
\hline Size (kW) & Size (hp) & \multicolumn{1}{|c|}{ Cost* $(\$)$} & $\begin{array}{c}\text { Cost/kW* } \\
(\$ / \mathrm{kW})\end{array}$ & $\begin{array}{c}\text { Cost/hp* } \\
(\$ / \mathrm{hp})\end{array}$ & Source \\
\hline 10 & 13 & $\mathrm{n} / \mathrm{a}$ & $\$ 6,600$ & $\$ 4,900$ & Zittel and Wurster 1996 \\
\hline 75 & 100 & $\$ 180,000$ & $\$ 2,400$ & $\$ 1,800$ & Taylor et al 1986 \\
\hline 250 & 335 & $\mathrm{n} / \mathrm{a}$ & $\$ 660-\$ 990$ & $\$ 490-\$ 735$ & Zittel and Wurster 1996 \\
\hline 2,700 & 3,600 & $\$ 2,330,000$ & $\$ 863$ & $\$ 647$ & Taylor et al. 1986 \\
\hline 3,700 & 5,000 & $\$ 2,440,000$ & $\$ 650$ & $\$ 480$ & Taylor et al. 1986 \\
\hline 4,500 & 6,000 & $\$ 3,160,000$ & $\$ 702$ & $\$ 527$ & Taylor et al. 1986 \\
\hline 28,300 & 38,000 & $\$ 20,000,000$ & $\$ 702$ & $\$ 526$ & TransCanada Pipeline, Ltd. \\
& & & & & $1996 \mathrm{a}$ \\
\hline
\end{tabular}

*All costs are adjusted to 1995 dollars. n/a - Specific information not provided.

\subsection{Liquefaction Capital Costs}

The capital cost of a liquid hydrogen plant can be estimated based upon the hydrogen production rate. Sizing exponents for liquid hydrogen plants range from 0.6-0.7 (Zittel and Wurster 1996; Garret 1985; Cuoco et al. 1995). One source gave the total capital cost breakdown as $10 \%$ planning, $60 \%$ equipment, and 30\% construction (Zittel and Wurster 1996).

Table 2 lists some capital costs for liquid hydrogen facilities of various sizes. Price ranged from 
$\$ 25,600 / \mathrm{kg} / \mathrm{hr}(\$ 11,600 / \mathrm{lb} / \mathrm{h})$ to $\$ 118,000 / \mathrm{kg} / \mathrm{hr}(\$ 53,300 / \mathrm{lb} / \mathrm{h})$.

Table 2 - Liquefier Capital Costs

\begin{tabular}{|r|r|r|r|l|l|}
\hline Size $(\mathrm{kg} / \mathrm{h})$ & Size $(\mathrm{lb} / \mathrm{h})$ & \multicolumn{1}{|c|}{$\operatorname{Cost}^{*}(\$)$} & $\begin{array}{c}\text { Cost* } \\
(\$ / \mathrm{kg} / \mathrm{h})\end{array}$ & $\begin{array}{c}\text { Cost* } \\
(\$ / \mathrm{lb} / \mathrm{h})\end{array}$ & Source \\
\hline 170 & 375 & $\$ 20,000,000$ & $\$ 118,000$ & $\$ 53,300$ & Zittel and Wurster 1996 \\
\hline 380 & 830 & $\mathrm{n} / \mathrm{a}$ & $\$ 31,750$ & $\$ 14,400$ & Taylor et al. 1986 \\
\hline 1,500 & 3,300 & $\$ 38,800,000$ & $\$ 25,600$ & $\$ 11,600$ & Taylor et al. 1986 \\
\hline $\mathrm{n} / \mathrm{a}$ & $\mathrm{n} / \mathrm{a}$ & $\mathrm{n} / \mathrm{a}$ & $\$ 116,000$ & $\$ 52,500$ & Cuoco et al. 1995 \\
\hline
\end{tabular}

*All costs are adjusted to 1995 dollars. n/a - Specific information not provided.

\subsection{Metal Hydride Capital Costs}

For metal hydrides, capital expenses include not only the storage material, but also a pressure vessel and an integrated heat exchanger for cooling and heating during absorption and desorption, respectively (Schwarz and Amonkwah 1993). In some cases, the gas may need to be compressed, depending on the particular properties of the hydride used (Schwarz and Amonkwah 1993). Because much of the capital cost is for the hydride material itself, there is little economy of scale for metal hydride storage (Carpetis 1994).

Table 3 gives some cost estimates for metal hydride storage. Values ranged from $\$ 820 / \mathrm{kg}(\$ 370 / \mathrm{lb})$ of hydrogen to $\$ 60,000 / \mathrm{kg}(\$ 29,000 / \mathrm{lb}$ ) for very small hydride units. Metal hydride units have been constructed for as much as $27 \mathrm{~kg}(59 \mathrm{lb})$ of hydrogen (Hydrogen Components, Inc. 1997). 
Table 3 - Metal Hydride Capital Costs

\begin{tabular}{|c|c|c|c|c|c|}
\hline Size (kg) & Size (lb) & Cost* $(\$)$ & $\begin{array}{c}\text { Cost } / \mathrm{kg} \mathrm{H}_{2} * \\
(\$ / \mathrm{kg})\end{array}$ & $\begin{array}{c}\operatorname{Cos} t / \mathrm{lb} \mathrm{H}_{2} * \\
(\$ / \mathrm{lb})\end{array}$ & Source \\
\hline $\mathrm{n} / \mathrm{a}$ & $\mathrm{n} / \mathrm{a}$ & $\mathrm{n} / \mathrm{a}$ & $\$ 1,765$ & $\$ 800$ & Carpetis 1994 \\
\hline $\mathrm{n} / \mathrm{a}$ & $\mathrm{n} / \mathrm{a}$ & $\mathrm{n} / \mathrm{a}$ & $\$ 2,100-\$ 2,600$ & $\$ 940-\$ 1,200$ & Carpetis 1994 \\
\hline 0.036 & 0.080 & $\$ 2,150$ & $\$ 60,000$ & $\$ 29,000$ & $\begin{array}{l}\text { Hydrogen } \\
\text { Components } \\
\text { Inc. } 1997\end{array}$ \\
\hline $0.089-8.9$ & $0.2-20$ & $\mathrm{n} / \mathrm{a}$ & $\$ 820-\$ 1,300$ & $\$ 370-\$ 570$ & Oy 1992 \\
\hline $8.9-890$ & $20-2000$ & $\mathrm{n} / \mathrm{a}$ & $\$ 1,400-\$ 1,800$ & $\$ 640-\$ 800$ & Oy 1992 \\
\hline 2.7 & 5.9 & $\$ 8,500-\$ 33,000$ & $\$ 3,150-\$ 12,200$ & $\$ 1,440-\$ 5,600$ & $\begin{array}{l}\text { Zittel and } \\
\text { Wurster } 1996\end{array}$ \\
\hline 0.089 & 0.2 & $\mathrm{n} / \mathrm{a}$ & $\$ 6,000-\$ 22,000$ & $\$ 3,000-\$ 10,000$ & $\begin{array}{l}\text { Zittel and } \\
\text { Wurster } 1996\end{array}$ \\
\hline 0.89 & 2 & $\mathrm{n} / \mathrm{a}$ & $\$ 3,000-\$ 11,000$ & $\$ 1,350-\$ 5,050$ & $\begin{array}{l}\text { Zittel and } \\
\text { Wurster } 1996\end{array}$ \\
\hline 8.9 & 20 & $\mathrm{n} / \mathrm{a}$ & $\$ 2,200-\$ 8,200$ & $\$ 1,000-\$ 3,700$ & $\begin{array}{l}\text { Zittel and } \\
\text { Wurster } 1996\end{array}$ \\
\hline
\end{tabular}

*All costs are adjusted to 1995 dollars. n/a - Specific information not provided.

\subsection{Compressed Gas (Above-Ground) Capital Costs}

Above-ground storage of hydrogen typically employs high-pressure spherical or cylindrical tanks with pressure ratings as high as $30 \mathrm{MPa}$ (4,350 psig), but low-pressure spherical tanks with large diameters are also used (Zittel and Wurster 1996; Hart 1997.) Pressure vessel sizing exponents vary from 0.62 to 0.75 based on the capacity (Garrett 1985; Carpetis 1994; Cuoco et al 1995).

Listed in Table 4 are some sample costs for hydrogen gas storage. Capital costs are $\$ 625-\$ 2,080 / \mathrm{kg}$ (\$280-\$940/b) of hydrogen. In many cases, small tanks are rented by the gas supplier for a couple thousand dollars per month (Zittel and Wurster 1996). 
Table 4 - Compressed Hydrogen Pressure Vessel Capital Costs

\begin{tabular}{|c|c|r|r|r|l|}
\hline Size $(\mathrm{kg})$ & Size $(\mathrm{lb})$ & Cost* $(\$)$ & $\begin{array}{c}\text { Cost } / \mathrm{kg} * \\
(\$ / \mathrm{kg})\end{array}$ & $\begin{array}{c}\text { Cost/lb* } \\
(\$ / \mathrm{lb})\end{array}$ & Source \\
\hline $\mathrm{n} / \mathrm{a}$ & $\mathrm{n} / \mathrm{a}$ & $\mathrm{n} / \mathrm{a}$ & $\$ 625-\$ 2,080$ & $\$ 280-\$ 940$ & Carpetis 1994 \\
\hline $8.9-890$ & $20-2,000$ & $\mathrm{n} / \mathrm{a}$ & $\$ 950-\$ 1,400$ & $\$ 430-\$ 640$ & Oy 1992 \\
\hline $0.089-8.9$ & $0.2-20$ & $\mathrm{n} / \mathrm{a}$ & $\$ 715-\$ 840$ & $\$ 325-\$ 380$ & Oy 1992 \\
\hline 250 & 550 & $\$ 180,000$ & $\$ 720$ & $\$ 330$ & Taylor et al. 1986 \\
\hline 1240 & 2750 & $\$ 840,000$ & $\$ 680$ & $\$ 305$ & Taylor et al. 1986 \\
\hline
\end{tabular}

*All costs are adjusted to 1995 dollars. n/a - Specific information not provided.

\subsection{Liquid Hydrogen Vessel Capital Costs}

Liquid hydrogen vessels are low pressure, but have high capital costs because of the insulation required to prevent boil-off (Zittel and Wurster 1996). The cost depends mainly on volume with a sizing exponent of around 0.7 (Carpetis 1994, Garrett 1989). Small vessels can be quite expensive and the economy of scale savings are not significant except with large volumes. There is also a reduction in hydrogen losses with larger vessels because of the lower surface area per unit volume at the larger sizes (Carpetis 1994). Perlite insulated tanks cost less than Mylar wrapped tanks, but still provide good insulating properties (International Journal of Ambient Energy 1992).

Table 5 lists some costs for liquid hydrogen vessels of various sizes. Costs were $\$ 31-\$ 700 / \mathrm{kg}(\$ 8.20$ $\$ 320 / \mathrm{lb})$.

Table 5 - Liquid Hydrogen Dewar Costs

\begin{tabular}{|c|c|r|c|c|l|}
\hline Size $(\mathrm{kg})$ & Size $(\mathrm{lb})$ & Cost* $\left.^{*} \$\right)$ & $\begin{array}{c}\text { Cost/kg* } \\
(\$ / \mathrm{kg})\end{array}$ & $\begin{array}{c}\text { Cost/lb* } \\
(\$ / \mathrm{lb})\end{array}$ & Source \\
\hline $\mathrm{n} / \mathrm{a}$ & $\mathrm{n} / \mathrm{a}$ & $\mathrm{n} / \mathrm{a}$ & $\$ 31-\$ 520$ & $\$ 14-\$ 235$ & Carpetis 1994 \\
\hline $8.9-890$ & $20-2,000$ & $\mathrm{n} / \mathrm{a}$ & $\$ 21-\$ 36$ & $\$ 9-\$ 16$ & Oy 1992 \\
\hline $0.089-8.9$ & $0.2-20$ & $\mathrm{n} / \mathrm{a}$ & $\$ 490-\$ 700$ & $\$ 220-\$ 320$ & Oy 1992 \\
\hline 270 & 590 & $\$ 120,000$ & $\$ 450$ & $\$ 200$ & Taylor et al. 1986 \\
\hline 300,000 & 660,000 & $\$ 5,400,000$ & $\$ 18$ & $\$ 8.20$ & Taylor et al. 1986 \\
\hline
\end{tabular}

*All costs are adjusted to 1995 dollars. n/a - Specific information not provided. 


\subsection{Underground Storage Capital Costs}

Underground storage is the most inexpensive means of storage for large quantities of hydrogen. Capital costs vary depending on whether there is a suitable natural cavern or rock formation, or whether a cavern must be mined. Using abandoned natural gas wells is the cheapest alternative, followed by solution salt mining and hard rock mining. Solution mining costs were estimated at $\$ 23 / \mathrm{m}^{3}\left(\$ 0.66 / \mathrm{ft}^{3}\right)$; hard rock mining costs were estimated at $\$ 34-\$ 84 / \mathrm{m}^{3}\left(\$ 1.00-\$ 2.50 / \mathrm{ft}^{3}\right)$ depending on the depth (Taylor et al. 1986).

New York State Electric \& Gas recently completed an underground natural gas storage system consisting of $89 \mathrm{~km}$ (55 mi) of high-pressure pipeline, a 1,930 kW (2,587 hp) compressor and a solution mined cavern with a 22.6 million $\mathrm{Nm}^{3}$ (800 million scf) working volume (roughly equivalent to 2 million $\mathrm{kg}$ [4.5 million $\mathrm{lb}$ ] of $\mathrm{H}_{2}$ ). The complete project cost was cost $\$ 57.2$ million (NYSEG 1996b, NYSEG 1996c). The cavern storage capacity was later expanded to 41 million $\mathrm{Nm}^{3}$ (1.45 billion scf, or about 3.6 million $\mathrm{kg}$ [8 million $\mathrm{lb}$ ] of $\mathrm{H}_{2}$ ) working volume by adding two more compressors and raising the operating pressure (NYSEG 1997).

One additional expense for underground storage is the value of the cushion gas that remains when the storage system is at the end of its discharge cycle. Brine can be used to displace this gas at an additional expense for pumping and storing the brine solution (Taylor et al, 1986).

Table 6 gives some underground storage capital cost estimates. Prices are $\$ 2.50-\$ 18.90 / \mathrm{kg}(\$ 1.10$ $\$ 9.00 / \mathrm{lb}$ ). This is an order of magnitude less than liquid hydrogen storage and two orders of magnitude less than compressed gas above-ground storage.

Table 6 - Underground Storage Capital Costs

\begin{tabular}{|c|c|c|c|c|l|}
\hline Size $(\mathrm{kg})$ & Size (lb) & $\operatorname{Cost}^{*}(\$)$ & $\begin{array}{c}\text { Cost/kg* } \\
(\$ / \mathrm{kg})\end{array}$ & $\begin{array}{c}\text { Cost/lb* } \\
(\$ / \mathrm{lb})\end{array}$ & Source \\
\hline $\mathrm{n} / \mathrm{a}$ & $\mathrm{n} / \mathrm{a}$ & $\mathrm{n} / \mathrm{a}$ & $\$ 10.00$ & $\$ 5.00$ & Carpetis 1994 \\
\hline $8.9-890$ & $20-2000$ & $\mathrm{n} / \mathrm{a}$ & $\$ 2.50-\$ 7.00$ & $\$ 1.10-\$ 3.20$ & Oy 1992 \\
\hline $\mathrm{n} / \mathrm{a}$ & $\mathrm{n} / \mathrm{a}$ & $\mathrm{n} / \mathrm{a}$ & $\$ 6.30-\$ 18.90$ & $\$ 3.50-\$ 9.00$ & Taylor et al. 1986 \\
\hline $2,000,000$ & $4,500,000$ & $\mathrm{n} / \mathrm{a}$ & $\$ 28.60 * *$ & $\$ 12.70 * *$ & NYSEG 1996b \\
\hline
\end{tabular}

*All costs are adjusted to 1995 dollars. n/a - Specific information not provided.

** Includes $89 \mathrm{~km}(55 \mathrm{mi})$ of pipeline.

\subsection{Pipeline Capital Costs}

Pipeline construction costs will be included later in the report with transportation costs. Storing hydrogen in a pipeline system by increasing the operating pressure requires no additional capital 
expense as long as the pressure rating of the pipe and the capacity of the compressors are not exceeded (Hart 1997; Report to Congress 1995).

\subsection{OPERATING COSTS FOR HYDROGEN STORAGE}

Utility costs for hydrogen storage consist of electricity, heat for the metal hydride, and cooling for all the processes. For liquid hydrogen, boil-off loses increase costs.

\subsection{Compressed Gas Operating Costs}

The largest operating cost with above-ground gas storage is the energy to compress the hydrogen. The exact energy requirements would, of course, depend on the final pressure, but because compression work is an exponential function of pressure, a high final storage pressure requires minimal power compared to the initial compression of the gas. Pressurized electrolyzers that produce hydrogen at an elevated pressure have lower power requirements for compression or liquefaction than electrolyzers operating at or near atmospheric pressures (Hart 1997).

The efficiency of the compressor will also affect the economics. Small compressors may have efficiencies as low as 40\%-50\%; larger alternating, double-action compressors may have efficiencies in the 65\%-70\% range (Zittel and Wurster 1996; Cuoco et al. 1995). The energy to compress hydrogen from 0.1 to $15-20 \mathrm{MPa}(14.5 \mathrm{psig}$ to $2,100-2,800 \mathrm{psig}$ ) can be $8 \%-10 \%$ of the energy content of the hydrogen (Cuoco et al. 1995).

Total costs for compressed gas storage, including equipment-related charges are listed in Table 7. One source breaks down the contributors to above-ground storage costs as follows: $\$ 0.46 / \mathrm{kg}(\$ 0.21 / \mathrm{lb})$ for the storage vessel, $\$ 0.06 / \mathrm{kg}(\$ 0.03 / \mathrm{lb})$ for compressor-related costs, and $\$ 0.08 / \mathrm{kg}(\$ 0.04 / \mathrm{lb})$ for the compressor energy (Schwarz and Amonkwah 1993). In other words, the capital cost of the tank was $75 \%$ of the storage costs, explaining the much lower cost for underground storage.

Table 7 - Compressed Gas Above-Ground Storage Total Costs

\begin{tabular}{|c|c|c|c|l|}
\hline Size (kg) & Size (lb) & $\begin{array}{c}\text { Cost/kg* } \\
(\$ / \mathrm{kg})\end{array}$ & $\begin{array}{c}\text { Cost/lb* } \\
(\$ / \mathrm{lb})\end{array}$ & Source \\
\hline 167,000 & 368,000 & $\$ 0.60$ & $\$ 0.28$ & Schwarz and Amonkwah 1993 \\
\hline $\mathrm{n} / \mathrm{a}$ & $\mathrm{n} / \mathrm{a}$ & $\$ 1.00-\$ 1.50$ & $\$ 0.46-\$ 0.67$ & Cuoco et al. 1995 \\
\hline $\mathrm{n} / \mathrm{a}$ & $\mathrm{n} / \mathrm{a}$ & $\$ 0.07 * *$ & $\$ 0.03 * *$ & Carpetis 1994 \\
\hline
\end{tabular}

*All costs are adjusted to 1995 dollars. n/a - Specific information not provided.

*** Power-related costs only. 


\subsection{Liquefaction Operating Costs}

The highest operating cost for liquefaction is electricity. Small amounts of nitrogen and cooling water are also needed. One source breaks down costs as $\$ 0.08 / \mathrm{kg}(\$ 0.04 / \mathrm{lb})$ for compression equipment and utilities, $\$ 0.13 / \mathrm{kg}(\$ 0.06 / \mathrm{lb})$ for the liquid hydrogen tank, and $\$ 0.99 / \mathrm{kg}(\$ 0.45 / \mathrm{lb})$ for electrical energy (Schwarz and Amonkwah, 1993). Compared to compressed gas storage, the storage vessels costs are lower, but for liquefaction the energy requirements are higher.

Table 8 - Liquefier Operating Costs

\begin{tabular}{|c|c|c|c|l|}
\hline Size $(\mathrm{kg})$ & Size $(\mathrm{lb})$ & $\begin{array}{c}\text { Cost//k* } \\
(\$ / \mathrm{kg})\end{array}$ & $\begin{array}{c}\text { Cost/lb* } \\
(\$ / 1 \mathrm{~b})\end{array}$ & Source \\
\hline 167,000 & 368,000 & $\$ 1.20$ & $\$ 0.55$ & Schwarz and Amonkwah 1993 \\
\hline $\mathrm{n} / \mathrm{a}$ & $\mathrm{n} / \mathrm{a}$ & $\$ 0.40 * *$ & $\$ 0.19 * *$ & Carpetis 1994 \\
\hline
\end{tabular}

*All costs are adjusted to 1995 dollars. n/a - Specific information not provided.

** Cost for power only.

Liquefaction power requirements varied from $8.0 \mathrm{kWh} / \mathrm{kg}(3.6 \mathrm{kWh} / \mathrm{lb})$ to $12.7 \mathrm{kWh} / \mathrm{kg}(5.8 \mathrm{kWh} / \mathrm{lb})$. Application of magnetocaloric cooling to liquefy hydrogen may result in energy requirements as low as $4.94 \mathrm{kWh} / \mathrm{kg}$ $(2.24 \mathrm{kWh} / \mathrm{lb})$ in the future (Schwarz and Amonkwah 1993; International Journal of Ambient Energy 1992; Zittel and Wurster 1996; Johannsen 1993; Cuoco et al. 1995). For comparison, the ideal energy of liquefaction of hydrogen is $3.228 \mathrm{kWh} / \mathrm{kg}(1.464 \mathrm{kWh} / \mathrm{lb})$ (Timmerhaus and Flynn 1989). Table 9 gives some liquefaction power requirements.

Table 9 - Liquefier Power Requirements

\begin{tabular}{|r|r|l|}
\hline $\begin{array}{c}\text { Liquefaction } \\
\text { Energy } \\
(\mathrm{kWh} / \mathrm{kg})\end{array}$ & $\begin{array}{c}\text { Liquefaction } \\
\text { Energy } \\
(\mathrm{kWh} / \mathrm{lb})\end{array}$ & Source \\
\hline 10.4 & 4.7 & Schwarz and Amonkwah 1993 \\
\hline 12.7 & 5.8 & Zittel and Wurster 1996 \\
\hline $9.0-11.0$ & $4.1-5.0$ & Johannsen 1993 \\
\hline 8.0 & 3.6 & Cuoco et al. 1995 \\
\hline
\end{tabular}

Boil-off rates depend on the size of the storage vessel and range from $2 \%-3 \%$ per day for small portable containers down to $0.06 \%$ per day for large vessels (International Journal of Ambient Energy 1992; Carpetis 1994; Timmerhaus and Flynn 1989; Johannsen 1993; Cuoco et al. 1995; Taylor et al. 1986). A typical boil-off rate is $0.1 \%$ (Timmerhaus and Flynn 1989; Johannsen 1993; Taylor et al. 1986). If this hydrogen is not recaptured by the process, the lost hydrogen 
represents an expense, and even if it is recaptured, energy is required to re-liquefy it. The industry target for boil-off rate is $0.03 \%$ per day (Johannsen 1993).

\subsection{Metal Hydride Operating Costs}

The main operating cost considerations with metal hydrides are the heating and cooling requirements for the desorption and absorption processes (Encyclopedia of Chemical Technology 1991; Carpetis 1994; Zittel and Wurster 1996). When a metal hydride is also used for purification, the $10 \%$ or so of hydrogen lost during blow-off of the contaminants results in an additional cost (Au et al 1996).

A breakdown of storage costs from one source was $\$ 0.04 / \mathrm{kg}(\$ 0.02 / \mathrm{lb})$ for utilities, $\$ 0.17 / \mathrm{kg}$ (\$0.08/lb) for energy, and $\$ 0.44 / \mathrm{kg}(\$ 0.20 / \mathrm{lb})$ for the vessel, heat exchanger and metal hydride (Schwarz and Amonkwah 1993). In this case, the capital cost of the hydride is two-thirds of the total storage cost and energy costs are another $27 \%$ of the total storage cost.

Heating and cooling requirements vary from 9,300-18,600 kJ/kg H$(4,000-8,000 \mathrm{Btu} / \mathrm{lb} \mathrm{H}$ ) $(\mathrm{T}$-Raissi and Sadhu 1994). In the case of low-temperature hydrides, the hydride temperature requirement is generally less than $100^{\circ} \mathrm{C}\left(212^{\circ} \mathrm{F}\right)$, but the heat source may need to be at a higher temperature to allow fast heat transfer with a minimum of heat transfer area (T-Raissi and Sadhu 1994).

\subsection{Underground Compressed Gas Operating Costs}

The operating costs for underground storage are limited to the energy and maintenance costs related to compressing the gas into underground storage and possibly boosting the pressure coming back out. One estimate of the operating costs of underground storage is $\$ 1.00-\$ 3.90 / \mathrm{kg}(\$ 0.47-\$ 1.80 / \mathrm{lb})$ (Oy 1992).

\subsection{CHOICE OF STORAGE}

The choice of which method of hydrogen storage is best depends on:

- $\quad$ The application (Is liquid hydrogen required? What pressure is required?)

- $\quad$ The required energy density (What form of hydrogen delivery will be used? Is space an issue?)

- $\quad$ The quantity of hydrogen to be stored (Is the storage used as a buffer, or primary storage for a large amount of hydrogen?)

- $\quad$ The storage period (Will the storage be used to keep hydrogen for a few hours, or is it seasonal storage?)

- What forms of energy are readily available (Is there waste heat available? Is there highpressure steam available for a turbine?)

- What is the geology of the area (Are there abandoned natural gas wells available?) 
- $\quad$ Any future expansion needs (Are there reasons to believe additional storage will be needed in the future?)

- Maintenance requirements (Is high reliability required? How often can the storage system be shut down for maintenance?)

- $\quad$ Capital costs (Are high capital costs prohibitive?)

(T-Raissi and Sadhu 1994; Oy 1992)

\subsection{Application}

If hydrogen is required for a cryogenic application, the only choice is liquid hydrogen. If on the other hand, hydrogen can be used as a gas, this would allow all forms of storage and delivery to be considered.

\subsection{Energy Density}

The energy density of the hydrogen may be an important consideration. For example, if the hydrogen must be delivered to a site far away, liquid hydrogen would probably be the best option. The higher density of liquid hydrogen means one truck can carry as much liquid hydrogen as 20 trucks carrying compressed gas.

Energy density can be expressed in terms of the volumetric energy density or the weight density. This is important in the case of metal hydrides because they have a high volumetric density, but a low weight density (Encyclopedia of Chemical Technology 1991; Hart 1997; Schwarz and Amonkwah 1993). In other words, a metal hydride storage tank may have a small footprint, but can weigh several tons. One reason metal hydrides are difficult to use in automobiles is weight limitation, but for stationary storage, size is usually of more concern than weight.

If hydrogen is being delivered continuously by pipeline, little if any hydrogen storage may be required, and it would not make sense to liquefy the hydrogen, then deliver it to a pipeline as a gas (Hart 1997; Report to Congress 1995). In pipelines with large variation in flow, hydrogen may need to be stored to meet peak demand. The method of storage in that case would depend on the quantity to be stored and the storage time.

\subsection{Quantity}

The quantity of hydrogen to be stored is a major consideration because the capital cost per pound of hydrogen is generally lower for larger capacity storage units. In the case of liquid hydrogen, boil-off rates are also inversely proportional to the vessel size, so larger storage units will have lower boil-off rates.

Compressed gas storage can be used for small quantities of hydrogen when cryogenic temperatures are not required (Carpetis 1994). Because of the high capital cost of a liquefaction 
plant, liquid hydrogen would be cost-prohibitive for small quantities of hydrogen, and the high boil-off rates associated with the smaller vessel size would raise this cost even more. A metal hydride might be a cost-effective option if the hydrogen is produced at a low pressure and a high- pressure gas is required. A metal hydride could also be used if the hydrogen must be purified. With very small quantities of hydrogen, the cost difference between compressed gas and metal hydride storage is not great because both require a pressure vessel and the metal hydride alloy cost is small compared to the vessel cost for small units (Carpetis 1994).

As the storage requirements increase, the metal hydride alloy becomes a larger percentage of the unit cost and becomes the driving cost factor. At the same time, the cost of compressed gas storage decreases per unit volume with larger vessels, making compressed gas storage more economical. Metal hydride storage may still be economical if high pressure hydrogen is needed and a source of waste heat is available (Carpetis 1994).

For even greater quantities of hydrogen, liquid hydrogen starts to become competitive because of the lower storage unit cost per pound of hydrogen. For small quantities of hydrogen, the pressure vessel cost for the compressed gas is lower than the combined costs of the insulated dewar, liquefier, high boiloff, and high energy use. However, as the quantity of hydrogen to be stored increases, the cost of the pressure vessel increases faster than the liquefaction costs (Taylor et al. 1986).

Underground storage is a special case of compressed gas storage where the "vessel" cost is very low. In most cases, underground storage in a natural geological formation will cost less than any other storage technique (Carpetis 1994; Oy 1992). The only case it wouldn't be cheaper is with small quantities of gas in large caverns where the amount of working capital invested in the cushion gas is large compared to the amount of hydrogen stored.

Compressed gas storage is generally limited to $1,300 \mathrm{~kg}(2,800 \mathrm{lb})$ of hydrogen or less because of high capital costs (Taylor et al. 1986). Over this, liquid hydrogen storage or underground storage should be considered.

\subsection{Storage Period}

The longer hydrogen is to be stored, the more favorable underground or liquid hydrogen storage becomes because of lower capital costs. If hydrogen is stored for a long time, the operating cost can be a small factor compared to the capital costs of storage (Carpetis 1994; Oy 1992).

Underground storage is the cheapest for short-term storage, followed by above-ground compressed gas storage, which should be considered for storage times of several hours to several days (Carpetis 1994; Oy 1992). Liquid storage and underground storage should be considered for seasonal or longterm storage of hydrogen for periods longer than a couple of days or 5\% annual turnover rates of gas (Carpetis 1994). Metal hydride storage is not economical for large quantities of gas because of the high capital cost of the metal hydride (Oy 1992). 


\subsection{Energy Availability}

The available energy may be another consideration when choosing methods of storage. For compressed gas storage and hydrogen liquefaction, compressor power consumption can be quite high. If inexpensive electricity, gas turbine, or steam turbine power is available, the compression costs will be lower. A cheap source of thermal energy or waste heat would benefit metal hydride storage by reducing the energy costs for releasing the hydrogen from the hydride (Carpetis 1994).

\subsection{Maintenance and Reliability}

Maintenance and reliability will depend on how simple the storage method is to operate and maintain. A liquefaction plant will be much more complicated and more costly to maintain than a metal hydride storage unit that has no rotating assemblies. Liquefaction will have the highest maintenance requirements, followed by compressed gas storage, and then metal hydrides.

\subsection{Safety}

Safety is a concern with any option. When the main options for storage are examined, metal hydrides appear to be the safest storage option because the storage unit is at low pressure. If there is a leak in the container, very little hydrogen will leak out because a source of continuous heat is required to release the bond between the metal and the hydrogen (Encyclopedia of Chemical Technology 1991; Hart 1997).

For compressed gas, there are two dangers. First, a high-pressure vessel always presents some level of risk, whether it is an inert gas or a reactive gas such as hydrogen (Schwarz and Amonkwah 1993; TRaissi and Sadhu 1994). Second, if a compressed gas tank develops a leak, it will result in the release of a large amount of hydrogen very quickly. Liquid hydrogen has the potential to release even more hydrogen than compressed gas if a storage container leaks because the liquid hydrogen will quickly vaporize. In open areas there is, however, little chance of detonation, because hydrogen diffuses into air quickly (Hart 1997).

\subsection{Summary}

Based on current hydrogen storage technology, the following generalizations can be made:

Underground Storage - For large quantities of gas or long-term storage.

Liquid Hydrogen - For large quantities of gas, long-term storage, low electricity costs or applications requiring liquid hydrogen.

Compressed Gas - For small quantities of gas, high cycle times or short storage times.

Metal Hydrides - For small quantities of gas. 


\subsection{ANALYSIS OF STORAGE COSTS}

An analysis was performed to estimate storage costs based on the major operating and capital expenses. For storage, there were two main factors: production rate and storage time. Production rate is used in sizing compressors and liquefaction plants, and determining the operating costs in each case. Production rate multiplied by the number of days of storage gives the storage capacity required, which in turn determines the storage unit size and capital costs. Flow rates are used to calculate the electricity, heating, and cooling requirements. These operating costs are independent of storage capacity. Sample calculations for each storage option are in Appendix A.

\subsection{Cost Assumptions}

Table 10 provides the factors used to estimate the capital costs associated with hydrogen storage. These particular numbers were used because they provided the best cost estimates over the entire range of flows examined.

Table 10 - Hydrogen Storage Capital Cost Assumptions

\begin{tabular}{|c|c|c|c|c|c|}
\hline & Base Size & Base Cost & Base Pressure & $\begin{array}{c}\text { Sizing } \\
\text { Exponent }\end{array}$ & $\begin{array}{c}\text { Pressure } \\
\text { Factor }\end{array}$ \\
\hline Compressor & $\begin{array}{l}4,000 \mathrm{~kW} \\
(5,400 \mathrm{hp})\end{array}$ & $\begin{array}{r}\$ 1,000 / \mathrm{kW} \\
(\$ 746 / \mathrm{hp})\end{array}$ & $\begin{array}{r}20 \mathrm{MPa} \\
(2,900 \mathrm{psia})\end{array}$ & 0.80 & 0.18 \\
\hline $\begin{array}{l}\text { Compressed } \\
\text { Gas Vessel }\end{array}$ & $\begin{array}{r}227 \mathrm{~kg} \\
(500 \mathrm{lb})\end{array}$ & $\begin{array}{r}\$ 1,323 / \mathrm{kg} \\
(\$ 600 / \mathrm{lb})\end{array}$ & $\begin{array}{r}20 \mathrm{MPa} \\
(2,900 \mathrm{psia})\end{array}$ & 0.75 & 0.44 \\
\hline Liquefier & $\begin{array}{r}454 \mathrm{~kg} / \mathrm{h} \\
(1,000 \mathrm{lb} / \mathrm{h})\end{array}$ & $\begin{array}{l}\$ 44,100 / \mathrm{kg} / \mathrm{hr} \\
(\$ 20,000 / \mathrm{lb} / \mathrm{h})\end{array}$ & $\mathrm{n} / \mathrm{a}$ & 0.65 & $\mathrm{n} / \mathrm{a}$ \\
\hline Dewar & $\begin{array}{r}45 \mathrm{~kg} \\
(100 \mathrm{lb})\end{array}$ & $\begin{array}{r}\$ 441 / \mathrm{kg} \\
(\$ 200 / \mathrm{lb})\end{array}$ & $\mathrm{n} / \mathrm{a}$ & 0.70 & $\mathrm{n} / \mathrm{a}$ \\
\hline $\begin{array}{l}\text { Metal } \\
\text { Hydride }\end{array}$ & $\mathrm{n} / \mathrm{a}$ & $\begin{array}{r}\$ 2,200 / \mathrm{kg} \\
(\$ 1,000 / \mathrm{lb})\end{array}$ & $\mathrm{n} / \mathrm{a}$ & 1.00 & $\mathrm{n} / \mathrm{a}$ \\
\hline Underground & $\mathrm{n} / \mathrm{a}$ & $\begin{array}{r}\$ 8.80 / \mathrm{kg} \\
(\$ 4.00 / \mathrm{lb})\end{array}$ & $\begin{array}{r}20 \mathrm{MPa} \\
(2,900 \mathrm{psia})\end{array}$ & 1.00 & 1.00 \\
\hline
\end{tabular}

n/a - Not applicable.

Table 11 gives the operating cost assumptions used in the analysis: 
Table 11 - Storage Operating Cost Assumptions

\begin{tabular}{|l|l|l|}
\hline & SI Units & English Units \\
\hline $\begin{array}{l}\text { Compressor Power }(0.1 \text { to } 20 \\
\text { MPa [14.7 to 2,900 psia]) }\end{array}$ & $2.2 \mathrm{kWh} / \mathrm{kg}$ & $1.0 \mathrm{kWh} / \mathrm{lb}$ \\
\hline $\begin{array}{l}\text { Compressor Cooling }(0.1 \text { to } 20 \\
\text { MPa [14.7 to 2,900 psia]) }\end{array}$ & $50 \mathrm{~L} / \mathrm{kg}$ & $6.0 \mathrm{gal} / \mathrm{lb}$ \\
\hline Liquefier Power & $10 \mathrm{kWh} / \mathrm{kg}$ & $4.5 \mathrm{kWh} / \mathrm{lb}$ \\
\hline Liquefier Cooling & $626 \mathrm{~L} / \mathrm{kg}$ & $75 \mathrm{gal} / \mathrm{lb}$ \\
\hline Boil-Off Rate & $0.1 \% / \mathrm{d}$ & $0.1 \% / \mathrm{d}$ \\
\hline Hydride Cooling & $209 \mathrm{~L} / \mathrm{kg}$ & $25 \mathrm{gal} / \mathrm{lb}$ \\
\hline Hydride Heat of Reaction & $23,260 \mathrm{~kJ} / \mathrm{kg}$ & $10,000 \mathrm{Btu} / \mathrm{lb}$ \\
\hline Electricity Cost & $\$ 0.05 / \mathrm{kWh}$ & $\$ 0.05 / \mathrm{kWh}$ \\
\hline Steam Cost & $\$ 3.80 / \mathrm{GJ}$ & $\$ 4.00 / \mathrm{MM}$ Btu \\
\hline Cooling Water Cost & $\$ 0.02 / 100 \mathrm{~L}$ & $\$ 0.07 / 1,000 \mathrm{gal}$ \\
\hline Operating Days & $350 / \mathrm{yr}$ & $350 / \mathrm{yr}$ \\
\hline Depreciation & $\begin{array}{l}22-\text { year, straight-line, } \\
\text { ADS method }\end{array}$ & $\begin{array}{l}22-\text { year, straight-line, } \\
\text { ADS method }\end{array}$ \\
\hline
\end{tabular}

\subsection{Compressed Gas Storage Methodology}

For compressed gas, the storage requirements are calculated from the production rate and storage time. Energy use is based on the flow rate and final outlet pressure. The base case for this power consumption assumes compression from 1 atmosphere to $20 \mathrm{MPa}(2,900 \mathrm{psia})$. For other outlet pressures, a ratio of the natural logs of the pressures is used to adjust the power requirements up or down. Compressor costs are based on the power of the compressor and are adjusted for outlet pressure. Compressor tank costs are based on an estimate of the storage cost at $20 \mathrm{MPa}(2,900$ psia) and this cost is adjusted for different sizes at different pressures. Although the base cost is given on a mass basis, it is scaled based on volume by multiplying by a ratio of the pressures (See Appendix A.1 for details). Capital costs include the compressor and pressure vessel; operating costs include the electricity and cooling water costs. Depreciation is calculated using the 22-year straight-line Alternative Depreciation System (ADS). 


\subsection{Liquid Hydrogen Storage Methodology}

The flow rate or production rate for the liquid hydrogen case is adjusted to account for hydrogen boiloff losses that occur during storage. A simple exponential rate equation is used in this calculation. The amount of hydrogen storage is based on the adjusted flow rate and storage time. Operating costs are also based on the adjusted production rate. When converting to costs per pound of hydrogen, the losses are taken into account. The electricity and cooling water requirements are based on the adjusted flow rate. The liquefier capital cost is also based on the adjusted flow rate and scaled using the factor noted earlier. The dewar capital cost is based on the total amount of hydrogen stored. The capital cost calculations include the cost of the liquefier and dewar and, as in the compressed gas case, are depreciated over 22 years. Appendix A.2 has a sample calculation for liquid hydrogen storage.

\subsection{Metal Hydride Methodology}

Like the other cases, the metal hydride storage requirements are calculated by multiplying the production rate times the storage time. Energy and cooling requirements are calculated based on the hydrogen flow rate. Cooling water is required to store the hydrogen in its hydride form, and heat is used to later release the hydrogen from the hydride. Hydride capital costs were based on a fixed storage cost for a given quantity of hydrogen with no scaling factor, so the resulting costs are independent of flow rate. Energy costs are calculated assuming a fixed steam cost, and a pre-existing heat source was assumed. Total costs include heating, cooling, and the depreciation cost of the metal hydride. These calculations are shown in Appendix A.3.

\subsection{Underground Storage Methodology}

The hydrogen flow rate is used to calculate the power and cooling requirements for compressing the hydrogen from 1 atmosphere to $20 \mathrm{MPa}$ (2,900 psia), as in the compressed gas case. Again, a ratio of the natural logs of the pressures is used to calculate the power requirements for pressures other than 20 MPa (2,900 psia). The compressor cost is based on the power and outlet pressure. The underground cavern cost is calculated based on a fixed cost per unit storage volume. When a pressure other than 20 $\mathrm{MPa}(2,900 \mathrm{psia})$ is used, a ratio of the pressures is used to take the volume change of the gas into account. No increased cavern costs are assumed for higher pressures; the cost difference is associated only with the change in volume. Capital costs include the cost of the compressor and cavern. Operating costs include electricity and cooling water. A sample underground storage cost calculation is shown in Appendix A.4.

\subsection{Storage Conclusions}

Underground storage was found to be the cheapest method at all production rates and storage times because of the low capital cost of the cavern. Most of the cost of underground storage is associated with the electricity requirements to compress the gas, which is independent of storage 
volume. This means the cost of underground storage is very insensitive to changes in production rate or storage time.

The metal hydride storage was assumed to provided no economy of scale, so its hydrogen storage costs were independent of flow rate. There were no savings at larger sizes, so it does not compete with the other storage options at long storage times or high hydrogen flows. Because the alloy capital cost is a major portion of the total hydride storage cost, hydride storage costs vary little with heating costs. Metal hydride storage, however, does compete with liquid hydrogen and compressed gas storage at low flow rates and short storage times.

Liquid hydrogen storage is not economical at low production rates because of the high capital cost of the liquefier. Even at higher production rates, compressed gas is more economical for short storage periods. However, as the storage time increases, liquid hydrogen has an advantage over compressed gas because of the low capital cost of a liquid hydrogen dewar compared to a compressed gas pressure vessel.

Because of the low cost of the dewar, liquid hydrogen storage costs are relatively insensitive to storage time. At high production rates, economy of scale factors reduce the liquid storage costs until they are eventually limited by the electricity costs associated with liquefaction. Liquid hydrogen storage cost is affected the greatest by changes in electricity price because it has the largest power requirement. The analysis found that boil-off rate did not become a major cost factor until the storage time was longer than a week or two, so for short-term storage, cheaper insulation may reduce overall costs.

Compressed gas storage competes with liquid hydrogen and metal hydride storage for small quantities of hydrogen and low production rates. At low production rates, the capital cost of the pressure vessel is large, but economy of scale reduces this cost at higher production rates, until the storage cost is eventually limited by the compressor electricity cost. As storage time increases, the capital cost of the pressure vessel drives up the storage cost.

One option for compressed gas storage is to increase the operating pressure of the system. This increases the cost of the pressure vessel and compressor, but the reduction in tank size can result in an overall savings. For short storage periods with compressed gas, an optimum occurs where the reduction in tank capital costs is balanced against the increased compressor and compressor electricity costs. At longer storage times, the capital cost reduction becomes the important factor, so the optimum occurs at the maximum operating pressure, which minimizes the tank size and cost.

A similar analysis was carried out for underground storage, and indicated that for short storage periods, the optimum occurs at the lowest possible storage pressure because this is where the compressor electricity requirements are the lowest. At longer storage times, the capital cost of the cavern becomes significant, and an optimum is formed where the electricity costs balance out the cavern costs. Note that the price of cushion gas was not taken into account. A high cushion 
gas cost would favor higher operating pressures, allowing more storage or working volume for the same amount of cushion gas.

For all storage options examined, cooling water costs were negligible compared to the energy and capital expenses.

Appendix D contains detailed data for each storage option at various production rates and storage times. Graphs identifying important trends in the data, along with some sensitivity analyses are included in Appendix F.

\subsection{TRANSPORTATION OF HYDROGEN}

Hydrogen can be transported as a compressed gas, a cryogenic liquid, or as a solid metal hydride. The cheapest method of transportation will depend on the quantity delivered and the distance. The methods of delivering the hydrogen considered were truck, rail, ship, and pipeline.

\subsection{Compressed Gas Transport}

Compressed gas can be transported using high-pressure cylinders, tube trailers or pipelines. If hydrogen is to be transported as a gas, it should be compressed it to a very high pressure to maximize tank capacities. High-pressure gas cylinders for example are rated as high as $40 \mathrm{MPa}(5,800 \mathrm{psig})$ and hold about $1.8 \mathrm{~kg}(4 \mathrm{lb})$ of hydrogen, but are very expensive to handle and transport (Encyclopedia of Chemical Technology 1991).

Tube trailers, consisting of several steel cylinders mounted to a protective framework, can be configured to hold 63-460 kg (140-1,000 lb) of hydrogen (Air Products 1997), depending on the number of tubes. Operating pressures are 20-60 MPa (2,900-8,700 psig) (Leiby 1994; Hart 1997; Zittel and Wurster 1996; Air Products 1997).

Hydrogen is delivered by pipeline in several industrial areas of the United States, Canada, and Europe. Typical operating pressures are 1-3 MPa (145-435 psig) with flows of 310-8,900 kg/h (685-20,000 lb/h) (Hart 1997; Zittel and Wurster 1996; Report to Congress 1995). Germany has a $210 \mathrm{~km}$ (130 mi) pipeline that has been operating since 1939 , carrying $8,900 \mathrm{~kg} / \mathrm{h}(20,000 \mathrm{lb} / \mathrm{h})$ of hydrogen through a $0.25 \mathrm{~m}$ (10 in.) pipeline operating at $2 \mathrm{MPa}$ (290 psig) (Hart 1997). The longest hydrogen pipeline in the world is owned by Air Liquide and runs $400 \mathrm{~km}$ (250 miles) from Northern France to Belgium (Hart 1997). The United States has more than $720 \mathrm{~km}$ (447 mi) of hydrogen pipelines concentrated along the Gulf Coast and Great Lakes (Hart 1997; Report to Congress 1995).

No information was found on the transport of compressed hydrogen by rail. 


\subsection{Liquid Hydrogen Transport}

Liquid hydrogen is transported using special double-walled insulated tanks to prevent boil-off of the liquid hydrogen. Some tankers also use liquid nitrogen heat shields to cool the outer wall of the liquid hydrogen vessel to further minimize heat transfer (Huston 1984).

Tank trucks can carry 360-4,300 kg (800-9,500 lb) of liquid hydrogen (Leiby 1994; International Journal of Ambient Energy 1992; Huston 1984; Timmerhaus and Flynn 1989). Railcars have even greater capacities, carrying 2,300-9,100 kg (5,000-20,000 lb) of hydrogen (Encyclopedia of Chemical Technology 1991; International Journal of Ambient Energy 1992; Huston 1984; Timmerhaus and Flynn 1989). Boil-off rates for trucks and railcars are 0.3\%-0.6\%/day (Encyclopedia of Chemical Technology 1991; Timmerhaus and Flynn 1989).

Barges or sea-going vessels have been considered for long-distance transport of hydrogen. Canada developed several ship designs for transatlantic transport of hydrogen. One uses five small barges carried in a larger ship that can be separated once the trip is complete. Each barge would carry 21,200 $\mathrm{kg}(46,800 \mathrm{lb})$ of hydrogen, with no venting during a 50-day trip. Other designs included a single tanker holding 7 million $\mathrm{kg}$ (16 million $\mathrm{lb}$ ) of hydrogen and another with four spherical tanks, each holding 3.5 million $\mathrm{kg}$ ( 8 million $\mathrm{lb}$ ). Boil-off rates for these vessels are estimated at $0.2 \%-0.4 \%$ day (Hart 1997). None of these vessels has been constructed, but liquid natural gas tankers transport as much as $125,000 \mathrm{~m}^{3}$ of natural gas (roughly equivalent to 9 million $\mathrm{kg}$ [20 million $\mathrm{lb}$ ] of hydrogen) (Timmerhaus and Flynn 1989).

One other idea for the delivery of liquid hydrogen is through an insulated pipeline that would also include a super-conducting wire. The liquid hydrogen would act as a refrigerant for the superconductor and would allow long distance transportation of electricity without the high current losses of conventional power lines (Oy 1992; Timmerhaus and Flynn 1989). The main problem with liquid hydrogen transport would be the specialized insulating requirements and losses from pumping and re-cooling the liquid hydrogen along the way (Timmerhaus and Flynn 1989).

\subsection{Metal Hydride Transport}

Metal hydrides can be used for transport by absorbing hydrogen with a metal hydride, then loading the entire container onto a truck or railcar for transport to the customer's site where it can be exchanged for an empty hydride container, or used as a conventional tanker (Huston 1984; Au et al. 1996). 


\subsection{CAPITAL COSTS OF TRANSPORTATION EQUIPMENT}

\subsection{Compressed Gas Transport Costs}

Tube trailer capital costs depend on the operating pressure of the truck, the storage capacity of each trailer, and the distance to the customer site. Higher operating pressures increase the capacity of a tube trailer, but increase the purchased price of each truck. This can result in lower overall capital costs by reducing the number of trucks required. The distance to the customer site also affects the number of trucks. For local delivery, the same truck can make several trips back and forth between the production site and the customer site, but for long distances, each truck might be able to make only one or two deliveries per day.

One capital cost of $\$ 340,000$ was found for a tube trailer containing 16 tubes with a total capacity of $460 \mathrm{~kg}$ (1,000 lb) of hydrogen. The cost of a truck cab to go with it was $\$ 110,000$ (Taylor et al. 1986). A recent budgetary estimate for a tube truck was $\$ 140,000$ (FIBA 1998).

Operating costs include fuel costs and driver wages or freight charges.

\subsection{Compressed Gas Pipeline Costs}

Hydrogen pipelines are constructed of 0.25-0.30 m (10-12 in.) commercial steel and operate at 1-3 $\mathrm{MPa}$ (145-435 psig). Natural gas mains for comparison are constructed of pipe as large as $2.5 \mathrm{~m}(5 \mathrm{ft})$ in diameter and have working pressures of 7.5 MPa (1,100 psig) (Hart, 1997).

Because a large fraction of the pipeline cost is for installation, natural gas construction prices were used to estimate the pipeline costs. Table 12 lists the installation costs of some recent projects. 
Table 12 - Pipeline Installation Costs

\begin{tabular}{|r|r|r|r|r|l|}
\hline $\begin{array}{c}\text { Length } \\
(\mathrm{km})\end{array}$ & $\begin{array}{c}\text { Length } \\
(\mathrm{mi})\end{array}$ & Cost* $(\$)$ & $\begin{array}{c}\text { Cost* } \\
(\$ / \mathrm{km})\end{array}$ & $\begin{array}{c}\text { Cost* } \\
(\$ / \mathrm{mi})\end{array}$ & Source \\
\hline 78.4 & 48.7 & $\$ 18,000,000$ & $\$ 237,000$ & $\$ 370,000$ & $\begin{array}{l}\text { TransCanada Pipeline, Ltd. } \\
1996 \mathrm{a}\end{array}$ \\
\hline 108.5 & 67.4 & $\$ 84,000,000$ & $\$ 774,000$ & $\$ 1,250,000$ & $\begin{array}{l}\text { TransCanada Pipeline, Ltd. } \\
1996 \mathrm{~b}\end{array}$ \\
\hline 46.9 & 29.1 & $\$ 48,000,000$ & $\$ 1,000,000$ & $\$ 1,650,000$ & $\begin{array}{l}\text { TransCanada Pipeline, Ltd. } \\
1996 \mathrm{c}\end{array}$ \\
\hline 731.0 & 454.0 & $\$ 910,000,000$ & $\$ 1,250,000$ & $\$ 2,000,000$ & $\begin{array}{l}\text { TransCanada Pipeline, Ltd. } \\
1993\end{array}$ \\
\hline 561.0 & 349.0 & $\$ 384,000,000$ & $\$ 685,000$ & $\$ 1,100,000$ & $\begin{array}{l}\text { TransCanada Pipeline, Ltd. } \\
1997\end{array}$ \\
\hline 40.2 & 25.0 & $\$ 5,300,000$ & $\$ 132,000$ & $\$ 212,000$ & NYSEG 1996a \\
\hline
\end{tabular}

*All costs are adjusted to 1995 dollars.

The major operating cost for hydrogen pipelines is compressor power and maintenance. Some hydrogen losses may occur in the piping network, but for natural gas piping systems, these losses are less than $1 \%$ (Hart, 1997). An estimate of the cost of piping hydrogen from North Africa to Central Europe $(3,300 \mathrm{~km}[2,050 \mathrm{mi}])$ was $\$ 0.90-\$ 1.20 / \mathrm{kg}(\$ 0.41-\$ 0.53 / \mathrm{b})$, including compression costs. Another estimate for the United States put the cost at $\$ 0.39 / \mathrm{kg}$ ( $\$ 0.18 / \mathrm{lb}$ ) (Report to Congress 1995). Two other studies also noted that for large quantities of hydrogen, pipelines are the cheapest means of transporting hydrogen, except for transport across the ocean, when liquid hydrogen transport is the cheapest means (Oy 1992; Johannsen 1993).

\subsection{Liquid Hydrogen Transport Costs}

The capital costs of liquid hydrogen transport will consist mainly of the insulated tank trailer or railcar, plus the cost of the cab for truck transport. Although hydrogen is not currently transported overseas, a hydrogen barge is expected to cost 3.5-4 times as much as a liquefied natural gas barge (Carpetis 1994).

The liquid hydrogen truck transport costs include the same fuel, driver wages and maintenance charges as for gas transport, but also include boil-off losses during transport. Expected boil-off losses during transfer between tanks is 10\%-20\%, but can be as high as 50\% (Huston 1984; Johannsen 1993; Taylor et al. 1986). As mentioned earlier, boil-off during transport is expected to be $0.3 \%-0.6 \% /$ day. Railcar transport of hydrogen includes boil-off losses during transport and transfer, plus rail freight charges. 
One source estimated long-distance transportation of liquid hydrogen from Africa to Europe at $\$ 1.80$ $\$ 2.10 / \mathrm{kg}$ (\$0.82-\$0.94/lb) (Johannsen 1993). Another source mentions that shipping liquid hydrogen across the Atlantic would triple its price (Oy 1992).

\subsection{Metal Hydride Transport Costs}

For transportation of hydrogen using metal hydrides, the major cost is the capital expense of buying the metal hydride and containers. Once filled, the hydride containers can be shipped like any other piece of freight, with charges depending on the distance and weight.

\subsection{CHOICE OF TRANSPORTATION}

The main factors affecting the choice of hydrogen transport are the application, quantity, and distance from the production site to the customer. As mentioned under storage, if liquid hydrogen is needed for the application, it should be delivered as liquid hydrogen.

\subsection{Quantities}

For large quantities of hydrogen, pipeline delivery is cheaper than all other methods except in the case of transport over an ocean, in which case liquid hydrogen transport would be cheapest. The next cheapest method of delivery would be liquid hydrogen. Pipeline delivery has the benefit of a very low operating cost, consisting mainly of compressor power costs, but has a high capital investment. Liquid hydrogen, on the other hand, would have a high operating cost, but possibly a lower capital cost, depending on the quantity of hydrogen and the delivery distance. The break-even point between liquid hydrogen and a pipeline will vary depending on the distance and quantity.

For smaller quantities of hydrogen, pipeline delivery is not competitive, but compressed gas delivery may be competitive. Compared to liquid hydrogen, compressed gas has lower power requirements and slightly lower capital costs for the tube trailers, but many more tube trailers are required to deliver the same quantity of hydrogen. Which delivery method is more economical will depend on the delivery distance, because it may be possible to use the same tube trailer for several trips per day if it is a short distance.

For still smaller quantities, the high capital cost of a pipeline eliminates it as an option. The deciding factor between liquid hydrogen and compressed gas becomes a matter of distance. For long distances, the higher energy costs of liquefaction will balance out against the higher capital and transportation expense of many compressed gas tube trailer trips back and forth. If the distance is relatively short, and the quantity of hydrogen transported is small, compressed gas may win out. 
Metal hydride transport costs tend to fall between those for liquid hydrogen transport and compressed gas transport. While metal hydride transport has a larger capital expense per truck, the hydrogen capacity per truck is greater compared to using compressed gas transport.

\subsection{Distance}

As mentioned earlier, distance is an important factor. For a short distance a pipeline can be very economical because the capital expense of a short pipeline may be close to the capital cost of tube trucks or tankers, and there are no transportation or liquefaction costs. As the distance increases, the capital cost of a pipeline increases rapidly, and the economics will depend on the quantity of hydrogen-pipelines will be favored for larger quantities of hydrogen. For small quantities of hydrogen, at some point the capital cost of the pipeline will be higher than the operational costs associated with delivering and liquefying the hydrogen.

Distance is a deciding factor between liquid and gaseous hydrogen. At long distances, the number of trucks required to deliver a given quantity of compressed hydrogen will be greater than the increased energy costs associated with liquefaction and fewer trucks.

\subsection{Special Case--Power Supply}

One special case related to hydrogen is when energy must be transmitted a long distance. Currently, energy is transmitted by high-voltage power lines, and current losses result in a 7\%-8\% loss in transmitted energy. Hydrogen gas transport through a pipeline on the other hand, results in somewhat lower losses, meaning it may be cheaper to produce hydrogen and pipe it to a location requiring heat or electrical energy because the energy losses are less with a hydrogen pipeline (Hart 1997). One source indicated the cutoff where hydrogen energy transport is cheaper than overhead lines is $1,000-2,250 \mathrm{~km}$ (631-1,398 miles) (Report to Congress 1995).

\subsection{Futures in Hydrogen Transport}

Several trends in hydrogen transportation were identified. First, there is continued research in longrange transport of hydrogen using barges or ships. Canada is especially interested because it has large hydroelectric resources that could be used to produce hydrogen. It has designed several vessels for carrying hydrogen across the Atlantic. One design uses five barges contained on a single ship, designed to go for 50 days without venting hydrogen. Once overseas, the barges can be separated to go to different destinations without incurring transfer losses (Hart 1997). Two other designs include a ship with four spherical dewars, each holding 3.5 million $\mathrm{kg}$ ( 8 million $\mathrm{lb}$ ) of hydrogen and a single-hull design capable of carrying 7 million $\mathrm{kg}$ (16 million $\mathrm{lb}$ ) of hydrogen with a boil-off rate of $0.2 \%-0.4 \% / \mathrm{d}$ (Hart 1997). Another option mentioned was the use of airplanes to delivery hydrogen over great distances to reduce transport times and consequently reduce boil-off loses. Work is also being done to reduce transfer losses in hydrogen transportation, with a goal of reducing losses to 8\% (Johannsen 1993). 
Pipeline delivery of liquid hydrogen was not analyzed, but there are pipes capable of carrying liquid hydrogen (Oy 1992; Timmerhaus and Flynn 1989). One special case of using a liquid hydrogen pipe is when it is combined with a superconducting wire. The liquid hydrogen could keep the wire cool enough to be a superconductor for very efficient transport of electricity, possibly justifying the higher capital costs of the liquid hydrogen pipeline (International Journal of Ambient Energy 1992).

Large-scale distribution networks for hydrogen must address storage issues to provide a buffer between production facilities and customers and to cover fluctuations in demand (Report to Congress 1995). Natural gas pipelines could be converted to hydrogen gas (Hart 1997), but there is some concern that hydrogen embrittlement of the fittings and piping would cause them to crack and leak (Report to Congress 1995).

Much work is being done to increase the storage density and reduce the costs of metal hydrides because of the reduced risk of catastrophic hydrogen releases. One option for metal hydrides is to use metal hydride "boxes" where a charged hydride container is exchanged for an empty one at the customer site. This would eliminate the need for separate storage units at the hydrogen plant and customer site if the price of the hydride were low enough to allow the use of several units (Huston 1984).

As mentioned in the storage section, liquid hydrides are being investigated and could be easily transported by pipeline, tanker truck, railcar, or supertanker (Hart 1997).

\subsection{Summary}

Below is a summary of the decision making criteria:

Pipeline - For large quantities or long-distance power transmission.

Liquid Hydrogen - For transport over long distances.

Compressed Gas - For small quantities over short distances.

Metal Hydride - For short distances.

\subsection{ANALYSIS OF THE COST TO TRANSPORT HYDROGEN}

The two main factors affecting the cost of transporting hydrogen are production rate and delivery distance. It is incorrect to calculate the delivered cost of hydrogen based on a per truck basis, because this does not take into account the fact that one truck can make several trips, or may sit idle much of the time. For example, if a liquid hydrogen tanker makes only one trip per day, its capital and operating costs are added to one truckload of hydrogen. If the same truck makes five trips, the capital expense for the truck is spread out over five times as much hydrogen. 
Truck capacity is an important factor, especially for longer distances, because it determines the number of trips that must be made and how many trucks are required. At higher production rates or longer distances, several trucks may be in transit at any given time.

Capital costs include the cost of the transport container, the cost of the truck cab and the cost of the trailer undercarriage, or the cost of pipeline installation and construction. For flexibility, a separate cost was included for the truck undercarriage and tank container. This reflects the trend by industry toward intermodal transport units that can be used with trucks, railcars, or even ships. Operating costs include labor for drivers, fuel, compressor electricity, and freight charges for rail and ship transport. Labor and truck availability are calculated based on average speeds and the delivery distance with added time for loading and unloading.

Appendix B contains sample calculations for each hydrogen transport method.

\subsection{Cost Assumptions for Hydrogen Transport}

Table 13 lists the assumptions that were used for the transportation capital costs.

Table 13 - Hydrogen Transport Capital Cost Assumptions

\begin{tabular}{|l|l|l|}
\hline & Cost & Hydrogen Capacity/Size \\
\hline Tube Truck Intermodal Unit & $\$ 100,000$ & $180 \mathrm{~kg}(400 \mathrm{lb})$ \\
\hline Truck Liquid Intermodal Unit & $\$ 350,000$ & $4,080 \mathrm{~kg}(9,000 \mathrm{lb})$ \\
\hline Metal Hydride Intermodal Unit & $\$ 2,200 / \mathrm{kg} \mathrm{H}(\$ 1,000 / \mathrm{lb})$ & $454 \mathrm{~kg} \mathrm{H}(1,000 \mathrm{lb})$ \\
\hline Truck Undercarriage & $\$ 60,000$ & \\
\hline Truck Cab & $\$ 90,000$ & \\
\hline Rail Tube Assembly & $\$ 200,000$ & $454 \mathrm{~kg}(1,000 \mathrm{lb})$ \\
\hline Rail Liquid Unit & $\$ 400,000$ & $9,090 \mathrm{~kg}(20,000 \mathrm{lb})$ \\
\hline Rail Hydride Unit & $\$ 2,200 / \mathrm{kg} \mathrm{H}(\$ 1,000 / \mathrm{kg})$ & $910 \mathrm{~kg}(2,000 \mathrm{lb})$ \\
\hline Rail Undercarriage & $\$ 100,000$ & \\
\hline Ship Liquid Unit & $\$ 350,000$ & $4,080 \mathrm{~kg}(9,000 \mathrm{lb})$ \\
\hline Pipeline Cost & $\$ 620,000 / \mathrm{km}(\$ 1 \mathrm{million} / \mathrm{mi})$ & \\
\hline Compressor Cost & $\$ 1,000 / \mathrm{kW}(\$ 746 / \mathrm{hp})$ & $4,000 \mathrm{~kW}(5,400 \mathrm{hp})$ \\
\hline
\end{tabular}

Table 14 gives the assumptions used for calculating the operating costs. 
Table 14 - Transport Operating Cost Assumptions

\begin{tabular}{|c|c|}
\hline Truck Mileage & $6 \mathrm{mpg}(2.6 \mathrm{~km} / \mathrm{L})$ \\
\hline Average Truck Speed & $50 \mathrm{mph}(80 \mathrm{~km} / \mathrm{h})$ \\
\hline Truck Load/Unload Time & $2 \mathrm{~h} /$ trip \\
\hline Truck Availability & $24 \mathrm{~h} / \mathrm{d}$ \\
\hline Driver Availability & $12 \mathrm{~h} / \mathrm{d}$ \\
\hline Driver Wage (Fully Loaded) & $\$ 28.75 / \mathrm{h}$ \\
\hline Diesel Price & $\$ 1.00 / \mathrm{gal}$ \\
\hline Truck Boil-Off Rate & $0.3 \% / \mathrm{d}$ \\
\hline Rail Average Speed & $25 \mathrm{mph}(40 \mathrm{~km} / \mathrm{h})$ \\
\hline Rail Load/Unload Time & $2 \mathrm{~h} /$ trip \\
\hline Rail Car Availability & $24 \mathrm{~h} / \mathrm{d}$ \\
\hline Rail Freight Charge & \$400/wagon \\
\hline Rail Boil-Off Rate & $0.3 \% / \mathrm{d}$ \\
\hline Average Ship Speed & $10 \mathrm{mph}(16 \mathrm{~km} / \mathrm{h})$ \\
\hline Ship Load/Unload Time & $48 \mathrm{~h} /$ trip \\
\hline Ship Tank Availability & 24 h/day \\
\hline Ship Freight Charge & $\$ 3,000 /$ intermodal unit \\
\hline Ship Boil-Off Rate & $0.3 \% / \mathrm{d}$ \\
\hline Pipeline Roughness & $4.6 \times 10^{5} \mathrm{~m}$ \\
\hline Pipeline Diameter & $0.25 \mathrm{~m}$ (10 in.) \\
\hline Pipeline Gas Temperature & $10 \quad \mathrm{C}(50 \mathrm{~F})$ \\
\hline Pipeline Delivery Pressure & $20 \mathrm{MPa}(2,900 \mathrm{psia})$ \\
\hline Hydrogen Viscosity & $8.62 \times 10^{-6} \mathrm{~kg} / \mathrm{m} \mathrm{s}$ \\
\hline Hydrogen Gas Constant & $4,124 \mathrm{~N} \mathrm{~m} / \mathrm{kg} \mathrm{K}$ \\
\hline Compressor Power (0.1 to $20 \mathrm{MPa}$ [14.6 to 2,900 psia]) & $2.2 \mathrm{kWh} / \mathrm{kg}(1.0 \mathrm{kWh} / \mathrm{lb})$ \\
\hline Electricity Cost & $\$ 0.05 / \mathrm{kWh}$ \\
\hline Operating Days & $350 \mathrm{~d} / \mathrm{yr}$ \\
\hline Trailer Depreciation & 6 years, straight-line, ADS method \\
\hline Truck Cab Depreciation & 4 years, straight-line, ADS method \\
\hline Railcar Depreciation & 15 years, straight-line, ADS method \\
\hline Pipeline Depreciation & 22 years, straight-line, ADS method \\
\hline
\end{tabular}




\subsection{Truck Transport Methodology}

The truck transportation costs were calculated as follows:

First the production rate is multiplied by the operating days to calculate the annual production rate. This annual production rate is divided by the truck capacity to find the number of trips. (It is possible to have less than one trip per day for small production rates.) The total number of miles traveled is calculated using the two-way drive distance times the number of trips per year. The travel time per trip is calculated by dividing the two-way distance by the average truck speed and rounding up to the next whole hour. The per trip travel time is multiplied by the total number of trips per year to get the total driving time per year. The total time for loading and unloading is calculated by multiplying the load/unload time by the number of trips per year. Adding the drive time and loading/unloading time gives the total delivery time. (See Appendix B for a sample calculation.)

The total delivery time is divided by the truck availability per year to determine the number of trucks needed (One truck may be used for several trips using this method). Dividing the total delivery time by the yearly driver availability determines the number of drivers needed (One driver may make multiple trips, or multiple drivers may be needed for long trips). Fuel use is based on the distance driven divided by the mileage. Fuel cost is then calculated based on usage.

The capital costs include the price of the truck cab, undercarriage, and intermodal storage unit. Depreciation is straight-lined separately for the cab and trailer since they have different Internal Revenue Service class lives. The labor costs are based on total driving hours. (Whether the driver wages were paid for time on the road or time driving was unclear. In the case of trips longer than 12 hours, two drivers are needed, but in these calculations, the wages were paid for time driving only.) Total cost consists of capital depreciation, labor, and fuel costs.

Trip frequency is calculated by dividing the trips per year by the number of operating days. Trip length was based on the total delivery time divided by the number of trips (or drive time per trip plus the delivery time). A utilization rate is calculated by dividing the trip frequency by the number of trucks.

A fixed price was assumed for all trailers. Metal hydride costs were calculated using a metal hydride storage price, but the capacity of the metal hydride truck was kept constant. For liquid hydrogen, boiloff losses were taken into account by assuming some hydrogen was lost during transit. No transfer losses during loading and unloading were included.

\subsection{Rail Delivery Methodology}

For rail transport, similar procedures were used to calculate the delivery time and number of railcars required, but there are no fuel or labor costs. Instead, a flat rate freight charge is assumed. The transit times were rounded up to the next whole day, and the loading/unloading 
time was changed to 24 hours, assuming one rail switch per day. The hydrogen producer was assumed to own the rail cars, so no demurrage or rental fees were included.

For the rail case, higher storage capacities were used. For the metal hydride, a higher railroad weight allowance allowed the storage capacity to be raised to $910 \mathrm{~kg}(2,000 \mathrm{lb})$. At 3\% storage density, this would result in a total hydride alloy weight of 30 tonnes (33 tons). The liquid hydrogen capacity was based on values for a jumbo liquid hydrogen railcar.

Capital costs for the rail case consist of the rail car storage unit and undercarriage. The only operating cost is the railroad freight charge. Hydrogen boil-off is accounted for in the liquid hydrogen case.

\subsection{Water Transport Methodology}

The cost calculations for shipping hydrogen by ship or barge are very similar to the calculations for shipping by rail, except the average speed is lower and the load/unload time is extended to 48 hours, assuming a shipping container must be there the day before the ship leaves and can't be picked up until the day after the ship arrives. Again, a flat rate is assumed for calculating shipping charges and the travel time is rounded up to the next whole day.

The storage capacities used for transport by ship are the same as for truck transport, because intermodal transport units are assumed to be used. In this case, no undercarriage charge was used. The costs of getting the intermodal units from the hydrogen plant to the shipyard were not included.

\subsection{Pipeline Delivery Methodology}

For pipelines, the costs considered included the installed pipeline costs, the compressor cost to overcome the friction losses in the pipe, and the electricity requirements for the compressor.

The pressure loss through the pipe was calculated assuming the roughness of steel pipe and a compressible gas flow equation. The gas being pumped was assumed to be coming out of storage at pressure, and the only compression needed was to provide motive force to overcome friction losses in the pipe. The compressor size and energy requirements were based on the same ratio of logs used to calculate the incremental increase in storage pressures. In most cases the pipeline losses, and therefore compressor size, were small.

Capital costs for the pipeline include all costs associated with purchasing the pipe, installing it and obtaining any required right-of-ways. The total cost for pipeline delivery includes the compressor, pipeline, and electricity costs. 


\subsection{Transport Conclusions}

Liquid hydrogen transport by truck is the cheapest alternative, except for large quantities of hydrogen, when pipeline delivery becomes competitive. At longer distances, the capital cost of the extra pipeline requires more hydrogen flow before it will compete with liquid hydrogen delivery. Sharing the expense of a pipeline among several suppliers and users would reduce these costs. Because the major expense is installing the pipeline, and not the pipeline cost itself, a larger pipeline can be installed to handle multiple users for about the same cost. This is currently done along the Gulf Coast and around the Great Lakes.

Very little energy is required to pump the hydrogen through the pipeline. Bringing the hydrogen up to pressure would require a great deal more energy than is shown. These power requirements were incorporated into the previous storage costs.

In all cases, except pipeline delivery, a minimum transport cost is associated with each delivery method for a given distance. This point is reached when the production rate is high enough that the truck or rail car is being fully utilized $100 \%$ of the time. As an example, a small hydrogen plant doubles its production rate and, instead of making one trip per day with a liquid hydrogen truck, it makes two trips per day. The total capital cost remains the same--the cost of one truck--but this cost is now spread out over twice as much hydrogen. If a truck is already fully utilized, however, any increase in production will require purchasing another truck and produces no reduction in transport costs. The lowest capacity methods level off first for any given distance as production rate increases.

Rail car costs vary little with production rate and distance; railcars quickly become fully utilized because of the long transit times associated with rail transport--they spend most of their time in transit or sitting in a rail yard. This results in high capital costs for many of rail cars, but the flat shipping rate makes rail transport charges insensitive to distance. Liquid transport by rail is almost as cheap as truck liquid transport and is cheaper than the other trucking options because of the large capacity per railcar.

As expected, the truck transport costs increase with distance because of the higher labor and fuel costs. Capital costs also increase with distance. For short distances, one truck can make multiple trips each day, but as the distance increases, more trucks are needed because more time is spent in transit--there is less chance to use the same truck for multiple trips. Compressed gas transport is affected the most-it requires the most trips because of the low hydrogen capacity per truck. For all methods, labor costs quickly start to dominate for distances longer than $160 \mathrm{~km}$ (100 mi). Compressed gas delivery costs also see the largest effect from fuel price because of the many trips.

For small production rates, liquid hydrogen transport costs are high because the truck is not fully utilized, it may only make a few trips per week. At these low flows, the truck capital cost contribution is the largest cost, but the costs are also less sensitive to distance because there are 
far fewer trips compared to larger production rates. At all flow rates, as distance increases, liquid hydrogen delivery charges become dominated by the labor costs. However, with liquid hydrogen, the effect is small compared to compressed gas because the driver is carrying more hydrogen per trip. One hydrogen tanker can carry more than 20 times the amount of hydrogen as a tube trailer.

At a medium production rate of $450 \mathrm{~kg} / \mathrm{h}(1,000 \mathrm{lb} / \mathrm{h})$ and a $160 \mathrm{~km}(100 \mathrm{mi})$ delivery distance, liquid hydrogen trucking was the cheapest means of transport, but metal hydride also competes because of its high storage density. To illustrate the effect of truck capacity for each delivery method, at the above production rate and delivery distance, 15 tube trailers would be needed, making 60 trips per day (four trips per truck), six hydride trucks making 24 trips per day (four trips per truck) or one liquid hydrogen truck making three trips per day.

The increased weight of the metal hydride was not taken into account when analyzing the transportation costs. Also, there is a great difference in capital expenditures required among the different transport methods. For the above example, the price of one liquid hydrogen tanker with cab is $\$ 500,000$, the price of 15 tube trailers with cabs is about $\$ 3.75$ million, and the price of six metal hydride transports is $\$ 6.9$ million to transport the same amount of hydrogen the same distance.

Detailed data on transportation costs for various production rates and delivery distances can be found in Appendix E. Appendix G contains figures showing important trends in the data.

\subsection{COMBINED STORAGE AND TRANSPORTATION COSTS}

When considering the delivered cost of hydrogen, it is important to understand that there are three factors must be considered: production rate, delivery distance, and storage time. In some cases, these factors are dependent on each other. For example, storage time may depend on delivery distance. If a small hydrogen plant is producing one truckload of hydrogen every 4 days, it might need 3 days of storage if the truck is making a delivery far away and is on the road the whole time. On the other hand, if the delivery distance is $16 \mathrm{~km}(10 \mathrm{mi})$, the most that would be needed is 1 day, because the truck would be gone from the site only a short time. This becomes more of an issue with rail cars, which may be gone for as long as 3 days for a short delivery distance ( 1 day in transit to the customer, 1 day to unload and switch and 1 day to bring it back).

Transport and delivery options can also be mixed. For example, metal hydride delivery would be compatible with compressed gas, underground, or even liquid hydrogen storage. Pipeline transport without any storage may also be an option. Appendix H contains four charts showing the combined effect of transportation and storage costs for two production rates with two delivery distances for each. 
The cost tables or graphs in the appendices can be used by selecting a production rate, delivery distance, and delivery method to give transport cost and delivery frequency. Based on the delivery frequency, a storage time can be chosen and used with a production rate to determine the cost of storage. Adding these two costs gives the total cost associated with hydrogen storage and delivery, including depreciation, but with no return on investment.

When the storage and delivery costs are added, the benefit of liquid hydrogen becomes apparent. For production rates of $450 \mathrm{~kg} / \mathrm{h}(1,000 \mathrm{lb} / \mathrm{h})$, one day of storage and a 160-km (100-mi) delivery distance, liquid hydrogen is only slightly cheaper than metal hydride transport, but at a longer distance of 1,600 $\mathrm{km}(1,000 \mathrm{mi})$ liquid hydrogen is four times cheaper than metal hydride and seven times cheaper than compressed gas.

\subsection{HYDROGEN MARKET}

In North America, the chief bulk hydrogen suppliers are Air Products, Airco/BOC, and Air Liquide (Leiby 1994). Almost all the hydrogen sold is consumed close to the production site (Encyclopedia of Chemical Technology 1991). More than $99 \%$ of all hydrogen produced comes from fossil fuels (Hart 1997), with $95 \%$ of it being produced by steam reforming (Report to Congress 1995). In 1980, there were six liquid hydrogen plants in the United States. The largest was in New Orleans with a hydrogen production capacity of $60 \mathrm{tpd}(2,300 \mathrm{~kg} / \mathrm{h}[5,000 \mathrm{lb} / \mathrm{h}])$ (Huston 1984). Merchant hydrogen represents only $3 \%$ of all hydrogen production (Encyclopedia of Chemical Technology 1991).

\subsection{Current Use}

Several sources cited current hydrogen consumption, but these numbers varied widely: 
Table 15 - Current Hydrogen Consumption

\begin{tabular}{|c|c|c|c|}
\hline Quoted Value & Quantity (kg/yr) & Quantity (lb/yr) & Source \\
\hline Total Consumption & 9.6 billion $\mathrm{kg} / \mathrm{yr}$ & 21 billion $\mathrm{lb} / \mathrm{yr}$ & $\begin{array}{l}\text { Encyclopedia of Chemical } \\
\text { Technology } 1991\end{array}$ \\
\hline Total Production & 0.6 billion $\mathrm{kg} / \mathrm{yr}$ & 1.3 billion $\mathrm{lb} / \mathrm{yr}$ & Hairston 1996 \\
\hline $\begin{array}{l}\text { Total World } \\
\text { Production }\end{array}$ & 35 billion $\mathrm{kg} / \mathrm{yr}$ & 78 billion $\mathrm{lb} / \mathrm{yr}$ & Hart 1997 \\
\hline Captive Production & 0.3 billion $\mathrm{kg} / \mathrm{yr}$ & 0.7 billion $\mathrm{lb} / \mathrm{yr}$ & Hairston 1996 \\
\hline Pipeline Delivery & 0.2 billion $\mathrm{kg} / \mathrm{yr}$ & 0.5 billion $\mathrm{lb} / \mathrm{yr}$ & Hairston, 1996 \\
\hline Captive Production & 5.8 billion $\mathrm{kg} / \mathrm{yr}$ & 12.7 billion $\mathrm{lb} / \mathrm{yr}$ & $\begin{array}{l}\text { Encyclopedia of Chemical } \\
\text { Technology } 1991\end{array}$ \\
\hline Merchant Use & 0.2 billion $\mathrm{kg} / \mathrm{yr}$ & 0.4 billion $\mathrm{lb} / \mathrm{yr}$ & $\begin{array}{l}\text { Encyclopedia of Chemical } \\
\text { Technology } 1991\end{array}$ \\
\hline Total U.S. Demand & 0.3 billion $\mathrm{kg} / \mathrm{yr}$ & 0.4 billion $\mathrm{lb} / \mathrm{yr}$ & Hairston 1996 \\
\hline $\begin{array}{l}\text { U.S. Hydrogen } \\
\text { Production }\end{array}$ & 8.5 billion $\mathrm{kg} / \mathrm{yr}$ & 18.7 billion $\mathrm{lb} / \mathrm{yr}$ & Report to Congress 1995 \\
\hline Merchant Use & 0.05 billion $\mathrm{kg} / \mathrm{yr}$ & 0.1 billion $\mathrm{lb} / \mathrm{yr}$ & Hairston 1996 \\
\hline
\end{tabular}

\subsection{Projected Demand}

Table 16 gives projections on hydrogen demand.

Table 16 - Projected Hydrogen Demand

\begin{tabular}{|l|l|l|l|}
\hline Quoted Value & Quantity $(\mathrm{kg} / \mathrm{yr})$ & Quantity $(\mathrm{lb} / \mathrm{yr})$ & Source \\
\hline Total Production (2000) & 0.9 billion kg/yr & 2.0 billion $\mathrm{lb} / \mathrm{yr}$ & Report to Congress 1995 \\
\hline Captive Production (2000) & 0.5 billion kg/yr & 1.1 billion $\mathrm{lb} / \mathrm{yr}$ & Hairston 1996 \\
\hline Pipeline Production (2000) & 0.4 billion kg/yr & 0.8 billion lb/yr & Hairston 1996 \\
\hline U.S. Demand (2000) & 0.4 billion kg/yr & 0.9 billion lb/yr & Hairston 1996 \\
\hline Merchant Demand (2000) & 0.08 billion kg/yr & 0.2 billion lb/yr & Hairston 1996 \\
\hline
\end{tabular}


Demand for industrial hydrogen is expected to grow 5\%/yr (Report to Congress 1995). Growth of $7.7 \% / \mathrm{yr}$ is projected for processing and production of chemicals, $4.2 \% / \mathrm{yr}$ for food processing in hydrogenation of fats and oils, and 3.3\%/yr in metal manufacture (Hairston 1996). There will also be higher demand for hydrogen in alcohols, acetic acid, and urethane production and at refineries for producing cleaner-burning fuels (Hairston 1996). Strong hydrogen demand is anticipated in South America, along the Pacific Rim, and in Western Europe (Hairston 1996).

\subsection{Uses}

Table 17 contains data on hydrogen use.

Table 17 - Merchant Hydrogen Demand

\begin{tabular}{|l|l|l|l|}
\hline Use & Quantity $(\mathrm{kg} / \mathrm{yr})$ & Quantity $(\mathrm{lb} / \mathrm{yr})$ & Source \\
\hline $\begin{array}{l}\text { Ammonia, Methanol, } \\
\text { and Refineries }\end{array}$ & 5.8 billion $\mathrm{kg} / \mathrm{yr}$ & 12.7 billion $\mathrm{lb} / \mathrm{yr}$ & $\begin{array}{l}\text { Encyclopedia of Chemical } \\
\text { Technology } 1991\end{array}$ \\
\hline Merchant Use & 0.2 billion $\mathrm{kg} / \mathrm{yr}$ & 0.4 billion $\mathrm{lb} / \mathrm{yr}$ & $\begin{array}{l}\text { Encyclopedia of Chemical } \\
\text { Technology } 1991\end{array}$ \\
\hline Chemical Processing & 0.2 billion $\mathrm{kg} / \mathrm{yr}$ & 0.5 billion $\mathrm{lb} / \mathrm{yr}$ & Hairston 1996 \\
\hline Electronics & 0.02 billion $\mathrm{kg} / \mathrm{yr}$ & 0.05 billion $\mathrm{lb} / \mathrm{yr}$ & Hairston 1996 \\
\hline Food Processing & 0.01 billion $\mathrm{kg} / \mathrm{yr}$ & 0.05 billion $\mathrm{lb} / \mathrm{yr}$ & Hairston 1996 \\
\hline Metal Manufacture & 0.008 billion $\mathrm{kg} / \mathrm{yr}$ & 0.02 billion $\mathrm{lb} / \mathrm{yr}$ & Hairston 1996 \\
\hline Other & 0.03 billion $\mathrm{kg} / \mathrm{yr}$ & 0.07 billion $\mathrm{lb} / \mathrm{yr}$ & Hairston 1996 \\
\hline Merchant Use & 0.05 billion $\mathrm{kg} / \mathrm{yr}$ & 0.11 billion $\mathrm{lb} / \mathrm{yr}$ & Hairston 1996 \\
\hline
\end{tabular}

Table 18 gives some projected merchant hydrogen demands for the year 2000.

Table 18 - Projected Merchant Hydrogen Demand

\begin{tabular}{|l|l|l|l|}
\hline Use & Quantity $(\mathrm{kg} / \mathrm{yr})$ & Quantity $(\mathrm{lb} / \mathrm{yr})$ & Source \\
\hline Chemicals & 0.3 billion $\mathrm{kg} / \mathrm{yr}$ & 0.7 billion $\mathrm{lb} / \mathrm{yr}$ & Hairston 1996 \\
\hline Electronics & 0.04 billion $\mathrm{kg} / \mathrm{yr}$ & 0.08 billion $\mathrm{lb} / \mathrm{yr}$ & Hairston 1996 \\
\hline Food & $0.01 \mathrm{billion} \mathrm{kg} / \mathrm{yr}$ & 0.03 billion $\mathrm{lb} / \mathrm{yr}$ & Hairston 1996 \\
\hline Metal Manufacture & 0.01 billion $\mathrm{kg} / \mathrm{yr}$ & 0.02 billion $\mathrm{lb} / \mathrm{yr}$ & Hairston 1996 \\
\hline Other & 0.04 billion $\mathrm{kg} / \mathrm{yr}$ & 0.1 billion $\mathrm{lb} / \mathrm{yr}$ & Hairston 1996 \\
\hline
\end{tabular}

Table 19 gives a breakdown for merchant hydrogen use from two sources, and the expected breakdown for the year 2000: 
Table 19 - Merchant Hydrogen Use

\begin{tabular}{|l|l|l|l|}
\hline Use & $\begin{array}{l}\text { (Merchant Use) } \\
\text { Encyclopedia of Chemical } \\
\text { Technology 1991 }\end{array}$ & $\begin{array}{l}\text { (U.S. Use) } \\
\text { Hairston 1996 }\end{array}$ & $\begin{array}{l}\text { (U.S. Use in 2000) } \\
\text { Hairston 1996 }\end{array}$ \\
\hline Chemicals & $83 \%$ & $74 \%$ & $76 \%$ \\
\hline Electronics & $5 \%$ & $8 \%$ & $9 \%$ \\
\hline Metals & $5 \%$ & $3 \%$ & $2 \%$ \\
\hline Government & $4 \%$ & $\mathrm{n} / \mathrm{a}$ & $\mathrm{n} / \mathrm{a}$ \\
\hline Glass & $1 \%$ & $\mathrm{n} / \mathrm{a}$ & $\mathrm{n} / \mathrm{a}$ \\
\hline Food & $1 \%$ & $4 \%$ & $3 \%$ \\
\hline Other & $\mathrm{n} / \mathrm{a}$ & $12 \%$ & $10 \%$ \\
\hline
\end{tabular}

n/a - Specific information not provided.

Table 20 gives a breakdown of all industrial hydrogen use.

Table 20 - Industrial Hydrogen Use (Hart 1997)

\begin{tabular}{|l|l|}
\hline Ammonia & $50 \%$ \\
\hline Refineries & $37 \%$ \\
\hline Methanol & $8 \%$ \\
\hline Space & $1 \%$ \\
\hline Other & $4 \%$ \\
\hline
\end{tabular}

\subsection{Delivery Method}

Bulk hydrogen delivery is economical for less than 20,000-25,000 kg/mo (45,000-56,000 lb/mo) (Leiby 1994). Tube trailers are used for small-scale distribution, but liquid hydrogen is important for large consumers (Carpetis 1994). It can be delivered as a liquid, pumped to a high pressure, then vaporized and fed into a process as a high-pressure gas (Carpetis 1994). Liquid hydrogen delivery can be up to an order of magnitude cheaper than compressed gas transport for long distances due to higher mass density (Carpetis 1994). Bulk liquid hydrogen shipments in United States number more than 10,000 per year to more than 300 locations (Report to Congress 1995), and can be delivered by barge, tank trailer, and railcars in quantities of 3,500-70,000 kg (7,700-154,000 lb) (Report to Congress 1995). 


\subsection{Current Prices}

Table 21 provides some hydrogen price estimates from different sources, adjusted to 1995 dollars using the Chemical Engineering CPI index.

Table 21 - Hydrogen Prices

\begin{tabular}{|l|l|l|l|}
\hline Delivery Method & Cost $(\$ / \mathrm{kg})$ & Cost $(\$ / \mathrm{lb})$ & Source \\
\hline Pipeline & $\$ 0.11-\$ 0.70 / \mathrm{kg}$ & $\$ 0.05-\$ 0.31 / \mathrm{lb}$ & $\begin{array}{l}\text { Encyclopedia of Chemical } \\
\text { Technology } 1991\end{array}$ \\
\hline Pipeline (Gulf Coast) & $\$ 10-\$ 18 / \mathrm{kg}$ & $\$ 5-\$ 8 / \mathrm{lb}$ & Leiby 1994 \\
\hline Reformed Hydrogen & $\$ 0.65 / \mathrm{kg}$ & $\$ 0.30 / \mathrm{lb}$ & Report to Congress 1995 \\
\hline Recovered Hydrogen & $\$ 0.80-\$ 1.20 / \mathrm{kg}$ & $\$ 0.36-\$ 0.53 / \mathrm{lb}$ & Report to Congress 1995 \\
\hline Electrolysis & $\$ 2.40-\$ 3.60 / \mathrm{kg}$ & $\$ 1.10-\$ 1.70 / \mathrm{lb}$ & Report to Congress 1995 \\
\hline Bulk Liquid & $\$ 3.22-\$ 8.48 / \mathrm{kg}$ & $\$ 1.46-\$ 3.85 / \mathrm{lb}$ & $\begin{array}{l}\text { Encyclopedia of Chemical } \\
\text { Technology } 1991\end{array}$ \\
\hline Bulk Liquid & $\$ 6.60 / \mathrm{kg}$ & $\$ 3.00 / \mathrm{lb}$ & Huston 1984 \\
\hline $\begin{array}{l}\text { Bulk Liquid, Standard } \\
\text { Grade }\end{array}$ & $\$ 21 / \mathrm{kg}$ & $\$ 10 / \mathrm{lb}$ & $\begin{array}{l}\text { Encyclopedia of Chemical } \\
\text { Technology 1991 }\end{array}$ \\
\hline $\begin{array}{l}\text { Bulk Liquid, } \\
\text { Electronics Grade }\end{array}$ & $\$ 107 / \mathrm{kg}$ & $\$ 48 / \mathrm{lb}$ & $\begin{array}{l}\text { Encyclopedia of Chemical } \\
\text { Technology 1991 }\end{array}$ \\
\hline
\end{tabular}




\section{REFERENCES AND PERTINENT LITERATURE}

Air Products. (1997). Web Page.

Au, M.; Chen, C.; Ye Z., Fong, T.; Wu, J.; Wang, O. (1996). "The Recovery, Purification, Storage and Transport of Hydrogen Separated from Industrial Purge Gas by Means of Mobile Hydride Containers." International Journal of Energy. (12:1); pp. 33-37.

Carpetis, C. (1994). "Technology and Costs of Hydrogen Storage." TERI Information Digest on Energy. Vol. 4:1, pp. 1-13.

Chemical Engineering. (December 1994). "Cyclohexane Makes the Grade as a Carrier of Hydrogen." (101:12); p. 19.

Cuoco, A.; Sgalambro, G.; Paolucci, M.; D’Alessio, L. (1995). "Is Photovoltaic Hydrogen in Italy Competitive with Traditional Fossil Fuels?” Energy. (20:12); pp. 1303-1309.

Encyclopedia of Chemical Technology. (1991). "Hydrogen." 4th edition. Vol. 13. New York: Wiley, pp. 838-894.

FIBA Technologies, Inc. (1998). Price Quote.

Flynn, T.M. (1992). "Liquification of Gases." McGraw-Hill Encyclopedia of Science \& Technology. 7th edition. Vol. 10. New York: McGraw-Hill; pp. 106-109.

Garret, D.E. (1989). Chemical Engineering Economics. New York: Von Nostrand Reinhold.

Hairston, D. (February 1996). "Hail Hydrogen." Chemical Engineering (103:2); pp. 59-62.

Hart, D. (1997). Hydrogen Power: The Commercial Future of 'the Ultimate Fuel.' London, UK: Financial Times Energy Publishing.

Huston, E.L. (1984). "Liquid and Solid Storage of Hydrogen." Proceedings of the 5th World Hydrogen Energy Conference. Vol. 3; July 15-20, 1984, Toronto, Canada.

Hydrogen Components, Inc. (1997). Web Page. Littleton, CO.

International Journal of Ambient Energy. (January 1992). "Towards a Hydrogen Economy: The Storage and Transmission of Hydrogen: Technical Note." (13:1).

Johannsen, T.B., ed. (1993) Renewable Energy: Sources for Fuels and Electricity. 
Leiby, S.M. (1994). Options for Refinery Hydrogen. Menlo Park, CA: SRI International.

New York State Electric \& Gas. (26 August 1996a). "NYSEG Brings Natural Gas to New York's North Country."

New York State Electric \& Gas. (10 October 1996b). "NYSEG Completes Seneca Lake Storage Project."

New York State Electric \& Gas. (18 December 1996c). "Seneca Lake Storage Project Completed."

New York State Electric \& Gas. (22 October 1997a). "FERC Approves Market Based Rate for NYSEG's Seneca Lake Storage Project."

New York State Electric \& Gas. (11 December 1997b). "NYSEG Community Partners Celebrate Seneca Lake Project Phase II."

Noganow, L.S. (1992). "Hydrogen." McGraw-Hill Encyclopedia of Science \& Technology. 7th edition. Vol. 8. New York: McGraw-Hill; pp. 581-588.

Oy, N. (1992) New Hydrogen Technologies Project Report: Evaluation of Techniques.

Report to Congress. (1995). Hydrogen: Technology and Policy. 95-540 SR.

Schwarz., J.A.; Amonkwah, K.A.G. (1993). Hydrogen Storage Systems. Washington, DC: U.S. Geological Survey.

Taylor, J.B.; Alderson, J.E. A.; Kalyanam, K.M.; Lyle, A.B.; Phillips, L.A.(1986). "Technical and Economic Assessment of Methods for the Storage of Large Quantities of Hydrogen." International Journal of Hydrogen Energy. (11:1); pp. 5-22.

Timmerhaus, C.; Flynn, T.M. (1989) Cryogenic Engineering. New York: Plenum Press.

T-Raissi, A.; Sadhu, A. (1994). "System Study of Metal Hydride Storage Requirements." Proceedings of 1994 DOE/NREL Hydrogen Program Review; April 18-21, 1994, Livermore, $C A$.

TransCanada Pipelines, Ltd. (13 May 1993). Press Release. "TransCanada Files \$1.1 Billion Pipeline Expansion Application." 
TransCanada Pipelines, Ltd. (17 July 1996a). Press Release. "Pipeline Construction Gives Saskatchewan Economy a Boost."

TransCanada Pipelines, Ltd. (17 July 1996b). Press Release. "Pipeline Construction Gives Manitoba Economy a Boost."

TransCanada Pipelines, Ltd. (17 July 1996c). Press Release. "Pipeline Construction Gives Northwestern Ontario Economy a Boost."

TransCanada Pipelines, Ltd. (3 November 1997). Press Release. ""ANG Pipeline to Build New Gas Link Across Southern B.C."

Worf, J.C. (1992). "Metal Hydrides." McGraw-Hill Encyclopedia of Science \& Technology. 7th edition. Vol. 11. New York: McGraw-Hill; pp. 37-41.

Zittel, W.; Wurster, R. (1996). Hydrogen in the Energy Sector. 


\section{APPENDIX A - SAMPLE CALCULATIONS OF HYDROGEN STORAGE COSTS}

A.0 Hydrogen Storage Cost Assumptions

A.1 Compressed Gas Storage

A.2 Liquid Hydrogen Storage

A.3 Metal Hydride Storage

A.4 Underground Storage

Appendix A contains sample cost calculations for each storage option. In each case, the hydrogen production rate is $450 \mathrm{~kg} / \mathrm{h}(1,000 \mathrm{lb} / \mathrm{h})$ with 1 day of storage. The calculations were done using MachCAD so all required unit conversions were done internal to the program. The resulting values are the same as those found in Appendix D for the above flowrate and storage time. 


\section{A.0 HYDROGEN STORAGE COST ASSUMPTIONS - English Units}

\begin{tabular}{|c|c|c|c|}
\hline CompCost $:=\frac{1000}{\mathrm{~kW}}$ & CompSize $:=4000 \cdot \mathrm{kW}$ & CompExp :=0.8 & $\begin{array}{l}\text { Compressor } \\
\text { Assumptions }\end{array}$ \\
\hline & CompPress $:=20 \cdot 10^{6} \cdot \mathrm{Pa}$ & CPExp $:=0.18$ & \\
\hline TankCost $:=\frac{600}{\mathrm{lb}}$ & TankSize $:=500 \cdot 1 \mathrm{~b}$ & TankExp := 0.75 & $\begin{array}{l}\text { Compressed Gas Tank } \\
\text { Assumptions }\end{array}$ \\
\hline & TankPress $:=20 \cdot 10^{6} \cdot \mathrm{Pa}$ & TPExp $:=0.44$ & \\
\hline LiqCost $:=\frac{20000}{\left\{\frac{\mathrm{lb}}{\mathrm{hr}}\right\}}$ & LiqSize $:=1000 \cdot\left\{\frac{\mathrm{lb}}{\mathrm{hr}}\right\}$ & LiqExp $:=0.65$ & Liquefier Assumptions \\
\hline DewarCost $:=\frac{200}{\mathrm{lb}}$ & DewarSize $:=100 \cdot \mathrm{lb}$ & DewarExp :=0.70 & Dewar Assumptions \\
\hline HydCost $:=\frac{1000}{1 b}$ & & HydExp := 1.0 & $\begin{array}{l}\text { Metal Hydride } \\
\text { Assumptions }\end{array}$ \\
\hline UnderCost $:=\frac{4}{\mathrm{lb}}$ & & UnderExp := 1.0 & $\begin{array}{l}\text { Underground Storage } \\
\text { Assumptions }\end{array}$ \\
\hline CompPower $:=1.0 \cdot \frac{\mathrm{kW} \cdot \mathrm{hr}}{\mathrm{lb}}$ & CompCool $:=6.0 \cdot \frac{\mathrm{gal}}{\mathrm{lb}}$ & & $\begin{array}{l}\text { Compressor Utility } \\
\text { Requirements }\end{array}$ \\
\hline LiqPower $:=4.5 \cdot \frac{\mathrm{kW} \cdot \mathrm{hr}}{\mathrm{lb}}$ & LiqCool $:=75 \cdot \frac{\text { gal }}{\mathrm{lb}}$ & & $\begin{array}{l}\text { Liquefier Utility } \\
\text { Requirements }\end{array}$ \\
\hline $\mathrm{BOR}:=0.1 \frac{\%}{\mathrm{day}}$ & & & Assumed Boil-Off Rate \\
\hline HydHeat $:=10000 \cdot \frac{\text { BTU }}{\mathrm{lb}}$ & HydCool $:=25 \cdot \frac{\text { gal }}{\mathrm{lb}}$ & & $\begin{array}{l}\text { Metal Hydride Utility } \\
\text { Requirements }\end{array}$ \\
\hline ElecCost $:=\frac{0.05}{\mathrm{~kW} \cdot \mathrm{hr}}$ & & Assumed Electri & Cost \\
\hline SteamCost $:=\frac{4}{\left(1 \cdot 10^{6} \cdot \mathrm{BTU}\right)}$ & & Assumed Steam & \\
\hline CoolWatCost $:=\frac{0.07}{(1000 \cdot \mathrm{gal})}$ & & Assumed Coolin & Vater Cost \\
\hline OpDays $:=\underline{350 \cdot \text { day }}$ & Life $:=22 \cdot y r$ & Cost Assumption & \\
\hline
\end{tabular}




\section{A.0 HYDROGEN STORAGE COST ASSUMPTIONS - SI Units}

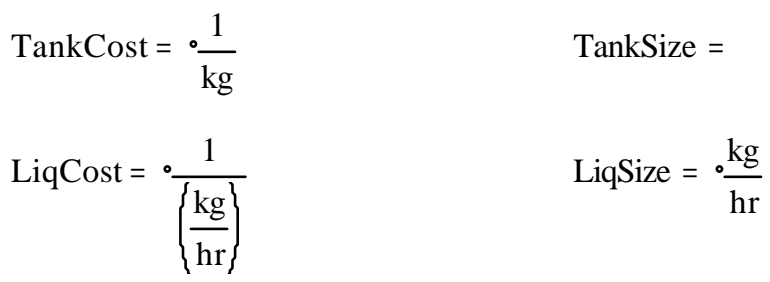

DewarCost $=\frac{\cdot 1}{\mathrm{~kg}}$

DewarSize $=$

HydCost $=\cdot \frac{1}{\mathrm{~kg}}$

UnderCost $=\frac{\cdot 1}{\mathrm{~kg}}$

CompPower $=\frac{\mathrm{kW} \cdot \mathrm{hr}}{\mathrm{kg}}$

CompCool $=\frac{\text { liter }}{\mathrm{kg}}$

LiqPower $=\frac{\mathrm{kW} \cdot \mathrm{hr}}{\mathrm{kg}}$

LiqCool $=\frac{\text { liter }}{\mathrm{kg}}$

HydHeat $=\frac{\cdot 1000 \cdot \text { joule }}{\mathrm{kg}}$

HydCool $=\frac{\text { liter }}{\mathrm{kg}}$

SteamCost $=\cdot \frac{1}{10^{9} \cdot \text { joule }}$

CoolWatCost $=\frac{1}{1000 \cdot \text { liter }}$ 


\section{A.1 COMPRESSED GAS STORAGE SAMPLE CALCULATION}
Flow $:=1000 \cdot \frac{\mathrm{lb}}{\mathrm{hr}}$
Flow $=\frac{\mathrm{kg}}{\mathrm{hr}}$
Production Rate
Time $:=1 \cdot$ day
Days of Storage
Storage := Flow·Time
Storage $=\cdot \mathrm{lb}$
Storage Capacity
Storage $=$

$$
\text { Prod :=Flow } \cdot \text { OpDays } \quad \begin{aligned}
\text { Prod } & =\frac{\mathrm{lb}}{\mathrm{yr}} \\
\operatorname{Prod} & =\frac{\mathrm{kg}}{\mathrm{yr}}
\end{aligned}
$$
Annual Production

$P:=20 \cdot 10^{6} \cdot \mathrm{Pa}$

Operating Pressure

Energy :=Flow.CompPower $\left[\frac{\ln \left(\frac{\mathrm{P}}{0.1 \cdot 10^{6} \cdot \mathrm{Pa}}\right\}}{\ln \left(\frac{20 \cdot 10^{6} \cdot \mathrm{Pa}}{0.1 \cdot 10^{6} \cdot \mathrm{Pa}}\right)}\right]$

Energy $={ }^{\circ} \mathrm{kW}$

Comp. Power

Cooling := Flow $\cdot$ CompCool $\cdot\left[\frac{\ln \left\{\frac{\mathrm{P}}{0.1 \cdot 10^{6} \cdot \mathrm{Pa}}\right\}}{\ln \left\{\frac{20 \cdot 10^{6} \cdot \mathrm{Pa}}{0.1 \cdot 10^{6} \cdot \mathrm{Pa}}\right\}}\right]$

Cooling $=\frac{\cdot \mathrm{gal}}{\mathrm{hr}} \quad$ Cooling Water

CompCap :=(CompCost CompSize $) \cdot\left(\frac{\text { Energy }}{\text { CompSize }}\right\}^{\text {CompExp }} \cdot\left(\frac{P}{\text { CompPress }}\right\}^{\text {CPExp }}$ Comp. Cost

CompCap $=$
TankCap $:=($ TankCost $\cdot$ TankSize $) \cdot\left\{\frac{\text { Storage } \cdot \frac{\text { TankPress }}{\mathrm{P}}}{\text { TankSize }}\right\}^{\text {TankExp }} \cdot\left(\frac{\mathrm{P}}{\text { TankPress }}\right)^{\text {TPExp }}$ Tank Cost

TankCap $=$

TotCap := CompCap + TankCap $\quad$ TotCap $=$

Total Capital Cost 


\section{A.1 COMPRESSED GAS STORAGE SAMPLE CALCULATION (continued)}
DepCost : $=\frac{\text { TotCap }}{\text { Life }}$
DepCost $=\cdot \frac{1}{\mathrm{yr}}$
Depreciation
EnerCost $:=$ Energy $\cdot$ ElecCost
EnerCost $=\frac{\cdot 1}{\mathrm{hr}}$
Annual Electricity
Cost
EnerCost $\cdot$ OpDays $=\cdot \frac{1}{\mathrm{yr}}$
CoolingCost $:=$ Cooling $\cdot$ CoolWatCost $\quad$ CoolingCost $=\frac{\cdot 1}{\mathrm{hr}}$
Annual Cooling
Water Cost
CoolingCost $\cdot$ OpDays $=\cdot \frac{1}{\mathrm{yr}}$
TotCost : $=$ EnerCost $\cdot$ OpDays + CoolingCost $\cdot$ OpDays + DepCost
TotCost $=\frac{\cdot 1}{\mathrm{yr}}$
Total Annual Cost
Dep := $\frac{\text { DepCost }}{\text { Prod }}$
Dep $=\frac{1}{\mathrm{lb}}$
Dep $=\frac{1}{\mathrm{~kg}}$
Capital Cost
Ener $:=\frac{\text { EnerCost }}{\text { Flow }}$
Ener $=\frac{1}{\mathrm{~kg}}$
Energy Cost
Cool $:=\frac{\text { CoolingCost }}{\text { Flow }} \quad$ Cool $=\frac{1}{\mathrm{lb}}$
Cool $=\cdot \frac{1}{\mathrm{~kg}}$
Cooling Cost
Tot $:=$ Ener + Cool + Dep $\quad$ Tot $=\frac{\cdot 1}{\mathrm{lb}}$
$\operatorname{Tot}=\cdot \frac{1}{\mathrm{~kg}}$
Total Cost
Comp $:=\frac{\text { CompCap }}{(\text { Prod } \cdot \text { Life })} \quad$ Comp $=\frac{1}{\mathrm{lb}}$
Comp $=\frac{\cdot 1}{\mathrm{~kg}}$
Comp. Cost
Tank $:=\frac{\text { TankCap }}{(\text { Prod } \cdot \text { Life })}$
Tank $=\frac{1}{\mathrm{lb}}$
Tank $=\frac{\cdot 1}{\mathrm{~kg}}$
Tank Cost
Comp $:=\frac{\text { CompCap }}{\text { Energy }} \quad$ Comp $=\cdot \frac{1}{\mathrm{~kW}}$
Comp. Capital
Tank $:=\frac{\text { TankCap }}{\text { Storage }}$
Tank $=\cdot \frac{1}{\mathrm{lb}}$
Tank $=\cdot \frac{1}{\mathrm{~kg}}$
Tank Capital 


\section{A.2 LIQUID HYDROGEN STORAGE SAMPLE CALCULATION}

Flow $:=1000 \cdot \frac{\mathrm{lb}}{\mathrm{hr}} \quad$ Flow $=\frac{\mathrm{kg}}{\mathrm{hr}}$

Production Rate

Time $:=1 \cdot$ day

Days of Storage

$\begin{aligned} \text { FlowBOR }:=\text { Flow }\left[1+\left(1-\mathrm{e}^{- \text {BOR } \cdot \text { Time }}\right)\right] & \text { FlowBOR }= \\ \text { FlowBOR } & =\frac{\mathrm{kg}}{\mathrm{hr}}\end{aligned}$

Production plus Boil-Off

Storage $:=$ FlowBOR $\cdot$ Time $\quad$ Storage $=\bullet l b$

Storage Capacity

Storage $=$

Prod := Flow·OpDays

$$
\begin{aligned}
& \text { Prod }=\frac{\circ \mathrm{lb}}{\mathrm{yr}} \\
& \text { Prod }=\frac{\circ \mathrm{kg}}{\mathrm{yr}}
\end{aligned}
$$

Annual Production

Energy $:=$ FlowBOR $\cdot$ LiqPower $\quad$ Energy $={ }^{\circ} \mathrm{kW}$

Liquefier Power

Cooling := FlowBOR $\cdot$ LiqCool

Cooling $=\frac{\mathrm{ggal}}{\mathrm{hr}}$

Cooling Water

$$
\text { Cooling }=\frac{\text { liter }}{\mathrm{hr}}
$$

LiqCap : $=($ LiqCost $\cdot$ LiqSize $) \cdot\left(\frac{\text { FlowBOR }}{\text { LiqSize }}\right\}^{\text {LiqExp }}$

Liquefier Cost

LiqCap $=$

DewarCap $:=($ DewarCost $\cdot$ DewarSize $) \cdot\left\{\frac{\text { Storage }}{\text { DewarSize }}\right\}^{\text {DewarExp }}$

Dewar Cost

DewarCap $=$

TotCap := LiqCap + DewarCap TotCap =

Total Capital Cost 


\section{A.2 LIQUID HYDROGEN STORAGE SAMPLE CALCULATION (continued)}
DepCost : $=\frac{\text { TotCap }}{\text { Life }}$
DepCost $=\frac{\cdot 1}{\mathrm{yr}}$
Depreciation
EnerCost :=Energy $\cdot$ ElecCost
EnerCost $=\cdot \frac{1}{\mathrm{hr}}$
Annual Electricity
Cost
EnerCost $\cdot$ OpDays $=\cdot \frac{1}{\mathrm{yr}}$
CoolingCost $:=$ Cooling $\cdot$ CoolWatCost CoolingCost $=\frac{\cdot 1}{\mathrm{hr}}$
Annual Cooling
CoolingCost $\cdot$ OpDays $=\cdot \frac{1}{\mathrm{yr}}$
Water Cost
TotCost $:=$ EnerCost $\cdot$ OpDays + CoolingCost $\cdot$ OpDays + DepCost
Total Annual Cost
$\operatorname{Tot} \operatorname{Cost}=\frac{\cdot 1}{\mathrm{yr}}$

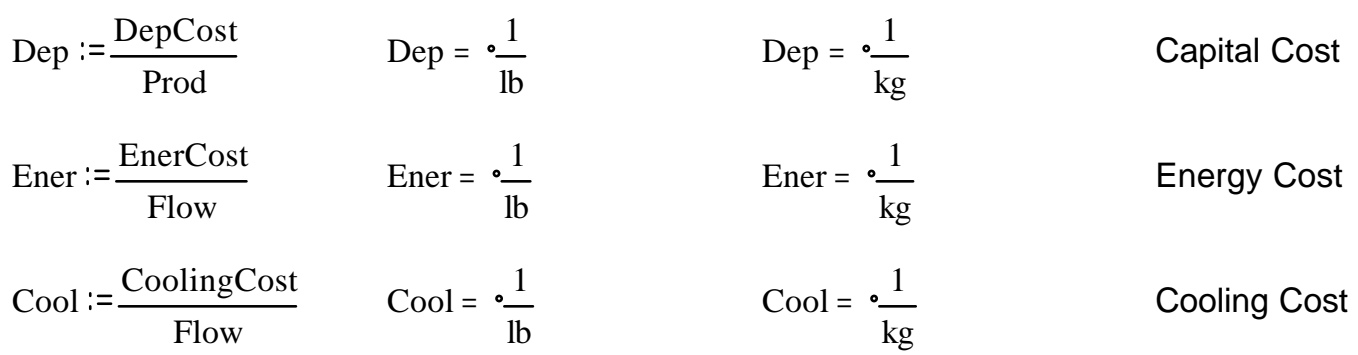
Tot $:=$ Ener + Cool + Dep $\quad$ Tot $=\frac{\cdot \frac{1}{\mathrm{lb}} \quad \text { Tot }=\frac{\cdot 1}{\mathrm{~kg}} \quad \text { Total Cost }}{}$

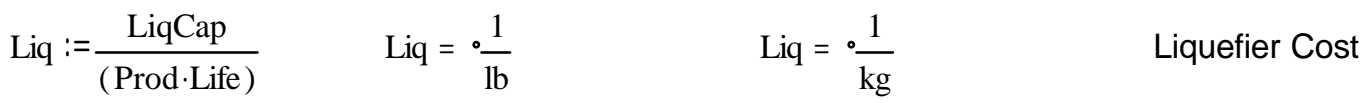
Tank $:=\frac{\text { DewarCap }}{(\text { Prod } \cdot \text { Life })} \quad$ Tank $=\frac{\circ}{\mathrm{lb}} \quad$ Tank $=\frac{1}{\mathrm{~kg}} \quad$ Tank Cost

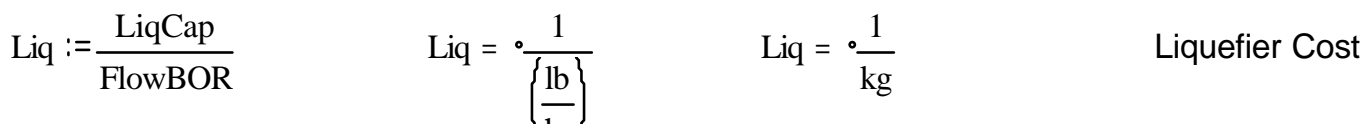
Tank $:=\frac{\text { DewarCap }}{\text { Storage }} \quad$ Tank $=\cdot \frac{1}{\mathrm{lb}} \quad$ Tank $=\cdot \frac{1}{\mathrm{~kg}} \quad$ Tank Cost 


\section{A.3 METAL HYDRIDE STORAGE SAMPLE CALCULATION}
Flow $:=1000 \cdot \frac{\mathrm{lb}}{\mathrm{hr}}$
Flow $=\frac{\mathrm{kg}}{\mathrm{hr}}$
Production Rate
Time $:=1 \cdot$ day
Days of Storage
Storage :=Flow $\cdot$ Time
Storage $=\cdot \mathrm{lb}$
Storage Capacity
Storage $=$
Prod :=Flow·OpDays
$\operatorname{Prod}=\frac{\mathrm{lb}}{\mathrm{yr}}$
Annual Production
Prod $=\frac{\mathrm{kg}}{\mathrm{yr}}$
Energy := Flow.HydHeat
Energy $=\cdot\left(10^{6} \cdot \frac{\mathrm{BTU}}{\mathrm{hr}}\right\}$
Heat Requirement
Energy $=\frac{\cdot 1000 \cdot \text { joule }}{\mathrm{hr}}$
Cooling := Flow $\cdot$ HydCool
Cooling $=\frac{\mathrm{gal}}{\mathrm{hr}}$
Cooling Requirement
Cooling $=\frac{\text { liter }}{\mathrm{hr}}$
HydCap := Storage $\cdot$ HydCost
HydCap =
Hydride Cost
TotCap := HydCap
TotCap =
Total Capital Cost
DepCost : $=\frac{\text { TotCap }}{\text { Life }}$
DepCost $=\frac{\cdot 1}{\mathrm{yr}}$
Depreciation
EnerCost $:=$ Energy $\cdot$ Stean
EnerCost OpDays $=\cdot \frac{1}{\mathrm{yr}}$
EnerCost $=\frac{\cdot 1}{\mathrm{hr}}$
Annual Steam Cost
CoolingCost $:=$ CoolWatCost $\cdot$ Cooling
CoolingCost $=\cdot \frac{1}{\mathrm{hr}}$
Annual Cooling Water
Cost

CoolingCost $\cdot$ OpDays $=\frac{\cdot 1}{\mathrm{yr}}$ 


\section{A.3 METAL HYDRIDE STORAGE SAMPLE CALCULATION (continued)}

TotCost $:=$ EnerCost $\cdot$ OpDays + CoolingCost $\cdot$ OpDays + DepCost

$\operatorname{TotCost}=\frac{1}{\mathrm{yr}}$

Total Annual Cost

Dep := $\frac{\text { DepCost }}{\text { Prod }}$

$\operatorname{Dep}=\frac{1}{\mathrm{lb}}$

Dep $=\frac{1}{\mathrm{~kg}}$

Capital Cost

Ener $:=\frac{\text { EnerCost }}{\text { Flow }}$

Ener $=\frac{\cdot 1}{\mathrm{lb}}$

Ener $=\frac{\cdot 1}{\mathrm{~kg}}$

Energy Cost

Cool := CoolingCost

Cool $=\frac{1}{\mathrm{lb}}$

Cool $=\frac{1}{\mathrm{~kg}}$

Cooling Cost

Hyd $:=\frac{\text { HydCap }}{(\text { Prod } \cdot \text { Life })}$

$\operatorname{Hyd}=\frac{\cdot \frac{1}{\mathrm{lb}}}{}$

Hyd $=\frac{\cdot 1}{\mathrm{~kg}}$

Hydride Cost

Tot $:=$ Ener + Cool + Dep $\quad$ Tot $=\frac{\cdot 1}{\mathrm{lb}}$

Tot $=\frac{\cdot 1}{\mathrm{~kg}}$

Total Cost 


\section{A.4 UNDERGROUND STORAGE SAMPLE CALCULATION}

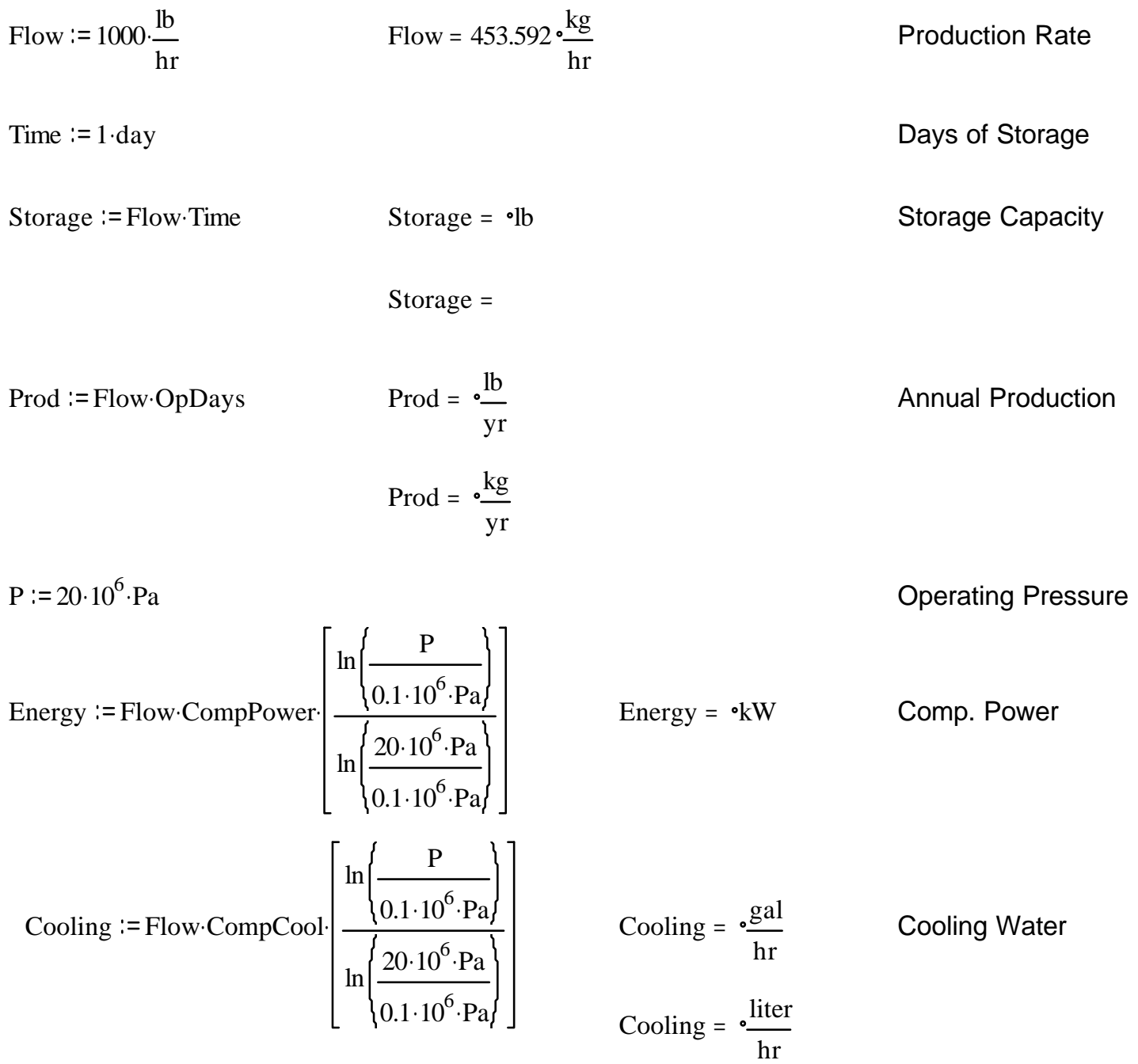

CompCap $:=($ CompCost $\cdot$ CompSize $) \cdot\left(\frac{\text { Energy }}{\text { CompSize }}\right\}^{\text {CompExp }} \cdot\left\{\frac{P}{\text { CompPress }}\right\}^{\text {CPExp }}$ Comp. Cost

CompCap $=$

CaveCap : $=\left[(\right.$ UnderCost $) \cdot\left\{\right.$ Storage $\left.\left.\cdot \frac{\text { TankPress }}{P}\right\}\right]$

Cavern Cost

CaveCap $=$

TotCap :=CompCap + CaveCap $\quad$ TotCap =

Total Capital 


\section{A.4 UNDERGROUND STORAGE SAMPLE CALCULATION (continued)}

\begin{tabular}{|c|c|c|c|}
\hline DepCost $:=\underline{\text { TotCap }}$ & & DepCost $=\frac{\cdot 1}{\mathrm{yr}}$ & Depreciation \\
\hline \multicolumn{2}{|c|}{ EnerCost $:=$ Energy $\cdot$ ElecCost } & $\frac{1}{\mathrm{hr}}$ & $\begin{array}{l}\text { Annual Electricity } \\
\text { Cost }\end{array}$ \\
\hline \multicolumn{4}{|l|}{ EnerCost $\cdot$ OpDays $=\cdot \frac{1}{\mathrm{yr}}$} \\
\hline \multicolumn{2}{|c|}{ CoolingCost $:=$ Cooling $\cdot$ CoolWatCost } & $=\frac{\cdot 1}{\mathrm{hr}}$ & $\begin{array}{l}\text { Annual Cooling } \\
\text { Water Cost }\end{array}$ \\
\hline \multicolumn{4}{|l|}{ CoolingCost $\cdot$ OpDays $=\cdot \frac{1}{\mathrm{yr}}$} \\
\hline \multicolumn{3}{|c|}{ TotCost $:=$ EnerCost $\cdot$ OpDays + CoolingCost $\cdot$ OpDays + DepCost } & Total Cost \\
\hline \multicolumn{4}{|l|}{$\operatorname{TotCost}=\frac{1}{\mathrm{yr}}$} \\
\hline Dep : $=\frac{\text { DepCost }}{\text { Prod }}$ & Dep $=\frac{\cdot 1}{\mathrm{lb}}$ & Dep $=\cdot \frac{1}{\mathrm{~kg}}$ & Capital Cost \\
\hline Ener $:=\frac{\text { EnerCost }}{\text { Flow }}$ & Ener $=\cdot \frac{1}{\mathrm{lb}}$ & Ener $=\cdot \frac{1}{\mathrm{~kg}}$ & Electricity Cost \\
\hline Cool : $=\frac{\text { CoolingCost }}{\text { Flow }}$ & Cool $=\frac{1}{1 b}$ & Cool $=\frac{1}{\mathrm{~kg}}$ & Cooling Cost \\
\hline Tot :=Ener+ Cool+ Dep & Tot $=\frac{\cdot 1}{\mathrm{lb}}$ & Tot $=\frac{\cdot 1}{\mathrm{~kg}}$ & Total Cost \\
\hline Comp $:=\frac{\text { CompCap }}{(\text { Prod } \cdot \text { Life })}$ & Comp $=\frac{\cdot 1}{\mathrm{lb}}$ & Comp $=\frac{1}{\mathrm{~kg}}$ & Comp. Cost \\
\hline Cave $:=\frac{\text { CaveCap }}{(\text { Prod } \cdot \text { Life })}$ & Cave $=\cdot \frac{1}{1 b}$ & Cave $=\cdot \frac{1}{\mathrm{~kg}}$ & Cavern Cost \\
\hline Comp := $\frac{\text { CompCap }}{\text { Energy }}$ & Comp $=\cdot \frac{1}{\mathrm{~kW}}$ & & Comp. Capital \\
\hline Cave $:=\frac{\text { CaveCap }}{\text { Storage }}$ & Cave $=\cdot \frac{1}{\mathrm{lb}}$ & Cave $=\cdot \frac{1}{\mathrm{~kg}}$ & Cavern Capital \\
\hline
\end{tabular}




\section{APPENDIX B - SAMPLE CALCULATIONS OF HYDROGEN TRANSPORT COSTS}

B.0 Hydrogen Transportation Cost Assumptions

B.1 Compressed Gas Delivery by Truck

B.2 Compressed Gas Delivery by Rail

B.3 Liquid Hydrogen Delivery by Truck

B.4 Liquid Hydrogen Delivery by Rail

B.5 Liquid Hydrogen Delivery by Ship

B.6 Metal Hydride Delivery by Truck

B.7 Metal Hydride Delivery by Rail

B.8 Pipeline Delivery

Appendix B contains sample cost calculations for the main transportation options. In each case, the hydrogen production rate is $450 \mathrm{~kg} / \mathrm{h}(1,000 \mathrm{lb} / \mathrm{h})$ and the delivery distance is $160 \mathrm{~km}(100$ $\mathrm{mi}$ ). These calculations were done using MathCAD so all required unit conversions were done internal to the program. The resulting values are the same as those found in Appendix E for the above flowrate and delivery distance. 


\section{B.0 HYDROGEN TRANSPORTATION COST ASSUMPTIONS - English Units}

TruckGH2Cost : $=100000$

TruckLH2Cost $:=350000$

TruckMH2Cost $:=\frac{1000}{\mathrm{lb}}$

TruckUnderCost $:=60000$

TruckMileage $:=6 \cdot \frac{\mathrm{mi}}{\mathrm{gal}}$

TruckLoadTime $:=2 \cdot \mathrm{hr}$

DriverWage $:=\frac{28.75}{\mathrm{hr}}$

DieselPrice $:=\frac{1}{\text { gal }}$

RailGH2Cost : $=200000$

RailLH2Cost : $=400000$

RailMH2Cost $:=\frac{1000}{\mathrm{lb}}$

RailSpeed $:=25 \cdot \frac{\mathrm{mi}}{\mathrm{hr}}$

RailAvail $:=24 \cdot \frac{\mathrm{hr}}{\mathrm{day}}$

RailBOR $:=0.3 \frac{\%}{\text { day }}$

ShipLH2Cost : $=350000$

ShipSpeed $:=10 \cdot \frac{\mathrm{mi}}{\mathrm{hr}}$

ShipAvail $:=24 \cdot \frac{\mathrm{hr}}{\mathrm{day}}$

ShipBOR $:=0.3 \frac{\%}{\text { day }}$
TruckGH2Size := 400·lb

TruckLH2Size $:=9000 \cdot \mathrm{lb}$

TruckMH2Size : $=1000 \cdot \mathrm{lb}$

TruckCabCost $:=90000$

TruckSpeed $:=50 \cdot \frac{\mathrm{mi}}{\mathrm{hr}}$

TruckAvail $:=24 \cdot \frac{\mathrm{hr}}{\mathrm{day}}$

DriverAvail $:=12 \cdot \frac{\mathrm{hr}}{\text { day }}$

TruckBOR : $=0.3 \frac{\%}{\text { day }}$

RailGH2Size := 1000·lb

RailLH2Size $:=20000 \cdot 1 \mathrm{~b}$

RailMH2Size $:=2000 \cdot \mathrm{lb}$

RailUnderCost : $=100000$

RailLoadTime $:=24 \cdot \mathrm{hr}$

RailFreight $:=400$

ShipLH2Size :=9000·lb

ShipLoadTime $:=48 \cdot \mathrm{hr}$

ShipFreight $:=3000$
Capacities \& Capital Costs

Trucking Assumptions

\section{Rail Assumptions}

\section{Ship Assumptions}


B.O HYDROGEN TRANSPORTATION COST ASSUMPTIONS - English Units (continued)

$\begin{array}{llll}\text { PipeCost }:=\frac{1000000}{\mathrm{mi}} & \text { Roughness }:=4.6 \cdot 10^{-5} \cdot \mathrm{m} & \text { PipeDia }:=0.25 \cdot \mathrm{m} & \text { Pipeline Assumptions } \\ \text { DelPress }:=2 \cdot 10^{6} \cdot \mathrm{Pa} & \text { Temp }:=283 \cdot \mathrm{K} & \text { FricFact }:=0.005 & \\ \mathrm{RH} 2:=4124 \cdot \frac{(\mathrm{N} \cdot \mathrm{m})}{\mathrm{kg} \cdot \mathrm{K}} & \text { Visc }:=8.62 \cdot 10^{-6} \cdot \frac{\mathrm{kg}}{(\mathrm{m} \cdot \mathrm{sec})} & \\ \text { CompCost }:=\frac{1000}{\mathrm{~kW}} & \text { CompSize }:=4000 \cdot \mathrm{kW} & \text { CompExp }:=0.80 & \text { Compressor } \\ & \text { CompPress }:=20 \cdot 10^{6} \cdot \mathrm{Pa} & \text { CPExp }:=0.18 & \text { Assumptions }\end{array}$

CompPower $:=1.0 \cdot \frac{(\mathrm{kW} \cdot \mathrm{hr})}{\mathrm{lb}}$

ElecCost $:=\frac{0.05}{(\mathrm{~kW} \cdot \mathrm{hr})}$

Electricity Cost

OpDays : $=350 \frac{\text { day }}{\mathrm{yr}}$

Operating Cost

Assumptions

TrailerDep : $=6 \cdot \mathrm{yr}$

TractorDep $:=4 \cdot \mathrm{yr}$

RailcarDep : $=15 \cdot \mathrm{yr}$

PipelineDep : $=22 \cdot \mathrm{yr}$ 


\section{B.0 HYDROGEN TRANSPORTATION COST ASSUMPTIONS - SI Units}

$$
\begin{array}{lc}
\text { TruckGH2Size }=181.437 \cdot \mathrm{kg} & \text { TruckLH2Size }=4.082 \cdot 10^{3} \cdot \mathrm{kg} \\
\text { TruckMH2Cost }=2.205 \cdot 10^{3} \cdot \frac{1}{\mathrm{~kg}} & \text { TruckMH2Size }=453.592 \cdot \mathrm{kg} \\
\text { TruckSpeed }=80.467 \cdot \frac{\mathrm{km}}{\mathrm{hr}} & \text { RailLH2Size }=9.072 \cdot 10^{3} \cdot \mathrm{kg} \\
\text { RailGH2Size }=453.592 \cdot \mathrm{kg} & \text { RailMH2Size }=907.185 \cdot \mathrm{kg} \\
\text { RailMH2Cost }=2.205 \cdot 10^{3} \cdot \frac{1}{\mathrm{~kg}} & \\
\text { RailSpeed }=40.234 \cdot \frac{\mathrm{km}}{\mathrm{hr}} & \text { ShipSpeed }=16.093 \cdot \frac{\mathrm{km}}{\mathrm{hr}} \\
\text { ShipLH2Size }=4.082 \cdot 10^{3} \cdot \mathrm{kg} &
\end{array}
$$$$
\text { PipeCost }=6.214 \cdot 10^{5} \cdot \frac{1}{\mathrm{~km}}
$$$$
\text { CompPower }=2.205 \cdot \frac{\mathrm{kW} \cdot \mathrm{hr}}{\mathrm{kg}}
$$ 


\section{B.1 COMPRESSED GAS TRUCKING SAMPLE CALCULATION}

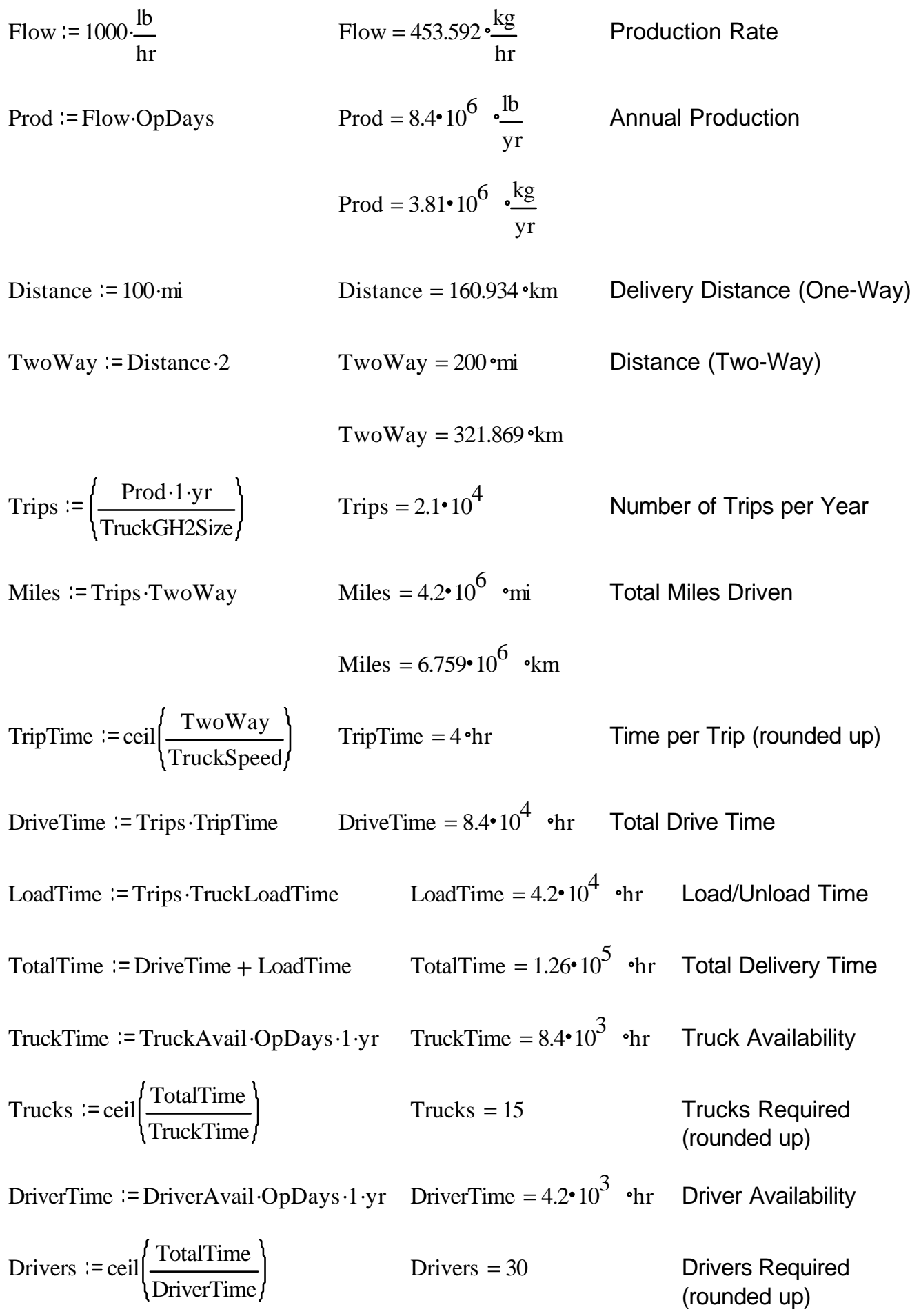




\section{B.1 COMPRESSED GAS TRUCKING SAMPLE CALCULATION (continued)}

$$
\begin{aligned}
& \text { FuelUse }:=\frac{\text { Miles }}{\text { TruckMileage }} \quad \text { FuelUse }=7 \cdot 10^{5} \cdot \text { gal } \quad \text { Annual Fuel Use } \\
& \text { CapCost }:=\text { Trucks } \cdot(\text { TruckGH2Cost }+ \text { TruckUnderCost }+ \text { TruckCabCost }) \\
& \text { CapCost }=3.75 \cdot 10^{6} \quad \text { Total Capital Cost } \\
& \begin{array}{l}
\text { DepCost }:=\frac{\text { Trucks } \cdot(\text { TruckGH2Cost }+ \text { TruckUnderCost })}{\text { TrailerDep }}+\frac{\text { Trucks } \cdot(\text { TruckCabCost })}{\text { TractorDep }} \\
\text { DepCost }=7.375 \cdot 10^{5} \cdot \frac{1}{\mathrm{yr}} \quad \text { FuelCost }=7 \cdot 10^{5} \cdot \frac{1}{\mathrm{yr}} \quad \text { Annual Fuel Cost } \\
\text { FuelCost }:=\text { FuelUse } \cdot \frac{\text { DieselPrice }}{\mathrm{yr}} \quad \text { LaborCost }=3.623 \cdot 10^{6} \quad \frac{1}{\mathrm{yr}} \quad \text { Annual Labor Cost }
\end{array} \\
& \text { LaborCost }:=\text { TotalTime } \cdot \frac{\text { DriverWage }}{\mathrm{yr}} \quad
\end{aligned}
$$$$
\text { TotalCost :=FuelCost }+ \text { DepCost }+ \text { LaborCost }
$$$$
\text { Total Annual Cost }
$$$$
\text { TotalCost }=5.06 \cdot 10^{6} \cdot \frac{1}{\mathrm{yr}}
$$$$
\text { Dep }:=\frac{\text { DepCost }}{\text { Prod }} \quad \text { Dep }=0.088 \cdot \frac{1}{\mathrm{lb}} \quad \text { Dep }=0.194 \cdot \frac{1}{\mathrm{~kg}} \quad \text { Capital Cost }
$$$$
\text { Fuel }:=\frac{\text { FuelCost }}{\text { Prod }} \quad \text { Fuel }=0.083 \circ \frac{1}{\mathrm{lb}} \quad \text { Fuel }=0.184 \cdot \frac{1}{\mathrm{~kg}} \quad \text { Fuel Cost }
$$$$
\text { Labor }:=\frac{\text { LaborCost }}{\text { Prod }} \quad \text { Labor }=0.431 \cdot \frac{1}{\mathrm{lb}} \quad \text { Labor }=0.951 \cdot \frac{1}{\mathrm{~kg}} \quad \text { Labor Cost }
$$$$
\text { Tot }:=\frac{\text { TotalCost }}{\text { Prod }} \quad \text { Tot }=0.602 \cdot \frac{1}{\mathrm{lb}} \quad \text { Tot }=1.328 \cdot \frac{1}{\mathrm{~kg}} \quad \text { Total Cost }
$$$$
\text { TripsFreq }:=\frac{\frac{\text { Trips }}{\mathrm{yr}}}{\frac{\text { OpDays }}{\text { day }}} \quad \text { TripsFreq }=60 \quad \text { Trip Frequency }
$$$$
\text { TripLength }:=\operatorname{ceil}\left(\frac{\text { TotalTime }}{\text { Trips }}\right) \quad \text { TripLength }=6{ }^{\circ} \mathrm{hr} \quad \text { Trip Length }
$$$$
\text { UtilRate }:=\frac{\text { TripsFreq }}{\text { Trucks }} \quad \text { UtilRate }=4 \quad \text { Truck Utilization Rate }
$$ 


\section{B.2 COMPRESSED GAS RAIL SAMPLE CALCULATION}

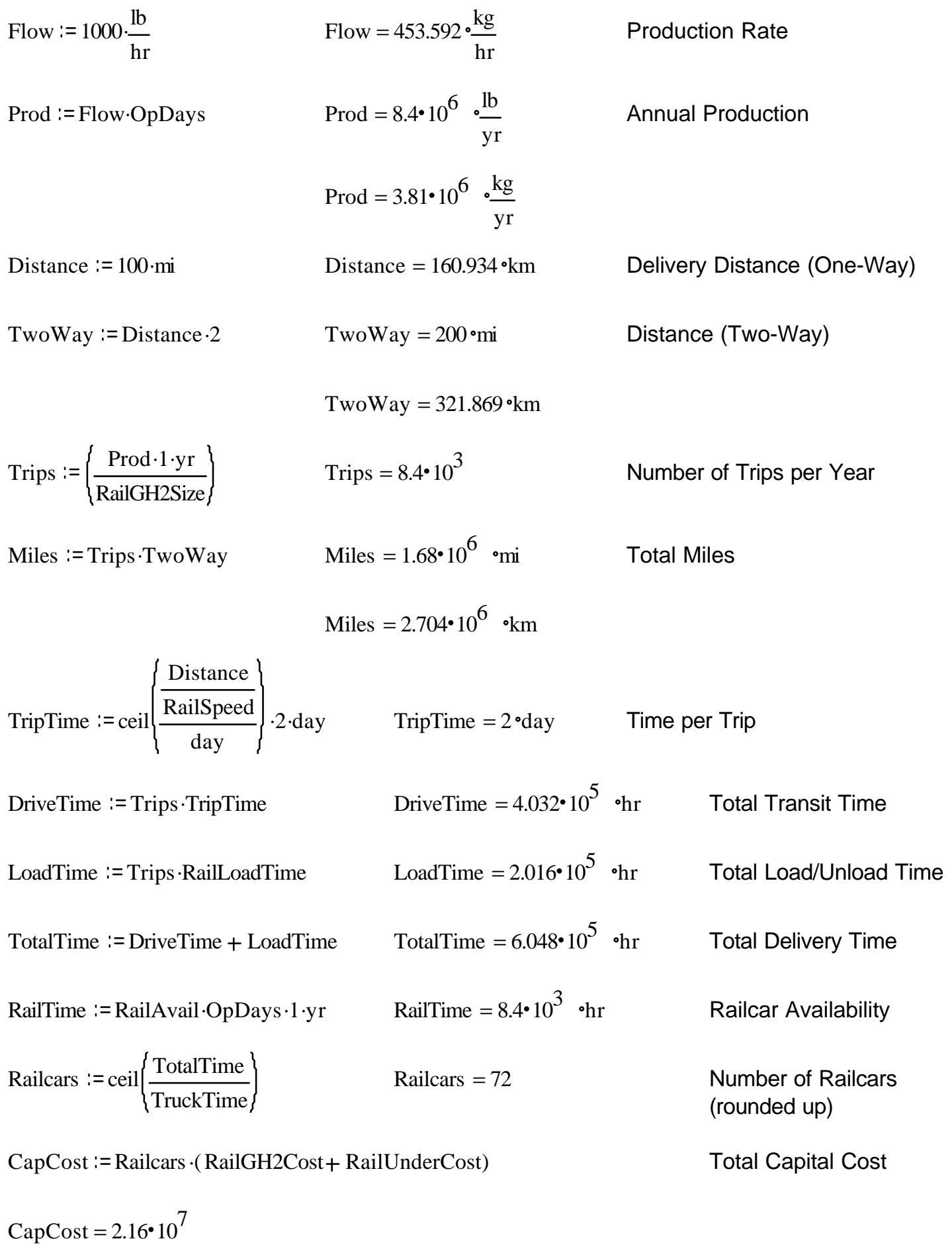




\section{B.2 COMPRESSED GAS RAIL SAMPLE CALCULATION (continued)}

DepCost $:=\frac{\text { CapCost }}{\text { RailcarDep }} \quad$ DepCost $=1.44 \cdot 10^{6} \cdot \frac{1}{\mathrm{yr}} \quad$ Depreciation

FreightCost $:=\frac{\text { Trips } \cdot \text { RailFreight } \cdot 2}{\mathrm{yr}} \quad$ FreightCost $=6.72 \cdot 10^{6} \cdot \frac{1}{\mathrm{yr}} \quad$ Annual Freight Cost

TotalCost :=FreightCost + DepCost Total Annual Cost

TotalCost $=8.16 \cdot 10^{6} \cdot \frac{1}{\mathrm{yr}}$

Dep $:=\frac{\text { DepCost }}{\text { Prod }} \quad$ Dep $=0.171 \cdot \frac{1}{\mathrm{lb}} \quad$ Dep $=0.378 \cdot \frac{1}{\mathrm{~kg}} \quad$ Capital Cost

Freight $:=\frac{\text { FreightCost }}{\text { Prod }} \quad$ Freight $=0.8 \cdot \frac{1}{\mathrm{lb}} \quad$ Freight $=1.764 \cdot \frac{1}{\mathrm{~kg}} \quad$ Freight Cost

Tot $:=\frac{\text { TotalCost }}{\text { Prod }} \quad$ Tot $=0.971 \cdot \frac{1}{\mathrm{lb}} \quad$ Tot $=2.142 \cdot \frac{1}{\mathrm{~kg}} \quad$ Total Cost

TripFreq $:=\frac{\frac{\text { Trips }}{\mathrm{yr}}}{\frac{\text { OpDays }}{\text { day }}} \quad$ TripFreq $=24 \quad$ Trip Frequency

TripLength $:=\operatorname{ceil}\left(\frac{\text { TotalTime }}{\text { Trips }}\right\} \quad$ TripLength $=72 \circ \mathrm{hr} \quad$ Trip Length

UtilRate $:=\frac{\text { TripFreq }}{\text { Railcars }} \quad$ UtilRate $=0.333 \quad$ Railcar Utilization Rate 


\section{B.3 LIQUID HYDROGEN TRUCKING SAMPLE CALCULATION}

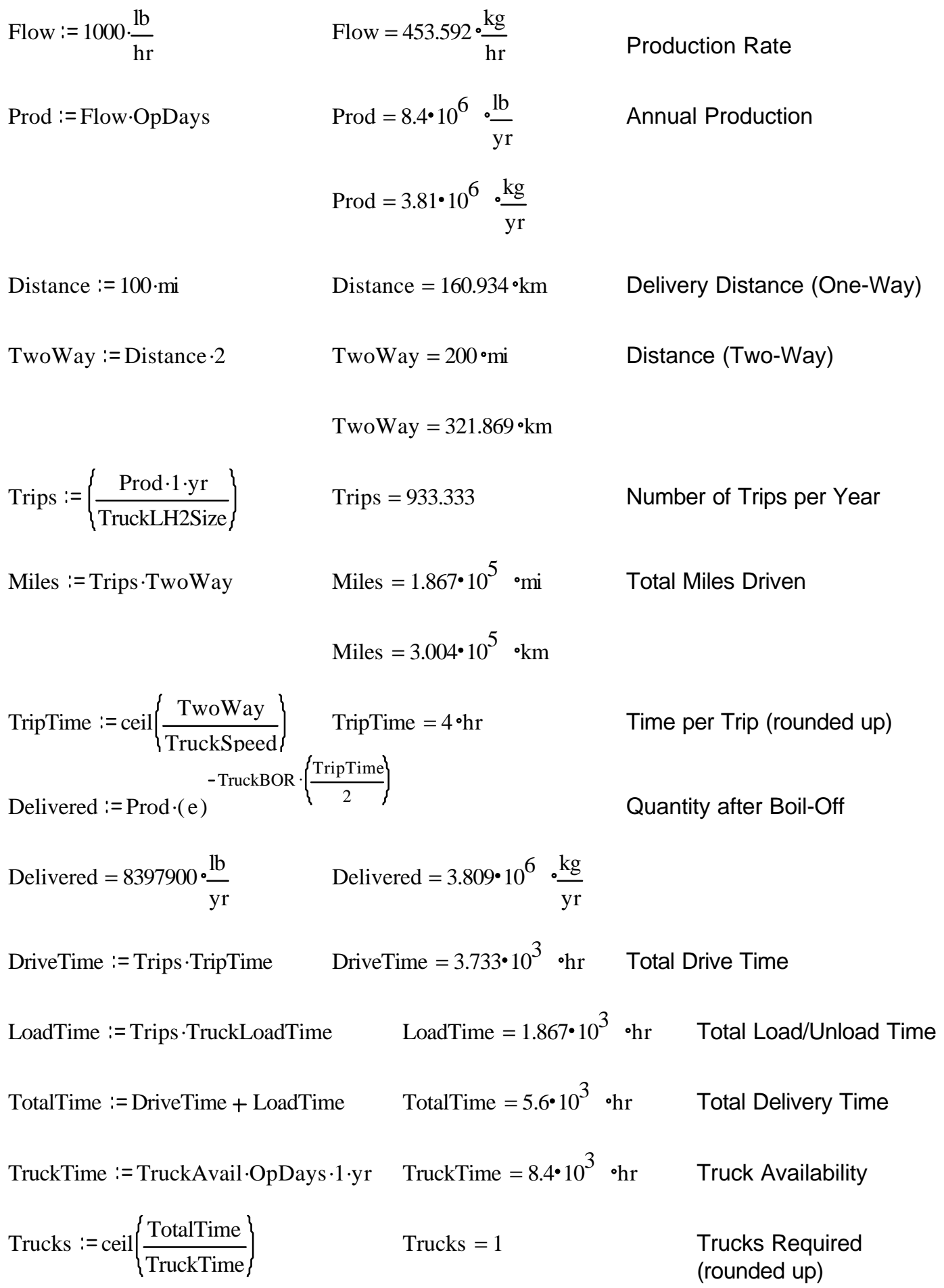




\section{B.3 LIQUID HYDROGEN TRUCKING SAMPLE CALCULATION (continued)}

$\begin{array}{lll}\text { DriverTime }:=\text { DriverAvail } \cdot \text { OpDays } \cdot 1 \cdot \mathrm{yr} & \text { DriverTime }=4.2 \cdot 10^{3} \cdot \mathrm{hr} & \text { Driver Availability } \\ \text { Drivers }:=\operatorname{ceil}\left(\frac{\text { TotalTime }}{\text { DriverTime }}\right\} & \text { Drivers }=2 & \begin{array}{l}\text { Drivers Required } \\ \text { (rounded up) }\end{array} \\ \text { FuelUse }:=\frac{\text { Miles }}{\text { TruckMileage }} & \text { FuelUse }=3.111 \cdot 10^{4} \cdot \mathrm{gal} & \text { Annual Fuel Use }\end{array}$

CapCost $:=$ Trucks $\cdot($ TruckLH2Cost + TruckUnderCost + TruckCabCost $) \quad$ Total Capital Cost

CapCost $=5 \cdot 10^{5}$

DepCost $:=\frac{\text { Trucks } \cdot(\text { TruckLH2Cost }+ \text { TruckUnderCost })}{\text { TrailerDep }}+\frac{\text { Trucks } \cdot(\text { TruckCabCost })}{\text { TractorDep }}$

DepCost $=9.083 \cdot 10^{4} \cdot \frac{1}{\mathrm{yr}} \quad$ Depreciation

FuelCost $:=$ FuelUse $\cdot \frac{\text { DieselPrice }}{\mathrm{yr}} \quad$ FuelCost $=3.111 \cdot 10^{4} \cdot \frac{1}{\mathrm{yr}} \quad$ Annual Fuel Cost

LaborCost $:=$ TotalTime $\cdot \frac{\text { DriverWage }}{\mathrm{yr}} \quad$ LaborCost $=1.61 \cdot 10^{5} \cdot \frac{1}{\mathrm{yr}} \quad$ Annual Labor Cost

TotalCost $:=$ FuelCost + DepCost + LaborCost Total Annual Cost

TotalCost $=2.829 \cdot 10^{5} \cdot \frac{1}{\mathrm{yr}}$

Dep : $=\frac{\text { DepCost }}{\text { Delivered }} \quad$ Dep $=0.011 \cdot \frac{1}{\mathrm{lb}} \quad$ Dep $=0.024 \cdot \frac{1}{\mathrm{~kg}} \quad$ Capital Cost

Fuel $:=\frac{\text { FuelCost }}{\text { Delivered }} \quad$ Fuel $=3.705 \cdot 10^{-3} \cdot \frac{1}{\mathrm{lb}} \quad$ Fuel $=8.167 \cdot 10^{-3} \cdot \frac{1}{\mathrm{~kg}} \quad$ Fuel Cost

Labor $:=\frac{\text { LaborCost }}{\text { Delivered }} \quad$ Labor $=0.019 \cdot \frac{1}{\mathrm{lb}} \quad$ Labor $=0.042 \cdot \frac{1}{\mathrm{~kg}} \quad$ Labor Cost

Tot $:=\frac{\text { TotalCost }}{\text { Delivered }} \quad$ Tot $=0.034 \cdot \frac{1}{\mathrm{lb}} \quad$ Tot $=0.074 \cdot \frac{1}{\mathrm{~kg}} \quad$ Total Cost 


\section{B.3 LIQUID HYDROGEN TRUCKING SAMPLE CALCULATION (continued)}

TripFreq $:=\frac{\frac{\text { Trips }}{\mathrm{yr}}}{\frac{\text { OpDays }}{\text { day }}}$

TripLength $:=\operatorname{ceil}\left\{\frac{\text { TotalTime }}{\text { Trips }}\right\}$

UtilRate : $=\frac{\text { TripFreq }}{\text { Trucks }}$
TripFreq $=2.667$

TripLength $=6 \bullet \mathrm{hr}$

UtilRate $=2.667$
Trip Frequency

Trip Length

Truck Utilization Rate 


\section{B.4 LIQUID HYDROGEN RAIL SAMPLE CALCULATION}
Flow $:=1000 \cdot \frac{\mathrm{lb}}{\mathrm{hr}}$
Flow $=453.592 \cdot \frac{\mathrm{kg}}{\mathrm{hr}}$
Production Rate
Prod := Flow $\cdot$ OpDays
$\operatorname{Prod}=8.4 \cdot 10^{6} \cdot \frac{\mathrm{lb}}{\mathrm{yr}}$
Annual Production
Prod $=3.81 \cdot 10^{6} \cdot \frac{\mathrm{kg}}{\mathrm{yr}}$
Distance : $=100 \cdot \mathrm{mi}$
Distance $=160.934^{\circ} \mathrm{km}$
Delivery Distance (One-Way)
TwoWay := Distance $\cdot 2$
TwoWay $=200^{\circ} \mathrm{mi}$
Distance (Two-Way)
TwoWay $=321.869 \circ \mathrm{km}$
Trips $:=\left\{\frac{\text { Prod } \cdot 1 \cdot \mathrm{yr}}{\text { RailLH2Size }}\right\}$
Trips $=420$
Number of Trips per Year
Miles := Trips $\cdot$ TwoWay
Miles $=8.4 \cdot 10^{4} \cdot \mathrm{mi}$
Total Miles
Miles $=1.352 \cdot 10^{5} \cdot \mathrm{km}$
TripTime $:=\operatorname{ceil}\left\{\frac{\frac{\text { Distance }}{\text { RailSpeed }}}{\text { day }}\right\} \cdot 2 \cdot$ day
Delivered $:=\operatorname{Prod} \cdot(\mathrm{e})^{- \text {RailBOR }} \cdot\left(\frac{\text { TripTime }}{2}\right\}$
TripTime $=2 \cdot$ day $\quad$ Trip Length
Delivered $=8374838 \cdot \frac{\mathrm{lb}}{\mathrm{yr}}$
Delivered $=3.799 \cdot 10^{6} \cdot \frac{\mathrm{kg}}{\mathrm{yr}}$
DriveTime := Trips $\cdot$ TripTime
DriveTime $=2.016 \cdot 10^{4} \cdot \mathrm{hr} \quad$ Total Transit Time
LoadTime := Trips $\cdot$ RailLoadTime
LoadTime $=1.008 \cdot 10^{4} \cdot \mathrm{hr}$
Total Load/Unload Time
TotalTime := DriveTime + LoadTime
TotalTime $=3.024 \cdot 10^{4} \cdot \mathrm{hr}$
Total Delivery Time
RailTime := RailAvail $\cdot$ OpDays $\cdot 1 \cdot \mathrm{yr}$
RailTime $=8.4 \cdot 10^{3} \circ \mathrm{hr}$
Railcar Availability
Railcars := ceil $\left\{\frac{\text { TotalTime }}{\text { TruckTime }}\right\}$
Railcars $=4$
Railcars Required (rounded up) 


\section{B.4 LIQUID HYDROGEN RAIL SAMPLE CALCULATION (continued)}

CapCost := Railcars $\cdot($ RailLH2Cost + RailUnderCost)

Total Capital Cost

CapCost $=2 \cdot 10^{6}$

DepCost $:=\frac{\text { CapCost }}{\text { RailcarDep }} \quad$ DepCost $=1.333 \cdot 10^{5} \cdot \frac{1}{\mathrm{yr}} \quad$ Depreciation

FreightCost $:=\frac{\text { Trips } \cdot \text { RailFreight } \cdot 2}{\mathrm{yr}} \quad$ FreightCost $=3.36 \cdot 10^{5} \cdot \frac{1}{\mathrm{yr}} \quad$ Annual Freight Cost

TotalCost $:=$ FreightCost + DepCost

Total Annual Cost

TotalCost $=4.693 \cdot 10^{5} \cdot \frac{1}{\mathrm{yr}}$

Dep : $=\frac{\text { DepCost }}{\text { Prod }} \quad$ Dep $=0.016 \cdot \frac{1}{\mathrm{lb}} \quad$ Dep $=0.035 \cdot \frac{1}{\mathrm{~kg}} \quad$ Depreciation

Freight $:=\frac{\text { FreightCost }}{\text { Prod }} \quad$ Freight $=0.04 \cdot \frac{1}{\mathrm{lb}} \quad$ Freight $=0.088 \cdot \frac{1}{\mathrm{~kg}} \quad$ Freight Cost

Tot $:=\frac{\text { TotalCost }}{\text { Prod }} \quad$ Tot $=0.056 \cdot \frac{1}{\mathrm{lb}} \quad$ Tot $=0.123 \cdot \frac{1}{\mathrm{~kg}} \quad$ Total Cost

TripFreq $:=\frac{\frac{\text { Trips }}{\mathrm{yr}}}{\frac{\text { OpDays }}{\text { day }}} \quad$ TripFreq $=1.2 \quad$ Trip Frequency

TripLength $:=\operatorname{ceil}\left(\frac{\text { TotalTime }}{\text { Trips }}\right) \quad$ TripLength $=72 \bullet \mathrm{hr} \quad$ Trip Length

UtilRate $:=\frac{\text { TripFreq }}{\text { Railcars }} \quad$ UtilRate $=0.3 \quad$ Railcar Utilization Rate 


\section{B.5 LIQUID HYDROGEN SHIP SAMPLE CALCULATION}

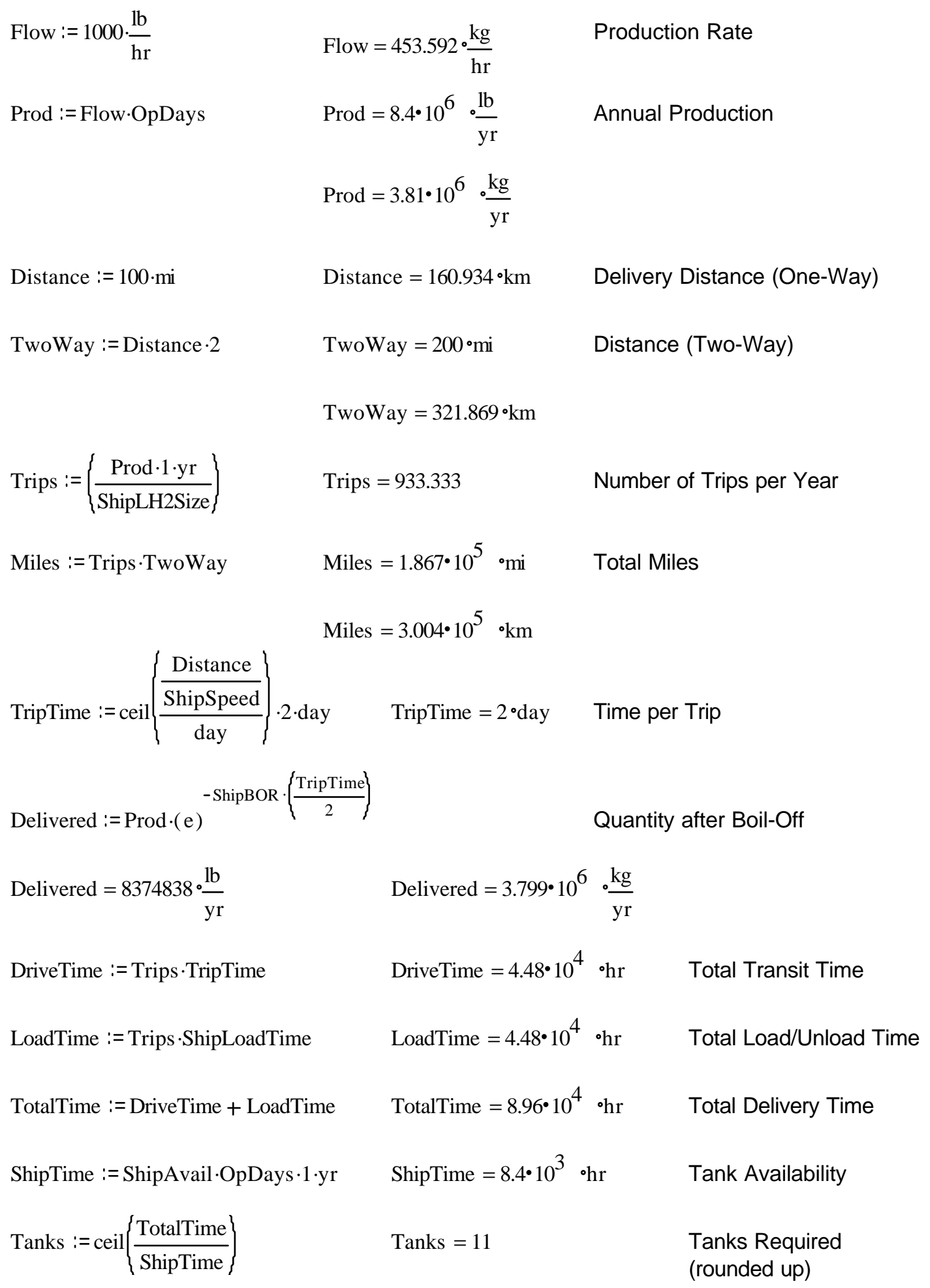




\section{B.5 LIQUID HYDROGEN SHIP SAMPLE CALCULATION (continued)}

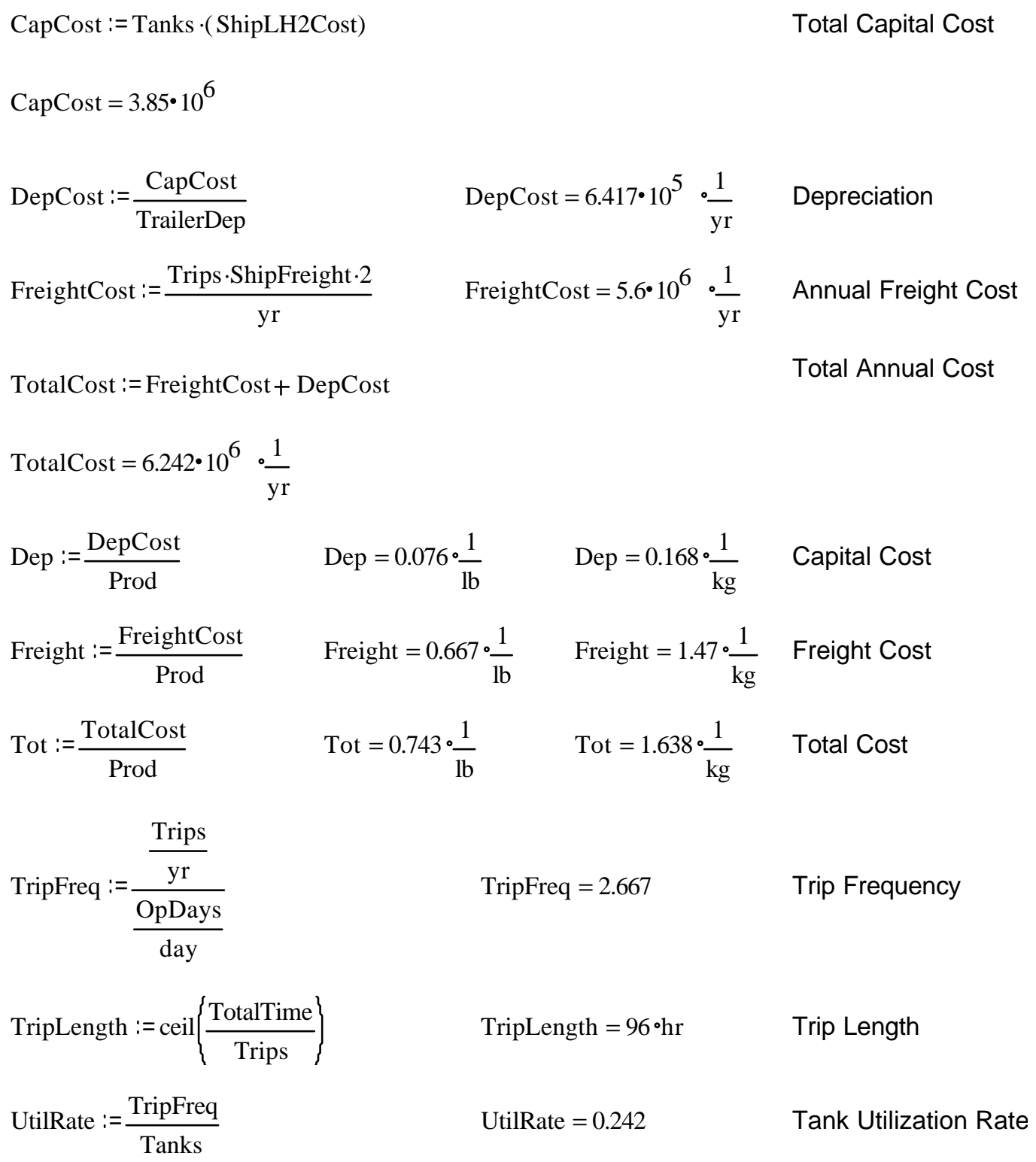




\section{B.6 METAL HYDRIDE TRUCKING SAMPLE CALCULATION}

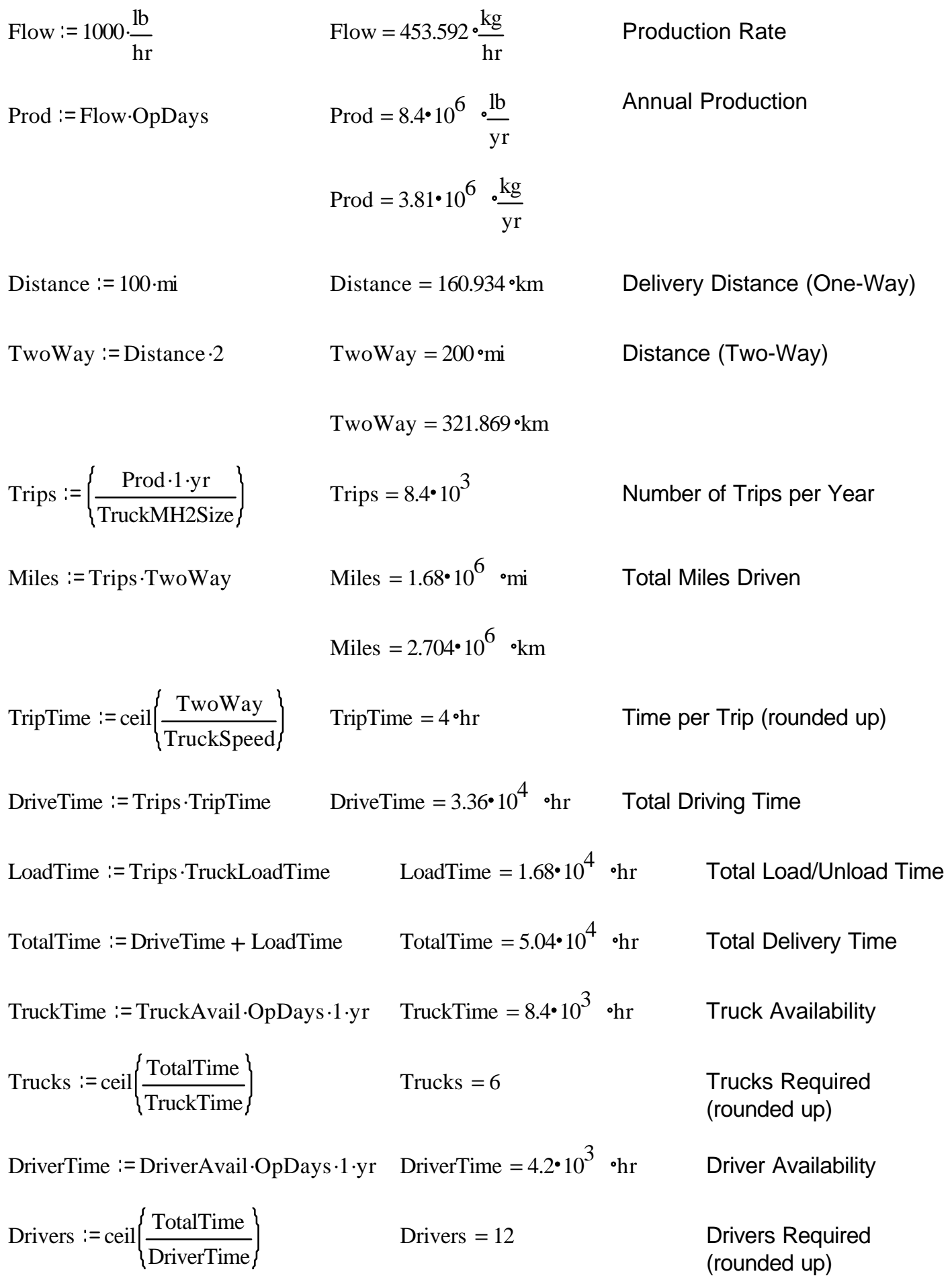




\section{B.6 METAL HYDRIDE TRUCKING SAMPLE CALCULATION (continued)}

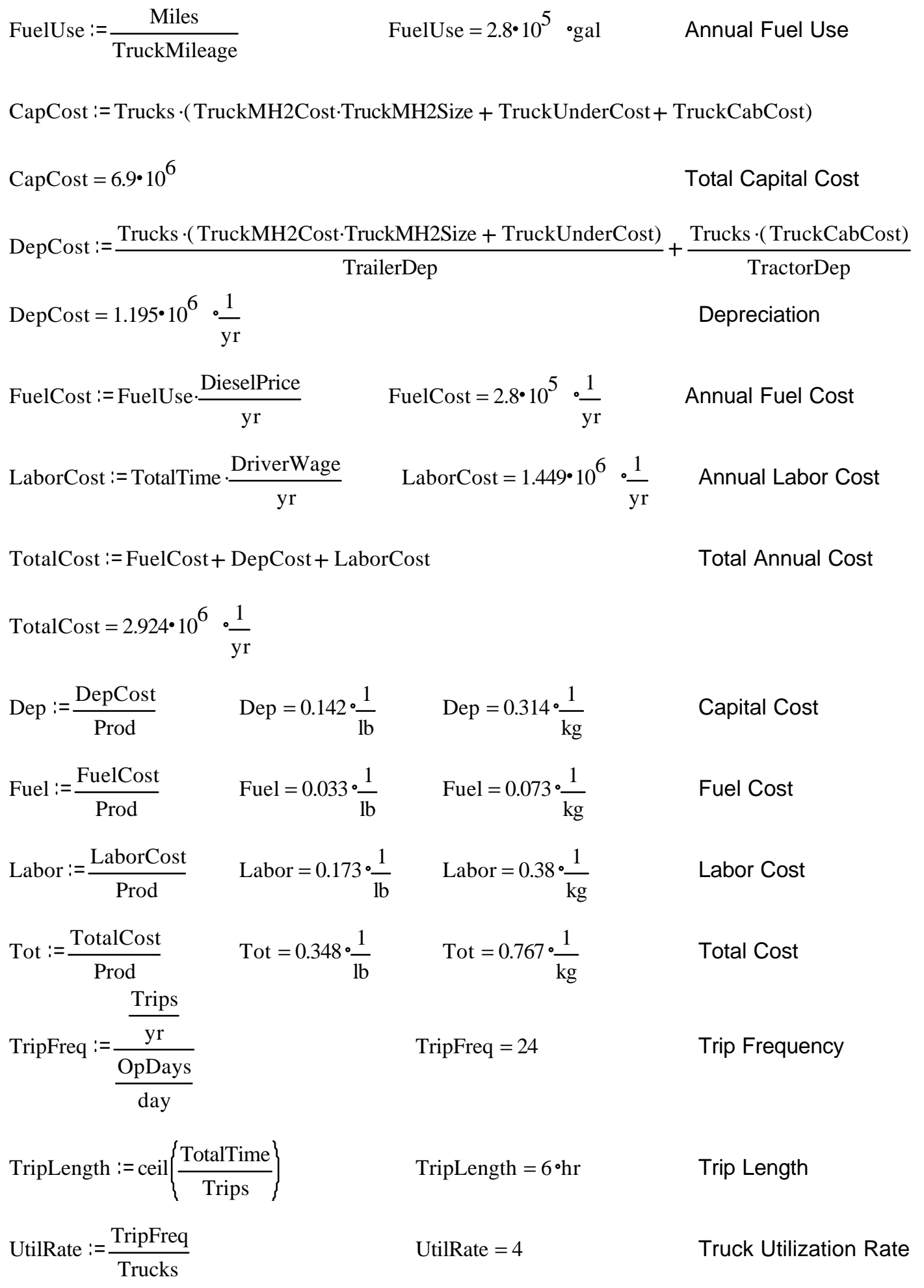




\section{B.7 METAL HYDRIDE RAIL SAMPLE CALCULATION}

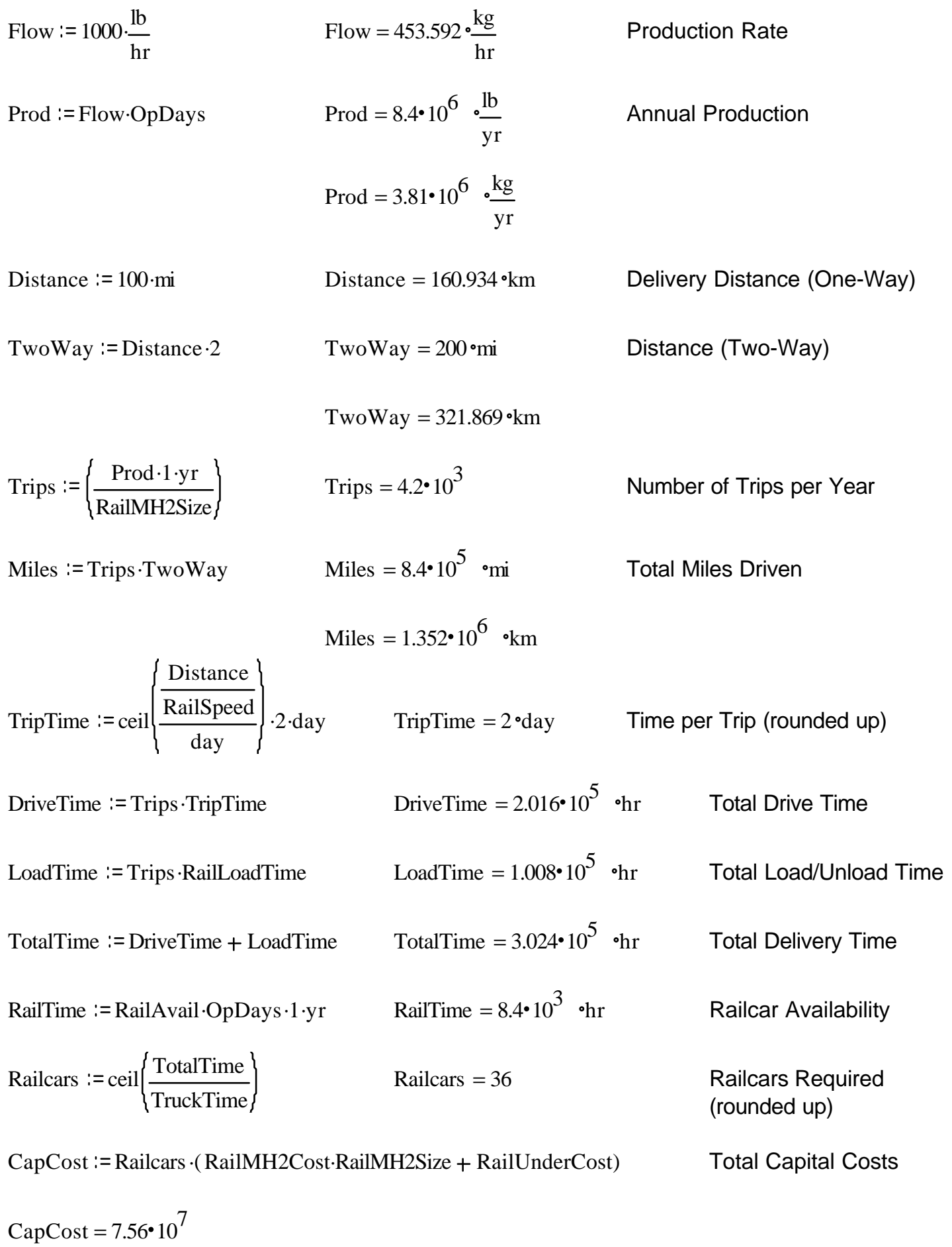




\section{B.7 METAL HYDRIDE RAIL SAMPLE CALCULATION (continued)}

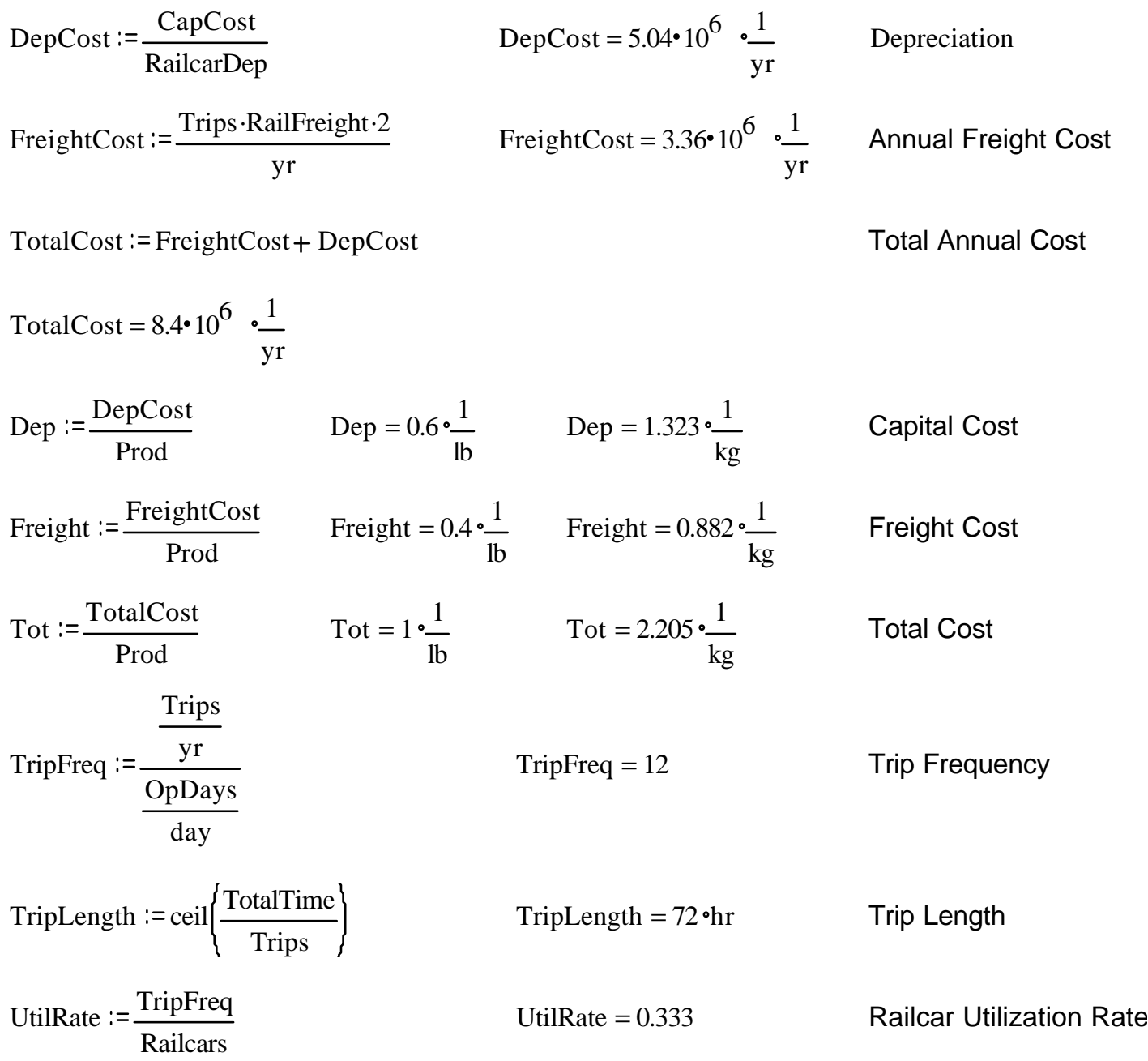




\section{B.8 PIPELINE SAMPLE CALCULATION}
Flow $:=1000 \cdot \frac{\mathrm{lb}}{\mathrm{hr}}$
Flow $=0.126 \cdot \frac{\mathrm{kg}}{\mathrm{s}}$
Production Rate
Prod := Flow·OpDays
$\operatorname{Prod}=8.4 \cdot 10^{6} \cdot \frac{\mathrm{lb}}{\mathrm{yr}}$
Annual Production
Prod $=3.81 \cdot 10^{6} \cdot \frac{\mathrm{kg}}{\mathrm{yr}}$
Distance $:=100 \cdot \mathrm{mi}$
Distance $=160.934{ }^{\circ} \mathrm{km}$
Distance (One-Way)
Area $:=\frac{\pi \cdot \text { PipeDia }^{2}}{4}$
Area $=0.049 \cdot \mathrm{m}^{2}$
Pipe Cross-Sectional Area
Flux $:=\frac{\text { Flow }}{\text { Area }}$
Flux $=2.567 \cdot \frac{\mathrm{kg}}{\left(\mathrm{m}^{2} \cdot \mathrm{s}\right)}$
Flux Through Pipe
NRe : $=\frac{\text { PipeDia } \cdot \text { Flux }}{\text { Visc }}$
$\mathrm{NRe}=7.444 \cdot 10^{4}$
Reynolds Number
RelRoughness := $\frac{\text { Roughness }}{\text { PipeDia }}$
RelRoughness $=0.00018$
Relative Roughness

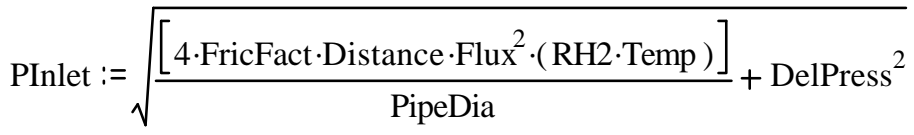
Inlet Pressure (Delivery Pressure plus Frictional
PInlet $=2.025 \cdot 10^{6} \cdot \mathrm{Pa}$ Losses)
Energy :=Flow CompPower $\left[\frac{\ln \left\{\frac{\text { PInlet }}{0.1 \cdot 10^{6} \cdot \mathrm{Pa}}\right\}}{\ln \left\{\frac{20 \cdot 10^{6} \cdot \mathrm{Pa}}{0.1 \cdot 10^{6} \cdot \mathrm{Pa}}\right\}}-\frac{\ln \left(\frac{\text { DelPress }}{0.1 \cdot 10^{6} \cdot \mathrm{Pa}}\right\}}{\ln \left(\frac{20 \cdot 10^{6} \cdot \mathrm{Pa}}{0.1 \cdot 10^{6} \cdot \mathrm{Pa}}\right\}}\right]$
Compressor Power to Overcome Frictional Losses
Energy $=2.307{ }^{\circ W}$
Energy $\cdot$ OpDays $=1.938 \cdot 10^{4} \cdot \frac{\mathrm{kW} \cdot \mathrm{hr}}{\mathrm{yr}}$
CompCap $:=($ CompCost $\cdot$ CompSize $) \cdot\left(\frac{\text { Energy }}{\text { CompSize }}\right\}^{\text {CompExp }} \cdot\left(\frac{\text { PInlet }}{\text { CompPress }}\right\}^{\text {CPExp }}$ Compressor Cost
CompCap $=6.789 \cdot 10^{3}$ 


\section{B.8 PIPELINE SAMPLE CALCULATION (continued)}

\begin{tabular}{|c|c|c|c|c|c|}
\hline \multicolumn{5}{|c|}{ PipelineCap := PipeCost.Distance } & Pipeline Cost \\
\hline \multicolumn{5}{|c|}{ CapCost :=CompCap + PipelineCap } & Total Capital Cost \\
\hline \multicolumn{6}{|l|}{ CapCost $=1 \cdot 10^{8}$} \\
\hline DepCost $:=\frac{\text { CapCost }}{\text { PipelineDep }}$ & & epCos & $=4.546 \cdot 10^{6} \cdot \frac{1}{\mathrm{yr}}$ & & Depreciation \\
\hline EnerCost $:=$ Energy $\cdot$ OpDays $\cdot$ & ElecCost & nerCo & $=969.019 \cdot \frac{1}{\mathrm{yr}}$ & & $\begin{array}{l}\text { Annual Electricity } \\
\text { Cost }\end{array}$ \\
\hline \multicolumn{5}{|c|}{ TotalCost $:=$ EnerCost + DepCost } & Total Annual Cost \\
\hline \multicolumn{6}{|l|}{ TotalCost $=4.547 \cdot 10^{6} \cdot \frac{1}{\mathrm{yr}}$} \\
\hline Dep : $=\frac{\text { DepCost }}{\text { Prod }}$ & Dep $=0.541 \cdot \frac{1}{\mathrm{lb}}$ & & Dep $=1.193 \cdot \frac{1}{\mathrm{~kg}}$ & & Capital Cost \\
\hline Ener : $=\frac{\text { EnerCost }}{\text { Prod }}$ & Ener $=1.154 \cdot 10^{-4}$ & $\cdot \frac{1}{\mathrm{lb}}$ & Ener $=2.543 \cdot 10^{-4}$ & $\cdot \frac{1}{\mathrm{~kg}}$ & Electricity Cost \\
\hline Labor : $=\frac{\text { LaborCost }}{\text { Prod }}$ & Labor $=0.173 \cdot \frac{1}{\mathrm{lb}}$ & & Labor $=0.38 \cdot \frac{1}{\mathrm{~kg}}$ & & Labor Cost \\
\hline Tot $:=\frac{\text { TotalCost }}{\text { Prod }}$ & Tot $=0.541 \cdot \frac{1}{\mathrm{lb}}$ & & Tot $=1.193 \cdot \frac{1}{\mathrm{~kg}}$ & & Total Cost \\
\hline Comp $:=\frac{\text { CompCap }}{(\text { Prod } \cdot \text { PipelineDep })}$ & Comp $=3.674 \cdot 10^{-5}$ & $\frac{1}{\mathrm{lb}}$ & Comp $=8.1 \cdot 10^{-5}$ & $\cdot \frac{1}{\mathrm{~kg}}$ & Compressor Cost \\
\hline Pipe $:=\frac{\text { PipelineCap }}{(\text { Prod } \cdot \text { PipelineDep })}$ & Pipe $=0.541 \cdot \frac{1}{\mathrm{lb}}$ & & Pipe $=1.193 \cdot \frac{1}{\mathrm{~kg}}$ & & Pipeline Cost \\
\hline
\end{tabular}




\section{APPENDIX C - SAMPLE POWER REQUIREMENT CALCULATIONS}

C.1 Ideal Liquefaction of Hydrogen

C.2 Linde Process for Liquefaction of Nitrogen

C.3 Pre-Cooled Linde Process for Liquefaction of Hydrogen

C.4 Hydrogen Compression Power Requirement

Appendix C contains sample work calculations for the compression and liquefaction of hydrogen and nitrogen. The thermodynamic data used in the calculations came from government Bureau of Standards temperature-entropy charts. The specific pressures and temperatures were chosen to demonstrate how to do the work calculations and do not necessarily represent actual operating conditions. The calculations were done using MachCAD so all required unit conversions were done internal to the program. 


\section{C.1 IDEAL LIQUEFACTION OF HYDROGEN}

$$
\begin{array}{lll}
\mathrm{S}_{1}:=16.75 \cdot \frac{\mathrm{cal}}{\mathrm{gm} \cdot \mathrm{K}} \quad \mathrm{h}_{1}:=1010 \cdot \frac{\mathrm{cal}}{\mathrm{gm}} & \mathrm{P}_{1}:=1 \cdot \mathrm{atm} & \mathrm{T}_{1}:=300 \cdot \mathrm{K} \\
\mathrm{S}_{2}:=4.35 \cdot \frac{\mathrm{cal}}{\mathrm{gm} \cdot \mathrm{K}} & \mathrm{T}_{2}:=300 \cdot \mathrm{K} \\
\mathrm{S}_{3}:=4.35 \cdot \frac{\mathrm{cal}}{\mathrm{gm} \cdot \mathrm{K}} \quad \mathrm{h}_{3}:=70 \cdot \frac{\mathrm{cal}}{\mathrm{gm}} \quad \mathrm{P}_{3}:=1 \cdot \mathrm{atm} \quad \mathrm{T}_{3}:=20 \cdot \mathrm{K} \\
\mathrm{w}:=\mathrm{T}_{1} \cdot\left(\mathrm{S}_{1}-\mathrm{S}_{2}\right)-\left(\mathrm{h}_{1}-\mathrm{h}_{3}\right) & \text { Calculate ideal work per pound } \\
\mathrm{w}=1.467 \cdot \frac{\mathrm{kW} \cdot \mathrm{hr}}{\mathrm{lb}} &
\end{array}
$$




\section{C.2 LINDE PROCESS FOR LIQUEFACTION OF NITROGEN}

$$
\begin{aligned}
& \mathrm{S}_{1}:=1.05 \cdot \frac{\mathrm{cal}}{\mathrm{gm} \cdot \mathrm{K}} \quad \mathrm{h}_{1}:=460 \cdot \frac{\text { joule }}{\mathrm{gm}} \quad \mathrm{P}_{1}:=1 \cdot \mathrm{atm} \quad \mathrm{T}_{1}:=300 \cdot \mathrm{K} \\
& \mathrm{S}_{2}:=0.725 \cdot \frac{\mathrm{cal}}{\mathrm{gm} \cdot \mathrm{K}} \quad \mathrm{h}_{2}:=445 \cdot \frac{\text { joule }}{\mathrm{gm}} \quad \mathrm{P}_{2}:=100 \cdot \mathrm{atm} \quad \mathrm{T}_{2}:=300 \cdot \mathrm{K} \\
& \mathrm{S}_{3}:=0.2 \cdot \frac{\mathrm{cal}}{\mathrm{gm} \cdot \mathrm{K}} \quad \mathrm{h}_{3}:=100 \cdot \frac{\text { joule }}{\mathrm{gm}} \quad \mathrm{P}_{3}:=100 \cdot \mathrm{atm} \quad \mathrm{T}_{3}:=105 \cdot \mathrm{K} \\
& \mathrm{S}_{4}:=0.35 \cdot \frac{\mathrm{cal}}{\mathrm{gm} \cdot \mathrm{K}} \quad \mathrm{h}_{4}:=100 \cdot \frac{\text { joule }}{\mathrm{gm}} \quad \mathrm{P}_{4}:=1 \cdot \mathrm{atm} \quad \mathrm{T}_{4}:=77 \cdot \mathrm{K} \\
& \mathrm{S}_{5}:=0.7 \cdot \frac{\mathrm{cal}}{\mathrm{gm} \cdot \mathrm{K}} \quad \mathrm{h}_{5}:=230 \cdot \frac{\text { joule }}{\mathrm{gm}} \quad \mathrm{P}_{5}:=1 \cdot \mathrm{atm} \quad \mathrm{T}_{5}:=77 \cdot \mathrm{K} \\
& \mathrm{S}_{6}:=0.1 \cdot \frac{\mathrm{cal}}{\mathrm{gm} \cdot \mathrm{K}} \quad \mathrm{h}_{6}:=30 \cdot \frac{\text { joule }}{\mathrm{gm}} \quad \mathrm{P}_{6}:=1 \cdot \mathrm{atm} \quad \mathrm{T}_{6}:=77 \cdot \mathrm{K} \\
& y:=\frac{\left(h_{1}-h_{2}\right)}{\left(h_{1}-h_{8}\right)} \quad \begin{array}{l}
\text { Calculate percentage of gas stream } \\
\text { liquefied on each pass }
\end{array} \\
& y=0.09 \\
& \mathrm{w}:=\mathrm{T}_{1} \cdot\left(\mathrm{S}_{1}-\mathrm{S}_{2}\right)-\left(\mathrm{h}_{1}-\mathrm{h}_{2}\right) \quad \text { Calculate work per pound of gas } \\
& \mathrm{w}=0.05 \cdot \frac{\mathrm{kW} \cdot \mathrm{hr}}{\mathrm{lb}} \\
& \frac{\mathrm{w}}{\mathrm{y}}=0.551 \cdot \frac{\mathrm{kW} \cdot \mathrm{hr}}{\mathrm{lb}} \quad \text { Calculate work per pound of liquid nitrogen } \\
& \frac{\mathrm{w}}{\mathrm{y}}=1.215 \cdot \mathrm{kW} \cdot \frac{\mathrm{hr}}{\mathrm{kg}} \quad \text { Work per } \mathrm{kg} \text { of liquid nitrogen }
\end{aligned}
$$$$
\text { C }-3
$$ 


\section{C.3 NITROGEN PRE-COOLED LIQUEFACTION OF HYDROGEN}

\begin{tabular}{|c|c|c|c|}
\hline $\mathrm{S}_{1}:=16.75 \cdot \frac{\mathrm{cal}}{\mathrm{gm} \cdot \mathrm{K}}$ & $\mathrm{h}_{1}:=1010 \cdot \frac{\mathrm{cal}}{\mathrm{gm}}$ & $P_{1}:=1 \cdot a t m$ & $\mathrm{~T}_{1}:=300 \cdot \mathrm{K}$ \\
\hline $\mathrm{S}_{2}:=12.5 \cdot \frac{\mathrm{cal}}{\mathrm{gm} \cdot \mathrm{K}}$ & $\mathrm{h}_{2}:=1020 \cdot \frac{\mathrm{cal}}{\mathrm{gm}}$ & $\mathrm{P}_{2}:=100 \cdot \mathrm{atm}$ & $\mathrm{T}_{2}:=300 \cdot \mathrm{K}$ \\
\hline $\mathrm{S}_{3}:=7.75 \cdot \frac{\mathrm{cal}}{\mathrm{gm} \cdot \mathrm{K}}$ & $\mathrm{h}_{3}:=280 \cdot \frac{\mathrm{cal}}{\mathrm{gm}}$ & $\mathrm{P}_{3}:=100 \cdot \mathrm{atm}$ & $\mathrm{T}_{3}:=77 \cdot \mathrm{K}$ \\
\hline $\mathrm{S}_{4}:=5 \cdot \frac{\mathrm{cal}}{\mathrm{gm} \cdot \mathrm{K}}$ & $\mathrm{h}_{4}:=120 \cdot \frac{\mathrm{cal}}{\mathrm{gm}}$ & $P_{4}:=100 \cdot a t m$ & $\mathrm{~T}_{4}:=35 \cdot \mathrm{K}$ \\
\hline $\mathrm{S}_{5}:=6.5 \cdot \frac{\mathrm{cal}}{\mathrm{gm} \cdot \mathrm{K}}$ & $\mathrm{h}_{5}:=120 \cdot \frac{\mathrm{cal}}{\mathrm{gm}}$ & $P_{5}:=1 \cdot a t m$ & $\mathrm{~T}_{5}:=20 \cdot \mathrm{K}$ \\
\hline $\mathrm{S}_{6}:=9.5 \cdot \frac{\mathrm{cal}}{\mathrm{gm} \cdot \mathrm{K}}$ & $\mathrm{h}_{6}:=170 \cdot \frac{\mathrm{cal}}{\mathrm{gm}}$ & $\mathrm{P}_{6}:=1 \cdot \mathrm{atm}$ & $\mathrm{T}_{6}:=20 \cdot \mathrm{K}$ \\
\hline $\mathrm{S}_{7}:=12.75 \cdot \frac{\mathrm{cal}}{\mathrm{gm} \cdot \mathrm{K}}$ & $\mathrm{h}_{7}:=320 \cdot \frac{\mathrm{cal}}{\mathrm{gm}}$ & $\mathrm{P}_{7}:=1 \cdot \mathrm{atm}$ & $\mathrm{T}_{7}:=77 \cdot \mathrm{K}$ \\
\hline $\mathrm{S}_{8}:=4.25 \cdot \frac{\mathrm{cal}}{\mathrm{gm} \cdot \mathrm{K}}$ & $\mathrm{h}_{8}:=70 \cdot \frac{\mathrm{cal}}{\mathrm{gm}}$ & $\mathrm{P}_{8}:=1 \cdot \mathrm{atm}$ & $\mathrm{T}_{8}:=20 \cdot \mathrm{K}$ \\
\hline $\mathrm{Sa}:=1.05 \cdot \frac{\mathrm{cal}}{\mathrm{gm} \cdot \mathrm{K}}$ & ha $:=460 \cdot \frac{\text { joule }}{\mathrm{gm}}$ & $\mathrm{Pa}:=1 \cdot \mathrm{atm}$ & $\mathrm{Ta}:=300 \cdot \mathrm{K}$ \\
\hline $\mathrm{Sb}:=0.725 \cdot \frac{\mathrm{cal}}{\mathrm{gm} \cdot \mathrm{K}}$ & $\mathrm{hb}:=445 \cdot \frac{\text { joule }}{\mathrm{gm}}$ & $\mathrm{Pb}:=100 \cdot \mathrm{atm}$ & $\mathrm{Tb}:=300 \cdot \mathrm{K}$ \\
\hline $\mathrm{Sd}:=0.35 \cdot \frac{\mathrm{cal}}{\mathrm{gm} \cdot \mathrm{K}}$ & hd $:=100 \cdot \frac{\text { joule }}{\mathrm{gm}}$ & $\mathrm{Pd}:=1 \cdot \mathrm{atm}$ & $\mathrm{Td}:=77 \cdot \mathrm{K}$ \\
\hline
\end{tabular}

C -4 


\section{C.3 NITROGEN PRE-COOLED LIQUEFACTION OF HYDROGEN (continued)}

$\begin{array}{ll}\mathrm{r}:=1 & \begin{array}{l}\text { Pounds of nitrogen refrigeration per } \\ \text { pound of hydrogen }\end{array} \\ \mathrm{y}:=\frac{\left(\mathrm{h}_{1}-\mathrm{h}_{2}\right)}{\left(\mathrm{h}_{1}-\mathrm{h}_{8}\right)}+\mathrm{r} \cdot\left[\frac{(\mathrm{ha}-\mathrm{hd})}{\left(\mathrm{h}_{1}-\mathrm{h}_{8}\right)}\right] & \begin{array}{l}\text { Calculate percentage of gas liquefied } \\ \text { compared to total gas flow }\end{array} \\ \mathrm{y}=0.081 & \quad \text { Calculate work per pound of gas } \\ \mathrm{w}:=\left[\mathrm{T}_{1} \cdot\left(\mathrm{S}_{1}-\mathrm{S}_{2}\right)-\left(\mathrm{h}_{1}-\mathrm{h}_{2}\right)\right]+\mathrm{r} \cdot(\mathrm{Ta} \cdot(\mathrm{Sa}-\mathrm{Sb})-(\mathrm{ha}-\mathrm{hb})) \\ \mathrm{w}=0.727 \cdot \frac{\mathrm{kW} \cdot \mathrm{hr}}{\mathrm{lb}} & \text { Calculate work per pound of liquid hydrogen } \\ \frac{\mathrm{w}}{\mathrm{y}}=8.999 \cdot \frac{\mathrm{kW} \cdot \mathrm{hr}}{\mathrm{lb}} & \text { Work per kg of liquid hydrogen } \\ \frac{\mathrm{w}}{\mathrm{y}}=19.839 \cdot \frac{\mathrm{kW} \cdot \mathrm{hr}}{\mathrm{kg}} & \end{array}$




\section{C.4 COMPRESSION OF HYDROGEN TO $20 \mathrm{MPa}$}

$$
\begin{aligned}
& \mathrm{S}_{1}:=16.75 \cdot \frac{\mathrm{cal}}{\mathrm{gm} \cdot \mathrm{K}} \quad \mathrm{h}_{1}:=1010 \cdot \frac{\mathrm{cal}}{\mathrm{gm}} \quad \mathrm{P}_{1}:=1 \cdot \mathrm{atm} \quad \mathrm{T}_{1}:=300 \cdot \mathrm{K} \\
& \mathrm{S}_{2}:=11.5 \cdot \frac{\mathrm{cal}}{\mathrm{gm} \cdot \mathrm{K}} \quad \mathrm{h}_{2}:=1040 \cdot \frac{\mathrm{cal}}{\mathrm{gm}} \quad \mathrm{P}_{2}:=200 \cdot \mathrm{atm} \quad \mathrm{T}_{2}:=300 \cdot \mathrm{K} \\
& \mathrm{Wc}_{\mathrm{c}}:=\mathrm{T}_{1} \cdot\left(\mathrm{S}_{1}-\mathrm{S}_{2}\right)-\left(\mathrm{h}_{1}-\mathrm{h}_{2}\right) \quad \text { Calculate compressor work per pound of hydrogen } \\
& \mathrm{Wc}=0.847 \cdot \frac{\mathrm{kW} \cdot \mathrm{hr}}{\mathrm{lb}} \\
& \mathrm{Wc}=1.867 \cdot \frac{\mathrm{kW} \cdot \mathrm{hr}}{\mathrm{kg}} \quad \text { Work per } \mathrm{kg} \text { of hydrogen }
\end{aligned}
$$




\section{APPENDIX D - HYDROGEN STORAGE COSTS}

D.0 Hydrogen Storage Assumptions

D.1 Compressed Gas Storage

D.2 Liquid Hydrogen Storage

D.3 Metal Hydride Storage

D.4 Underground Gas Storage

Appendix D contains some of the cost data from the analysis of storage costs for the different hydrogen storage options. Costs are given in both SI and traditional English units for each storage method. Costs are arranged in the tables by production rate and the number of days of hydrogen storage. 


\begin{tabular}{|c|c|c|c|c|}
\hline D.0 HYDROGEN STORAG & JMPTION & & & \\
\hline Compressor Capital Cost= & $\$ 1,000$ & per kW & & \\
\hline Comp. Gas Capital Cost= & $\$ 1,323$ & per kg & $\$ 600$ & per lb \\
\hline Liquefaction Capital Cost= & $\$ 44,093$ & per kg/hr & $\$ 20,000$ & per lb/hr \\
\hline Liquid Dewar Capital Cost= & $\$ 441$ & per kg & $\$ 200$ & per lb \\
\hline Hydride Capital Cost= & $\$ 2,205$ & per kg & $\$ 1,000$ & per lb \\
\hline Underground Capital Cost= & $\$ 9$ & per kg & $\$ 4$ & per lb \\
\hline Compressor Size $=$ & 4,000 & $\mathrm{~kW}$ & & \\
\hline Comp. Gas Tank Size $=$ & 227 & $\mathrm{~kg}$ & 500 & $\mathrm{Ib}$ \\
\hline Liquefaction Size $=$ & 454 & $\mathrm{~kg} / \mathrm{hr}$ & 1,000 & $\mathrm{lb} / \mathrm{hr}$ \\
\hline Liquid Dewar Size $=$ & 45 & $\mathrm{~kg}$ & 100 & $\mathrm{Ib}$ \\
\hline Compressor Pressure $=$ & 20 & $\mathrm{MPa}$ & & \\
\hline Comp. Pressure Scale-Up= & 0.18 & & & \\
\hline Comp. Gas Tank Pressure= & 20 & $\mathrm{MPa}$ & & \\
\hline Tank Pressure Scale-Up= & 0.44 & & & \\
\hline Comn Coct Soglofln- & 080 & & & \\
\hline $\begin{array}{l}\text { Comp. Cost Scale-Up= }= \\
\text { Comp. Gas Tank Scale-Up }=\end{array}$ & 0.00 & & & \\
\hline Liquefaction Scale-Up= & 0.65 & & & \\
\hline Dewar Scale-Up= & 0.70 & & & \\
\hline Hydride Scale-Up= & 1.00 & & & \\
\hline Underground Scale-Up= & 1.00 & & & \\
\hline Compressor Power= & 2.2 & $\mathrm{kWh} / \mathrm{kg}(20 \mathrm{MPa})$ & 1.0 & kWh/lb (20 MPa) \\
\hline Compressor Cooling $=$ & 50 & liter/kg (20 MPa) & 6.0 & $\mathrm{gal} / \mathrm{lb}(20 \mathrm{MPa})$ \\
\hline Liquefaction Power $=$ & 9.9 & $\mathrm{kWh} / \mathrm{kg}$ & 4.5 & $\mathrm{kWh} / \mathrm{lb}$ \\
\hline Liquefaction Cooling $=$ & 626 & liter/kg & 75 & $\mathrm{gal} / \mathrm{lb}$ \\
\hline Boil-off Rate $=$ & $0.1 \%$ & per day & & \\
\hline Hydride Cooling= & 209 & liter $/ \mathrm{kg}$ & 25 & gal//b \\
\hline Hydride Heating $=$ & 23,260 & $\mathrm{~kJ} / \mathrm{kg}$ & 10,000 & Btu/lb \\
\hline Electric Cost $=$ & $\$ 0.05$ & per kWh & & \\
\hline Steam Cost $=$ & $\$ 3.79$ & per GJ & $\$ 4.00$ & per MM Btu \\
\hline Cooling Cost $=$ & $\$ 0.02$ & per M liters & $\$ 0.07$ & per M gal \\
\hline Operating Days/Year= & 350 & days/yr & & \\
\hline Depreciation $=$ & 22 & years & & \\
\hline
\end{tabular}




\begin{tabular}{|c|c|c|c|c|c|c|c|c|c|c|}
\hline \multicolumn{11}{|c|}{ D.1 COMPRESSED GAS STORAGE - SI Units } \\
\hline & & & & & & & & & & \\
\hline \multicolumn{2}{|c|}{ Compressor Capital Cost= } & $\$ 1.000$ & per kW & & & & & & & \\
\hline \multicolumn{2}{|c|}{ Comp. Gas Capital Cost $=$} & $\$ 1,323$ & per $\mathrm{kg}$ & & & & & & & \\
\hline \multicolumn{2}{|c|}{ Compressor Size $=$} & 4.000 & $\mathrm{~kW}$ & & & & & & & \\
\hline \multicolumn{2}{|c|}{ Comp. Gas Tank Size $=$} & 227 & $\mathrm{~kg}$ & & & & & & & \\
\hline \multicolumn{2}{|c|}{ Compressor Pressure $=$} & 20 & $\mathrm{MPa}$ & & & & & & & \\
\hline \multicolumn{2}{|c|}{ Comp. Pressure Scale- $U p=$} & 0.18 & & & & & & & & \\
\hline \multicolumn{2}{|c|}{ Comp. Gas Tank Pressure $=$} & 20 & $\mathrm{MPa}$ & & & & & & & \\
\hline \multicolumn{2}{|c|}{ Tank Pressure Scale-Up= } & 0.44 & & & & & & & & \\
\hline \multicolumn{2}{|c|}{ Comp. Cost Scale-Up $=$} & 0.80 & & & & & & & & \\
\hline \multirow{2}{*}{\multicolumn{2}{|c|}{ Comp. Gas Tank Scale-Up $=$}} & 0.75 & & & & & & & & \\
\hline & & 2.20 & $\mathrm{kWh} / \mathrm{kg}(20 \mathrm{MPa}$ & & & & & & & \\
\hline \multicolumn{2}{|c|}{\begin{tabular}{|l} 
Compressor Power $=$ \\
Compressor Cooling $=$
\end{tabular}} & 50 & $\mathrm{gal} / \mathrm{kg}(20 \mathrm{MPa})$ & & & & & & & \\
\hline Electric Cost $=$ & & $\$ 0.05$ & per kWh & & & & & & & \\
\hline Cooling Cost $=$ & & $\$ 0.02$ & per M liters & & & & & & & \\
\hline \multicolumn{2}{|c|}{ Operating Days $/$ Year $=$} & 350 & days/yr & & & & & & & \\
\hline \multirow{2}{*}{ Depreciation $=$} & & 22 & years & & & & & & & \\
\hline & & & & & & & & & & \\
\hline Production & Days of & Operating & Storage & Annual & Compressor & Cooling & Compressor & Compressor & Tank & Total Capital \\
\hline Rate & Storage & Pressure & Capacity & Production & Power & Water & Size & Cost & Cost & Cost \\
\hline$(\mathrm{kg} / \mathrm{hr})$ & (days) & $(\mathrm{MPa})$ & $(\mathrm{kg})$ & $(\mathrm{kg} / \mathrm{yr})$ & $(\mathrm{kWh} / \mathrm{hr})$ & (liter/hr) & $(\mathrm{kW})$ & $(\$)$ & $(\$)$ & $(\$)$ \\
\hline 5 & 1 & 20 & 109 & 38,102 & 10 & 227 & 10 & $\$ 33,145$ & $\$ 173,002$ & $\$ 206,147$ \\
\hline 45 & 1 & 20 & 1,089 & 381,016 & 100 & 2,271 & 100 & $\$ 209,128$ & $\$ 972,864$ & $\$ 1,181,992$ \\
\hline 454 & 1 & 20 & 10,886 & $3,810,156$ & 1,000 & 22,712 & 1,000 & $\$ 1,319,508$ & $\$ 5,470,817$ & $\$ 6,790,325$ \\
\hline 4,536 & 1 & 20 & 108,862 & $38,101,560$ & 10,000 & 227,124 & 10,000 & $\$ 8,325,532$ & $\$ 30,764,664$ & $\$ 39,090,197$ \\
\hline 45,359 & 1 & 20 & $1,088,616$ & $381,015,600$ & 100,000 & $2,271,240$ & 100,000 & $\$ 52,530,556$ & $\$ 173,002,422$ & $\$ 225,532,978$ \\
\hline 5 & 2 & 20 & 218 & 38,102 & 10 & 227 & 10 & $\$ 33,145$ & $\$ 290,954$ & $\$ 324,099$ \\
\hline 45 & 2 & 20 & 2,177 & 381,016 & 100 & 2,271 & 100 & $\$ 209,128$ & $\$ 1,636,156$ & $\$ 1,845,284$ \\
\hline 454 & 2 & 20 & 21,772 & $3,810,156$ & 1,000 & 22,712 & 1,000 & $\$ 1,319,508$ & $\$ 9,200,781$ & $\$ 10,520,289$ \\
\hline 4,536 & 2 & 20 & 217,723 & $38,101,560$ & 10,000 & 227,124 & 10,000 & $\$ 8,325,532$ & $\$ 51,739,792$ & $\$ 60,065,324$ \\
\hline 45,359 & 2 & 20 & $2,177,232$ & $381,015,600$ & 100,000 & $2,271,240$ & 100,000 & $\$ 52,530,556$ & $\$ 290,954,233$ & $\$ 343,484,789$ \\
\hline 5 & 4 & 20 & 435 & 38,102 & 10 & 227 & 10 & $\$ 33,145$ & $\$ 489,325$ & $\$ 522,469$ \\
\hline 45 & 4 & 20 & 4,354 & $\begin{array}{l}381,016 \\
\end{array}$ & 100 & 2,271 & 100 & $\$ 209,128$ & $\$ 2,751,675$ & $\$ 2,960,803$ \\
\hline 454 & 4 & 20 & 43,545 & $3,810,156$ & 1,000 & 22,712 & 1,000 & $\$ 1,319,508$ & $\$ 15,473,807$ & $\$ 16,793,315$ \\
\hline 4,536 & 4 & 20 & 435,446 & $38,101,560$ & 10,000 & 227,124 & 10,000 & $\$ 8,325,532$ & $\$ 87,015,611$ & $\$ 95,341,144$ \\
\hline 45,359 & 4 & 20 & $4,354,464$ & $381,015,600$ & 100,000 & $2,271,240$ & 100,000 & $\$ 52,530,556$ & $\$ 489,324,743$ & $\$ 541,855,299$ \\
\hline 5 & 7 & 20 & 762 & 38,102 & 10 & 227 & 10 & $\$ 33,145$ & $\$ 744,519$ & $\$ 777,663$ \\
\hline 45 & 7 & 20 & 7,620 & 381,016 & 100 & 2,271 & 100 & $\$ 209,128$ & $\$ 4,186,737$ & $\$ 4,395,865$ \\
\hline 454 & 7 & 20 & 76,203 & $3,810,156$ & 1,000 & 22,712 & 1,000 & $\$ 1,319,508$ & $\$ 23,543,754$ & $\$ 24,863,262$ \\
\hline 4,536 & 7 & 20 & 762,031 & $38,101,560$ & 10,000 & 227,124 & 10,000 & $\$ 8,325,532$ & $\$ 132,396,259$ & $\$ 140,721,791$ \\
\hline 45,359 & 7 & 20 & $7,620,312$ & $381,015,600$ & 100,000 & $2,271,240$ & 100,000 & $\$ 52,530,556$ & $\$ 744,518,876$ & $\$ 797,049,432$ \\
\hline 5 & 14 & 20 & 1,524 & 38,102 & 10 & 227 & 10 & $\$ 33,145$ & $\$ 1,252,127$ & $\$ 1,285,271$ \\
\hline 45 & 14 & 20 & 15,241 & 381,016 & 100 & 2,271 & 100 & $\$ 209,128$ & $\$ 7,041,225$ & $\$ 7,250,353$ \\
\hline 454 & 14 & 20 & 152,406 & $3,810,156$ & 1,000 & 22,712 & 1,000 & $\$ 1,319,508$ & $\$ 39,595,717$ & $\$ 40,915,225$ \\
\hline 4,536 & 14 & 20 & $1,524,062$ & $38,101,560$ & 10,000 & 227,124 & 10,000 & $\$ 8,325,532$ & $\$ 222,663,079$ & $\$ 230,988,611$ \\
\hline 45,359 & 14 & 20 & $15,240,624$ & $381,015,600$ & 100,000 & $2,271,240$ & 100,000 & $\$ 52,530,556$ & $\$ 1,252,126,507$ & $\$ 1,304,657,063$ \\
\hline 5 & 30 & 20 & 3,266 & 38,102 & 10 & 227 & 10 & $\$ 33,145$ & $\$ 2,217,651$ & $\$ 2,250,795$ \\
\hline 45 & 30 & 20 & 32,658 & 381,016 & 100 & 2,271 & 100 & $\$ 209,128$ & $\$ 12,470,766$ & $\$ 12,679,894$ \\
\hline 454 & 30 & 20 & 326,585 & $3,810,156$ & 1,000 & 22,712 & 1,000 & $\$ 1,319,508$ & $\$ 70,128,270$ & $\$ 71,447,778$ \\
\hline 4,536 & 30 & 20 & $3,265,848$ & $38,101,560$ & 10,000 & 227,124 & 10,000 & $\$ 8,325,532$ & $\$ 394,360,241$ & $\$ 402,685,773$ \\
\hline 45,359 & 30 & 20 & $32,658,480$ & $381,015,600$ & 100,000 & $2,271,240$ & 100,000 & $\$ 52,530,556$ & $\$ 2,217,650,608$ & $\$ 2,270,181,164$ \\
\hline
\end{tabular}

D - 3 


\begin{tabular}{|c|c|c|c|c|c|c|c|c|c|c|c|c|c|c|}
\hline \multicolumn{15}{|c|}{ D.1 COMPRESSED GAS STORAGE - SI Units (Continued) } \\
\hline Production & Days of & Depreciation & Annual Electricity & Annual Cooling & Total Annual & Capital & Energy & Cooling & Total & & Comp. & Tank & Comp. & Tank \\
\hline Rate & Storage & & & Water Cost & Cost & Cost & Cost & Cost & Cost & & Cost & Cost & Capital & Capital \\
\hline$(\mathrm{kg} / \mathrm{hr})$ & (days) & $(\$ / y r)$ & $(\$ / y r)$ & $(\$ / y r)$ & $(\$ / y r)$ & $(\$ / \mathrm{kg})$ & $(\$ / \mathrm{kg})$ & $(\$ / \mathrm{kg})$ & $(\$ / \mathrm{kg})$ & & $(\$ / \mathrm{kg})$ & $(\$ / \mathrm{kg})$ & $(\$ / \mathrm{kW})$ & $(\$ / \mathrm{kg})$ \\
\hline 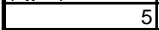 & & $\$ 9,370$ & $\$ 4,200$ & $\$ 35$ & $\$ 13,606$ & $\$ 0.25$ & $\$ 0.11$ & $\$ 0.00$ & $\$ 0.36$ & & $\$ 0.04$ & $\$ 0.21$ & $\$ 3,314$ & $\$ 1,589$ \\
\hline 45 & & $\$ 53.727$ & $\$ 42.000$ & $\$ 353$ & $\$ 96.080$ & $\$ 0.14$ & $\$ 0.11$ & $\$ 0.00$ & $\$ 0.25$ & & $\$ 0.02$ & $\$ 0.12$ & $\$ 2.091$ & $\$ 894$ \\
\hline 454 & & $\$ 308.651$ & $\$ 420.000$ & $\$ 3.528$ & $\$ 732.179$ & $\$ 0.08$ & $\$ 0.11$ & $\$ 0.00$ & $\$ 0.19$ & & $\$ 0.02$ & $\$ 0.07$ & $\$ 1.320$ & $\$ 503$ \\
\hline 4,536 & & $\$ 1,776,827$ & $\$ 4,200,000$ & $\$ 35,280$ & $\$ 6,012,107$ & $\$ 0.05$ & $\$ 0.11$ & $\$ 0.00$ & $\$ 0.16$ & & $\$ 0.01$ & $\$ 0.04$ & $\$ 833$ & $\$ 283$ \\
\hline 45,359 & & $\$ 10,251,499$ & $\$ 42,000,000$ & $\$ 352,800$ & $\$ 52,604,299$ & $\$ 0.03$ & $\$ 0.11$ & $\$ 0.00$ & $\$ 0.14$ & & $\$ 0.01$ & $\$ 0.02$ & $\$ 525$ & $\$ 159$ \\
\hline 4 & & $\$ 14,732$ & $\$ 4,200$ & $\$ 35$ & $\$ 18,967$ & $\$ 0.39$ & $\$ 0.11$ & $\$ 0.00$ & $\$ 0.50$ & & $\$ 0.04$ & $\$ 0.35$ & $\$ 3,314$ & $\$ 1,336$ \\
\hline 45 & & $\$ 83,877$ & $\$ 42,000$ & $\$ 353$ & $\$ 126,229$ & $\$ 0.22$ & $\$ 0.11$ & $\$ 0.00$ & $\$ 0.33$ & & $\$ 0.02$ & $\$ 0.20$ & $\$ 2,091$ & $\$ 751$ \\
\hline 454 & & $\$ 478,195$ & $\$ 420,000$ & $\$ 3,52 \varepsilon$ & $\$ 901,723$ & $\$ 0.13$ & $\$ 0.11$ & $\$ 0.00$ & $\$ 0.24$ & & $\$ 0.02$ & $\$ 0.11$ & $\$ 1,320$ & $\$ 423$ \\
\hline 4.536 & & $\$ 2,730,242$ & $\$ 4,200,000$ & $\$ 35.280$ & $\$ 6.965,522$ & $\$ 0.07$ & $\$ 0.11$ & $\$ 0.00$ & $\$ 0.18$ & & $\$ 0.01$ & $\$ 0.06$ & $\$ 833$ & $\$ 238$ \\
\hline 45.359 & & $\$ 15,612,945$ & $\$ 42,000,000$ & $\$ 352,800$ & $\$ 57,965,745$ & $\$ 0.04$ & $\$ 0.11$ & $\$ 0.00$ & $\$ 0.15$ & & $\$ 0.01$ & $\$ 0.03$ & $\$ 525$ & $\$ 134$ \\
\hline 5 & & $\$ 23,749$ & $\$ 4.200$ & $\$ 35$ & $\$ 27.984$ & $\$ 0.62$ & $\$ 0.11$ & $\$ 0.00$ & $\$ 0.73$ & & $\$ 0.04$ & $\$ 0.58$ & $\$ 3,314$ & $\$ 1,124$ \\
\hline 45 & & $\$ 134,582$ & $\$ 42,000$ & $\$ 353$ & $\$ 176,935$ & $\$ 0.35$ & $\$ 0.11$ & $\$ 0.00$ & $\$ 0.46$ & & $\$ 0.02$ & $\$ 0.33$ & $\$ 2,091$ & $\$ 632$ \\
\hline 454 & & $\$ 763,332$ & $\$ 420,000$ & $\$ 3,52 \varepsilon$ & $\$ 1,186,860$ & $\$ 0.20$ & $\$ 0.11$ & $\$ 0.00$ & $\$ 0.31$ & & $\$ 0.02$ & $\$ 0.18$ & $\$ 1,320$ & $\$ 355$ \\
\hline 4,536 & & $\$ 4,333,688$ & $\$ 4,200,000$ & $\$ 35,280$ & $\$ 8,568,968$ & $\$ 0.11$ & $\$ 0.11$ & $\$ 0.00$ & $\$ 0.22$ & & $\$ 0.01$ & $\$ 0.10$ & $\$ 833$ & $\$ 200$ \\
\hline 45,359 & & $\$ 24,629,786$ & $\$ 42,000,000$ & $\$ 352,800$ & $\$ 66,982,586$ & $\$ 0.06$ & $\$ 0.11$ & $\$ 0.00$ & $\$ 0.18$ & & $\$ 0.01$ & $\$ 0.06$ & $\$ 525$ & $\$ 112$ \\
\hline 5 & & $\$ 35,348$ & $\$ 4,200$ & $\$ 35$ & $\$ 39,584$ & $\$ 0.93$ & $\$ 0.11$ & $\$ 0.00$ & $\$ 1.04$ & & $\$ 0.04$ & $\$ 0.89$ & $\$ 3,314$ & $\$ 977$ \\
\hline 45 & & $\$ 199,812$ & $\$ 42,000$ & $\$ 353$ & $\$ 242,165$ & $\$ 0.52$ & $\$ 0.11$ & $\$ 0.00$ & $\$ 0.64$ & & $\$ 0.02$ & $\$ 0.50$ & $\$ 2,091$ & $\$ 549$ \\
\hline 454 & & $\$ 1,130,148$ & $\$ 420,000$ & $\$ 3,528$ & $\$ 1,553,676$ & $\$ 0.30$ & $\$ 0.11$ & $\$ 0.00$ & $\$ 0.41$ & & $\$ 0.02$ & $\$ 0.28$ & $\$ 1,320$ & $\$ 309$ \\
\hline 4,536 & & $\$ 6,396,445$ & $\$ 4,200,000$ & $\$ 35,280$ & $\$ 10,631,725$ & $\$ 0.17$ & $\$ 0.11$ & $\$ 0.00$ & $\$ 0.28$ & & $\$ 0.01$ & $\$ 0.16$ & $\$ 833$ & $\$ 174$ \\
\hline 45,359 & & $\$ 36,229,520$ & $\$ 42,000,000$ & $\$ 352,800$ & $\$ 78,582,320$ & $\$ 0.10$ & $\$ 0.11$ & $\$ 0.00$ & $\$ 0.21$ & & $\$ 0.01$ & $\$ 0.09$ & $\$ 525$ & $\$ 98$ \\
\hline 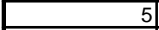 & 14 & $\$ 58,421$ & $\$ 4,200$ & $\$ 35$ & $\$ 62,657$ & $\$ 1.53$ & $\$ 0.11$ & $\$ 0.00$ & $\$ 1.64$ & & $\$ 0.04$ & $\$ 1.49$ & $\$ 3,314$ & $\$ 822$ \\
\hline 45 & 14 & $\$ 329,561$ & $\$ 42,000$ & $\$ 353$ & $\$ 371,914$ & $\$ 0.86$ & $\$ 0.11$ & $\$ 0.00$ & $\$ 0.98$ & & $\$ 0.02$ & $\$ 0.84$ & $\$ 2,091$ & $\$ 462$ \\
\hline 454 & 14 & $\$ 1,859,783$ & $\$ 420,000$ & $\$ 3,52 \varepsilon$ & $\$ 2,283,311$ & $\$ 0.49$ & $\$ 0.11$ & $\$ 0.00$ & $\$ 0.60$ & & $\$ 0.02$ & $\$ 0.47$ & $\$ 1,320$ & $\$ 260$ \\
\hline 4.536 & 14 & $\$ 10.499 .482$ & $\$ 4.200 .000$ & $\$ 35.280$ & $\$ 14.734 .762$ & $\$ 0.28$ & $\$ 0.11$ & $\$ 0.00$ & $\$ 0.39$ & & $\$ 0.01$ & $\$ 0.27$ & $\$ 833$ & $\$ 146$ \\
\hline 45,359 & 14 & $\$ 59,302,594$ & $\$ 42,000,000$ & $\$ 352,800$ & $\$ 101,655,394$ & $\$ 0.16$ & $\$ 0.11$ & $\$ 0.00$ & $\$ 0.27$ & & $\$ 0.01$ & $\$ 0.15$ & $\$ 525$ & $\$ 82$ \\
\hline 4 & 30 & $\$ 102,309$ & $\$ 4,200$ & $\$ 35$ & $\$ 106,544$ & $\$ 2.69$ & $\$ 0.11$ & $\$ 0.00$ & $\$ 2.80$ & & $\$ 0.04$ & $\$ 2.65$ & $\$ 3,314$ & $\$ 679$ \\
\hline 45 & 30 & $\$ 576,359$ & $\$ 42,000$ & $\$ 353$ & $\$ 618,712$ & $\$ 1.51$ & $\$ 0.11$ & $\$ 0.00$ & $\$ 1.62$ & & $\$ 0.02$ & $\$ 1.49$ & $\$ 2,091$ & $\$ 3$ \\
\hline 454 & 30 & $\$ 3,247,626$ & $\$ 420,000$ & $\$ 3,52 \varepsilon$ & $\$ 3,671,154$ & $\$ 0.85$ & $\$ 0.11$ & $\$ 0.00$ & $\$ 0.96$ & & $\$ 0.02$ & $\$ 0.84$ & $\$ 1,320$ & $\$ 215$ \\
\hline 4,536 & 30 & $\$ 18,303,899$ & $\$ 4,200,000$ & $\$ 35,280$ & $\$ 22,539,179$ & $\$ 0.48$ & $\$ 0.11$ & $\$ 0.00$ & $\$ 0.59$ & & $\$ 0.01$ & $\$ 0.47$ & $\$ 833$ & $\$ 121$ \\
\hline 45,359 & 30 & $\$ 103,190,053$ & $\$ 42,000,000$ & $\$ 352,800$ & $\$ 145,542,853$ & $\$ 0.27$ & $\$ 0.11$ & $\$ 0.00$ & $\$ 0.38$ & & $\$ 0.01$ & $\$ 0.26$ & $\$ 525$ & $\$ 68$ \\
\hline
\end{tabular}




\begin{tabular}{|c|c|c|c|c|c|c|c|c|c|c|}
\hline \multicolumn{11}{|c|}{ D.1 COMPRESSED GAS STORAGE - English Units } \\
\hline & & & & & & & & & & \\
\hline \multicolumn{2}{|c|}{ Compressor Capital Cost= } & $\$ 1,000$ & per kW & & & & & & & \\
\hline \multicolumn{2}{|c|}{ Comp. Gas Capital Cost= } & $\$ 600$ & per lb & & & & & & & \\
\hline \multicolumn{2}{|c|}{ Compressor $\mathrm{Size}=$} & 4,000 & kW & & & & & & & \\
\hline \multicolumn{2}{|c|}{ Comp. Gas Tank Size $=$} & 500 & $\mathrm{Ib}$ & & & & & & & \\
\hline \multicolumn{2}{|c|}{ Compressor Pressure $=$} & 20 & $\mathrm{MPa}$ & & & & & & & \\
\hline \multicolumn{2}{|c|}{ Comp. Pressure Scale-Up= } & 0.18 & & & & & & & & \\
\hline \multicolumn{2}{|c|}{ Comp. Gas Tank Pressure $=$} & 20 & $\mathrm{MPa}$ & & & & & & & \\
\hline \multicolumn{2}{|c|}{ Tank Pressure Scale- $U p=$} & 0.44 & & & & & & & & \\
\hline \multicolumn{2}{|c|}{ Comp. Cost Scale-Up= } & 0.80 & & & & & & & & \\
\hline \multicolumn{2}{|c|}{ Comp. Gas Tank Scale-Up= } & 0.75 & & & & & & & & \\
\hline \multicolumn{2}{|c|}{ Compressor Power $=$} & 1.00 & $\mathrm{kWh} / \mathrm{lb}(20 \mathrm{MPa})$ & & & & & & & \\
\hline \multicolumn{2}{|c|}{ Compressor Cooling $=$} & 6.0 & $\mathrm{gal} / \mathrm{lb}(20 \mathrm{MPa})$ & & & & & & & \\
\hline Electric Cost $=$ & & $\$ 0.05$ & perkWh & & & & & & & \\
\hline Cooling Cost $=$ & & $\$ 0.07$ & per M gal & & & & & & & \\
\hline \multicolumn{2}{|c|}{ Operating Days/Year= } & 350 & days/yr & & & & & & & \\
\hline \multirow{2}{*}{ Depreciation $=$} & & 22 & years & & & & & & & \\
\hline & & & & & & & & & & \\
\hline \multirow{2}{*}{\begin{tabular}{|l|} 
Production \\
Rate
\end{tabular}} & Days of & Operating & Storage & Annual & Compressor & Cooling & Compressor & Compressor & Tank & Total Capital \\
\hline & Storage & Pressure & Capacity & Production & Power & Water & Size & Cost & Cost & Cost \\
\hline \multirow[t]{2}{*}{$(\mathrm{lb} / \mathrm{hr})$} & (days) & $(\mathrm{MPa})$ & (lb) & $(\mathrm{lb} / \mathrm{yr})$ & $(\mathrm{kWh} / \mathrm{hr})$ & (gal/hr) & $(\mathrm{kW})$ & $(\$)$ & (\$) & $(\$)$ \\
\hline & 1 & 20 & 240 & 84,000 & 10 & 60 & 10 & $\$ 33,145$ & $\$ 173,002$ & $\$ 206,147$ \\
\hline 100 & 1 & 20 & 2,400 & 840,000 & 100 & 600 & 100 & $\$ 209,128$ & $\$ 972,864$ & $\$ 1,181,992$ \\
\hline 1,000 & 1 & 20 & 24,000 & $8,400,000$ & 1,000 & 6,000 & 1,000 & $\$ 1,319,508$ & $\$ 5,470,817$ & $\$ 6,790,325$ \\
\hline 10,000 & 1 & 20 & 240,000 & $84,000,000$ & 10,000 & 60,000 & 10,000 & $\$ 8,325,532$ & $\$ 30,764,664$ & $\$ 39,090,197$ \\
\hline 100,000 & 1 & 20 & $2,400,000$ & $840,000,000$ & 100,000 & 600,000 & 100,000 & $\$ 52,530,556$ & $\$ 173,002,422$ & $\$ 225,532,978$ \\
\hline 10 & 2 & 20 & 480 & 84,000 & 10 & 60 & 10 & $\$ 33,145$ & $\$ 290,954$ & $\$ 324,099$ \\
\hline 100 & 2 & 20 & 4,800 & 840,000 & 100 & 600 & 100 & $\$ 209,128$ & $\$ 1,636,156$ & $\$ 1,845,284$ \\
\hline 1,000 & 2 & 20 & 48,000 & $8,400,000$ & 1,000 & 6,000 & 1,000 & $\$ 1,319,508$ & $\$ 9,200,781$ & $\$ 10,520,289$ \\
\hline 10,000 & 2 & 20 & 480,000 & $84,000,000$ & 10,000 & 60,000 & 10,000 & $\$ 8,325,532$ & $\$ 51,739,792$ & $\$ 60,065,324$ \\
\hline 100,000 & 2 & 20 & $4,800,000$ & $840,000,000$ & 100,000 & 600,000 & 100,000 & $\$ 52,530,556$ & $\$ 290,954,233$ & $\$ 343,484,789$ \\
\hline 10 & 4 & 20 & 960 & 84,000 & 10 & 60 & 10 & $\$ 33,145$ & $\$ 489,325$ & $\$ 522,469$ \\
\hline 100 & 4 & 20 & 9,600 & 840,000 & 100 & 600 & 100 & $\$ 209,128$ & $\$ 2,751,675$ & $\$ 2,960,803$ \\
\hline 1,000 & 4 & 20 & 96,000 & $8,400,000$ & 1,000 & 6,000 & 1,000 & $\$ 1,319,508$ & $\$ 15,473,807$ & $\$ 16,793,315$ \\
\hline 10,000 & 4 & 20 & 960,000 & $84,000,000$ & 10,000 & 60,000 & 10,000 & $\$ 8,325,532$ & $\$ 87,015,611$ & $\$ 95,341,144$ \\
\hline 100,000 & 4 & 20 & $9,600,000$ & $840,000,000$ & 100,000 & 600,000 & 100,000 & $\$ 52,530,556$ & $\$ 489,324,743$ & $\$ 541,855,299$ \\
\hline 10 & 7 & 20 & 1,680 & 84,000 & 10 & 60 & 10 & $\$ 33,145$ & $\$ 744,519$ & $\$ 777,663$ \\
\hline 100 & 7 & 20 & 16,800 & 840,000 & 100 & 600 & 100 & $\$ 209,128$ & $\$ 4,186,737$ & $\$ 4,395,865$ \\
\hline 1,000 & 7 & 20 & 168,000 & $8,400,000$ & 1,000 & 6,000 & 1,000 & $\$ 1,319,508$ & $\$ 23,543,754$ & $\$ 24,863,262$ \\
\hline 10,000 & 7 & 20 & $1,680,000$ & $84,000,000$ & 10,000 & 60,000 & 10,000 & $\$ 8,325,532$ & $\$ 132,396,259$ & $\$ 140,721,791$ \\
\hline 100,000 & 7 & 20 & $16,800,000$ & $840,000,000$ & 100,000 & 600,000 & 100,000 & $\$ 52,530,556$ & $\$ 744,518,876$ & $\$ 797,049,432$ \\
\hline 10 & 14 & 20 & 3,360 & 84,000 & 10 & 60 & 10 & $\$ 33,145$ & $\$ 1,252,127$ & $\$ 1,285,271$ \\
\hline 100 & 14 & 20 & 33,600 & 840,000 & 100 & 600 & 100 & $\$ 209,128$ & $\$ 7,041,225$ & $\$ 7,250,353$ \\
\hline 1,000 & 14 & 20 & 336,000 & $8,400,000$ & 1,000 & 6,000 & 1,000 & $\$ 1,319,508$ & $\$ 39,595,717$ & $\$ 40,915,225$ \\
\hline 10,000 & 14 & 20 & $3,360,000$ & $84,000,000$ & 10,000 & 60,000 & 10,000 & $\$ 8,325,532$ & $\$ 222,663,079$ & $\$ 230,988,611$ \\
\hline 100,000 & 14 & 20 & $33,600,000$ & $840,000,000$ & 100,000 & 600,000 & 100,000 & $\$ 52,530,556$ & $\$ 1,252,126,507$ & $\$ 1,304,657,063$ \\
\hline 10 & 30 & 20 & 7,200 & 84,000 & 10 & 60 & 10 & $\$ 33,145$ & $\$ 2,217,651$ & $\$ 2,250,795$ \\
\hline 100 & 30 & 20 & 72,000 & 840,000 & 100 & 600 & 100 & $\$ 209,128$ & $\$ 12,470,766$ & $\$ 12,679,894$ \\
\hline 1,000 & 30 & 20 & 720,000 & $8,400,000$ & 1,000 & 6,000 & 1,000 & $\$ 1,319,508$ & $\$ 70,128,270$ & $\$ 71,447,778$ \\
\hline 10,000 & 30 & 20 & $7,200,000$ & $84,000,000$ & 10,000 & 60,000 & 10,000 & $\$ 8,325,532$ & $\$ 394,360,241$ & $\$ 402,685,773$ \\
\hline 100,000 & 30 & 20 & $72,000,000$ & $840,000,000$ & 100,000 & 600,000 & 100,000 & $\$ 52,530,556$ & $\$ 2,217,650,608$ & $\$ 2,270,181,164$ \\
\hline
\end{tabular}




\begin{tabular}{|c|c|c|c|c|c|c|c|c|c|c|c|c|c|c|}
\hline \multicolumn{15}{|c|}{ D.1 COMPRESSED GAS STORAGE - English Units (Continued) } \\
\hline Production & Days of & Depreciation & Annual Electricity & Annual Cooling & Total Annual & Capital & Energy & Cooling & Total & & Comp. & Tank & Comp. & Tank \\
\hline Rate & Storage & & Cost & Water Cost & Cost & Cost & Cost & Cost & Cost & & Cost & Cost & Capital & Capital \\
\hline$(\mid \mathrm{b} / \mathrm{hr})$ & (days) & $(\$ / y r)$ & $(\$ / y r)$ & $(\$ / y r)$ & $(\$ / \mathrm{yr})$ & $(\$ / \mathrm{lb})$ & $(\$ / \mathrm{lb})$ & $(\$ / \mathrm{lb})$ & $(\$ / \mathrm{lb})$ & & $(\$ / b)$ & $(\$ / b)$ & $(\$ / \mathrm{kW})$ & $(\$ / \mathrm{lb})$ \\
\hline & & $\$ 9,370.32$ & $\$ 4,200$ & $\$ 35$ & $\$ 13,606$ & $\$ 0.11$ & $\$ 0.05$ & $\$ 0.000$ & $\$ 0.16$ & & $\$ 0.02$ & $\$ 0.09$ & $\$ 3,314$ & $\$ 721$ \\
\hline$\frac{100}{100}$ & & $\$ 53.726 .91$ & $\$ 42,000$ & $\$ 353$ & $\frac{\$ 1,000}{\$ 96.080}$ & $\$ 0.06$ & $\$ 0.05$ & $\$ 0.000$ & $\$ 0.11$ & & $\$ 0.01$ & $\$ 0.05$ & $\$ 2.091$ & $\$ 405$ \\
\hline 1.000 & & $\$ 308.651 .13$ & $\$ 420.000$ & $\$ 3.528$ & $\$ 732.179$ & $\$ 0.04$ & $\$ 0.05$ & $\$ 0.000$ & $\$ 0.09$ & & $\$ 0.01$ & $\$ 0.03$ & $\$ 1.320$ & $\$ 228$ \\
\hline 10,000 & & $\$ 1,776,827.12$ & $\$ 4,200,000$ & $\$ 35,280$ & $\$ 6,012,107$ & $\$ 0.02$ & $\$ 0.05$ & $\$ 0.000$ & $\$ 0.07$ & & $\$ 0.00$ & $\$ 0.02$ & $\$ 833$ & $\$ 128$ \\
\hline 100,000 & & $\$ 10,251,499.00$ & $\$ 42,000,000$ & $\$ 352,800$ & $\$ 52,604,299$ & $\$ 0.01$ & $\$ 0.05$ & $\$ 0.000$ & $\$ 0.06$ & & $\$ 0.00$ & $\$ 0.01$ & $\$ 525$ & $\$ 72$ \\
\hline 10 & & $\$ 14,731.76$ & $\$ 4,200$ & $\$ 35$ & $\$ 18,967$ & $\$ 0.18$ & $\$ 0.05$ & $\$ 0.000$ & $\$ 0.23$ & & $\$ 0.02$ & $\$ 0.16$ & $\$ 3,314$ & $\$ 606$ \\
\hline 100 & & $\$ 83,876.54$ & $\$ 42,000$ & $\$ 353$ & $\$ 126,229$ & $\$ 0.10$ & $\$ 0.05$ & $\$ 0.000$ & $\$ 0.15$ & & $\$ 0.01$ & $\$ 0.09$ & $\$ 2,091$ & $\$ 341$ \\
\hline 1,000 & & $\$ 478,194.94$ & $\$ 420,000$ & $\$ 3,52 \varepsilon$ & $\$ 901,723$ & $\$ 0.06$ & $\$ 0.05$ & $\$ 0.000$ & $\$ 0.11$ & & $\$ 0.01$ & $\$ 0.05$ & $\$ 1,320$ & $\$ 192$ \\
\hline 10,000 & & $\$ 2,730,242.01$ & $\$ 4.200,000$ & $\$ 35,280$ & $\$ 6,965,522$ & $\$ 0.03$ & $\$ 0.05$ & $\$ 0.000$ & $\$ 0.08$ & & $\$ 0.00$ & $\$ 0$. & $\$ 833$ & $\$ 108$ \\
\hline 100,000 & & $\$ 15.612 .944 .94$ & $\$ 42,000,000$ & $\$ 352.800$ & $\$ 57,965,745$ & $\$ 0.02$ & $\$ 0.05$ & $\$ 0.000$ & $\$ 0.07$ & & $\$ 0.00$ & $\$ 0.02$ & $\$ 525$ & $\$ 61$ \\
\hline 10 & & $\$ 23,748.60$ & $\$ 4.200$ & $\$ 35$ & $\$ 27.984$ & $\$ 0.28$ & $\$ 0.05$ & $\$ 0.000$ & $\$ 0.33$ & & $\$ 0.02$ & $\$ 0.26$ & $\$ 3.314$ & $\$ 510$ \\
\hline 100 & & $\$ 134,581.96$ & $\$ 42,000$ & $\$ 353$ & $\$ 176,935$ & $\$ 0.16$ & $\$ 0.05$ & $\$ 0.000$ & $\$ 0.21$ & & $\$ 0.01$ & $\$ 0.15$ & $\$ 2,091$ & $\$ 287$ \\
\hline 1,000 & & $\$ 763,332.50$ & $\$ 420,000$ & $\$ 3,52$ & $\$ 1,186,860$ & $\$ 0.09$ & $\$ 0.05$ & $\$ 0.000$ & $\$ 0.14$ & & $\$ 0.01$ & $\$ 0.08$ & $\$ 1,320$ & $\$ 161$ \\
\hline 10,000 & & $\$ 4,333,688.34$ & $\$ 4,200,000$ & $\$ 35,280$ & $\$ 8,568,968$ & $\$ 0.05$ & $\$ 0.05$ & $\$ 0.000$ & $\$ 0.10$ & & $\$ 0.00$ & $\$ 0.0$ & $\$ 833$ & $\$ 91$ \\
\hline 100,000 & & $\$ 24,629,786.30$ & $\$ 42,000,000$ & $\$ 352,800$ & $\$ 66,982,586$ & $\$ 0.03$ & $\$ 0.05$ & $\$ 0.000$ & $\$ 0.08$ & & $\$ 0.00$ & $\$ 0.03$ & $\$ 525$ & $\$ 51$ \\
\hline & & $\$ 35,348.34$ & $\$ 4,200$ & $\$ 35$ & $\$ 39,584$ & $\$ 0.42$ & $\$ 0.05$ & $\$ 0.000$ & $\$ 0.47$ & & $\$ 0.02$ & $\$ 0.40$ & $\$ 3,314$ & $\$ 443$ \\
\hline 100 & & $\$ 199,812.06$ & $\$ 42,000$ & $\$ 353$ & $\$ 242.165$ & $\$ 0.24$ & $\$ 0.05$ & $\$ 0.000$ & $\$ 0.29$ & & $\$ 0.01$ & $\$ 0.23$ & $\$ 2.091$ & $\$ 249$ \\
\hline 1,000 & & $\$ 1,130,148.27$ & $\$ 420,000$ & $\$ 3.528$ & $\$ 1,553,676$ & $\$ 0.13$ & $\$ 0.0$ & $\$ 0.000$ & $\$ 0.18$ & & $\$ 0.01$ & $\$ 0.13$ & $\$ 1,320$ & $\$ 140$ \\
\hline 10,000 & & $\$ 6,396,445.03$ & $\$ 4,200,000$ & $\$ 35,280$ & $\$ 10,631,725$ & $\$ 0.08$ & $\$ 0.05$ & $\$ 0.000$ & $\$ 0.13$ & & $\$ 0.00$ & $\$ 0.07$ & $\$ 833$ & $\$ 79$ \\
\hline 100,000 & & $\$ 36,229,519.62$ & $\$ 42,000,000$ & $\$ 352,800$ & $\$ 78,582,320$ & $\$ 0.04$ & $\$ 0.05$ & $\$ 0.000$ & $\$ 0.09$ & & $\$ 0.00$ & $\$ 0.04$ & $\$ 525$ & $\$ 44$ \\
\hline 10 & 14 & $\$ 58,421.41$ & $\$ 4,200$ & $\$ 35$ & $\$ 62,657$ & $\$ 0.70$ & $\$ 0.05$ & $\$ 0.000$ & $\$ 0.75$ & & $\$ 0.02$ & $\$ 0.68$ & $\$ 3,314$ & $\$ 373$ \\
\hline 100 & 14 & $\$ 329,561.49$ & $\$ 42,000$ & $\$ 353$ & $\$ 371,914$ & $\$ 0.39$ & $\$ 0.05$ & $\$ 0.000$ & $\$ 0.44$ & & $\$ 0.01$ & $\$ 0.38$ & $\$ 2,091$ & $\$ 210$ \\
\hline 1,000 & 14 & $\$ 1,859,782.94$ & $\$ 420,000$ & $\$ 3,528$ & $\$ 2,283,311$ & $\$ 0.22$ & $\$ 0.05$ & $\$ 0.000$ & $\$ 0.27$ & & $\$ 0.01$ & $\$ 0.21$ & $\$ 1,320$ & $\$ 118$ \\
\hline 10.000 & 14 & $\$ 10.499 .482 .30$ & $\$ 4.200 .000$ & $\$ 35.280$ & $\$ 14.734 .762$ & $\$ 0.12$ & $\$ 0.1$ & $\$ 0.000$ & $\$ 0.18$ & & $\$ 0.00$ & $\$ 0.12$ & $\$ 833$ & $\$ 66$ \\
\hline 100,000 & 14 & $\$ 59,302,593.78$ & $\$ 42,000,000$ & $\$ 352,800$ & $\$ 101,655,394$ & $\$ 0.07$ & $\$ 0.05$ & $\$ 0.000$ & $\$ 0.12$ & & $\$ 0.00$ & $\$ 0.07$ & $\$ 525$ & $\$ 37$ \\
\hline 10 & 30 & $\$ 102,308.87$ & $\$ 4,200$ & $\$ 35$ & $\$ 106,544$ & $\$ 1.22$ & $\$ 0.05$ & $\$ 0.000$ & $\$ 1.27$ & & $\$ 0.02$ & $\$ 1.20$ & $\$ 3,314$ & $\$ 308$ \\
\hline 100 & 30 & $\$ 576,358.81$ & $\$ 42,000$ & $\$ 353$ & $\$ 618,712$ & $\$ 0.69$ & $\$ 0.05$ & $\$ 0.000$ & $\$ 0.74$ & & $\$ 0.01$ & $\$ 0.67$ & $\$ 2,091$ & $\$ 173$ \\
\hline 1,000 & 30 & $\$ 3,247,626.26$ & $\$ 420,000$ & $\$ 3,528$ & $\$ 3,671,154$ & $\$ \$ 0.39$ & $\$ 0.05$ & $\$ 0.000$ & $\$ 0.144$ & & $\$ \$ 0.01$ & $\$ 0.38$ & $\$ 1,320$ & $\$ 97$ \\
\hline 10,000 & 30 & $\$ 18,303,898.79$ & $\$ 4,200,000$ & $\$ 35,280$ & $\$ 22,539,179$ & $\$ 0.22$ & $\$ 0.05$ & $\$ 0.000$ & $\$ 0.27$ & & $\$ 0.00$ & $\$ 0.21$ & $\$ 833$ & 401 \\
\hline 100,000 & 30 & $\$ 103,190,052.89$ & $\$ 42,000,000$ & $\$ 352,800$ & $\$ 145,542,853$ & $\$ 0.12$ & $\$ 0.05$ & $\$ 0.000$ & $\$ 0.17$ & & $\$ 0.00$ & $\$ 0.12$ & $\$ 525$ & $\$ 31$ \\
\hline
\end{tabular}




\begin{tabular}{|c|c|c|c|c|c|c|c|c|c|}
\hline \multicolumn{10}{|c|}{ D.2 LIQUID HYDROGEN STORAGE - SI Units } \\
\hline & & & & & & & & & \\
\hline \multicolumn{2}{|c|}{ Liquefaction Capital Cost $=$} & $\$ 44,093$ & per kg/hr & & & & & & \\
\hline \multicolumn{2}{|c|}{ Liquid Dewar Capital Cost= } & $\$ 441$ & per kg/hr & & & & & & \\
\hline \multicolumn{2}{|c|}{ Liquefaction Size $=$} & 2,205 & $\mathrm{~kg} / \mathrm{hr}$ & & & & & & \\
\hline \multicolumn{2}{|c|}{ Liquid Dewar Size= } & 220 & $\mathrm{~kg} / \mathrm{hr}$ & & & & & & \\
\hline \multicolumn{2}{|c|}{ Liquefaction Scale-Up $=$} & 0.65 & & & & & & & \\
\hline \multicolumn{2}{|c|}{ Dewar Scale-Up $=$} & 0.70 & & & & & & & \\
\hline \multicolumn{2}{|c|}{ Liquefaction Power $=$} & 9.9 & $\mathrm{kWh} / \mathrm{kg}$ & & & & & & \\
\hline \multicolumn{2}{|c|}{ Liquefaction Cooling $=$} & 626 & $\mathrm{gal} / \mathrm{lb}$ & & & & & & \\
\hline Boil-off Rate $=$ & & $0.1 \%$ & per day & & & & & & \\
\hline Electric Cost $=$ & & $\$ 0.05$ & per kWh & & & & & & \\
\hline Cooling Cost $=$ & & $\$ 0.02$ & per M liters & & & & & & \\
\hline \multicolumn{2}{|c|}{ Operating Days $/$ Year $=$} & 350 & days/yr & & & & & & \\
\hline \multirow[t]{2}{*}{ Depreciation $=$} & & 22 & years & & & & & & \\
\hline & & & & & & & & & \\
\hline Production & Days of & Production & Storage & Annual & Liquefier & Cooling & Liquefier & Dewar & Total Capital \\
\hline Rate & Storage & plus Boil-Off & Capacity & Production & Power & Water & Cost & Cost & Cost \\
\hline$(\mathrm{kg} / \mathrm{hr})$ & (days) & $(\mathrm{kg} / \mathrm{hr})$ & $(\mathrm{kg})$ & $(\mathrm{kg} / \mathrm{yr})$ & $(\mathrm{kWh} / \mathrm{hr})$ & (liters/hr) & $(\$)$ & $(\$)$ & $(\$)$ \\
\hline 5 & $\overline{1}$ & 5 & 109 & 38,102 & 45 & 2,842 & $\$ 1,003,026$ & $\$ 36,939$ & $\$ 1,039,964$ \\
\hline 45 & 1 & 45 & 1,090 & 381,016 & 450 & 28,419 & $\$ 4,480,351$ & $\$ 185,132$ & $\$ 4,665,483$ \\
\hline 454 & 1 & 454 & 10,897 & $3,810,156$ & 4,504 & 284,189 & $\$ 20,012,991$ & $\$ 927,858$ & $\$ 20,940,849$ \\
\hline 4,536 & 1 & 4,540 & 108,970 & $38,101,560$ & 45,045 & $2,841,888$ & $\$ 89,394,748$ & $\$ 4,650,306$ & $\$ 94,045,055$ \\
\hline 45,359 & 1 & 45,404 & $1,089,704$ & $381,015,600$ & 450,450 & $28,418,876$ & $\$ 399,311,672$ & $\$ 23,306,742$ & $\$ 422,618,414$ \\
\hline 5 & 2 & 5 & 218 & 38,102 & 45 & 2,845 & $\$ 1,003,676$ & $\$ 60,049$ & $\$ 1,063,725$ \\
\hline 45 & 2 & 45 & 2,182 & 381,016 & 451 & 28,447 & $\$ 4,483,255$ & $\$ 300,958$ & $\$ 4,784,213$ \\
\hline 454 & 2 & 454 & 21,816 & $3,810,156$ & 4,509 & 284,472 & $\$ 20,025,965$ & $\$ 1,508,362$ & $\$ 21,534,327$ \\
\hline 4,536 & 2 & 4,545 & 218,158 & $38,101,560$ & 45,090 & $2,844,722$ & $\$ 89,452,700$ & $\$ 7,559,719$ & $\$ 97,012,419$ \\
\hline 45,359 & 2 & 45,450 & $2,181,582$ & $381,015,600$ & 450,899 & $28,447,224$ & $\$ 399,570,532$ & $\$ 37,888,347$ & $\$ 437,458,879$ \\
\hline 5 & 4 & 5 & 437 & 38,102 & 45 & 2,850 & $\$ 1,004,974$ & $\$ 97,686$ & $\$ 1,102,659$ \\
\hline 45 & 4 & 46 & 4,372 & 381,016 & 452 & 28,504 & $\$ 4,489,052$ & $\$ 489,588$ & $\$ 4,978,641$ \\
\hline 454 & 4 & 455 & 43,718 & $3,810,156$ & 4,518 & 285,038 & $\$ 20,051,860$ & $\$ 2,453,754$ & $\$ 22,505,614$ \\
\hline 4,536 & 4 & 4,554 & 437,185 & $38,101,560$ & 45,180 & $2,850,384$ & $\$ 89,568,368$ & $\$ 12,297,902$ & $\$ 101,866,271$ \\
\hline 45,359 & 4 & 45,540 & $4,371,847$ & $381,015,600$ & 451,796 & $28,503,835$ & $\$ 400,087,205$ & $\$ 61,635,516$ & $\$ 461,722,721$ \\
\hline 5 & 7 & 5 & 767 & 38,102 & 45 & 2,859 & $\$ 1,006,914$ & $\$ 144,830$ & $\$ 1,151,744$ \\
\hline 45 & 7 & 46 & 7,673 & 381,016 & 453 & 28,589 & $\$ 4,497,719$ & $\$ 725,871$ & $\$ 5,223,590$ \\
\hline 454 & 7 & 457 & 76,735 & $3,810,156$ & 4,531 & 285,885 & $\$ 20,090,572$ & $\$ 3,637,975$ & $\$ 23,728,547$ \\
\hline 4,536 & 7 & 4,568 & 767,347 & $38,101,560$ & 45,314 & $2,858,854$ & $\$ 89,741,288$ & $\$ 18,233,068$ & $\$ 107,974,356$ \\
\hline 45,359 & 7 & 45,675 & $7,673,468$ & $381,015,600$ & 453,139 & $28,588,540$ & $\$ 400,859,610$ & $\$ 91,381,807$ & $\$ 492,241,417$ \\
\hline 5 & 14 & 5 & 1,545 & 38,102 & 46 & 2,879 & $\$ 1,011,411$ & $\$ 236,409$ & $\$ 1,247,820$ \\
\hline 45 & 14 & 46 & 15,453 & 381,016 & 456 & 28,785 & $\$ 4,517,805$ & $\$ 1,184,854$ & $\$ 5,702,659$ \\
\hline 454 & 14 & 460 & 154,525 & $3,810,156$ & 4,563 & 287,852 & $\$ 20,180,295$ & $\$ 5,938,337$ & $\$ 26,118,632$ \\
\hline 4,536 & 14 & 4,599 & $1,545,251$ & $38,101,560$ & 45,626 & $2,878,520$ & $\$ 90,142,066$ & $\$ 29,762,185$ & $\$ 119,904,251$ \\
\hline 45,359 & 14 & 45,990 & $15,452,506$ & $381,015,600$ & 456,256 & $28,785,198$ & $\$ 402,649,820$ & $\$ 149,164,272$ & $\$ 551,814,092$ \\
\hline 5 & 30 & 5 & 3,362 & 38,102 & 46 & 2,923 & $\$ 1,021,532$ & $\$ 407,396$ & $\$ 1,428,929$ \\
\hline 45 & 30 & 47 & 33,624 & 381,016 & 463 & 29,230 & $\$ 4,563,017$ & $\$ 2,041,819$ & $\$ 6,604,836$ \\
\hline 454 & 30 & 467 & 336,237 & $3,810,156$ & 4,633 & 292,296 & $\$ 20,382,247$ & $\$ 10,233,337$ & $\$ 30,615,584$ \\
\hline 4,536 & 30 & 4,670 & $3,362,368$ & $38,101,560$ & 46,330 & $2,922,957$ & $\$ 91,044,153$ & $\$ 51,288,178$ & $\$ 142,332,331$ \\
\hline 45,359 & 30 & 46,700 & $33,623,684$ & $381,015,600$ & 463,300 & $29,229,566$ & $\$ 406,679,291$ & $\$ 257,049,801$ & $\$ 663,729,093$ \\
\hline
\end{tabular}

D - 7 


\begin{tabular}{|c|c|c|c|c|c|c|c|c|c|c|c|c|c|c|}
\hline \multicolumn{15}{|c|}{ D.2 LIQUID HYDROGEN STORAGE - SI Units (Continued) } \\
\hline & & & & & & & & & & & & & & \\
\hline Production & Days of & Depreciation & Annual Electric & Annual Cooling & Total Annual & Capital & Energy & Cooling & Total & & Liquefier & Dewar & Liquefier & Dewar \\
\hline Rate & Storage & & Cost & Water Cost & Cost & Cost & Cost & Cost & Cost & & Cost & Cost & Capital & Capital \\
\hline$(\mathrm{kg} / \mathrm{hr})$ & (days) & $(\$ / y r)$ & $(\$ / y r)$ & $(\$ / y r)$ & $(\$ / y r)$ & $(\$ / \mathrm{kg})$ & $(\$ / \mathrm{kg})$ & $(\$ / \mathrm{kg})$ & $(\$ / \mathrm{kg})$ & & $(\$ / \mathrm{kg})$ & $(\$ / \mathrm{kg})$ & $(\$ / \mathrm{kg})$ & $(\$ / \mathrm{kg})$ \\
\hline & & $\$ 47,271$ & $\$ 18,919$ & $\$ 441$ & $\$ 66,631$ & $\$ 1.24$ & $\$ 0.50$ & $\$ 0.01$ & $\$ 1.75$ & & $\$ 1.20$ & $\$ 0.04$ & $\$ 221,130$ & $\$ 339$ \\
\hline 45 & & $\$ 212.067$ & $\$ 189,189$ & $\$ 4.414$ & $\$ 405,671$ & $\$ 0.56$ & $\$ 0.50$ & $\$ 0.01$ & $\$ 1.06$ & & $\$ 0.53$ & $\$ 0.02$ & $\$ 98,775$ & $\$ 170$ \\
\hline 454 & & $\$ 951.857$ & $\$ 1,891,889$ & $\$ 44,144$ & $\$ 2,887,890$ & $\$ 0.25$ & $\$ 0.50$ & $\$ 0.01$ & $\$ 0.76$ & & $\$ 0.24$ & $\$ 0.01$ & $\$ 44,121$ & $\$ 85$ \\
\hline 4,536 & & $\$ 4,274,775$ & $\$ 18,918,891$ & $\$ 441,441$ & $\$ 23,635,107$ & $\$ 0.11$ & $\$ 0.50$ & $\$ 0.01$ & $\$ 0.62$ & & $\$ 0.11$ & $\$ 0.01$ & $\$ 19,708$ & $\$ 43$ \\
\hline 45,359 & & $\$ 19,209,928$ & $\$ 189,188,906$ & $\$ 4,414,408$ & $\$ 212,813,241$ & $\$ 0.05$ & $\$ 0.50$ & $\$ 0.01$ & $\$ 0.56$ & & $\$ 0.05$ & $\$ 0.00$ & $\$ 8,803$ & $\$ 21$ \\
\hline 5 & & $\$ 48,351$ & $\$ 18,938$ & $\$ 442$ & $\$ 67,731$ & $\$ 1.27$ & $\$ 0.50$ & $\$ 0.01$ & $\$ 1.78$ & & $\$ 1.20$ & $\$ 0.07$ & $\$ 221,274$ & $\$ 275$ \\
\hline 45 & & $\$ 217,464$ & $\$ 189,378$ & $\$ 4,419$ & $\$ 411,261$ & $\$ 0.57$ & $\$ 0.50$ & $\$ 0.01$ & $\$ 1.08$ & & $\$ 0.53$ & $\$ 0.04$ & $\$ 98,839$ & $\$ 138$ \\
\hline 454 & & $\$ 978,833$ & $\$ 1,893,776$ & $\$ 44,188$ & $\$ 2,916,797$ & $\$ 0.26$ & $\$ 0.50$ & $\$ 0.01$ & $\$ 0.77$ & & $\$ 0.24$ & $\$ 0.02$ & $\$ 44,150$ & $\$ 69$ \\
\hline 4,536 & & $\$ 4.409,655$ & $\$ 18,937,762$ & $\$ 441.881$ & $\$ 23,789,299$ & $\$ 0.12$ & $\$ 0.50$ & $\$ 0.01$ & $\$ 0.62$ & & $\$ 0.11$ & $\$ 0.01$ & $\$ 19,721$ & $\$ 35$ \\
\hline 45,359 & & $\$ 19,884,494$ & $\$ 189,377,622$ & $\$ 4,418,811$ & $\$ 213,680,928$ & $\$ 0.05$ & $\$ 0.50$ & $\$ 0.01$ & $\$ 0.56$ & & $\$ 0.05$ & $\$ 0.00$ & $\$ 8,809$ & $\$ 17$ \\
\hline 5 & & $\$ 50,121$ & $\$ 18,975$ & $\$ 443$ & $\$ 69,539$ & $\$ 1.32$ & $\$ 0.50$ & $\$ 0.01$ & $\$ 1.83$ & & $\$ 1.20$ & $\$ 0.12$ & $\$ 221.560$ & $\$ 223$ \\
\hline 45 & & $\$ 226,302$ & $\$ 189,754$ & $\$ 4,428$ & $\$ 420,484$ & $\$ 0.59$ & $\$ 0.50$ & $\$ 0.01$ & $\$ 1.10$ & & $\$ 0.54$ & $\$ 0.06$ & $\$ 98,967$ & $\$ 112$ \\
\hline 454 & & $\$ 1,022,982$ & $\$ 1,897,545$ & $\$ 44,276$ & $\$ 2,964,803$ & $\$ 0.27$ & $\$ 0.50$ & $\$ 0.01$ & $\$ 0.78$ & & $\$ 0.24$ & $\$ 0.03$ & $\$ 44,207$ & $\$ 56$ \\
\hline 4,536 & & $\$ 4,630,285$ & $\$ 18,975,449$ & $\$ 442,760$ & $\$ 24,048,495$ & $\$ 0.12$ & $\$ 0.50$ & $\$ 0.01$ & $\$ 0.63$ & & $\$ 0.11$ & $\$ 0.01$ & $\$ 19,747$ & $\$ 28$ \\
\hline 45,359 & & $\$ 20,987,396$ & $\$ 189,754,490$ & $\$ 4,427,605$ & $\$ 215,169,491$ & $\$ 0.06$ & $\$ 0.50$ & $\$ 0.01$ & $\$ 0.56$ & & $\$ 0.05$ & $\$ 0.01$ & $\$ 8,820$ & $\$ 14$ \\
\hline & & $\$ 52,352$ & $\$ 19,032$ & $\$ 444$ & $\$ 71,828$ & $\$ 1.37$ & $\$ 0.50$ & $\$ 0.01$ & $\$ 1.89$ & & $\$ 1.20$ & $\$ 0.17$ & $\$ 221,988$ & $\$ 189$ \\
\hline 45 & & $\$ 237.436$ & $\$ 190.318$ & $\$ 4.441$ & $\$ 432.195$ & $\$ 0.62$ & $\$ 0.50$ & $\$ 0.01$ & $\$ 1.13$ & & $\$ 0.54$ & $\$ 0.09$ & $\$ 99.158$ & $\$ 95$ \\
\hline 454 & & $\$ 1,078,570$ & $\$ 1,903,184$ & $\$ 44,408$ & $\$ 3,026,162$ & $\$ 0.28$ & $\$ 0.50$ & $\$ 0.01$ & $\$ 0.79$ & & $\$ 0.24$ & $\$ 0.04$ & $\$ 44,292$ & $\$ 47$ \\
\hline 4,536 & & $\$ 4,907,925$ & $\$ 19,031,838$ & $\$ 444,076$ & $\$ 24,383,840$ & $\$ 0.13$ & $\$ 0.50$ & $\$ 0.01$ & $\$ 0.64$ & & $\$ 0.11$ & $\$ 0.02$ & $\$ 19,785$ & $\$ 24$ \\
\hline 45,359 & & $\$ 22,374,610$ & $\$ 190,318,380$ & $\$ 4,440,762$ & $\$ 217,133,752$ & $\$ 0.06$ & $\$ 0.50$ & $\$ 0.01$ & $\$ 0.57$ & & $\$ 0.05$ & $\$ 0.01$ & $\$ 8,837$ & $\$ 12$ \\
\hline 5 & 14 & $\$ 56,719$ & $\$ 19,163$ & $\$ 447$ & $\$ 76,329$ & $\$ 1.49$ & $\$ 0.50$ & $\$ 0.01$ & $\$ 2.00$ & & $\$ 1.21$ & $\$ 0.28$ & $\$ 222,979$ & $\$ 153$ \\
\hline 45 & 14 & $\$ 259,212$ & $\$ 191,628$ & $\$ 4,471$ & $\$ 455,311$ & $\$ 0.68$ & $\$ 0.50$ & $\$ 0.01$ & $\$ 1.19$ & & $\$ 0.54$ & $\$ 0.14$ & $\$ 99,601$ & $\$ 77$ \\
\hline 454 & 14 & $\$ 1,187,211$ & $\$ 1,916,276$ & $\$ 44,713$ & $\$ 3,148,199$ & $\$ 0.31$ & $\$ 0.50$ & $\$ 0.01$ & $\$ 0.83$ & & $\$ 0.24$ & $\$ 0.07$ & $\$ 44,490$ & $\$ 38$ \\
\hline 4.536 & 14 & $\$ 5.450,193$ & $\$ 19,162,756$ & $\$ 447.131$ & $\$ 25.060,081$ & $\$ 0.14$ & $\$ 0.50$ & $\$ 0.01$ & $\$ 0.66$ & & $\$ 0.11$ & $\$ 0.04$ & $\$ 19.873$ & $\$ 19$ \\
\hline 45.359 & 14 & $\$ 25,082,459$ & $\$ 191,627,564$ & $\$ 4,471,310$ & $\$ 221,181,333$ & $\$ 0.07$ & $\$ 0.50$ & $\$ 0.01$ & $\$ 0.58$ & & $\$ 0.6$ & $\$ 0$ & $\$ 8.877$ & $\$ 10$ \\
\hline 5 & 30 & $\$ 64,951$ & $\$ 19,459$ & $\$ 454$ & $\$ 84,864$ & $\$ 1.70$ & $\$ 0.51$ & $\$ 0.01$ & $\$ 2.23$ & & $\$ 1.22$ & $\$ 0.49$ & $\$ 225,210$ & $\$ 121$ \\
\hline 45 & 30 & $\$ 300,220$ & $\$ 194,586$ & $\$ 4,540$ & $\$ 499,346$ & $\$ 0.79$ & $\$ 0.51$ & $\$ 0.01$ & $\$ 1.31$ & & $\$ 0.54$ & $\$ 0.24$ & $\$ 100,598$ & $\$ 61$ \\
\hline 454 & 30 & $\$ 1,391,617$ & $\$ 1,945,858$ & $\$ 45,403$ & $\$ 3,382,879$ & $\$ 0.37$ & $\$ 0.51$ & $\$ 0.01$ & $\$ 0.89$ & & $\$ 0.24$ & $\$ 0.12$ & $\$ 44,935$ & $\$ 30$ \\
\hline 4,536 & 30 & $\$ 6,469,651$ & $\$ 19,458,579$ & $\$ 454,034$ & $\$ 26,382,264$ & $\$ 0.17$ & $\$ 0.51$ & $\$ 0.01$ & $\$ 0.69$ & & $\$ 0.11$ & $\$ 0.06$ & $\$ 20,072$ & $\$ 15$ \\
\hline 45,359 & 30 & $\$ 30,169,504$ & $\$ 194,585,794$ & $\$ 4,540,335$ & $\$ 229,295,634$ & $\$ 0.08$ & $\$ 0.51$ & $\$ 0.01$ & $\$ 0.60$ & & $\$ 0.05$ & $\$ 0.03$ & $\$ 8,966$ & $\$ 8$ \\
\hline
\end{tabular}




\begin{tabular}{|c|c|c|c|c|c|c|c|c|c|}
\hline \multicolumn{10}{|c|}{ D.2 LIQUID HYDROGEN STORAGE - English Units } \\
\hline & & & & & & & & & \\
\hline \multicolumn{2}{|c|}{ Liquefaction Capital Cost= } & $\$ 20,000$ & per lb/hr & & & & & & \\
\hline \multicolumn{2}{|c|}{ Liquid Dewar Capital Cost $=$} & $\$ 200$ & per lb & & & & & & \\
\hline \multicolumn{2}{|c|}{ Liquefaction Size $=$} & 1,000 & $\mathrm{Ib} / \mathrm{hr}$ & & & & & & \\
\hline \multicolumn{2}{|c|}{ Liquid Dewar Size $=$} & 100 & ib & & & & & & \\
\hline \multicolumn{2}{|c|}{ Liquefaction Scale-Up= } & 0.65 & & & & & & & \\
\hline \multicolumn{2}{|c|}{ Dewar Scale-Up= } & 0.70 & & & & & & & \\
\hline \multicolumn{2}{|c|}{ Liquefaction Power $=$} & 4.5 & $\mathrm{kWh} / \mathrm{lb}$ & & & & & & \\
\hline \multicolumn{2}{|c|}{ Liquefaction Cooling = } & 75 & $\mathrm{gal} / \mathrm{lb}$ & & & & & & \\
\hline Boil-off Rate $=$ & & $0.1 \%$ & per day & & & & & & \\
\hline Electric Cost $=$ & & $\$ 0.05$ & per kWh & & & & & & \\
\hline Cooling Cost= & & $\$ 0.07$ & per M gal & & & & & & \\
\hline \multicolumn{2}{|c|}{ Operating Days/Year $=$} & 350 & days/yr & & & & & & \\
\hline \multirow[t]{2}{*}{ Depreciation $=$} & & 22 & years & & & & & & \\
\hline & & & & & & & & & \\
\hline Production & Days of & Production & Storage & Annual & Liquefier & Cooling & Liquefier & Dewar & Total Capital \\
\hline Rate & Storage & plus Boil-Off & Capacity & Production & Power & Water & Cost & Cost & Cost \\
\hline$(\mathrm{lb} / \mathrm{hr})$ & (days) & $(\mathrm{lb} / \mathrm{hr})$ & (lb) & $(\mathrm{lb} / \mathrm{yr})$ & (kWh/hr) & (gal/hr) & $(\$)$ & $(\$)$ & $(\$)$ \\
\hline 10 & 1 & 10 & 240 & 84,000 & 45 & 751 & $\$ 1,003,026$ & $\$ 36,939$ & $\$ 1,039,964$ \\
\hline 100 & 1 & 100 & 2,402 & 840,000 & 450 & 7,507 & $\$ 4,480,351$ & $\$ 185,132$ & $\$ 4,665,483$ \\
\hline 1,000 & 1 & 1,001 & 24,024 & $8,400,000$ & 4,504 & 75,075 & $\$ 20,012,991$ & $\$ 927,858$ & $\$ 20,940,849$ \\
\hline 10,000 & 1 & 10,010 & 240,240 & $84,000,000$ & 45,045 & 750,750 & $\$ 89,394,748$ & $\$ 4,650,306$ & $\$ 94,045,055$ \\
\hline 100,000 & 1 & 100,100 & $2,402,399$ & $840,000,000$ & 450,450 & $7,507,496$ & $\$ 399,311,672$ & $\$ 23,306,742$ & $\$ 422,618,414$ \\
\hline 10 & 2 & 10 & 481 & 84,000 & 45 & 751 & $\$ 1,003,676$ & $\$ 60,049$ & $\$ 1,063,725$ \\
\hline 100 & 2 & 100 & 4,810 & 840,000 & 451 & 7,515 & $\$ 4,483,255$ & $\$ 300,958$ & $\$ 4,784,213$ \\
\hline 1,000 & 2 & 1,002 & 48,096 & $8,400,000$ & 4,509 & 75,150 & $\$ 20,025,965$ & $\$ 1,508,362$ & $\$ 21,534,327$ \\
\hline 10,000 & 2 & 10,020 & 480,959 & $84,000,000$ & 45,090 & 751,499 & $\$ 89,452,700$ & $\$ 7,559,719$ & $\$ 97,012,419$ \\
\hline 100,000 & 2 & 100,200 & $4,809,590$ & $840,000,000$ & 450,899 & $7,514,985$ & $\$ 399,570,532$ & $\$ 37,888,347$ & $\$ 437,458,879$ \\
\hline 10 & 4 & 10 & 964 & 84,000 & 45 & 753 & $\$ 1,004,974$ & $\$ 97,686$ & $\$ 1,102,659$ \\
\hline 100 & 4 & 100 & 9,638 & 840,000 & 452 & 7,530 & $\$ 4,489,052$ & $\$ 489,588$ & $\$ 4,978,641$ \\
\hline 1,000 & 4 & 1,004 & 96,383 & $8,400,000$ & 4,518 & 75,299 & $\$ 20,051,860$ & $\$ 2,453,754$ & $\$ 22,505,614$ \\
\hline 10,000 & 4 & 10,040 & 963,832 & $84,000,000$ & 45,180 & 752,994 & $\$ 89,568,368$ & $\$ 12,297,902$ & $\$ 101,866,271$ \\
\hline 100,000 & 4 & 100,399 & $9,638,323$ & $840,000,000$ & 451,796 & $7,529,940$ & $\$ 400,087,205$ & $\$ 61,635,516$ & $\$ 461,722,721$ \\
\hline 10 & 7 & 10 & 1,692 & 84,000 & 45 & 755 & $\$ 1,006,914$ & $\$ 144,830$ & $\$ 1,151,744$ \\
\hline 100 & 7 & 101 & 16,917 & 840,000 & 453 & 7,552 & $\$ 4,497,719$ & $\$ 725,871$ & $\$ 5,223,590$ \\
\hline 1,000 & 7 & 1,007 & 169,172 & $8,400,000$ & 4,531 & 75,523 & $\$ 20,090,572$ & $\$ 3,637,975$ & $\$ 23,728,547$ \\
\hline 10,000 & 7 & 10,070 & $1,691,719$ & $84,000,000$ & 45,314 & 755,232 & $\$ 89,741,288$ & $\$ 18,233,068$ & $\$ 107,974,356$ \\
\hline 100,000 & 7 & 100,698 & $16,917,189$ & $840,000,000$ & 453,139 & $7,552,317$ & $\$ 400,859,610$ & $\$ 91,381,807$ & $\$ 492,241,417$ \\
\hline 10 & 14 & 10 & 3,407 & 84,000 & 46 & 760 & $\$ 1,011,411$ & $\$ 236,409$ & $\$ 1,247,820$ \\
\hline 100 & 14 & 101 & 34,067 & 840,000 & 456 & 7,604 & $\$ 4,517,805$ & $\$ 1,184,854$ & $\$ 5,702,659$ \\
\hline 1,000 & 14 & 1,014 & 340,671 & $8,400,000$ & 4,563 & 76,043 & $\$ 20,180,295$ & $\$ 5,938,337$ & $\$ 26,118,632$ \\
\hline 10,000 & 14 & 10,139 & $3,406,712$ & $84,000,000$ & 45,626 & 760,427 & $\$ 90,142,066$ & $\$ 29,762,185$ & $\$ 119,904,251$ \\
\hline 100,000 & 14 & 101,390 & $34,067,123$ & $840,000,000$ & 456,256 & $7,604,268$ & $\$ 402,649,820$ & $\$ 149,164,272$ & $\$ 551,814,092$ \\
\hline 10 & 30 & 10 & 7,413 & 84,000 & 46 & 772 & $\$ 1,021,532$ & $\$ 407,396$ & $\$ 1,428,929$ \\
\hline 100 & 30 & 103 & 74,128 & 840,000 & 463 & 7,722 & $\$ 4,563,017$ & $\$ 2,041,819$ & $\$ 6,604,836$ \\
\hline 1,000 & 30 & 1,030 & 741,279 & $8,400,000$ & 4,633 & 77,217 & $\$ 20,382,247$ & $\$ 10,233,337$ & $\$ 30,615,584$ \\
\hline 10,000 & 30 & 10,296 & $7,412,792$ & $84,000,000$ & 46,330 & 772,166 & $\$ 91,044,153$ & $\$ 51,288,178$ & $\$ 142,332,331$ \\
\hline 100,000 & 30 & 102,955 & $74,127,922$ & $840,000,000$ & 463,300 & $7,721,658$ & $\$ 406,679,291$ & $\$ 257,049,801$ & $\$ 663,729,093$ \\
\hline
\end{tabular}




\begin{tabular}{|c|c|c|c|c|c|c|c|c|c|c|c|c|c|c|}
\hline \multicolumn{15}{|c|}{ D.2 LIQUID HYDROGEN STORAGE - English Units (Continued) } \\
\hline Production & Days of & Depreciation & Annual Electric & Annual Cooling & Total Annual & Capital & Energy & Cooling & Total & & Liquefier & Dewar & Liquefier & Dewar \\
\hline Rate & Storage & & Cost & Water Cost & Cost & Cost & Cost & Cost & Cost & & Cost & Cost & Capital & Capital \\
\hline$(\mathrm{lb} / \mathrm{hr})$ & (days) & $(\$ / y r)$ & $(\$ / y r)$ & $(\$ / y r)$ & $(\$ / y r)$ & $(\$ / b)$ & $(\$ /$ /b) & $(\$ / \mathrm{lb})$ & $(\$ / \mathrm{lb})$ & & $(\$ / b)$ & Cost/lb & $(\$ / \mathrm{lb})$ & $(\$ / \mathrm{lb})$ \\
\hline 10 & & $\$ 47,271$ & $\$ 18,919$ & $\$ 441$ & $\$ 66,631$ & $\$ 0.56$ & $\$ 0.23$ & $\$ 0.01$ & $\$ 0.79$ & & $\$ 0.54$ & $\$ 0.02$ & $\$ 100,303$ & $\$ 154$ \\
\hline 100 & & $\$ 212.067$ & $\$ 189.189$ & $\$ 4.414$ & $\$ 405.671$ & $\$ 0.25$ & $\$ 0.23$ & $\$ 0.01$ & $\$ 0.48$ & & $\$ 0.24$ & $\$ 0.01$ & $\$ 44.804$ & $\$ 77$ \\
\hline 1.000 & & $\$ 951.857$ & $\$ 1.891 .889$ & $\$ 44.144$ & $\$ 2.887 .890$ & $\$ 0.11$ & $\$ 0.23$ & $\$ 0.01$ & $\$ 0.34$ & & $\$ 0.11$ & $\$ 0.01$ & $\$ 20.013$ & $\$ 39$ \\
\hline 10,000 & & $\$ 4,274,775$ & $\$ 18,918,891$ & $\$ 441,44$ & $\$ 23,635,107$ & $\$ 0.05$ & $\$ 0.23$ & $\$ 0.01$ & $\$ 0.28$ & & $\$ 0.05$ & $\$ 0.00$ & $\$ 8,939$ & $\$ 19$ \\
\hline 100,000 & & $\$ 19,209,928$ & $\$ 189,188,906$ & $\$ 4,414,408$ & $\$ 212,813,241$ & $\$ 0.02$ & $\$ 0.23$ & $\$ 0.01$ & $\$ 0.25$ & & $\$ 0.02$ & $\$ 0.00$ & $\$ 3,993$ & $\$ 10$ \\
\hline 10 & & $\$ 48,351$ & $\$ 18,938$ & $\$ 442$ & $\$ 67,731$ & $\$ 0.58$ & $\$ 0.23$ & $\$ 0.01$ & $\$ 0.81$ & & $\$ 0.54$ & $\$ 0.03$ & $\$ 100,368$ & $\$ 125$ \\
\hline 100 & & $\$ 217,464$ & $\$ 189,378$ & $\$ 4,41 c$ & $\$ 411,261$ & $\$ 0.26$ & $\$ 0.23$ & $\$ 0.01$ & $\$ 0.49$ & & $\$ 0.24$ & $\$ 0.02$ & $\$ 44,833$ & $\$ 63$ \\
\hline 1,000 & & $\$ 978,833$ & $\$ 1,893,776$ & $\$ 44,188$ & $\$ 2,916,797$ & $\$ 0.12$ & $\$ 0.23$ & $\$ 0.01$ & $\$ 0.35$ & & $\$ 0.11$ & $\$ 0.01$ & $\$ 20,026$ & $\$ 31$ \\
\hline 10,000 & & $\$ 4.409,655$ & $\$ 18,937,762$ & $\$ 441,88$ & $\$ 23,789,299$ & $\$ 0.05$ & $\$ 0.23$ & $\$ 0.01$ & $\$ 0.28$ & & $\$ 0.05$ & $\$ 0.00$ & $\$ 8.945$ & $\$ 16$ \\
\hline 100,000 & & $\$ 19,884,494$ & $\$ 189,377,622$ & $\$ 4,418,811$ & $\$ 213,680,928$ & $\$ 0.02$ & $\$ 0.23$ & $\$ 0.01$ & $\$ 0.25$ & & $\$ 0.02$ & $\$ 0.00$ & $\$ 3.996$ & $\$ 8$ \\
\hline 10 & & $\$ 50,121$ & $\$ 18,975$ & $\$ 443$ & $\$ 69,539$ & $\$ 0.60$ & $\$ 0.23$ & $\$ 0.01$ & $\$ 0.83$ & & $\$ 0.54$ & $\$ 0.05$ & $\$ 100,497$ & $\$ 101$ \\
\hline 100 & & $\$ 226,302$ & $\$ 189,754$ & $\$ 4,42 \varepsilon$ & $\$ 420,484$ & $\$ 0.27$ & $\$ 0.23$ & $\$ 0.01$ & $\$ 0.50$ & & $\$ 0.24$ & $\$ 0.03$ & $\$ 44,891$ & $\$ 51$ \\
\hline 1,000 & & $\$ 1,022,982$ & $\$ 1,897,545$ & $\$ 44,276$ & $\$ 2,964,803$ & $\$ 0.12$ & $\$ 0.23$ & $\$ 0.01$ & $\$ 0.35$ & & $\$ 0.11$ & $\$ 0.01$ & $\$ 20,052$ & $\$ 25$ \\
\hline 10,000 & & $\$ 4,630,285$ & $\$ 18,975,449$ & $\$ 442,760$ & $\$ 24,048,495$ & $\$ 0.06$ & $\$ 0.23$ & $\$ 0.01$ & $\$ 0.29$ & & $\$ 0.05$ & $\$ 0.01$ & $\$ 8,957$ & $\$ 13$ \\
\hline 100,000 & & $\$ 20,987,396$ & $\$ 189,754,490$ & $\$ 4,427,605$ & $\$ 215,169,491$ & $\$ 0.02$ & $\$ 0.23$ & $\$ 0.01$ & $\$ 0.26$ & & $\$ 0.02$ & $\$ 0.00$ & $\$ 4,001$ & $\$ 6$ \\
\hline 10 & & $\$ 52,352$ & $\$ 19,032$ & $\$ 444$ & $\$ 71,828$ & $\$ 0.62$ & $\$ 0.23$ & $\$ 0.01$ & $\$ 0.86$ & & $\$ 0.54$ & $\$ 0.08$ & $\$ 100,691$ & $\$ 86$ \\
\hline 100 & & $\$ 237.436$ & $\$ 190,318$ & $\$ 4.44$ & $\$ 432,195$ & $\$ 0.28$ & $\$ 0.23$ & $\$ 0.01$ & $\$ 0.51$ & & $\$ 0.24$ & $\$ 0.04$ & $\$ 44,977$ & $\$ 43$ \\
\hline 1,000 & & $\$ 1,078,570$ & $\$ 1,903,184$ & $\$ 44,408$ & $\$ 3,026,162$ & $\$ 0.13$ & $\$ 0.23$ & $\$ 0.01$ & $\$ 0.36$ & & $\$ 0.11$ & $\$ 0.02$ & $\$ 20,091$ & $\$ 22$ \\
\hline 10,000 & & $\$ 4,907,925$ & $\$ 19,031,838$ & $\$ 444,07 €$ & $\$ 24,383,840$ & $\$ 0.06$ & $\$ 0.23$ & $\$ 0.01$ & $\$ 0.29$ & & $\$ 0.05$ & $\$ 0.01$ & $\$ 8,974$ & $\$ 11$ \\
\hline 100,000 & & $\$ 22,374,610$ & $\$ 190,318,380$ & $\$ 4,440,762$ & $\$ 217,133,752$ & $\$ 0.03$ & $\$ 0.23$ & $\$ 0.01$ & $\$ 0.26$ & & $\$ 0.02$ & $\$ 0.00$ & $\$ 4,009$ & $\$ 5$ \\
\hline 10 & 14 & $\$ 56,719$ & $\$ 19,163$ & $\$ 447$ & $\$ 76,329$ & $\$ 0.68$ & $\$ 0.23$ & $\$ 0.01$ & $\$ 0.91$ & & $\$ 0.55$ & $\$ 0.13$ & $\$ 101,141$ & $\$ 69$ \\
\hline 100 & 14 & $\$ 259,212$ & $\$ 191,628$ & $\$ 4,47$ & $\$ 455,311$ & $\$ 0.31$ & $\$ 0.23$ & $\$ 0.01$ & $\$ 0.54$ & & $\$ 0.24$ & $\$ 0.06$ & $\$ 45,178$ & $\$ 35$ \\
\hline 1,000 & 14 & $\$ 1,187,211$ & $\$ 1,916,276$ & $\$ 44,713$ & $\$ 3,148,199$ & $\$ 0.14$ & $\$ 0.23$ & $\$ 0.01$ & $\$ 0.37$ & & $\$ 0.11$ & $\$ 0.03$ & $\$ 20,180$ & $\$ 17$ \\
\hline 10.000 & 14 & $\$ 5.450 .193$ & $\$ 19.162 .756$ & $\$ 447.13$ & $\$ 25.060 .081$ & $\$ 0.06$ & $\$ 0.23$ & $\$ 0.01$ & $\$ 0.30$ & & $\$ 0.05$ & $\$ 0.02$ & $\$ 9.014$ & $\$ 9$ \\
\hline 100,000 & 14 & $\$ 25,082,459$ & $\$ 191,627,564$ & $\$ 4,471,310$ & $\$ 221,181,333$ & $\$ 0.03$ & $\$ 0$ & $\$ 0.0$ & $\$ 0.26$ & & $\$ 0.02$ & $\$ 0.01$ & $\$ 4.026$ & $\$ 4$ \\
\hline 10 & 30 & $\$ 64,951$ & $\$ 19,459$ & $\$ 454$ & $\$ 84,864$ & $\$ 0.77$ & $\$ 0.2$ & $\$ 0.01$ & $\$ 1.01$ & & $\$ 0.55$ & $\$ 0.22$ & $\$ 102,153$ & $\$ 55$ \\
\hline 100 & 30 & $\$ 300,220$ & $\$ 194,586$ & $\$ 4,54 \mathrm{C}$ & $\$ 499,346$ & $\$ 0.36$ & $\$ 0.23$ & $\$ 0.01$ & $\$ 0.59$ & & $\$ 0.25$ & $\$ 0.11$ & $\$ 45,630$ & $\$ 28$ \\
\hline 1,000 & 30 & $\$ 1,391,617$ & $\$ 1,945,858$ & $\$ 45,403$ & $\$ 3,382,879$ & $\$ 0.17$ & $\$ 0.23$ & $\$ 0.01$ & $\$ 0.40$ & & $\$ 0.11$ & $\$ 0.06$ & $\$ 20,382$ & $\$ 14$ \\
\hline 10,000 & 30 & $\$ 6,469,651$ & $\$ 19,458,579$ & $\$ 454,03$ & $\$ 26,382,264$ & $\$ 0.08$ & $\$ 0.23$ & $\$ 0.01$ & $\$ 0.31$ & & $\$ 0.05$ & $\$ 0.03$ & $\$ 9,104$ & $\$ 7$ \\
\hline 100,000 & 30 & $\$ 30,169,504$ & $\$ 194,585,794$ & $\$ 4,540,335$ & $\$ 229,295,634$ & $\$ 0.04$ & $\$ 0.23$ & $\$ 0.01$ & $\$ 0.27$ & & $\$ 0.02$ & $\$ 0.01$ & $\$ 4,067$ & \\
\hline
\end{tabular}




\begin{tabular}{|c|c|c|c|c|c|c|c|}
\hline \multicolumn{8}{|c|}{ D.3 METAL HYDRIDE STORAGE - SI Units } \\
\hline \multirow{2}{*}{\multicolumn{2}{|c|}{ Hydride Capital Cost $=$}} & & & & & & \\
\hline & & $\$ 2,205$ & per kg & & & & \\
\hline \multicolumn{2}{|c|}{ Hydride Scale-Up= } & 1.00 & & & & & \\
\hline \multicolumn{2}{|c|}{ Hydride Cooling $=$} & 209 & liters/kg & & & & \\
\hline \multicolumn{2}{|l|}{ Hydride Heating $=$} & 23,260 & $\mathrm{~kJ} / \mathrm{kg}$ & & & & \\
\hline Steam Cost $=$ & & $\$ 3.79$ & per kJ & & & & \\
\hline Cooling Cost $=$ & & $\$ 0.02$ & per M liters & & & & \\
\hline \multicolumn{2}{|c|}{ Operating Days/Year $=$} & 350 & days/yr & & & & \\
\hline \multicolumn{2}{|l|}{ Depreciation= } & 22 & years & & & & \\
\hline & & & & & & & \\
\hline Production & Days of & Storage & Annual & Heat & Cooling & Hydride & Total Capital \\
\hline Rate & Storage & Capacity & Production & Requirement & Requirement & Cost & Cost \\
\hline$(\mathrm{kg} / \mathrm{hr})$ & (days) & $(\mathrm{kg})$ & $(\mathrm{kg} / \mathrm{yr})$ & $(\mathrm{kJ} / \mathrm{hr})$ & (liters/hr) & $(\$)$ & $(\$)$ \\
\hline 5 & 1 & 109 & 38,102 & 105,506 & 946 & $\$ 240,000$ & $\$ 240,000$ \\
\hline 45 & 1 & 1,089 & 381,016 & $1,055,060$ & 9,464 & $\$ 2,400,000$ & $\$ 2,400,000$ \\
\hline 454 & 1 & 10,886 & $3,810,156$ & $10,550,600$ & 94,635 & $\$ 24,000,000$ & $\$ 24,000,000$ \\
\hline 4,536 & 1 & 108,862 & $38,101,560$ & $105,506,000$ & 946,350 & $\$ 240,000,000$ & $\$ 240,000,000$ \\
\hline 45,359 & 1 & $1,088,616$ & $381,015,600$ & $1,055,060,000$ & $9,463,500$ & $\$ 2,400,000,000$ & $\$ 2,400,000,000$ \\
\hline 5 & 2 & 218 & 38,102 & 105,506 & 946 & $\$ 480,000$ & $\$ 480,000$ \\
\hline 45 & 2 & 2,177 & 381,016 & $1,055,060$ & 9,464 & $\$ 4,800,000$ & $\$ 4,800,000$ \\
\hline 454 & 2 & 21,772 & $3,810,156$ & $10,550,600$ & 94,635 & $\$ 48,000,000$ & $\$ 48,000,000$ \\
\hline 4,536 & 2 & 217,723 & $38,101,560$ & $105,506,000$ & 946,350 & $\$ 480,000,000$ & $\$ 480,000,000$ \\
\hline 45,359 & 2 & $2,177,232$ & $381,015,600$ & $1,055,060,000$ & $9,463,500$ & $\$ 4,800,000,000$ & $\$ 4,800,000,000$ \\
\hline 5 & 4 & 435 & 38,102 & 105,506 & 946 & $\$ 960,000$ & $\$ 960,000$ \\
\hline 45 & 4 & 4,354 & 381,016 & $1,055,060$ & 9,464 & $\$ 9,600,000$ & $\$ 9,600,000$ \\
\hline 454 & 4 & 43,545 & $3,810,156$ & $10,550,600$ & 94,635 & $\$ 96,000,000$ & $\$ 96,000,000$ \\
\hline 4,536 & 4 & 435,446 & $38,101,560$ & $105,506,000$ & 946,350 & $\$ 960,000,000$ & $\$ 960,000,000$ \\
\hline 45,359 & 4 & $4,354,464$ & $381,015,600$ & $1,055,060,000$ & $9,463,500$ & $\$ 9,600,000,000$ & $\$ 9,600,000,000$ \\
\hline 5 & 7 & 762 & 38,102 & 105,506 & 946 & $\$ 1,680,000$ & $\$ 1,680,000$ \\
\hline 45 & 7 & 7,620 & 381,016 & $1,055,060$ & 9,464 & $\$ 16,800,000$ & $\$ 16,800,000$ \\
\hline 454 & 7 & 76,203 & $3,810,156$ & $10,550,600$ & 94,635 & $\$ 168,000,000$ & $\$ 168,000,000$ \\
\hline \begin{tabular}{l|}
4,536 \\
\end{tabular} & 7 & 762,031 & $38,101,560$ & $105,506,000$ & 946,350 & $\$ 1,680,000,000$ & $\$ 1,680,000,000$ \\
\hline 45,359 & 7 & $7,620,312$ & $381,015,600$ & $1,055,060,000$ & $9,463,500$ & $\$ 16,800,000,000$ & $\$ 16,800,000,000$ \\
\hline 5 & 14 & 1,524 & 38,102 & 105,506 & 946 & $\$ 3,360,000$ & $\$ 3,360,000$ \\
\hline 45 & 14 & 15,241 & 381,016 & $1,055,060$ & 9,464 & $\$ 33,600,000$ & $\$ 33,600,000$ \\
\hline 454 & 14 & 152,406 & $3,810,156$ & $10,550,600$ & 94,635 & $\$ 336,000,000$ & $\$ 336,000,000$ \\
\hline 4,536 & 14 & $1,524,062$ & $38,101,560$ & $105,506,000$ & 946,350 & $\$ 3,360,000,000$ & $\$ 3,360,000,000$ \\
\hline 45,359 & 14 & $15,240,624$ & $381,015,600$ & $1,055,060,000$ & $9,463,500$ & $\$ 33,600,000,000$ & $\$ 33,600,000,000$ \\
\hline 5 & 30 & 3,266 & 38,102 & 105,506 & 946 & $\$ 7,200,000$ & $\$ 7,200,000$ \\
\hline 45 & 30 & 32,658 & 381,016 & $1,055,060$ & 9,464 & $\$ 72,000,000$ & $\$ 72,000,000$ \\
\hline 454 & 30 & 326,585 & $3,810,156$ & $10,550,600$ & 94,635 & $\$ 720,000,000$ & $\$ 720,000,000$ \\
\hline 4,536 & 30 & $3,265,848$ & $38,101,560$ & $105,506,000$ & 946,350 & $\$ 7,200,000,000$ & $\$ 7,200,000,000$ \\
\hline 45,359 & 30 & $32,658,480$ & $381,015,600$ & $1,055,060,000$ & $9,463,500$ & $\$ 72,000,000,000$ & $\$ 72,000,000,000$ \\
\hline
\end{tabular}

D - 11 


\begin{tabular}{|c|c|c|c|c|c|c|c|c|c|}
\hline \multicolumn{10}{|c|}{ D.3 METAL HYDRIDE STORAGE - SI Units (Continued) } \\
\hline & & & & & & & & & \\
\hline Production & Days of & Depreciation & Annual Electric & Annual Cooling & Total Annual & Capital & Energy & Cooling & Total \\
\hline Rate & Storage & & Cost & Water Cost & Cost & Cost & Cost & Cost & Cost \\
\hline$(\mathrm{kg} / \mathrm{hr})$ & (days) & $(\$ / y r)$ & $(\$ / y r)$ & $(\$ / \mathrm{yr})$ & $(\$ / y r)$ & $(\$ / \mathrm{kg})$ & $(\$ / \mathrm{kg})$ & $(\$ / \mathrm{kg})$ & $(\$ / \mathrm{kg})$ \\
\hline 5 & 1 & $\$ 10,909$ & $\$ 3,360$ & $\$ 147$ & $\$ 14,416$ & $\$ 0.29$ & $\$ 0.09$ & $\$ 0.00$ & $\$ 0.38$ \\
\hline 45 & 1 & $\$ 109,091$ & $\$ 33,600$ & $\$ 1,470$ & $\$ 144,161$ & $\$ 0.29$ & $\$ 0.09$ & $\$ 0.00$ & $\$ 0.38$ \\
\hline 454 & 1 & $\$ 1,090,909$ & $\$ 336,000$ & $\$ 14,700$ & $\$ 1,441,609$ & $\$ 0.29$ & $\$ 0.09$ & $\$ 0.00$ & $\$ 0.38$ \\
\hline 4,536 & 1 & $\$ 10,909,091$ & $\$ 3,360,000$ & $\$ 147,000$ & $\$ 14,416,091$ & $\$ 0.29$ & $\$ 0.09$ & $\$ 0.00$ & $\$ 0.38$ \\
\hline 45,359 & 1 & $\$ 109,090,909$ & $\$ 33,600,000$ & $\$ 1,470,000$ & $\$ 144,160,909$ & $\$ 0.29$ & $\$ 0.09$ & $\$ 0.00$ & $\$ 0.38$ \\
\hline 5 & 2 & $\$ 21,818$ & $\$ 3,360$ & $\$ 147$ & $\$ 25,325$ & $\$ 0.57$ & $\$ 0.09$ & $\$ 0.00$ & $\$ 0.66$ \\
\hline 45 & 2 & $\$ 218,182$ & $\$ 33,600$ & $\$ 1,470$ & $\$ 253,252$ & $\$ 0.57$ & $\$ 0.09$ & $\$ 0.00$ & $\$ 0.66$ \\
\hline 454 & 2 & $\$ 2,181,818$ & $\$ 336,000$ & $\$ 14,700$ & $\$ 2,532,518$ & $\$ 0.57$ & $\$ 0.09$ & $\$ 0.00$ & $\$ 0.66$ \\
\hline 4,536 & 2 & $\$ 21,818,182$ & $\$ 3,360,000$ & $\$ 147,000$ & $\$ 25,325,182$ & $\$ 0.57$ & $\$ 0.09$ & $\$ 0.00$ & $\$ 0.66$ \\
\hline 45,359 & 2 & $\$ 218,181,818$ & $\$ 33,600,000$ & $\$ 1,470,000$ & $\$ 253,251,818$ & $\$ 0.57$ & $\$ 0.09$ & $\$ 0.00$ & $\$ 0.66$ \\
\hline 5 & 4 & $\$ 43,636$ & $\$ 3,360$ & $\$ 147$ & $\$ 47,143$ & $\$ 1.15$ & $\$ 0.09$ & $\$ 0.00$ & $\$ 1.24$ \\
\hline 45 & 4 & $\$ 436,364$ & $\$ 33,600$ & $\$ 1,470$ & $\$ 471,434$ & $\$ 1.15$ & $\$ 0.09$ & $\$ 0.00$ & $\$ 1.24$ \\
\hline 454 & 4 & $\$ 4,363,636$ & $\$ 336,000$ & $\$ 14,700$ & $\$ 4,714,336$ & $\$ 1.15$ & $\$ 0.09$ & $\$ 0.00$ & $\$ 1.24$ \\
\hline 4,536 & 4 & $\$ 43,636,364$ & $\$ 3,360,000$ & $\$ 147,000$ & $\$ 47,143,364$ & $\$ 1.15$ & $\$ 0.09$ & $\$ 0.00$ & $\$ 1.24$ \\
\hline 45,359 & 4 & $\$ 436,363,636$ & $\$ 33,600,000$ & $\$ 1,470,000$ & $\$ 471,433,636$ & $\$ 1.15$ & $\$ 0.09$ & $\$ 0.00$ & $\$ 1.24$ \\
\hline 5 & 7 & $\$ 76,364$ & $\$ 3,360$ & $\$ 147$ & $\$ 79,871$ & $\$ 2.00$ & $\$ 0.09$ & $\$ 0.00$ & $\$ 2.10$ \\
\hline 45 & 7 & $\$ 763,636$ & $\$ 33,600$ & $\$ 1,470$ & $\$ 798,706$ & $\$ 2.00$ & $\$ 0.09$ & $\$ 0.00$ & $\$ 2.10$ \\
\hline 454 & 7 & $\$ 7,636,364$ & $\$ 336,000$ & $\$ 14,700$ & $\$ 7,987,064$ & $\$ 2.00$ & $\$ 0.09$ & $\$ 0.00$ & $\$ 2.10$ \\
\hline 4,536 & 7 & $\$ 76,363,636$ & $\$ 3,360,000$ & $\$ 147,000$ & $\$ 79,870,636$ & $\$ 2.00$ & $\$ 0.09$ & $\$ 0.00$ & $\$ 2.10$ \\
\hline 45,359 & 7 & $\$ 763,636,364$ & $\$ 33,600,000$ & $\$ 1,470,000$ & $\$ 798,706,364$ & $\$ 2.00$ & $\$ 0.09$ & $\$ 0.00$ & $\$ 2.10$ \\
\hline 5 & 14 & $\$ 152,727$ & $\$ 3,360$ & $\$ 147$ & $\$ 156,234$ & $\$ 4.01$ & $\$ 0.09$ & $\$ 0.00$ & $\$ 4.10$ \\
\hline 45 & 14 & $\$ 1,527,273$ & $\$ 33,600$ & $\$ 1,470$ & $\$ 1,562,343$ & $\$ 4.01$ & $\$ 0.09$ & $\$ 0.00$ & $\$ 4.10$ \\
\hline 454 & 14 & $\$ 15,272,727$ & $\$ 336,000$ & $\$ 14,700$ & $\$ 15,623,427$ & $\$ 4.01$ & $\$ 0.09$ & $\$ 0.00$ & $\$ 4.10$ \\
\hline 4,536 & 14 & $\$ 152,727,273$ & $\$ 3,360,000$ & $\$ 147,000$ & $\$ 156,234,273$ & $\$ 4.01$ & $\$ 0.09$ & $\$ 0.00$ & $\$ 4.10$ \\
\hline 45,359 & 14 & $\$ 1,527,272,727$ & $\$ 33,600,000$ & $\$ 1,470,000$ & $\$ 1,562,342,727$ & $\$ 4.01$ & $\$ 0.09$ & $\$ 0.00$ & $\$ 4.10$ \\
\hline 5 & 30 & $\$ 327,273$ & $\$ 3,360$ & $\$ 147$ & $\$ 330,780$ & $\$ 8.59$ & $\$ 0.09$ & $\$ 0.00$ & $\$ 8.68$ \\
\hline 45 & 30 & $\$ 3,272,727$ & $\$ 33,600$ & $\$ 1,470$ & $\$ 3,307,797$ & $\$ 8.59$ & $\$ 0.09$ & $\$ 0.00$ & $\$ 8.68$ \\
\hline 454 & 30 & $\$ 32,727,273$ & $\$ 336,000$ & $\$ 14,700$ & $\$ 33,077,973$ & $\$ 8.59$ & $\$ 0.09$ & $\$ 0.00$ & $\$ 8.68$ \\
\hline 4,536 & 30 & $\$ 327,272,727$ & $\$ 3,360,000$ & $\$ 147,000$ & $\$ 330,779,727$ & $\$ 8.59$ & $\$ 0.09$ & $\$ 0.00$ & $\$ 8.68$ \\
\hline 45,359 & 30 & $\$ 3,272,727,273$ & $\$ 33,600,000$ & $\$ 1,470,000$ & $\$ 3,307,797,273$ & $\$ 8.59$ & $\$ 0.09$ & $\$ 0.00$ & $\$ 8.68$ \\
\hline
\end{tabular}




\begin{tabular}{|c|c|c|c|c|c|c|c|}
\hline \multicolumn{8}{|c|}{ D.3 METAL HYDRIDE STORAGE - English Units } \\
\hline & & & & & & & \\
\hline \multicolumn{2}{|c|}{ Hydride Capital Cost $=$} & $\$ 1,000$ & per lb & & & & \\
\hline \multicolumn{2}{|c|}{ Hydride Scale-Up $=$} & 1.00 & & & & & \\
\hline \multicolumn{2}{|c|}{ Hydride Cooling $=$} & 25 & gal/lb & & & & \\
\hline \multicolumn{2}{|l|}{ Hydride Heating= } & 10,000 & Btu/lb & & & & \\
\hline Steam Cost $=$ & & $\$ 4.00$ & per MM Btu & & & & \\
\hline Cooling Cost $=$ & & $\$ 0.07$ & per M gal & & & & \\
\hline \multicolumn{2}{|c|}{ Operating Days/Year $=$} & 350 & days/yr & & & & \\
\hline \multicolumn{2}{|l|}{ Depreciation= } & 22 & years & & & & \\
\hline & & & & & & & \\
\hline Production & Days of & Storage & Annual & Heat & Cooling & Hydride & Total Capital \\
\hline Rate & Storage & Capacity & Production & Requirement & Requirement & Cost & Cost \\
\hline$(\mathrm{lb} / \mathrm{hr})$ & (days) & (Ib) & $(\mathrm{lb} / \mathrm{yr})$ & (Btu/hr) & (gal/hr) & $(\$)$ & $(\$)$ \\
\hline 10 & 1 & 240 & 84,000 & 100,000 & 250 & $\$ 240,000$ & $\$ 240,000$ \\
\hline 100 & 1 & 2,400 & 840,000 & $1,000,000$ & 2,500 & $\$ 2,400,000$ & $\$ 2,400,000$ \\
\hline \begin{tabular}{l|l}
1,000 \\
\end{tabular} & 1 & 24,000 & $8,400,000$ & $10,000,000$ & 25,000 & $\$ 24,000,000$ & $\$ 24,000,000$ \\
\hline 10,000 & 1 & 240,000 & $84,000,000$ & $100,000,000$ & 250,000 & $\$ 240,000,000$ & $\$ 240,000,000$ \\
\hline 100,000 & 1 & $2,400,000$ & $840,000,000$ & $1,000,000,000$ & $2,500,000$ & $\$ 2,400,000,000$ & $\$ 2,400,000,000$ \\
\hline 10 & 2 & 480 & 84,000 & 100,000 & 250 & $\$ 480,000$ & $\$ 480,000$ \\
\hline 100 & 2 & 4,800 & 840,000 & $1,000,000$ & 2,500 & $\$ 4,800,000$ & $\$ 4,800,000$ \\
\hline 1,000 & 2 & 48,000 & $8,400,000$ & $10,000,000$ & 25,000 & $\$ 48,000,000$ & $\$ 48,000,000$ \\
\hline 10,000 & 2 & 480,000 & $84,000,000$ & $100,000,000$ & 250,000 & $\$ 480,000,000$ & $\$ 480,000,000$ \\
\hline 100,000 & 2 & $4,800,000$ & $840,000,000$ & $1,000,000,000$ & $2,500,000$ & $\$ 4,800,000,000$ & $\$ 4,800,000,000$ \\
\hline 10 & 4 & 960 & 84,000 & 100,000 & 250 & $\$ 960,000$ & $\$ 960,000$ \\
\hline 100 & 4 & 9,600 & 840,000 & $1,000,000$ & 2,500 & $\$ 9,600,000$ & $\$ 9,600,000$ \\
\hline 1,000 & 4 & 96,000 & $8,400,000$ & $10,000,000$ & 25,000 & $\$ 96,000,000$ & $\$ 96,000,000$ \\
\hline 10,000 & 4 & 960,000 & $84,000,000$ & $100,000,000$ & 250,000 & $\$ 960,000,000$ & $\$ 960,000,000$ \\
\hline 100,000 & 4 & $9,600,000$ & $840,000,000$ & $1,000,000,000$ & $2,500,000$ & $\$ 9,600,000,000$ & $\$ 9,600,000,000$ \\
\hline 10 & 7 & 1,680 & 84,000 & 100,000 & 250 & $\$ 1,680,000$ & $\$ 1,680,000$ \\
\hline 100 & 7 & 16,800 & 840,000 & $1,000,000$ & 2,500 & $\$ 16,800,000$ & $\$ 16,800,000$ \\
\hline 1,000 & 7 & 168,000 & $8,400,000$ & $10,000,000$ & 25,000 & $\$ 168,000,000$ & $\$ 168,000,000$ \\
\hline 10,000 & 7 & $1,680,000$ & $84,000,000$ & $100,000,000$ & 250,000 & $\$ 1,680,000,000$ & $\$ 1,680,000,000$ \\
\hline 100,000 & 7 & $16,800,000$ & $840,000,000$ & $1,000,000,000$ & $2,500,000$ & $\$ 16,800,000,000$ & $\$ 16,800,000,000$ \\
\hline 10 & 14 & 3,360 & 84,000 & 100,000 & 250 & $\$ 3,360,000$ & $\$ 3,360,000$ \\
\hline 100 & 14 & 33,600 & 840,000 & $1,000,000$ & 2,500 & $\$ 33,600,000$ & $\$ 33,600,000$ \\
\hline \begin{tabular}{l|l}
1,000 \\
\end{tabular} & 14 & 336,000 & $8,400,000$ & $10,000,000$ & 25,000 & $\$ 336,000,000$ & $\$ 336,000,000$ \\
\hline 10,000 & 14 & $3,360,000$ & $84,000,000$ & $100,000,000$ & 250,000 & $\$ 3,360,000,000$ & $\$ 3,360,000,000$ \\
\hline 100,000 & 14 & $33,600,000$ & $840,000,000$ & $1,000,000,000$ & $2,500,000$ & $\$ 33,600,000,000$ & $\$ 33,600,000,000$ \\
\hline 10 & 30 & 7,200 & 84,000 & 100,000 & 250 & $\$ 7,200,000$ & $\$ 7,200,000$ \\
\hline 100 & 30 & 72,000 & 840,000 & $1,000,000$ & 2,500 & $\$ 72,000,000$ & $\$ 72,000,000$ \\
\hline 1,000 & 30 & 720,000 & $8,400,000$ & $10,000,000$ & 25,000 & $\$ 720,000,000$ & $\$ 720,000,000$ \\
\hline 10,000 & 30 & $7,200,000$ & $84,000,000$ & $100,000,000$ & 250,000 & $\$ 7,200,000,000$ & $\$ 7,200,000,000$ \\
\hline 100,000 & 30 & $72,000,000$ & $840,000,000$ & $1,000,000,000$ & $2,500,000$ & $\$ 72,000,000,000$ & $\$ 72,000,000,000$ \\
\hline
\end{tabular}

D -13 


\begin{tabular}{|c|c|c|c|c|c|c|c|c|c|}
\hline \multicolumn{10}{|c|}{ D.3 METAL HYDRIDE STORAGE - English Units (Continued) } \\
\hline & & & & & & & & & \\
\hline Production & Days of & Depreciation & Annual Electric & Annual Cooling & Total Annual & Capital & Energy & Cooling & Total \\
\hline Rate & Storage & & Cost & Water Cost & Cost & Cost & Cost & Cost & Cost \\
\hline$(\mathrm{lb} / \mathrm{hr})$ & (days) & $(\$ / y r)$ & $(\$ / y r)$ & $(\$ / y r)$ & $(\$ / y r)$ & $(\$ / \mathrm{lb})$ & $(\$ / l b)$ & $(\$ / \mathrm{lb})$ & $(\$ / \mathrm{lb})$ \\
\hline 10 & 1 & $\$ 10,909$ & $\$ 3,360$ & $\$ 147$ & $\$ 14,416$ & $\$ 0.13$ & $\$ 0.04$ & $\$ 0.00$ & $\$ 0.17$ \\
\hline 100 & 1 & $\$ 109,091$ & $\$ 33,600$ & $\$ 1,470$ & $\$ 144,161$ & $\$ 0.13$ & $\$ 0.04$ & $\$ 0.00$ & $\$ 0.17$ \\
\hline 1,000 & 1 & $\$ 1,090,909$ & $\$ 336,000$ & $\$ 14,700$ & $\$ 1,441,609$ & $\$ 0.13$ & $\$ 0.04$ & $\$ 0.00$ & $\$ 0.17$ \\
\hline 10,000 & 1 & $\$ 10,909,091$ & $\$ 3,360,000$ & $\$ 147,000$ & $\$ 14,416,091$ & $\$ 0.13$ & $\$ 0.04$ & $\$ 0.00$ & $\$ 0.17$ \\
\hline 100,000 & 1 & $\$ 109,090,909$ & $\$ 33,600,000$ & $\$ 1,470,000$ & $\$ 144,160,909$ & $\$ 0.13$ & $\$ 0.04$ & $\$ 0.00$ & $\$ 0.17$ \\
\hline 10 & 2 & $\$ 21,818$ & $\$ 3,360$ & $\$ 147$ & $\$ 25,325$ & $\$ 0.26$ & $\$ 0.04$ & $\$ 0.00$ & $\$ 0.30$ \\
\hline 100 & 2 & $\$ 218,182$ & $\$ 33,600$ & $\$ 1,470$ & $\$ 253,252$ & $\$ 0.26$ & $\$ 0.04$ & $\$ 0.00$ & $\$ 0.30$ \\
\hline 1,000 & 2 & $\$ 2,181,818$ & $\$ 336,000$ & $\$ 14,700$ & $\$ 2,532,518$ & $\$ 0.26$ & $\$ 0.04$ & $\$ 0.00$ & $\$ 0.30$ \\
\hline 10,000 & 2 & $\$ 21,818,182$ & $\$ 3,360,000$ & $\$ 147,000$ & $\$ 25,325,182$ & $\$ 0.26$ & $\$ 0.04$ & $\$ 0.00$ & $\$ 0.30$ \\
\hline 100,000 & 2 & $\$ 218,181,818$ & $\$ 33,600,000$ & $\$ 1,470,000$ & $\$ 253,251,818$ & $\$ 0.26$ & $\$ 0.04$ & $\$ 0.00$ & $\$ 0.30$ \\
\hline 10 & 4 & $\$ 43,636$ & $\$ 3,360$ & $\$ 147$ & $\$ 47,143$ & $\$ 0.52$ & $\$ 0.04$ & $\$ 0.00$ & $\$ 0.56$ \\
\hline 100 & 4 & $\$ 436,364$ & $\$ 33,600$ & $\$ 1,470$ & $\$ 471,434$ & $\$ 0.52$ & $\$ 0.04$ & $\$ 0.00$ & $\$ 0.56$ \\
\hline 1,000 & 4 & $\$ 4,363,636$ & $\$ 336,000$ & $\$ 14,700$ & $\$ 4,714,336$ & $\$ 0.52$ & $\$ 0.04$ & $\$ 0.00$ & $\$ 0.56$ \\
\hline 10,000 & 4 & $\$ 43,636,364$ & $\$ 3,360,000$ & $\$ 147,000$ & $\$ 47,143,364$ & $\$ 0.52$ & $\$ 0.04$ & $\$ 0.00$ & $\$ 0.56$ \\
\hline 100,000 & 4 & $\$ 436,363,636$ & $\$ 33,600,000$ & $\$ 1,470,000$ & $\$ 471,433,636$ & $\$ 0.52$ & $\$ 0.04$ & $\$ 0.00$ & $\$ 0.56$ \\
\hline 10 & 7 & $\$ 76,364$ & $\$ 3,360$ & $\$ 147$ & $\$ 79,871$ & $\$ 0.91$ & $\$ 0.04$ & $\$ 0.00$ & $\$ 0.95$ \\
\hline 100 & 7 & $\$ 763,636$ & $\$ 33,600$ & $\$ 1,470$ & $\$ 798,706$ & $\$ 0.91$ & $\$ 0.04$ & $\$ 0.00$ & $\$ 0.95$ \\
\hline 1,000 & 7 & $\$ 7,636,364$ & $\$ 336,000$ & $\$ 14,700$ & $\$ 7,987,064$ & $\$ 0.91$ & $\$ 0.04$ & $\$ 0.00$ & $\$ 0.95$ \\
\hline 10,000 & 7 & $\$ 76,363,636$ & $\$ 3,360,000$ & $\$ 147,000$ & $\$ 79,870,636$ & $\$ 0.91$ & $\$ 0.04$ & $\$ 0.00$ & $\$ 0.95$ \\
\hline 100,000 & 7 & $\$ 763,636,364$ & $\$ 33,600,000$ & $\$ 1,470,000$ & $\$ 798,706,364$ & $\$ 0.91$ & $\$ 0.04$ & $\$ 0.00$ & $\$ 0.95$ \\
\hline 10 & 14 & $\$ 152,727$ & $\$ 3,360$ & $\$ 147$ & $\$ 156,234$ & $\$ 1.82$ & $\$ 0.04$ & $\$ 0.00$ & $\$ 1.86$ \\
\hline 100 & 14 & $\$ 1,527,273$ & $\$ 33,600$ & $\$ 1,470$ & $\$ 1,562,343$ & $\$ 1.82$ & $\$ 0.04$ & $\$ 0.00$ & $\$ 1.86$ \\
\hline 1,000 & 14 & $\$ 15,272,727$ & $\$ 336,000$ & $\$ 14,700$ & $\$ 15,623,427$ & $\$ 1.82$ & $\$ 0.04$ & $\$ 0.00$ & $\$ 1.86$ \\
\hline 10,000 & 14 & $\$ 152,727,273$ & $\$ 3,360,000$ & $\$ 147,000$ & $\$ 156,234,273$ & $\$ 1.82$ & $\$ 0.04$ & $\$ 0.00$ & $\$ 1.86$ \\
\hline 100,000 & 14 & $\$ 1,527,272,727$ & $\$ 33,600,000$ & $\$ 1,470,000$ & $\$ 1,562,342,727$ & $\$ 1.82$ & $\$ 0.04$ & $\$ 0.00$ & $\$ 1.86$ \\
\hline 10 & 30 & $\$ 327,273$ & $\$ 3,360$ & $\$ 147$ & $\$ 330,780$ & $\$ 3.90$ & $\$ 0.04$ & $\$ 0.00$ & $\$ 3.94$ \\
\hline 100 & 30 & $\$ 3,272,727$ & $\$ 33,600$ & $\$ 1,470$ & $\$ 3,307,797$ & $\$ 3.90$ & $\$ 0.04$ & $\$ 0.00$ & $\$ 3.94$ \\
\hline 1,000 & 30 & $\$ 32,727,273$ & $\$ 336,000$ & $\$ 14,700$ & $\$ 33,077,973$ & $\$ 3.90$ & $\$ 0.04$ & $\$ 0.00$ & $\$ 3.94$ \\
\hline 10,000 & 30 & $\$ 327,272,727$ & $\$ 3,360,000$ & $\$ 147,000$ & $\$ 330,779,727$ & $\$ 3.90$ & $\$ 0.04$ & $\$ 0.00$ & $\$ 3.94$ \\
\hline 100,000 & 30 & $\$ 3,272,727,273$ & $\$ 33,600,000$ & $\$ 1,470,000$ & $\$ 3,307,797,273$ & $\$ 3.90$ & $\$ 0.04$ & $\$ 0.00$ & $\$ 3.94$ \\
\hline
\end{tabular}




\begin{tabular}{|c|c|c|c|c|c|c|c|c|c|c|}
\hline \multicolumn{11}{|c|}{ D4. UNDERGROUND STORAGE - SI Units } \\
\hline & & & & & & & & & & \\
\hline \multicolumn{2}{|c|}{ Compressor Capital Cost $=$} & $\$ 1,000$ & per kW & & & & & & & \\
\hline \multicolumn{2}{|c|}{ Underground Capital Cost= } & $\$ 9$ & per kg & & & & & & & \\
\hline \multicolumn{2}{|c|}{ Compressor Size $=$} & 4,000 & $\mathrm{~kW}$ & & & & & & & \\
\hline \multicolumn{2}{|c|}{ Compressor Pressure $=$} & 20 & $\mathrm{MPa}$ & & & & & & & \\
\hline \multicolumn{2}{|c|}{ Comp. Pressure Scale-Up= } & 0.18 & & & & & & & & \\
\hline \multicolumn{2}{|c|}{ Comp. Cost Scale-Up $=$} & 0.80 & & & & & & & & \\
\hline \multicolumn{2}{|c|}{ Underground Scale- $U p=$} & 1.00 & & & & & & & & \\
\hline \multicolumn{2}{|c|}{ Compressor Power= } & 2.20 & \multicolumn{2}{|l|}{$\mathrm{kWh} / \mathrm{kg}(20 \mathrm{MPa})$} & & & & & & \\
\hline \multicolumn{2}{|c|}{ Compressor Cooling= } & 50 & liters $/ \mathrm{kg} \mathrm{(20} \mathrm{MPa}$ & & & & & & & \\
\hline Electric Cost $=$ & & $\$ 0.05$ & per kWh & & & & & & & \\
\hline Cooling Cost $=$ & & $\$ 0.02$ & per M liters & & & & & & & \\
\hline \multicolumn{2}{|c|}{ Operating Days/Year $=$} & 350 & days/yr & & & & & & & \\
\hline \multirow[t]{2}{*}{ Depreciation $=$} & & 22 & years & & & & & & & \\
\hline & & & & & & & & & & \\
\hline Production & Days of & Operating & Storage & Annual & Comp. & Cooling & Compressor & Compressor & Cavern & Total Capital \\
\hline Rate & Storage & Pressure & Capacity & Production & Power & Requirement & Size & Cost & Cost & Cost \\
\hline$(\mathrm{kg} / \mathrm{hr})$ & (days) & $(\mathrm{MPa})$ & $(\mathrm{kg})$ & $(\mathrm{kg} / \mathrm{yr})$ & $(\mathrm{kWh} / \mathrm{hr})$ & (liters/hr) & $(\mathrm{kW})$ & $(\$)$ & $(\$)$ & $(\$)$ \\
\hline 5 & 1 & 20 & 109 & 38,102 & 10 & 227 & 10 & $\$ 33,145$ & $\$ 960$ & $\$ 34,105$ \\
\hline 45 & 1 & 20 & 1,089 & 381,016 & 100 & 2,271 & 100 & $\$ 209,128$ & $\$ 9,600$ & $\$ 218,728$ \\
\hline 454 & 1 & 20 & 10,886 & $3,810,156$ & 1,000 & 22,712 & 1,000 & $\$ 1,319,508$ & $\$ 96,000$ & $\$ 1,415,508$ \\
\hline 4,536 & 1 & 20 & 108,862 & $38,101,560$ & 10,000 & 227,124 & 10,000 & $\$ 8,325,532$ & $\$ 960,000$ & $\$ 9,285,532$ \\
\hline 45,359 & 1 & 20 & $1,088,616$ & $381,015,600$ & 100,000 & $2,271,240$ & 100,000 & $\$ 52,530,556$ & $\$ 9,600,000$ & $\$ 62,130,556$ \\
\hline 5 & 2 & 20 & 218 & 38,102 & 10 & 227 & 10 & $\$ 33,145$ & $\$ 1,920$ & $\$ 35,065$ \\
\hline 45 & 2 & 20 & 2,177 & 381,016 & 100 & 2,271 & 100 & $\$ 209,128$ & $\$ 19,200$ & $\$ 228,328$ \\
\hline 454 & 2 & 20 & 21,772 & $3,810,156$ & 1,000 & 22,712 & 1,000 & $\$ 1,319,508$ & $\$ 192,000$ & $\$ 1,511,508$ \\
\hline 4,536 & 2 & 20 & 217,723 & $38,101,560$ & 10,000 & 227,124 & 10,000 & $\$ 8,325,532$ & $\$ 1,920,000$ & $\$ 10,245,532$ \\
\hline 45,359 & 2 & 20 & $2,177,232$ & $381,015,600$ & 100,000 & $2,271,240$ & 100,000 & $\$ 52,530,556$ & $\$ 19,200,000$ & $\$ 71,730,556$ \\
\hline 5 & 4 & 20 & 435 & 38,102 & 10 & 227 & 10 & $\$ 33,145$ & $\$ 3,840$ & $\$ 36,985$ \\
\hline 45 & 4 & 20 & 4,354 & 381,016 & 100 & 2,271 & 100 & $\$ 209,128$ & $\$ 38,400$ & $\$ 247,528$ \\
\hline 454 & 4 & 20 & 43,545 & $3,810,156$ & 1,000 & 22,712 & 1,000 & $\$ 1,319,508$ & $\$ 384,000$ & $\$ 1,703,508$ \\
\hline 4,536 & 4 & 20 & 435,446 & $38,101,560$ & 10,000 & 227,124 & 10,000 & $\$ 8,325,532$ & $\$ 3,840,000$ & $\$ 12,165,532$ \\
\hline 45,359 & 4 & 20 & $4,354,464$ & $381,015,600$ & 100,000 & $2,271,240$ & 100,000 & $\$ 52,530,556$ & $\$ 38,400,000$ & $\$ 90,930,556$ \\
\hline 5 & 7 & 20 & 762 & 38,102 & 10 & 227 & 10 & $\$ 33,145$ & $\$ 6,720$ & $\$ 39,865$ \\
\hline 45 & 7 & 20 & 7,620 & 381,016 & 100 & 2,271 & 100 & $\$ 209,128$ & $\$ 67,200$ & $\$ 276,328$ \\
\hline 454 & 7 & 20 & 76,203 & $3,810,156$ & 1,000 & 22,712 & 1,000 & $\$ 1,319,508$ & $\$ 672,000$ & $\$ 1,991,508$ \\
\hline 4,536 & 7 & 20 & 762,031 & $38,101,560$ & 10,000 & 227,124 & 10,000 & $\$ 8,325,532$ & $\$ 6,720,000$ & $\$ 15,045,532$ \\
\hline 45,359 & 7 & 20 & $7,620,312$ & $381,015,600$ & 100,000 & $2,271,240$ & 100,000 & $\$ 52,530,556$ & $\$ 67,200,000$ & $\$ 119,730,556$ \\
\hline 5 & 14 & 20 & 1,524 & 38,102 & 10 & 227 & 10 & $\$ 33,145$ & $\$ 13,440$ & $\$ 46,585$ \\
\hline 45 & 14 & 20 & 15,241 & 381,016 & 100 & 2,271 & 100 & $\$ 209,128$ & $\$ 134,400$ & $\$ 343,528$ \\
\hline 454 & 14 & 20 & 152,406 & $3,810,156$ & 1,000 & 22,712 & 1,000 & $\$ 1,319,508$ & $\$ 1,344,000$ & $\$ 2,663,508$ \\
\hline 4,536 & 14 & 20 & $1,524,062$ & $38,101,560$ & 10,000 & 227,124 & 10,000 & $\$ 8,325,532$ & $\$ 13,440,000$ & $\$ 21,765,532$ \\
\hline 45,359 & 14 & 20 & $15,240,624$ & $381,015,600$ & 100,000 & $2,271,240$ & 100,000 & $\$ 52,530,556$ & $\$ 134,400,000$ & $\$ 186,930,556$ \\
\hline 5 & 30 & 20 & 3,266 & 38,102 & 10 & 227 & 10 & $\$ 33,145$ & $\$ 28,800$ & $\$ 61,945$ \\
\hline 45 & 30 & 20 & 32,658 & 381,016 & 100 & 2,271 & 100 & $\$ 209,128$ & $\$ 288,000$ & $\$ 497,128$ \\
\hline 454 & 30 & 20 & 326,585 & $3,810,156$ & 1,000 & 22,712 & 1,000 & $\$ 1,319,508$ & $\$ 2,880,000$ & $\$ 4,199,508$ \\
\hline \begin{tabular}{l|}
4,536 \\
\end{tabular} & 30 & 20 & $3,265,848$ & $38,101,560$ & 10,000 & 227,124 & 10,000 & $\$ 8,325,532$ & $\$ 28,800,000$ & $\$ 37,125,532$ \\
\hline 45,359 & 30 & 20 & $32,658,480$ & $381,015,600$ & 100,000 & $2,271,240$ & 100,000 & $\$ 52,530,556$ & $\$ 288,000,000$ & $\$ 340,530,556$ \\
\hline
\end{tabular}

D -15 


\begin{tabular}{|c|c|c|c|c|c|c|c|c|c|c|c|c|c|c|}
\hline \multicolumn{15}{|c|}{ D4. UNDERGROUND STORAGE - SI Units (Continued) } \\
\hline Production & Days of & Depreciation & Annual Electric & Annual Cooling & Total Annual & Capital & Electricity & Cooling & Total & & Comp. & Cavern & Comp. & Cavern \\
\hline Rate & Storage & & & Water Costs & Cost & Cost & & Cost & Cost & & Cost & Cost/lb & Capital & Capital \\
\hline$(\mathrm{kg} / \mathrm{hr})$ & (days) & $(\$ / y r)$ & $(\$ / y r)$ & $(\$ / y r)$ & $(\$ / y r)$ & $(\$ / \mathrm{kg})$ & $(\$ / \mathrm{kg})$ & $(\$ / \mathrm{kg})$ & $(\$ / \mathrm{kg})$ & & $(\$ / \mathrm{kg})$ & $(\$ / \mathrm{kg})$ & $(\$ / k W)$ & $(\$ / \mathrm{kg})$ \\
\hline & 1 & $\$ 1,550$ & $\$ 4,200$ & $\$ 35$ & $\$ 5,785$ & $\$ 0.04$ & $\$ 0.11$ & $\$ 0.00$ & $\$ 0.15$ & & $\$ 0.04$ & $\$ 0.00$ & $\$ 3,314$ & $\$ 8.82$ \\
\hline 45 & & $\$ 9.942$ & $\$ 42.000$ & $\$ 353$ & $\$ 52.295$ & $\$ 0.03$ & $\$ 0.11$ & $\$ 0.00$ & $\$ 0.14$ & & $\$ 0.02$ & $\$ 0.00$ & $\$ 2.091$ & $\$ 8.82$ \\
\hline 454 & & $\$ 64.341$ & $\$ 420.000$ & $\$ 3.528$ & $\$ 487.869$ & $\$ 0.02$ & $\$ 0.11$ & $\$ 0.00$ & $\$ 0.13$ & & $\$ 0.02$ & $\$ 0.00$ & $\$ 1,320$ & $\$ 8.82$ \\
\hline 4,536 & & $\$ 422,070$ & $\$ 4,200,000$ & $\$ 35,280$ & $\$ 4,657,350$ & $\$ 0.01$ & $\$ 0.11$ & $\$ 0.00$ & $\$ 0.12$ & & $\$ 0.01$ & $\$ 0.00$ & $\$ 833$ & $\$ 8.82$ \\
\hline 45,359 & 1 & $\$ 2,824,116$ & $\$ 42,000,000$ & $\$ 352,800$ & $\$ 45,176,916$ & $\$ 0.01$ & $\$ 0.11$ & $\$ 0.00$ & $\$ 0.12$ & & $\$ 0.01$ & $\$ 0.00$ & $\$ 525$ & $\$ 8.82$ \\
\hline & 2 & $\$ 1,594$ & $\$ 4,200$ & $\$ 35$ & $\$ 5,829$ & $\$ 0.04$ & $\$ 0.11$ & $\$ 0.00$ & $\$ 0.15$ & & $\$ 0.04$ & $\$ 0.00$ & $\$ 3,314$ & $\$ 8.82$ \\
\hline 45 & & $\$ 10,379$ & $\$ 42,000$ & $\$ 353$ & $\$ 52,731$ & $\$ 0.03$ & $\$ 0.11$ & $\$ 0.00$ & $\$ 0.14$ & & $\$ 0.02$ & $\$ 0.00$ & $\$ 2,091$ & $\$ 8.82$ \\
\hline 454 & & $\$ 68,705$ & $\$ 420,000$ & $\$ 3,528$ & $\$ 492,233$ & $\$ 0.02$ & $\$ 0.11$ & $\$ 0.00$ & $\$ 0.13$ & & $\$ 0.02$ & $\$ 0.00$ & $\$ 1,320$ & $\$ 8.82$ \\
\hline 4.536 & & $\$ 465,706$ & $\$ 4.200 .000$ & $\$ 35.280$ & $\$ 4,700,986$ & $\$ 0.01$ & $\$ 0.11$ & $\$ 0.00$ & $\$ 0.12$ & & $\$ 0.01$ & $\$ 0.00$ & $\$ 833$ & $\$ 8.82$ \\
\hline 45,359 & 2 & $\$ 3,260,480$ & $\$ 42,000,000$ & $\$ 352,800$ & $\$ 45,613,280$ & $\$ 0.01$ & $\$ 0.11$ & $\$ 0.00$ & $\$ 0.12$ & & $\$ 0.01$ & $\$ 0.00$ & $\$ 525$ & $\$ 8.82$ \\
\hline 3 & 4 & $\$ 1,681$ & $\$ 4.200$ & $\$ 35$ & $\$ 5,916$ & $\$ 0.04$ & $\$ 0.11$ & $\$ 0.00$ & $\$ 0.16$ & & $\$ 0.04$ & $\$ 0.00$ & $\$ 3,314$ & $\$ 8.82$ \\
\hline 45 & 4 & $\$ 11,251$ & $\$ 42,000$ & $\$ 353$ & $\$ 53,604$ & $\$ 0.03$ & $\$ 0.11$ & $\$ 0.00$ & $\$ 0.14$ & & $\$ 0.02$ & $\$ 0.00$ & $\$ 2,091$ & $\$ 8.82$ \\
\hline 454 & 4 & $\$ 77,432$ & $\$ 420,000$ & $\$ 3,528$ & $\$ 500,960$ & $\$ 0.02$ & $\$ 0.11$ & $\$ 0.00$ & $\$ 0.13$ & & $\$ 0.02$ & $\$ 0.00$ & $\$ 1,320$ & $\$ 8.82$ \\
\hline 4,536 & 4 & $\$ 552,979$ & $\$ 4,200,000$ & $\$ 35,280$ & $\$ 4,788,259$ & $\$ 0.01$ & $\$ 0.11$ & $\$ 0.00$ & $\$ 0.13$ & & $\$ 0.01$ & $\$ 0.00$ & $\$ 833$ & $\$ 8.82$ \\
\hline 45,359 & 4 & $\$ 4,133,207$ & $\$ 42,000,000$ & $\$ 352,800$ & $\$ 46,486,000$ & $\$ 0.01$ & $\$ 0.11$ & $\$ 0.00$ & $\$ 0.12$ & & $\$ 0.01$ & $\$ 0.00$ & $\$ 525$ & $\$ 8.82$ \\
\hline 5 & 7 & $\$ 1,812$ & $\$ 4,200$ & $\$ 35$ & $\$ 6,047$ & $\$ 0.05$ & $\$ 0.11$ & $\$ 0.00$ & $\$ 0.16$ & & $\$ 0.04$ & $\$ 0.01$ & $\$ 3,314$ & $\$ 8.82$ \\
\hline 45 & & $\$ 12,560$ & $\$ 42,000$ & $\$ 353$ & $\$ 54,913$ & $\$ 0.03$ & $\$ 0.11$ & $\$ 0.00$ & $\$ 0.14$ & & $\$ 0.02$ & $\$ 0.01$ & $\$ 2,091$ & $\$ 8.82$ \\
\hline 454 & & $\$ 90,523$ & $\$ 420,000$ & $\$ 3,528$ & $\$ 514,051$ & $\$ 0.02$ & $\$ 0.11$ & $\$ 0.00$ & $\$ 0.13$ & & $\$ 0.02$ & $\$ 0.01$ & $\$ 1,320$ & $\$ 8.82$ \\
\hline 4,536 & & $\$ 683,888$ & $\$ 4,200,000$ & $\$ 35,280$ & $\$ 4,919,168$ & $\$ 0.02$ & $\$ 0.11$ & $\$ 0.00$ & $\$ 0.13$ & & $\$ 0.01$ & $\$ 0.01$ & $\$ 833$ & $\$ 8.82$ \\
\hline 45,359 & 7 & $\$ 5,442,298$ & $\$ 42,000,000$ & $\$ 352,800$ & $\$ 47,795,098$ & $\$ 0.01$ & $\$ 0.11$ & $\$ 0.00$ & $\$ 0.13$ & & $\$ 0.01$ & $\$ 0.01$ & $\$ 525$ & $\$ 8.82$ \\
\hline 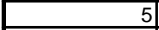 & 14 & $\$ 2,117$ & $\$ 4,200$ & $\$ 35$ & $\$ 6,353$ & $\$ 0.06$ & $\$ 0.11$ & $\$ 0.00$ & $\$ 0.17$ & & $\$ 0.04$ & $\$ 0.02$ & $\$ 3,314$ & $\$ 8.82$ \\
\hline 45 & 14 & $\$ 15,615$ & $\$ 42,000$ & $\$ 353$ & $\$ 57,968$ & $\$ 0.04$ & $\$ 0.11$ & $\$ 0.00$ & $\$ 0.15$ & & $\$ 0.02$ & $\$ 0.02$ & $\$ 2,091$ & $\$ 8.82$ \\
\hline 454 & 14 & $\$ 121,069$ & $\$ 420,000$ & $\$ 3,528$ & $\$ 544,597$ & $\$ 0.03$ & $\$ 0.11$ & $\$ 0.00$ & $\$ 0.14$ & & $\$ 0.02$ & $\$ 0.02$ & $\$ 1,320$ & $\$ 8.82$ \\
\hline 4.536 & 14 & $\$ 989.342$ & $\$ 4.200 .000$ & $\$ 35.280$ & $\$ 5.224 .622$ & $\$ 0.03$ & $\$ 0.11$ & $\$ 0.00$ & $\$ 0.14$ & & $\$ 0.01$ & $\$ 0.02$ & $\$ 833$ & $\$ 8.82$ \\
\hline 45.359 & 14 & $\$ 8,496,843$ & $\$ 42,000,000$ & $\$ 352,80 \mathrm{C}$ & $\$ 50,849,643$ & $\$ 0.02$ & $\$ 0.11$ & $\$ 0.00$ & $\$ 0.13$ & & $\$ 0.01$ & $\$ 0.02$ & $\$ 525$ & $\$ 8.82$ \\
\hline 2 & 30 & $\$ 2,816$ & $\$ 4,200$ & $\$ 35$ & $\$ 7,051$ & $\$ 0.07$ & $\$ 0.11$ & $\$ 0.00$ & $\$ 0.19$ & & $\$ 0.04$ & $\$ 0.03$ & $\$ 3,314$ & $\$ 8.82$ \\
\hline 45 & 30 & $\$ 22,597$ & $\$ 42,000$ & $\$ 353$ & $\$ 64,950$ & $\$ 0.06$ & $\$ 0.11$ & $\$ 0.00$ & $\$ 0.17$ & & $\$ 0.02$ & $\$ 0.03$ & $\$ 2,091$ & $\$ 8$. \\
\hline 454 & 30 & $\$ 190,887$ & $\$ 420,000$ & $\$ 3,528$ & $\$ 614,415$ & $\$ 0.05$ & $\$ 0.11$ & $\$ 0.00$ & $\$ 0.16$ & & $\$ 0.02$ & $\$ 0.03$ & $\$ 1,320$ & $\$ 8.82$ \\
\hline 4,536 & 30 & $\$ 1,687,524$ & $\$ 4,200,000$ & $\$ 35,280$ & $\$ 5,922,804$ & $\$ 0.04$ & $\$ 0.11$ & $\$ 0.00$ & $\$ 0.16$ & & $\$ 0.01$ & $\$ 0.03$ & $\$ 833$ & $\$ 8.82$ \\
\hline 45,359 & 30 & $\$ 15,478,662$ & $\$ 42,000,000$ & $\$ 352,800$ & $\$ 57,831,462$ & $\$ 0.04$ & $\$ 0.11$ & $\$ 0.00$ & $\$ 0.15$ & & $\$ 0.01$ & $\$ 0.03$ & $\$ 525$ & $\$ 8.82$ \\
\hline
\end{tabular}




\begin{tabular}{|c|c|c|c|c|c|c|c|c|c|c|}
\hline \multicolumn{11}{|c|}{ D4. UNDERGROUND STORAGE - English Units } \\
\hline & & & & & & & & & & \\
\hline \multicolumn{2}{|c|}{ Compressor Capital Cost= } & $\$ 1,000$ & perkW & & & & & & & \\
\hline \multicolumn{2}{|c|}{ Underground Capital Cost= } & $\$ 4$ & per lb & & & & & & & \\
\hline \multicolumn{2}{|c|}{ Compressor Size $=$} & 4,000 & $\mathrm{~kW}$ & & & & & & & \\
\hline \multicolumn{2}{|c|}{ Compressor Pressure $=$} & 20 & $\mathrm{MPa}$ & & & & & & & \\
\hline \multicolumn{2}{|c|}{ Comp. Pressure Scale-Up= } & 0.18 & & & & & & & & \\
\hline \multicolumn{2}{|c|}{ Comp. Cost Scale-Up= } & 0.80 & & & & & & & & \\
\hline \multicolumn{2}{|c|}{ Underground Scale- $U \mathrm{p}=$} & 1.00 & & & & & & & & \\
\hline \multicolumn{2}{|c|}{ Compressor Power $=$} & 1.00 & $\mathrm{kWh} / \mathrm{lb}(20 \mathrm{MPa})$ & & & & & & & \\
\hline \multicolumn{2}{|c|}{ Compressor Cooling= } & 6.0 & $\mathrm{gal} / \mathrm{lb}(20 \mathrm{MPa})$ & & & & & & & \\
\hline Electric Cost $=$ & & $\$ 0.05$ & per kWh & & & & & & & \\
\hline Cooling Cost= & & $\$ 0.07$ & per M gal & & & & & & & \\
\hline \multicolumn{2}{|c|}{ Operating Days/Year $=$} & 350 & days/yr & & & & & & & \\
\hline \multicolumn{2}{|c|}{\begin{tabular}{|l|l|} 
Depreciation $=$ & \\
\end{tabular}} & 22 & years & & & & & & & \\
\hline & & & & & & & & & & \\
\hline Production & Days of & Operating & Storage & Annual & Comp. & Cooling & Compressor & Compressor & Cavern & Total Capital \\
\hline Rate & Storage & Pressure & Capacity & Production & Power & Requirement & Size & Cost & Cost & Cost \\
\hline$(\mathrm{lb} / \mathrm{hr})$ & (days) & $(\mathrm{MPa})$ & (lb) & $(\mathrm{lb} / \mathrm{yr})$ & $(\mathrm{kWh} / \mathrm{hr})$ & (gal/hr) & $(\mathrm{kW})$ & $(\$)$ & (\$) & $(\$)$ \\
\hline 10 & 1 & 20 & 240 & 84,000 & 10 & 60 & 10 & $\$ 33,145$ & $\$ 960$ & $\$ 34,105$ \\
\hline 100 & 1 & 20 & 2,400 & 840,000 & 100 & 600 & 100 & $\$ 209,128$ & $\$ 9,600$ & $\$ 218,728$ \\
\hline 1,000 & 1 & 20 & 24,000 & $8,400,000$ & 1,000 & 6,000 & 1,000 & $\$ 1,319,508$ & $\$ 96,000$ & $\$ 1,415,508$ \\
\hline 10,000 & 1 & 20 & 240,000 & $84,000,000$ & 10,000 & 60,000 & 10,000 & $\$ 8,325,532$ & $\$ 960,000$ & $\$ 9,285,532$ \\
\hline 100,000 & 1 & 20 & $2,400,000$ & $840,000,000$ & 100,000 & 600,000 & 100,000 & $\$ 52,530,556$ & $\$ 9,600,000$ & $\$ 62,130,556$ \\
\hline 10 & 2 & 20 & 480 & 84,000 & 10 & 60 & 10 & $\$ 33,145$ & $\$ 1,920$ & $\$ 35,065$ \\
\hline 100 & 2 & 20 & 4,800 & 840,000 & 100 & 600 & 100 & $\$ 209,128$ & $\$ 19,200$ & $\$ 228,328$ \\
\hline 1,000 & 2 & 20 & 48,000 & $8,400,000$ & 1,000 & 6,000 & 1,000 & $\$ 1,319,508$ & $\$ 192,000$ & $\$ 1,511,508$ \\
\hline 10,000 & 2 & 20 & 480,000 & $84,000,000$ & 10,000 & 60,000 & 10,000 & $\$ 8,325,532$ & $\$ 1,920,000$ & $\$ 10,245,532$ \\
\hline 100,000 & 2 & 20 & $4,800,000$ & $840,000,000$ & 100,000 & 600,000 & 100,000 & $\$ 52,530,556$ & $\$ 19,200,000$ & $\$ 71,730,556$ \\
\hline 10 & 4 & 20 & 960 & 84,000 & 10 & 60 & 10 & $\$ 33,145$ & $\$ 3,840$ & $\$ 36,985$ \\
\hline 100 & 4 & 20 & 9,600 & 840,000 & 100 & 600 & 100 & $\$ 209,128$ & $\$ 38,400$ & $\$ 247,528$ \\
\hline 1,000 & 4 & 20 & 96,000 & $8,400,000$ & 1,000 & 6,000 & 1,000 & $\$ 1,319,508$ & $\$ 384,000$ & $\$ 1,703,508$ \\
\hline 10,000 & 4 & 20 & 960,000 & $84,000,000$ & 10,000 & 60,000 & 10,000 & $\$ 8,325,532$ & $\$ 3,840,000$ & $\$ 12,165,532$ \\
\hline 100,000 & 4 & 20 & $9,600,000$ & $840,000,000$ & 100,000 & 600,000 & 100,000 & $\$ 52,530,556$ & $\$ 38,400,000$ & $\$ 90,930,556$ \\
\hline 10 & 7 & 20 & 1,680 & 84,000 & 10 & 60 & 10 & $\$ 33,145$ & $\$ 6,720$ & $\$ 39,865$ \\
\hline 100 & 7 & 20 & 16,800 & 840,000 & 100 & 600 & 100 & $\$ 209,128$ & $\$ 67,200$ & $\$ 276,328$ \\
\hline 1,000 & 7 & 20 & 168,000 & $8,400,000$ & 1,000 & 6,000 & 1,000 & $\$ 1,319,508$ & $\$ 672,000$ & $\$ 1,991,508$ \\
\hline 10,000 & 7 & 20 & $1,680,000$ & $84,000,000$ & 10,000 & 60,000 & 10,000 & $\$ 8,325,532$ & $\$ 6,720,000$ & $\$ 15,045,532$ \\
\hline 100,000 & 7 & 20 & $16,800,000$ & $840,000,000$ & 100,000 & 600,000 & 100,000 & $\$ 52,530,556$ & $\$ 67,200,000$ & $\$ 119,730,556$ \\
\hline 10 & 14 & 20 & 3,360 & 84,000 & 10 & 60 & 10 & $\$ 33,145$ & $\$ 13,440$ & $\$ 46,585$ \\
\hline 100 & 14 & 20 & 33,600 & 840,000 & 100 & 600 & 100 & $\$ 209,128$ & $\$ 134,400$ & $\$ 343,528$ \\
\hline 1,000 & 14 & 20 & 336,000 & $8,400,000$ & 1,000 & 6,000 & 1,000 & $\$ 1,319,508$ & $\$ 1,344,000$ & $\$ 2,663,508$ \\
\hline 10,000 & $\overline{14}$ & 20 & $3,360,000$ & $84,000,000$ & 10,000 & 60,000 & 10,000 & $\$ 8,325,532$ & $\$ 13,440,000$ & $\$ 21,765,532$ \\
\hline 100,000 & 14 & 20 & $33,600,000$ & $840,000,000$ & 100,000 & 600,000 & 100,000 & $\$ 52,530,556$ & $\$ 134,400,000$ & $\$ 186,930,556$ \\
\hline 10 & 30 & 20 & 7,200 & 84,000 & 10 & 60 & 10 & $\$ 33,145$ & $\$ 28,800$ & $\$ 61,945$ \\
\hline 100 & 30 & 20 & 72,000 & 840,000 & 100 & 600 & 100 & $\$ 209,128$ & $\$ 288,000$ & $\$ 497,128$ \\
\hline 1,000 & 30 & 20 & 720,000 & $8,400,000$ & 1,000 & 6,000 & 1,000 & $\$ 1,319,508$ & $\$ 2,880,000$ & $\$ 4,199,508$ \\
\hline 10,000 & 30 & 20 & $7,200,000$ & $84,000,000$ & 10,000 & 60,000 & 10,000 & $\$ 8,325,532$ & $\$ 28,800,000$ & $\$ 37,125,532$ \\
\hline 100,000 & 30 & 20 & $72,000,000$ & $840,000,000$ & 100,000 & 600,000 & 100,000 & $\$ 52,530,556$ & $\$ 288,000,000$ & $\$ 340,530,556$ \\
\hline
\end{tabular}

D - 17 


\begin{tabular}{|c|c|c|c|c|c|c|c|c|c|c|c|c|c|c|}
\hline \multicolumn{15}{|c|}{ D4. UNDERGROUND STORAGE - English Units (Continued) } \\
\hline Production & Days of & Depreciation & Annual Electric & Annual Cooling & Total Annual & Capital & Electricity & Cooling & Total & & Comp. & Cavern & Comp. & Cavern \\
\hline Rate & Storage & & & Water Costs & Cost & Cost & Cost & Cost & Cost & & Cost & Cost $/ 1 \mathrm{~b}$ & Capital & Capital \\
\hline$(\mathrm{dib} / \mathrm{hr})$ & (days) & $(\$ / y r)$ & $(\$ / y r)$ & $(\$ / y r)$ & $(\$ / y r)$ & $(\$ / 1 \mathrm{~b})$ & $(\$ / 1 \mathrm{~b})$ & $(\$ / 1 / b)$ & $(\$ / \mathrm{lb})$ & & $(\$ / 1 \mathrm{~b})$ & Cost/lb & $(\$ / k W)$ & $(\$ / \mathrm{lb})$ \\
\hline 10 & 1 & $\$ 1,550$ & $\$ 4,200$ & $\$ 35$ & $\$ 5,78$ & $\$ 0.02$ & $\$ 0.05$ & $\$ 0.00$ & $\$ 0.07$ & & $\$ 0.02$ & $\$ 0.00$ & $\$ 3,314$ & $\$ 4.00$ \\
\hline 100 & & $\$ 9.942$ & $\$ 42.000$ & $\$ 353$ & $\$ 52.295$ & $\$ 0.01$ & $\$ 0.05$ & $\$ 0.00$ & $\$ 0.06$ & & $\$ 0.01$ & $\$ 0.00$ & $\$ 2.091$ & $\$ 4.00$ \\
\hline 1.000 & & $\$ 64.341$ & $\$ 420.000$ & $\$ 3.528$ & $\$ 487.869$ & $\$ 0.01$ & $\$ 0.05$ & $\$ 0.00$ & $\$ 0.06$ & & $\$ 0.01$ & $\$ 0.00$ & $\$ 1,320$ & $\$ 4.00$ \\
\hline 10,000 & 1 & $\$ 422,070$ & $\$ 4,200,000$ & $\$ 35,280$ & $\$ 4,657,350$ & $\$ 0.01$ & $\$ 0.05$ & $\$ 0.00$ & $\$ 0.06$ & & $\$ 0.00$ & $\$ 0.00$ & $\$ 833$ & $\$ 4.00$ \\
\hline 100,000 & 1 & $\$ 2,824,116$ & $\$ 42,000,000$ & $\$ 352,800$ & $\$ 45,176,916$ & $\$ 0.00$ & $\$ 0.05$ & $\$ 0.00$ & $\$ 0.05$ & & $\$ 0.00$ & $\$ 0.00$ & $\$ 525$ & $\$ 4.00$ \\
\hline 10 & 2 & $\$ 1,594$ & $\$ 4,200$ & $\$ 35$ & $\$ 5,829$ & $\$ 0.02$ & $\$ 0.05$ & $\$ 0.00$ & $\$ 0.07$ & & $\$ 0.02$ & $\$ 0.00$ & $\$ 3,314$ & $\$ 4.00$ \\
\hline 100 & & $\$ 10,379$ & $\$ 42,000$ & $\$ 353$ & $\$ 52,731$ & $\$ 0.01$ & $\$ 0.05$ & $\$ 0.00$ & $\$ 0.06$ & & $\$ 0.01$ & $\$ 0.00$ & $\$ 2,091$ & $\$ 4.00$ \\
\hline 1,000 & & $\$ 68,705$ & $\$ 420,000$ & $\$ 3,528$ & $\$ 492,233$ & $\$ 0.01$ & $\$ 0.05$ & $\$ 0.00$ & $\$ 0.06$ & & $\$ 0.01$ & $\$ 0.00$ & $\$ 1,320$ & $\$ 4.00$ \\
\hline 10,000 & & $\$ 465,706$ & $\$ 4,200,000$ & $\$ 35.280$ & $\$ 4,700,986$ & $\$ 0.01$ & $\$ 0.05$ & $\$ 0.00$ & $\$ 0.06$ & & $\$ 0.00$ & $\$ 0.00$ & $\$ 833$ & $\$ 4.00$ \\
\hline 100,000 & 2 & $\$ 3,260,480$ & $\$ 42,000,000$ & $\$ 352,800$ & $\$ 45,613,280$ & $\$ 0.00$ & $\$ 0.05$ & $\$ 0.00$ & $\$ 0.05$ & & $\$ 0.00$ & $\$ 0.00$ & $\$ 525$ & $\$ 4.00$ \\
\hline 10 & 4 & $\$ 1,681$ & $\$ 4.200$ & $\$ 35$ & $\$ 5,916$ & $\$ 0.02$ & $\$ 0.05$ & $\$ 0.00$ & $\$ 0.07$ & & $\$ 0.02$ & $\$ 0.00$ & $\$ 3,314$ & $\$ 4.00$ \\
\hline 100 & 4 & $\$ 11,251$ & $\$ 42,000$ & $\$ 353$ & $\$ 53,604$ & $\$ 0.01$ & $\$ 0.05$ & $\$ 0.00$ & $\$ 0.06$ & & $\$ 0.01$ & $\$ 0.00$ & $\$ 2,091$ & $\$ 4.00$ \\
\hline 1,000 & 4 & $\$ 77,432$ & $\$ 420,000$ & $\$ 3,528$ & $\$ 500,960$ & $\$ 0.01$ & $\$ 0.05$ & $\$ 0.00$ & $\$ 0.06$ & & $\$ 0.01$ & $\$ 0.00$ & $\$ 1,320$ & $\$ 4.00$ \\
\hline 10,000 & 4 & $\$ 552,979$ & $\$ 4,200,000$ & $\$ 35,280$ & $\$ 4,788,259$ & $\$ 0.01$ & $\$ 0.05$ & $\$ 0.00$ & $\$ 0.06$ & & $\$ 0.00$ & $\$ 0.00$ & $\$ 833$ & $\$ 4.00$ \\
\hline 100,000 & 4 & $\$ 4,133,207$ & $\$ 42,000,000$ & $\$ 352,800$ & $\$ 46,486,000$ & $\$ 0.00$ & $\$ 0.05$ & $\$ 0.00$ & $\$ 0.06$ & & $\$ 0.00$ & $\$ 0.00$ & $\$ 525$ & $\$ 4.00$ \\
\hline 10 & & $\$ 1,812$ & $\$ 4,200$ & $\$ 35$ & $\$ 6,047$ & $\$ 0.02$ & $\$ 0.05$ & $\$ 0.00$ & $\$ 0.07$ & & $\$ 0.02$ & $\$ 0.00$ & $\$ 3,314$ & $\$ 4.00$ \\
\hline 100 & & $\$ 12,560$ & $\$ 42,000$ & $\$ 353$ & $\$ 54,913$ & $\$ 0.01$ & $\$ 0.05$ & $\$ 0.00$ & $\$ 0.07$ & & $\$ 0.01$ & $\$ 0.00$ & $\$ 2,091$ & $\$ 4.00$ \\
\hline 1,000 & & $\$ 90,523$ & $\$ 420,000$ & $\$ 3,528$ & $\$ 514,051$ & $\$ 0.01$ & $\$ 0.05$ & $\$ 0.00$ & $\$ 0.06$ & & $\$ 0.01$ & $\$ 0.00$ & $\$ 1,320$ & $\$ 4.00$ \\
\hline 10,000 & & $\$ 683,888$ & $\$ 4,200,000$ & $\$ 35,280$ & $\$ 4,919,168$ & $\$ 0.01$ & $\$ 0.05$ & $\$ 0.00$ & $\$ 0.06$ & & $\$ 0.00$ & $\$ 0.00$ & $\$ 833$ & $\$ 4.00$ \\
\hline 100,000 & 7 & $\$ 5,442,298$ & $\$ 42,000,000$ & $\$ 352,800$ & $\$ 47,795,098$ & $\$ 0.01$ & $\$ 0.05$ & $\$ 0.00$ & $\$ 0.06$ & & $\$ 0.00$ & $\$ 0.00$ & $\$ 525$ & $\$ 4.00$ \\
\hline 10 & 14 & $\$ 2,117$ & $\$ 4,200$ & $\$ 35$ & $\$ 6,353$ & $\$ 0.03$ & $\$ 0.05$ & $\$ 0.00$ & $\$ 0.08$ & & $\$ 0.02$ & $\$ 0.01$ & $\$ 3,314$ & $\$ 4.00$ \\
\hline 100 & 14 & $\$ 15,615$ & $\$ 42,000$ & $\$ 353$ & $\$ 57,968$ & $\$ 0.02$ & $\$ 0.05$ & $\$ 0.00$ & $\$ 0.07$ & & $\$ 0.01$ & $\$ 0.01$ & $\$ 2,091$ & $\$ 4.00$ \\
\hline 1,000 & 14 & $\$ 121,069$ & $\$ 420,000$ & $\$ 3,528$ & $\$ 544,597$ & $\$ 0.01$ & $\$ 0.05$ & $\$ 0.00$ & $\$ 0.06$ & & $\$ 0.01$ & $\$ 0.01$ & $\$ 1,320$ & $\$ 4.00$ \\
\hline 10.000 & 14 & $\$ 989.342$ & $\$ 4.200 .000$ & $\$ 35.280$ & $\$ 5.224 .622$ & $\$ 0.01$ & $\$ 0.05$ & $\$ 0.00$ & $\$ 0.06$ & & $\$ 0.00$ & $\$ 0.01$ & $\$ 833$ & $\$ 4.00$ \\
\hline 100,000 & 14 & $\$ 8,496,843$ & $\$ 42,000,000$ & $\$ 352,800$ & $\$ 50,849,643$ & & & $\$ 0.00$ & $\$ 0.06$ & & & & $\$ 525$ & $\$ 4.00$ \\
\hline 10 & 30 & $\$ 2,816$ & $\$ 4,200$ & $\$ 35$ & $\frac{100}{\$ 7,051}$ & $\$ 0.03$ & $\$ 0.05$ & $\$ 0.00$ & $\$ 0.08$ & & $\$ 0.02$ & $\$ 0.02$ & $\$ 3,314$ & $\$ 4.00$ \\
\hline 100 & 30 & $\$ 22,597$ & $\$ 42,000$ & $\$ 353$ & $\$ 64,950$ & $\$ 0.03$ & $\$ 0.05$ & $\$ 0.00$ & $\$ 0.08$ & & $\$ 0.01$ & $\$ 0.02$ & $\$ 2,091$ & $\$ 4.00$ \\
\hline 1,000 & 30 & $\$ 190,887$ & $\$ 420,000$ & $\$ 3,528$ & $\$ 614,415$ & $\$ 0.02$ & $\$ 0.05$ & $\$ 0.00$ & $\$ 0.07$ & & $\$ 0.01$ & $\$ 0.02$ & $\$ 1,320$ & $\$ 4.00$ \\
\hline 10,000 & 30 & $\$ 1,687,524$ & $\$ 4,200,000$ & $\$ 35,280$ & $\$ 5,922,804$ & $\$ 0.02$ & $\$ 0.05$ & $\$ 0.00$ & $\$ 0.07$ & & $\$ 0.00$ & $\$ 0.02$ & $\$ 833$ & $\$ 4.00$ \\
\hline 100,000 & 30 & $\$ 15,478,662$ & $\$ 42,000,000$ & $\$ 352,800$ & $\$ 57,831,462$ & $\$ 0.02$ & $\$ 0.05$ & $\$ 0.00$ & $\$ 0.07$ & & $\$ 0.00$ & $\$ 0.02$ & $\$ 525$ & $\$ 4.00$ \\
\hline
\end{tabular}




\section{APPENDIX E - HYDROGEN TRANSPORT COSTS}

E.0 Hydrogen Transportation Assumptions

E.1 Compressed Gas Delivery by Truck

E.2 Compressed Gas Delivery by Rail

E.3 Liquid Hydrogen Delivery by Truck

E.4 Liquid Hydrogen Delivery by Rail

E.5 Liquid Hydrogen Delivery by Ship

E.6 Metal Hydride Delivery by Truck

E.7 Metal Hydride Delivery by Rail

E.8 Pipeline Delivery

Appendix E contains some of the cost data from the analysis of transport costs for the different hydrogen delivery options. Costs are given in both SI and traditional English units for each storage method. Costs are arranged in the tables by production rate and delivery distance. 


\begin{tabular}{|c|c|c|c|c|}
\hline \multicolumn{5}{|c|}{ E.0 HYDROGEN TRANSPORTATION ASSUMPTIONS } \\
\hline Truck Tube Unit= & $\$ 100000$ & normodull & & \\
\hline Truck Tube Capacity= & 181 & $\mathrm{~kg} /$ truck & 400 & Ib/truck \\
\hline Truck Liquid Tank= & $\$ 350,000$ & per module & & \\
\hline Truck Liquid Capacity= & 4,082 & $\mathrm{~kg} /$ truck & 9,000 & lb/truck \\
\hline Truck Hydride Container $=$ & $\$ 2,205$ & per kg hydrogen & $\$ 1,000$ & per lb hydrogen \\
\hline Truck Hydride Capacity $=$ & 454 & $\mathrm{~kg} /$ truck & 1,000 & lb/truck \\
\hline Truck Undercarriage $=$ & $\$ 60,000$ & per trailer & & \\
\hline Truck $\mathrm{Cab}=$ & $\$ 90,000$ & per cab & & \\
\hline Truck Mileage $=$ & 6 & $\mathrm{mpg}$ & & \\
\hline Truck Average Speed= & 80 & $\mathrm{~km} / \mathrm{hr}$ & 50 & mph \\
\hline Truck Load/Unload Time $=$ & 2 & hr/trip & & \\
\hline Truck Availability $=$ & 24 & hr/day & & \\
\hline Hours/Driver $=$ & 12 & hr/driver & & \\
\hline Driver Wage $\mathrm{w} /$ Benefits= & $\$ 28.75$ & per hour & & \\
\hline Diesel Price $=$ & $\$ 1.00$ & per gal & & \\
\hline Truck Boil-Off Rate $=$ & $0.30 \%$ & day & & \\
\hline Rail Tube Unit= & $\$ 200,000$ & per module & & \\
\hline Rail Tube Capacity= & 454 & $\mathrm{~kg} / \mathrm{railcar}$ & 1,000 & Ib/railcar \\
\hline Rail Liquid Tank= & $\$ 400,000$ & per tank & & \\
\hline Rail Tank Capacity= & 9,072 & $\mathrm{~kg} / \mathrm{railcar}$ & 20,000 & Ib/railcar \\
\hline Rail Hydride Container= & $\$ 1,000$ & per lb hydrogen & & \\
\hline Rail Hydride Capacity= & 907 & $\mathrm{~kg} / \mathrm{railcar}$ & 2,000 & Ib/railcar \\
\hline Rail Undercarriage $=$ & $\$ 100,000$ & per railcar & & \\
\hline Rail Average Speed= & 40 & $\mathrm{~km} / \mathrm{hr}$ & 25 & $\mathrm{mph}$ \\
\hline Rail Load/Unload Time= & 24 & hr/trip & & \\
\hline Rail Car Availability= & 24 & hr/day & & \\
\hline Rail Freight= & $\$ 400$ & per rail car & & \\
\hline Rail Boil-Off Rate $=$ & $0.30 \%$ & per day & & \\
\hline & & & & \\
\hline Ship Liquid Tank= & $\$ 350,000$ & per container & & \\
\hline Ship Liquid Capacity= & 4,082 & lb/tank & 9,000 & lb/tank \\
\hline Ship Average Speed= & 16 & $\mathrm{~km} / \mathrm{hr}$ & 10 & $\mathrm{mph}$ \\
\hline Ship Load/Unload Time $=$ & 48 & hr/trip & & \\
\hline Ship Tank Availability= & 24 & hr/day & & \\
\hline Shipping Charge $=$ & $\$ 3,000$ & per container & & \\
\hline Ship Boil-Off Rate $=$ & $0.30 \%$ & per day & & \\
\hline & & & & \\
\hline Pipeline Cost= & $\$ 621,504$ & per km & $\$ 1,000,000$ & per mile \\
\hline Steel Roughness= & $4.6 \mathrm{E}-05$ & $m$ & & \\
\hline Pipe Diameter= & 0.25 & $m$ & & \\
\hline Temperaure $=$ & 283 & $\mathrm{~K}$ & & \\
\hline Delivery Pressure $=$ & 2 & $\mathrm{MPa}$ & & \\
\hline Viscosity $=$ & $8.62 \mathrm{E}-06$ & $\mathrm{~kg} / \mathrm{m}^{*} \mathrm{~s}$ & & \\
\hline $\mathrm{R}$ (hydrogen)= & 4124 & $\mathrm{~N}^{*} \mathrm{~m} / \mathrm{kg} \mathrm{K}$ & & \\
\hline Compressor Capital Cost= & $\$ 1,000$ & per kW & & \\
\hline Compressor Size $=$ & 4,000 & $\mathrm{~kW}$ & & \\
\hline Compressor Pressure $=$ & 20 & $\mathrm{MPa}$ & & \\
\hline Comp. Pressure Scale-Up= & 0.18 & & & \\
\hline Comp. Cost Scale-Up= & 0.80 & & & \\
\hline Compressor Power= & 2.2 & $\mathrm{kWh} / \mathrm{kg}(20 \mathrm{MPa})$ & 1.00 & $\mathrm{kWh} / \mathrm{lb}(20 \mathrm{MPa})$ \\
\hline Electric Cost $=$ & $\$ 0.05$ & per kWh & & \\
\hline Operating Days/Year= & 350 & days/year & & \\
\hline Trailer/Tank Depreciation $=$ & 6 & years & & \\
\hline Tractor Depreciation $=$ & 4 & years & & \\
\hline Railcar Depreciation= & 15 & years & & \\
\hline Pipeline Depreciation $=$ & 22 & years & & \\
\hline
\end{tabular}




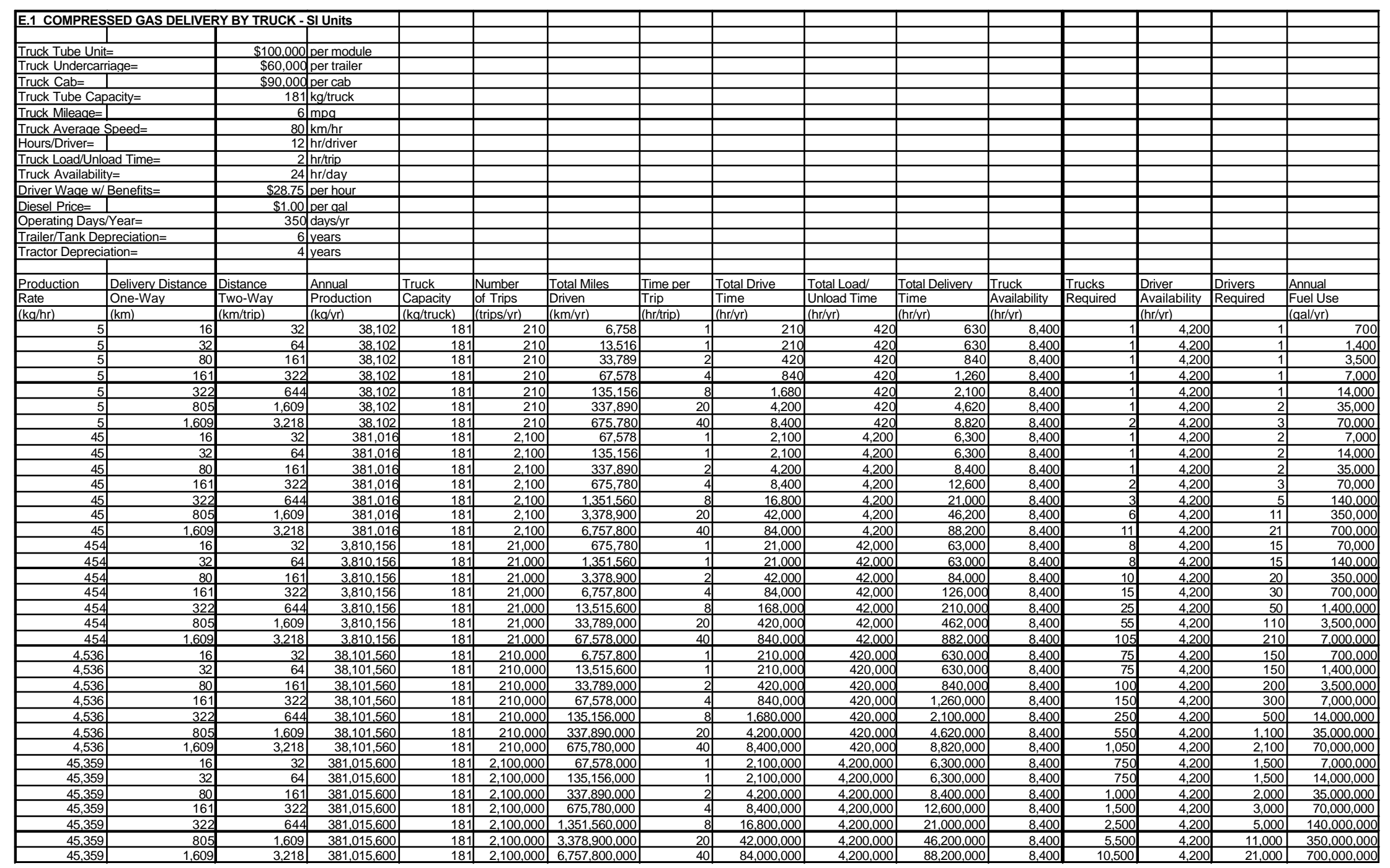

E - 3 


\begin{tabular}{|c|c|c|c|c|c|c|c|c|c|c|c|c|c|}
\hline \multirow{2}{*}{\multicolumn{14}{|c|}{\begin{tabular}{|l|l|l|} 
E.1 COMPRESSED GAS DELIVERY BY TRUCK - SI Units (Continued) \\
\end{tabular}}} \\
\hline & & & & & & & & & & & & & \\
\hline \begin{tabular}{|l|} 
Production \\
\end{tabular} & Delivery Distanc & Total Capital & Depreciation & Annual Fuel & Annual Labor & Total Annual & Capital & Fuel & Labor & Total & Trip & Trip & Truck \\
\hline Rate & One-Way & Cost & & Cost & Cost & Cost & Cost & Cost & Cost & Cost & Frequency & Length & Utilization \\
\hline$(\mathrm{kg} / \mathrm{hr})$ & $(\mathrm{km})$ & $(\$)$ & $(\$ / y r)$ & $(\$ / y r)$ & $(\$ / y r)$ & $(\$ / y r)$ & $(\$ / \mathrm{kg})$ & $(\$ / \mathrm{kg})$ & $(\$ / \mathrm{kg})$ & $(\$ / \mathrm{kg})$ & (trips/day) & (hours) & (Trips/truck/d) \\
\hline 5 & 16 & $\$ 250,000$ & $\$ 49,167$ & $\$ 700$ & $\$ 18,113$ & $\$ 268,813$ & $\$ 1.29$ & $\begin{array}{r}\$ 0.02 \\
\end{array}$ & $\$ 0.48$ & $\$ 7.06$ & 0.6 & 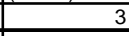 & $\begin{array}{r}0.60 \\
\end{array}$ \\
\hline 5 & 32 & $\$ 250,000$ & $\$ 49,167$ & $\$ 1,400$ & $\$ 18,113$ & $\$ 68,679$ & $\$ 1.29$ & $\$ 0.04$ & $\$ 0.48$ & $\$ 1.80$ & 0.6 & 3 & 0.60 \\
\hline 5 & 80 & $\$ 250,000$ & $\$ 49,167$ & $\$ 3,500$ & $\$ 24,150$ & $\$ 76,817$ & $\$ 1.29$ & $\$ 0.09$ & $\$ 0.63$ & $\$ 2.02$ & 0.6 & 4 & 0.60 \\
\hline 5 & 161 & $\$ 250,000$ & $\$ 49,167$ & $\$ 7,000$ & $\$ 36,225$ & $\$ 92,392$ & $\$ 1.29$ & $\$ 0.18$ & $\$ 0.95$ & $\$ 2.42$ & 0.6 & 6 & 0.60 \\
\hline 5 & 322 & $\$ 250,000$ & $\$ 49,167$ & $\$ 14,000$ & $\$ 60,375$ & $\$ 123,542$ & $\$ 1.29$ & $\$ 0.37$ & $\$ 1.58$ & $\$ 3.24$ & 0.6 & 10 & 0.60 \\
\hline 5 & 805 & $\$ 250,000$ & $\$ 49,167$ & $\$ 35,000$ & $\$ 132,825$ & $\$ 216,992$ & $\$ 1.29$ & $\$ 0.92$ & $\$ 3.49$ & $\$ 5.70$ & 0.6 & 22 & 0.60 \\
\hline 5 & 1,609 & $\$ 500,000$ & $\$ 98,333$ & $\$ 70,000$ & $\$ 253,575$ & $\$ 421,908$ & $\$ 2.58$ & $\$ 1.84$ & $\$ 6.66$ & $\$ 11.07$ & 0.6 & 42 & 0.30 \\
\hline 45 & 16 & $\$ 250,000$ & $\$ 49,167$ & $\$ 7,000$ & $\$ 181,125$ & $\$ 237,292$ & $\$ 0.13$ & $\$ 0.02$ & $\$ 0.48$ & $\$ 0.62$ & 6 & 3 & 6.00 \\
\hline 45 & 32 & $\$ 250,000$ & $\$ 49,167$ & $\$ 14,000$ & $\$ 181,125$ & $\$ 244,292$ & $\$ 0.13$ & $\$ 0.04$ & $\$ 0.48$ & $\$ 0.64$ & fo & 4 & 6.00 \\
\hline 45 & 80 & $\$ 250,000$ & $\$ 49,167$ & $\$ 35,000$ & $\$ 241,500$ & $\$ 325,667$ & $\$ 0.13$ & $\$ 0.09$ & $\$ 0.63$ & $\$ 0.85$ & 6 & 4 & 6.00 \\
\hline 45 & 161 & $\$ 500,000$ & $\$ 98,333$ & $\$ 70,000$ & $\$ 362,250$ & $\$ 530,583$ & $\$ 0.26$ & $\$ 0.18$ & $\$ 0.95$ & $\$ 1.39$ & 6 & 6 & 3.00 \\
\hline 45 & 322 & $\$ 750,000$ & $\$ 147,500$ & $\$ 140,000$ & $\$ 603,750$ & $\$ 891,250$ & $\$ 0.39$ & $\$ 0.37$ & $\$ 1.58$ & $\$ 2.34$ & 6 & 10 & 2.00 \\
\hline 45 & 805 & $\$ 1,500,000$ & $\$ 295,000$ & $\$ 350,000$ & $\$ 1,328,250$ & $\$ 1,973,250$ & $\$ 0.77$ & $\$ 0.92$ & $\$ 3.49$ & $\$ 5.18$ & 6 & 22 & 1.00 \\
\hline 45 & 1,609 & $\$ 2,750,000$ & $\$ 540,833$ & $\$ 700,000$ & $\$ 2,535,750$ & $\$ 3,776,583$ & $\$ 1.42$ & $\$ 1.84$ & $\$ 6.66$ & $\$ 9.91$ & 6 & 42 & 0.55 \\
\hline 454 & 16 & $\$ 2,000,000$ & $\$ 393,333$ & $\$ 70,000$ & $\$ 1,811,250$ & $\$ 2,274,583$ & $\$ 0.10$ & $\$ 0.02$ & $\$ 0.48$ & $\$ 0.60$ & 60 & ? & 7.50 \\
\hline 454 & 32 & $\$ 2,000,000$ & $\$ 393,333$ & $\$ 140,000$ & $\$ 1,811,250$ & $\$ 2,344,583$ & $\$ 0.10$ & $\$ 0.04$ & $\$ 0.48$ & $\$ 0.62$ & 60 & 3 & 7.50 \\
\hline 454 & 80 & $\$ 2,500,000$ & $\$ 491,667$ & $\$ 350,000$ & $\$ 2,415,000$ & $\$ 3,256,667$ & $\$ 0.13$ & $\$ 0.09$ & $\$ 0.63$ & $\$ 0.85$ & 60 & 4 & 6.00 \\
\hline 454 & 161 & $\$ 3,750,000$ & $\$ 737,500$ & $\$ 700,000$ & $\$ 3,622,500$ & $\$ 5,060,000$ & $\$ 0.19$ & $\$ 0.18$ & $\$ 0.95$ & $\$ 1.33$ & 60 & 6 & 4.00 \\
\hline 454 & 322 & $\$ 6,250,000$ & $\$ 1,229,167$ & $\$ 1,400,000$ & $\$ 6,037,500$ & $\$ 8,666,667$ & $\$ 0.32$ & $\$ 0.37$ & $\$ 1.58$ & $\$ 2.27$ & 60 & 10 & 2.40 \\
\hline 454 & 805 & $\$ 13,750,000$ & $\$ 2,704,167$ & $\$ 3,500,000$ & $\$ 13,282,500$ & $\$ 19,486,667$ & $\$ 0.71$ & $\$ 0.92$ & $\$ 3.49$ & $\$ 5.11$ & 60 & 22 & 1.09 \\
\hline 454 & 1,609 & $\$ 26,250,000$ & $\$ 5,162,500$ & $\$ 7,000,000$ & $\$ 25,357,500$ & $\$ 37,520,000$ & $\$ 1.35$ & $\$ 1.84$ & $\$ 6.66$ & $\$ 9.85$ & 60 & 42 & 0.57 \\
\hline 4,536 & 16 & $\$ 18,750,000$ & $\$ 3,687,500$ & $\$ 700,000$ & $\$ 18,112,500$ & $\$ 22,500,000$ & $\$ 0.10$ & $\$ 0.02$ & $\$ 0.48$ & $\$ 0.59$ & 600 & 3 & 8.00 \\
\hline 4,536 & 32 & $\$ 18,750,000$ & $\$ 3,687,500$ & $\$ 1,400,000$ & $\$ 18,112,500$ & $\$ 23,200,000$ & $\$ 0.10$ & $\$ 0.04$ & $\$ 0.48$ & $\$ 0.61$ & 600 & 3 & 8.00 \\
\hline 4,536 & 80 & $\$ 25,000,000$ & $\$ 4,916,667$ & $\$ 3,500,000$ & $\$ 24,150,000$ & $\$ 32,566,667$ & $\$ 0.13$ & $\$ 0.09$ & $\$ 0.63$ & $\$ 0.85$ & 600 & 4 & 6.00 \\
\hline 4,536 & 161 & $\$ 37,500,000$ & $\$ 7,375,000$ & $\$ 7,000,000$ & $\$ 36,225,000$ & $\$ 50,600,000$ & $\$ 0.19$ & $\$ 0.18$ & $\$ 0.95$ & $\$ 1.33$ & 600 & 6 & 4.00 \\
\hline 4,536 & 322 & $\$ 62,500,000$ & $\$ 12,291,667$ & $\$ 14,000,000$ & $\$ 60,375,000$ & $\$ 86,666,667$ & $\$ 0.32$ & $\$ 0.37$ & $\$ 1.58$ & $\$ 2.27$ & 600 & 10 & 2.40 \\
\hline 4,536 & 805 & $\$ 137,500,000$ & $\$ 27,041,667$ & $\$ 35,000,000$ & $\$ 132,825,000$ & $\$ 194,866,667$ & $\$ 0.71$ & $\$ 0.92$ & $\$ 3.49$ & $\$ 5.11$ & 600 & 22 & 1.09 \\
\hline 4,536 & 1,609 & $\$ 262,500,000$ & $\$ 51,625,000$ & $\$ 70,000,000$ & $\$ 253,575,000$ & $\$ 375,200,000$ & $\$ 1.35$ & $\$ 1.84$ & $\$ 6.66$ & $\$ 9.85$ & 600 & 42 & 0.57 \\
\hline 45,359 & 16 & $\$ 187,500,000$ & $\$ 36,875,000$ & $\$ 7,000,000$ & $\$ 181,125,000$ & $\$ 225,000,000$ & $\$ 0.10$ & $\$ 0.02$ & $\$ 0.48$ & $\$ 0.59$ & 6000 & 3 & 8.00 \\
\hline 45,359 & 32 & $\$ 187,500,000$ & $\$ 36,875,000$ & $\$ 14,000,000$ & $\$ 181,125,000$ & $\$ 232,000,000$ & $\$ 0.10$ & $\$ 0.04$ & $\$ 0.48$ & $\$ 0.61$ & 6000 & 3 & 8.00 \\
\hline 45,359 & 80 & $\$ 250,000,000$ & $\$ 49,166,667$ & $\$ 35,000,000$ & $\$ 241,500,000$ & $\$ 325,666,667$ & $\$ 0.13$ & $\$ 0.09$ & $\$ 0.63$ & $\$ 0.85$ & 6000 & & 6.00 \\
\hline 45,359 & 161 & $\$ 375,000,000$ & $\$ 73,750,000$ & $\$ 70,000,000$ & $\$ 362,250,000$ & $\$ 506,000,000$ & $\$ 0.19$ & $\$ 0.18$ & $\$ 0.95$ & $\$ 1.33$ & 6000 & 6 & 4.00 \\
\hline 45,359 & 322 & $\$ 625,000,000$ & $\$ 122,916,667$ & $\$ 140,000,000$ & $\$ 603,750,000$ & $\$ 866,666,667$ & $\$ 0.32$ & $\$ 0.37$ & $\$ 1.58$ & $\$ 2.27$ & 6000 & 10 & 2.40 \\
\hline 45,359 & 805 & $\$ 1,375,000,000$ & $\$ 270,416,667$ & $\$ 350,000,000$ & $\$ 1,328,250,000$ & $\$ 1,948,666,667$ & $\$ 0.71$ & $\$ 0.92$ & $\$ 3.49$ & $\$ 5.11$ & 6000 & 22 & 1.09 \\
\hline 45,359 & 1,609 & $\$ 2,625,000,000$ & $\$ 516,250,000$ & $\$ 700,000,000$ & $\$ 2,535,750,000$ & $\$ 3,752,000,000$ & $\$ 1.35$ & $\$ 1.84$ & $\$ 6.66$ & $\$ 9.85$ & 6000 & 42 & 0.57 \\
\hline
\end{tabular}




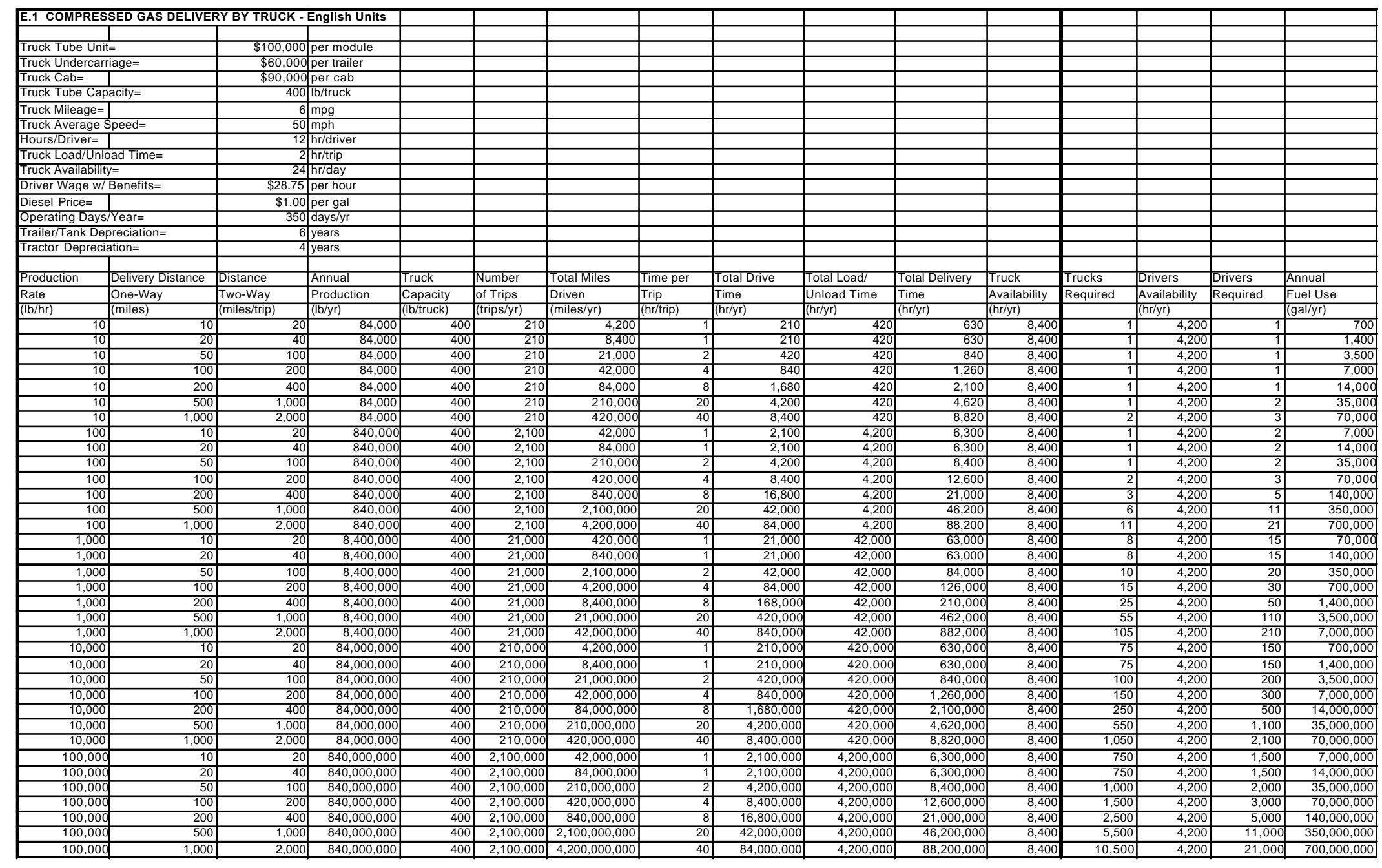

E - 5 


\begin{tabular}{|c|c|c|c|c|c|c|c|c|c|c|c|c|c|}
\hline 1 COMPRESS & SED GAS DELIV & IERY BY TRUCK - & English Units (Cont & ntinued) & & & & & & & & & \\
\hline Production & Delivery Distanc & Total Capital & Depreciation & Annual Fuel & Annual Labor & Total Annual & Capital & Fuel & Labor & Total & Trip & Trip & Truck \\
\hline Rate & One-Way & Cost & & Cost & Cost & Cost & Cost & Cost & Cost & Cost & Frequency & Length & Utilization \\
\hline$(\mathrm{lb} / \mathrm{hr})$ & (miles) & $(\$)$ & $(\$ / y r)$ & $(\$ / y r)$ & $(\$ / y r)$ & $(\$ / y r)$ & $(\$ / \mathrm{lb})$ & $(\$ / b)$ & $\$ / / \mathrm{b})$ & $(\$ / b)$ & (trips/day) & (hours) & (Trips/truck/d) \\
\hline 10 & 10 & $\$ 250,000$ & $\$ 49,167$ & $\$ 700$ & $\$ 18,113$ & $\$ 268,813$ & $\$ 0.59$ & $\$ 0.01$ & $\$ 0.22$ & $\$ 3.20$ & 0.6 & & 0.60 \\
\hline 10 & 20 & $\$ 250,000$ & $\$ 49,167$ & $\$ 1,400$ & $\$ 18,113$ & $\$ 68,679$ & $\$ 0.59$ & $\$ 0.02$ & $\$ 0.22$ & $\$ 0.82$ & 0.6 & 3 & 0.60 \\
\hline 10 & 50 & $\$ 250,000$ & $\$ 49,167$ & $\$ 3,500$ & $\$ 24,150$ & $\$ 76,817$ & $\$ 0.59$ & $\$ 0.04$ & $\$ 0.29$ & $\$ 0.91$ & 0.6 & 4 & 0.60 \\
\hline 10 & 100 & $\$ 250,000$ & $\$ 49,167$ & $\$ 7,000$ & $\$ 36,225$ & $\$ 92,392$ & $\$ 0.59$ & $\$ 0.08$ & $\$ 0.43$ & $\$ 1.10$ & 0.6 & 6 & 0.60 \\
\hline 10 & 200 & $\$ 250,000$ & $\$ 49,167$ & $\$ 14,000$ & $\$ 60,375$ & $\$ 123,542$ & $\$ 0.59$ & $\$ 0.17$ & $\$ 0.72$ & $\$ 1.47$ & 0.6 & 10 & 0.60 \\
\hline 10 & 500 & $\$ 250,000$ & $\$ 49,167$ & $\$ 35,000$ & $\$ 132,825$ & $\$ 216,992$ & $\$ 0.59$ & $\$ 0.42$ & $\$ 1.58$ & $\$ 2.58$ & 0.6 & 22 & 0.60 \\
\hline 10 & 1,000 & $\$ 500,000$ & $\$ 98,333$ & $\$ 70,000$ & $\$ 253,575$ & $\$ 421,908$ & $\$ 1.17$ & $\$ 0.83$ & $\$ 3.02$ & $\$ 5.02$ & 0.6 & 42 & 0.30 \\
\hline 100 & 10 & $\$ 250,000$ & $\$ 49,167$ & $\$ 7,000$ & $\$ 181,125$ & $\$ 237,292$ & $\$ 0.06$ & $\$ 0.01$ & $\$ 0.22$ & $\$ 0.28$ & 6 & 3 & 6.00 \\
\hline 100 & 20 & $\$ 250,000$ & $\$ 49,167$ & $\$ 14,000$ & $\$ 181,125$ & $\$ 244,292$ & $\$ 0.06$ & $\$ 0.02$ & $\$ 0.22$ & $\$ 0.29$ & 6 & T & 6.00 \\
\hline 100 & 50 & $\$ 250,000$ & $\$ 49,167$ & $\$ 35,000$ & $\$ 241,500$ & $\$ 325,667$ & $\$ 0.06$ & $\$ 0.04$ & $\$ 0.29$ & $\$ 0.39$ & 6 & 4 & 6.00 \\
\hline 100 & 100 & $\$ 500,000$ & $\$ 98,333$ & $\$ 70,000$ & $\$ 362,250$ & $\$ 530,583$ & $\$ 0.12$ & $\$ 0.08$ & $\$ 0.43$ & $\$ 0.63$ & T & 6 & 3.00 \\
\hline 100 & 200 & $\$ 750,000$ & $\$ 147,500$ & $\$ 140,000$ & $\$ 603,750$ & $\$ 891,250$ & $\$ 0.18$ & $\$ 0.17$ & $\$ 0.72$ & $\$ 1.06$ & 0 & 10 & 2.00 \\
\hline 100 & 500 & $\$ 1,500,000$ & $\$ 295,000$ & $\$ 350,000$ & $\$ 1,328,250$ & $\$ 1,973,250$ & $\$ 0.35$ & $\$ 0.42$ & $\$ 1.58$ & $\$ 2.35$ & 6 & 22 & 1.00 \\
\hline 100 & 1,000 & $\$ 2,750,000$ & $\$ 540,833$ & $\$ 700,000$ & $\$ 2,535,750$ & $\$ 3,776,583$ & $\$ 0.64$ & $\$ 0.83$ & $\$ 3.02$ & $\$ 4.50$ & 6 & 42 & 0.55 \\
\hline 1,000 & 10 & $\$ 2,000,000$ & $\$ 393,333$ & $\$ 70,000$ & $\$ 1,811,250$ & $\$ 2,274,583$ & $\$ 0.05$ & $\$ 0.01$ & $\$ 0.22$ & $\$ 0.27$ & 60 & 3 & 7.50 \\
\hline 1,000 & 20 & $\$ 2,000,000$ & $\$ 393,333$ & $\$ 140,000$ & $\$ 1,811,250$ & $\$ 2,344,583$ & $\$ 0.05$ & $\$ 0.02$ & $\$ 0.22$ & $\$ 0.28$ & 60 & t & 7.50 \\
\hline 1,000 & 50 & $\$ 2,500,000$ & $\$ 491,667$ & $\$ 350,000$ & $\$ 2,415,000$ & $\$ 3,256,667$ & $\$ 0.06$ & $\$ 0.04$ & $\$ 0.29$ & $\$ 0.39$ & 60 & 4 & 6.00 \\
\hline 1,000 & 100 & $\$ 3,750,000$ & $\$ 737,500$ & $\$ 700,000$ & $\$ 3,622,500$ & $\$ 5,060,000$ & $\$ 0.09$ & $\$ 0.08$ & $\$ 0.43$ & $\$ 0.60$ & 60 & 6 & 4.00 \\
\hline 1,000 & 200 & $\$ 6,250,000$ & $\$ 1,229,167$ & $\$ 1,400,000$ & $\$ 6,037,500$ & $\$ 8,666,667$ & $\$ 0.15$ & $\$ 0.17$ & $\$ 0.72$ & $\$ 1.03$ & 60 & 10 & 2.40 \\
\hline 1,000 & 500 & $\$ 13,750,000$ & $\$ 2,704,167$ & $\$ 3,500,000$ & $\$ 13,282,500$ & $\$ 19,486,667$ & $\$ 0.32$ & $\$ 0.42$ & $\$ 1.58$ & $\$ 2.32$ & 60 & 22 & 1.09 \\
\hline 1,000 & 1,000 & $\$ 26,250,000$ & $\$ 5,162,500$ & $\$ 7,000,000$ & $\$ 25,357,500$ & $\$ 37,520,000$ & $\$ 0.61$ & $\$ 0.83$ & $\$ 3.02$ & $\$ 4.47$ & 60 & 42 & 0.57 \\
\hline 10,000 & 10 & $\$ 18,750,000$ & $\$ 3,687,500$ & $\$ 700,000$ & $\$ 18,112,500$ & $\$ 22,500,000$ & $\$ 0.04$ & $\$ 0.01$ & $\$ 0.22$ & $\$ 0.27$ & 600 & 3 & 8.00 \\
\hline 10,000 & 20 & $\$ 18,750,000$ & $\$ 3,687,500$ & $\$ 1,400,000$ & $\$ 18,112,500$ & $\$ 23,200,000$ & $\$ 0.04$ & $\$ 0.02$ & $\$ 0.22$ & $\$ 0.28$ & 600 & 가 & 8.00 \\
\hline 10,000 & 50 & $\$ 25,000,000$ & $\$ 4,916,667$ & $\$ 3,500,000$ & $\$ 24,150,000$ & $\$ 32,566,667$ & $\$ 0.06$ & $\$ 0.04$ & $\$ 0.29$ & $\$ 0.39$ & 600 & & 6.00 \\
\hline 10,000 & 100 & $\$ 37,500,000$ & $\$ 7,375,000$ & $\$ 7,000,000$ & $\$ 36,225,000$ & $\$ 50,600,000$ & $\$ 0.09$ & $\$ 0.08$ & $\$ 0.43$ & $\$ 0.60$ & 600 & 6 & 4.00 \\
\hline 10,000 & 200 & $\$ 62,500,000$ & $\$ 12,291,667$ & $\$ 14,000,000$ & $\$ 60,375,000$ & $\$ 86,666,667$ & $\$ 0.15$ & $\$ 0.17$ & $\$ 0.72$ & $\$ 1.03$ & 600 & 10 & 2.40 \\
\hline 10,000 & 500 & $\$ 137,500,000$ & $\$ 27,041,667$ & $\$ 35,000,000$ & $\$ 132,825,000$ & $\$ 194,866,667$ & $\$ 0.32$ & $\$ 0.42$ & $\$ 1.58$ & $\$ 2.32$ & 600 & 22 & 1.09 \\
\hline 10,000 & 1,000 & $\$ 262,500,000$ & $\$ 51,625,000$ & $\$ 70,000,000$ & $\$ 253,575,000$ & $\$ 375,200,000$ & $\$ 0.61$ & $\$ 0.83$ & $\$ 3.02$ & $\$ 4.47$ & 600 & 42 & 0.57 \\
\hline 100,000 & 10 & $\$ 187,500,000$ & $\$ 36,875,000$ & $\$ 7,000,000$ & $\$ 181,125,000$ & $\$ 225,000,000$ & $\$ 0.04$ & $\$ 0.01$ & $\$ 0.22$ & $\$ 0.27$ & 6000 & 3 & 8.00 \\
\hline 100,000 & 20 & $\$ 187,500,000$ & $\$ 36,875,000$ & $\$ 14,000,000$ & $\$ 181,125,000$ & $\$ 232,000,000$ & $\$ 0.04$ & $\$ 0.02$ & $\$ 0.22$ & $\$ 0.28$ & 6000 & 3 & 8.00 \\
\hline 100,000 & 50 & $\$ 250,000,000$ & $\$ 49,166,667$ & $\$ 35,000,000$ & $\$ 241,500,000$ & $\$ 325,666,667$ & $\$ 0.06$ & $\$ 0.04$ & $\$ 0.29$ & $\$ 0.39$ & 6000 & & (1) \\
\hline 100,000 & 100 & $\$ 375,000,000$ & $\$ 73,750,000$ & $\$ 70,000,000$ & $\$ 362,250,000$ & $\$ 506,000,000$ & $\$ 0.09$ & $\$ 0.08$ & $\$ 0.43$ & $\$ 0.60$ & 6000 & 6 & 4.00 \\
\hline 100,000 & 200 & $\$ 625,000,000$ & $\$ 122,916,667$ & $\$ 140,000,000$ & $\$ 603,750,000$ & $\$ 866,666,667$ & $\$ 0.15$ & $\$ 0.17$ & $\$ 0.72$ & $\$ 1.03$ & 6000 & 10 & 2.40 \\
\hline 100,000 & 500 & $\$ 1,375,000,000$ & $\$ 270,416,667$ & $\$ 350,000,000$ & $\$ 1,328,250,000$ & $\$ 1,948,666,667$ & $\$ 0.32$ & $\$ 0.42$ & $\$ 1.58$ & $\$ 2.32$ & 6000 & 22 & 1.09 \\
\hline 100,000 & 1,000 & $\$ 2,625,000,000$ & $\$ 516,250,000$ & $\$ 700,000,000$ & $\$ 2,535,750,000$ & $\$ 3,752,000,000$ & $\$ 0.61$ & $\$ 0.83$ & $\$ 3.02$ & $\$ 4.47$ & 6000 & 42 & 0.57 \\
\hline
\end{tabular}




\begin{tabular}{|c|c|c|c|c|c|c|c|c|c|c|c|c|}
\hline \multicolumn{13}{|c|}{ E.2 COMPRESSED GAS DELIVERY BY RAIL - SI Units } \\
\hline & & & & & & & & & & & & \\
\hline Rail Tube Unit= & & $\$ 200,000$ & per module & & & & & & & & & \\
\hline \multicolumn{2}{|c|}{ Rail Undercarriage= } & $\$ 100,000$ & per rail car & & & & & & & & & \\
\hline \multicolumn{2}{|c|}{ Rail Tube Capacity= } & 454 & kg/rail car & & & & & & & & & \\
\hline \multicolumn{2}{|c|}{ Rail Average Speed= } & 40 & $\mathrm{~km} / \mathrm{hr}$ & & & & & & & & & \\
\hline \multicolumn{2}{|c|}{ Rail Load/Unload Time= } & 24 & hr/trip & & & & & & & & & \\
\hline \multicolumn{2}{|c|}{ Rail Car Availability $=$} & 24 & hr/day & & & & & & & & & \\
\hline \multirow{2}{*}{\multicolumn{2}{|c|}{\begin{tabular}{l|l} 
Rail Freight $=$ & \\
Operating Days $/$ Year $=$
\end{tabular}}} & $\$ 400$ & per rail car & & & & & & & & & \\
\hline & & 350 & days/yr & & & & & & & & & \\
\hline \multicolumn{2}{|c|}{ Railcar Depreciation $=$} & 15 & years & & & & & & & & & \\
\hline & & & & & & & & & & & & \\
\hline & & & & & & & & & & & & \\
\hline Hydrogen & Delivery Distance & Distance & Annual & Railcar & Number & Total Miles & Transit & Total Transit & Total Load/ & Total Delivery & Railcar & Railcars \\
\hline Production & One-Way & Two-Way & Production & Capacity & of Trips & & Time & Time & Unload Time & Time & Availability & Required \\
\hline$(\mathrm{kg} / \mathrm{hr})$ & $(\mathrm{km})$ & (km/trip) & $(\mathrm{kg} / \mathrm{yr})$ & (kg/truck) & (trips/yr) & $(\mathrm{km} / \mathrm{yr})$ & (days/trip) & $(\mathrm{hr} / \mathrm{yr})$ & $(\mathrm{hr} / \mathrm{yr})$ & $(\mathrm{hr} / \mathrm{yr})$ & $(\mathrm{hr} / \mathrm{yr})$ & \\
\hline 5 & 16 & 32 & 38,102 & 454 & 84 & 2,703 & 2 & 4,032 & 2,016 & 6,048 & 8,400 & 1 \\
\hline 5 & 32 & 64 & 38,102 & 454 & 84 & 5,406 & 2 & 4,032 & 2,016 & 6,048 & 8,400 & 1 \\
\hline 5 & 80 & 161 & 38,102 & 454 & 84 & 13,516 & 2 & 4,032 & 2,016 & 6,048 & 8,400 & 1 \\
\hline 5 & 161 & 322 & 38,102 & 454 & 84 & 27,031 & 2 & 4,032 & 2,016 & 6,048 & 8,400 & 1 \\
\hline 5 & 322 & 644 & 38,102 & 454 & 84 & 54,062 & 2 & 4,032 & 2,016 & 6,048 & 8,400 & 1 \\
\hline 5 & 805 & 1,609 & 38,102 & 454 & 84 & 135,156 & 2 & 4,032 & 2,016 & 6,048 & 8,400 & 1 \\
\hline 5 & 1,609 & 3,218 & 38,102 & 454 & 84 & 270,312 & 4 & 8,064 & 2,016 & 10,080 & 8,400 & 2 \\
\hline 45 & 16 & 32 & 381,016 & 454 & 840 & 27,031 & 2 & 40,320 & 20,160 & 60,480 & 8,400 & 8 \\
\hline 45 & 32 & 64 & 381,016 & 454 & 840 & 54,062 & 2 & 40,320 & 20,160 & 60,480 & 8,400 & 8 \\
\hline 45 & 80 & 161 & 381,016 & 454 & 840 & 135,156 & 2 & 40,320 & 20,160 & 60,480 & 8,400 & 8 \\
\hline 45 & 161 & 322 & 381,016 & 454 & 840 & 270,312 & 2 & 40,320 & 20,160 & 60,480 & 8,400 & 8 \\
\hline 45 & 322 & 644 & 381,016 & 454 & 840 & 540,624 & 2 & 40,320 & 20,160 & 60,480 & 8,400 & 8 \\
\hline 45 & 805 & 1,609 & 381,016 & 454 & 840 & $1,351,560$ & 2 & 40,320 & 20,160 & 60,480 & 8,400 & 8 \\
\hline 45 & 1,609 & 3,218 & 381,016 & 454 & 840 & $2,703,120$ & 4 & 80,640 & 20,160 & 100,800 & 8,400 & 12 \\
\hline 454 & 16 & 32 & $3,810,156$ & 454 & 8,400 & 270,312 & 2 & 403,200 & 201,600 & 604,800 & 8,400 & 72 \\
\hline 454 & 32 & 64 & $3,810,156$ & 454 & 8,400 & 540,624 & 2 & 403,200 & 201,600 & 604,800 & 8,400 & 72 \\
\hline 454 & 80 & 161 & $3,810,156$ & 454 & 8,400 & $1,351,560$ & 2 & 403,200 & 201,600 & 604,800 & 8,400 & 72 \\
\hline 454 & 161 & 322 & $3,810,156$ & 454 & 8,400 & $2,703,120$ & 2 & 403,200 & 201,600 & 604,800 & 8,400 & 72 \\
\hline 454 & 322 & 644 & $3,810,156$ & 454 & 8,400 & $5,406,240$ & 2 & 403,200 & 201,600 & 604,800 & 8,400 & 72 \\
\hline 454 & 805 & 1,609 & $3,810,156$ & 454 & 8,400 & $13,515,600$ & 2 & 403,200 & 201,600 & 604,800 & 8,400 & 72 \\
\hline 454 & 1,609 & 3,218 & $3,810,156$ & 454 & 8,400 & $27,031,200$ & 4 & 806,400 & 201,600 & $1,008,000$ & 8,400 & 120 \\
\hline 4,536 & 16 & 32 & $38,101,560$ & 454 & 84,000 & $2,703,120$ & 2 & $4,032,000$ & $2,016,000$ & $6,048,000$ & 8,400 & 720 \\
\hline 4,536 & 32 & 64 & $38,101,560$ & 454 & 84,000 & $5,406,240$ & 2 & $4,032,000$ & $2,016,000$ & $6,048,000$ & 8,400 & 720 \\
\hline 4,536 & 80 & 161 & $38,101,560$ & 454 & 84,000 & $13,515,600$ & 2 & $4,032,000$ & $2,016,000$ & $6,048,000$ & 8,400 & 720 \\
\hline 4,536 & 161 & 322 & $38,101,560$ & 454 & 84,000 & $27,031,200$ & 2 & $4,032,000$ & $2,016,000$ & $6,048,000$ & 8,400 & 720 \\
\hline 4,536 & 322 & 644 & $38,101,560$ & 454 & 84,000 & $54,062,400$ & 2 & $4,032,000$ & $2,016,000$ & $6,048,000$ & 8,400 & 720 \\
\hline 4,536 & 805 & 1,609 & $38,101,560$ & 454 & 84,000 & $135,156,000$ & 2 & $4,032,000$ & $2,016,000$ & $6,048,000$ & 8,400 & 720 \\
\hline 4,536 & 1,609 & 3,218 & $38,101,560$ & 454 & 84,000 & $270,312,000$ & 4 & $8,064,000$ & $2,016,000$ & $10,080,000$ & 8,400 & 1,200 \\
\hline 45,359 & 16 & 32 & $381,015,600$ & 454 & 840,000 & $27,031,200$ & 2 & $40,320,000$ & $20,160,000$ & $60,480,000$ & 8,400 & 7,200 \\
\hline 45,359 & 32 & 64 & $381,015,600$ & 454 & 840,000 & $54,062,400$ & 2 & $40,320,000$ & $20,160,000$ & $60,480,000$ & 8,400 & 7,200 \\
\hline 45,359 & 80 & 161 & $381,015,600$ & 454 & 840,000 & $135,156,000$ & 2 & $40,320,000$ & $20,160,000$ & $60,480,000$ & 8,400 & 7,200 \\
\hline 45,359 & 161 & 322 & $381,015,600$ & 454 & 840,000 & $270,312,000$ & 2 & $40,320,000$ & $20,160,000$ & $60,480,000$ & 8,400 & 7,200 \\
\hline 45,359 & 322 & 644 & $381,015,600$ & 454 & 840,000 & $540,624,000$ & 2 & $40,320,000$ & $20,160,000$ & $60,480,000$ & 8,400 & 7,200 \\
\hline 45,359 & 805 & 1,609 & $381,015,600$ & 454 & 840,000 & \begin{tabular}{|l|}
$1,351,560,000$ \\
\end{tabular} & 2 & $40,320,000$ & $20,160,000$ & $60,480,000$ & 8,400 & 7,200 \\
\hline 45,359 & 1,609 & 3,218 & $381,015,600$ & 454 & 840,000 & \begin{tabular}{|l|}
$2,703,120,000$ \\
\end{tabular} & 4 & $80,640,000$ & $20,160,000$ & $100,800,000$ & 8,400 & 12,000 \\
\hline
\end{tabular}

E - 7 


\begin{tabular}{|c|c|c|c|c|c|c|c|c|c|c|c|}
\hline \multicolumn{12}{|c|}{ E.2 COMPRESSED GAS DELIVERY BY RAIL - SI Units (Continued) } \\
\hline & & & & & & & & & & & \\
\hline & & & & & & & & & & & \\
\hline Hydrogen & Delivery Distanc & Total Capital & Depreciation & Annual Freight & Total Annual & Capital & Freight & Total & Trip & Trip & Railcar \\
\hline Production & One-Way & Cost & & Cost & Cost & Cost & Cost & Cost & Frequency & Length & Utilization \\
\hline$(\mathrm{kg} / \mathrm{hr})$ & $(\mathrm{km})$ & (\$) & $(\$ / y r)$ & $(\$ / \mathrm{yr})$ & $(\$ / \mathrm{yr})$ & $(\$ / \mathrm{kg})$ & $(\$ / \mathrm{kg})$ & $(\$ / \mathrm{kg})$ & (trips/day) & (hours) & (trips/railcar/d) \\
\hline 5 & 16 & $\$ 300,000$ & $\$ 20,000$ & $\$ 67,200$ & $\$ 87,200$ & $\$ 0.52$ & $\$ 1.76$ & $\$ 2.29$ & 0.24 & 72 & 0.24 \\
\hline 5 & 32 & $\$ 300,000$ & $\$ 20,000$ & $\$ 67,200$ & $\$ 87,200$ & $\$ 0.52$ & $\$ 1.76$ & $\$ 2.29$ & 0.24 & 72 & 0.24 \\
\hline 5 & 80 & $\$ 300,000$ & $\$ 20,000$ & $\$ 67,200$ & $\$ 87,200$ & $\$ 0.52$ & $\$ 1.76$ & $\$ 2.29$ & 0.24 & 72 & 0.24 \\
\hline 5 & 161 & $\$ 300,000$ & $\$ 20,000$ & $\$ 67,200$ & $\$ 87,200$ & $\$ 0.52$ & $\$ 1.76$ & $\$ 2.29$ & 0.24 & 72 & 0.24 \\
\hline 5 & 322 & $\$ 300,000$ & $\$ 20,000$ & $\$ 67,200$ & $\$ 87,200$ & $\$ 0.52$ & $\$ 1.76$ & $\$ 2.29$ & 0.24 & 72 & 0.24 \\
\hline 5 & 805 & $\$ 300,000$ & $\$ 20,000$ & $\$ 67,200$ & $\$ 87,200$ & $\$ 0.52$ & $\$ 1.76$ & $\$ 2.29$ & 0.24 & 72 & 0.24 \\
\hline 5 & 1,609 & $\$ 600,000$ & $\$ 40,000$ & $\$ 67,200$ & $\$ 107,200$ & $\$ 1.05$ & $\$ 1.76$ & $\$ 2.81$ & 0.24 & 120 & 0.12 \\
\hline 45 & 16 & $\$ 2,400,000$ & $\$ 160,000$ & $\$ 672,000$ & $\$ 832,000$ & $\$ 0.42$ & $\$ 1.76$ & $\$ 2.18$ & 2.4 & 72 & 0.30 \\
\hline 45 & 32 & $\$ 2,400,000$ & $\$ 160,000$ & $\$ 672,000$ & $\$ 832,000$ & $\$ 0.42$ & $\$ 1.76$ & $\$ 2.18$ & 2.4 & 72 & 0.30 \\
\hline 45 & 80 & $\$ 2,400,000$ & $\$ 160,000$ & $\$ 672,000$ & $\$ 832,000$ & $\$ 0.42$ & $\$ 1.76$ & $\$ 2.18$ & 2.4 & 72 & 0.30 \\
\hline 45 & 161 & $\$ 2,400,000$ & $\$ 160,000$ & $\$ 672,000$ & $\$ 832,000$ & $\$ 0.42$ & $\$ 1.76$ & $\$ 2.18$ & 2.4 & 72 & 0.30 \\
\hline 45 & 322 & $\$ 2,400,000$ & $\$ 160,000$ & $\$ 672,000$ & $\$ 832,000$ & $\$ 0.42$ & $\$ 1.76$ & $\$ 2.18$ & 2.4 & 72 & 0.30 \\
\hline 45 & 805 & $\$ 2,400,000$ & $\$ 160,000$ & $\$ 672,000$ & $\$ 832,000$ & $\$ 0.42$ & $\$ 1.76$ & $\$ 2.18$ & 2.4 & 72 & 0.30 \\
\hline 45 & 1,609 & $\$ 3,600,000$ & $\$ 240,000$ & $\$ 672,000$ & $\$ 912,000$ & $\$ 0.63$ & $\$ 1.76$ & $\$ 2.39$ & 2.4 & 120 & 0.20 \\
\hline 454 & 16 & $\$ 21,600,000$ & $\$ 1,440,000$ & $\$ 6,720,000$ & $\$ 8,160,000$ & $\$ 0.38$ & $\$ 1.76$ & $\$ 2.14$ & 24 & 72 & 0.33 \\
\hline 454 & 32 & $\$ 21,600,000$ & $\$ 1,440,000$ & $\$ 6,720,000$ & $\$ 8,160,000$ & $\$ 0.38$ & $\$ 1.76$ & $\$ 2.14$ & 24 & 72 & 0.33 \\
\hline 454 & 80 & $\$ 21,600,000$ & $\$ 1,440,000$ & $\$ 6,720,000$ & $\$ 8,160,000$ & $\$ 0.38$ & $\$ 1.76$ & $\$ 2.14$ & 24 & 72 & 0.33 \\
\hline 454 & 161 & $\$ 21,600,000$ & $\$ 1,440,000$ & $\$ 6,720,000$ & $\$ 8,160,000$ & $\$ 0.38$ & $\$ 1.76$ & $\$ 2.14$ & 24 & 72 & 0.33 \\
\hline 454 & 322 & $\$ 21,600,000$ & $\$ 1,440,000$ & $\$ 6,720,000$ & $\$ 8,160,000$ & $\$ 0.38$ & $\$ 1.76$ & $\$ 2.14$ & 24 & 72 & 0.33 \\
\hline 454 & 805 & $\$ 21,600,000$ & $\$ 1,440,000$ & $\$ 6,720,000$ & $\$ 8,160,000$ & $\$ 0.38$ & $\$ 1.76$ & $\$ 2.14$ & 24 & 72 & 0.33 \\
\hline 454 & 1,609 & $\$ 36,000,000$ & $\$ 2,400,000$ & $\$ 6,720,000$ & $\$ 9,120,000$ & $\$ 0.63$ & $\$ 1.76$ & $\$ 2.39$ & 24 & 120 & 0.20 \\
\hline 4,536 & 16 & $\$ 216,000,000$ & $\$ 14,400,000$ & $\$ 67,200,000$ & $\$ 81,600,000$ & $\$ 0.38$ & $\$ 1.76$ & $\$ 2.14$ & 240 & 72 & 0.33 \\
\hline 4,536 & 32 & $\$ 216,000,000$ & $\$ 14,400,000$ & $\$ 67,200,000$ & $\$ 81,600,000$ & $\$ 0.38$ & $\$ 1.76$ & $\$ 2.14$ & 240 & 72 & 0.33 \\
\hline 4,536 & 80 & $\$ 216,000,000$ & $\$ 14,400,000$ & $\$ 67,200,000$ & $\$ 81,600,000$ & $\$ 0.38$ & $\$ 1.76$ & $\$ 2.14$ & 240 & 72 & 0.33 \\
\hline 4,536 & 161 & $\$ 216,000,000$ & $\$ 14,400,000$ & $\$ 67,200,000$ & $\$ 81,600,000$ & $\$ 0.38$ & $\$ 1.76$ & $\$ 2.14$ & 240 & 72 & 0.33 \\
\hline 4,536 & 322 & $\$ 216,000,000$ & $\$ 14,400,000$ & $\$ 67,200,000$ & $\$ 81,600,000$ & $\$ 0.38$ & $\$ 1.76$ & $\$ 2.14$ & 240 & 72 & 0.33 \\
\hline 4,536 & 805 & $\$ 216,000,000$ & $\$ 14,400,000$ & $\$ 67,200,000$ & $\$ 81,600,000$ & $\$ 0.38$ & $\$ 1.76$ & $\$ 2.14$ & 240 & 72 & 0.33 \\
\hline 45,359 & 1,609 & $\$ 360,000,000$ & $\$ 24,000,000$ & $\$ 67,200,000$ & $\$ 91,200,000$ & $\$ 0.63$ & $\$ 1.76$ & $\$ 2.39$ & 240 & 120 & 0.20 \\
\hline 45,359 & 16 & $\$ 2,160,000,000$ & $\$ 144,000,000$ & $\$ 672,000,000$ & $\$ 816,000,000$ & $\$ 0.38$ & $\$ 1.76$ & $\$ 2.14$ & 2400 & 72 & 0.33 \\
\hline 45,359 & 32 & $\$ 2,160,000,000$ & $\$ 144,000,000$ & $\$ 672,000,000$ & $\$ 816,000,000$ & $\$ 0.38$ & $\$ 1.76$ & $\$ 2.14$ & 2400 & 72 & 0.33 \\
\hline 45,359 & 80 & $\$ 2,160,000,000$ & $\$ 144,000,000$ & $\$ 672,000,000$ & $\$ 816,000,000$ & $\$ 0.38$ & $\$ 1.76$ & $\$ 2.14$ & 2400 & 72 & 0.33 \\
\hline 45,359 & 161 & $\$ 2,160,000,000$ & $\$ 144,000,000$ & $\$ 672,000,000$ & $\$ 816,000,000$ & $\$ 0.38$ & $\$ 1.76$ & $\$ 2.14$ & 2400 & 72 & 0.33 \\
\hline 45,359 & 322 & $\$ 2,160,000,000$ & $\$ 144,000,000$ & $\$ 672,000,000$ & $\$ 816,000,000$ & $\$ 0.38$ & $\$ 1.76$ & $\$ 2.14$ & 2400 & 72 & 0.33 \\
\hline 45,359 & 805 & $\$ 2,160,000,000$ & $\$ 144,000,000$ & $\$ 672,000,000$ & $\$ 816,000,000$ & $\$ 0.38$ & $\$ 1.76$ & $\$ 2.14$ & 2400 & 72 & 0.33 \\
\hline 45,359 & 1,609 & $\$ 3,600,000,000$ & $\$ 240,000,000$ & $\$ 672,000,000$ & $\$ 912,000,000$ & $\$ 0.63$ & $\$ 1.76$ & $\$ 2.39$ & 2400 & 120 & 0.20 \\
\hline
\end{tabular}




\begin{tabular}{|c|c|c|c|c|c|c|c|c|c|c|c|c|}
\hline \multicolumn{13}{|c|}{ E.2 COMPRESSED GAS DELIVERY BY RAIL - English Units } \\
\hline & & & & & & & & & & & & \\
\hline Rail Tube Unit= & & $\$ 200,000$ & per module & & & & & & & & & \\
\hline \multicolumn{2}{|c|}{ Rail Undercarriage $=$} & $\$ 100,000$ & per rail car & & & & & & & & & \\
\hline \multicolumn{2}{|c|}{ Rail Tube Capacity= } & 1,000 & Ib/rail car & & & & & & & & & \\
\hline \multicolumn{2}{|c|}{ Rail Average Speed= } & 25 & $\mathrm{mph}$ & & & & & & & & & \\
\hline \multicolumn{2}{|c|}{ Rail Load/Unload Time= } & 24 & hr/trip & & & & & & & & & \\
\hline \multicolumn{2}{|c|}{ Rail Car Availability= } & 24 & $\mathrm{hr} / \mathrm{day}$ & & & & & & & & & \\
\hline Rail Freight $=$ & & $\$ 400$ & per rail car & & & & & & & & & \\
\hline \multicolumn{2}{|c|}{ Operating Days/Year= } & 350 & days/yr & & & & & & & & & \\
\hline \multicolumn{2}{|c|}{ Railcar Depreciation $=$} & 15 & years & & & & & & & & & \\
\hline & & & & & & & & & & & & \\
\hline Hydrogen & Delivery Distance & & Annual & Railcar & Number & Total Miles & Transit & Total Transit & Total Load/ & Total Delivery & Railcar & Railcars \\
\hline Production & \begin{tabular}{|l} 
\\
\end{tabular} & Two-Way & Production & Capacity & of Trips & & Time & \begin{tabular}{|l} 
Time \\
\end{tabular} & \begin{tabular}{|l} 
Unload Time \\
\end{tabular} & Time & \begin{tabular}{|l} 
Availability \\
\end{tabular} & Required \\
\hline$(\mathrm{lb} / \mathrm{hr})$ & (miles) & (miles/trip) & $(\mathrm{lb} / \mathrm{yr})$ & (Ib/truck) & (trips/yr) & (miles/yr) & (days/trip) & $(\mathrm{hr} / \mathrm{yr})$ & $(\mathrm{hr} / \mathrm{yr})$ & $(\mathrm{hr} / \mathrm{yr})$ & $(\mathrm{hr} / \mathrm{yr})$ & \\
\hline 10 & 10 & 20 & 84,000 & 1,000 & 84 & 1,680 & 2 & 4,032 & 2,016 & 6,048 & 8,400 & 1 \\
\hline 10 & 20 & 40 & 84,000 & 1,000 & 84 & 3,360 & 2 & 4,032 & 2,016 & 6,048 & 8,400 & 1 \\
\hline 10 & 50 & 100 & 84,000 & 1,000 & 84 & 8,400 & 2 & 4,032 & 2,016 & 6,048 & 8,400 & 1 \\
\hline 10 & 100 & 200 & 84,000 & 1,000 & 84 & 16,800 & 2 & 4,032 & 2,016 & 6,048 & 8,400 & 1 \\
\hline 10 & 200 & 400 & 84,000 & 1,000 & 84 & 33,600 & 2 & 4,032 & 2,016 & 6,048 & 8,400 & 1 \\
\hline 10 & 500 & 1,000 & 84,000 & 1,000 & 84 & 84,000 & 2 & 4,032 & 2,016 & 6,048 & 8,400 & 1 \\
\hline 10 & 1,000 & 2,000 & 84,000 & 1,000 & 84 & 168,000 & 4 & 8,064 & 2,016 & 10,080 & 8,400 & 2 \\
\hline 100 & 10 & 20 & 840,000 & 1,000 & 840 & 16,800 & 2 & 40,320 & 20,160 & 60,480 & 8,400 & 8 \\
\hline 100 & 20 & 40 & 840,000 & 1,000 & 840 & 33,600 & 2 & 40,320 & 20,160 & 60,480 & 8,400 & 8 \\
\hline 100 & 50 & 100 & 840,000 & 1,000 & 840 & 84,000 & 2 & 40,320 & 20,160 & 60,480 & 8,400 & 8 \\
\hline 100 & 100 & 200 & 840,000 & 1,000 & 840 & 168,000 & 2 & 40,320 & 20,160 & 60,480 & 8,400 & 8 \\
\hline 100 & 200 & 400 & 840,000 & 1,000 & 840 & 336,000 & 2 & 40,320 & 20,160 & 60,480 & 8,400 & 8 \\
\hline 100 & 500 & 1,000 & 840,000 & 1,000 & 840 & 840,000 & 2 & 40,320 & 20,160 & 60,480 & 8,400 & 8 \\
\hline 100 & 1,000 & 2,000 & 840,000 & 1,000 & 840 & $1,680,000$ & 4 & 80,640 & 20,160 & 100,800 & 8,400 & 12 \\
\hline \begin{tabular}{l|}
1,000 \\
\end{tabular} & 10 & 20 & $8,400,000$ & 1,000 & 8,400 & 168,000 & 2 & 403,200 & 201,600 & 604,800 & 8,400 & 72 \\
\hline 1,000 & 20 & 40 & $8,400,000$ & 1,000 & 8,400 & 336,000 & 2 & 403,200 & 201,600 & 604,800 & 8,400 & 72 \\
\hline 1,000 & 50 & 100 & $8,400,000$ & 1,000 & 8,400 & 840,000 & 2 & 403,200 & 201,600 & 604,800 & 8,400 & 72 \\
\hline 1,000 & 100 & 200 & $8,400,000$ & 1,000 & 8,400 & $1,680,000$ & 2 & 403,200 & 201,600 & 604,800 & 8,400 & 72 \\
\hline 1,000 & 200 & 400 & $8,400,000$ & 1,000 & 8,400 & $3,360,000$ & 2 & 403,200 & 201,600 & 604,800 & 8,400 & 72 \\
\hline 1,000 & 500 & 1,000 & $8,400,000$ & 1,000 & 8,400 & $8,400,000$ & 2 & 403,200 & 201,600 & 604,800 & 8,400 & 72 \\
\hline 1,000 & 1,000 & 2,000 & $8,400,000$ & 1,000 & 8,400 & $16,800,000$ & 4 & 806,400 & 201,600 & $1,008,000$ & 8,400 & 120 \\
\hline 10,000 & 10 & 20 & $84,000,000$ & 1,000 & 84,000 & $1,680,000$ & 2 & $4,032,000$ & $2,016,000$ & $6,048,000$ & 8,400 & 720 \\
\hline 10,000 & 20 & 40 & $84,000,000$ & 1,000 & 84,000 & $3,360,000$ & 2 & $4,032,000$ & $2,016,000$ & $6,048,000$ & 8,400 & 720 \\
\hline 10,000 & 50 & 100 & $84,000,000$ & 1,000 & 84,000 & $8,400,000$ & 2 & $4,032,000$ & $2,016,000$ & $6,048,000$ & 8,400 & 720 \\
\hline 10,000 & 100 & 200 & $84,000,000$ & 1,000 & 84,000 & $16,800,000$ & 2 & $4,032,000$ & $2,016,000$ & $6,048,000$ & 8,400 & 720 \\
\hline 10,000 & 200 & 400 & $84,000,000$ & 1,000 & 84,000 & $33,600,000$ & 2 & $4,032,000$ & $2,016,000$ & $6,048,000$ & 8,400 & 720 \\
\hline 10,000 & 500 & 1,000 & $84,000,000$ & 1,000 & 84,000 & $84,000,000$ & 2 & $4,032,000$ & $2,016,000$ & $6,048,000$ & 8,400 & 720 \\
\hline 10,000 & 1,000 & 2,000 & $84,000,000$ & 1,000 & 84,000 & $168,000,000$ & 4 & $8,064,000$ & $2,016,000$ & $10,080,000$ & 8,400 & 1,200 \\
\hline 100,000 & 10 & 20 & $840,000,000$ & 1,000 & 840,000 & $16,800,000$ & 2 & $40,320,000$ & $20,160,000$ & $60,480,000$ & 8,400 & 7,200 \\
\hline 100,000 & 20 & 40 & $840,000,000$ & 1,000 & 840,000 & $33,600,000$ & 2 & $40,320,000$ & $20,160,000$ & $60,480,000$ & 8,400 & 7,200 \\
\hline 100,000 & 50 & 100 & $840,000,000$ & 1,000 & 840,000 & $84,000,000$ & 2 & $40,320,000$ & $20,160,000$ & $60,480,000$ & 8,400 & 7,200 \\
\hline \begin{tabular}{l|l}
100,000 \\
\end{tabular} & 100 & 200 & $840,000,000$ & 1,000 & 840,000 & $168,000,000$ & 2 & $40,320,000$ & $20,160,000$ & $60,480,000$ & 8,400 & 7,200 \\
\hline 100,000 & 200 & 400 & $840,000,000$ & 1,000 & 840,000 & $336,000,000$ & 2 & $40,320,000$ & $20,160,000$ & $60,480,000$ & 8,400 & 7,200 \\
\hline \begin{tabular}{l|l}
100,000 \\
\end{tabular} & 500 & 1,000 & $840,000,000$ & 1,000 & 840,000 & $840,000,000$ & 2 & $40,320,000$ & $20,160,000$ & $60,480,000$ & 8,400 & 7,200 \\
\hline \begin{tabular}{l|}
100,000 \\
\end{tabular} & 1,000 & 2,000 & $840,000,000$ & 1,000 & 840,000 & \begin{tabular}{|l|}
$1,680,000,000$ \\
\end{tabular} & 4 & $80,640,000$ & $20,160,000$ & $100,800,000$ & 8,400 & 12,000 \\
\hline
\end{tabular}




\begin{tabular}{|c|c|c|c|c|c|c|c|c|c|c|c|}
\hline \multicolumn{12}{|c|}{ E.2 COMPRESSED GAS DELIVERY BY RAIL - English Units (Continued) } \\
\hline & & & & & & & & & & & \\
\hline & & & & & & & & & & & \\
\hline Hydrogen & Delivery Distand & Total Capital & Depreciation & Annual Freight & Total Annual & Capital & Freight & Total & Trip & Trip & Railcar \\
\hline Production & One-Way & Cost & & Cost & Cost & Cost & Cost & Cost & Frequency & Length & \begin{tabular}{|l|} 
Utilization \\
\end{tabular} \\
\hline$(\mathrm{lb} / \mathrm{hr})$ & (miles) & $(\$)$ & $(\$ / y r)$ & $(\$ / \mathrm{yr})$ & $(\$ / y r)$ & $(\$ / / \mathrm{lb})$ & $(\$ / \mathrm{lb})$ & $(\$ / / \mathrm{b})$ & (trips/day) & (hours) & (trips/railcar/d) \\
\hline 10 & 10 & $\$ 300,000$ & $\$ 20,000$ & $\$ 67,200$ & $\$ 87,200$ & $\$ 0.24$ & $\$ 0.80$ & $\$ 1.04$ & 0.24 & 72 & 0.24 \\
\hline 10 & 20 & $\$ 300,000$ & $\$ 20,000$ & $\$ 67,200$ & $\$ 87,200$ & $\$ 0.24$ & $\$ 0.80$ & $\$ 1.04$ & 0.24 & 72 & 0.24 \\
\hline 10 & 50 & $\$ 300,000$ & $\$ 20,000$ & $\$ 67,200$ & $\$ 87,200$ & $\$ 0.24$ & $\$ 0.80$ & $\$ 1.04$ & 0.24 & 72 & 0.24 \\
\hline 10 & 100 & $\$ 300,000$ & $\$ 20,000$ & $\$ 67,200$ & $\$ 87,200$ & $\$ 0.24$ & $\$ 0.80$ & $\$ 1.04$ & 0.24 & 72 & 0.24 \\
\hline 10 & 200 & $\$ 300,000$ & $\$ 20,000$ & $\$ 67,200$ & $\$ 87,200$ & $\$ 0.24$ & $\$ 0.80$ & $\$ 1.04$ & 0.24 & 72 & 0.24 \\
\hline 10 & 500 & $\$ 300,000$ & $\$ 20,000$ & $\$ 67,200$ & $\$ 87,200$ & $\$ 0.24$ & $\$ 0.80$ & $\$ 1.04$ & 0.24 & 72 & 0.24 \\
\hline 10 & 1,000 & $\$ 600,000$ & $\$ 40,000$ & $\$ 67,200$ & $\$ 107,200$ & $\$ 0.48$ & $\$ 0.80$ & $\$ 1.28$ & 0.24 & 120 & 0.12 \\
\hline 100 & 10 & $\$ 2,400,000$ & $\$ 160,000$ & $\$ 672,000$ & $\$ 832,000$ & $\$ 0.19$ & $\$ 0.80$ & $\$ 0.99$ & 2.4 & 72 & 0.30 \\
\hline 100 & 20 & $\$ 2,400,000$ & $\$ 160,000$ & $\$ 672,000$ & $\$ 832,000$ & $\$ 0.19$ & $\$ 0.80$ & $\$ 0.99$ & 2.4 & 72 & 0.30 \\
\hline 100 & 50 & $\$ 2,400,000$ & $\$ 160,000$ & $\$ 672,000$ & $\$ 832,000$ & $\$ 0.19$ & $\$ 0.80$ & $\$ 0.99$ & 2.4 & 72 & 0.30 \\
\hline 100 & 100 & $\$ 2,400,000$ & $\$ 160,000$ & $\$ 672,000$ & $\$ 832,000$ & $\$ 0.19$ & $\$ 0.80$ & $\$ 0.99$ & 2.4 & 72 & 0.30 \\
\hline 100 & 200 & $\$ 2,400,000$ & $\$ 160,000$ & $\$ 672,000$ & $\$ 832,000$ & $\$ 0.19$ & $\$ 0.80$ & $\$ 0.99$ & 2.4 & 72 & 0.30 \\
\hline 100 & 500 & $\$ 2,400,000$ & $\$ 160,000$ & $\$ 672,000$ & $\$ 832,000$ & $\$ 0.19$ & $\$ 0.80$ & $\$ 0.99$ & 2.4 & 72 & 0.30 \\
\hline 100 & 1,000 & $\$ 3,600,000$ & $\$ 240,000$ & $\$ 672,000$ & $\$ 912,000$ & $\$ 0.29$ & $\$ 0.80$ & $\$ 1.09$ & 2.4 & 120 & 0.20 \\
\hline 1,000 & 10 & $\$ 21,600,000$ & $\$ 1,440,000$ & $\$ 6,720,000$ & $\$ 8,160,000$ & $\$ 0.17$ & $\$ 0.80$ & $\$ 0.97$ & 24 & 72 & 0.33 \\
\hline 1,000 & 20 & $\$ 21,600,000$ & $\$ 1,440,000$ & $\$ 6,720,000$ & $\$ 8,160,000$ & $\$ 0.17$ & $\$ 0.80$ & $\$ 0.97$ & 24 & 72 & 0.33 \\
\hline 1,000 & 50 & $\$ 21,600,000$ & $\$ 1,440,000$ & $\$ 6,720,000$ & $\$ 8,160,000$ & $\$ 0.17$ & $\$ 0.80$ & $\$ 0.97$ & 24 & 72 & 0.33 \\
\hline 1,000 & 100 & $\$ 21,600,000$ & $\$ 1,440,000$ & $\$ 6,720,000$ & $\$ 8,160,000$ & $\$ 0.17$ & $\$ 0.80$ & $\$ 0.97$ & 24 & 72 & 0.33 \\
\hline 1,000 & 200 & $\$ 21,600,000$ & $\$ 1,440,000$ & $\$ 6,720,000$ & $\$ 8,160,000$ & $\$ 0.17$ & $\$ 0.80$ & $\$ 0.97$ & 24 & 72 & 0.33 \\
\hline 1,000 & 500 & $\$ 21,600,000$ & $\$ 1,440,000$ & $\$ 6,720,000$ & $\$ 8,160,000$ & $\$ 0.17$ & $\$ 0.80$ & $\$ 0.97$ & 24 & 72 & 0.33 \\
\hline 1,000 & 1,000 & $\$ 36,000,000$ & $\$ 2,400,000$ & $\$ 6,720,000$ & $\$ 9,120,000$ & $\$ 0.29$ & $\$ 0.80$ & $\$ 1.09$ & 24 & 120 & 0.20 \\
\hline 10,000 & 10 & $\$ 216,000,000$ & $\$ 14,400,000$ & $\$ 67,200,000$ & $\$ 81,600,000$ & $\$ 0.17$ & $\$ 0.80$ & $\$ 0.97$ & 240 & 72 & 0.33 \\
\hline 10,000 & 20 & $\$ 216,000,000$ & $\$ 14,400,000$ & $\$ 67,200,000$ & $\$ 81,600,000$ & $\$ 0.17$ & $\$ 0.80$ & $\$ 0.97$ & 240 & 72 & 0.33 \\
\hline 10,000 & 50 & $\$ 216,000,000$ & $\$ 14,400,000$ & $\$ 67,200,000$ & $\$ 81,600,000$ & $\$ 0.17$ & $\$ 0.80$ & $\$ 0.97$ & 240 & 72 & 0.33 \\
\hline 10,000 & 100 & $\$ 216,000,000$ & $\$ 14,400,000$ & $\$ 67,200,000$ & $\$ 81,600,000$ & $\$ 0.17$ & $\$ 0.80$ & $\$ 0.97$ & 240 & 72 & 0.33 \\
\hline 10,000 & 200 & $\$ 216,000,000$ & $\$ 14,400,000$ & $\$ 67,200,000$ & $\$ 81,600,000$ & $\$ 0.17$ & $\$ 0.80$ & $\$ 0.97$ & 240 & 72 & 0.33 \\
\hline 10,000 & 500 & $\$ 216,000,000$ & $\$ 14,400,000$ & $\$ 67,200,000$ & $\$ 81,600,000$ & $\$ 0.17$ & $\$ 0.80$ & $\$ 0.97$ & 240 & 72 & 0.33 \\
\hline 100,000 & 1,000 & $\$ 360,000,000$ & $\$ 24,000,000$ & $\$ 67,200,000$ & $\$ 91,200,000$ & $\$ 0.29$ & $\$ 0.80$ & $\$ 1.09$ & 240 & 120 & 0.20 \\
\hline 100,000 & 10 & $\$ 2,160,000,000$ & $\$ 144,000,000$ & $\$ 672,000,000$ & $\$ 816,000,000$ & $\$ 0.17$ & $\$ 0.80$ & $\$ 0.97$ & 2400 & 72 & 0.33 \\
\hline 100,000 & 20 & $\$ 2,160,000,000$ & $\$ 144,000,000$ & $\$ 672,000,000$ & $\$ 816,000,000$ & $\$ 0.17$ & $\$ 0.80$ & $\$ 0.97$ & 2400 & 72 & 0.33 \\
\hline 100,000 & 50 & $\$ 2,160,000,000$ & $\$ 144,000,000$ & $\$ 672,000,000$ & $\$ 816,000,000$ & $\$ 0.17$ & $\$ 0.80$ & $\$ 0.97$ & 2400 & 72 & 0.33 \\
\hline 100,000 & 100 & $\$ 2,160,000,000$ & $\$ 144,000,000$ & $\$ 672,000,000$ & $\$ 816,000,000$ & $\$ 0.17$ & $\$ 0.80$ & $\$ 0.97$ & 2400 & 72 & 0.33 \\
\hline 100,000 & 200 & $\$ 2,160,000,000$ & $\$ 144,000,000$ & $\$ 672,000,000$ & $\$ 816,000,000$ & $\$ 0.17$ & $\$ 0.80$ & $\$ 0.97$ & 2400 & 72 & 0.33 \\
\hline 100,000 & 500 & $\$ 2,160,000,000$ & $\$ 144,000,000$ & $\$ 672,000,000$ & $\$ 816,000,000$ & $\$ 0.17$ & $\$ 0.80$ & $\$ 0.97$ & 2400 & 72 & 0.33 \\
\hline 100,000 & 1,000 & $\$ 3,600,000,000$ & $\$ 240,000,000$ & $\$ 672,000,000$ & $\$ 912,000,000$ & $\$ 0.29$ & $\$ 0.80$ & $\$ 1.09$ & 2400 & 120 & 0.20 \\
\hline
\end{tabular}




\begin{tabular}{|c|c|c|c|c|c|c|c|c|c|c|c|c|c|c|c|c|}
\hline \multicolumn{17}{|c|}{ E.3 LIQUID HYDROGEN DELIVERY BY TRUCK - SI Units } \\
\hline Truck licuid & & & ther madule & & & & & & & & & & & & & \\
\hline \multicolumn{2}{|c|}{ Truck Liquid Tank= } & $\frac{\$ 350,000}{\$ 60,000}$ & $\begin{array}{l}\text { per mooule } \\
\text { per traller }\end{array}$ & & & & & & & & & & & & & \\
\hline Truck Cab $=$ & & $\$ 90,000$ & per cab & & & & & & & & & & & & & \\
\hline \multicolumn{2}{|c|}{ Truck Liquid Capacity= } & 4,082 & lib/truck & & & & & & & & & & & & & \\
\hline \multicolumn{2}{|c|}{ Truck Boil-Off Rate $=$} & $0.30 \%$ & day & & & & & & & & & & & & & \\
\hline \multirow{2}{*}{\multicolumn{2}{|c|}{$\begin{array}{l}\text { Truck Mileage }= \\
\text { Truck Average Speed }\end{array}$}} & & $\mathrm{mpg}$ & & & & & & & & & & & & & \\
\hline & & 80 & $\mathrm{~km} / \mathrm{hr}$ & & & & & & & & & & & & & \\
\hline \multirow{2}{*}{\multicolumn{2}{|c|}{\begin{tabular}{|l|} 
Hours/Driver= \\
Truck Load/Unload Time=
\end{tabular}}} & 12 & hr/driver & & & & & & & & & & & & & \\
\hline & & & hr/trip & & & & & & & & & & & & & \\
\hline \multicolumn{2}{|c|}{ Truck Availability= } & 24 & hr/day & & & & & & & & & & & & & \\
\hline \multicolumn{2}{|c|}{ Driver Wage w/Benefits= } & $\$ 28.75$ & per hour & & & & & & & & & & & & & \\
\hline \multirow{4}{*}{\multicolumn{2}{|c|}{\begin{tabular}{|l} 
Operating Days/Year $=$ \\
Trailer/Tank Depreciation $=$ \\
Tractor Depreciation=
\end{tabular}}} & $\$ 1.00$ & pergal & & & & & & & & & & & & & \\
\hline & & 350 & days/yr & & & & & & & & & & & & & \\
\hline & & & years & & & & & & & & & & & & & \\
\hline & & 4 & years & & & & & & & & & & & & & \\
\hline \begin{tabular}{|l} 
\\
Production
\end{tabular} & Delivery Distance & Distance & Annual & Truck & Boil-Off Rate & Number & \begin{tabular}{|l} 
Total Miles \\
$\mid$
\end{tabular} & Time per & Quantity after & Total Drive & Total Load/ & Total Delivery & Trucks & iver & Drivers & |Annual \\
\hline & One-Way & Two-way & Production & Capacity & & of Trips & Driven & Trip & Boil-Off & Time & Unload Time & Time & Required & Avallability & Required & Fueluse \\
\hline \multirow[t]{7}{*}{$(\mathrm{kg} / \mathrm{hr})$} & $(\mathrm{km})$ & $(\mathrm{km} / \mathrm{trip})$ & $(\mathrm{kg} / \mathrm{yr})$ & $(\mathrm{kg} /$ truck) & $\%$ & 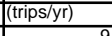 & $(\mathrm{km} / \mathrm{yr})$ & $($ hr/trip) & $(\mathrm{kg} / \mathrm{yr})$ & $(h r / y r)$ & (hr/yr) & $(n r / y r)$ & & $(h r / y r)$ & & $(g a l / y r)$ \\
\hline & & 32 & $\frac{38,10}{3810}$ & 4,082 & $0.30 \%$ & & $\frac{187}{372}$ & & $\begin{array}{l}38,099 \\
38090\end{array}$ & & & & & & & \\
\hline & $\frac{32}{80}$ & $\frac{64}{161}$ & $\begin{array}{l}38,102 \\
38,102\end{array}$ & $\begin{array}{r}4,082 \\
4,082\end{array}$ & \begin{tabular}{|l}
$0.30 \%$ \\
$0.30 \%$
\end{tabular} & & \begin{tabular}{|l}
373 \\
933
\end{tabular} & & $\begin{array}{l}38,099 \\
38,097\end{array}$ & 15 & $\frac{19}{19}$ & $\begin{array}{ll}28 \\
37\end{array}$ & & 4,200 & & $\begin{aligned} 62 \\
156\end{aligned}$ \\
\hline & 161 & 322 & $\frac{30,102}{38,102}$ & $\frac{4,002}{4,082}$ & $0.30 \%$ & & $\begin{array}{r}935 \\
1,867\end{array}$ & $\frac{2}{4}$ & $\frac{3,0,091}{38,092}$ & 37 & $\frac{19}{19}$ & $\frac{31}{56}$ & & $\frac{4,200}{4,200}$ & & 311 \\
\hline & 322 & 644 & 38,102 & 4,082 & $0.30 \%$ & & 3,733 & 8 & 38,083 & 75 & 19 & 93 & & 4,200 & & 622 \\
\hline & 805 & 1,609 & 38,102 & 4,082 & $0.30 \%$ & & 9,333 & 20 & 38,054 & 187 & 19 & 205 & & 4,200 & & 1,556 \\
\hline & 1,609 & 3,218 & 38,102 & 4,082 & $0.30 \%$ & & 18,667 & 40 & 38,006 & 373 & 19 & 392 & & 4,200 & & 3,111 \\
\hline \multirow{3}{*}{\begin{tabular}{|r|}
45 \\
45 \\
4
\end{tabular}} & 16 & 32 & 381,016 & 4,082 & $0.30 \%$ & 93 & 1,867 & 7 & 380,992 & 93 & 187 & 280 & & 4,200 & & 311 \\
\hline & 32 & 64 & 381,016 & 4,082 & $0.30 \%$ & 93 & 3,733 & & 380,992 & 93 & 187 & 280 & & 4,200 & & 622 \\
\hline & 80 & 161 & 381,016 & 4,082 & $0.30 \%$ & 93 & 9,333 & 2 & 380,968 & 187 & 187 & 373 & & 4,200 & & 1,556 \\
\hline \multirow{2}{*}{\begin{tabular}{|r|}
45 \\
45 \\
45
\end{tabular}} & 161 & 322 & 381,016 & 4,082 & $0.30 \%$ & 93 & 18,667 & 4 & 380,920 & 373 & 187 & 560 & & 4,200 & & 3,111 \\
\hline & 322 & 644 & 381,016 & 4,082 & $0.30 \%$ & 93 & 37,333 & 8 & 380,825 & 747 & 187 & 933 & & 4,200 & & 6,222 \\
\hline & 805 & 1,609 & 381,016 & 4,082 & $0.30 \%$ & 93 & 93,333 & 20 & 380,540 & 1,867 & 187 & 2,053 & & 4,200 & & 15,556 \\
\hline 45 & 1,609 & 3,218 & 381,016 & 4,082 & $0.30 \%$ & 93 & 186,667 & 40 & 380,064 & 3,733 & 187 & 3,920 & & 4,200 & & 31,111 \\
\hline 454 & 16 & 32 & $3,810,156$ & 4,082 & $0.30 \%$ & 933 & 18,667 & 1 & $3,809,918$ & 933 & 1,867 & 2,800 & & 4,200 & & 3,111 \\
\hline 454 & 32 & 64 & $3,810,156$ & 4,082 & $0.30 \%$ & 933 & 37,333 & & $3,809,918$ & 933 & 1,867 & 2,800 & & 4,200 & & 6,222 \\
\hline 454 & 80 & 161 & $3,810,156$ & 4,082 & $0.30 \%$ & 933 & 93,333 & 2 & $3,809,680$ & 1,867 & 1,867 & 3,733 & & 4,200 & & 15,556 \\
\hline 454 & 161 & 322 & $3,810,156$ & 4,082 & & 933 & 186,667 & 4 & $3,809,204$ & 3,733 & 1,867 & 5,600 & & 4,200 & & 31,111 \\
\hline 454 & 322 & 644 & $3,810,156$ & 4,082 & $0.30 \%$ & 933 & 373,333 & 8 & $3,808,251$ & 7,467 & 1,867 & 9,333 & & 4,200 & & 62,222 \\
\hline 454 & 805 & 1,609 & $3,810,156$ & 4,082 & & 933 & 933,333 & 20 & $3,805,396$ & 18,667 & 1,867 & 20,533 & & 4,200 & & 155,556 \\
\hline 454 & 1,609 & 3,218 & $3,810,156$ & 4,082 & & 933 & $1,866,667$ & 40 & $3,800,643$ & 37,333 & 1,867 & 39,200 & & 4,200 & & 311,111 \\
\hline 4,536 & 16 & 32 & $38,101,560$ & 4,082 & & 9,333 & 186,667 & 1 & $38,099,179$ & 9,333 & 18,667 & 28,000 & & 4,200 & & 31,111 \\
\hline 4,536 & 32 & 64 & $38,101,560$ & 4,082 & & 9,333 & 373,333 & & $38,099,179$ & 9,333 & 18,667 & 28,000 & & 4,200 & & 62,222 \\
\hline 4,536 & 80 & 161 & $38,101,560$ & 4,082 & & 9,333 & 933,333 & & 38,0 & 18,667 & 18,667 & 37,333 & & 4,200 & & 155,556 \\
\hline 4,536 & 161 & 322 & $38,101,560$ & 4,082 & & 9,333 & $1,866,667$ & 4 & $38,092,036$ & 37,333 & 18,667 & 56,000 & & 4,200 & & 311,111 \\
\hline 4,536 & 322 & 644 & $38,101,560$ & 4,082 & & 9,333 & 3,7 & 8 & 38,4 & 74,667 & 18,667 & 93,333 & & 4,200 & & 622,222 \\
\hline 4,536 & 805 & 1,609 & $38,101,560$ & 4,082 & & 9,333 & 3,333 & 20 & & 18 & 18,667 & 205,333 & 25 & 4,200 & 49 & $1,555,556$ \\
\hline 4,536 & 1,609 & 3,218 & 38, & 4,082 & & 9,333 & 18,6 & 40 & 38 & 373 & 18,667 & 392,000 & 47 & 4,200 & & $3,111,111$ \\
\hline 45,359 & 16 & 32 & 381, & 4,082 & & 93 & 1,8 & 1 & 386 & 93 & 186 & 280,000 & 34 & 4,200 & 67 & 311,111 \\
\hline 45,359 & 32 & 64 & 381, & 4,082 & & 93 & 3, & 1 & 386 & & 186 & 280,000 & 34 & 4,200 & 67 & 622,222 \\
\hline & 80 & 161 & 381, & 4,082 & & & & 2 & 38 & 18 & 18 & 37 & 45 & 4,200 & $8 c$ & $7,555,556$ \\
\hline 45 & 161 & 322 & 381, & 4,082 & & 9 & 18 & 4 & & & 18 & 000 & 67 & 4,200 & 134 & $3,111,111$ \\
\hline 45 & 322 & 644 & & 4, & & & & 8 & & & 186,667 & & 112 & 4,200 & 223 & $6,222,222$ \\
\hline 45,359 & 805 & $\begin{array}{l}1,609 \\
321\end{array}$ & \begin{tabular}{|l|}
$381,015,600$ \\
381,6
\end{tabular} & 4,082 & $0.30 \%$ & 93,333 & $\begin{array}{r}93,333,333 \\
\end{array}$ & 20 & $\begin{array}{r}380,539,628 \\
38,251\end{array}$ & \begin{tabular}{|l|l|l|l}
$1,866,667$ \\
372323
\end{tabular} & 186,667 & $2,053,333$ & 245 & 4,200 & $485^{\circ}$ & $\begin{array}{l}15,555,556 \\
31111411\end{array}$ \\
\hline 45,359 & 1,609 & & & & & & & & & & & & & 4,200 & 934 & $31,111,111$ \\
\hline
\end{tabular}




\begin{tabular}{|c|c|c|c|c|c|c|c|c|c|c|c|c|c|}
\hline E.3 LIQUID HY & DROGEN DELIV & VERY BY TRUCK - S & SI Units (Continue & & & & & & & & & & \\
\hline Production & Delivery Distanc & Total Capital & Depreciation & Annual Fuel & Annual Labor & Total Annual & Capital & Fuel & Labor & Total & Trip & Trip & Truck \\
\hline Rate & One-Way & Cost & & Cost & Cost & Cost & Cost & Cost & Cost & Cost & Frequency & Length & Utilization \\
\hline$(\mathrm{kg} / \mathrm{hr})$ & $(\mathrm{km})$ & $(\$)$ & $(\$ / y r)$ & $(\$ / y r)$ & $(\$ / y r)$ & $(\$ / y r)$ & $(\$ / \mathrm{kg})$ & $(\$ / \mathrm{kg})$ & $(\$ / \mathrm{kg})$ & $(\$ / \mathrm{kg})$ & (trips/day) & (hours) & (trips/truck/d) \\
\hline 5 & 16 & $\$ 500,000$ & $\$ 90,833$ & $\$ 31$ & $\$ 805$ & $\$ 91,669$ & $\$ 2.38$ & $\$ 0.00$ & $\$ 0.02$ & $\$ 2.41$ & 0.03 & 3 & 0.03 \\
\hline 5 & 32 & $\$ 500,000$ & $\$ 90,833$ & $\$ 62$ & $\$ 805$ & $\$ 91,701$ & $\$ 2.38$ & $\$ 0.00$ & $\$ 0.02$ & $\$ 2.41$ & 0.03 & 3 & 0.03 \\
\hline 5 & 80 & $\$ 500,000$ & $\$ 90,833$ & $\$ 156$ & $\$ 1,073$ & $\$ 92,062$ & $\$ 2.38$ & $\$ 0.00$ & $\$ 0.03$ & $\$ 2.42$ & 0.03 & 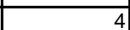 & 0.03 \\
\hline 5 & 161 & $\$ 500,000$ & $\$ 90,833$ & $\$ 311$ & $\$ 1,610$ & $\$ 92,754$ & $\$ 2.38$ & $\$ 0.01$ & $\$ 0.04$ & $\$ 2.44$ & 0.03 & 4 & 0.03 \\
\hline 5 & 322 & $\$ 500,000$ & $\$ 90,833$ & $\$ 622$ & $\$ 2,683$ & $\$ 94,139$ & $\$ 2.39$ & $\$ 0.02$ & $\$ 0.07$ & $\$ 2.47$ & 0.03 & 10 & 0.03 \\
\hline$\frac{5}{5}$ & 805 & $\$ 500,000$ & $\begin{array}{l}\$ 90,833 \\
90,03\end{array}$ & $\$ 1,556$ & $\$ 5,903$ & $\$ 98,292$ & $\$ 2.39$ & $\$ 0.04$ & $\$ 0.16$ & $\$ 2.58$ & 0.03 & 22 & 0.03 \\
\hline 5 & 1,609 & $\$ 500,000$ & $\$ 90,833$ & $\$ 3,111$ & $\$ 11,270$ & $\$ 105,214$ & $\$ 2.39$ & $\$ 0.08$ & $\$ 0.30$ & $\$ 2.77$ & 0.03 & 42 & 0.03 \\
\hline 45 & 16 & $\$ 500,000$ & $\$ 90,833$ & $\$ 311$ & $\$ 8,050$ & $\$ 99,194$ & $\$ 0.24$ & $\$ 0.00$ & $\$ 0.02$ & $\$ 0.26$ & 0.27 & 3 & 0.27 \\
\hline 45 & 32 & $\$ 500,000$ & $\$ 90,833$ & $\$ 622$ & $\$ 8,050$ & $\$ 99,506$ & $\$ 0.24$ & $\$ 0.00$ & $\$ 0.02$ & $\$ 0.26$ & 0.27 & . & 0.27 \\
\hline 45 & 80 & $\$ 500,000$ & $\$ 90,833$ & $\$ 1,556$ & $\$ 10,733$ & $\$ 103,122$ & $\$ 0.24$ & $\$ 0.00$ & $\$ 0.03$ & $\$ 0.27$ & 0.27 & 4 & 0.27 \\
\hline 45 & 161 & $\$ 500,000$ & $\$ 90,833$ & $\$ 3,111$ & $\$ 16,100$ & $\$ 110,044$ & $\$ 0.24$ & $\$ 0.01$ & $\$ 0.04$ & $\$ 0.29$ & 0.27 & 6 & 0.27 \\
\hline 45 & 322 & $\$ 500,000$ & $\$ 90,833$ & $\$ 6,222$ & $\$ 26,833$ & $\$ 123,889$ & $\$ 0.24$ & $\$ 0.02$ & $\$ 0.07$ & $\$ 0.33$ & 0.27 & 10 & 0.27 \\
\hline 45 & 805 & $\$ 500,000$ & $\begin{array}{l}\$ 90,833 \\
\$ 90\end{array}$ & 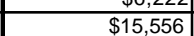 & 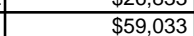 & $\$ 165,422$ & $\$ 0.24$ & $\$ 0.04$ & $\$ \$ 0.16$ & $\$ 0.43$ & 0.27 & 22 & 0.27 \\
\hline 45 & 1,609 & $\$ 500,000$ & $\$ 90,833$ & $\$ 31,111$ & $\$ 112,700$ & $\$ 234,644$ & $\$ 0.24$ & $\$ 0.08$ & $\$ 0.30$ & $\$ 0.62$ & 0.27 & 42 & 0.27 \\
\hline 454 & 16 & $\$ 500,000$ & $\$ 90,833$ & $\$ 3,111$ & $\$ 80,500$ & $\$ 174,444$ & $\$ 0.02$ & $\$ 0.00$ & $\$ 0.02$ & $\$ 0.05$ & 2.67 & 3 & 2.67 \\
\hline 454 & 32 & $\$ 500,000$ & $\$ \$ 90,833$ & $\$ 6,222$ & $\$ 80,500$ & $\$ 177,556$ & $\$ 0.02$ & $\$ 0.00$ & $\$ 0.02$ & $\$ 0.05$ & 2.67 & 3 & 2.67 \\
\hline 454 & 80 & $\$ 500,000$ & $\$ 90,833$ & $\$ 15,556$ & $\$ 107,333$ & $\$ 213,722$ & $\$ 0.02$ & $\$ 0.00$ & $\$ 0.03$ & $\$ 0.06$ & 2.67 & 4 & 2.67 \\
\hline 454 & $\frac{00}{161}$ & $\$ \$ \$ 500,000$ & $\begin{array}{l}\$ \$ 90,833 \\
\$ 933\end{array}$ & $\begin{array}{l}\$ 1,030 \\
\$ 31,111\end{array}$ & $\$ 161,000$ & $\$ 282,944$ & $\$ 0.02$ & $\$ 0.01$ & $\begin{array}{l}\$ 0.00 \\
0.04\end{array}$ & $\$ \$ 0.07$ & 2.67 & $\frac{4}{6}$ & 2.67 \\
\hline 454 & 322 & $\$ 1,000,000$ & $\$ 181,667$ & $\$ 62,222$ & $\$ 268,333$ & $\$ 512,222$ & $\$ 0.05$ & $\$ 0.02$ & $\$ 0.07$ & $\$ 0.13$ & 2.67 & 10 & 1.33 \\
\hline 454 & 805 & $\$ 1,500,000$ & $\$ 272,500$ & $\$ 155,556$ & $\$ 590,333$ & $\$ 1,018,389$ & $\$ 0.07$ & $\$ 0.04$ & $\$ 0.16$ & $\$ 0.27$ & 2.67 & 22 & 0.89 \\
\hline 454 & 1,609 & $\$ 2,500,000$ & $\$ 454,167$ & $\$ 311,111$ & $\$ 1,127,000$ & $\$ 1,892,278$ & $\$ 0.12$ & $\$ 0.08$ & $\$ 0.30$ & $\$ 0.50$ & 2.67 & 42 & 0.53 \\
\hline 4,536 & 16 & $\$ 2,000,000$ & $\$ 363,333$ & $\$ 31,111$ & $\$ 805,000$ & $\$ 1,199,444$ & $\$ 0.01$ & $\$ 0.00$ & $\$ 0.02$ & $\$ 0.03$ & 26.67 & & 6.67 \\
\hline$\frac{4,300}{4,536}$ & 32 & $\begin{array}{l}\phi, 2,000,000 \\
\$ 2,000\end{array}$ & $\frac{\$ 000,030}{\$ 363,333}$ & $\frac{\phi 3,11}{\$ 62,222}$ & $\$ 805,000$ & $\frac{\phi 1,155,44}{\$ 1,230,556}$ & $\$ 0.01$ & $\$ 0.00$ & $\begin{array}{l}\$ 0.04 \\
00.02 \\
\end{array}$ & $\frac{\$ 0.00}{\$ 0.03}$ & $\frac{20.07}{26.67}$ & & $\frac{0.01}{6.67}$ \\
\hline 4,536 & 80 & $\$ 2,500,000$ & $\$ 454,167$ & $\$ 155,556$ & $\$ 1,073,333$ & $\$ 1,683,056$ & $\$ 0.01$ & $\$ 0.00$ & $\$ 0.03$ & $\$ 0.04$ & 26.67 & 4 & 5.33 \\
\hline 4,536 & 161 & $\$ 3,500,000$ & $\$ 635,833$ & $\$ 311,111$ & $\$ 1,610,000$ & $\$ 2,556,944$ & $\$ 0.02$ & $\$ 0.01$ & $\$ 0.04$ & $\$ 0.07$ & 26.67 & 6 & 3.81 \\
\hline 4,536 & 322 & $\$ 6,000,000$ & $\$ 1,090,000$ & $\$ 622,222$ & $\$ 2,683,333$ & $\$ 4,395,556$ & $\$ 0.03$ & $\$ 0.02$ & $\$ 0.07$ & $\$ 0.12$ & 26.67 & 10 & 2.22 \\
\hline 4,536 & 805 & $\$ 12,500,000$ & $\$ 2,270,833$ & $\$ 1,555,556$ & $\$ 5,903,333$ & $\$ 9,729,722$ & $\$ 0.06$ & $\$ 0.04$ & $\$ 0.16$ & $\$ 0.26$ & 26.67 & 22 & 1.07 \\
\hline 45,359 & 1,609 & $\$ 23,500,000$ & $\$ 4,269,167$ & $\$ 3,111,111$ & $\$ 11,270,000$ & $\$ 18,650,278$ & $\$ 0.11$ & $\$ 0.08$ & $\$ 0.30$ & $\$ 0.49$ & 26.67 & 42 & 0.57 \\
\hline 45,359 & 16 & $\$ 17,000,000$ & $\$ 3,088,333$ & $\$ 311,111$ & $\$ 8,050,000$ & $\$ 11,449,444$ & $\$ 0.01$ & $\$ 0.00$ & $\$ 0.02$ & $\$ 0.03$ & 266.67 & 3 & 7.84 \\
\hline 45,359 & 32 & $\$ 17,000,000$ & $\$ 3,088,333$ & $\$ 622,222$ & $\$ 8,050,000$ & $\$ 11,760,556$ & $\$ 0.01$ & $\$ 0.00$ & $\$ 0.02$ & $\$ 0.03$ & 266.67 & 3 & 7.84 \\
\hline 45,359 & 80 & $\$ 22,500,000$ & $\$ 4,087,500$ & $\$ 1,555,556$ & $\$ 10,733,333$ & $\$ 16,376,389$ & $\$ 0.01$ & $\$ 0.00$ & $\$ 0.03$ & $\$ 0.04$ & 266.67 & 4 & 5.93 \\
\hline 45,359 & 161 & $\$ 33,500,000$ & $\$ 6,085,833$ & $\$ 3,111,111$ & $\$ 16,100,000$ & $\$ 25,296,944$ & $\$ 0.02$ & $\$ 0.01$ & $\$ 0.04$ & $\$ 0.07$ & 266.67 & 6 & 3.98 \\
\hline 45,359 & 322 & $\$ \$ 56,000,000$ & $\$ 10,173,333$ & $\$ 6,222,222$ & $\$ 26,833,333$ & $\$ 43,228,889$ & $\$ 0.03$ & $\$ 0.02$ & $\frac{90.04}{\$ 0.07}$ & $\$ 0.11$ & 266.67 & 10 & 2.38 \\
\hline 45,359 & 805 & $\$ 122,500,000$ & $\$ 22,254,167$ & $\$ 15,555,556$ & $\$ 59,033,333$ & $\$ 96,843,056$ & $\$ 0.06$ & $\$ 0.04$ & $\$ 0.16$ & $\$ 0.25$ & 266.67 & 22 & 1.0 \\
\hline 45,359 & 1,609 & $\$ 233,500,000$ & $\begin{array}{l}\$<<,<4,19 \\
\$ 42,419,167\end{array}$ & $\begin{array}{l}10,111,111 \\
\$ 31,11,\end{array}$ & $\$ 112,700,000$ & $\$ 186,230,278$ & $\$ 0.11$ & $\$ 0.08$ & $\$ 0.30$ & $\frac{\$ 0.45}{\$ 0.49}$ & 266.67 & 42 & 0.57 \\
\hline
\end{tabular}




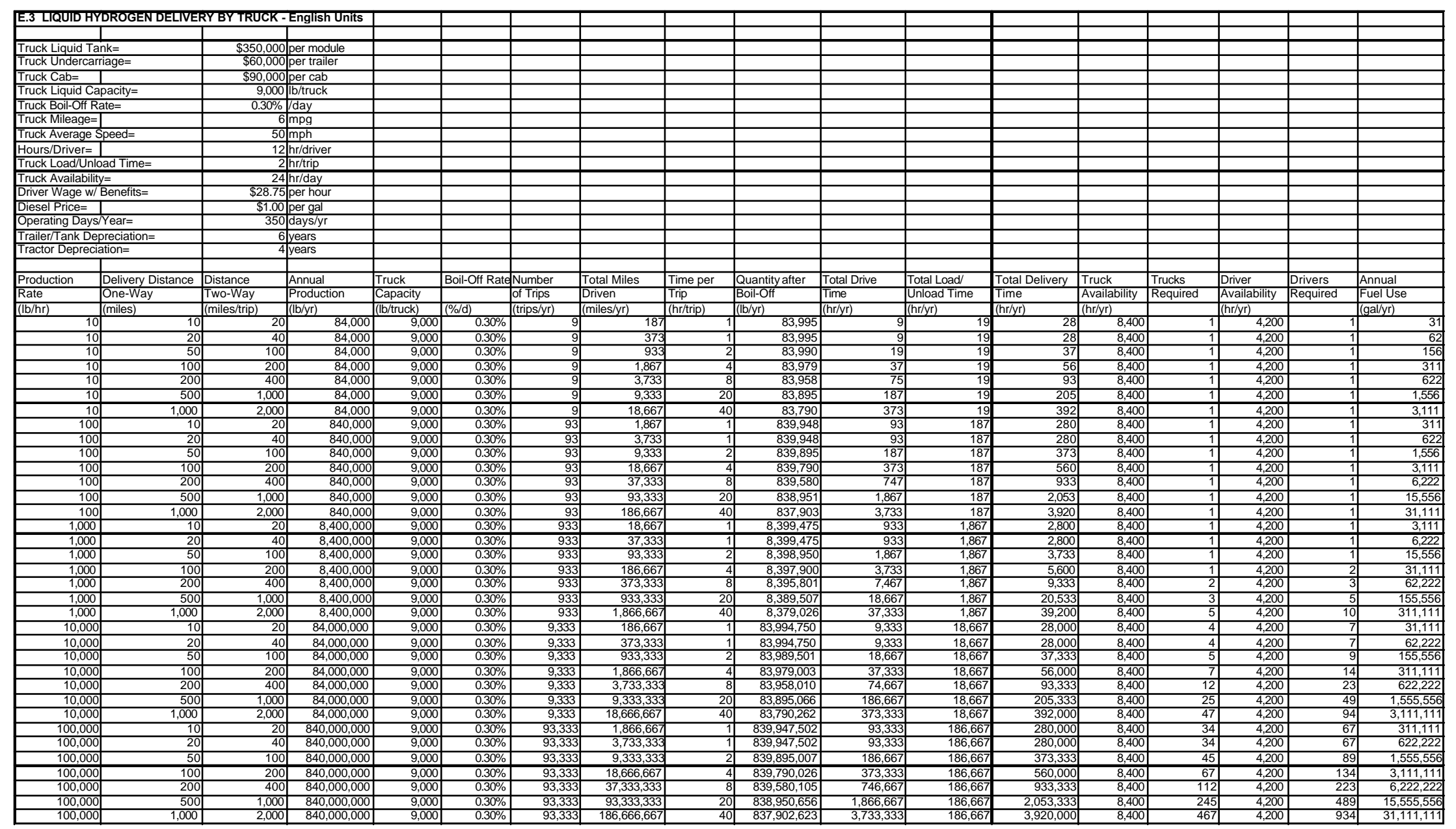




\begin{tabular}{|c|c|c|c|c|c|c|c|c|c|c|c|c|c|}
\hline \multicolumn{14}{|c|}{ E.3 LIQUID HYDROGEN DELIVERY BY TRUCK - English Units (Continued) } \\
\hline Production & Delivery Distand & Total Capital & Denreciation & AnnualFuel & Annual| abor & TotalAnnual & Canital & Fut & & & in & & Truck \\
\hline Rate & One-Way & Cost & & Cost & Cost & Cost & Cost & Cost & Cost & Cost & Frequency & Length & Utilization \\
\hline$(\mathrm{lb} / \mathrm{hr})$ & (miles) & (\$) & $(\$ / y r)$ & $(\$ / y r)$ & $(\$ / y r)$ & $(\$ / y r)$ & $(\$ / \mathrm{lb})$ & $(\$ / \mathrm{lb})$ & $\frac{\$(1 / b)}{(1 / 2)}$ & $(\$ / \mathrm{lb})$ & (trips/day) & (hours) & (trips/truck/d) \\
\hline 10 & 10 & $\$ 500,000$ & $\$ 90,833$ & $\$ 31$ & $\$ 805$ & $\$ 91,669$ & $\$ 1.08$ & $\$ 0.00$ & $\$ 0.01$ & $\$ 1.09$ & \begin{tabular}{|r|}
0.03 \\
\end{tabular} & , & 0.03 \\
\hline 10 & 20 & $\$ 500,000$ & $\$ 90,833$ & $\$ 62$ & $\$ 805$ & $\$ 91,701$ & $\$ 1.08$ & $\$ 0.00$ & $\$ 0.01$ & $\$ 1.09$ & 0.03 & 20 & 0.03 \\
\hline 10 & 50 & $\$ 500,000$ & $\$ 90,833$ & $\$ 156$ & $\$ 1,073$ & $\$ 92,062$ & $\$ 1.08$ & $\$ 0.00$ & $\$ 0.01$ & $\$ 1.10$ & 0.03 & 4 & 0.03 \\
\hline 10 & 100 & $\$ 500,000$ & $\$ 90,833$ & $\$ 311$ & $\$ 1,610$ & $\$ 92,754$ & $\$ 1.08$ & $\$ 0.00$ & $\$ 0.02$ & $\$ 1.10$ & 0.03 & 6 & 0.03 \\
\hline 10 & 200 & $\$ 500,000$ & $\$ 90,833$ & $\$ 622$ & $\$ 2,683$ & $\$ 94,139$ & $\$ 1.08$ & $\$ 0.01$ & $\$ 0.03$ & $\$ 1.12$ & 0.03 & 10 & 0.03 \\
\hline 10 & 500 & $\$ 500,000$ & $\$ 90,833$ & $\$ 1,556$ & $\$ 5,903$ & $\$ 98,292$ & $\$ 1.08$ & $\$ 0.02$ & $\$ 0.07$ & $\$ 1.17$ & 0.03 & 22 & 0.03 \\
\hline 10 & 1,000 & $\$ 500,000$ & $\$ 90,833$ & $\$ 3,111$ & $\$ 11,270$ & $\$ 105,214$ & $\$ 1.08$ & $\$ 0.04$ & $\$ 0.13$ & $\$ 1.26$ & 0.03 & 42 & 0.03 \\
\hline 100 & 10 & $\$ 500,000$ & $\$ 90,833$ & $\$ 311$ & $\$ 8,050$ & $\$ 99,194$ & $\$ 0.11$ & $\$ 0.00$ & $\$ 0.01$ & $\$ 0.12$ & \begin{tabular}{|c|}
0.27 \\
\end{tabular} & 2 & 0.27 \\
\hline 100 & 20 & $\$ 500,000$ & $\$ 90,833$ & $\$ 622$ & $\$ 8,050$ & $\$ 99,506$ & $\$ 0.11$ & $\$ 0.00$ & $\$ 0.01$ & $\$ 0.12$ & \begin{tabular}{l|l|}
0.27 \\
\end{tabular} & 3 & 0.27 \\
\hline 100 & 50 & $\$ 500,000$ & $\$ 90,833$ & $\$ 1,556$ & $\$ 10,733$ & $\$ 103,122$ & $\$ 0.11$ & $\$ 0.00$ & $\$ 0.01$ & $\$ 0.12$ & 0.27 & 4 & 0.27 \\
\hline 100 & 100 & $\$ 500,000$ & $\$ 90,833$ & $\$ 3,111$ & $\$ 16,100$ & $\$ 110,044$ & $\$ 0.11$ & $\$ 0.00$ & $\$ 0.02$ & $\$ 0.13$ & 0.27 & 6 & 0.27 \\
\hline 100 & 200 & $\$ 500,000$ & $\$ 90,833$ & $\$ 6,222$ & $\$ 26,833$ & $\$ 123,889$ & $\$ 0.11$ & $\$ 0.01$ & $\$ 0.03$ & $\$ 0.15$ & 0.27 & 10 & 0.27 \\
\hline 100 & 500 & $\$ 500,000$ & $\$ 90,833$ & $\$ 15,556$ & $\$ 59,033$ & $\$ 165,422$ & $\$ 0.11$ & $\$ 0.02$ & $\$ 0.07$ & $\$ 0.20$ & \begin{tabular}{|c|}
0.27 \\
\end{tabular} & 22 & 0.27 \\
\hline 100 & 1,000 & $\$ 500,000$ & $\$ 90,833$ & $\$ 31,111$ & $\$ 112,700$ & $\$ 234,644$ & $\$ 0.11$ & $\$ 0.04$ & $\$ 0.13$ & $\$ 0.28$ & 0.27 & 42 & 0.27 \\
\hline 1,000 & 10 & $\$ 500,000$ & $\$ 90,833$ & $\$ 3,111$ & $\$ 80,500$ & $\$ 174,444$ & $\$ 0.01$ & $\$ 0.00$ & $\$ 0.01$ & $\$ 0.02$ & 2.67 & 3 & 2.67 \\
\hline 1,000 & 20 & $\$ 500,000$ & $\$ 90,833$ & $\$ 6,222$ & $\$ 80,500$ & $\$ 177,556$ & $\$ 0.01$ & $\$ 0.00$ & $\$ 0.01$ & $\$ 0.02$ & 2.67 & T & 2.67 \\
\hline 1,000 & 50 & $\$ 500,000$ & $\$ 90,833$ & $\$ 15,556$ & $\$ 107,333$ & $\$ 213,722$ & $\$ 0.01$ & $\$ 0.00$ & $\$ 0.01$ & $\$ 0.03$ & 2.67 & 4 & 2.67 \\
\hline 1,000 & 100 & $\$ 500,000$ & $\$ 90,833$ & $\$ 31,111$ & $\$ 161,000$ & $\$ 282,944$ & $\$ 0.01$ & $\$ 0.00$ & $\$ 0.02$ & $\$ 0.03$ & 2.67 & 6 & 2.67 \\
\hline 1,000 & 200 & $\$ 1,000,000$ & $\$ 181,667$ & $\$ 62,222$ & $\$ 268,333$ & $\$ 512,222$ & $\$ 0.02$ & $\$ 0.01$ & $\$ 0.03$ & $\$ 0.06$ & 2.67 & 10 & 1.33 \\
\hline 1,000 & 500 & $\$ 1,500,000$ & $\$ 272,500$ & $\$ 155,556$ & $\$ 590,333$ & $\$ 1,018,389$ & $\$ 0.03$ & $\$ 0.02$ & $\$ 0.07$ & $\$ 0.12$ & 2.67 & 22 & 0.89 \\
\hline 1,000 & 1,000 & $\$ 2,500,000$ & $\$ 454,167$ & $\$ 311,111$ & $\$ 1,127,000$ & $\$ 1,892,278$ & $\$ 0.05$ & $\$ 0.04$ & $\$ 0.13$ & $\$ 0.23$ & 2.67 & 42 & 0.53 \\
\hline 10,000 & 10 & $\$ 2,000,000$ & $\$ 363,333$ & $\$ 31,111$ & $\$ 805,000$ & $\$ 1,199,444$ & $\$ 0.00$ & $\$ 0.00$ & $\$ 0.01$ & $\$ 0.01$ & 26.67 & S & 6.67 \\
\hline 10,000 & 20 & $\$ 2,000,000$ & $\$ 363,333$ & $\$ 62,222$ & $\$ 805,000$ & $\$ 1,230,556$ & $\$ 0.00$ & $\$ 0.00$ & $\$ 0.01$ & $\$ 0.01$ & 26.67 & ( & 6.67 \\
\hline 10,000 & 50 & $\$ 2,500,000$ & $\$ 454,167$ & $\$ 155,556$ & $\$ 1,073,333$ & $\$ 1,683,056$ & $\$ 0.01$ & $\$ 0.00$ & $\$ 0.01$ & $\$ 0.02$ & 26.67 & & 5.33 \\
\hline 10,000 & 100 & $\$ 3,500,000$ & $\$ 635,833$ & $\$ 311,111$ & $\$ 1,610,000$ & $\$ 2,556,944$ & $\$ 0.01$ & $\$ 0.00$ & $\$ 0.02$ & $\$ 0.03$ & 26.67 & 6 & 3.81 \\
\hline 10,000 & 200 & $\$ 6,000,000$ & $\$ 1,090,000$ & $\$ 622,222$ & $\$ 2,683,333$ & $\$ 4,395,556$ & $\$ 0.01$ & $\$ 0.01$ & $\$ 0.03$ & $\$ 0.05$ & 26.67 & 10 & \\
\hline 10,000 & 500 & $\$ 12,500,000$ & $\$ 2,270,833$ & $\$ 1,555,556$ & $\$ 5,903,333$ & $\$ 9,729,722$ & $\$ 0.03$ & $\$ 0.02$ & $\$ 0.07$ & $\$ 0.12$ & 26.67 & 22 & 1.07 \\
\hline 100,000 & 1,000 & $\$ 23,500,000$ & $\$ 4,269,167$ & $\$ 3,111,111$ & $\$ 11,270,000$ & $\$ 18,650,278$ & $\$ 0.05$ & $\$ 0.04$ & $\$ 0.13$ & $\$ 0.22$ & 26.67 & 42 & 0.57 \\
\hline 100,000 & 10 & $\$ 17,000,000$ & $\$ 3,088,333$ & $\$ 311,111$ & $\$ 8,050,000$ & $\$ 11,449,444$ & $\$ 0.00$ & $\$ 0.00$ & $\$ 0.01$ & $\$ 0.01$ & 266.67 & 3 & 7.84 \\
\hline 100,000 & 20 & $\$ 17,000,000$ & $\$ 3,088,333$ & $\$ 622,222$ & $\$ 8,050,000$ & $\$ 11,760,556$ & $\$ 0.00$ & $\$ 0.00$ & $\$ 0.01$ & $\$ 0.01$ & 266.67 & 3 & 7.84 \\
\hline 100,000 & 50 & $\$ 22,500,000$ & $\$ 4,087,500$ & $\$ 1,555,556$ & $\$ 10,733,333$ & $\$ 16,376,389$ & $\$ 0.00$ & $\$ 0.00$ & $\$ 0.01$ & $\$ 0.02$ & 266.67 & 4 & 5.93 \\
\hline 100,000 & 100 & $\$ 33,500,000$ & $\$ 6,085,833$ & $\$ 3,111,111$ & $\$ 16,100,000$ & $\$ 25,296,944$ & $\$ 0.01$ & $\$ 0.00$ & $\$ 0.02$ & $\$ 0.03$ & 266.67 & 6 & 3.98 \\
\hline 100,000 & 200 & $\$ 56,000,000$ & $\$ 10,173,333$ & $\$ 6,222,222$ & $\$ 26,833,333$ & $\$ 43,228,889$ & $\$ 0.01$ & $\$ 0.01$ & $\$ 0.03$ & $\$ 0.05$ & 266.67 & 10 & \\
\hline 100,000 & 500 & $\$ 122,500,000$ & $\$ 22,254,167$ & $\$ 15,555,556$ & $\$ 59,033,333$ & $\$ 96,843,056$ & $\$ 0.03$ & $\$ 0.02$ & $\$ 0.07$ & $\$ 0.12$ & 266. & 22 & \\
\hline 100,000 & 1,000 & $\$ 233,500,000$ & $\$ 42,419,167$ & $\$ 31,111,111$ & $\$ 112,700,000$ & $\$ 186,230,278$ & $\$ 0.05$ & $\$ 0.04$ & $\$ 0.13$ & $\$ 0.22$ & 266.67 & 42 & 0.57 \\
\hline
\end{tabular}




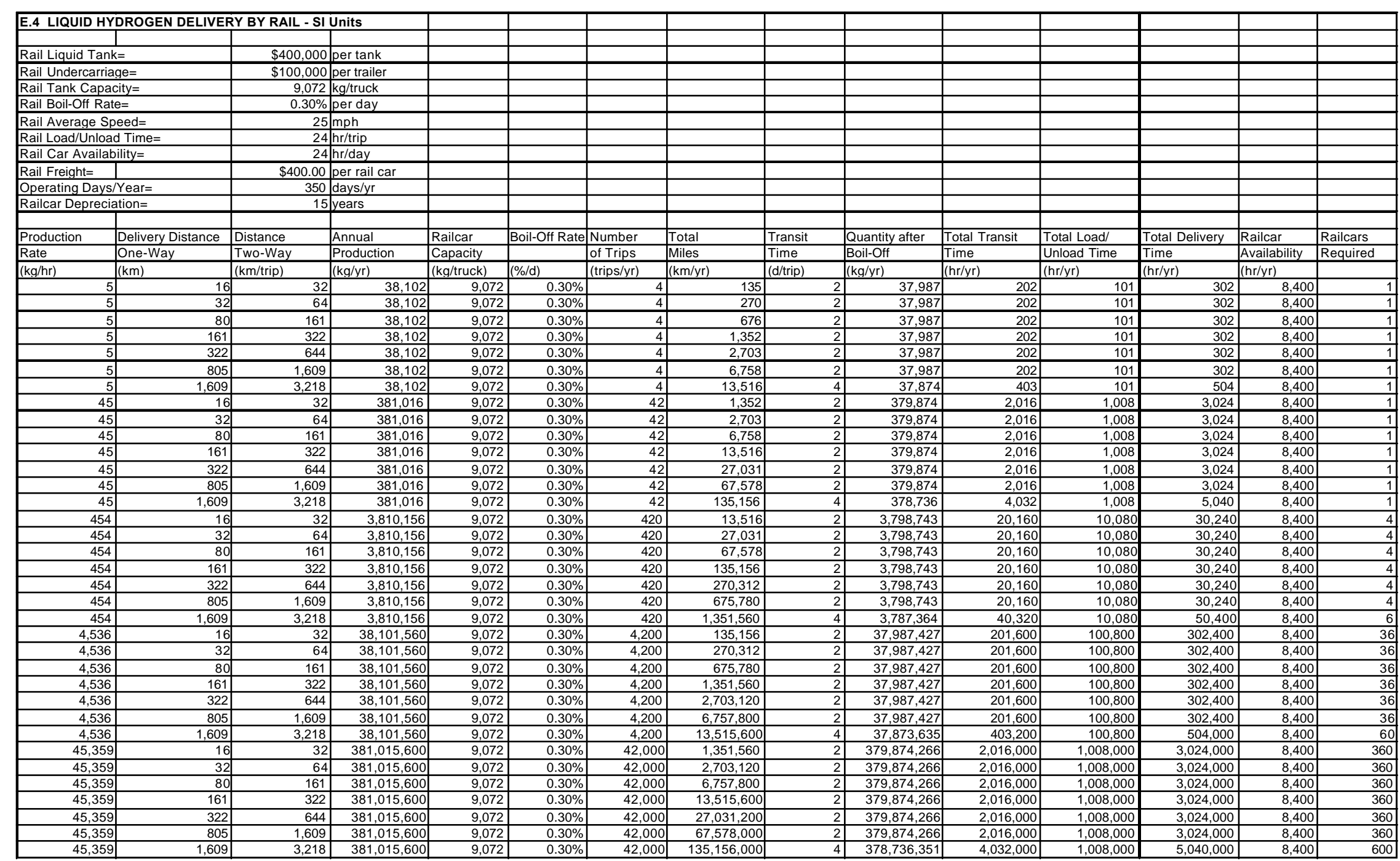

E - 15 


\begin{tabular}{|c|c|c|c|c|c|c|c|c|c|c|c|}
\hline \multicolumn{12}{|c|}{ E.4 LIQUID HYDROGEN DELIVERY BY RAIL - SI Units (Continued) } \\
\hline & & & & & & & & & & & \\
\hline \begin{tabular}{|l|} 
Production \\
\end{tabular} & Delivery Distanc & Total Capital & Depreciation & Annual Freight & Total Annual & Capital & Freight & Total & Trip & Trip & Railcar \\
\hline Rate & One-Way & Cost & & Cost & Cost & Cost & Cost & Cost & Frequency & Length & Utilization \\
\hline$(\mathrm{kg} / \mathrm{hr})$ & $(\mathrm{km})$ & $(\$)$ & $(\$ / y r)$ & $(\$ / y r)$ & $(\$ / y r)$ & $(\$ / \mathrm{kg})$ & $(\$ / \mathrm{kg})$ & $(\$ / \mathrm{kg})$ & (trips/day) & (hr) & (trips/railcar/d) \\
\hline 5 & 16 & $\$ 500,000$ & $\$ 33,333$ & $\$ 3,360$ & $\$ 36,693$ & $\$ 0.88$ & $\$ 0.09$ & $\$ 0.97$ & $\begin{array}{r}0.012 \\
\end{array}$ & 72 & 0.01 \\
\hline 5 & 32 & $\$ 500,000$ & $\$ 33,333$ & $\$ 3,360$ & $\$ 36,693$ & $\$ 0.88$ & $\$ 0.09$ & $\$ 0.97$ & 0.012 & 72 & 0.01 \\
\hline 5 & 80 & $\$ 500,000$ & $\$ 33,333$ & $\$ 3,360$ & $\$ 36,693$ & $\$ 0.88$ & $\$ 0.09$ & $\$ 0.97$ & 0.012 & 72 & 0.01 \\
\hline 5 & 161 & $\$ 500,000$ & $\$ 33,333$ & $\$ 3,360$ & $\$ 36,693$ & $\$ 0.88$ & $\$ 0.09$ & $\$ 0.97$ & 0.012 & 72 & 0.01 \\
\hline 5 & 322 & $\$ 500,000$ & $\$ 33,333$ & $\$ 3,360$ & $\$ 36,693$ & $\$ 0.88$ & $\$ 0.09$ & $\$ 0.97$ & 0.012 & 72 & 0.01 \\
\hline 5 & 805 & $\$ 500,000$ & $\$ 33,333$ & $\$ 3,360$ & $\$ 36,693$ & $\$ 0.88$ & $\$ 0.09$ & $\$ 0.97$ & 0.012 & 72 & 0.01 \\
\hline 5 & 1,609 & $\$ 500,000$ & $\$ 33,333$ & $\$ 3,360$ & $\$ 36,693$ & $\$ 0.88$ & $\$ 0.09$ & $\$ 0.97$ & 0.012 & 120 & 0.01 \\
\hline 45 & 16 & $\$ 500,000$ & $\$ 33,333$ & $\$ 33,600$ & $\$ 66.933$ & $\$ 0.09$ & $\$ 0.09$ & $\$ 0.18$ & 0.12 & 72 & 0.12 \\
\hline 45 & 32 & $\$ 500,000$ & $\$ 33,333$ & $\$ 33,600$ & $\$ 66,933$ & $\$ 0.09$ & $\$ 0.09$ & $\$ 0.18$ & 0.12 & 72 & 0.12 \\
\hline 45 & 80 & $\$ 500,000$ & $\$ 33,333$ & $\$ 33,600$ & $\$ 66,933$ & $\$ 0.09$ & $\$ 0.09$ & $\$ 0.18$ & 0.12 & 72 & 0.12 \\
\hline 45 & 161 & $\$ 500,000$ & $\$ 33,333$ & $\$ 33,600$ & $\$ 66,933$ & $\$ 0.09$ & $\$ 0.09$ & $\$ 0.18$ & 0.12 & 72 & 0.12 \\
\hline 45 & 322 & $\$ 500,000$ & $\$ 33,333$ & $\$ 33,600$ & $\$ 66,933$ & $\$ 0.09$ & $\$ 0.09$ & $\$ 0.18$ & 0.12 & 72 & 0.12 \\
\hline 45 & 805 & $\$ 500,000$ & $\$ 33,333$ & $\$ 33,600$ & $\$ 66,933$ & $\$ 0.09$ & $\$ 0.09$ & $\$ 0.18$ & 0.12 & 72 & 0.12 \\
\hline 45 & 1,609 & $\$ 500,000$ & $\$ 33,333$ & $\$ 33,600$ & $\$ 66,933$ & $\$ 0.09$ & $\$ 0.09$ & $\$ 0.18$ & 0.12 & 120 & 0.12 \\
\hline 454 & 16 & $\$ 2,000,000$ & $\$ 133,333$ & $\$ 336,000$ & $\$ 469,333$ & $\$ 0.04$ & $\$ 0.09$ & $\$ 0.12$ & 1.2 & 72 & 0.30 \\
\hline 454 & 32 & $\$ 2,000,000$ & $\$ 133,333$ & $\$ 336,000$ & $\$ 469,333$ & $\$ 0.04$ & $\$ 0.09$ & $\$ 0.12$ & 1.2 & 72 & 0.30 \\
\hline 454 & 80 & $\$ 2,000,000$ & $\$ 133,333$ & $\$ 336,000$ & $\$ 469,333$ & $\$ 0.04$ & $\$ 0.09$ & $\$ 0.12$ & 1.2 & 72 & 0.30 \\
\hline 454 & 161 & $\$ 2,000,000$ & $\$ 133,333$ & $\$ 336,000$ & $\$ 469,333$ & $\$ 0.04$ & $\$ 0.09$ & $\$ 0.12$ & 1.2 & 72 & 0.30 \\
\hline 454 & 322 & $\$ 2,000,000$ & $\$ 133,333$ & $\$ 336,000$ & $\$ 469,333$ & $\$ 0.04$ & $\$ 0.09$ & $\$ 0.12$ & 1.2 & 72 & 0.30 \\
\hline 454 & 805 & $\$ 2,000,000$ & $\$ 133,333$ & $\$ 336,000$ & $\$ 469,333$ & $\$ 0.04$ & $\$ 0.09$ & $\$ 0.12$ & 1.2 & 72 & 0.30 \\
\hline 454 & 1,609 & $\$ 3,000,000$ & $\$ 200,000$ & $\$ 336,000$ & $\$ 536,000$ & $\$ 0.05$ & $\$ 0.09$ & $\$ 0.14$ & 1.2 & 120 & 0.20 \\
\hline 4,536 & 16 & $\$ 18,000,000$ & $\$ 1,200,000$ & $\$ 3,360,000$ & $\$ 4,560,000$ & $\$ 0.03$ & $\$ 0.09$ & $\$ 0.12$ & 12 & 72 & 0.33 \\
\hline 4,536 & 32 & $\$ 18,000,000$ & $\$ 1,200,000$ & $\$ 3,360,000$ & $\$ 4,560,000$ & $\$ 0.03$ & $\$ 0.09$ & $\$ 0.12$ & 12 & 72 & 0.33 \\
\hline 4,536 & 80 & $\$ 18,000,000$ & $\$ 1,200,000$ & $\$ 3,360,000$ & $\$ 4,560,000$ & $\$ 0.03$ & $\$ 0.09$ & $\$ 0.12$ & 12 & 72 & 0.33 \\
\hline 4,536 & 161 & $\$ 18,000,000$ & $\$ 1,200,000$ & $\$ 3,360,000$ & $\$ 4,560,000$ & $\$ 0.03$ & $\$ 0.09$ & $\$ 0.12$ & 12 & 72 & 0.33 \\
\hline 4,536 & 322 & $\$ 18,000,000$ & $\$ 1,200,000$ & $\$ 3,360,000$ & $\$ 4,560,000$ & $\$ 0.03$ & $\$ 0.09$ & $\$ 0.12$ & 12 & 72 & 0.33 \\
\hline 4,536 & 805 & $\$ 18,000,000$ & $\$ 1,200,000$ & $\$ 3,360,000$ & $\$ 4,560,000$ & $\$ 0.03$ & $\$ 0.09$ & $\$ 0.12$ & 12 & 72 & 0.33 \\
\hline 4.536 & 1.609 & $\$ 30,000,000$ & $\$ 2,000,000$ & $\$ 3,360,000$ & $\$ 5,360,000$ & $\$ 0.05$ & $\$ 0.09$ & $\$ 0.14$ & 12 & 120 & 0.20 \\
\hline 45,359 & 16 & $\$ 180,000,000$ & $\$ 12,000,000$ & $\$ 33,600,000$ & $\$ 45,600,000$ & $\$ 0.03$ & $\$ 0.09$ & $\$ 0.12$ & 120 & 72 & 0.33 \\
\hline 45,359 & 32 & $\$ 180,000,000$ & $\$ 12,000,000$ & $\$ 33,600,000$ & $\$ 45,600,000$ & $\$ 0.03$ & $\$ 0.09$ & $\$ 0.12$ & 120 & 72 & 0.33 \\
\hline 45,359 & 80 & $\$ 180,000,000$ & $\$ 12,000,000$ & $\$ 33,600,000$ & $\$ 45,600,000$ & $\$ 0.03$ & $\$ 0.09$ & $\$ 0.12$ & 120 & 72 & 0.33 \\
\hline 45,359 & 161 & $\$ 180,000,000$ & $\$ 12,000,000$ & $\$ 33,600,000$ & $\$ 45,600,000$ & $\$ 0.03$ & $\$ 0.09$ & $\$ 0.12$ & 120 & 72 & 0.33 \\
\hline 45,359 & 322 & $\$ 180,000,000$ & $\$ 12,000,000$ & $\$ 33,600,000$ & $\$ 45,600,000$ & $\$ 0.03$ & $\$ 0.09$ & $\$ 0.12$ & 120 & 72 & 0.33 \\
\hline 45,359 & 805 & $\$ 180,000,000$ & $\$ 12,000,000$ & $\$ 33,600,000$ & $\$ 45,600,000$ & $\$ 0.03$ & $\$ 0.09$ & $\$ 0.12$ & 120 & 72 & 0.33 \\
\hline 45,359 & 1,609 & $\$ 300,000,000$ & $\$ 20,000,000$ & $\$ 33,600,000$ & $\$ 53,600,000$ & $\$ 0.05$ & $\$ 0.09$ & $\$ 0.14$ & 120 & 120 & 0.20 \\
\hline
\end{tabular}




\begin{tabular}{|c|c|c|c|c|c|c|c|c|c|c|c|c|c|c|}
\hline \multirow{2}{*}{\multicolumn{15}{|c|}{ E.4 LIQUID HYDROGEN DELIVERY BY RAlL - English Units }} \\
\hline & & & & & & & & & & & & & & \\
\hline \multicolumn{2}{|l|}{ Rail Liquid Tank= } & $\$ 400,000$ & per tank & & & & & & & & & & & \\
\hline \multicolumn{2}{|c|}{ Rail Undercarriage $=$} & $\$ 100,000$ & per trailer & & & & & & & & & & & \\
\hline \multicolumn{2}{|c|}{ Rail Tank Capacity= } & 20,000 & Ib/truck & & & & & & & & & & & \\
\hline \multicolumn{2}{|c|}{ Rail Boil-Off Rate $=$} & $0.30 \%$ & per day & & & & & & & & & & & \\
\hline \multicolumn{2}{|c|}{ Rail Average Speed= } & 25 & $\mathrm{mph}$ & & & & & & & & & & & \\
\hline \multicolumn{2}{|c|}{ Rail Load/Unload Time= } & 24 & hr/trip & & & & & & & & & & & \\
\hline \multicolumn{2}{|c|}{ Rail Car Availability $=$} & 24 & hr/day & & & & & & & & & & & \\
\hline \multirow{2}{*}{\multicolumn{2}{|c|}{\begin{tabular}{l|l} 
Rail Freight= & \\
Operating Days/Year=
\end{tabular}}} & $\$ 400.00$ & per rail car & & & & & & & & & & & \\
\hline & & 350 & days/yr & & & & & & & & & & & \\
\hline \multicolumn{2}{|c|}{ Railcar Depreciation= } & 15 & years & & & & & & & & & & & \\
\hline & & & & & & & & & & & & & & \\
\hline Production & Delivery Distance & Distance & Annual & Railcar & Boil-Off Rate & Number & \begin{tabular}{|l} 
Total \\
\end{tabular} & Transit & Quantity after & Total Transit & Total Load/ & \begin{tabular}{|l} 
Total Delivery \\
\end{tabular} & Railcar & Railcars \\
\hline Rate & One-Way & Two-Way & Production & Capacity & & of Trips & Miles & Time & Boil-Off & Time & Unload Time & Time & Availability & Required \\
\hline (ib/hr) & (miles) & (miles/trip) & $(\mathrm{lb} / \mathrm{yr})$ & \begin{tabular}{|l|l|l} 
(lb/truck) \\
\end{tabular} & $(\% / d)$ & (trips/yr) & (miles/yr) & (d/trip) & $(\mathrm{lb} / \mathrm{yr})$ & $(\mathrm{hr} / \mathrm{yr})$ & $(\mathrm{hr} / \mathrm{yr})$ & $(\mathrm{hr} / \mathrm{yr})$ & (hr/yr) & \\
\hline 10 & 10 & 20 & 84,000 & \begin{tabular}{r|}
20,000 \\
\end{tabular} & $0.30 \%$ & 4 & 84 & & 83,748 & 202 & 101 & 302 & 8,400 & \\
\hline 10 & 20 & 40 & 84,000 & 20,000 & $0.30 \%$ & 4 & 168 & & 83,748 & 202 & 101 & 302 & 8,400 & \\
\hline 10 & 50 & 100 & 84,000 & 20,000 & $0.30 \%$ & $\frac{4}{4}$ & 420 & & 83,748 & 202 & 101 & $\frac{302}{302}$ & 8,400 & \\
\hline 10 & 100 & 200 & 84,000 & 20,000 & $0.30 \%$ & 4 & 840 & & 83,748 & 202 & 101 & 302 & 8,400 & \\
\hline 10 & $\frac{100}{200}$ & 400 & 84,000 & 20,000 & $0.30 \%$ & 4 & 1,680 & & 83,748 & 202 & 101 & 302 & 8,400 & \\
\hline 10 & 500 & 1,000 & 84,000 & 20,000 & $0.30 \%$ & 4 & 4,200 & & 83,748 & 202 & 101 & 302 & 8,400 & \\
\hline 10 & 1.000 & 2.000 & 84,000 & 20,000 & $0.30 \%$ & 4 & 8.400 & & 83.498 & 403 & 101 & 504 & 8.400 & \\
\hline 100 & 10 & 20 & 840.000 & 20.000 & $0.30 \%$ & 42 & 840 & & 837.484 & 2.016 & 1.008 & 3.024 & 8.400 & \\
\hline 100 & 20 & 40 & 840.000 & 20.000 & $0.30 \%$ & 42 & 1.680 & 2 & 837.484 & 2.016 & 1.008 & 3.024 & 8.400 & \\
\hline 100 & 50 & 100 & 840,000 & 20,000 & $0.30 \%$ & 42 & 4,200 & & 837,484 & 2,016 & 1,008 & 3,024 & 8,400 & \\
\hline 100 & 100 & 200 & 840,000 & 20,000 & $0.30 \%$ & 42 & 8,400 & & 837,484 & 2,016 & 1,008 & 3,024 & 8,400 & \\
\hline 100 & 200 & 400 & 840,000 & 20,000 & $0.30 \%$ & 42 & 16,800 & & 837,484 & 2,016 & 1,008 & 3,024 & 8,400 & \\
\hline 100 & 500 & 1,000 & 840,000 & 20,000 & $0.30 \%$ & 42 & \begin{tabular}{l|l|}
42,000 \\
\end{tabular} & & 837,484 & 2,016 & 1,008 & 3,024 & 8,400 & \\
\hline 100 & 1,000 & 2,000 & 840,000 & 20,000 & $0.30 \%$ & 42 & \begin{tabular}{|l|}
84,000 \\
\end{tabular} & 4 & 834,975 & 4,032 & 1,008 & 5,040 & 8,400 & \\
\hline 1,000 & $\frac{1,000}{10}$ & $\frac{2,000}{20}$ & $8,400,000$ & 20,000 & $0.30 \%$ & 420 & $\frac{84,400}{8,40}$ & & $8,374,838$ & 20,160 & 10,080 & 30,240 & 8,400 & \\
\hline 1,000 & 20 & 40 & $8,400,000$ & 20,000 & $0.30 \%$ & 420 & \begin{tabular}{l|}
16,800 \\
\end{tabular} & & $8,374,838$ & 20,160 & 10,080 & 30,240 & 8,400 & \\
\hline 1,000 & 50 & 100 & $8,400,000$ & 20,000 & $0.30 \%$ & 420 & 42,000 & & $8,374,838$ & 20,160 & 10,080 & 30,240 & 8,400 & \\
\hline 1,000 & 100 & 200 & $8,400,000$ & 20,000 & $0.30 \%$ & 420 & 84,000 & & $8,374,838$ & 20,160 & 10,080 & 30,240 & 8,400 & \\
\hline 1,000 & 200 & 400 & $8,400,000$ & 20,000 & $0.30 \%$ & 420 & 168,000 & & $8,374,838$ & 20,160 & 10,080 & 30,240 & 8,400 & \\
\hline$\frac{1,000}{1,000}$ & $\frac{200}{500}$ & 1,000 & $8,400,000$ & 20,000 & $0.30 \%$ & 420 & 年, & & 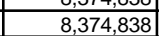 & 20,160 & 10,080 & 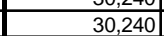 & 8,400 & \\
\hline 1,000 & 1,000 & 2,000 & $8,400,000$ & 20,000 & $0.30 \%$ & 420 & 840,000 & 4 & $8,349,751$ & 40,320 & 10,080 & 50,400 & 8,400 & \\
\hline 10,000 & 10 & 20 & $84,000,000$ & 20,000 & $0.30 \%$ & 4,200 & \begin{tabular}{|c|}
84,000 \\
\end{tabular} & & $83,748,378$ & 201,600 & 100,800 & 302,400 & 8,400 & 36 \\
\hline 10,000 & 20 & 40 & $84,000,000$ & 20,000 & $0.30 \%$ & 4,200 & 168,000 & & $83,748,378$ & 201,600 & 100,800 & 302,400 & 8,400 & \\
\hline 10,000 & 50 & 100 & $84,000,000$ & 20,000 & $0.30 \%$ & 4,200 & 420,000 & & $83,748,378$ & 201,600 & 100,800 & 302,400 & 8,400 & 36 \\
\hline 10,000 & 100 & 200 & $84,000,000$ & 20,000 & $0.30 \%$ & 4,200 & 840,000 & & $83,748,378$ & 201,600 & 100,800 & 302,400 & 8,400 & 36 \\
\hline 10,000 & 200 & 400 & $84,000,000$ & 20,000 & $0.30 \%$ & 4,200 & $1,680,000$ & 2 & $83,748,378$ & 201,600 & 100,800 & 302,400 & 8,400 & 36 \\
\hline 10,000 & 500 & 1,000 & $84,000,000$ & 20,000 & $0.30 \%$ & 4,200 & $4,200,000$ & 2 & $83,748,378$ & 201,600 & 100,800 & 302,400 & 8,400 & 36 \\
\hline 10,000 & 1,000 & 2,000 & $84,000,000$ & 20,000 & $0.30 \%$ & 4,200 & \begin{tabular}{|l|l}
$8,400,000$ \\
\end{tabular} & 4 & $83,497,509$ & 403,200 & 100,800 & 504,000 & 8,400 & 60 \\
\hline 100,000 & 10 & 20 & $840,000,000$ & 20,000 & $0.30 \%$ & 42,000 & 840,000 & & $837,483,776$ & $2,016,000$ & $1,008,000$ & $3,024,000$ & 8.400 & 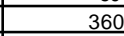 \\
\hline 100,000 & 20 & 40 & $840,000,000$ & 20,000 & $0.30 \%$ & 42,000 & $1,680,000$ & 4 & $837,483,776$ & $2,016,000$ & $1,008,000$ & $3,024,000$ & 8.400 & 360 \\
\hline 100,000 & 50 & 100 & $840,000,000$ & 20,000 & $0.30 \%$ & 42,000 & $\begin{array}{l}.200,000 \\
\end{array}$ & & $837,483,776$ & $2,016,000$ & $1,008,000$ & $3,024,000$ & 8.400 & 360 \\
\hline 100,000 & 100 & 200 & $840,000,000$ & 20,000 & $0.30 \%$ & 42,000 & $8.400,000$ & & $837,483,776$ & $2,016,000$ & 1.008 .000 & $3.024,000$ & 8.400 & 360 \\
\hline 100,000 & 200 & 400 & $840,000,000$ & 20,000 & $0.30 \%$ & 42,000 & $16,800,000$ & & $837,483,776$ & $2,016,000$ & $1,008,000$ & $3,024,000$ & 8,400 & 360 \\
\hline 100,000 & 500 & 1,000 & $840,000,000$ & 20,000 & $0.30 \%$ & 42,000 & $42,000,000$ & & $837,483,776$ & $2,016,000$ & $1,008,000$ & $3,024,000$ & 8,400 & 360 \\
\hline 100,000 & 1,000 & 2,000 & $840,000,000$ & 20,000 & $0.30 \%$ & 42,000 & $84,000,000$ & T & $834,975,090$ & $4,032,000$ & $1,008,000$ & $5,040,000$ & 8,400 & 600 \\
\hline
\end{tabular}




\begin{tabular}{|c|c|c|c|c|c|c|c|c|c|c|c|}
\hline \multicolumn{12}{|c|}{ E.4 LIQUID HYDROGEN DELIVERY BY RAIL - English Units (Continued) } \\
\hline & & & & & & & & & & & \\
\hline Production & Delivery Distance & Total Capital & Depreciation & Annual Freight & Total Annual & Capital & Freight & Total & Trip & Trip & Railcar \\
\hline Rate & One-Way & Cost & & Cost & Cost & Cost & Cost & Cost & Frequency & Length & Utilization \\
\hline$(\mathrm{lb} / \mathrm{hr})$ & (miles) & (\$) & $(\$ / \mathrm{yr})$ & $(\$ / \mathrm{yr})$ & $(\$ / \mathrm{yr})$ & $(\$ / / b)$ & $(\$ / \mathrm{lb})$ & $\$ / / \mathrm{lb})$ & (trips/dav) & $(\mathrm{hr})$ & (trips/railcar/d) \\
\hline 10 & 10 & $\$ 500,000$ & $\$ 33,333$ & $\$ 3,360$ & $\$ 36,693$ & $\$ 0.40$ & $\$ 0.04$ & $\$ 0.44$ & 0.012 & 72 & 0.01 \\
\hline 10 & 20 & $\$ 500,000$ & $\$ 33,333$ & $\$ 3,360$ & $\$ 36,693$ & $\$ 0.40$ & $\$ 0.04$ & $\$ 0.44$ & 0.012 & 72 & 0.01 \\
\hline 10 & 50 & $\$ 500,000$ & $\$ 33,333$ & $\$ 3,360$ & $\$ 36,693$ & $\$ 0.40$ & $\$ 0.04$ & $\$ 0.44$ & 0.012 & 72 & 0.01 \\
\hline 10 & 100 & $\$ 500,000$ & $\$ 33,333$ & $\$ 3,360$ & $\$ 36,693$ & $\$ 0.40$ & $\$ 0.04$ & $\$ 0.44$ & 0.012 & 72 & 0.01 \\
\hline 10 & 200 & $\$ 500,000$ & $\$ 33,333$ & $\$ 3,360$ & $\$ 36,693$ & $\$ 0.40$ & $\$ 0.04$ & $\$ 0.44$ & 0.012 & 72 & 0.01 \\
\hline 10 & 500 & $\$ 500,000$ & $\$ 33,333$ & $\$ 3,360$ & $\$ 36,693$ & $\$ 0.40$ & $\$ 0.04$ & $\$ 0.44$ & 0.012 & 72 & 0.01 \\
\hline 10 & 1,000 & $\$ 500,000$ & $\$ 33,333$ & $\$ 3,360$ & $\$ 36,693$ & $\$ 0.40$ & $\$ 0.04$ & $\$ 0.44$ & 0.012 & 120 & 0.01 \\
\hline 100 & 10 & $\$ 500,000$ & $\$ 33,333$ & $\$ 33,600$ & $\$ 66,933$ & $\$ 0.04$ & $\$ 0.04$ & $\$ 0.08$ & 0.12 & 72 & 0.12 \\
\hline 100 & 20 & $\$ 500,000$ & $\$ 33,333$ & $\$ 33,600$ & $\$ 66,933$ & $\$ 0.04$ & $\$ 0.04$ & $\$ 0.08$ & 0.12 & 72 & 0.12 \\
\hline 100 & 50 & $\$ 500,000$ & $\$ 33,333$ & $\$ 33,600$ & $\$ 66,933$ & $\$ 0.04$ & $\$ 0.04$ & $\$ 0.08$ & 0.12 & 72 & 0.12 \\
\hline 100 & 100 & $\$ 500,000$ & $\$ 33,333$ & $\$ 33,600$ & $\$ 66,933$ & $\$ 0.04$ & $\$ 0.04$ & $\$ 0.08$ & 0.12 & 72 & 0.12 \\
\hline 100 & 200 & $\$ 500,000$ & $\$ 33,333$ & $\$ 33,600$ & $\$ 66,933$ & $\$ 0.04$ & $\$ 0.04$ & $\$ 0.08$ & 0.12 & 72 & 0.12 \\
\hline 100 & 500 & $\$ 500,000$ & $\$ 33,333$ & $\$ 33,600$ & $\$ 66,933$ & $\$ 0.04$ & $\$ 0.04$ & $\$ 0.08$ & 0.12 & 72 & 0.12 \\
\hline 100 & 1,000 & $\$ 500,000$ & $\$ 33,333$ & $\$ 33,600$ & $\$ 66,933$ & $\$ 0.04$ & $\$ 0.04$ & $\$ 0.08$ & 0.12 & 120 & 0.12 \\
\hline 1,000 & 10 & $\$ 2,000,000$ & $\$ 133,333$ & $\$ 336,000$ & $\$ 469,333$ & $\$ 0.02$ & $\$ 0.04$ & $\$ 0.06$ & 1.2 & 72 & 0.30 \\
\hline 1,000 & 20 & $\$ 2,000,000$ & $\$ 133,333$ & $\$ 336,000$ & $\$ 469,333$ & $\$ 0.02$ & $\$ 0.04$ & $\$ 0.06$ & 1.2 & 72 & 0.30 \\
\hline 1,000 & 50 & $\$ 2,000,000$ & $\$ 133,333$ & $\$ 336,000$ & $\$ 469,333$ & $\$ 0.02$ & $\$ 0.04$ & $\$ 0.06$ & 1.2 & 72 & 0.30 \\
\hline 1,000 & 100 & $\$ 2,000,000$ & $\$ 133,333$ & $\$ 336,000$ & $\$ 469,333$ & $\$ 0.02$ & $\$ 0.04$ & $\$ 0.06$ & 1.2 & 72 & 0.30 \\
\hline 1,000 & 200 & $\$ 2,000,000$ & $\$ 133,333$ & $\$ 336,000$ & $\$ 469,333$ & $\$ 0.02$ & $\$ 0.04$ & $\$ 0.06$ & 1.2 & 72 & 0.30 \\
\hline 1,000 & 500 & $\$ 2,000,000$ & $\$ 133,333$ & $\$ 336,000$ & $\$ 469,333$ & $\$ 0.02$ & $\$ 0.04$ & $\$ 0.06$ & 1.2 & 72 & 0.30 \\
\hline 1,000 & 1,000 & $\$ 3,000,000$ & $\$ 200,000$ & $\$ 336,000$ & $\$ 536,000$ & $\$ 0.02$ & $\$ 0.04$ & $\$ 0.06$ & 1.2 & 120 & 0.20 \\
\hline 10,000 & 10 & $\$ 18,000,000$ & $\$ 1,200,000$ & $\$ 3,360,000$ & $\$ 4,560,000$ & $\$ 0.01$ & $\$ 0.04$ & $\$ 0.05$ & 12 & 72 & 0.33 \\
\hline 10,000 & 20 & $\$ 18,000,000$ & $\$ 1,200,000$ & $\$ 3,360,000$ & $\$ 4,560,000$ & $\$ 0.01$ & $\$ 0.04$ & $\$ 0.05$ & 12 & 72 & 0.33 \\
\hline 10,000 & 50 & $\$ 18,000,000$ & $\$ 1,200,000$ & $\$ 3,360,000$ & $\$ 4,560,000$ & $\$ 0.01$ & $\$ 0.04$ & $\$ 0.05$ & 12 & 72 & 0.33 \\
\hline 10,000 & 100 & $\$ 18,000,000$ & $\$ 1,200,000$ & $\$ 3,360,000$ & $\$ 4,560,000$ & $\$ 0.01$ & $\$ 0.04$ & $\$ 0.05$ & 12 & 72 & 0.33 \\
\hline 10,000 & 200 & $\$ 18,000,000$ & $\$ 1,200,000$ & $\$ 3,360,000$ & $\$ 4,560,000$ & $\$ 0.01$ & $\$ 0.04$ & $\$ 0.05$ & 12 & 72 & 0.33 \\
\hline 10,000 & 500 & $\$ 18,000,000$ & $\$ 1,200,000$ & $\$ 3,360,000$ & $\$ 4,560,000$ & $\$ 0.01$ & $\$ 0.04$ & $\$ 0.05$ & 12 & 72 & 0.33 \\
\hline 10,000 & 1,000 & $\$ 30,000,000$ & $\$ 2,000,000$ & $\$ 3,360,000$ & $\$ 5,360,000$ & $\$ 0.02$ & $\$ 0.04$ & $\$ 0.06$ & 12 & 120 & 0.20 \\
\hline 100,000 & 10 & $\$ 180,000,000$ & $\$ 12,000,000$ & $\$ 33,600,000$ & $\$ 45,600,000$ & $\$ 0.01$ & $\$ 0.04$ & $\$ 0.05$ & 120 & 72 & 0.33 \\
\hline 100,000 & 20 & $\$ 180,000,000$ & $\$ 12,000,000$ & $\$ 33,600,000$ & $\$ 45,600,000$ & $\$ 0.01$ & $\$ 0.04$ & $\$ 0.05$ & 120 & 72 & 0.33 \\
\hline 100,000 & 50 & $\$ 180,000,000$ & $\$ 12,000,000$ & $\$ 33,600,000$ & $\$ 45,600,000$ & $\$ 0.01$ & $\$ 0.04$ & $\$ 0.05$ & 120 & 72 & 0.33 \\
\hline 100,000 & 100 & $\$ 180,000,000$ & $\$ 12,000,000$ & $\$ 33,600,000$ & $\$ 45,600,000$ & $\$ 0.01$ & $\$ 0.04$ & $\$ 0.05$ & 120 & 72 & 0.33 \\
\hline 100,000 & 200 & $\$ 180,000,000$ & $\$ 12,000,000$ & $\$ 33,600,000$ & $\$ 45,600,000$ & $\$ 0.01$ & $\$ 0.04$ & $\$ 0.05$ & 120 & 72 & 0.33 \\
\hline 100,000 & 500 & $\$ 180,000,000$ & $\$ 12,000,000$ & $\$ 33,600,000$ & $\$ 45,600,000$ & $\$ 0.01$ & $\$ 0.04$ & $\$ 0.05$ & 120 & 72 & 0.33 \\
\hline 100,000 & 1,000 & $\$ 300,000,000$ & $\$ 20,000,000$ & $\$ 33,600,000$ & $\$ 53,600,000$ & $\$ 0.02$ & $\$ 0.04$ & $\$ 0.06$ & 120 & 120 & 0.20 \\
\hline
\end{tabular}




\begin{tabular}{|c|c|c|c|c|c|c|c|c|c|c|c|c|c|c|}
\hline \multicolumn{15}{|c|}{ E.5 LIQUID HYDROGEN DELIVERY BY SHIP - SI Units } \\
\hline \multirow{2}{*}{\multicolumn{2}{|c|}{ Ship Liquid Tank= }} & & & & & & & & & & & & & \\
\hline & & $\$ 350,000$ & per container & & & & & & & & & & & \\
\hline \multicolumn{2}{|c|}{ Ship Liquid Capacity= } & 4,082 & $\mathrm{~kg} / \operatorname{tank}$ & & & & & & & & & & & \\
\hline \multicolumn{2}{|c|}{ Ship Boil-Off Rate= } & $0.30 \%$ & per day & & & & & & & & & & & \\
\hline & 16 & $\mathrm{~km} / \mathrm{hr}$ & & & & & & & & & & & \\
\hline \multirow{2}{*}{\multicolumn{2}{|c|}{$\begin{array}{l}\text { Ship Load/Unload Time }= \\
\text { Ship Tank Availability }=\end{array}$}} & 48 & hr/trip & & & & & & & & & & & \\
\hline & & 24 & hr/day & & & & & & & & & & & \\
\hline \multicolumn{2}{|c|}{ Shipping Charge $=$} & $\$ 3,000$ & per container & & & & & & & & & & & \\
\hline \multirow{2}{*}{\multicolumn{2}{|c|}{$\begin{array}{l}\text { Operating Days/Year= } \\
\text { Trailer/Tank Depreciation }=\end{array}$}} & 350 & days/yr & & & & & & & & & & & \\
\hline & & 6 & years & & & & & & & & & & & \\
\hline \multirow{2}{*}{\begin{tabular}{|l|} 
Production \\
\end{tabular}} & & & & & & & & & & & & & & \multirow{3}{*}{\begin{tabular}{|l|l|} 
Tanks \\
Required
\end{tabular}} \\
\hline & \begin{tabular}{|l|} 
Delivery Distance \\
\end{tabular} & Distance & Annual & Tank & Boil-Off Rate & Number & Total Miles & Time per & Quantity after & Total Transit & Total Load/ & \begin{tabular}{|l} 
Total Delivery \\
\end{tabular} & Tank & \\
\hline Rate & One-Way & Two-Way & Production & Capacity & & of Trips & & Trip & Boil-Off & Time & Unload Time & Time & Availability & \\
\hline \multirow{2}{*}{$(\mathrm{kg} / \mathrm{hr})$} & $(\mathrm{km})$ & (km/trip) & $(\mathrm{kg} / \mathrm{yr})$ & $(\mathrm{kg} / \operatorname{tank})$ & $(\% / d)$ & (trips/yr) & $(\mathrm{km} / \mathrm{yr})$ & (days/trip) & $(\mathrm{kg} / \mathrm{yr})$ & $(h r / y r)$ & $(h r / y r)$ & $($ hr/yr) & $(h r / y r)$ & \multirow{3}{*}{1} \\
\hline & 16 & 32 & 38,102 & 4,082 & $0.30 \%$ & 9 & 300 & 2 & 37,987 & 448 & 448 & 896 & 8,400 & \\
\hline \multirow{2}{*}{\begin{tabular}{r|}
5 \\
5 \\
\end{tabular}} & 32 & $\frac{64}{64}$ & 38,102 & 4,082 & $0.30 \%$ & 9 & 601 & 2 & 37,987 & 448 & 448 & 896 & 8,400 & \\
\hline & 80 & 161 & 38,102 & 4,082 & $0.30 \%$ & 9 & 1,502 & 4 & 37,987 & 448 & 448 & 896 & 8,400 & 1 \\
\hline \multirow{2}{*}{$\begin{array}{r}5 \\
5 \\
5 \\
\end{array}$} & 161 & 322 & 38,102 & 4,082 & $0.30 \%$ & 9 & 3,003 & $\frac{4}{2}$ & 37,987 & 448 & 448 & 896 & 8,400 & $\frac{1}{1}$ \\
\hline & 322 & 6464 & 38,102 & 4,082 & $0.30 \%$ & 9 & $\begin{array}{l}, 0,007 \\
6\end{array}$ & $\frac{4}{2}$ & 37,987 & 448 & 448 & 896 & 8,400 & $\frac{1}{1}$ \\
\hline \multirow{2}{*}{$\begin{array}{r}5 \\
5\end{array}$} & 805 & 1,609 & 38,102 & 4,082 & $0.30 \%$ & 9 & 15,017 & 6 & 37,760 & 1,344 & 448 & 1,792 & 8,400 & \\
\hline & 1,609 & $\mid \begin{array}{l}\mid, 003 \\
3,218\end{array}$ & $\frac{30,104}{38,102}$ & $\begin{array}{ll}4,0042 \\
4,082\end{array}$ & $0.30 \%$ & $\frac{3}{9}$ & 30,035 & $\frac{0}{10}$ & $\frac{31,104}{37,534}$ & $\frac{1,044}{2,240}$ & $\frac{440}{448}$ & $\frac{2,194}{2,688}$ & $\frac{0,400}{8,400}$ & $\frac{1}{1}$ \\
\hline \multirow{2}{*}{45} & 16 & 32 & 381,016 & 4,082 & $0.30 \%$ & 93 & 3,003 & 2 & 379,874 & 4,480 & 4,480 & 8,960 & 8,400 & 2 \\
\hline & 32 & 64 & 381,016 & 4,082 & $0.30 \%$ & 93 & 6,007 & 2 & 379,874 & 4,480 & 4,480 & 8,960 & 8,400 & 2 \\
\hline$\frac{45}{45}$ & 80 & 161 & 381,016 & $\begin{array}{ll}4,004 \\
4,082\end{array}$ & $0.30 \%$ & 93 & $\frac{0,017}{15,017}$ & $\frac{4}{2}$ & $\begin{array}{l}379,874 \\
37\end{array}$ & $4,4,480$ & $\begin{array}{l}\frac{4,400}{4,480} \\
\end{array}$ & $\begin{array}{l}, 0,960 \\
\end{array}$ & 8,400 & $\frac{2}{2}$ \\
\hline 45 & 161 & 322 & 381,016 & 4,082 & $0.30 \%$ & 93 & 30,035 & 4 & 379,874 & 4.480 & 4.480 & 8,960 & 8.400 & $\frac{2}{2}$ \\
\hline$\frac{45}{45}$ & 322 & $\frac{3264}{644}$ & 381,016 & $\begin{array}{ll}4,004 \\
4,082\end{array}$ & $0.30 \%$ & 93 & 60,069 & $\frac{4}{2}$ & $\begin{array}{l}379,874 \\
379\end{array}$ & 4,480 & $\frac{4,400}{4,480}$ & $\begin{array}{l}, 0,960 \\
8\end{array}$ & $\frac{0,400}{8,400}$ & $\frac{2}{2}$ \\
\hline 45 & 805 & 1,609 & 381,016 & 4,082 & $0.30 \%$ & 93 & 150,173 & 6 & 377,602 & 13,440 & 4,480 & 17,920 & 8,400 & 3 \\
\hline$\frac{45}{45}$ & 1,609 & $\begin{array}{l}\mid, 004 \\
3,218\end{array}$ & 3801,016 & $\begin{array}{l}4,004 \\
4,082\end{array}$ & $0.00 \%$ & 93 & 300,347 & 10 & $\begin{array}{l}37,00< \\
375,343\end{array}$ & $\frac{10,440}{22,400}$ & $\begin{array}{l}\frac{4,400}{4,480} \\
\end{array}$ & 26,880 & $\frac{0,400}{8,400}$ & $\frac{3}{4}$ \\
\hline 454 & 16 & 32 & $3,810,156$ & 4,082 & $0.30 \%$ & 933 & 30,035 & 2 & $3,798,743$ & 44,800 & 44,800 & 89,600 & 8,400 & 11 \\
\hline 454 & 32 & 64 & $3,810,156$ & 4,082 & $0.30 \%$ & 933 & 60,069 & 2 & $3,798,743$ & 44,800 & 44,800 & 89,600 & 8.400 & 11 \\
\hline 454 & 80 & 161 & $3,810,156$ & 4,082 & $0.30 \%$ & 933 & 150,173 & 2 & $3,798,743$ & 44.800 & 44,800 & 89,600 & 8.400 & 11 \\
\hline 454 & 161 & 322 & $3,810,156$ & 4,082 & $0.30 \%$ & 933 & 300,347 & 4 & $3,798,743$ & 44.800 & 44,800 & 89,600 & 8.400 & 11 \\
\hline 454 & 322 & 644 & $\begin{array}{l}3,010,100 \\
3,810,156\end{array}$ & 4,082 & $0.30 \%$ & 933 & $\begin{array}{l}600,693 \\
600,61\end{array}$ & $\frac{4}{2}$ & $\begin{array}{l}3,70,740 \\
3,798,743 \\
\end{array}$ & 44,800 & $\begin{array}{l}44,000 \\
44,800\end{array}$ & 89,600 & $\frac{8,400}{8,400}$ & 11 \\
\hline 454 & 805 & 1,609 & $3,810,156$ & 4,082 & $0.30 \%$ & 933 & $1,501,733$ & 6 & $3,776,018$ & 134,400 & 44,800 & 179,200 & 8,400 & 22 \\
\hline$\frac{454}{454}$ & $\frac{005}{1,609}$ & $\frac{\mid, 009}{3,218}$ & $\frac{3,010,150}{3,810,156}$ & $\frac{4,004}{4,082}$ & $\begin{array}{l}0.30 \% \\
0.30 \%\end{array}$ & $\begin{array}{ll}953 \\
933 \\
\end{array}$ & $\frac{1,001,103}{3,003,467}$ & $\frac{0}{10}$ & $\begin{array}{l}3,1710,0110 \\
3,753,430\end{array}$ & $\begin{array}{l}13,400 \\
224,000\end{array}$ & $\frac{44,000}{44,800}$ & $\begin{array}{l}11,2600 \\
268,800\end{array}$ & $\frac{0,400}{8,400}$ & $\frac{24}{32}$ \\
\hline 4,536 & 16 & 32 & $38,101,560$ & 4,082 & $0.30 \%$ & 9,333 & $\frac{300,347}{30}$ & 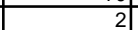 & $37,987,427$ & 448,000 & 448,000 & 896,000 & 8,400 & 107 \\
\hline 4,536 & 32 & 64 & $38,101,560$ & 4,082 & $0.30 \%$ & 9,333 & 600,693 & 2 & $37,987,427$ & 448,000 & 448,000 & 896,000 & 8,400 & 107 \\
\hline 4,536 & 80 & 161 & $38,101,560$ & 4,082 & $0.30 \%$ & 9,333 & $\begin{array}{r}1,501,733 \\
\end{array}$ & 2 & $37,987,427$ & 448,000 & 448,000 & 896,000 & 8,400 & 107 \\
\hline 4,536 & 161 & 322 & $38,101,560$ & 4.082 & $0.30 \%$ & 9,333 & $3,003,467$ & & $37,987,427$ & 448,000 & 448,000 & 896,000 & 8.400 & 107 \\
\hline 4,536 & 322 & 644 & $38,101,560$ & 4,082 & $0.30 \%$ & 9,00 & $6,006,933$ & 2 & $37,987,427$ & 448,000 & 448,000 & 896,000 & 8.400 & 107 \\
\hline 4,536 & 805 & 1,609 & $38,101,560$ & 4,082 & $0.30 \%$ & 9,333 & $15,017,333$ & 6 & $37,760,184$ & $1,344,000$ & 448,000 & $1,792,000$ & 8,400 & 214 \\
\hline$\frac{4,030}{4,536}$ & 1,609 & $\mid \begin{array}{l}, 003 \\
3,218\end{array}$ & $\frac{30,101,000}{38,101,560}$ & $\begin{array}{ll}4,002 \\
4,082\end{array}$ & $0.00 \%$ & $\begin{array}{l}, 000 \\
9,333\end{array}$ & $30,034,667$ & $\frac{0}{10}$ & $\begin{array}{l}31,100,04 \\
37,534,302\end{array}$ & $\frac{1,244,000}{2,240,000}$ & $\frac{440,000}{448,000}$ & $\frac{1,68,000}{2,688,000}$ & $\frac{0,400}{8,400}$ & 320 \\
\hline 45,359 & 16 & 32 & $381,015,600$ & 4,082 & $0.30 \%$ & 93,333 & $3,003,467$ & & $379,874,266$ & $4,480,000$ & $4,480,000$ & $8,960,000$ & 8,400 & 1,067 \\
\hline 45,359 & 32 & 64 & $381,015,600$ & 4,082 & $0.30 \%$ & 93,333 & \begin{tabular}{|l|}
$6,006,933$ \\
\end{tabular} & 2 & $379,874,266$ & $4,480,000$ & $4,480,000$ & $8,960,000$ & 8,400 & 1,067 \\
\hline 45,359 & 80 & 161 & $381,015,600$ & 4,082 & $0.30 \%$ & 93,333 & \begin{tabular}{|c|}
$15,017,333$ \\
\end{tabular} & 2 & $379,874,266$ & $4,480,000$ & $4,480,000$ & $8,960,000$ & 8,400 & 1,067 \\
\hline 45,359 & 161 & 322 & $381,015,600$ & 4,082 & $0.30 \%$ & 93,333 & $30,034,667$ & 2 & $379,874,266$ & $4,480,000$ & $4,480,000$ & $8,960,000$ & 8,400 & 1,067 \\
\hline 45,359 & 322 & 644 & $381,015,600$ & 4,082 & $0.30 \%$ & 93,333 & $60,069,333$ & 2 & $379,874,266$ & $4,480,000$ & $4,480,000$ & $8,960,000$ & 8,400 & 1,067 \\
\hline 45,359 & 805 & 1,609 & $381,015,600$ & 4,082 & $0.30 \%$ & 93,333 & $150,173,333$ & 6 & $377,601,845$ & $13,440,000$ & $4,480,000$ & $17,920,000$ & 8,400 & 2,134 \\
\hline 45,359 & 1,609 & 3,218 & $381,015,600$ & 4.082 & $0.30 \%$ & 93.333 & $300,346,667$ & 10 & $375,343,017$ & $22,400,000$ & $4.480,000$ & $26,880,000$ & 8.400 & 3.200 \\
\hline
\end{tabular}




\begin{tabular}{|c|c|c|c|c|c|c|c|c|c|c|c|}
\hline \multicolumn{12}{|c|}{ E.5 LIQUID HYDROGEN DELIVERY BY SHIP - SI Units (Continued) } \\
\hline & & & & & & & & & & & \\
\hline \begin{tabular}{|l|} 
Production \\
\end{tabular} & Delivery Distanc & Total Capital & Depreciation & Annual Freight & Total Annual & Capital & Freight & Total & Trip & Trip & Tank \\
\hline Rate & One-Way & Cost & & Cost & Cost & Cost & Cost & Cost & Frequency & Length & Utilization \\
\hline$(\mathrm{kg} / \mathrm{hr})$ & $(\mathrm{km})$ & $(\$)$ & $(\$ / y r)$ & $(\$ / y r)$ & $(\$ / y r)$ & $(\$ / \mathrm{kg})$ & $(\$ / \mathrm{kg})$ & $(\$ / \mathrm{kg})$ & (trips/day) & (hours) & (trips/tank/d) \\
\hline 5 & 16 & $\$ 350,000$ & $\$ 58,333$ & $\$ 56,000$ & $\$ 114,333$ & $\$ 1.54$ & $\$ 1.47$ & $\$ 3.01$ & 0.03 & 96 & 0.03 \\
\hline 5 & 32 & $\$ 350,000$ & $\$ 58,333$ & $\$ 56,000$ & $\$ 114,333$ & $\$ 1.54$ & $\$ 1.47$ & $\$ 3.01$ & 0.03 & 96 & 0.03 \\
\hline 5 & 80 & $\$ 350,000$ & $\$ 58,333$ & $\$ 56,000$ & $\$ 114,333$ & $\$ 1.54$ & $\$ 1.47$ & $\$ 3.01$ & 0.03 & 96 & 0.03 \\
\hline 5 & 161 & $\$ 350,000$ & $\$ 58,333$ & $\$ 56,000$ & $\$ 114,333$ & $\$ 1.54$ & $\$ 1.47$ & $\$ 3.01$ & 0.03 & 96 & 0.03 \\
\hline 5 & 322 & $\$ 350,000$ & $\$ 58,333$ & $\$ 56,000$ & $\$ 114,333$ & $\$ 1.54$ & $\$ 1.47$ & $\$ 3.01$ & 0.03 & 96 & 0.03 \\
\hline 5 & 805 & $\$ 350,000$ & $\$ 58,333$ & $\$ 56,000$ & $\$ 114,333$ & $\$ 1.54$ & $\$ 1.48$ & $\$ 3.03$ & 0.03 & 192 & 0.03 \\
\hline 5 & 1,609 & $\$ 350,000$ & $\$ 58,333$ & $\$ 56,000$ & $\$ 114,333$ & $\$ 1.55$ & $\$ 1.49$ & $\$ 3.05$ & 0.03 & 288 & 0.03 \\
\hline 45 & 16 & $\$ 700,000$ & $\$ 116,667$ & $\$ 560,000$ & $\$ 676,667$ & $\$ 0.31$ & $\$ 1.47$ & $\$ 1.78$ & 0.27 & 96 & 0.13 \\
\hline 45 & 32 & $\$ 700,000$ & $\$ 116,667$ & $\$ 560,000$ & $\$ 676,667$ & $\$ 0.31$ & $\$ 1.47$ & $\$ 1.78$ & 0.27 & 96 & 0.13 \\
\hline 45 & 80 & $\$ 700,000$ & $\$ 116,667$ & $\$ 560,000$ & $\$ 676,667$ & $\$ 0.31$ & $\$ 1.47$ & $\$ 1.78$ & 0.27 & 96 & 0.13 \\
\hline 45 & 161 & $\$ 700,000$ & $\$ 116,667$ & $\$ 560,000$ & $\$ 676,667$ & $\$ 0.31$ & $\$ 1.47$ & $\$ 1.78$ & 0.27 & 96 & 0.13 \\
\hline 45 & 322 & $\$ 700,000$ & $\$ 116,667$ & $\$ 560,000$ & $\$ 676,667$ & $\$ 0.31$ & $\$ 1.47$ & $\$ 1.78$ & 0.27 & 96 & 0.13 \\
\hline 45 & 805 & $\$ 1,050,000$ & $\$ 175,000$ & $\$ 560,000$ & $\$ 735,000$ & $\$ 0.46$ & $\$ 1.48$ & $\$ 1.95$ & 0.27 & 192 & 0.09 \\
\hline 45 & 1,609 & $\$ 1,400,000$ & $\$ 233,333$ & $\$ 560,000$ & $\$ 793,333$ & $\$ 0.62$ & $\$ 1.49$ & $\$ 2.11$ & 0.27 & 288 & 0.07 \\
\hline 454 & 16 & $\$ 3,850,000$ & $\$ 641,667$ & $\$ 5,600,000$ & $\$ 6,241,667$ & $\$ 0.17$ & $\$ 1.47$ & $\$ 1.64$ & 2.67 & 96 & 0.24 \\
\hline 454 & 32 & $\$ 3,850,000$ & $\$ 641,667$ & $\$ 5,600,000$ & $\$ 6,241,667$ & $\$ 0.17$ & $\$ 1.47$ & $\$ 1.64$ & 2.67 & 96 & 0.24 \\
\hline 454 & 80 & $\$ 3,850,000$ & $\$ 641,667$ & $\$ 5,600,000$ & $\$ 6,241,667$ & $\$ 0.17$ & $\$ 1.47$ & $\$ 1.64$ & 2.67 & 96 & 0.24 \\
\hline 454 & 161 & $\$ 3,850,000$ & $\$ 641,667$ & $\$ 5,600,000$ & $\$ 6,241,667$ & $\$ 0.17$ & $\$ 1.47$ & $\$ 1.64$ & 2.67 & 96 & 0.24 \\
\hline 454 & 322 & $\$ 3,850,000$ & $\$ 641,667$ & $\$ 5,600,000$ & $\$ 6,241,667$ & $\$ 0.17$ & $\$ 1.47$ & $\$ 1.64$ & 2.67 & 96 & 0.24 \\
\hline 454 & 805 & $\$ 7,700,000$ & $\$ 1,283,333$ & $\$ 5,600,000$ & $\$ 6,883,333$ & $\$ 0.34$ & $\$ 1.48$ & $\$ 1.82$ & 2.67 & 192 & 0.12 \\
\hline 454 & 1,609 & $\$ 11,200,000$ & $\$ 1,866,667$ & $\$ 5,600,000$ & $\$ 7,466,667$ & $\$ 0.50$ & $\$ 1.49$ & $\$ 1.99$ & 2.67 & 288 & 0.08 \\
\hline 4,536 & 16 & $\$ 37,450,000$ & $\$ 6,241,667$ & $\$ 56,000,000$ & $\$ 62,241,667$ & $\$ 0.16$ & $\$ 1.47$ & $\$ 1.64$ & 26.67 & 96 & 0.25 \\
\hline 4,536 & 32 & $\$ 37,450,000$ & $\$ 6,241,667$ & $\$ 56,000,000$ & $\$ 62,241,667$ & $\$ 0.16$ & $\$ 1.47$ & $\$ 1.64$ & 26.67 & 96 & 0.25 \\
\hline 4,536 & 80 & $\$ 37,450,000$ & $\$ 6,241,667$ & $\$ 56,000,000$ & $\$ 62,241,667$ & $\$ 0.16$ & $\$ 1.47$ & $\$ 1.64$ & 26.67 & 96 & 0.25 \\
\hline 4,536 & 161 & $\$ 37,450,000$ & $\$ 6,241,667$ & $\$ 56,000,000$ & $\$ 62,241,667$ & $\$ 0.16$ & $\$ 1.47$ & $\$ 1.64$ & 26.67 & 96 & 0.25 \\
\hline 4,536 & 322 & $\$ 37,450,000$ & $\$ 6,241,667$ & $\$ 56,000,000$ & $\$ 62,241,667$ & $\$ 0.16$ & $\$ 1.47$ & $\$ 1.64$ & 26.67 & 96 & 0.25 \\
\hline 4,536 & 805 & $\$ 74,900,000$ & $\$ 12,483,333$ & $\$ 56,000,000$ & $\$ 68,483,333$ & $\$ 0.33$ & $\$ 1.48$ & $\$ 1.81$ & 26.67 & 192 & 0.12 \\
\hline 45,359 & 1,609 & $\$ 112,000,000$ & $\$ 18,666,667$ & $\$ 56,000,000$ & $\$ 74,666,667$ & $\$ 0.50$ & $\$ 1.49$ & $\$ 1.99$ & 26.67 & 288 & 0.08 \\
\hline 45,359 & 16 & $\$ 373,450,000$ & $\$ 62,241,667$ & $\$ 560,000,000$ & $\$ 622,241,667$ & $\$ 0.16$ & $\$ 1.47$ & $\$ 1.64$ & 266.67 & 96 & 0.25 \\
\hline 45,359 & 32 & $\$ 373,450,000$ & $\$ 62,241,667$ & $\$ 560,000,000$ & $\$ 622,241,667$ & $\$ 0.16$ & $\$ 1.47$ & $\$ 1.64$ & 266.67 & 96 & 0.25 \\
\hline 45,359 & 80 & $\$ 373,450,000$ & $\$ 62,241,667$ & $\$ 560,000,000$ & $\$ 622,241,667$ & $\$ 0.16$ & $\$ 1.47$ & $\$ 1.64$ & 266.67 & 96 & 0.25 \\
\hline 45,359 & 161 & $\$ 373,450,000$ & $\$ 62,241,667$ & $\$ 560,000,000$ & $\$ 622,241,667$ & $\$ 0.16$ & $\$ 1.47$ & $\$ 1.64$ & 266.67 & 96 & 0.25 \\
\hline 45,359 & 322 & $\$ 373,450,000$ & $\$ 62,241,667$ & $\$ 560,000,000$ & $\$ 622,241,667$ & $\$ 0.16$ & $\$ 1.47$ & $\$ 1.64$ & 266.67 & 96 & 0.25 \\
\hline 45,359 & 805 & $\$ 746,900,000$ & $\$ 124,483,333$ & $\$ 560,000,000$ & $\$ 684,483,333$ & $\$ 0.33$ & $\$ 1.48$ & $\$ 1.81$ & 266.67 & 192 & 0.12 \\
\hline 45,359 & 1,609 & $\$ 1,120,000,000$ & $\$ 186,666,667$ & $\$ 560,000,000$ & $\$ 746,666,667$ & $\$ 0.50$ & $\$ 1.49$ & $\$ 1.99$ & 266.67 & 288 & 0.08 \\
\hline
\end{tabular}




\begin{tabular}{|c|c|c|c|c|c|c|c|c|c|c|c|c|c|c|}
\hline \multicolumn{15}{|c|}{ E.5 LIQUID HYDROGEN DELIVERY BY SHIP - English Units } \\
\hline & & & & & & & & & & & & & & \\
\hline \multicolumn{2}{|l|}{ Ship Liquid Tank= } & $\$ 350,000$ & per container & & & & & & & & & & & \\
\hline \multicolumn{2}{|c|}{ Ship Liquid Capacity= } & 9,000 & lb/tank & & & & & & & & & & & \\
\hline \multicolumn{2}{|c|}{ Ship Boil-Off Rate $=$} & $0.30 \%$ & per day & & & & & & & & & & & \\
\hline \multicolumn{2}{|c|}{ Ship Average Speed $=$} & 10 & $\mathrm{mph}$ & & & & & & & & & & & \\
\hline \multirow{2}{*}{\multicolumn{2}{|c|}{ Ship Tank Availability = }} & 48 & hr/trip & & & & & & & & & & & \\
\hline & & 24 & hr/day & & & & & & & & & & & \\
\hline \multicolumn{2}{|l|}{ Shipping Charge $=$} & $\$ 3,000$ & per container & & & & & & & & & & & \\
\hline \multirow{2}{*}{\multicolumn{2}{|c|}{$\begin{array}{l}\text { Operating Days } / \text { Year }= \\
\text { Trailer/Tank Depreciation }=\end{array}$}} & 350 & days/yr & & & & & & & & & & & \\
\hline & & 6 & years & & & & & & & & & & & \\
\hline & & & & & & & & & & & & & & \\
\hline Production & \begin{tabular}{|l|} 
Delivery Distance \\
\end{tabular} & Distance & Annual & Tank & Boil-Off Rate & Number & \begin{tabular}{|l|} 
Total Miles \\
\end{tabular} & Time per & Quantity after & Total Transit & Total Load/ & Total Delivery & Tank & Tanks \\
\hline Rate & One-Way & Two-Way & \begin{tabular}{|l|} 
Production \\
\end{tabular} & Capacity & & \begin{tabular}{|l|} 
of Trips \\
\end{tabular} & & Trip & Boil-Off & Time & Unload Time & Time & Availability & Required \\
\hline$(\mathrm{lb} / \mathrm{hr})$ & (miles) & \begin{tabular}{|l} 
(miles/trip) \\
\end{tabular} & $(\mathrm{lb} / \mathrm{yr} \mathrm{r})$ & \begin{tabular}{|l|l|l}
$(\mathrm{lb} / \operatorname{tank})$ \\
\end{tabular} & $(\% / d)$ & \begin{tabular}{|l|l|} 
(trips/yr) \\
\end{tabular} & (miles/yr) & (days/trip) & $(\mathrm{lb} / \mathrm{yr})$ & $(\mathrm{hr} / \mathrm{yr})$ & $(h r / y r)$ & $(\mathrm{hr} / \mathrm{yr})$ & $(h r / y r)$ & \\
\hline 10 & 10 & 20 & 84,000 & 9,000 & $0.30 \%$ & 9 & 187 & & 83,748 & 448 & 448 & 896 & 8,400 & \\
\hline 10 & 20 & 40 & 84,000 & 9,000 & $0.30 \%$ & 9 & 373 & 2 & 83,748 & 448 & 448 & 896 & 8,400 & \\
\hline 10 & 50 & 100 & 84,000 & 9,000 & $0.30 \%$ & 9 & 933 & 4 & 83,748 & 448 & 448 & 896 & 8,400 & \\
\hline 10 & 100 & 200 & 84,000 & 9,000 & $0.30 \%$ & 9 & 1,867 & 4 & 83,748 & 448 & 448 & 896 & 8,400 & \\
\hline 10 & 200 & 400 & 84,000 & 9,000 & $0.30 \%$ & 9 & 3,733 & 2 & 83,748 & 448 & 448 & 896 & 8,400 & \\
\hline 10 & 500 & 1,000 & 84,000 & 9,000 & $0.30 \%$ & 9 & 9,333 & 6 & 83,247 & 1,344 & 448 & 1,792 & 8,400 & \\
\hline 10 & 1,000 & 2,000 & 84,000 & 9,000 & $0.30 \%$ & 9 & 18,667 & 10 & 82,749 & 2,240 & 448 & 2,688 & 8,400 & \\
\hline 100 & 10 & 20 & 840,000 & 9,000 & $0.30 \%$ & 93 & $\begin{array}{l}1,867 \\
\end{array}$ & & 837,484 & 4,480 & 4,480 & 8,960 & 8,400 & \\
\hline 100 & 20 & 40 & 840,000 & 9,000 & $0.30 \%$ & 93 & 3,733 & 2 & 837,484 & 4,480 & 4,480 & 8,960 & 8,400 & \\
\hline 100 & 50 & 100 & 840,000 & 9,000 & $0.30 \%$ & 93 & 9,333 & & 837,484 & 4,480 & 4,480 & 8,960 & 8,400 & \\
\hline 100 & 100 & 200 & 840,000 & 9,000 & $0.30 \%$ & 93 & $\mid$\begin{tabular}{|c|}
18,667 \\
\end{tabular} & $\frac{4}{2}$ & 837,484 & 4 & 4,480 & 8,960 & 8,400 & \\
\hline 100 & 200 & 400 & 840,000 & 9,000 & $0.30 \%$ & 93 & 37,333 & 2 & 837,484 & 4,480 & 4,480 & 8,960 & 8,400 & \\
\hline 100 & 500 & 1,000 & 840,000 & 9,000 & $0.30 \%$ & 93 & 93,333 & 6 & 832,474 & 13,440 & 4,480 & \begin{tabular}{|l|l|}
17,920 \\
\end{tabular} & 8,400 & \\
\hline 100 & 1,000 & 2,000 & 840,000 & 9,000 & $0.30 \%$ & 93 & 186,667 & 10 & 827,494 & 22,400 & 4,480 & 26,880 & 8,400 & 4 \\
\hline 1,000 & 10 & 20 & $8,400,000$ & 9,000 & $0.30 \%$ & 933 & 18,667 & & $8,374,838$ & 44,800 & 44,800 & 89,600 & 8,400 & 11 \\
\hline $\begin{array}{l}1,000 \\
\end{array}$ & 20 & 40 & $8,400,000$ & 9,000 & $0.30 \%$ & 933 & 37,333 & 2 & $8,374,838$ & 44,800 & 44,800 & 89,600 & 8,400 & 11 \\
\hline 1,000 & 50 & 100 & $8,400,000$ & 9,000 & $0.30 \%$ & 933 & 93,333 & & $8,374,838$ & 44,800 & 44,800 & 89,600 & 8,400 & 11 \\
\hline $\begin{array}{l}1,000 \\
\end{array}$ & 100 & 200 & $8,400,000$ & 9,000 & $0.30 \%$ & 933 & \begin{tabular}{|c|}
186,667 \\
\end{tabular} & & $8,374,838$ & $\begin{array}{l}44,800 \\
\end{array}$ & 44,800 & 89,600 & 8,400 & 11 \\
\hline 1,000 & 200 & 400 & $8,400,000$ & 9,000 & $0.30 \%$ & 933 & 373,333 & 7 & $8,374,838$ & 44,800 & 44,800 & 89,600 & 8,400 & 11 \\
\hline 1,000 & 500 & 1,000 & $8,400,000$ & 9,000 & $0.30 \%$ & 933 & 933,333 & 6 & $8,324,739$ & 134,400 & 44,800 & 179,200 & 8,400 & 22 \\
\hline $\begin{array}{l}1,000 \\
\end{array}$ & 1,000 & 2,000 & $8,400,000$ & 9,000 & $0.30 \%$ & 933 & $1,866,667$ & 10 & $8,274,940$ & 224,000 & 44,800 & 268,800 & 8,400 & 32 \\
\hline 10,000 & 10 & 20 & $84,000,000$ & 9,000 & $0.30 \%$ & 9,333 & 186,667 & & $83,748,378$ & 448,000 & 448,000 & 896,000 & 8,400 & 107 \\
\hline 10,000 & 20 & 40 & $84,000,000$ & 9,000 & $0.30 \%$ & 9,333 & 373,333 & 2 & $83,748,378$ & $\begin{array}{l}448,000 \\
\end{array}$ & 448,000 & 896,000 & 8,400 & 107 \\
\hline 10,000 & 50 & 100 & $84,000,000$ & 9,000 & $0.30 \%$ & 9,333 & 933,333 & & $83,748,378$ & 448,000 & 448,000 & 896,000 & 8,400 & 107 \\
\hline$\frac{10,000}{10,000}$ & 100 & 200 & $84,000,000$ & 9,000 & $0.30 \%$ & $\frac{3,000}{9,333}$ & $\mid$ & & $\mid$\begin{tabular}{|c|}
$83,748,378$ \\
\end{tabular} & \begin{tabular}{|l|}
448,000 \\
4
\end{tabular} & $\begin{array}{l}448,000 \\
448,000\end{array}$ & 年 & 8,400 & 107 \\
\hline 10,000 & 200 & 400 & $84,000,000$ & 9,000 & $0.30 \%$ & 9,333 & $3,733,333$ & & $83,748,378$ & 448,000 & 448,000 & 896,000 & 8,400 & 107 \\
\hline 10,000 & 500 & 1,000 & $84,000,000$ & 9,000 & $0.30 \%$ & 9,333 & $9,333,333$ & 6 & $83,247,392$ & $1,344,000$ & 448,000 & $1,792,000$ & 8,400 & 214 \\
\hline 10,000 & 1,000 & 2,000 & $84,000,000$ & 9,000 & $0.30 \%$ & 9,333 & $18,666,667$ & 10 & $82,749,403$ & $2,240,000$ & 448,000 & $2,688,000$ & 8,400 & 320 \\
\hline \begin{tabular}{|l|l|}
100,000 \\
\end{tabular} & 10 & 20 & $840,000,000$ & 9,000 & $0.30 \%$ & 93,333 & $\begin{array}{l}1,866,667 \\
\end{array}$ & & $837,483,776$ & $4,480,000$ & $4,480,000$ & $8,960,000$ & 8,400 & 1,067 \\
\hline 100,000 & 20 & 40 & $840,000,000$ & 9,000 & $0.30 \%$ & 93,333 & $3,733,333$ & 2 & $837,483,776$ & $4,480,000$ & $4,480,000$ & $8,960,000$ & 8,400 & 1,067 \\
\hline \begin{tabular}{l|l|}
100,000 \\
\end{tabular} & 50 & 100 & $840,000,000$ & 9,000 & $0.30 \%$ & 93,333 & $9,333,333$ & 2 & $837,483,776$ & $4,480,000$ & $4,480,000$ & $8,960,000$ & 8,400 & 1,067 \\
\hline 100,000 & 100 & 200 & $840,000,000$ & 9,000 & $0.30 \%$ & 93,333 & $\mid$ & & $837,483,776$ & 4,480,000 & $4,480,000$ & $8,960,000$ & 8,400 & 1,067 \\
\hline 100,000 & 200 & 400 & $840,000,000$ & 9,000 & $0.30 \%$ & 93,333 & $37,333,333$ & 2 & $837,483,776$ & $4,480,000$ & $4,480,000$ & $8,960,000$ & 8,400 & 1,067 \\
\hline 100,000 & 500 & 1,000 & $840,000,000$ & 9,000 & $0.30 \%$ & 93,333 & $93,333,333$ & 6 & $832,473,918$ & $13,440,000$ & $4,480,000$ & $17,920,000$ & 8,400 & 2,134 \\
\hline 100,000 & 1,000 & 2,000 & $840,000,000$ & 9,000 & $0.30 \%$ & 93,333 & $186,666,667$ & 10 & $827,494,029$ & $22,400,000$ & $4,480,000$ & $26,880,000$ & 8.400 & 3,200 \\
\hline
\end{tabular}




\begin{tabular}{|c|c|c|c|c|c|c|c|c|c|c|c|}
\hline \multicolumn{12}{|c|}{ E.5 LIQUID HYDROGEN DELIVERY BY SHIP - English Units (Continued) } \\
\hline & & & & & & & & & & & \\
\hline \begin{tabular}{|l|} 
Production \\
\end{tabular} & Delivery Distanc & Total Capital & Depreciation & Annual Freight & Total Annual & Capital & Freight & Total & Trip & Trip & Tank \\
\hline Rate & One-Way & Cost & & Cost & Cost & Cost & Cost & Cost & Frequency & Length & Utilization \\
\hline$(\mathrm{lb} / \mathrm{hr})$ & (miles) & $(\$)$ & $(\$ / y r)$ & $(\$ / y r)$ & $(\$ / y r)$ & $(\$ / \mathrm{lb})$ & $(\$ / \mathrm{lb})$ & $(\$ / \mathrm{lb})$ & (trips/day) & (hours) & (trips/tank/d) \\
\hline 10 & 10 & $\$ 350,000$ & $\$ 58,333$ & $\$ 56,000$ & $\$ 114,333$ & $\$ 0.70$ & $\$ 0.67$ & $\$ 1.37$ & 0.03 & 96 & 0.03 \\
\hline 10 & 20 & $\$ 350,000$ & $\$ 58,333$ & $\$ 56,000$ & $\$ 114,333$ & $\$ 0.70$ & $\$ 0.67$ & $\$ 1.37$ & 0.03 & 96 & 0.03 \\
\hline 10 & 50 & $\$ 350,000$ & $\$ 58,333$ & $\$ 56,000$ & $\$ 114,333$ & $\$ 0.70$ & $\$ 0.67$ & $\$ 1.37$ & 0.03 & 96 & 0.03 \\
\hline 10 & 100 & $\$ 350,000$ & $\$ 58,333$ & $\$ 56,000$ & $\$ 114,333$ & $\$ 0.70$ & $\$ 0.67$ & $\$ 1.37$ & 0.03 & 96 & 0.03 \\
\hline 10 & 200 & $\$ 350,000$ & $\$ 58,333$ & $\$ 56,000$ & $\$ 114,333$ & $\$ 0.70$ & $\$ 0.67$ & $\$ 1.37$ & 0.03 & 96 & 0.03 \\
\hline 10 & 500 & $\$ 350,000$ & $\$ 58,333$ & $\$ 56,000$ & $\$ 114,333$ & $\$ 0.70$ & $\$ 0.67$ & $\$ 1.37$ & 0.03 & 192 & 0.03 \\
\hline 10 & 1,000 & $\$ 350,000$ & $\$ 58,333$ & $\$ 56,000$ & $\$ 114,333$ & $\$ 0.70$ & $\$ 0.68$ & $\$ 1.38$ & 0.03 & 288 & 0.03 \\
\hline 100 & 10 & $\$ 700,000$ & $\$ 116,667$ & $\$ 560,000$ & $\$ 676,667$ & $\$ 0.14$ & $\$ 0.67$ & $\$ 0.81$ & 0.27 & 96 & 0.13 \\
\hline 100 & 20 & $\$ 700,000$ & $\$ 116,667$ & $\$ 560,000$ & $\$ 676,667$ & $\$ 0.14$ & $\$ 0.67$ & $\$ 0.81$ & 0.27 & 96 & 0.13 \\
\hline 100 & 50 & $\$ 700,000$ & $\$ 116,667$ & $\$ 560,000$ & $\$ 676,667$ & $\$ 0.14$ & $\$ 0.67$ & $\$ 0.81$ & 0.27 & 96 & 0.13 \\
\hline 100 & 100 & $\$ 700,000$ & $\$ 116,667$ & $\$ 560,000$ & $\$ 676,667$ & $\$ 0.14$ & $\$ 0.67$ & $\$ 0.81$ & 0.27 & 96 & 0.13 \\
\hline 100 & 200 & $\$ 700,000$ & $\$ 116,667$ & $\$ 560,000$ & $\$ 676,667$ & $\$ 0.14$ & $\$ 0.67$ & $\$ 0.81$ & 0.27 & 96 & 0.13 \\
\hline 100 & 500 & $\$ 1,050,000$ & $\$ 175,000$ & $\$ 560,000$ & $\$ 735,000$ & $\$ 0.21$ & $\$ 0.67$ & $\$ 0.88$ & 0.27 & 192 & 0.09 \\
\hline 100 & 1,000 & $\$ 1,400,000$ & $\$ 233,333$ & $\$ 560,000$ & $\$ 793,333$ & $\$ 0.28$ & $\$ 0.68$ & $\$ 0.96$ & 0.27 & 288 & 0.07 \\
\hline 1,000 & 10 & $\$ 3,850,000$ & $\$ 641,667$ & $\$ 5,600,000$ & $\$ 6,241,667$ & $\$ 0.08$ & $\$ 0.67$ & $\$ 0.75$ & 2.67 & 96 & 0.24 \\
\hline 1,000 & 20 & $\$ 3,850,000$ & $\$ 641,667$ & $\$ 5,600,000$ & $\$ 6,241,667$ & $\$ 0.08$ & $\$ 0.67$ & $\$ 0.75$ & 2.67 & 96 & 0.24 \\
\hline 1,000 & 50 & $\$ 3,850,000$ & $\$ 641,667$ & $\$ 5,600,000$ & $\$ 6,241,667$ & $\$ 0.08$ & $\$ 0.67$ & $\$ 0.75$ & 2.67 & 96 & 0.24 \\
\hline 1,000 & 100 & $\$ 3,850,000$ & $\$ 641,667$ & $\$ 5,600,000$ & $\$ 6,241,667$ & $\$ 0.08$ & $\$ 0.67$ & $\$ 0.75$ & 2.67 & 96 & 0.24 \\
\hline 1,000 & 200 & $\$ 3,850,000$ & $\$ 641,667$ & $\$ 5,600,000$ & $\$ 6,241,667$ & $\$ 0.08$ & $\$ 0.67$ & $\$ 0.75$ & 2.67 & 96 & 0.24 \\
\hline 1,000 & 500 & $\$ 7,700,000$ & $\$ 1,283,333$ & $\$ 5,600,000$ & $\$ 6,883,333$ & $\$ 0.15$ & $\$ 0.67$ & $\$ 0.83$ & 2.67 & 192 & 0.12 \\
\hline 1,000 & 1,000 & $\$ 11,200,000$ & $\$ 1,866,667$ & $\$ 5,600,000$ & $\$ 7,466,667$ & $\$ 0.23$ & $\$ 0.68$ & $\$ 0.90$ & 2.67 & 288 & 0.08 \\
\hline 10,000 & 10 & $\$ 37,450,000$ & $\$ 6,241,667$ & $\$ 56,000,000$ & $\$ 62,241,667$ & $\$ 0.07$ & $\$ 0.67$ & $\$ 0.74$ & 26.67 & 96 & 0.25 \\
\hline 10,000 & 20 & $\$ 37,450,000$ & $\$ 6,241,667$ & $\$ 56,000,000$ & $\$ 62,241,667$ & $\$ 0.07$ & $\$ 0.67$ & $\$ 0.74$ & 26.67 & 96 & 0.25 \\
\hline 10,000 & 50 & $\$ 37,450,000$ & $\$ 6,241,667$ & $\$ 56,000,000$ & $\$ 62,241,667$ & $\$ 0.07$ & $\$ 0.67$ & $\$ 0.74$ & 26.67 & 96 & 0.25 \\
\hline 10,000 & 100 & $\$ 37,450,000$ & $\$ 6,241,667$ & $\$ 56,000,000$ & $\$ 62,241,667$ & $\$ 0.07$ & $\$ 0.67$ & $\$ 0.74$ & 26.67 & 96 & 0.25 \\
\hline 10,000 & 200 & $\$ 37,450,000$ & $\$ 6,241,667$ & $\$ 56,000,000$ & $\$ 62,241,667$ & $\$ 0.07$ & $\$ 0.67$ & $\$ 0.74$ & 26.67 & 96 & 0.25 \\
\hline 10,000 & 500 & $\$ 74,900,000$ & $\$ 12,483,333$ & $\$ 56,000,000$ & $\$ 68,483,333$ & $\$ 0.15$ & $\$ 0.67$ & $\$ 0.82$ & 26.67 & 192 & 0.12 \\
\hline 100.000 & 1,000 & $\$ 112,000,000$ & $\$ 18,666,667$ & $\$ 56,000,000$ & $\$ 74,666,667$ & $\$ 0.23$ & $\$ 0.68$ & $\$ 0.90$ & 26.67 & 288 & 0.08 \\
\hline 100,000 & 10 & $\$ 373,450,000$ & $\$ 62,241,667$ & $\$ 560,000,000$ & $\$ 622,241,667$ & $\$ 0.07$ & $\$ 0.67$ & $\$ 0.74$ & 266.67 & 96 & 0.25 \\
\hline 100,000 & 20 & $\$ 373,450,000$ & $\$ 62,241,667$ & $\$ 560,000,000$ & $\$ 622,241,667$ & $\$ 0.07$ & $\$ 0.67$ & $\$ 0.74$ & 266.67 & 96 & 0.25 \\
\hline 100,000 & 50 & $\$ 373,450,000$ & $\$ 62,241,667$ & $\$ 560,000,000$ & $\$ 622,241,667$ & $\$ 0.07$ & $\$ 0.67$ & $\$ 0.74$ & 266.67 & 96 & 0.25 \\
\hline 100,000 & 100 & $\$ 373,450,000$ & $\$ 62,241,667$ & $\$ 560,000,000$ & $\$ 622,241,667$ & $\$ 0.07$ & $\$ 0.67$ & $\$ 0.74$ & 266.67 & 96 & 0.25 \\
\hline 100,000 & 200 & $\$ 373,450,000$ & $\$ 62,241,667$ & $\$ 560,000,000$ & $\$ 622,241,667$ & $\$ 0.07$ & $\$ 0.67$ & $\$ 0.74$ & 266.67 & 96 & 0.25 \\
\hline 100,000 & 500 & $\$ 746,900,000$ & $\$ 124,483,333$ & $\$ 560,000,000$ & $\$ 684,483,333$ & $\$ 0.15$ & $\$ 0.67$ & $\$ 0.82$ & 266.67 & 192 & 0.12 \\
\hline 100,000 & 1,000 & $\$ 1,120,000,000$ & $\$ 186,666,667$ & $\$ 560,000,000$ & $\$ 746,666,667$ & $\$ 0.23$ & $\$ 0.68$ & $\$ 0.90$ & 266.67 & 288 & 0.08 \\
\hline
\end{tabular}




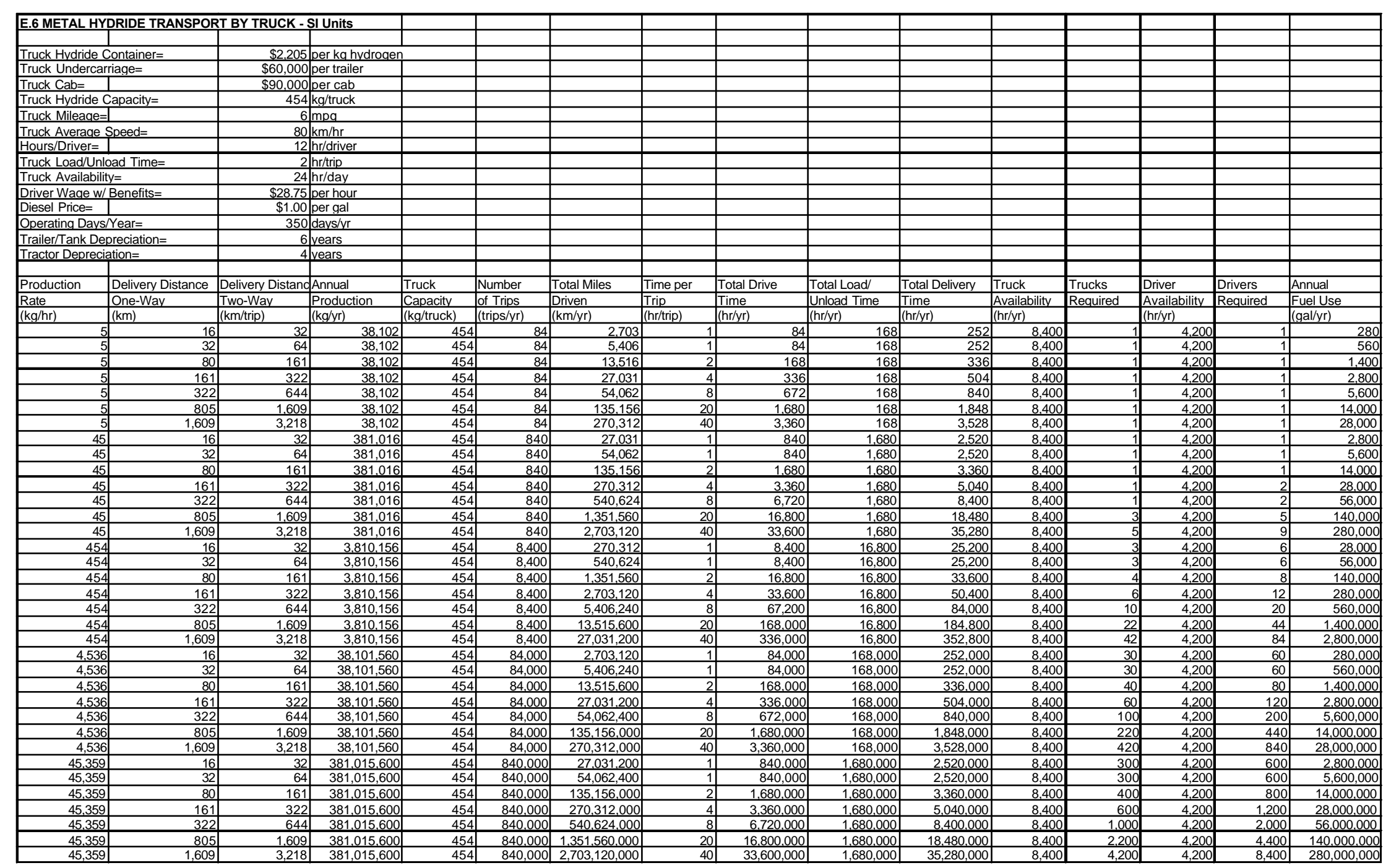

E - 23 


\begin{tabular}{|c|c|c|c|c|c|c|c|c|c|c|c|c|c|}
\hline \multirow{2}{*}{\multicolumn{14}{|c|}{ E.6 METAL HYDRIDE TRANSPORT BY TRUCK - SI Units (Continued) }} \\
\hline & & & & & & & & & & & & & \\
\hline Production & & Total Capital & \begin{tabular}{|l|} 
Depreciation \\
\end{tabular} & Annual & Annual Labor & Total Annual & Capital & Fuel & Labor & Total & & & Truck \\
\hline Rate & One-Way & Cost & & Fuel Cost & Cost & Cost & $\begin{array}{l}\text { Cost } \\
\text { est }\end{array}$ & Cost & $\begin{array}{l}\text { Cost } \\
\end{array}$ & Cost & Frequency & Length & Utilization \\
\hline$(\mathrm{kg} / \mathrm{hr})$ & $(\mathrm{km})$ & (\$) & $(\$ / y r)$ & $(\$ / y r)$ & $(\$ / y r)$ & $(\$ / y r)$ & $(\$ / \mathrm{kg})$ & $(\$ / \mathrm{kg})$ & $(\$ / \mathrm{kg})$ & $(\$ / \mathrm{kg})$ & (trips/day) & (Hours) & (Trips/truck/day) \\
\hline 5 & 16 & $\$ 1,150,000$ & $\$ 199,167$ & $\$ 280$ & $\$ 7,245$ & $\$ 1,157,525$ & $\$ 5.23$ & $\$ 0.01$ & $\$ 0.19$ & $\$ 30.38$ & 0.24 & , & 0.24 \\
\hline 5 & 32 & $\$ 1,150,000$ & $\$ 199,167$ & $\$ 560$ & $\$ 7,245$ & $\$ 206,972$ & $\$ 5.23$ & $\$ 0.01$ & $\$ 0.19$ & $\$ 5.43$ & 0.24 & & 0.24 \\
\hline 5 & 80 & $\$ 1,150,000$ & $\$ 199,167$ & $\$ 1,400$ & $\$ 9,660$ & $\$ 210,227$ & $\$ 5.23$ & $\$ 0.04$ & $\$ 0.25$ & $\$ 5.52$ & 0.24 & 4 & 0.24 \\
\hline 5 & 161 & $\$ 1,150,000$ & $\$ 199,167$ & $\$ 2,800$ & $\$ 14,490$ & $\$ 216,457$ & $\$ 5.23$ & $\$ 0.07$ & $\$ 0.38$ & $\$ 5.68$ & 0.24 & 6 & 0.24 \\
\hline 5 & 322 & $\$ 1,150,000$ & $\$ 199,167$ & $\$ 5,600$ & $\$ 24,150$ & $\$ 228,917$ & $\$ 5.23$ & $\$ 0.15$ & $\$ 0.63$ & $\$ 6.01$ & 0.24 & 10 & 0.24 \\
\hline 5 & 805 & $\$ 1,150,000$ & $\$ 199,167$ & $\$ 14,000$ & $\$ 53,130$ & $\$ 266,297$ & $\$ 5.23$ & $\$ 0.37$ & $\$ 1.39$ & $\$ 6.99$ & 0.24 & 22 & 0.24 \\
\hline 5 & 1,609 & $\$ 1,150,000$ & $\$ 199,167$ & $\$ 28,000$ & $\$ 101,430$ & $\$ 328,597$ & $\$ 5.23$ & $\$ 0.73$ & $\$ 2.66$ & $\$ 8.62$ & 0.24 & 42 & 0.24 \\
\hline 45 & 16 & $\$ 1,150,000$ & $\$ 199,167$ & $\$ 2,800$ & $\$ 72,450$ & $\$ 274,417$ & $\$ 0.52$ & $\$ 0.01$ & $\$ 0.19$ & $\$ 0.72$ & 2.4 & 2 & 2.40 \\
\hline 45 & 32 & $\$ 1,150,000$ & $\$ 199,167$ & $\$ 5,600$ & $\$ 72,450$ & $\$ 277,217$ & $\$ 0.52$ & $\$ 0.01$ & $\$ 0.19$ & $\$ 0.73$ & 2.4 & 3 & 2.40 \\
\hline 45 & 80 & $\$ 1,150,000$ & $\$ 199,167$ & $\$ 14,000$ & $\$ 96,600$ & $\$ 309,767$ & $\$ 0.52$ & $\$ 0.04$ & $\$ 0.25$ & $\$ 0.81$ & 2.4 & 4 & 2.40 \\
\hline 45 & 161 & $\$ 1,150,000$ & $\$ 199,167$ & $\$ 28,000$ & $\$ 144,900$ & $\$ 372,067$ & $\$ 0.52$ & $\$ 0.07$ & $\$ 0.38$ & $\$ 0.98$ & 2.4 & 6 & 2.40 \\
\hline 45 & 322 & $\$ 1,150,000$ & $\$ 199,167$ & $\$ 56,000$ & $\$ 241,500$ & $\$ 496,667$ & $\$ 0.52$ & $\$ 0.15$ & $\$ 0.63$ & $\$ 1.30$ & 2.4 & 10 & 2.40 \\
\hline 45 & 805 & $\$ 3,450,000$ & $\$ 597,500$ & $\$ 140,000$ & $\$ 531,300$ & $\$ 1,268,800$ & $\$ 1.57$ & $\$ 0.37$ & $\$ 1.3$ & $\$ 3.33$ & 2.4 & 22 & 0.80 \\
\hline 45 & 1,609 & $\$ 5,750,000$ & $\$ 995,833$ & $\$ 280,000$ & $\$ 1,014,300$ & $\$ 2,290,133$ & $\$ 2.61$ & $\$ 0.73$ & $\$ 2.66$ & $\$ 6.01$ & 2.4 & 42 & 0.48 \\
\hline 454 & 16 & $\$ 3,450,000$ & $\$ 597,500$ & $\$ 28,000$ & $\$ 724,500$ & $\$ 1,350,000$ & $\$ 0.16$ & $\$ 0.01$ & $\$ 0.19$ & $\$ 0.35$ & 24 & 2 & 8.00 \\
\hline 454 & 32 & $\$ 3,450,000$ & $\$ 597,500$ & $\$ 56,000$ & $\$ 724,500$ & $\$ 1,378,000$ & $\$ 0.16$ & $\$ 0.01$ & $\$ 0.19$ & $\$ 0.36$ & 24 & 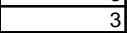 & 8.00 \\
\hline 454 & 80 & $\$ 4,600,000$ & $\$ 796,667$ & $\$ 140,000$ & $\$ 966,000$ & $\$ 1,902,667$ & $\$ 0.21$ & $\$ 0.04$ & $\$ 0.25$ & $\$ 0.50$ & 24 & 4 & 6.00 \\
\hline 454 & 161 & $\$ 6,900,000$ & $\$ 1,195,000$ & $\$ 280,000$ & $\$ 1,449,000$ & $\$ 2,924,000$ & $\$ 0.31$ & $\$ 0.07$ & $\$ 0.38$ & $\$ 0.77$ & 24 & 6 & 4.00 \\
\hline 454 & 322 & $\$ 11,500,000$ & $\$ 1,991,667$ & $\$ 560,000$ & $\$ 2,415,000$ & $\$ 4,966,667$ & $\$ 0.52$ & $\$ 0.15$ & $\$ 0.63$ & $\$ 1.30$ & 24 & 10 & 2.40 \\
\hline 454 & 805 & $\$ 25,300,000$ & $\$ 4,381,667$ & $\$ 1,400,000$ & $\$ 5,313,000$ & $\$ 11,094,667$ & $\$ 1.15$ & $\$ 0.37$ & $\$ 1.39$ & $\$ 2.91$ & 24 & 22 & 1.09 \\
\hline 454 & 1,609 & $\$ 48,300,000$ & $\$ 8,365,000$ & $\$ 2,800,000$ & $\$ 10,143,000$ & $\$ 21,308,000$ & $\$ 2.20$ & $\$ 0.73$ & $\$ 2.66$ & $\$ 5.59$ & 24 & 42 & 0.57 \\
\hline 4,536 & 16 & $\$ 34,500,000$ & $\$ 5,975,000$ & $\$ 280,000$ & $\$ 7,245,000$ & $\$ 13,500,000$ & $\$ 0.16$ & $\$ 0.01$ & $\$ 0.19$ & $\$ 0.35$ & 240 & 3 & 8.00 \\
\hline 4.536 & 32 & $\$ 34,500,000$ & $\$ 5,975,000$ & $\$ 560,000$ & $\$ 7,245,000$ & $\$ 13,780,000$ & $\$ 0.16$ & $\$ 0.01$ & $\$ 0.19$ & $\$ 0.36$ & 240 & 3 & 8.00 \\
\hline 4,536 & $\frac{50}{80}$ & $\$ 46,000,000$ & $\$ 7,966,667$ & $\$ 1,400,000$ & $\$ 9,660,000$ & $\$ 19,026,667$ & $\$ 0.21$ & $\$ 0.04$ & $\$ 0.25$ & $\$ 0.50$ & 240 & 4 & 6.00 \\
\hline 4,536 & 161 & $\$ 69,0$ & $\$ 11,950,000$ & $\$ 2,800,000$ & $\$ 14,490,000$ & $\$ 29,240,000$ & $\$ 0.31$ & $\$ 0.07$ & $\$ 0.38$ & $\$ 0.77$ & 240 & & 4.00 \\
\hline 4,536 & 322 & $\$ 115,000,000$ & $\$ 19,916,667$ & $\$ 5,600,000$ & $\$ 24,150,000$ & $\$ 49,666,667$ & $\$ 0.52$ & $\$ 0.15$ & $\$ 0.63$ & $\$ 1.30$ & 240 & 10 & 2.40 \\
\hline 4,536 & 805 & $\$ 253,000,000$ & $\$ 43,816,667$ & $\$ 14,000,000$ & $\$ 53,130,000$ & $\$ 110,946,667$ & $\$ 1.15$ & $\$ 0.37$ & $\$ 1.39$ & $\$ 2.91$ & 240 & 22 & 1.09 \\
\hline 4,536 & 1,609 & $\$ 483,000,000$ & $\$ 83,650,000$ & $\$ 28,000,000$ & $\$ 101,430,000$ & $\$ 213,080,000$ & $\$ 2.20$ & $\$ 0.73$ & $\$ 2.66$ & $\$ 5.59$ & 240 & 42 & 0.57 \\
\hline 45,359 & 16 & $\$ 345,000,000$ & $\$ 59,750,000$ & $\$ 2,800,000$ & $\$ 72,450,000$ & $\$ 135,000,000$ & $\$ 0.16$ & $\$ 0.01$ & $\$ 0.19$ & $\$ 0.35$ & 2400 & 3 & 8.00 \\
\hline 45,359 & 32 & $\$ 345,000,000$ & $\$ 59,750,000$ & $\$ 5,600,000$ & $\$ 72,450,000$ & $\$ 137,800,000$ & $\$ 0.16$ & $\$ 0.01$ & $\$ 0.19$ & $\$ 0.36$ & 2400 & 3 & 8.00 \\
\hline 45,359 & 80 & $\$ 460,000,000$ & $\$ 79,666,667$ & $\$ 14,000,000$ & $\$ 96,600,000$ & $\$ 190,266,667$ & $\$ 0.21$ & $\$ 0.04$ & $\$ 0.25$ & $\$ 0.50$ & 2400 & 4 & 6.00 \\
\hline 45,359 & 161 & $\$ 690,000,000$ & $\$ 119,500,000$ & $\$ 28,000,000$ & $\$ 144,900,000$ & $\$ 292,400,000$ & $\$ 0.31$ & $\$ 0.07$ & $\$ 0.38$ & $\$ 0.77$ & 2400 & 6 & 4.00 \\
\hline 45,359 & 322 & $1,150,000,000$ & $\$ 199,166,667$ & $6,000,000$ & $\$ 241,500,000$ & $\$ 496,666,667$ & $\$ 0.52$ & $\$ 0.15$ & $\$ 0.63$ & $\$ 1.30$ & 2400 & 10 & 2.40 \\
\hline 45,359 & 805 & $\$ 2,530,000,000$ & $\$ 438,166,667$ & $\$ 140,000,000$ & $\$ 531,300,000$ & $\$ 1,109,466,667$ & $\$ 1.15$ & $\$ 0.37$ & $\$ 1.39$ & $\$ 2.91$ & 2400 & 22 & 1.09 \\
\hline 45,359 & 1,609 & \begin{tabular}{|l|l}
$\$ 4,830,000,000$ \\
\end{tabular} & $\$ 836,500,000$ & $\$ 280,000,000$ & $\$ 1,014,300,000$ & $\$ 2,130,800,000$ & $\$ 2.20$ & $\$ 0.73$ & $\$ 2.66$ & $\$ 5.59$ & 2400 & 42 & 0.57 \\
\hline
\end{tabular}




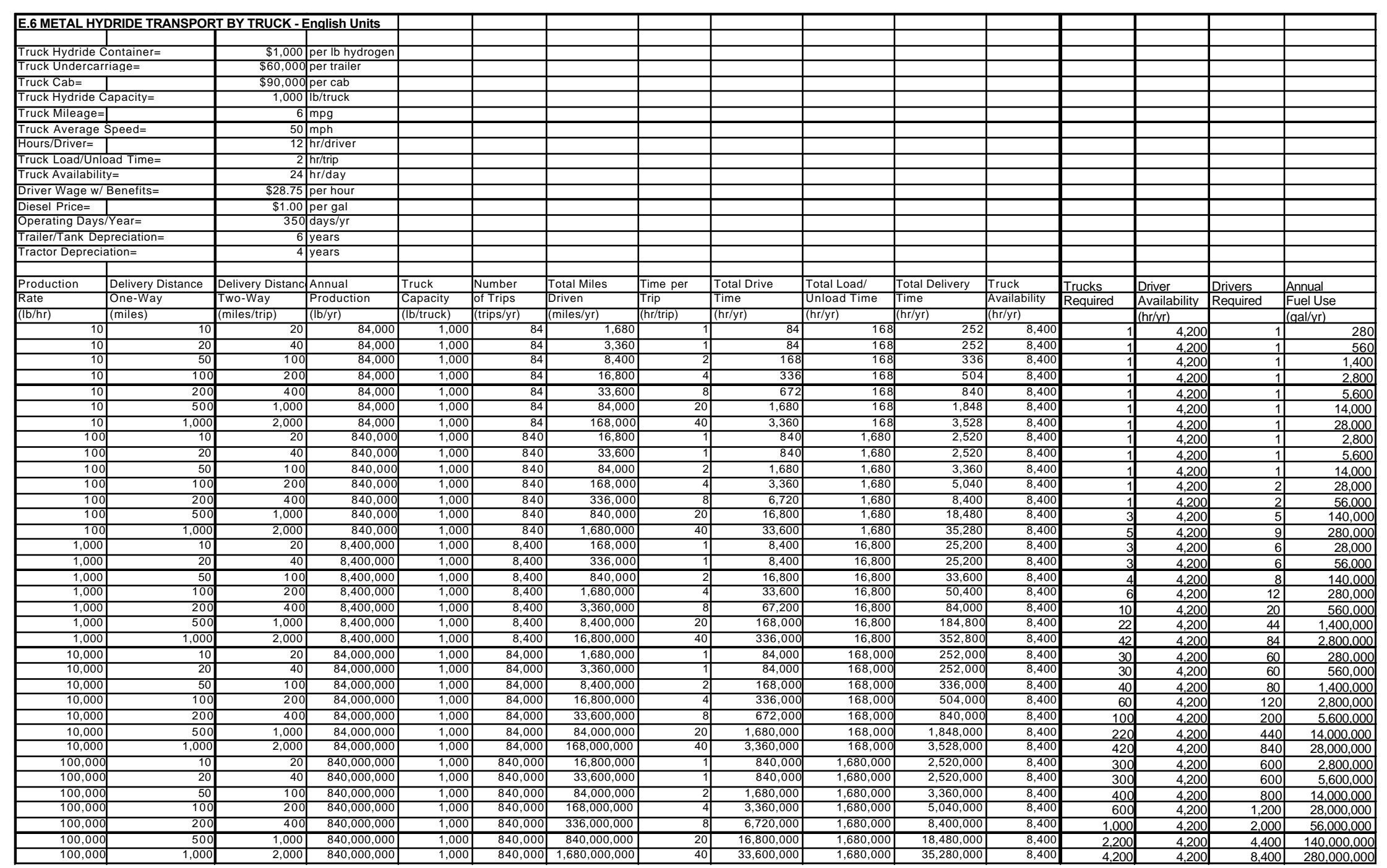

E - 25 


\begin{tabular}{|c|c|c|c|c|c|c|c|c|c|c|c|c|c|}
\hline \multirow{2}{*}{\multicolumn{14}{|c|}{ E.6 METAL HYDRIDE TRANSPORT BY TRUCK -English Units (Continued) }} \\
\hline & & & & & & & & & & & & & \\
\hline Production & Delivery Distanc & Total Capital & Depreciation & Annual & Annual Labor & Total Annual & Capital & |Fuel & Labor & Total & Trip & Trip & Truck \\
\hline Rate & One-Way & Cost & & Fuel Cost & Cost & Cost & Cost & Cost & Cost & Cost & Frequency & Length & Utilization \\
\hline$(\mathrm{b} / \mathrm{hr})$ & (miles) & (\$) & $(\$ / y r)$ & $(\$ / y r)$ & $(\$ / y r)$ & $(\$ / y r)$ & $(\$ / \mathrm{lb})$ & $(\$ / \mathrm{lb})$ & $(\$ / \mathrm{lb})$ & $(\$ / \mathrm{lb})$ & (trips/day) & (Hours) & (Trips/truck/day) \\
\hline 10 & 10 & $\$ 1,150,000$ & $\$ 199,167$ & $\$ 280$ & $\$ 7,245$ & $\$ 1,157,525$ & $\$ 2.37$ & $\$ 0.00$ & $\$ 0.09$ & $\$ 13.78$ & 0.24 & & 0.24 \\
\hline 10 & 20 & $\$ 1,150,000$ & $\$ 199,167$ & $\$ 560$ & $\$ 7,245$ & $\$ 206,972$ & $\$ 2.37$ & $\$ 0.01$ & $\$ 0.09$ & $\$ 2.46$ & 0.24 & 3 & 0.24 \\
\hline 10 & 50 & $\$ 1,150,000$ & $\$ 199,167$ & $\$ 1,400$ & $\$ 9,660$ & $\$ 210,227$ & $\$ 2.37$ & $\$ 0.02$ & $\$ 0.12$ & $\$ 2.50$ & 0.24 & 4 & 0.24 \\
\hline 10 & 100 & $\$ 1,150,000$ & $\$ 199,167$ & $\$ 2,800$ & $\$ 14,490$ & $\$ 216,457$ & $\$ 2.37$ & $\$ 0.03$ & $\$ 0.17$ & $\$ 2.58$ & 0.24 & 6 & 0.24 \\
\hline 10 & 200 & $\$ 1,150,000$ & $\$ 199,167$ & $\$ 5,600$ & $\$ 24,150$ & $\$ 228,917$ & $\$ 2.37$ & $\$ 0.07$ & $\$ 0.29$ & $\$ 2.73$ & 0.24 & 10 & 0.24 \\
\hline 10 & 500 & $\$ 1,150,000$ & $\$ 199,167$ & $\$ 14,000$ & $\$ 53,130$ & $\$ 266,297$ & $\$ 2.37$ & $\$ 0.17$ & $\$ 0.63$ & $\$ 3.17$ & 0.24 & 22 & 0.24 \\
\hline 10 & 1,000 & $\$ 1,150,000$ & $\$ 199,167$ & $\$ 28,000$ & $\$ 101,430$ & $\$ 328,597$ & $\$ 2.37$ & $\$ 0.33$ & $\$ 1.21$ & $\$ 3.91$ & 0.24 & 42 & 0.24 \\
\hline 100 & 10 & $\$ 1,150,000$ & $\$ 199,167$ & $\$ 2,800$ & $\$ 72,450$ & $\$ 274,417$ & $\$ 0.24$ & $\$ 0.00$ & $\$ 0.09$ & $\$ 0.33$ & 2.4 & & 2.40 \\
\hline 100 & 20 & $\$ 1,150,000$ & $\$ 199,167$ & $\$ 5,600$ & $\$ 72,450$ & $\$ 277,217$ & $\$ 0.24$ & $\$ 0.01$ & $\$ 0.09$ & $\$ 0.33$ & 2.4 & 3 & 2.40 \\
\hline 100 & 50 & $\$ 1,150,000$ & $\$ 199,167$ & $\$ 14,000$ & $\$ 96,600$ & $\$ 309,767$ & $\$ 0.24$ & $\$ 0.02$ & $\$ 0.12$ & $\$ 0.37$ & 2.4 & 4 & 2.40 \\
\hline 100 & 100 & $\$ 1,150,000$ & $\$ 199,167$ & $\$ 28,000$ & $\$ 144,900$ & $\$ 372,067$ & $\$ 0.24$ & $\$ 0.03$ & $\$ 0.17$ & $\$ 0.44$ & 2.4 & 6 & 2.40 \\
\hline 100 & 200 & $\$ 1,150,000$ & $\$ 199,167$ & $\$ 56,000$ & $\$ 241,500$ & $\$ 496,667$ & $\$ 0.24$ & $\$ 0.07$ & $\$ 0.29$ & $\$ 0.59$ & 2.4 & 10 & 2.40 \\
\hline 100 & 500 & $\$ 3,450,000$ & $\$ 597,500$ & $\$ 140,000$ & $\$ 531,300$ & $\$ 1,268,800$ & $\$ 0.71$ & $\$ 0.17$ & $\$ 0.63$ & $\$ 1.51$ & 2.4 & 22 & 0.80 \\
\hline 100 & 1,000 & $\$ 5,750,000$ & $\$ 995,833$ & $\$ 280,000$ & $\$ 1,014,300$ & $\$ 2,290,133$ & $\$ 1.19$ & $\$ 0.33$ & $\$ 1.21$ & $\$ 2.73$ & 2.4 & 42 & 0.48 \\
\hline 1,000 & 10 & $\$ 3,450,000$ & $\$ 597,500$ & $\$ 28,000$ & $\$ 724,500$ & $\$ 1,350,000$ & $\$ 0.07$ & $\$ 0.00$ & $\$ 0.09$ & $\$ 0.16$ & 24 & & 8.00 \\
\hline 1,000 & 20 & $\$ 3,450,000$ & $\$ 597,500$ & $\$ 56,000$ & $\$ 724,500$ & $\$ 1,378,000$ & $\$ 0.07$ & $\$ 0.01$ & $\$ 0.09$ & $\$ 0.16$ & 24 & 3 & 8.00 \\
\hline 1,000 & 50 & $\$ 4,600,000$ & $\$ 796,667$ & $\$ 140,000$ & $\$ 966,000$ & $\$ 1,902,667$ & $\$ 0.09$ & $\$ 0.02$ & $\$ 0.12$ & $\$ 0.23$ & 24 & 4 & 6.00 \\
\hline 1,000 & 100 & $\$ 6,900,000$ & $\$ 1,195,000$ & $\$ 280,000$ & $\$ 1,449,000$ & $\$ 2,924,000$ & $\$ 0.14$ & $\$ 0.03$ & $\$ 0.17$ & $\$ 0.35$ & 24 & 6 & 4.00 \\
\hline 1,000 & 200 & $\$ 11,500,000$ & $\$ 1,991,667$ & $\$ 560,000$ & $\$ 2,415,000$ & $\$ 4,966,667$ & $\$ 0.24$ & $\$ 0.07$ & $\$ 0.29$ & $\$ 0.59$ & 24 & 10 & 2.40 \\
\hline 1,000 & 500 & $\$ 25,300,000$ & $\$ 4,381,667$ & $\$ 1,400,000$ & $\$ 5,313,000$ & $\$ 11,094,667$ & $\$ 0.52$ & $\$ 0.17$ & $\$ 0.63$ & $\$ 1.32$ & 24 & 22 & 1.09 \\
\hline 1,000 & 1,000 & $\$ 48,300,000$ & $\$ 8,365,000$ & $\$ 2,800,000$ & $\$ 10,143,000$ & $\$ 21,308,000$ & $\$ 1.00$ & $\$ 0.33$ & $\$ 1.21$ & $\$ 2.54$ & 24 & 42 & 0.57 \\
\hline 10,000 & 10 & $\$ 34,500,000$ & $\$ 5,975,000$ & $\$ 280,000$ & $\$ 7,245,000$ & $\$ 13,500,000$ & $\$ 0.07$ & $\$ 0.00$ & $\$ 0.09$ & $\$ 0.16$ & 240 & 3 & 8.00 \\
\hline 10,000 & 20 & $\$ 34.500,000$ & $\$ 5,975,000$ & $\$ 560.000$ & $\$ 7,245,000$ & $\$ 13,780,000$ & $\$ 0.07$ & $\$ 0.01$ & $\$ 0.09$ & $\$ 0.16$ & 240 & 3 & 8.00 \\
\hline 10,000 & 50 & $\$ 46,000,000$ & $\$ 7,966,667$ & $\$ 1,400,000$ & $\$ 9,660,000$ & $\$ 19,026,667$ & $\$ 0.09$ & $\$ 0.02$ & $\$ 0.12$ & $\$ 0.23$ & 240 & 4 & 6.00 \\
\hline 10,000 & 100 & $\$ 69,000,000$ & $\$ 11,950,000$ & $\$ 2,800,000$ & $\$ 14,490,000$ & $\$ 29,240,000$ & $\$ 0.14$ & $\$ 0.03$ & $\$ 0.17$ & $\$ 0.35$ & 240 & 6 & 4.00 \\
\hline 10,000 & 200 & $\$ 115,000,000$ & $\$ 19,916,667$ & $\$ 5,600,000$ & $\$ 24,150,000$ & $\$ 49,666,667$ & $\$ 0.24$ & $\$ 0.07$ & $\$ 0.29$ & $\$ 0.59$ & 240 & 10 & 2.40 \\
\hline 10,000 & 500 & $\$ 253,000,000$ & $\$ 43,816,667$ & $\$ 14,000,000$ & $\$ 53,130,000$ & $\$ 110,946,667$ & $\$ 0.52$ & $\$ 0.17$ & $\$ 0.63$ & $\$ 1.32$ & 240 & 22 & 1.09 \\
\hline 10,000 & 1,000 & $\$ 483,000,000$ & $\$ 83,650,000$ & $\$ 28,000,000$ & $\$ 101,430,000$ & $\$ 213,080,000$ & $\$ 1.00$ & $\$ 0.33$ & $\$ 1.21$ & $\$ 2.54$ & 240 & 42 & 0.57 \\
\hline 100,000 & 10 & $\$ 345,000,000$ & $\$ 59,750,000$ & $\$ 2,800,000$ & $\$ 72,450,000$ & $\$ 135,000,000$ & $\$ 0.07$ & $\$ 0.00$ & $\$ 0.09$ & $\$ 0.16$ & 2400 & 3 & 8.00 \\
\hline 100,000 & 20 & 0,000 & $, 750,000$ & $\$ 5,600,000$ & 0,000 & $\$ 137,800,000$ & $\$ 0.07$ & $\$ 0$. & $\$ 0$. & $\$ 0.16$ & 2400 & 3 & 8.00 \\
\hline 100,000 & 50 & $\$ 460,000,000$ & $\$ 79,666,667$ & $\$ 14,000,000$ & $\$ 96,600,000$ & $\$ 190,266,667$ & $\$ 0.09$ & $\$ 0.02$ & $\$ 0.12$ & $\$ 0.23$ & 2400 & 4 & 6.00 \\
\hline 100,000 & 100 & $\$ 690,000,000$ & $\$ 119,500,000$ & $\$ 28,000,000$ & $\$ 144,900,000$ & $\$ 292,400,000$ & $\$ 0.14$ & $\$ 0.03$ & $\$ 0.17$ & $\$ 0.35$ & 2400 & 6 & 4.00 \\
\hline 100,000 & 200 & $\$ 1,150,000,000$ & $\$ 199,166,667$ & $\$ 56,000,000$ & $\$ 241,500,000$ & $\$ 496,666,667$ & $\$ 0.24$ & $\$ 0.07$ & $\$ 0.29$ & $\$ 0.59$ & 2400 & 10 & 2.40 \\
\hline 100,000 & 500 & $\$ 2,530,000,000$ & $\$ 438,166,667$ & $\$ 140,000,000$ & $\$ 531,300,000$ & $\$ 1,109,466,667$ & $\$ 0.52$ & $\$ 0.17$ & $\$ 0.63$ & $\$ 1.32$ & 2400 & 22 & 1.09 \\
\hline 100,000 & 1,000 & $\$ 4,830,000,000$ & $\$ 836,500,000$ & $\$ 280,000,000$ & $\$ 1,014,300,000$ & $\$ 2,130,800,000$ & $\$ 1.00$ & $\$ 0.33$ & $\$ 1.2$ & $\$ 2.54$ & 2400 & 42 & 0.57 \\
\hline
\end{tabular}




\begin{tabular}{|c|c|c|c|c|c|c|c|c|c|c|c|c|}
\hline \multicolumn{13}{|c|}{ E.7 METAL HYDRIDE TRANSPORT BY RAIL - SI Units } \\
\hline & & & & & & & & & & & & \\
\hline \multicolumn{2}{|c|}{ Rail Hydride Container= } & $\$ 2,205$ & per kg hydrogen & & & & & & & & & \\
\hline \multicolumn{2}{|c|}{ Rail Undercarriage $=$} & $\$ 100,000$ & per rail car & & & & & & & & & \\
\hline \multicolumn{2}{|c|}{ Rail Hydride Capacity= } & 907 & $\mathrm{~kg} /$ truck & & & & & & & & & \\
\hline \multicolumn{2}{|c|}{ Rail Average Speed $=$} & 40 & $\mathrm{~km} / \mathrm{hr}$ & & & & & & & & & \\
\hline \multicolumn{2}{|c|}{ Rail Load/Unload Time $=$} & 24 & $\mathrm{hr} / \mathrm{trip}$ & & & & & & & & & \\
\hline \multicolumn{2}{|c|}{ Rail Car Availability $=$} & 24 & $\mathrm{hr} / \mathrm{day}$ & & & & & & & & & \\
\hline Rail Freight= & & $\$ 400.00$ & per rail car & & & & & & & & & \\
\hline \multicolumn{2}{|c|}{ Operating Davs/Year= } & 350 & davs/vr & & & & & & & & & \\
\hline \multicolumn{2}{|c|}{ Railcar Depreciation $=$} & 15 & vears & & & & & & & & & \\
\hline & & & & & & & & & & & & \\
\hline Production & Deliverv Distance & Distance & Annual & Railcar & Number & Total Miles & Time per & Total Transit & Total Load/ & Total Delivery & Railcar & Railcars \\
\hline Rate & One-Way & Two-Way & Production & Capacity & of Trips & & Trip & Time & Unload Time & Time & Availability & Required \\
\hline$(\mathrm{kg} / \mathrm{hr})$ & $(\mathrm{km})$ & (km/trip) & $(\mathrm{kg} / \mathrm{yr})$ & (kg/truck) & (trips/yr) & $(\mathrm{km} / \mathrm{yr})$ & (d/trip) & $(\mathrm{hr} / \mathrm{yr})$ & (hr/yr) & (hr/yr) & $(\mathrm{hr} / \mathrm{yr})$ & \\
\hline 5 & 16 & 32 & 38,102 & 907 & 42 & 1,352 & 2 & 2,016 & 1,008 & 3,024 & 8,400 & \\
\hline 5 & 32 & 64 & 38,102 & 907 & 42 & 2,703 & 2 & 2,016 & 1,008 & 3,024 & 8,400 & \\
\hline 5 & 80 & 161 & 38,102 & 907 & 42 & 6,758 & 2 & 2,016 & 1,008 & 3,024 & 8,400 & 1 \\
\hline 5 & 161 & 322 & 38,102 & 907 & 42 & 13,516 & 2 & 2,016 & 1,008 & 3,024 & 8,400 & f \\
\hline 5 & 322 & 644 & 38.102 & 907 & 42 & 27.031 & 2 & 2.016 & 1.008 & 3.024 & 8.400 & \\
\hline 5 & 805 & 1.609 & 38,102 & 907 & 42 & 67.578 & 2 & 2.016 & 1,008 & 3,024 & 8.400 & 1 \\
\hline 5 & 1,609 & 3,218 & 38,102 & 907 & 42 & 135,156 & 4 & 4.032 & 1,008 & 5,040 & 8.400 & 1 \\
\hline 45 & 16 & 32 & 381.016 & 907 & 420 & 13,516 & 2 & 20,160 & 10,080 & 30,240 & 8,400 & 4 \\
\hline 45 & 32 & 64 & 381,016 & 907 & 420 & 27,031 & 2 & 20,160 & 10,080 & 30,240 & 8,400 & 4 \\
\hline 45 & 80 & 161 & 381,016 & 907 & 420 & 67,578 & 2 & 20,160 & 10,080 & 30,240 & 8,400 & 4 \\
\hline 45 & 161 & 322 & 381,016 & 907 & 420 & 135,156 & 2 & 20,160 & 10,080 & 30,240 & 8,400 & 4 \\
\hline 45 & 322 & 644 & 381,016 & 907 & 420 & 270,312 & 2 & 20,160 & 10,080 & 30,240 & 8,400 & 4 \\
\hline 45 & 805 & 1,609 & 381,016 & 907 & 420 & 675,780 & 2 & 20,160 & 10,080 & 30,240 & 8,400 & 4 \\
\hline 45 & 1,609 & 3,218 & 381,016 & 907 & 420 & $1,351,560$ & 4 & 40,320 & 10,080 & 50,400 & 8,400 & 6 \\
\hline 454 & 16 & 32 & $3,810,156$ & 907 & 4,200 & 135,156 & 2 & 201,600 & 100,800 & 302,400 & 8,400 & 36 \\
\hline 454 & 32 & 64 & $3,810,156$ & 907 & 4,200 & 270,312 & 2 & 201,600 & 100,800 & 302.400 & 8.400 & 36 \\
\hline 454 & 80 & 161 & $3,810,156$ & 907 & 4,200 & 675,780 & 2 & 201,600 & 100,800 & 302,400 & 8,400 & 36 \\
\hline 454 & 161 & 322 & $3,810,156$ & 907 & 4,200 & $1,351,560$ & 2 & 201,600 & 100,800 & 302.400 & 8.400 & 36 \\
\hline 454 & 322 & 644 & $3,810,156$ & 907 & 4,200 & $2,703,120$ & 2 & 201,600 & 100,800 & 302,400 & 8,400 & 36 \\
\hline 454 & 805 & 1,609 & $3,810,156$ & 907 & 4,200 & $6,757,800$ & 2 & 201,600 & 100,800 & 302,400 & 8,400 & 36 \\
\hline 454 & 1,609 & 3,218 & $3,810,156$ & 907 & 4,200 & $13,515,600$ & 4 & 403,200 & 100,800 & 504,000 & 8,400 & 60 \\
\hline 4,536 & 16 & 32 & $38,101,560$ & 907 & 42,000 & $1,351,560$ & 2 & $2,016,000$ & $1,008,000$ & $3,024,000$ & 8,400 & 360 \\
\hline 4,536 & 32 & 64 & $38,101,560$ & 907 & 42,000 & $2,703,120$ & 2 & $2,016,000$ & $1,008,000$ & $3,024,000$ & 8,400 & 360 \\
\hline 4,536 & 80 & 161 & $38,101,560$ & 907 & 42,000 & $6,757,800$ & 2 & $2,016,000$ & $1,008,000$ & $3,024,000$ & 8,400 & 360 \\
\hline 4,536 & 161 & 322 & $38,101,560$ & 907 & 42,000 & $13,515,600$ & 2 & $2,016,000$ & $1,008,000$ & $3,024,000$ & 8,400 & 360 \\
\hline 4.536 & 322 & 644 & $38,101,560$ & 907 & 42,000 & $27,031,200$ & 2 & $2,016,000$ & $1,008,000$ & $3,024,000$ & 8.400 & 360 \\
\hline 4.536 & 805 & 1,609 & $38,101,560$ & 907 & 42.000 & $67,578,000$ & 2 & $2,016.000$ & $1,008,000$ & $3,024,000$ & 8.400 & 360 \\
\hline 45,359 & 1,609 & 3.218 & $381,015,600$ & 907 & 420,000 & \begin{tabular}{|l|}
$1,351,560,000$ \\
\end{tabular} & 4 & $40,320,000$ & $10,080,000$ & $50,400,000$ & 8.400 & 6,000 \\
\hline 45,359 & 16 & 32 & $381,015,600$ & 907 & 420,000 & $13,515,600$ & 2 & $20,160,000$ & $10,080,000$ & $30,240,000$ & 8,400 & 3,600 \\
\hline 45,359 & 32 & 64 & $381,015,600$ & 907 & 420,000 & $27,031,200$ & 2 & $20,160,000$ & $10,080,000$ & $30,240,000$ & 8,400 & 3,600 \\
\hline \begin{tabular}{l|l}
45,359 \\
\end{tabular} & 80 & 161 & $381,015,600$ & 907 & 420,000 & $67,578,000$ & 2 & $20,160,000$ & $10,080,000$ & $30,240,000$ & 8,400 & 3,600 \\
\hline 4 & 161 & 322 & $381,015,600$ & 907 & 420,000 & $135,156,000$ & 2 & $20,160,000$ & $10,080,000$ & $30,240,000$ & 8,400 & 3,600 \\
\hline 4 & 322 & 644 & $381,015,600$ & 907 & 420,000 & $270,312,000$ & 2 & $20,160,000$ & $10,080,000$ & $30,240,000$ & 8,400 & 3,600 \\
\hline 45,359 & 805 & 1,609 & $381,015,600$ & 907 & 420,000 & $675,780,000$ & 2 & $20,160,000$ & $10,080,000$ & $30,240,000$ & 8,400 & 3,600 \\
\hline 45,359 & 1,609 & 3,218 & $381,015,600$ & 907 & 420,000 & $1,351,560,000$ & 4 & $40,320,000$ & $10,080,000$ & $50,400,000$ & 8,400 & 6,000 \\
\hline
\end{tabular}




\begin{tabular}{|c|c|c|c|c|c|c|c|c|c|c|c|}
\hline \multicolumn{12}{|c|}{ E.7 METAL HYDRIDE TRANSPORT BY RAIL - SI Units (Continued) } \\
\hline & & & & & & & & & & & \\
\hline \begin{tabular}{|l|} 
Production \\
\end{tabular} & Delivery Distan & Total Capital & Depreciation & Annual Freight & Total Annual & Freight & Capital & Total & Trip & Trip & Railcar \\
\hline Rate & One-Way & Cost & & Cost & Cost & Cost & Cost & Cost & Frequency & Length & Utilization \\
\hline$(\mathrm{kg} / \mathrm{hr})$ & $(\mathrm{km})$ & $(\$)$ & $(\$ / y r)$ & $(\$ / y r)$ & $(\$ / y r)$ & $(\$ / \mathrm{kg})$ & $(\$ / \mathrm{kg})$ & $(\$ / \mathrm{kg})$ & (trips/day) & (hours) & (trips/railcar/d) \\
\hline 5 & 16 & $\$ 2,100,000$ & $\$ 140,000$ & $\$ 33,600$ & $\$ 173,600$ & $\$ 0.88$ & $\$ 3.67$ & $\$ 4.56$ & 0.12 & 72 & 0.12 \\
\hline 5 & 32 & $\$ 2,100,000$ & $\$ 140,000$ & $\$ 33,600$ & $\$ 173,600$ & $\$ 0.88$ & $\$ 3.67$ & $\$ 4.56$ & 0.12 & 72 & 0.12 \\
\hline 5 & 80 & $\$ 2,100,000$ & $\$ 140,000$ & $\$ 33,600$ & $\$ 173,600$ & $\$ 0.88$ & $\$ 3.67$ & $\$ 4.56$ & 0.12 & 72 & 0.12 \\
\hline 5 & 161 & $\$ 2,100,000$ & $\$ 140,000$ & $\$ 33,600$ & $\$ 173,600$ & $\$ 0.88$ & $\$ 3.67$ & $\$ 4.56$ & 0.12 & 72 & 0.12 \\
\hline 5 & 322 & $\$ 2,100,000$ & $\$ 140,000$ & $\$ 33,600$ & $\$ 173,600$ & $\$ 0.88$ & $\$ 3.67$ & $\$ 4.56$ & 0.12 & 72 & 0.12 \\
\hline 5 & 805 & $\$ 2,100,000$ & $\$ 140,000$ & $\$ 33,600$ & $\$ 173,600$ & $\$ 0.88$ & $\$ 3.67$ & $\$ 4.56$ & 0.12 & 72 & 0.12 \\
\hline 5 & 1,609 & $\$ 2,100,000$ & $\$ 140,000$ & $\$ 33,600$ & $\$ 173,600$ & $\$ 0.88$ & $\$ 3.67$ & $\$ 4.56$ & 0.12 & 120 & 0.12 \\
\hline 45 & 16 & $\$ 8,400,000$ & $\$ 560.000$ & $\$ 336,000$ & $\$ 896.000$ & $\$ 0.88$ & $\$ 1.47$ & $\$ 2.35$ & 1.2 & 72 & 0.30 \\
\hline 45 & 32 & $\$ 8,400,000$ & $\$ 560,000$ & $\$ 336,000$ & $\$ 896,000$ & $\$ 0.88$ & $\$ 1.47$ & $\$ 2.35$ & 1.2 & 72 & 0.30 \\
\hline 45 & 80 & $\$ 8,400,000$ & $\$ 560,000$ & $\$ 336,000$ & $\$ 896,000$ & $\$ 0.88$ & $\$ 1.47$ & $\$ 2.35$ & 1.2 & 72 & 0.30 \\
\hline 45 & 161 & $\$ 8,400,000$ & $\$ 560,000$ & $\$ 336,000$ & $\$ 896,000$ & $\$ 0.88$ & $\$ 1.47$ & $\$ 2.35$ & 1.2 & 72 & 0.30 \\
\hline 45 & 322 & $\$ 8,400,000$ & $\$ 560,000$ & $\$ 336,000$ & $\$ 896,000$ & $\$ 0.88$ & $\$ 1.47$ & $\$ 2.35$ & 1.2 & 72 & 0.30 \\
\hline 45 & 805 & $\$ 8,400,000$ & $\$ 560,000$ & $\$ 336,000$ & $\$ 896,000$ & $\$ 0.88$ & $\$ 1.47$ & $\$ 2.35$ & 1.2 & 72 & 0.30 \\
\hline 45 & 1,609 & $\$ 12,600,000$ & $\$ 840,000$ & $\$ 336,000$ & $\$ 1,176,000$ & $\$ 0.88$ & $\$ 2.20$ & $\$ 3.09$ & 1.2 & 120 & 0.20 \\
\hline 454 & 16 & $\$ 75,600,000$ & $\$ 5,040,000$ & $\$ 3,360,000$ & $\$ 8,400,000$ & $\$ 0.88$ & $\$ 1.32$ & $\$ 2.20$ & 12 & 72 & 0.33 \\
\hline 454 & 32 & $\$ 75,600,000$ & $\$ 5,040,000$ & $\$ 3,360,000$ & $\$ 8,400,000$ & $\$ 0.88$ & $\$ 1.32$ & $\$ 2.20$ & 12 & 72 & 0.33 \\
\hline 454 & 80 & $\$ 75,600,000$ & $\$ 5,040,000$ & $\$ 3,360,000$ & $\$ 8,400,000$ & $\$ 0.88$ & $\$ 1.32$ & $\$ 2.20$ & 12 & 72 & 0.33 \\
\hline 454 & 161 & $\$ 75,600,000$ & $\$ 5,040,000$ & $\$ 3,360,000$ & $\$ 8,400,000$ & $\$ 0.88$ & $\$ 1.32$ & $\$ 2.20$ & 12 & 72 & 0.33 \\
\hline 454 & 322 & $\$ 75,600,000$ & $\$ 5,040,000$ & $\$ 3,360,000$ & $\$ 8,400,000$ & $\$ 0.88$ & $\$ 1.32$ & $\$ 2.20$ & 12 & 72 & 0.33 \\
\hline 454 & 805 & $\$ 75,600,000$ & $\$ 5,040,000$ & $\$ 3,360,000$ & $\$ 8,400,000$ & $\$ 0.88$ & $\$ 1.32$ & $\$ 2.20$ & 12 & 72 & 0.33 \\
\hline 454 & 1,609 & $\$ 126,000,000$ & $\$ 8,400,000$ & $\$ 3,360,000$ & $\$ 11,760,000$ & $\$ 0.88$ & $\$ 2.20$ & $\$ 3.09$ & 12 & 120 & 0.20 \\
\hline 4,536 & 16 & $\$ 756,000,000$ & $\$ 50,400,000$ & $\$ 33,600,000$ & $\$ 84,000,000$ & $\$ 0.88$ & $\$ 1.32$ & $\$ 2.20$ & 120 & 72 & 0.33 \\
\hline 4,536 & 32 & $\$ 756,000,000$ & $\$ 50,400,000$ & $\$ 33,600,000$ & $\$ 84,000,000$ & $\$ 0.88$ & $\$ 1.32$ & $\$ 2.20$ & 120 & 72 & 0.33 \\
\hline 4,536 & 80 & $\$ 756,000,000$ & $\$ 50,400,000$ & $\$ 33,600,000$ & $\$ 84,000,000$ & $\$ 0.88$ & $\$ 1.32$ & $\$ 2.20$ & 120 & 72 & 0.33 \\
\hline 4,536 & 161 & $\$ 756,000,000$ & $\$ 50,400,000$ & $\$ 33,600,000$ & $\$ 84,000,000$ & $\$ 0.88$ & $\$ 1.32$ & $\$ 2.20$ & 120 & 72 & 0.33 \\
\hline 4,536 & 322 & $\$ 756,000,000$ & $\$ 50,400,000$ & $\$ 33,600,000$ & $\$ 84,000,000$ & $\$ 0.88$ & $\$ 1.32$ & $\$ 2.20$ & 120 & 72 & 0.33 \\
\hline 4,536 & 805 & $\$ 756,000,000$ & $\$ 50,400,000$ & $\$ 33,600,000$ & $\$ 84,000,000$ & $\$ 0.88$ & $\$ 1.32$ & $\$ 2.20$ & 120 & 72 & 0.33 \\
\hline 45,359 & 1,609 & $\$ 12,600,000,000$ & $\$ 840,000,000$ & $\$ 336,000,000$ & $\$ 1,176,000,000$ & $\$ 0.88$ & $\$ 2.20$ & $\$ 3.09$ & 1200 & 120 & 0.20 \\
\hline 45,359 & 16 & $\$ 7,560,000,000$ & $\$ 504,000,000$ & $\$ 336,000,000$ & $\$ 840,000,000$ & $\$ 0.88$ & $\$ 1.32$ & $\$ 2.20$ & 1200 & 72 & 0.33 \\
\hline 45,359 & 32 & $\$ 7,560,000,000$ & $\$ 504,000,000$ & $\$ 336,000,000$ & $\$ 840,000,000$ & $\$ 0.88$ & $\$ 1.32$ & $\$ 2.20$ & 1200 & 72 & 0.33 \\
\hline 45,359 & 80 & $\$ 7,560,000,000$ & $\$ 504,000,000$ & $\$ 336,000,000$ & $\$ 840,000,000$ & $\$ 0.88$ & $\$ 1.32$ & $\$ 2.20$ & 1200 & 72 & 0.33 \\
\hline 45,359 & 161 & $\$ 7,560,000,000$ & $\$ 504,000,000$ & $\$ 336,000,000$ & $\$ 840,000,000$ & $\$ 0.88$ & $\$ 1.32$ & $\$ 2.20$ & 1200 & 72 & 0.33 \\
\hline 45,359 & 322 & $\$ 7,560,000,000$ & $\$ 504,000,000$ & $\$ 336,000,000$ & $\$ 840,000,000$ & $\$ 0.88$ & $\$ 1.32$ & $\$ 2.20$ & 1200 & 72 & 0.33 \\
\hline 45,359 & 805 & $\$ 7,560,000,000$ & $\$ 504,000,000$ & $\$ 336,000,000$ & $\$ 840,000,000$ & $\$ 0.88$ & $\$ 1.32$ & $\$ 2.20$ & 1200 & 72 & 0.33 \\
\hline 45,359 & 1,609 & $\$ 12,600,000,000$ & $\$ 840,000,000$ & $\$ 336,000,000$ & $\$ 1,176,000,000$ & $\$ 0.88$ & $\$ 2.20$ & $\$ 3.09$ & 1200 & 120 & 0.20 \\
\hline
\end{tabular}




\begin{tabular}{|c|c|c|c|c|c|c|c|c|c|c|c|c|}
\hline \multicolumn{13}{|c|}{ E.7 METAL HYDRIDE TRANSPORT BY RAIL - Enqlish Units } \\
\hline & & & & & & & & & & & & \\
\hline \multicolumn{2}{|c|}{ Rail Hydride Container= } & $\$ 1,000$ & per lb hydrogen & & & & & & & & & \\
\hline \multicolumn{2}{|c|}{ Rail Undercarriage $=$} & $\$ 100,000$ & per rail car & & & & & & & & & \\
\hline \multicolumn{2}{|c|}{ Rail Hydride Capacity= } & 2,000 & $\mathrm{lb} /$ truck & & & & & & & & & \\
\hline \multicolumn{2}{|c|}{ Rail Average Speed $=$} & 25 & $\mathrm{mph}$ & & & & & & & & & \\
\hline \multicolumn{2}{|c|}{ Rail Load/Unload Time= } & 24 & $\mathrm{hr} /$ trip & & & & & & & & & \\
\hline \multicolumn{2}{|c|}{ Rail Car Availability= } & 24 & $\mathrm{hr} / \mathrm{day}$ & & & & & & & & & \\
\hline \multicolumn{2}{|c|}{\begin{tabular}{|l|l|} 
Rail Freight $=$ \\
\end{tabular}} & $\$ 400.00$ & per rail car & & & & & & & & & \\
\hline \multicolumn{2}{|c|}{ Operating Davs/Year= } & 350 & davs/yr & & & & & & & & & \\
\hline \multicolumn{2}{|c|}{ Railcar Depreciation $=$} & 15 & vears & & & & & & & & & \\
\hline & & & & & & & & & & & & \\
\hline Production & Delivery Distance & Distance & Annual & Railcar & Number & Total Miles & Time per & Total Transit & Total Load/ & Total Delivery & Railcar & Railcars \\
\hline Rate & One-Way & Two-Way & Production & Capacity & of Trips & & Trip & Time & Unload Time & Time & Availability & Required \\
\hline$(\mathrm{lb} / \mathrm{hr})$ & (miles) & (miles/trip) & $(\mathrm{lb} / \mathrm{yr})$ & (lb/truck) & (trips/yr) & (miles/yr) & (d/trip) & $(\mathrm{hr} / \mathrm{yr})$ & $(\mathrm{hr} / \mathrm{yr})$ & $(\mathrm{hr} / \mathrm{yr})$ & $(\mathrm{hr} / \mathrm{yr})$ & \\
\hline 10 & 10 & 20 & 84,000 & 2,000 & 42 & 840 & 2 & 2,016 & 1,008 & 3,024 & 8,400 & \\
\hline 10 & 20 & 40 & 84,000 & 2,000 & 42 & 1,680 & 2 & 2,016 & 1,008 & 3,024 & 8,400 & 1 \\
\hline 10 & 50 & 100 & 84,000 & 2,000 & 42 & 4,200 & 2 & 2,016 & 1,008 & 3,024 & 8,400 & 1 \\
\hline 10 & 100 & 200 & 84,000 & 2,000 & 42 & 8,400 & 2 & 2,016 & 1,008 & 3,024 & 8,400 & 1 \\
\hline 10 & 200 & 400 & 84.000 & 2.000 & 42 & 16.800 & 2 & 2.016 & 1.008 & 3.024 & 8.400 & 1 \\
\hline 10 & 500 & 1.000 & 84.000 & 2.000 & 42 & 42.000 & 2 & 2.016 & 1,008 & 3,024 & 8.400 & \\
\hline 10 & 1,000 & 2.000 & 84,000 & 2.000 & 42 & 84,000 & 4 & 4.032 & 1,008 & 5,040 & 8.400 & 1 \\
\hline 100 & 10 & 20 & 840.000 & 2.000 & 420 & 8,400 & 2 & 20,160 & 10,080 & 30,240 & 8.400 & \\
\hline 100 & 20 & 40 & 840,000 & 2,000 & 420 & 16,800 & 2 & 20,160 & 10,080 & 30,240 & 8,400 & 4 \\
\hline 100 & 50 & 100 & 840,000 & 2,000 & 420 & 42,000 & 2 & 20,160 & 10,080 & 30,240 & 8,400 & $\overline{4}$ \\
\hline 100 & 100 & 200 & 840,000 & 2,000 & 420 & 84,000 & 2 & 20,160 & 10,080 & 30,240 & 8,400 & 4 \\
\hline 100 & 200 & 400 & 840,000 & 2,000 & 420 & 168,000 & 2 & 20,160 & 10,080 & 30,240 & 8,400 & \\
\hline 100 & 500 & 1,000 & 840,000 & 2,000 & 420 & 420,000 & 2 & 20,160 & 10,080 & 30,240 & 8,400 & 4 \\
\hline 100 & 1,000 & 2,000 & 840,000 & 2,000 & 420 & 840,000 & 4 & 40,320 & 10,080 & 50,400 & 8,400 & 6 \\
\hline 1,000 & 10 & 20 & $8,400,000$ & 2,000 & 4,200 & 84,000 & 2 & 201,600 & 100,800 & 302,400 & 8,400 & 36 \\
\hline 1,000 & 20 & 40 & $8,400,000$ & 2.000 & 4,200 & 168,000 & 2 & 201,600 & 100,800 & 302,400 & 8.400 & 36 \\
\hline 1.000 & 50 & 100 & $8,400,000$ & 2,000 & 4,200 & 420,000 & 2 & 201,600 & 100,800 & 302,400 & 8.400 & 36 \\
\hline 1.000 & 100 & 200 & $8,400,000$ & 2.000 & 4.200 & 840,000 & 2 & 201,600 & 100,800 & 302,400 & 8.400 & 36 \\
\hline 1,000 & 200 & 400 & $8,400,000$ & 2,000 & 4,200 & $1,680,000$ & 2 & 201,600 & 100,800 & 302,400 & 8,400 & 36 \\
\hline 1,000 & 500 & 1,000 & $8,400,000$ & 2,000 & 4,200 & $4,200,000$ & 2 & 201,600 & 100,800 & 302,400 & 8,400 & 36 \\
\hline 1,000 & 1,000 & 2,000 & $8,400,000$ & 2,000 & 4,200 & $8,400,000$ & 4 & 403,200 & 100,800 & 504,000 & 8,400 & 60 \\
\hline 10,000 & 10 & 20 & $84,000,000$ & 2,000 & 42,000 & 840,000 & 2 & $2,016,000$ & $1,008,000$ & $3,024,000$ & 8,400 & 360 \\
\hline 10,000 & 20 & 40 & $84,000,000$ & 2,000 & 42,000 & $1,680,000$ & 2 & $2,016,000$ & $1,008,000$ & $3,024,000$ & 8,400 & 360 \\
\hline 10,000 & 50 & 100 & $84,000,000$ & 2,000 & 42,000 & $4,200,000$ & 2 & $2,016,000$ & $1,008,000$ & $3,024,000$ & 8,400 & 360 \\
\hline 10,000 & 100 & 200 & $84,000,000$ & 2,000 & 42,000 & $8,400,000$ & 2 & $2,016,000$ & $1,008,000$ & $3,024,000$ & 8,400 & 360 \\
\hline 10,000 & 200 & 400 & $84,000,000$ & 2,000 & 42,000 & $16,800,000$ & 2 & $2.016,000$ & $1,008,000$ & $3,024,000$ & 8.400 & 360 \\
\hline 10,000 & 500 & 1,000 & $84,000,000$ & 2,000 & 42,000 & $42,000,000$ & 2 & $2.016,000$ & $1,008,000$ & $3,024,000$ & 8.400 & 360 \\
\hline 100,000 & 1,000 & 2.000 & $840,000,000$ & 2.000 & 420,000 & $840,000,000$ & 4 & $40,320,000$ & $10,080,000$ & $50,400,000$ & 8.400 & 6,000 \\
\hline 100,000 & 10 & 20 & $840,000,000$ & 2,000 & 420,000 & $8,400,000$ & 2 & $20,160,000$ & $10,080,000$ & $30,240,000$ & 8,400 & 3,600 \\
\hline 100,000 & 20 & 40 & $840,000,000$ & 2,000 & 420,000 & $16,800,000$ & 2 & $20,160,000$ & $10,080,000$ & $30,240,000$ & 8,400 & 3,600 \\
\hline 100,000 & 50 & 100 & $840,000,000$ & 2,000 & 420,000 & $42,000,000$ & 2 & $20,160,000$ & $10,080,000$ & $30,240,000$ & 8,400 & 3,600 \\
\hline 100,000 & 100 & 200 & $840,000,000$ & 2,000 & 420,000 & $84,000,000$ & 2 & $20,160,000$ & $10,080,000$ & $30,240,000$ & 8,400 & 3,600 \\
\hline 100,000 & 200 & 400 & $840,000,000$ & 2,000 & 420,000 & $168,000,000$ & 2 & $20,160,000$ & $10,080,000$ & $30,240,000$ & 8,400 & 3,600 \\
\hline 100,000 & 500 & 1,000 & $840,000,000$ & 2,000 & 420,000 & $420,000,000$ & 2 & $20,160,000$ & $10,080,000$ & $30,240,000$ & 8,400 & 3,600 \\
\hline 100,000 & 1,000 & 2,000 & $840,000,000$ & 2,000 & 420,000 & $840,000,000$ & 4 & $40,320,000$ & $10,080,000$ & $50,400,000$ & 8,400 & 6,000 \\
\hline
\end{tabular}




\begin{tabular}{|c|c|c|c|c|c|c|c|c|c|c|c|}
\hline \multicolumn{12}{|c|}{ E.7 METAL HYDRIDE TRANSPORT BY RAIL - English Units (Continued) } \\
\hline Production & Delivery Distan & Total Capital & Depreciation & Annual Freight & Total Annual & Freight & Capital & Total & Trip & Trip & Railcar \\
\hline Rate & One-Way & Cost & & Cost & Cost & Cost & Cost & Cost & Frequency & Length & Utilization \\
\hline$(\mathrm{lb} / \mathrm{hr})$ & (miles) & $(\$)$ & $(\$ / y r)$ & $(\$ / y r)$ & $(\$ / y r)$ & $(\$ / \mathrm{lb})$ & $(\$ / \mathrm{lb})$ & $(\$ / \mathrm{lb})$ & (trips/day) & (hours) & (trips/railcar/d) \\
\hline 10 & 10 & $\$ 2,100,000$ & $\$ 140,000$ & $\$ 33,600$ & $\$ 173,600$ & $\$ 0.40$ & $\$ 1.67$ & $\$ 2.07$ & 0.12 & 72 & 0.12 \\
\hline 10 & 20 & $\$ 2,100,000$ & $\$ 140,000$ & $\$ 33,600$ & $\$ 173,600$ & $\$ 0.40$ & $\$ 1.67$ & $\$ 2.07$ & 0.12 & 72 & 0.12 \\
\hline 10 & 50 & $\$ 2,100,000$ & $\$ 140,000$ & $\$ 33,600$ & $\$ 173,600$ & $\$ 0.40$ & $\$ 1.67$ & $\$ 2.07$ & 0.12 & 72 & 0.12 \\
\hline 10 & 100 & $\$ 2,100,000$ & $\$ 140,000$ & $\$ 33,600$ & $\$ 173,600$ & $\$ 0.40$ & $\$ 1.67$ & $\$ 2.07$ & 0.12 & 72 & 0.12 \\
\hline 10 & 200 & $\$ 2,100,000$ & $\$ 140,000$ & $\$ 33,600$ & $\$ 173,600$ & $\$ 0.40$ & $\$ 1.67$ & $\$ 2.07$ & 0.12 & 72 & 0.12 \\
\hline 10 & 500 & $\$ 2,100,000$ & $\$ 140,000$ & $\$ 33,600$ & $\$ 173,600$ & $\$ 0.40$ & $\$ 1.67$ & $\$ 2.07$ & 0.12 & 72 & 0.12 \\
\hline 10 & 1,000 & $\$ 2,100,000$ & $\$ 140,000$ & $\$ 33,600$ & $\$ 173,600$ & $\$ 0.40$ & $\$ 1.67$ & $\$ 2.07$ & 0.12 & 120 & 0.12 \\
\hline 100 & 10 & $\$ 8,400,000$ & $\$ 560,000$ & $\$ 336,000$ & $\$ 896.000$ & $\$ 0.40$ & $\$ 0.67$ & $\$ 1.07$ & 1.2 & 72 & 0.30 \\
\hline 100 & 20 & $\$ 8,400,000$ & $\$ 560,000$ & $\$ 336,000$ & $\$ 896,000$ & $\$ 0.40$ & $\$ 0.67$ & $\$ 1.07$ & 1.2 & 72 & 0.30 \\
\hline 100 & 50 & $\$ 8,400,000$ & $\$ 560,000$ & $\$ 336,000$ & $\$ 896,000$ & $\$ 0.40$ & $\$ 0.67$ & $\$ 1.07$ & 1.2 & 72 & 0.30 \\
\hline 100 & 100 & $\$ 8,400,000$ & $\$ 560,000$ & $\$ 336,000$ & $\$ 896,000$ & $\$ 0.40$ & $\$ 0.67$ & $\$ 1.07$ & 1.2 & 72 & 0.30 \\
\hline 100 & 200 & $\$ 8,400,000$ & $\$ 560,000$ & $\$ 336,000$ & $\$ 896,000$ & $\$ 0.40$ & $\$ 0.67$ & $\$ 1.07$ & 1.2 & 72 & 0.30 \\
\hline 100 & 500 & $\$ 8,400,000$ & $\$ 560,000$ & $\$ 336,000$ & $\$ 896,000$ & $\$ 0.40$ & $\$ 0.67$ & $\$ 1.07$ & 1.2 & 72 & 0.30 \\
\hline 100 & 1,000 & $\$ 12,600,000$ & $\$ 840,000$ & $\$ 336,000$ & $\$ 1,176,000$ & $\$ 0.40$ & $\$ 1.00$ & $\$ 1.40$ & 1.2 & 120 & 0.20 \\
\hline 1,000 & 10 & $\$ 75,600,000$ & $\$ 5,040,000$ & $\$ 3,360,000$ & $\$ 8,400,000$ & $\$ 0.40$ & $\$ 0.60$ & $\$ 1.00$ & 12 & 72 & 0.33 \\
\hline 1,000 & 20 & $\$ 75,600,000$ & $\$ 5,040,000$ & $\$ 3,360,000$ & $\$ 8,400,000$ & $\$ 0.40$ & $\$ 0.60$ & $\$ 1.00$ & 12 & 72 & 0.33 \\
\hline 1,000 & 50 & $\$ 75,600,000$ & $\$ 5,040,000$ & $\$ 3,360,000$ & $\$ 8,400,000$ & $\$ 0.40$ & $\$ 0.60$ & $\$ 1.00$ & 12 & 72 & 0.33 \\
\hline 1,000 & 100 & $\$ 75,600,000$ & $\$ 5,040,000$ & $\$ 3,360,000$ & $\$ 8,400,000$ & $\$ 0.40$ & $\$ 0.60$ & $\$ 1.00$ & 12 & 72 & 0.33 \\
\hline 1,000 & 200 & $\$ 75,600,000$ & $\$ 5,040,000$ & $\$ 3,360,000$ & $\$ 8,400,000$ & $\$ 0.40$ & $\$ 0.60$ & $\$ 1.00$ & 12 & 72 & 0.33 \\
\hline 1,000 & 500 & $\$ 75,600,000$ & $\$ 5,040,000$ & $\$ 3,360,000$ & $\$ 8,400,000$ & $\$ 0.40$ & $\$ 0.60$ & $\$ 1.00$ & 12 & 72 & 0.33 \\
\hline 1,000 & 1,000 & $\$ 126,000,000$ & $\$ 8,400,000$ & $\$ 3,360,000$ & $\$ 11,760,000$ & $\$ 0.40$ & $\$ 1.00$ & $\$ 1.40$ & 12 & 120 & 0.20 \\
\hline 10,000 & 10 & $\$ 756,000,000$ & $\$ 50,400,000$ & $\$ 33,600,000$ & $\$ 84,000,000$ & $\$ 0.40$ & $\$ 0.60$ & $\$ 1.00$ & 120 & 72 & 0.33 \\
\hline 10,000 & 20 & $\$ 756,000,000$ & $\$ 50,400,000$ & $\$ 33,600,000$ & $\$ 84,000,000$ & $\$ 0.40$ & $\$ 0.60$ & $\$ 1.00$ & 120 & 72 & 0.33 \\
\hline 10,000 & 50 & $\$ 756,000,000$ & $\$ 50,400,000$ & $\$ 33,600,000$ & $\$ 84,000,000$ & $\$ 0.40$ & $\$ 0.60$ & $\$ 1.00$ & 120 & 72 & 0.33 \\
\hline 10,000 & 100 & $\$ 756,000,000$ & $\$ 50,400,000$ & $\$ 33,600,000$ & $\$ 84,000,000$ & $\$ 0.40$ & $\$ 0.60$ & $\$ 1.00$ & 120 & 72 & 0.33 \\
\hline 10,000 & 200 & $\$ 756,000,000$ & $\$ 50,400,000$ & $\$ 33,600,000$ & $\$ 84,000,000$ & $\$ 0.40$ & $\$ 0.60$ & $\$ 1.00$ & 120 & 72 & 0.33 \\
\hline 10,000 & 500 & $\$ 756,000,000$ & $\$ 50,400,000$ & $\$ 33,600,000$ & $\$ 84,000,000$ & $\$ 0.40$ & $\$ 0.60$ & $\$ 1.00$ & 120 & 72 & 0.33 \\
\hline 100,000 & 1,000 & $\$ 12,600,000,000$ & $\$ 840,000,000$ & $\$ 336,000,000$ & $\$ 1,176,000,000$ & $\$ 0.40$ & $\$ 1.00$ & $\$ 1.40$ & 1200 & 120 & 0.20 \\
\hline 100,000 & 10 & $\$ 7,560,000,000$ & $\$ 504,000,000$ & $\$ 336,000,000$ & $\$ 840,000,000$ & $\$ 0.40$ & $\$ 0.60$ & $\$ 1.00$ & 1200 & 72 & 0.33 \\
\hline 100,000 & 20 & $\$ 7,560,000,000$ & $\$ 504,000,000$ & $\$ 336,000,000$ & $\$ 840,000,000$ & $\$ 0.40$ & $\$ 0.60$ & $\$ 1.00$ & 1200 & 72 & 0.33 \\
\hline 100,000 & 50 & $\$ 7,560,000,000$ & $\$ 504,000,000$ & $\$ 336,000,000$ & $\$ 840,000,000$ & $\$ 0.40$ & $\$ 0.60$ & $\$ 1.00$ & 1200 & 72 & 0.33 \\
\hline 100,000 & 100 & $\$ 7,560,000,000$ & $\$ 504,000,000$ & $\$ 336,000,000$ & $\$ 840,000,000$ & $\$ 0.40$ & $\$ 0.60$ & $\$ 1.00$ & 1200 & 72 & 0.33 \\
\hline 100,000 & 200 & $\$ 7,560,000,000$ & $\$ 504,000,000$ & $\$ 336,000,000$ & $\$ 840,000,000$ & $\$ 0.40$ & $\$ 0.60$ & $\$ 1.00$ & 1200 & 72 & 0.33 \\
\hline 100,000 & 500 & $\$ 7,560,000,000$ & $\$ 504,000,000$ & $\$ 336,000,000$ & $\$ 840,000,000$ & $\$ 0.40$ & $\$ 0.60$ & $\$ 1.00$ & 1200 & 72 & 0.33 \\
\hline 100,000 & 1,000 & $\$ 12,600,000,000$ & $\$ 840,000,000$ & $\$ 336,000,000$ & $\$ 1,176,000,000$ & $\$ 0.40$ & $\$ 1.00$ & $\$ 1.40$ & 1200 & 120 & 0.20 \\
\hline
\end{tabular}




\begin{tabular}{|c|c|c|c|c|c|c|c|c|c|}
\hline \multicolumn{10}{|c|}{ E.8 PIPELINE DELIVERY OF HYDROGEN - SI Units } \\
\hline \multicolumn{2}{|c|}{ Compressor Capital Cost= } & $\$ 1,000$ & per kW & & & & & & \\
\hline \multicolumn{2}{|c|}{ Compressor Size $=$} & $\frac{\phi 1,000}{4,000}$ & $\begin{array}{ll}\text { ker nw } \\
\mathrm{kW}\end{array}$ & & & & & & \\
\hline \multicolumn{2}{|c|}{ Compressor Pressure $=$} & 20 & $\mathrm{MPa}$ & & & & & & \\
\hline \multicolumn{2}{|c|}{ Comp. Cost Scale-Up= } & 0.80 & & & & & & & \\
\hline \multicolumn{2}{|c|}{ Comp. Pressure Scale-Up= } & 0.18 & & & & & & & \\
\hline \multirow{2}{*}{\multicolumn{2}{|c|}{\begin{tabular}{|l|} 
Pipeline Cost $=$ \\
Electric Cost= \\
\end{tabular}}} & $\$ 621.504$ & per km & & & & & & \\
\hline & & $\$ 0.05$ & per kWh & & & & & & \\
\hline \multirow{2}{*}{\multicolumn{2}{|c|}{\begin{tabular}{|l} 
Compressor Power $=$ \\
Steel Roughness $=$ \\
\end{tabular}}} & 2.20 & $\mathrm{kWh} / \mathrm{kg}(20$ & $\mathrm{MPa}$ & & & & & \\
\hline & & $4.6 \mathrm{E}-05$ & $\mathrm{~m}$ & & & & & & \\
\hline Steel Roughness= & & 0.25 & $\mathrm{~m}$ & & & & & & \\
\hline \multicolumn{2}{|c|}{\begin{tabular}{|l|l|l|} 
Temperature $=$ \\
\end{tabular}} & 283 & & & & & & & \\
\hline \multicolumn{2}{|c|}{ Delivery Pressure $=$} & & Mpa & & & & & & \\
\hline \multirow{2}{*}{\multicolumn{2}{|c|}{\begin{tabular}{|l|l} 
Viscosity $=$ \\
R(hydrogen) $=$
\end{tabular}}} & $8.62 \mathrm{E}-06$ & $\mathrm{~kg} / \mathrm{m}^{*} \mathrm{~s}$ & & & & & & \\
\hline & & 4124 & $\mathrm{~N}^{*} \mathrm{~m} / \mathrm{kg} \mathrm{K}$ & & & & & & \\
\hline \multirow{2}{*}{\multicolumn{2}{|c|}{ Operating Days/Year= }} & 350 & days/yr & & & & & & \\
\hline & & 22 & years & & & & & & \\
\hline \multirow{2}{*}{\multicolumn{2}{|c|}{\begin{tabular}{|c|} 
Plpelline Depreciation= \\
\\
\end{tabular}}} & & & & & & & & \\
\hline & & 0.000184 & & & & & & & \\
\hline \multicolumn{2}{|c|}{$\mid \frac{\text { Roughness/Diameter }=}{\text { Fanning friction factor } \mathrm{f}=}$} & 0.005 & & & & & & & \\
\hline Pipe Area $=$ & & 0.049 & sq. $m$ & & & & & & \\
\hline Production & Delivery Distance & Annual & Flowrate & Distance & Gas Flux & Reynolds & Inlet & Compressor & Annual Electric \\
\hline Rate & One-Way & Production & & & & Number & Pressure & Size & Use \\
\hline$(1 \mathrm{lb} / \mathrm{hr})$ & (miles) & $(\mathrm{lb} / \mathrm{yr})_{1}$ & $(\mathrm{~kg} / \mathrm{s})$ & (m) & $\left(\mathrm{kg} / \mathrm{s}^{*} \mathrm{~m}^{\wedge} 2\right)$ & & $(\mathrm{MPa})$ & $(\mathrm{kW})$ & $(\mathrm{kWh} / \mathrm{yr})$ \\
\hline & 16 & 38,102 & 0.001 & 16,094 & 0.026 & 744 & 2.000 & 0 & \\
\hline & 32 & 38.102 & 0.001 & 32,187 & 0.026 & 744 & 2.000 & 0 & \\
\hline & 80 & 38,102 & 0.001 & 80,468 & 0.026 & 744 & 2.000 & 0 & \\
\hline & 161 & 38,102 & 0.001 & 100,936 & $\frac{0.026}{0.026}$ & 744 & 2.000 & 0 & \\
\hline 5 & 322 & 38,102 & 0.001 & 321,873 & 0.026 & 744 & 2.000 & 0 & \\
\hline & 805 & 38,102 & 0.001 & 804,682 & 0.026 & 744 & 2.000 & 0 & \\
\hline 5 & 1,609 & 38,102 & 0.001 & $1,609,364$ & 0.026 & 744 & 2.000 & 0 & \\
\hline 45 & $\frac{16}{16}$ & 381,016 & 0.013 & 16,094 & 0.257 & 7,444 & 2.000 & 0 & \\
\hline 45 & 32 & 381,016 & 0.013 & 32,187 & 0.257 & 7,444 & 2.000 & & 4 \\
\hline 45 & 80 & 381.016 & 0.013 & 80,468 & 0.257 & 7,444 & 2.000 & & 10 \\
\hline 45 & 161 & 381.016 & 0.013 & 160.936 & 0.257 & 7,444 & 2.000 & 0 & 20 \\
\hline 45 & 322 & 381,016 & 0.013 & 321,873 & 0.257 & 7,444 & 2.000 & & 39 \\
\hline 45 & 805 & 381,016 & 0.013 & 804,682 & 0.257 & 7,444 & 2.001 & 0 & 98 \\
\hline 45 & 1,609 & 381,016 & 0.013 & $|1,609,364|$ & 0.257 & 7,444 & 2.002 & & 196 \\
\hline 454 & 16 & $3,810,156$ & 0.126 & $\begin{array}{l}16,094 \\
\end{array}$ & 2.567 & 74,443 & 2.002 & 0 & 1,960 \\
\hline 454 & 32 & $3,810,156$ & 0.126 & 32,187 & 2.567 & 74,443 & 2.005 & 0 & 3,914 \\
\hline 454 & 80 & $3,810,156$ & 0.126 & 80,468 & 2.567 & 74,443 & 2.012 & & 9,749 \\
\hline 454 & 161 & $3,810,156$ & 0.126 & 160,936 & 2.567 & 74,443 & 2.025 & & 19,380 \\
\hline$\frac{454}{454}$ & $\frac{10}{322}$ & $\frac{3,010,150}{3,810,156}$ & 0.120 & \begin{tabular}{|l|}
321,873 \\
321,0
\end{tabular} & 2.567 & 74,443 & 2.049 & $\frac{4}{5}$ & $\frac{1,300}{38,298}$ \\
\hline 454 & 805 & $3,810,156$ & 0.126 & 804.682 & 2.567 & 74.443 & 2.120 & 11 & 92,485 \\
\hline 454 & 1,609 & $3,810,156$ & 0.126 & $\mid 1,609,364$ & 2.567 & 74,443 & 2.234 & 21 & 175,299 \\
\hline 4,536 & 16 & $38,101,560$ & 1.260 & 16,094 & 25.668 & 744,430 & 2.234 & 209 & $1,752,985$ \\
\hline 4,536 & 32 & $38,101,560$ & 1.260 & 32,187 & 25.668 & 744,430 & 2.445 & 379 & $3,187,650$ \\
\hline $\begin{array}{l}4,000 \\
4,536 \\
\end{array}$ & 80 & $38,101,560$ & 1.260 & $\begin{array}{l}3<, 468 \\
80,46\end{array}$ & 25.668 & 744,430 & 2.4992 & 760 & $\begin{array}{l}6,384,080 \\
6,030\end{array}$ \\
\hline 4,536 & 161 & $38,101,560$ & 1.260 & $\begin{array}{ll}160,936 \\
\end{array}$ & 25.668 & 744,430 & 3.728 & 1,175 & $9,873,834$ \\
\hline 4,536 & 322 & $38,101,560$ & 1.260 & 321,873 & 25.668 & 744,430 & 4.879 & 1,683 & $14,136,965$ \\
\hline 4,536 & 805 & $38,101,560$ & 1.260 & 804,682 & 25.668 & 744,430 & 7.314 & 2,447 & $20,557,833$ \\
\hline 4.536 & 1.609 & 38.101 .560 & 1.260 & $1,609.364$ & 25.668 & 744.430 & 10.149 & 3.066 & $25,750,421$ \\
\hline 45.359 & 16 & 381.015 .600 & 12.600 & 16.094 & 256.679 & 7.444 .299 & 10.149 & 30.655 & 257.504 .206 \\
\hline 45,359 & 32 & $381,015,600$ & 12.600 & 32,187 & 256.679 & $7,444,299$ & 14.213 & 37,011 & $310,895,909$ \\
\hline 45,359 & 80 & $381,015,600$ & 12.600 & 80,468 & 256.679 & $7,444,299$ & 22.338 & 45,546 & $382,583,212$ \\
\hline 45,359 & 161 & $381,015,600$ & 12.600 & 160,936 & 256.679 & $7,444,299$ & 31.528 & 52,049 & $437,210,943$ \\
\hline 45,359 & 322 & $381,015,600$ & 12.600 & 321,873 & 256.679 & $7,444,299$ & 44.542 & 58.571 & $491,997,371$ \\
\hline 45,359 & 805 & 381015600 & 12600 & 804.682 & 256.679 & 7.444 .299 & 70,384 & 67207 & 564.536 .199 \\
\hline 45,359 & 1.609 & $381,015,600$ & 12.600 & $\mid 1,609,364$ & 256.679 & $7,444.299$ & 99.518 & 73,744 & $619,450,278$ \\
\hline
\end{tabular}




\begin{tabular}{|c|c|c|c|c|c|c|c|c|c|c|c|c|c|}
\hline E.8 PIPELINE D & DELIVERY OF H & YYDROGEN - SI Un & its (continued) & & & & & & & & & & \\
\hline Production & Delivery Distanc & Compressor & |Pipeline & Total Capital & Annual Electric & Depreciation & Total Annual & Capital & Electric & Total & & Compressor & Pipeline \\
\hline Rate & One-Way & Cost & Cost & Cost & Cost & & Cost & Cost & Cost & Cost & & Cost & Cost \\
\hline$(\mathrm{lb} / \mathrm{hr})$ & (miles) & (\$) & (\$) & $(\$)$ & $(\$ / y r)$ & $(\$ / y r)$ & $(\$ / y r)$ & $(\$ / / b)$ & $(\$ / / b)$ & $(\$ / l b)$ & & $(\$ / \mathrm{lb})$ & $(\$ / \mathrm{lb})$ \\
\hline 5 & 16 & 0 & $10,000,000$ & $10,000,000$ & $\$ 0$ & $\$ 454,545$ & $\$ 454,545$ & $\$ 11.93$ & $\$ 0.00$ & $\$ 11.93$ & & $\$ 0.00$ & $\$ 11.93$ \\
\hline 5 & 32 & 0 & $20,000,000$ & $20,000,000$ & $\$ 0$ & $\$ 909,091$ & $\$ 909,091$ & $\$ 23.86$ & $\$ 0.00$ & $\$ 23.86$ & & $\$ 0.00$ & $\$ 23.86$ \\
\hline 5 & 80 & 0 & $50,000,000$ & $50,000,000$ & $\$ 0$ & $\$ 2,272,727$ & $\$ 2,272,727$ & $\$ 59.65$ & $\$ 0.00$ & $\$ 59.65$ & & $\$ 0.00$ & $\$ 59.65$ \\
\hline 5 & 161 & 0 & $100,000,000$ & $100,000,000$ & $\$ 0$ & $\$ 4,545,455$ & $\$ 4,545,455$ & $\$ 119.30$ & $\$ 0.00$ & $\$ 119.30$ & & $\$ 0.00$ & $\$ 119.30$ \\
\hline & 322 & $\overline{0}$ & $200,000,000$ & $200,000,000$ & $\$ 0$ & $\$ 9,090,909$ & $\$ 9,090,909$ & $\$ 238.60$ & $\$ 0.00$ & $\$ 238.60$ & & $\$ 0.00$ & $\$ 238.60$ \\
\hline 5 & 805 & 0 & $500,000,000$ & $500,000,000$ & $\$ 0$ & $\$ 22,727,273$ & $\$ 22,727,273$ & $\$ 596.49$ & $\$ 0.00$ & $\$ 596.49$ & & $\$ 0.00$ & $\$ 596.49$ \\
\hline 5 & 1,609 & 1 & $1,000,000,000$ & $1,000,000,001$ & $\$ 0$ & $\$ 45,454,545$ & $\$ 45,454,545$ & $\$ 1,192.98$ & $\$ 0.00$ & $\$ 1,192.98$ & & $\$ 0.00$ & $\$ 1,192.98$ \\
\hline 45 & 16 & 4 & $10,000,000$ & 10,000,004 & $\$ 0$ & $\$ 454,546$ & \$454,546 & $\$ 1.19$ & $\$ 0.00$ & $\$ 1.19$ & & $\$ 0.00$ & $\$ \$ 1.19$ \\
\hline 45 & 32 & 8 & $20,000,000$ & $20,000,008$ & $\$ 0$ & $\$ 909,091$ & $\$ 909,091$ & $\$ 2.39$ & $\$ 0.00$ & $\$ 2.39$ & & $\$ 0.00$ & $\$ 2.39$ \\
\hline 45 & 80 & 16 & $50,000,000$ & $50,000,016$ & $\$ 0$ & $\$ 2,272,728$ & $\$ 2,272,728$ & $\$ 5.96$ & $\$ 0.00$ & $\$ 5.96$ & & $\$ 0.00$ & $\$ 5.96$ \\
\hline 45 & 161 & 27 & $100,000,000$ & $100,000,027$ & $\$ 1$ & $\$ 4,545,456$ & $\$ 4,545,457$ & $\$ 11.93$ & $\$ 0.00$ & $\$ 11.93$ & & $\$ 0.00$ & $\$ 11.93$ \\
\hline 45 & 322 & 47 & $200,000,000$ & $200,000,047$ & $\$ 2$ & $\$ 9,090,911$ & $\$ 9,090,913$ & $\$ 23.86$ & $\$ 0.00$ & $\$ 23.86$ & & $\$ 0.00$ & $\$ 23.86$ \\
\hline 45 & 805 & 99 & $500,000,000$ & $500,000,099$ & $\$ 5$ & $\$ 22,727,277$ & $\$ 22,727,282$ & $\$ 59.65$ & $\$ 0.00$ & $\$ 59.65$ & & $\$ 0.00$ & $\$ 59.65$ \\
\hline 45 & 1,609 & 172 & $1,000,000,000$ & $1,000,000,172$ & $\$ 10$ & $\$ 45,454,553$ & $\$ 45,454,563$ & $\$ 119.30$ & $\$ 0.00$ & $\$ 119.30$ & & $\$ 0.00$ & $\$ 119.30$ \\
\hline 454 & $\frac{16}{16}$ & 1,083 & $10,000,000$ & $10,001,083$ & $\$ 98$ & $\$ 454,595$ & $\$ 454,693$ & $\$ 0.12$ & $\$ 0.00$ & $\$ 0.12$ & & $\$ 0.00$ & $\$ 0.12$ \\
\hline 454 & 32 & 1,885 & $20,000,000$ & $20,001,885$ & $\$ 196$ & $\$ 909,177$ & $\$ 909,372$ & $\$ 0.24$ & $\$ 0.00$ & $\$ 0.24$ & & $\$ 0.00$ & $\$ 0.24$ \\
\hline 454 & 80 & 3,914 & $50,000,000$ & $50,003,914$ & $\$ 487$ & $\$ 2,272,905$ & $\$ 2,273,393$ & $\$ 0.60$ & $\$ 0.00$ & $\$ 0.60$ & & $\$ 0.00$ & $\$ 0.60$ \\
\hline 454 & 161 & 6,789 & $100,000,000$ & $100,006,789$ & $\$ 969$ & $\$ 4,545,763$ & $\$ 4,546,732$ & $\$ 1.19$ & $\$ 0.00$ & $\$ 1.19$ & & $\$ 0.00$ & $\$ 1.19$ \\
\hline 454 & 322 & 11,733 & $200,000,000$ & $200,011,733$ & $\$ 1,915$ & $\$ 9,091,442$ & $\$ 9,093,357$ & $\$ 2.39$ & $\$ 0.00$ & $\$ 2.39$ & & $\$ 0.00$ & $\$ 2.39$ \\
\hline 454 & 805 & 23,900 & $500,000,000$ & $500,023,900$ & $\$ 4,624$ & $\$ 22,728,359$ & $\$ 22,732,983$ & $\$ 5.97$ & $\$ 0.00$ & $\$ 5.97$ & & $\$ 0.00$ & $\$ 5.96$ \\
\hline 454 & 1,609 & 40,240 & $1,000,000,000$ & $1,000,040,240$ & $\$ 8,765$ & $\$ 45,456,375$ & $\$ 45,465,139$ & $\$ 11.93$ & $\$ 0.00$ & $\$ 11.93$ & & $\$ 0.00$ & $\$ 11.93$ \\
\hline 4,536 & 16 & 253,895 & $10,000,000$ & $10,253,895$ & $\$ 87,649$ & $\$ 466,086$ & $\$ 553,735$ & $\$ 0.01$ & $\$ 0.00$ & $\$ 0.01$ & & $\$ 0.00$ & $\$ 0.01$ \\
\hline 4,536 & 32 & 416,373 & $20,000,000$ & $20,416,373$ & $\$ 159,382$ & $\$ 928,017$ & $\$ 1,087,399$ & $\$ 0.02$ & $\$ 0.00$ & $\$ 0.03$ & & $\$ 0.00$ & $\$ 0.02$ \\
\hline 4,536 & 80 & 752,568 & $50,000,000$ & $50,752,568$ & $\$ 319,204$ & $\$ 2,306,935$ & $\$ 2,626,139$ & $\$ 0.06$ & $\$ 0.01$ & $\$ 0.07$ & & $\$ 0.00$ & $\$ 0.06$ \\
\hline 4,536 & 161 & $1,109,846$ & $100,000,000$ & $101,109,846$ & $\$ 493,692$ & $\begin{array}{l}\$, 0005,902 \\
\$ 4,595\end{array}$ & $\begin{array}{l}\$, 089,594 \\
\$ 5,08\end{array}$ & $\$ 0.12$ & $\$ 0.01$ & $\$ 0.13$ & & $\$ 0.00$ & $\$ 0.12$ \\
\hline 4,536 & 322 & $1,552,315$ & $200,000,000$ & $201,552,315$ & $\$ 706,848$ & $\$ 9,161,469$ & $\$ 9,868,317$ & $\$ 0.24$ & $\$ 0.02$ & $\$ 0.26$ & & $\$ 0.00$ & $\$ 0.24$ \\
\hline 4,536 & 805 & $2,252,872$ & $500,000,000$ & $502,252,872$ & $\$ 1,027,892$ & $\$ 22,829,676$ & $\$ 23,857,568$ & $\$ 0.60$ & $\$ 0.03$ & $\$ 0.63$ & & $\$ 0.00$ & $\$ 0.60$ \\
\hline 4,536 & 1,609 & $2,861,447$ & $1,000,000,000$ & $1,002,861,447$ & $\$ 1,287,521$ & $\$ 45,584,611$ & $\$ 46,872,132$ & $\$ 1.20$ & $\$ 0.03$ & $\$ 1.23$ & & $\$ 0.00$ & $\$ 1.19$ \\
\hline 45,359 & 16 & $18,054,508$ & $10,000,000$ & $28,054,508$ & $\$ 12,875,210$ & $\$ 1,275,205$ & $\$ 14,150,415$ & $\$ 0.00$ & $\$ 0.03$ & $\$ 0.04$ & & $\$ 0.00$ & $\$ 0.00$ \\
\hline 45,359 & 32 & $22,303,677$ & 1,000 & $42,303,677$ & $\$ 15,544,795$ & $\$ 1,922,894$ & $\$ 17,467,690$ & $\$ 0.01$ & $\$ 0.04$ & $\$ 0$. & & $\$ 0.00$ & $\$ 0$. \\
\hline 45,359 & 80 & $28,563,578$ & $50,000,000$ & $78,563,578$ & $\$ 19,129,161$ & $\$ 3,571,072$ & $\$ 22,700,232$ & $\$ 0.01$ & $\$ 0.05$ & $\$ 0.06$ & & $\$ 0.00$ & $\$ 0.01$ \\
\hline 45,359 & 161 & $33,815,859$ & $100,000,000$ & $133,815,859$ & $\$ 21,860,547$ & $\$ 6,082,539$ & $\$ 27,943,086$ & $\$ 0.02$ & $\$ 0.06$ & $\$ 0.07$ & & $\$ 0.00$ & $\$ 0.01$ \\
\hline 45,359 & 322 & $39,550,484$ & $200,000,000$ & $239,550,484$ & $\$ 24,599,869$ & $\$ 10,888,658$ & $\$ 35,488,527$ & $\$ 0.03$ & $\$ 0.06$ & $\$ 0.09$ & & $\$ 0.00$ & $\$ 0.02$ \\
\hline 45,359 & 805 & $47,940,472$ & $500,000,000$ & $547,940,472$ & $\$ 28,226,810$ & $\$ 24,906,385$ & $\$ 53,133,199$ & $\$ 0.07$ & $\$ 0.07$ & $\$ 0.14$ & & $\$ 0.01$ & $\$ 0.06$ \\
\hline 45,359 & 1,609 & $54,958,003$ & $1,000,000,000$ & $1,054,958,003$ & $\$ 30,972,514$ & $\$ 47,952,637$ & $\$ 78,925,150$ & $\$ 0.13$ & $\$ 0.08$ & $\$ 0.21$ & & $\$ 0.01$ & $\$ 0.12$ \\
\hline
\end{tabular}




\begin{tabular}{|c|c|c|c|c|c|c|c|c|c|}
\hline \multicolumn{10}{|c|}{ E.8 PIPELINE DELIVERY OF HYDROGEN - English Units } \\
\hline Compressor $\mathrm{Ca}$ & pital Cost $=$ & $\$ 1,000$ & perkW & & & & & & \\
\hline Compressor Siz & & 4,000 & $\mathrm{~kW}$ & & & & & & \\
\hline Compressor Pre & essure $=$ & 20 & $\mathrm{MPa}$ & & & & & & \\
\hline Comp. Cost Sca & ale-Up= & 0.80 & & & & & & & \\
\hline Comp. Pressure & Scale-Up= & 0.18 & & & & & & & \\
\hline Pipeline Cost= & & $\$ 1.000 .000$ & per mile & & & & & & \\
\hline Electric Cost $=$ & & $\$ 0.05$ & per kWh & & & & & & \\
\hline Compressor Po & wer $=$ & 1.00 & $\mathrm{kWh} / \mathrm{lb}(20 \mathrm{~N}$ & $\mathrm{MPa})$ & & & & & \\
\hline Steel Roughnes & & $4.6 \mathrm{E}-05$ & $\mathrm{~m}$ & & & & & & \\
\hline Pipe Diameter $=$ & & 0.25 & $\mathrm{~m}$ & & & & & & \\
\hline Temperature $=$ & & 283 & & & & & & & \\
\hline Delivery Pressu & & & Mpa & & & & & & \\
\hline Viscosity= & & $8.62 \mathrm{E}-06$ & $\mathrm{~kg} / \mathrm{m}^{*} \mathrm{~s}$ & & & & & & \\
\hline$R$ (hydrogen)= & & 4124 & $\mathrm{~N}^{*} \mathrm{~m} / \mathrm{kg} \mathrm{K}$ & & & & & & \\
\hline Operating Days & Year $=$ & 350 & days/yr & & & & & & \\
\hline Pipeline Deprec & ation $=$ & 22 & years & & & & & & \\
\hline & & & & & & & & & \\
\hline Roughness/Dia & meter $=$ & 0.000184 & & & & & & & \\
\hline Fanning friction & factor, $\mathrm{f}=$ & 0.005 & & & & & & & \\
\hline Pipe Area $=$ & & 0.049 & sq. $m$ & & & & & & \\
\hline & & & & & & & & & \\
\hline \begin{tabular}{|l} 
Production \\
Rate
\end{tabular} & \begin{tabular}{|l|} 
Delivery Distance \\
One-Way
\end{tabular} & \begin{tabular}{|l} 
Annual \\
Production
\end{tabular} & Flowrate & Distance & Gas Flux & $\begin{array}{l}\text { Reynolds } \\
\text { Number }\end{array}$ & $\frac{\mid \text { nilet }}{\text { Pressure }}$ & \begin{tabular}{|l|} 
Compressor \\
Size
\end{tabular} & \begin{tabular}{|l} 
Annual Electric \\
Use
\end{tabular} \\
\hline$(1 \mathrm{~b} / \mathrm{hr})$ & \begin{tabular}{|l|} 
(miles) \\
\end{tabular} & $(\mathrm{lb} / \mathrm{yr})$ & $(\mathrm{kg} / \mathrm{s})$ & $(\mathrm{m})$ & $\left(\mathrm{kg} / \mathrm{s}^{*} \mathrm{~m}^{\wedge} 2\right)$ & & (MPa) & $\begin{array}{ll}\text { net } \\
(\mathrm{kW}) \\
\end{array}$ & \begin{tabular}{|l|l|l|l|l} 
(kWh/yr) \\
\end{tabular} \\
\hline 10 & 10 & 84,000 & 0.001 & 16,094 & 0.026 & 744 & 2.000 & 0 & \\
\hline 10 & 20 & 84,000 & 0.001 & 32,187 & 0.026 & 744 & 2.000 & 0 & \\
\hline & 50 & 84,000 & 0.001 & 80,468 & 0.026 & 744 & 2.000 & 0 & \\
\hline & 100 & 84,000 & 0.001 & $\begin{array}{ll}160,936 \\
\end{array}$ & $\frac{0.026}{0.026}$ & 744 & 2.000 & 0 & \\
\hline 10 & 200 & 84,000 & 0.001 & 321,873 & 0.026 & 744 & 2.000 & 0 & \\
\hline 10 & 500 & 84,000 & 0.001 & 804,682 & 0.026 & 744 & 2.000 & 0 & \\
\hline 10 & 1.000 & 84.000 & 0.001 & $1,609,364$ & 0.026 & 744 & 2.000 & 0 & \\
\hline 100 & 10 & 840,000 & 0.013 & 16,094 & 0.257 & 7,444 & 2.000 & 0 & \\
\hline 100 & 20 & 840,000 & 0.013 & 32,187 & 0.257 & 7,444 & 2.000 & 0 & \\
\hline 100 & 50 & 840,000 & 0.013 & 80,468 & 0.257 & 7,444 & 2.000 & 0 & 10 \\
\hline 100 & 100 & 840,000 & 0.013 & 160,936 & 0.257 & 7,444 & 2.000 & 0 & 20 \\
\hline 100 & 200 & 840,000 & 0.013 & 321,873 & 0.257 & 7,444 & 2.000 & 0 & 39 \\
\hline 100 & 500 & 840.000 & 0.013 & 804.682 & 0.257 & 7.444 & 2.001 & & 98 \\
\hline 100 & 1.000 & 840,000 & 0.013 & 1.609 .364 & 0.257 & 7.444 & 2.002 & & $\frac{50}{196}$ \\
\hline 1,000 & $\frac{10}{10}$ & $8,400,000$ & 0.126 & $\frac{16,094}{16,09}$ & 2.567 & 74,443 & 2.002 & 0 & 1,960 \\
\hline 1,000 & 20 & $8,400,000$ & 0.126 & 32,187 & 2.567 & 74,443 & 2.005 & s & 3,914 \\
\hline 1,000 & 50 & $8,400,000$ & 0.126 & 80,468 & 2.567 & 74,443 & 2.012 & 1 & 9,749 \\
\hline 1,000 & 100 & $8,400,000$ & 0.126 & 160,936 & 2.567 & 74,443 & 2.025 & & 19,380 \\
\hline 1,000 & 200 & $8,400,000$ & 0.126 & 321,873 & 2.567 & 74,443 & 2.049 & 5 & 38,298 \\
\hline$\frac{1,000}{1,000}$ & 500 & $\frac{0,40,000}{8,400,000}$ & 0.120 & \begin{tabular}{|l|}
$3<1,01,682$ \\
804,62
\end{tabular} & $\frac{2.501}{2.567}$ & $\begin{array}{l}74,443 \\
74,443 \\
\end{array}$ & $\frac{2.045}{2.120}$ & 11 & $\begin{array}{l}30,290 \\
92,485 \\
\end{array}$ \\
\hline 1,000 & 1.000 & $8.400,000$ & 0.126 & $1,609,364$ & 2.567 & 74.443 & 2.234 & 21 & 175,299 \\
\hline 10,000 & 10 & $84,000,000$ & 1.260 & 16,094 & 25.668 & 744.430 & 2.234 & 209 & 1.752 .985 \\
\hline 10,000 & 20 & $84,000,000$ & 1.260 & 32,187 & 25.668 & 744,430 & 2.445 & 379 & $3,187,650$ \\
\hline 10,000 & 50 & $84,000,000$ & 1.260 & 80,468 & 25.668 & 744,430 & 2.992 & 760 & $6,384,080$ \\
\hline$\frac{10,000}{10,000}$ & 100 & $84,000,000$ & 1.260 & \begin{tabular}{|l|}
160,436 \\
\end{tabular} & 25.668 & 744,430 & 3.728 & 1,175 & $\begin{array}{l}9,873,834 \\
9,87\end{array}$ \\
\hline 10,000 & 200 & $84,000,000$ & 1.260 & 321,873 & 25.668 & 744,430 & 4.879 & 1,683 & $14,136,965$ \\
\hline 10,000 & 500 & $84,000,000$ & 1.260 & 804,682 & 25.668 & 744,430 & 7.314 & 2,447 & $20,557,833$ \\
\hline 10,000 & 1,000 & $84,000,000$ & 1.260 & $1,609,364$ & 25.668 & 744,430 & 10.149 & 3,066 & $25,750,421$ \\
\hline 100,000 & 10 & $840,000,000$ & 12.600 & 16,094 & 256.679 & 7.444 .299 & 10.149 & 30,655 & 257.504 .20 \\
\hline 100,000 & 20 & $840,000,000$ & 12.600 & 32,187 & 256.679 & $7,444.299$ & 14.213 & 37,011 & $310,895,909$ \\
\hline 100,000 & 50 & $840,000,000$ & 12.600 & $\begin{array}{l}3<, 101 \\
80,468\end{array}$ & $\frac{250.019}{256.679}$ & $\begin{array}{l}7,44,299 \\
7,444,299\end{array}$ & $\frac{14.210}{22.338}$ & 45,546 & $382,583,212$ \\
\hline 100,000 & 100 & $840,000,000$ & 12.600 & $\begin{array}{l}160,936 \\
\end{array}$ & 256.679 & $7,444,299$ & 31.528 & 52,049 & $437,210,943$ \\
\hline 100,000 & 200 & $840,000,000$ & 12.600 & 321,873 & 256.679 & $7,444,299$ & 44.542 & 58,571 & $491,997,37$ \\
\hline 100,000 & 500 & $840,000,000$ & 12.600 & 804,682 & 256.679 & $7,444,299$ & 70.384 & 67,207 & $564,536,199$ \\
\hline 100,000 & 1,000 & $840,000,000$ & 12.600 & $\mid 1,609,364$ & 256.679 & $7,444.299$ & 99.518 & 73,744 & $619,450,278$ \\
\hline
\end{tabular}




\begin{tabular}{|c|c|c|c|c|c|c|c|c|c|c|c|c|c|}
\hline E.8 PIPELINE D & DELIVERY OF H & YYDROGEN - Englis & sh Units (continue & & & & & & & & & & \\
\hline Production & Delivery Distanc & Compressor & Pipeline & Total Capital & Annual Electric & Depreciation & Total Annual & $\mid$ Capital & Electric & Total & & Compressor & Pipeline \\
\hline Rate & One-Way & Cost & Cost & Cost & Cost & & Cost & Cost & Cost & Cost & & Cost & Cost \\
\hline$(\mathrm{lb} / \mathrm{hr})$ & (miles) & (\$) & $(\$)$ & (\$) & $(\$ / y r)$ & $(\$ / y r)$ & $(\$ / y r)$ & $(\$ / \mathrm{lb})$ & (\$/lb) & $(\$ / / b)$ & & $(\$ / / b)$ & $(\$ / 1 \mathrm{~b})$ \\
\hline 10 & 10 & 0 & $10,000,000$ & $10,000,000$ & $\$ 0$ & $\$ 454,545$ & $\$ 454,545$ & $\$ 5.41$ & $\$ 0.00$ & $\$ 5.41$ & & $\$ 0.00$ & $\$ 5.41$ \\
\hline 10 & 20 & 0 & $20,000,000$ & $20,000,000$ & $\$ 0$ & $\$ 909,091$ & $\$ 909,091$ & $\$ 10.82$ & $\$ 0.00$ & $\$ 10.82$ & & $\$ 0.00$ & $\$ 10.82$ \\
\hline 10 & 50 & 0 & $50,000,000$ & $50,000,000$ & $\$ 0$ & $\$ 2,272,727$ & $\$ 2,272,727$ & $\$ 27.06$ & $\$ 0.00$ & $\$ 27.06$ & & $\$ 0.00$ & $\$ 27.06$ \\
\hline 10 & 100 & 0 & $100,000,000$ & $100,000,000$ & $\$ 0$ & $\$ 4,545,455$ & $\$ 4,545,455$ & $\$ 54.11$ & $\$ 0.00$ & $\$ 54.11$ & & $\$ 0.00$ & $\$ 54.11$ \\
\hline 10 & 200 & 0 & $200,000,000$ & $200,000,000$ & $\$ 0$ & $\$ 9,090,909$ & $\$ 9,090,909$ & $\$ 108.23$ & $\$ 0.00$ & $\$ 108.23$ & & $\$ 0.00$ & $\$ 108.23$ \\
\hline 10 & 500 & 0 & $500,000,000$ & $500,000,000$ & $\$ 0$ & $\$ 22,727,273$ & $\$ 22,727,273$ & $\$ 270.56$ & $\$ 0.00$ & $\$ 270.56$ & & $\$ 0.00$ & $\$ 270.56$ \\
\hline 10 & 1,000 & 1 & $1,000,000,000$ & $1,000,000,001$ & $\$ 0$ & $\$ 45,454,545$ & $\$ 45,454,545$ & $\$ 541.13$ & $\$ 0.00$ & $\$ 541.13$ & & $\$ 0.00$ & $\$ 541.13$ \\
\hline 100 & $\frac{1,00}{10}$ & 4 & $\frac{1,00,000,000}{10,000}$ & $\frac{10,000,004}{10,000,004}$ & $\$ 0$ & $\$ \$ 454,546$ & $\$ \$ 454,546$ & $\$ 0.54$ & $\$ 0.00$ & $\$ 0.54$ & & $\$ 0.00$ & $\$ 0.54$ \\
\hline 100 & 20 & 8 & $20,000,000$ & $20,000,008$ & $\$ 0$ & $\$ 909,091$ & $\$ 909,091$ & $\$ 1.08$ & $\$ 0.00$ & $\$ 1.08$ & & $\$ 0.00$ & $\$ 1.08$ \\
\hline 100 & 50 & 16 & $50,000,000$ & $50,000,016$ & $\$ 0$ & $\$ 2,272,728$ & $\$ 2,272,728$ & $\$ 2.71$ & $\$ 0.00$ & $\$ 2.71$ & & $\$ 0.00$ & $\$ 2.71$ \\
\hline 100 & 100 & 27 & $100,000,000$ & $100,000,027$ & $\$ 1$ & $\$ 4,545,456$ & $\$ 4,545,457$ & $\$ 5.41$ & $\$ 0.00$ & $\$ 5.41$ & & $\$ 0.00$ & $\$ 5.41$ \\
\hline 100 & 200 & 47 & $200,000,000$ & $200,000,047$ & $\$ 2$ & $\$ 9,090,911$ & $\$ 9,090,913$ & $\$ 10.82$ & $\$ 0.00$ & $\$ 10.82$ & & $\$ 0.00$ & $\$ 10.82$ \\
\hline 100 & 500 & 99 & $500,000,000$ & $500,000,099$ & $\$ 5$ & $\$ 22,727,277$ & $\$ 22,727,282$ & $\$ 27.06$ & $\$ 0.00$ & $\$ 27.06$ & & $\$ 0.00$ & $\$ 27.06$ \\
\hline 100 & 1,000 & 172 & $1,000,000,000$ & $1,000,000,172$ & $\$ 10$ & $\$ 45,454,553$ & $\$ 45,454,563$ & $\$ 54.11$ & $\$ 0.00$ & $\$ 54.11$ & & $\$ 0.00$ & $\$ 54.11$ \\
\hline 1,000 & $\frac{10}{10}$ & 1,083 & $10,000,000$ & $10,001,083$ & $\$ 98$ & $\$ 454,595$ & $\$ 454,693$ & $\$ 0.05$ & $\$ 0.00$ & $\$ 0.05$ & & $\$ 0.00$ & $\$ 0.05$ \\
\hline 1,000 & 20 & 1,885 & $20,000,000$ & $20,001,885$ & $\$ 196$ & $\$ 909,177$ & $\$ 909,372$ & $\$ 0.11$ & $\$ 0.00$ & $\$ 0.11$ & & $\$ 0.00$ & $\$ 0.11$ \\
\hline 1,000 & 50 & 3,914 & $50,000,000$ & $50,003,914$ & $\$ 487$ & $\$ 2,272,905$ & $\$ 2,273,393$ & $\$ 0.27$ & $\$ 0.00$ & $\$ 0.27$ & & $\$ 0.00$ & $\$ 0.27$ \\
\hline 1,000 & 100 & 6,789 & $100,000,000$ & $100,006,789$ & $\$ 969$ & $\$ 4,545,763$ & $\$ 4,546,732$ & $\$ 0.54$ & $\$ 0.00$ & $\$ 0.54$ & & $\$ 0.00$ & $\$ 0.54$ \\
\hline 1,000 & 200 & 11,733 & $200,000,000$ & $200,011,733$ & $\$ 1,915$ & $\$ 9,091,442$ & $\$ 9,093,357$ & $\$ 1.08$ & $\$ 0.00$ & $\$ 1.08$ & & $\$ 0.00$ & $\$ 1.08$ \\
\hline 1,000 & 500 & 23,900 & $500,000,000$ & $500,023,900$ & $\$ 4,624$ & $\$ 22,728,359$ & $\$ 22,732,983$ & $\$ 2.71$ & $\$ 0.00$ & $\$ 2.71$ & & $\$ 0.00$ & $\$ 2.71$ \\
\hline 1,000 & 1,000 & 40,240 & $1,000,000,000$ & $1,000,040,240$ & $\$ 8,765$ & $\$ 45,456,375$ & $\$ 45,465,139$ & $\$ 5.41$ & $\$ 0.00$ & $\$ 5.41$ & & $\$ 0.00$ & $\$ 5.41$ \\
\hline 10,000 & $\frac{1,00}{10}$ & 253,895 & $\frac{1,00,000,000}{10,000}$ & $\begin{array}{r}10,253,895 \\
\end{array}$ & $\$ 87,649$ & $\$ 466,086$ & $\$ \$ 553,735$ & $\$ 0.01$ & $\$ 0.00$ & $\$ 0.01$ & & $\$ 0.00$ & $\$ 0.01$ \\
\hline 10,000 & 20 & 416,373 & $20,000,000$ & $20,416,373$ & $\$ 159,382$ & $\$ 928,017$ & $\$ 1,087,399$ & $\$ 0.01$ & $\$ 0.00$ & $\$ 0.01$ & & $\$ 0.00$ & $\$ 0.01$ \\
\hline 10,000 & 50 & 752,568 & $50,000,000$ & $50,752,568$ & $\$ 319,204$ & $\$ 2,306,935$ & $\$ 2,626,139$ & $\$ 0.03$ & $\$ 0.00$ & $\$ 0.03$ & & $\$ 0.00$ & $\$ 0.03$ \\
\hline 10,000 & 100 & $1,109,846$ & $100,000,000$ & $101,109,846$ & $\$ 493,692$ & $\begin{array}{l}\$ \$, 005,302 \\
4,595,902\end{array}$ & $\begin{array}{l}\$, 0<9,104 \\
\$ 5,089,54\end{array}$ & $\$ 0.05$ & $\$ 0.01$ & $\$ 0.06$ & & $\$ 0.00$ & $\$ 0.05$ \\
\hline 10,000 & 200 & $1,552,315$ & $200,000,000$ & $201,552,315$ & $\$ 706,848$ & $\$ 9,161,469$ & $\$ 9,868,317$ & $\$ 0.11$ & $\$ 0.01$ & $\$ 0.12$ & & $\$ 0.00$ & $\$ 0.11$ \\
\hline 10,000 & 500 & $2,252,872$ & $500,000,000$ & $502,252,872$ & $\$ 1,027,892$ & $\$ 22,829,676$ & $\$ 23,857,568$ & $\$ 0.27$ & $\$ 0.01$ & $\$ 0.28$ & & $\$ 0.00$ & $\$ 0.27$ \\
\hline 10,000 & 1,000 & $2,861,447$ & $1,000,000,000$ & $1,002,861,447$ & $\$ 1,287,521$ & $\$ 45,584,611$ & $\$ 46,872,132$ & $\$ 0.54$ & $\$ 0.02$ & $\$ 0.56$ & & $\$ 0.00$ & $\$ 0.54$ \\
\hline 100,000 & 10 & $\begin{array}{l}18,054,508 \\
\end{array}$ & $10,000,000$ & $\begin{array}{l}28,054,508 \\
\end{array}$ & $\$ 12,875,210$ & $\$ 1,275,205$ & $\$ 14,150,415$ & $\$ 0.00$ & $\$ 0.02$ & $\$ 0.02$ & & $\$ 0.00$ & $\$ 0.00$ \\
\hline 100,000 & 20 & $22,303,677$ & 000 & $42,303,677$ & $\$ 15,544,795$ & $\$ 1,922,894$ & $\$ 17,467,690$ & $\$ 0.00$ & $\$ 0.02$ & $\$ 0.02$ & & $\$ 0.00$ & $\$ 0$. \\
\hline 100,000 & 50 & $28,563,578$ & $50,000,000$ & $78,563,578$ & $\$ 19,129,161$ & $\$ 3,571,072$ & $\$ 22,700,232$ & $\$ 0.00$ & $\$ 0.02$ & $\$ 0.03$ & & $\$ 0.00$ & $\$ 0.00$ \\
\hline 100,000 & 100 & $33,815,859$ & $100,000,000$ & $133,815,859$ & $\$ 21,860,547$ & $\$ 6,082,539$ & $\$ 27,943,086$ & $\$ 0.01$ & $\$ 0.03$ & $\$ 0.03$ & & $\$ 0.00$ & $\$ 0.01$ \\
\hline 100,000 & 200 & $39,550,484$ & $200,000,000$ & $239,550,484$ & $\$ 24,599,869$ & $\$ 10,888,658$ & $\$ 35,488,527$ & $\$ 0.01$ & $\$ 0.03$ & $\$ 0.04$ & & $\$ 0.00$ & $\$ 0.01$ \\
\hline 100,000 & 500 & $47,940,472$ & $500,000,000$ & $547,940,472$ & $\$ 28,226,810$ & $\$ 24,906,385$ & $\$ 53,133,195$ & $\$ 0.03$ & $\$ 0.03$ & $\$ 0.06$ & & $\$ 0.00$ & $\$ 0.03$ \\
\hline 100,000 & 1,000 & $54,958,003$ & $1,000,000,000$ & $1,054,958,003$ & $\$ 30,972,514$ & $\$ 47,952,637$ & $\$ 78,925,150$ & $\$ 0.06$ & $\$ 0.04$ & $\$ 0.09$ & & $\$ 0.00$ & $\$ 0.05$ \\
\hline
\end{tabular}




\section{APPENDIX F - HYDROGEN STORAGE FIGURES}

Appendix F contains figures showing important trends and sensitivity analyses for the storage of hydrogen. An index for the figures is included to help find specific information quickly. Most of the graphs either compare the different storage methods, or show a cost breakdown of the capital and operating cost contributions for one storage option. 


\begin{tabular}{|c|c|c|c|c|c|c|c|c|}
\hline \multicolumn{9}{|c|}{ F.0 INDEX TO HYDROGEN STORAGE FIGURES } \\
\hline Fiqure & Method & $y$-axis & $x$-axis & Dep. Var. & Ind Var & Flow & Time & Lines \\
\hline & & & & $(y)$ & $(x)$ & $(\mathrm{kg} / \mathrm{hr})$ & (days) & \\
\hline & & & & & & & & \\
\hline 1 & All & Norm & Log & Cost $(\$ / \mathrm{kg})$ & Flow $(\mathrm{kg} / \mathrm{hr})$ & & 1 & Comp \\
\hline 2 & All & Norm & Log & Cost $(\$ / \mathrm{kg})$ & Flow $(\mathrm{kg} / \mathrm{hr})$ & & 2 & Comp \\
\hline 3 & All & Norm & $\log$ & Cost $(\$ / \mathrm{kg})$ & Flow $(\mathrm{kg} / \mathrm{hr})$ & & 7 & Comp. \\
\hline 4 & All & Log & Norm & Cost $(\$ / \mathrm{kg})$ & Time $(d)$ & 5 & & Comp. \\
\hline 5 & All & Log & Norm & Cost $(\$ / \mathrm{kg})$ & Time (d) & 450 & & Comp. \\
\hline 6 & All & Norm & Norm & Cost $(\$ / \mathrm{kg})$ & Elec. Cost $(\$ / k W h)$ & 450 & 1 & Comp. \\
\hline 7 & $\mathrm{GH} 2$ & Norm & Log & Cost $(\$ / \mathrm{kg})$ & Pressure (MPa) & & 1 & Flow (kg/hr) \\
\hline 8 & $\mathrm{GH} 2$ & Norm & Log & Cost $(\$ / \mathrm{kg})$ & Pressure (MPa) & & 7 & Flow (kg/hr) \\
\hline 9 & $\mathrm{GH} 2$ & Norm & Log & Cost $(\$ / \mathrm{kg})$ & Flow $(\mathrm{kg} / \mathrm{hr})$ & & 1 & Costs \\
\hline 10 & $\mathrm{GH} 2$ & Norm & Norm & Cost $(\$ / \mathrm{kg})$ & Time (d) & 450 & & Costs \\
\hline 11 & $\mathrm{GH} 2$ & Norm & Log & Cost $(\$ / \mathrm{kg})$ & Pressure (MPa) & 450 & 1 & Costs \\
\hline 12 & $\mathrm{GH} 2$ & Norm & Norm & Cost $(\$ / \mathrm{kg})$ & Pressure (MPa) & 450 & 1 & Costs \\
\hline 13 & $\mathrm{GH} 2$ & Norm & $\log$ & Tank Cost $(\$ / \mathrm{kg})$ & Capacity $(\mathrm{kg})$ & & & Pressure (MPa) \\
\hline 14 & $\mathrm{GH} 2$ & Norm & Norm & Tank Cost $(\$ / \mathrm{kg})$ & Pressure (MPa) & & & Capacity (kg) \\
\hline 15 & $\mathrm{GH} 2$, Under & Norm & $\log$ & Comp. Cost $(\$ / \mathrm{kW})$ & Flow $(\mathrm{kg} / \mathrm{hr})$ & & & Pressure (MPa) \\
\hline 16 & $\mathrm{GH} 2$, Under & Norm & Norm & Comp. Cost $(\$ / \mathrm{kW})$ & Pressure (MPa) & & & Flow $(\mathrm{kg} / \mathrm{hr})$ \\
\hline 17 & $\mathrm{LH} 2$ & Norm & Log & Cost $(\$ / \mathrm{kg})$ & Flow $(\mathrm{kg} / \mathrm{hr})$ & & 1 & Costs \\
\hline 18 & $\mathrm{LH} 2$ & Norm & Norm & Cost $(\$ / \mathrm{kg})$ & Time (d) & 450 & & Costs \\
\hline 19 & $\mathrm{LH} 2$ & Norm & Norm & Cost $(\$ / \mathrm{kg})$ & $\operatorname{BOR}(\% / d)$ & 450 & & Time $(d)$ \\
\hline 20 & $\mathrm{MH} 2$ & Norm & Norm & Cost $(\$ / \mathrm{kg})$ & Time (d) & 450 & & Costs \\
\hline 21 & $\mathrm{MH} 2$ & Norm & Norm & Cost $(\$ / \mathrm{kg})$ & Steam Cost (\$/GJ) & 450 & & Time $(d)$ \\
\hline 22 & Under & Norm & Log & Cost $(\$ / \mathrm{kg})$ & Flow $(\mathrm{kg} / \mathrm{hr})$ & & 1 & Costs \\
\hline 23 & Under & Norm & Norm & Cost $(\$ / \mathrm{kg})$ & Time (d) & 450 & & Costs \\
\hline 24 & Under & Norm & Log & Cost $(\$ / \mathrm{kg})$ & Pressure (MPa) & & 1 & Flow (Ib/hr) \\
\hline 25 & Under & Norm & Log & Cost $(\$ / \mathrm{kg})$ & Pressure (MPa) & & 7 & Flow (kg/hr) \\
\hline 26 & Under & Norm & Log & Cost $(\$ / \mathrm{kg})$ & Pressure (MPa) & 450 & 1 & Costs \\
\hline 27 & Under & Norm & Norm & Cost $(\$ / \mathrm{kg})$ & Pressure (MPa) & 450 & 1 & Costs \\
\hline 28 & Under & Norm & Log & Cost $(\$ / \mathrm{kg})$ & Pressure (MPa) & 450 & 7 & Costs \\
\hline 29 & Under & Norm & Norm & Cost $(\$ / \mathrm{kg})$ & Pressure (MPa) & 450 & 7 & Costs \\
\hline
\end{tabular}




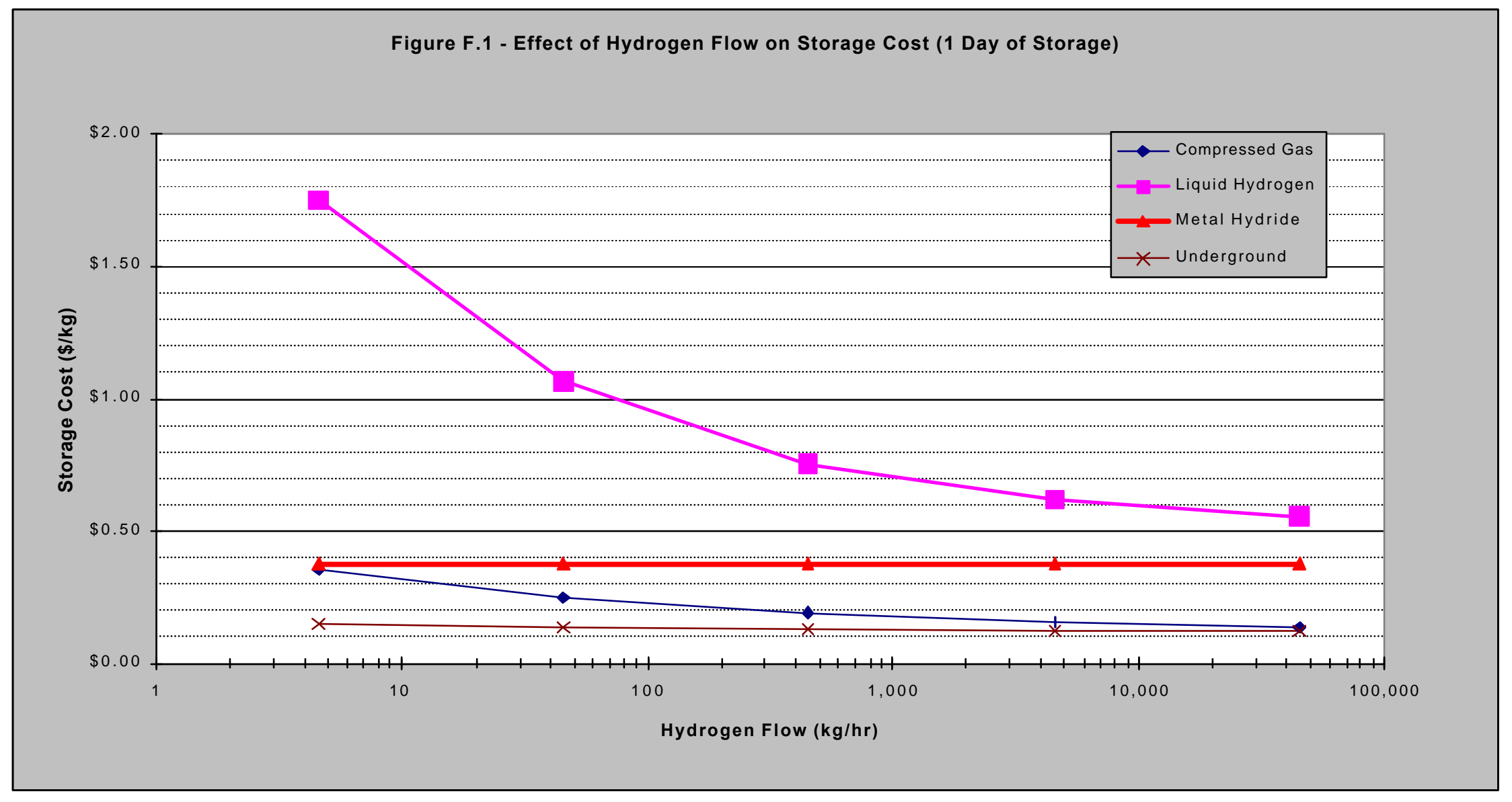

Figure F.1 - Economy of scale drops the liquid hydrogen storage cost as the production rate increases. 


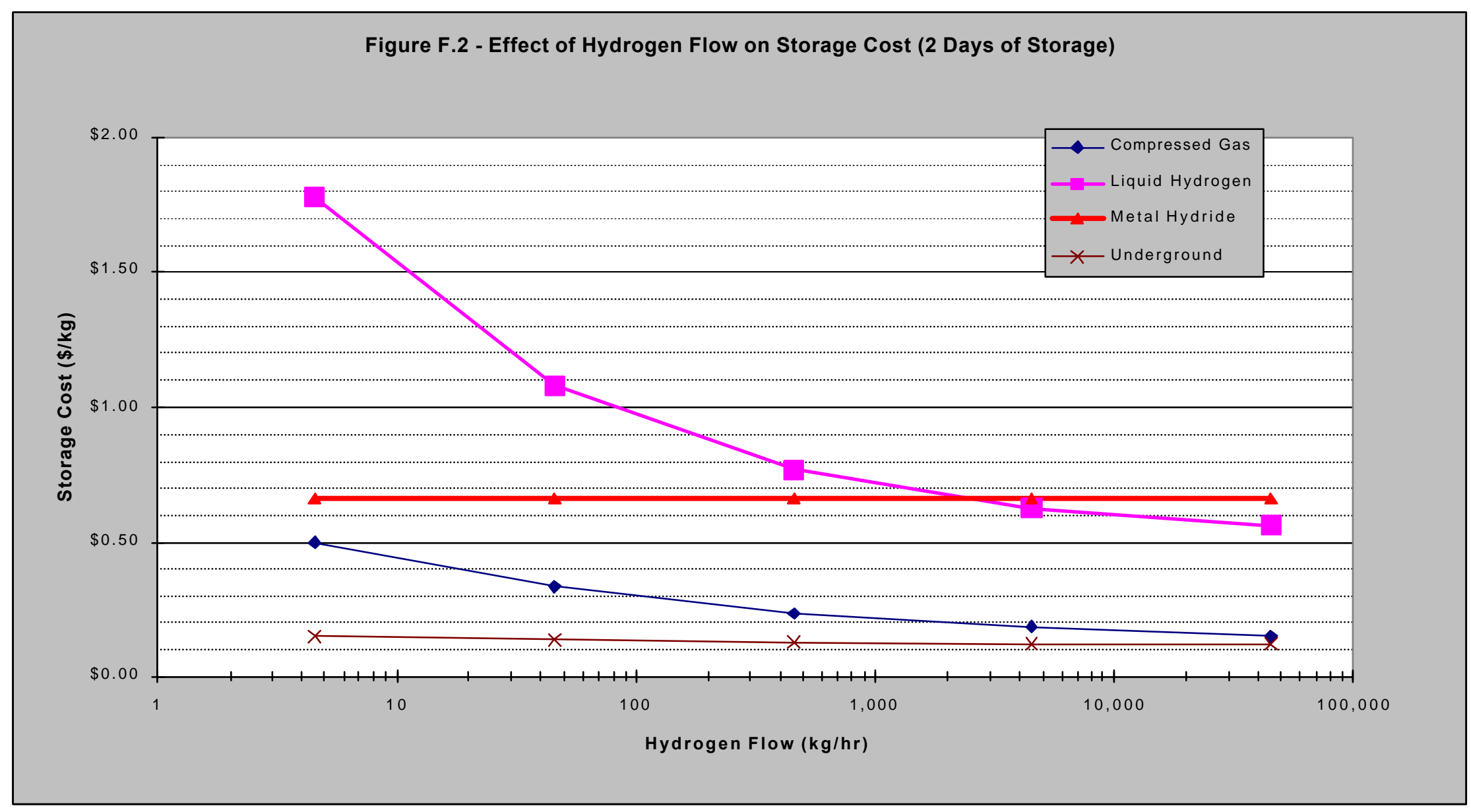

Figure F.2 - At longer storage times, liquid hydrogen storage starts to compete with other methods. 


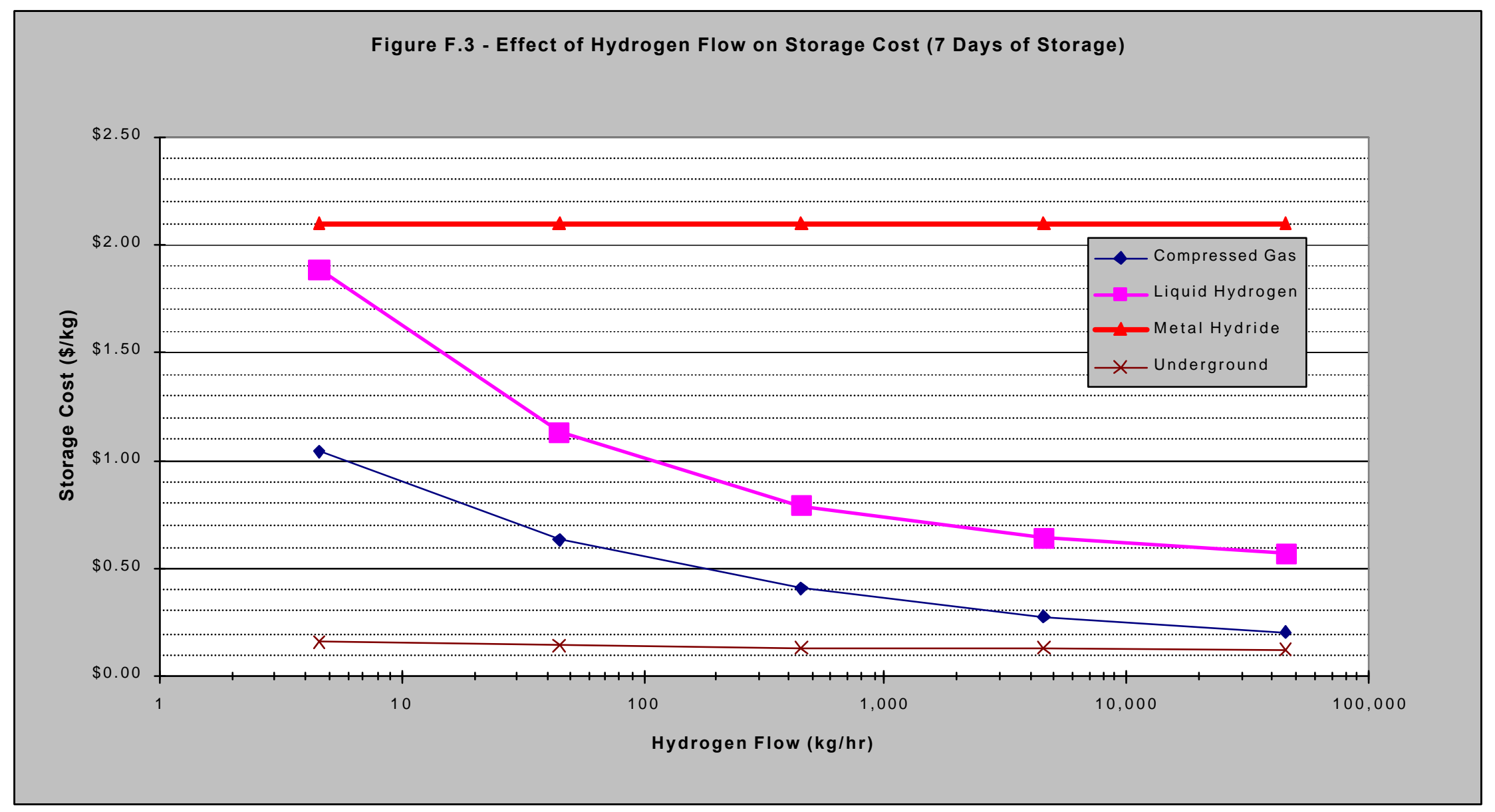

Figure F.3 - Metal hydride storage is not competitive for long storage times due to the high capital cost. 


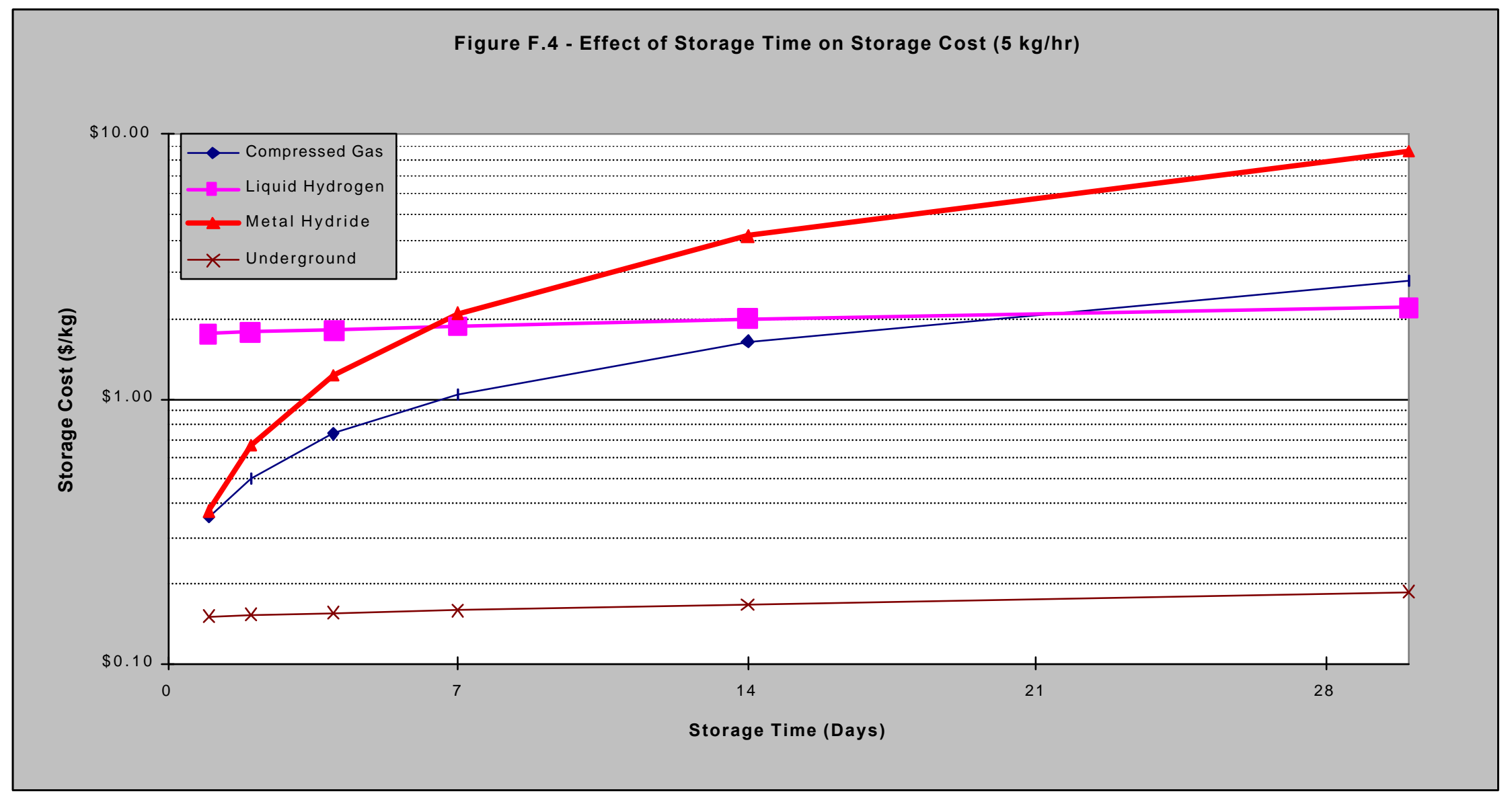

Figure F.4 - Metal hydride and compressed gas storage have comparable costs at low production rates and short storage times. 


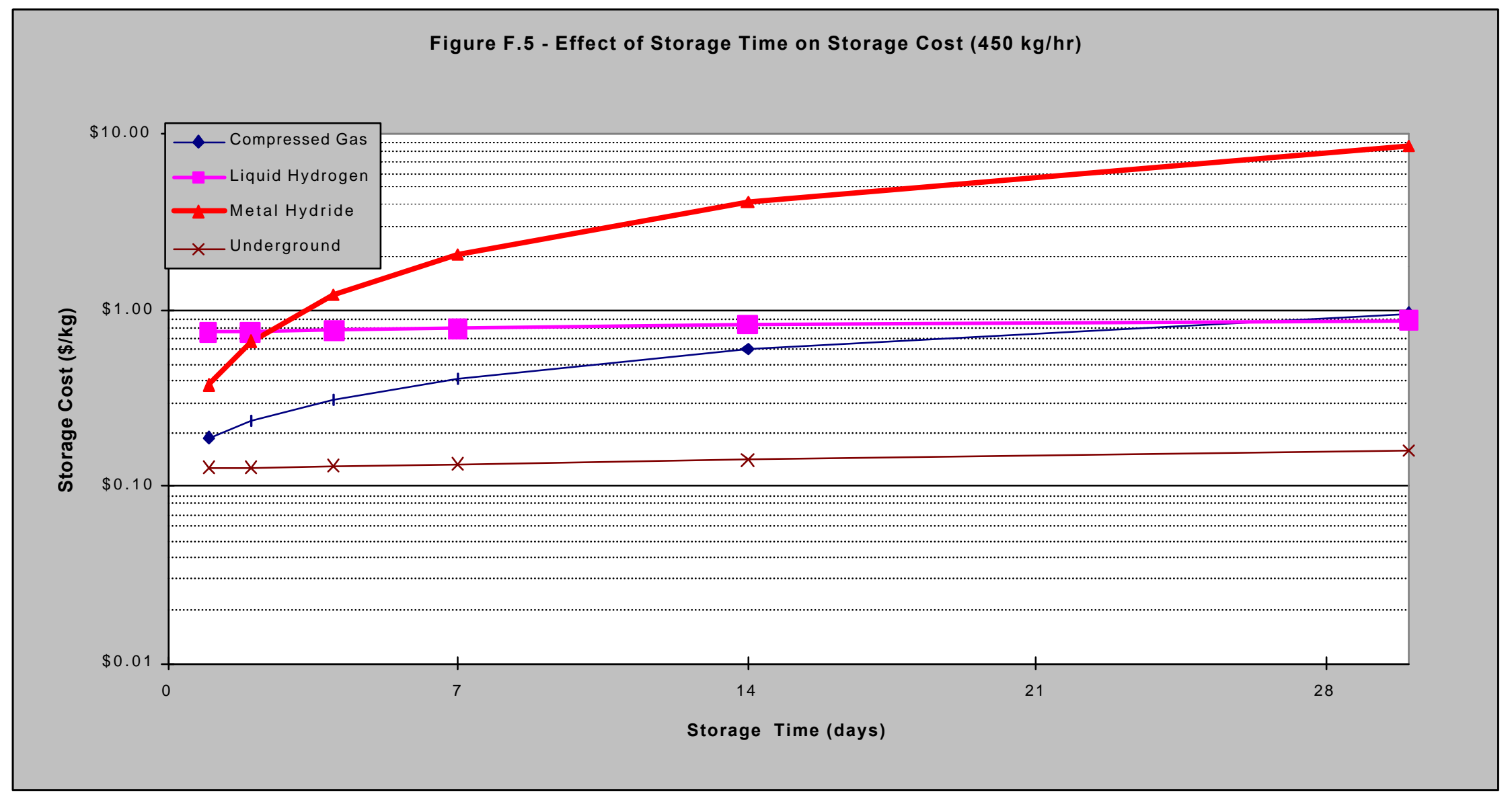

Figure F.5 - Liquid hydrogen and underground storage show relatively little increase in cost with longer storage times due to low capital costs of storage. 


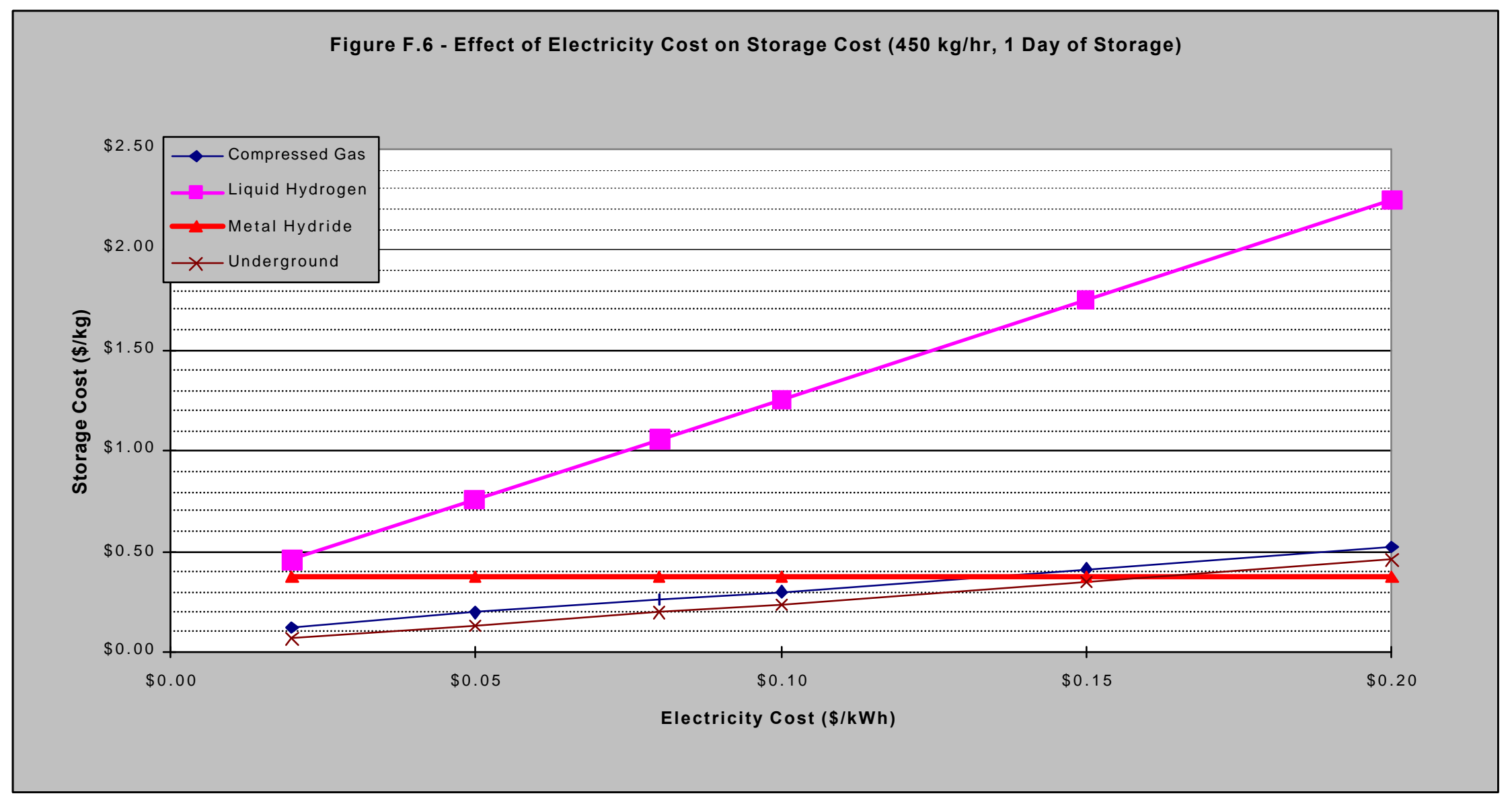

Figure F.6 - Electricity cost has the largest effect on liquid hydrogen storage since it has the highest electricity requirement. 


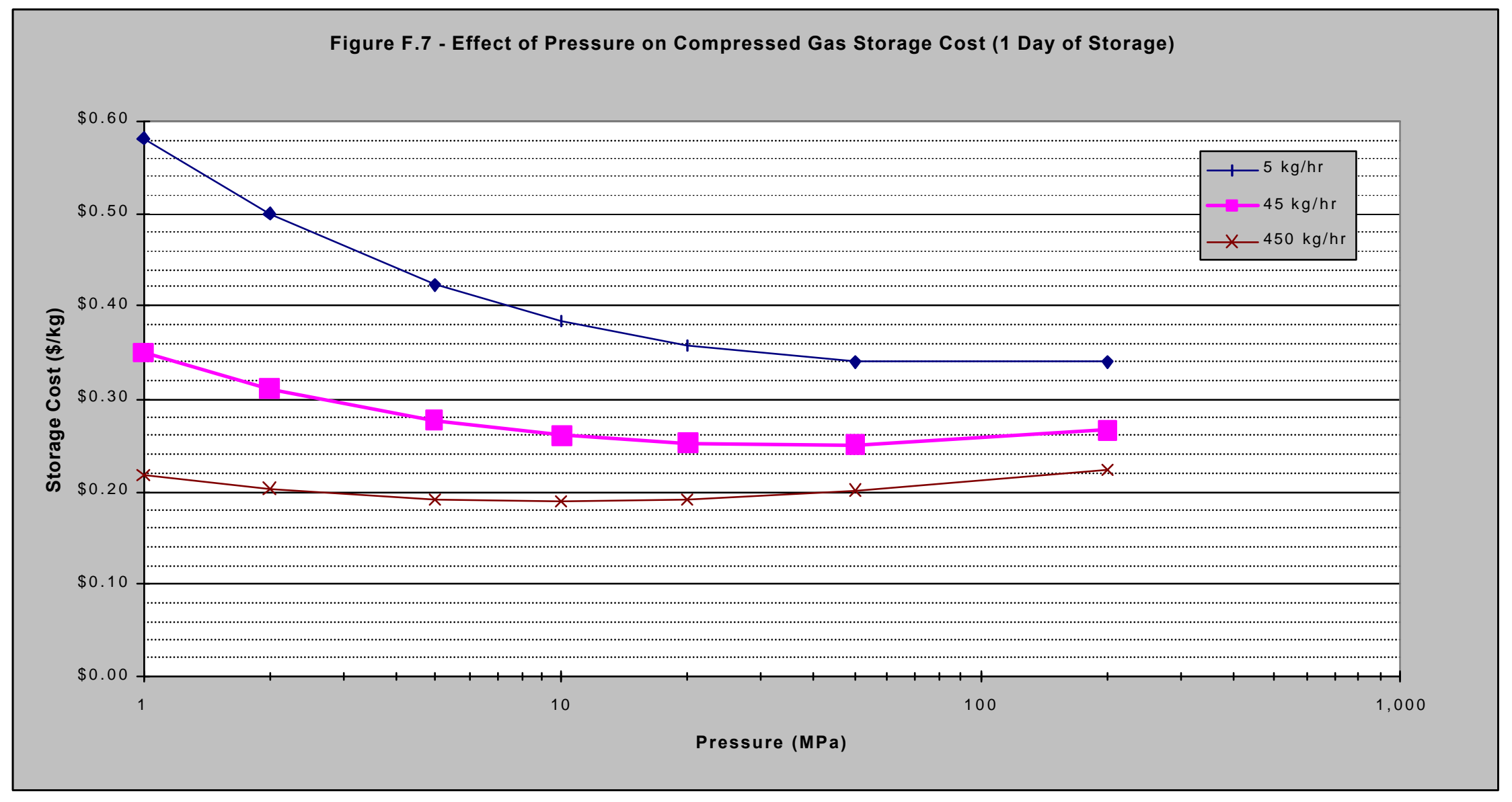

Figure F.7 - For short storage times, an optimum pressure exists for compressed gas storage. 


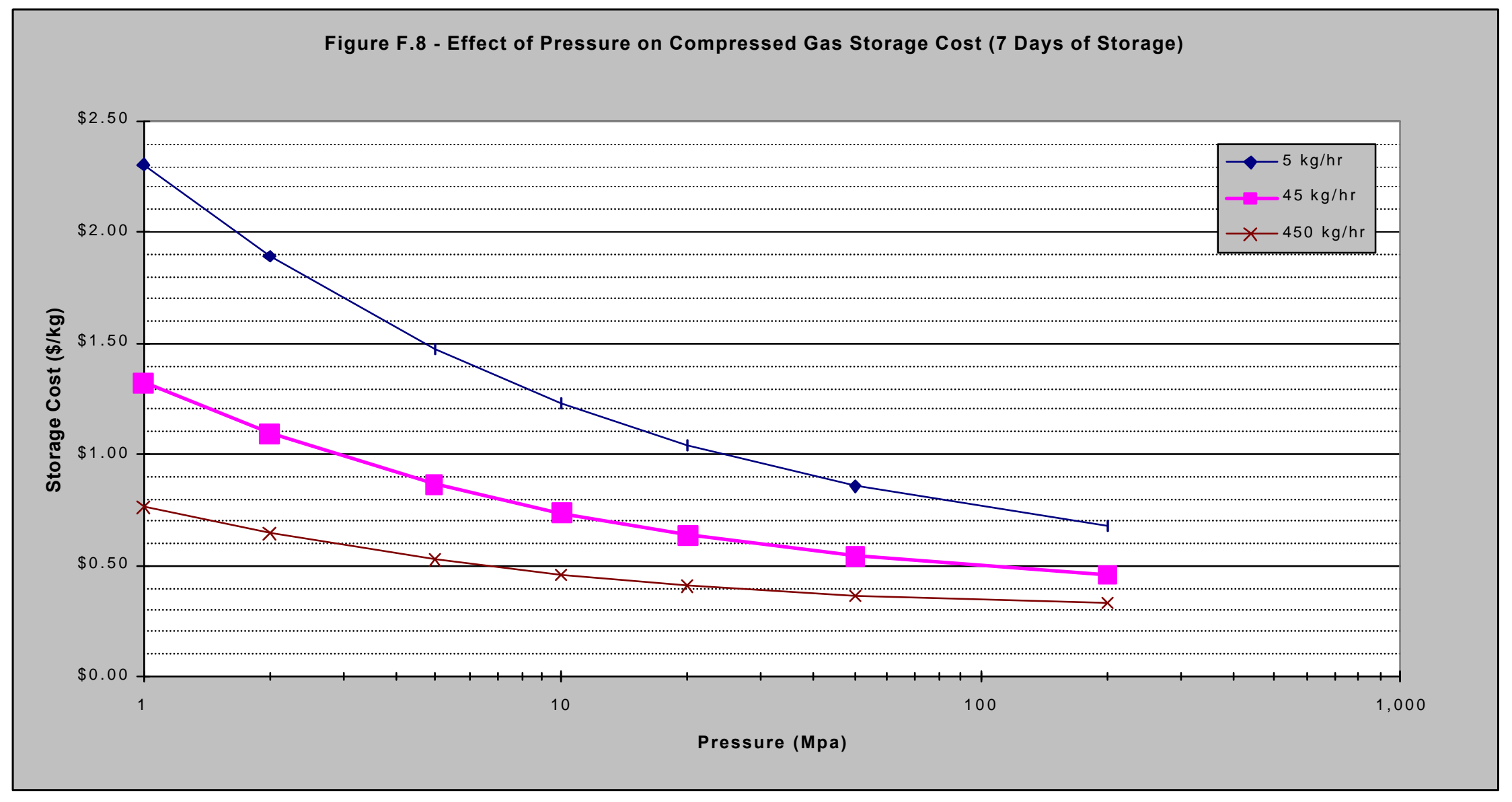

Figure F.8 - For longer storage times, increased capital costs cause high pressures to give the lowest compressed gas storage costs. 


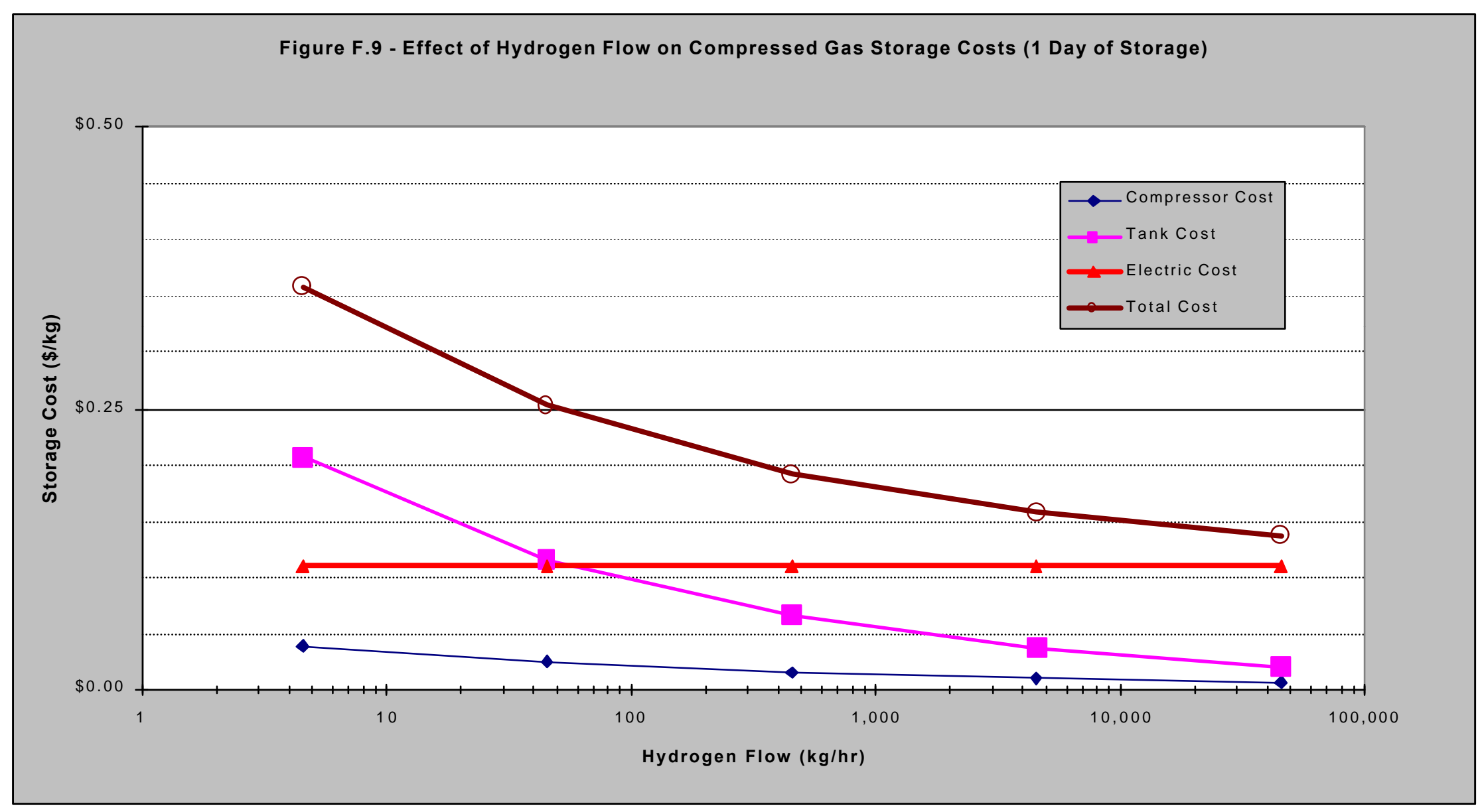

Figure F.9 - The tank cost dominates at low flows, then the compressed gas storage costs are eventually limited by electricity costs.

$$
\mathrm{F}-11
$$




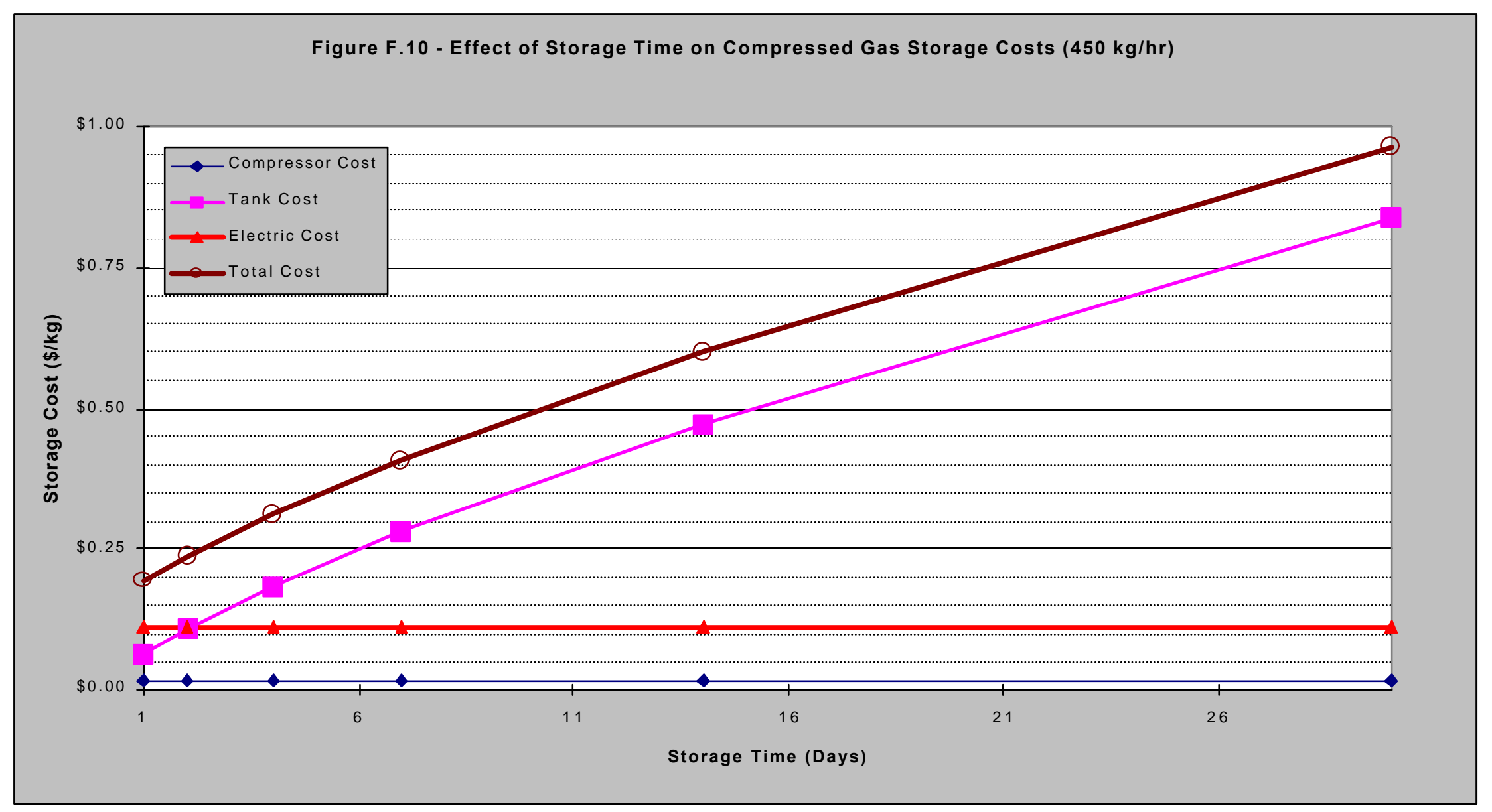

Figure F.10 - The tank cost skyrockets as the storage time increases. 


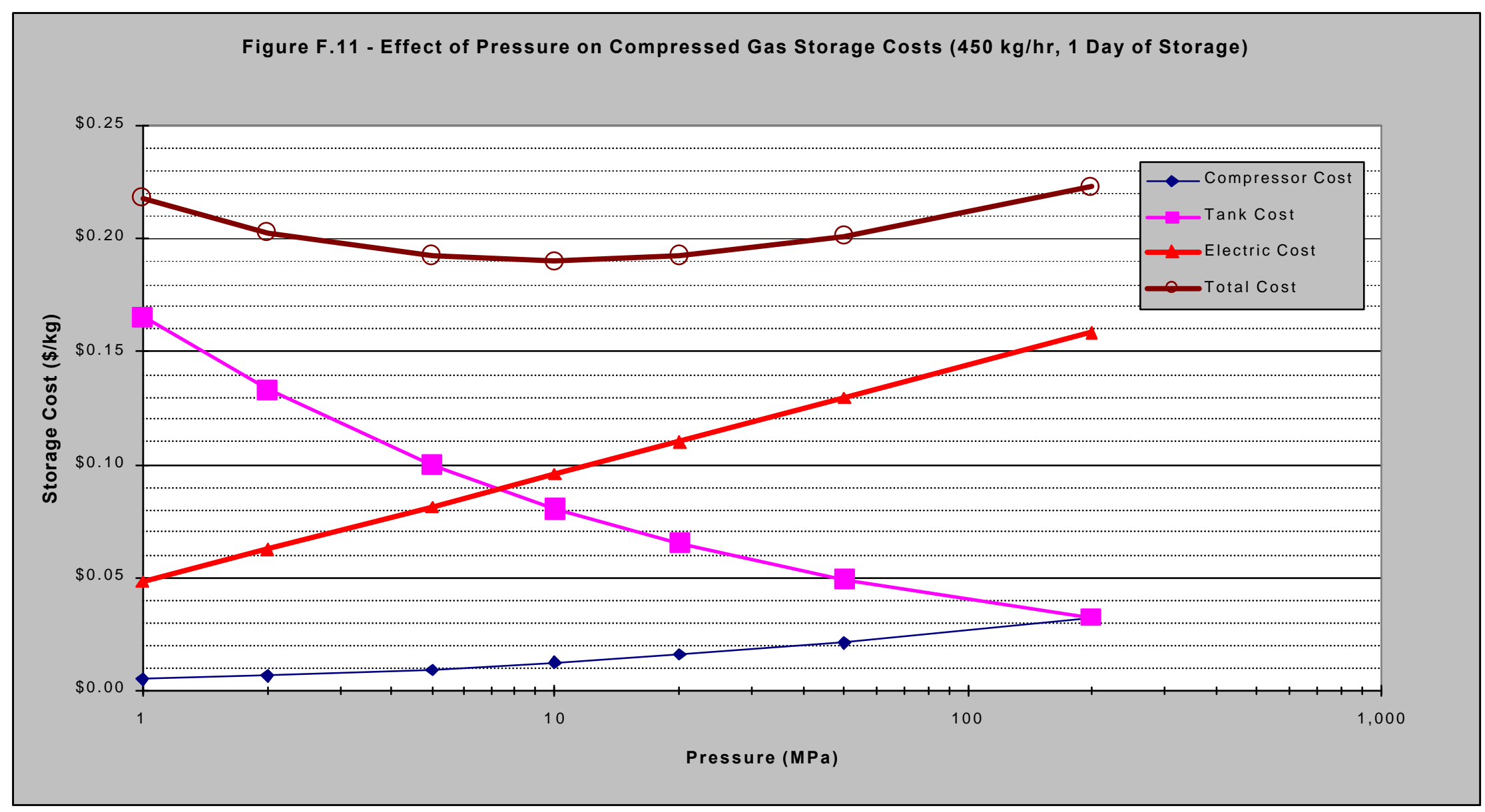

Figure F.11 - The optimum pressure for compressed gas storage occurs due to increasing the electricity cost compared to the reduced tank cost. 


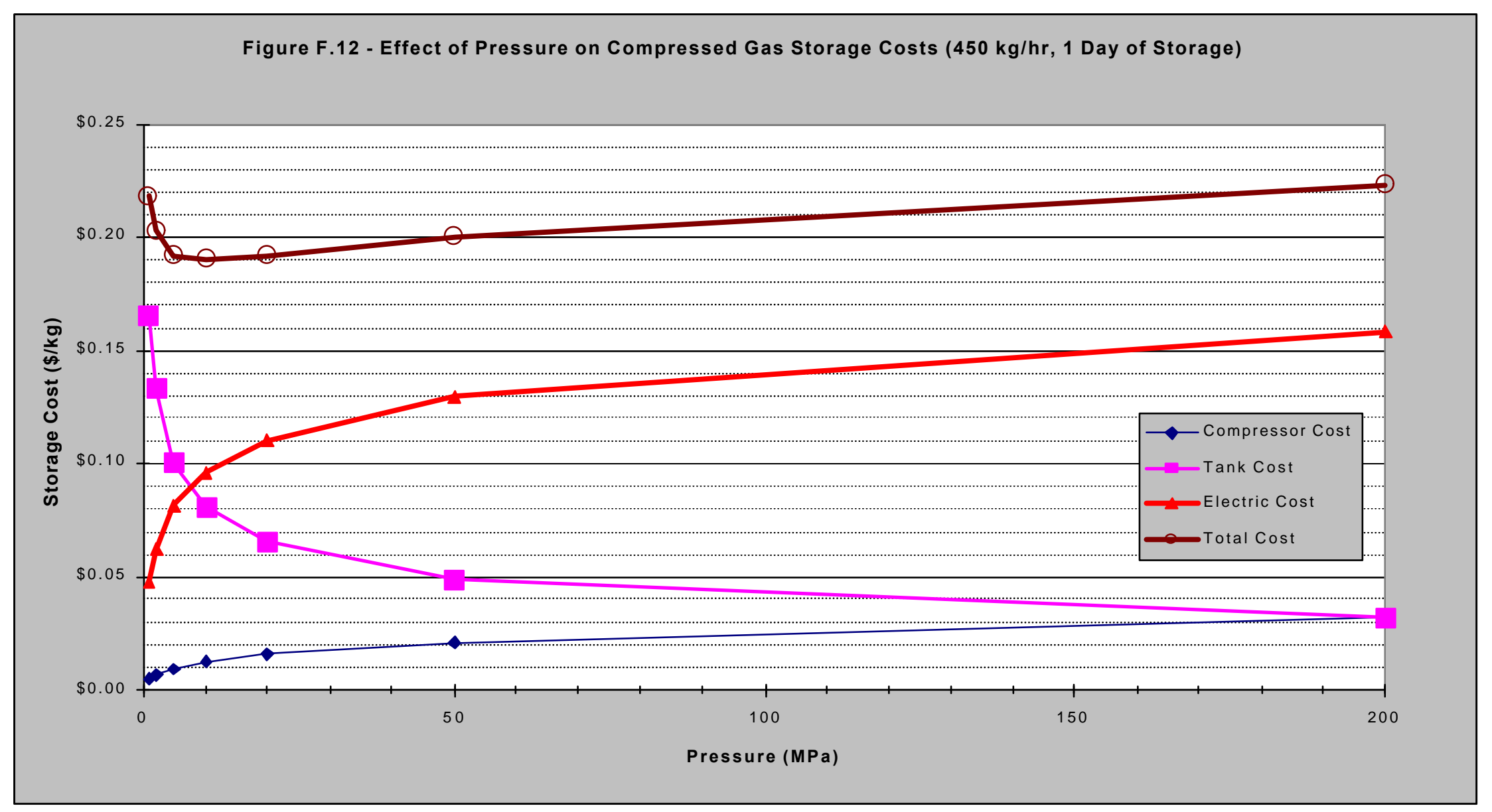

Figure F.12 - Compressor electricity costs initially increase quickly with pressure. 


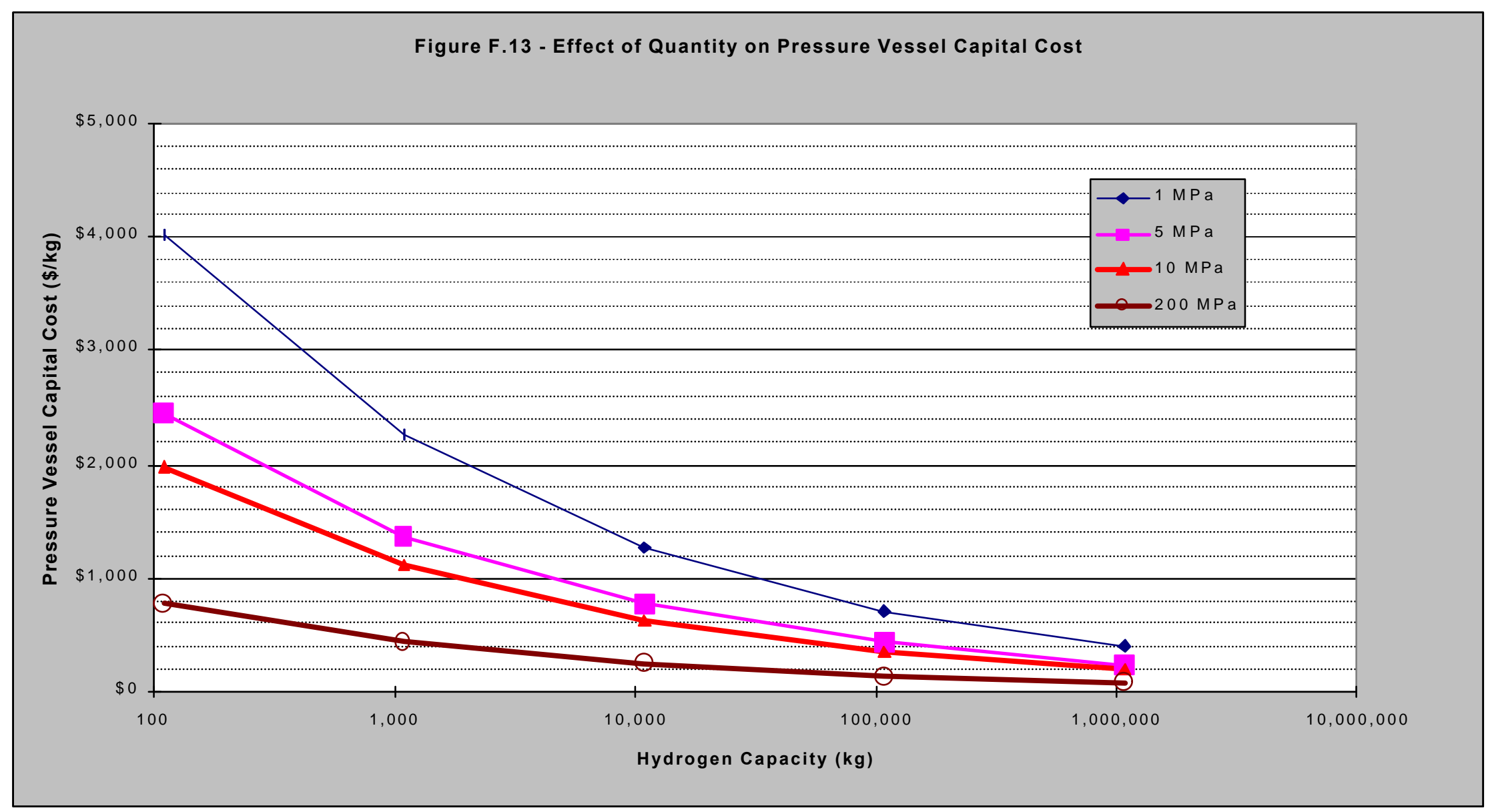

Figure F.13 - Economy of scale reduces compressed gas tank costs and lessons the effect of pressure on the tank capital cost. 


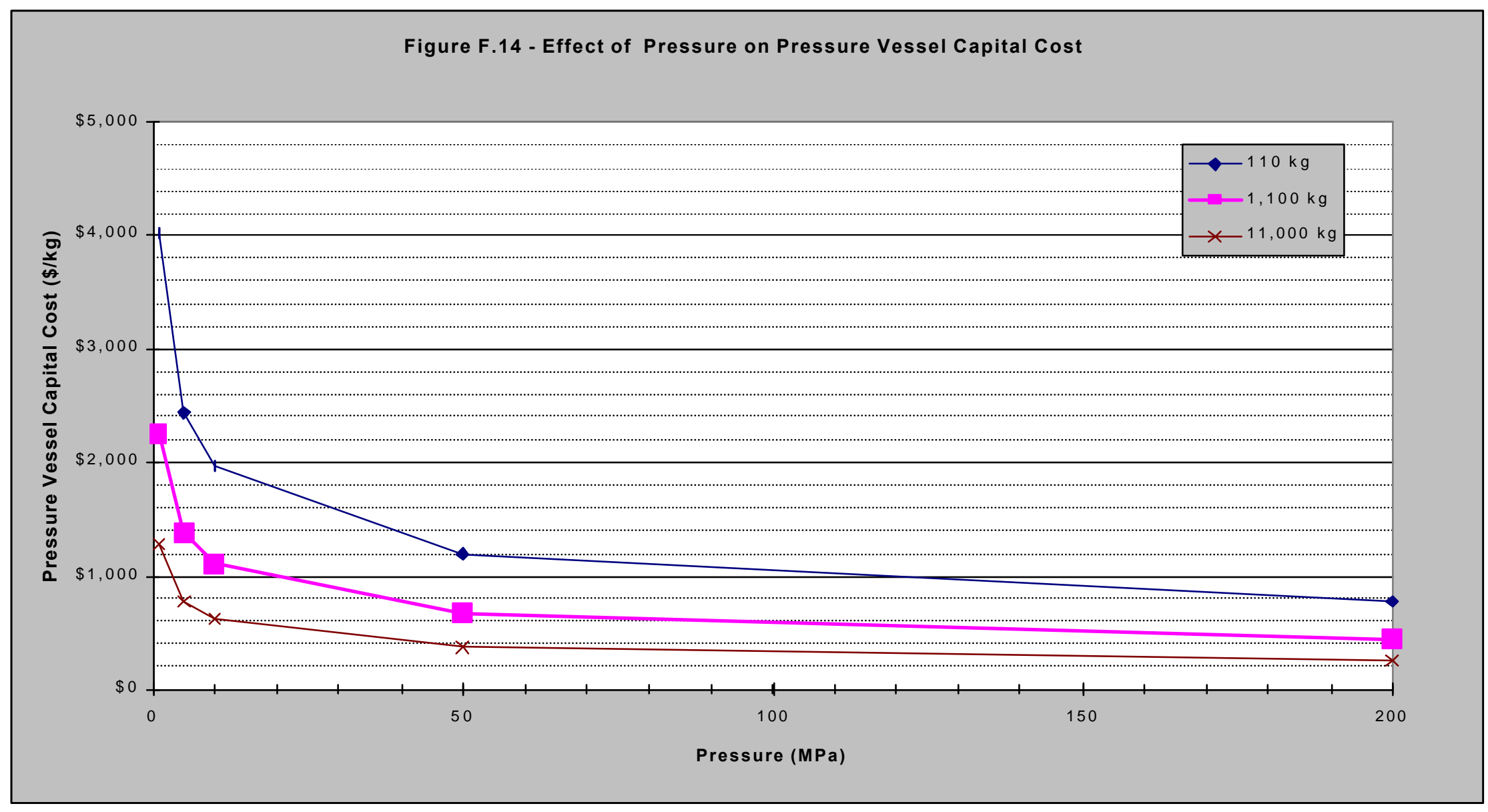

Figure F.14 - Tank costs drop with increased pressures due to smaller vessel size. 


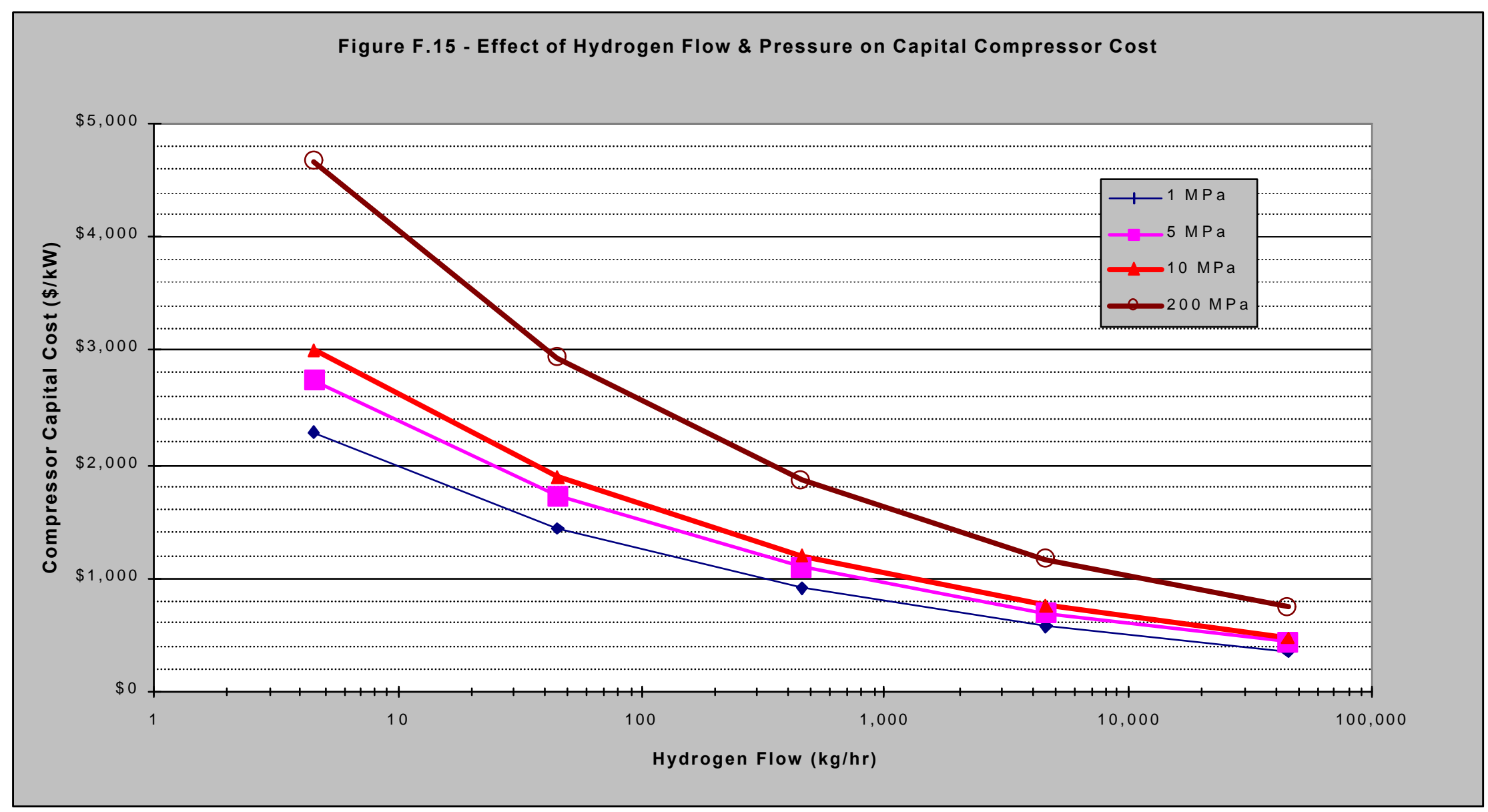

Figure F.15 - Economy of scale reduces compressor capital costs at high flowrates. 


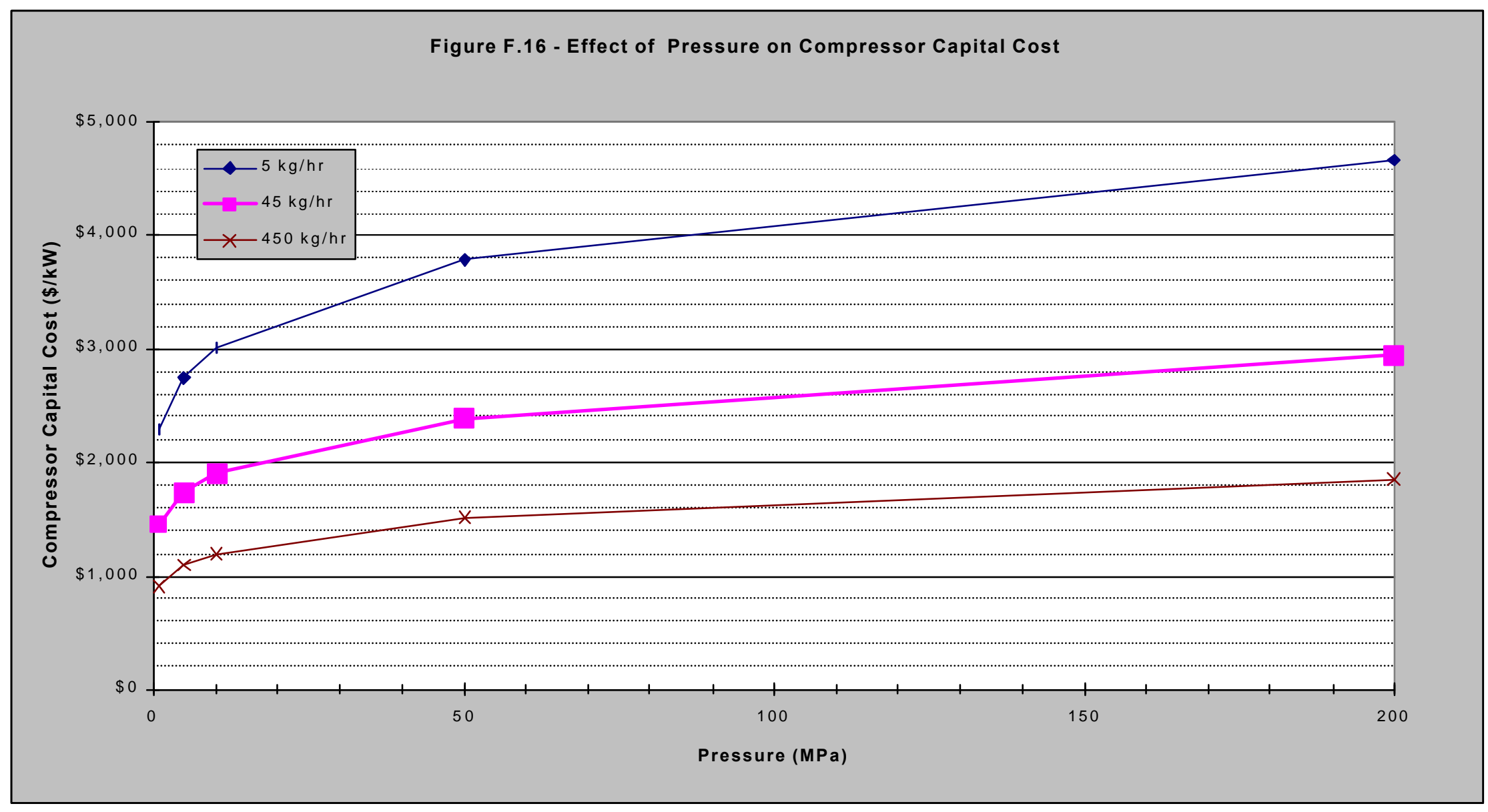

Figure F.16 - Compressor capital costs increase with increased operating pressures. 


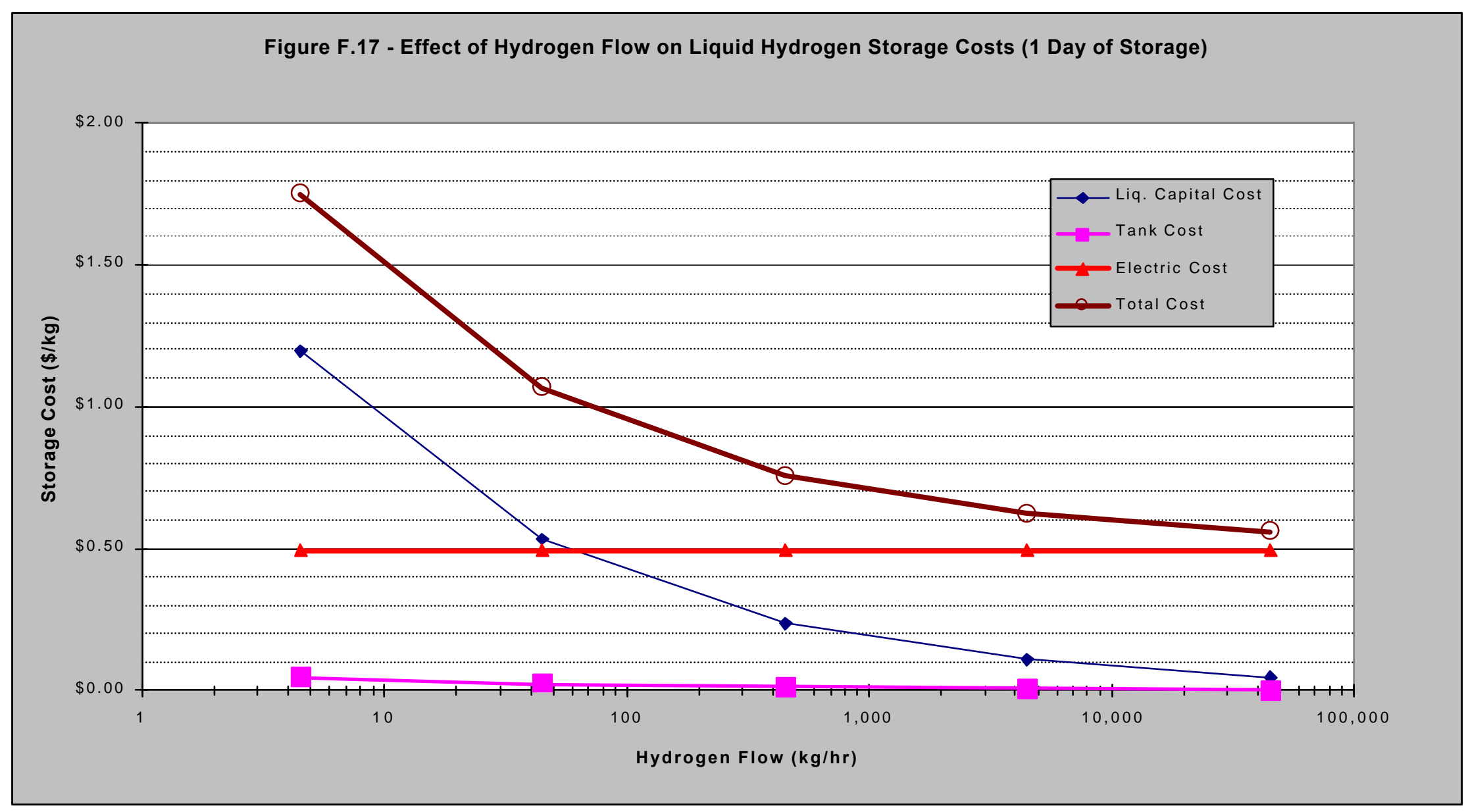

Figure F.17 - Economy of scale reduces liquid hydrogen storage costs until limited by electricity cost. 


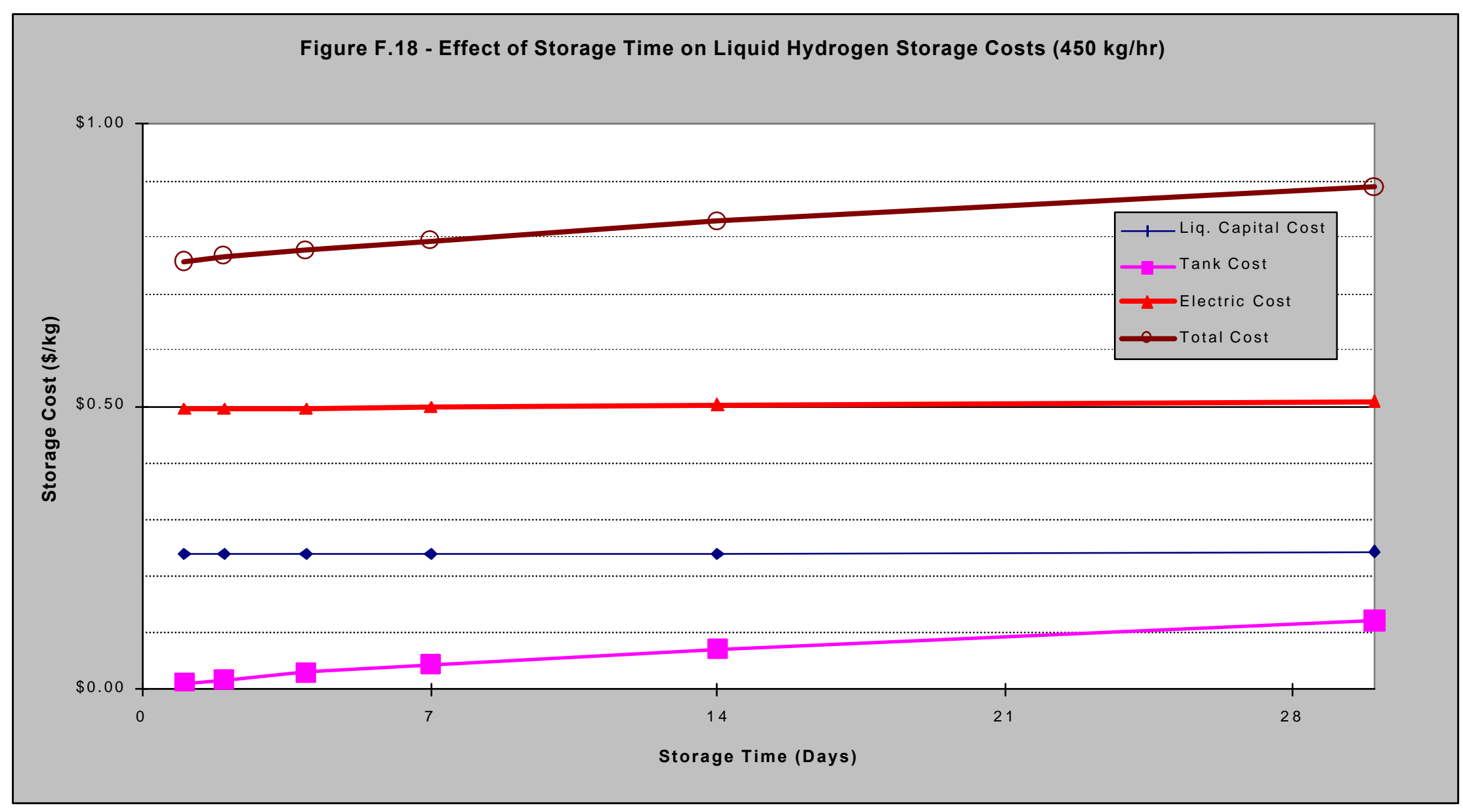

Figure F.18 - Storage time has little effect on liquid hydrogen storage costs since the dewar storage costs are relatively small. 


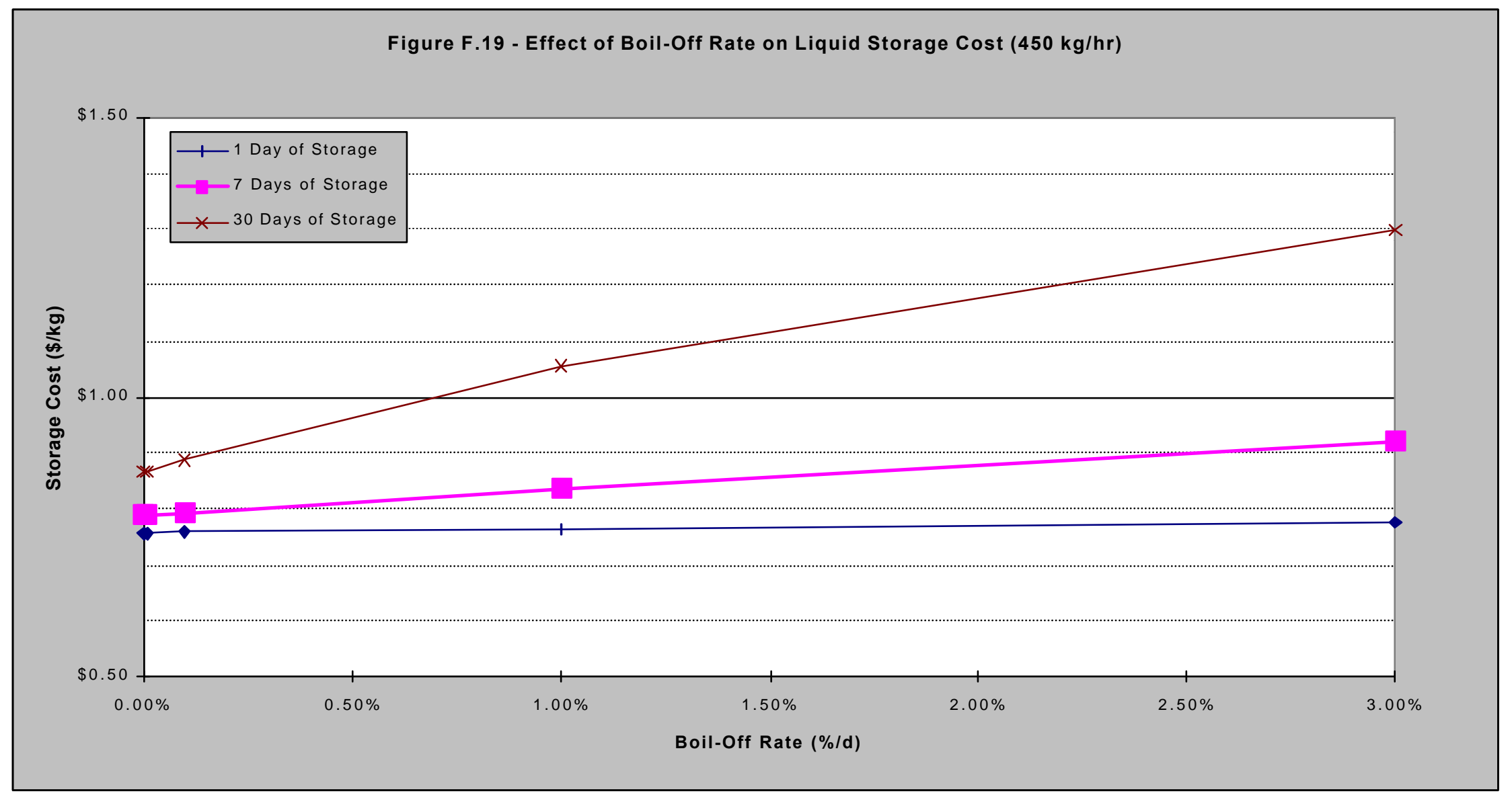

Figure F.19 - Boil-off rate has only a minor effect on costs for short storage times. 


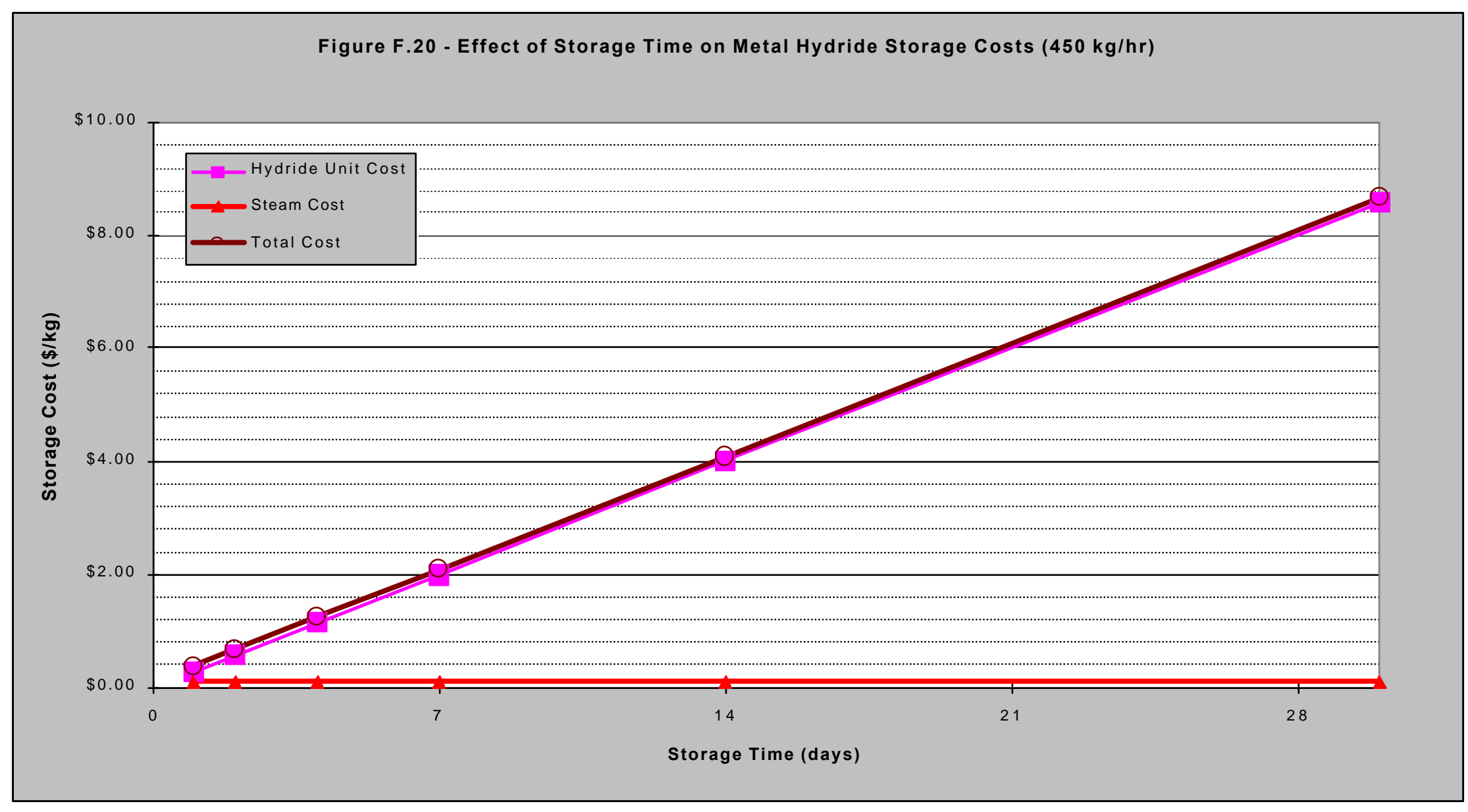

Figure F.20 - Most of the metal hydride storage cost is associated with the alloy capital cost, which provides no economy of scale savings. 


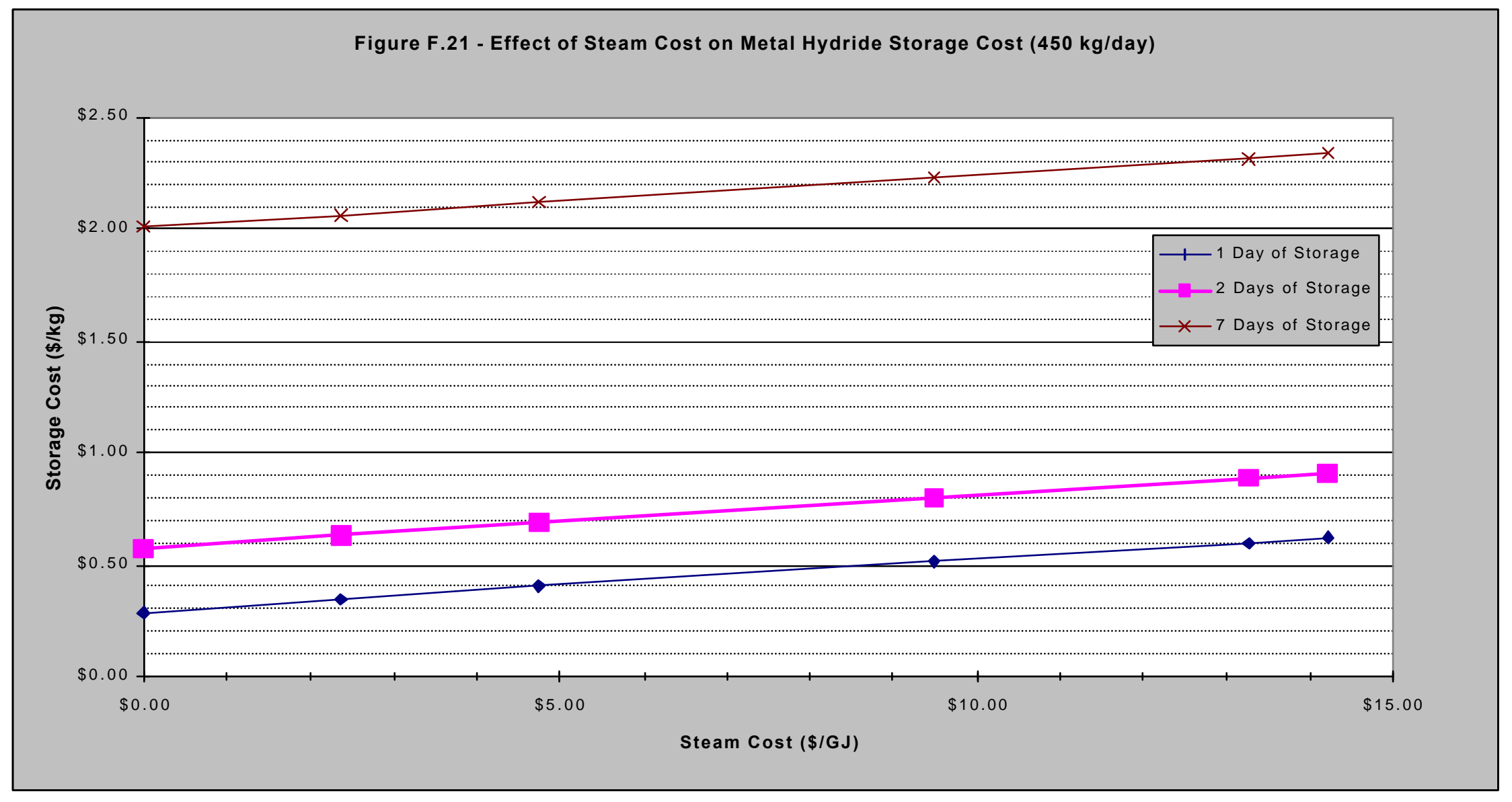

Figure F.21 - Steam cost will affect metal hydride storage costs. 


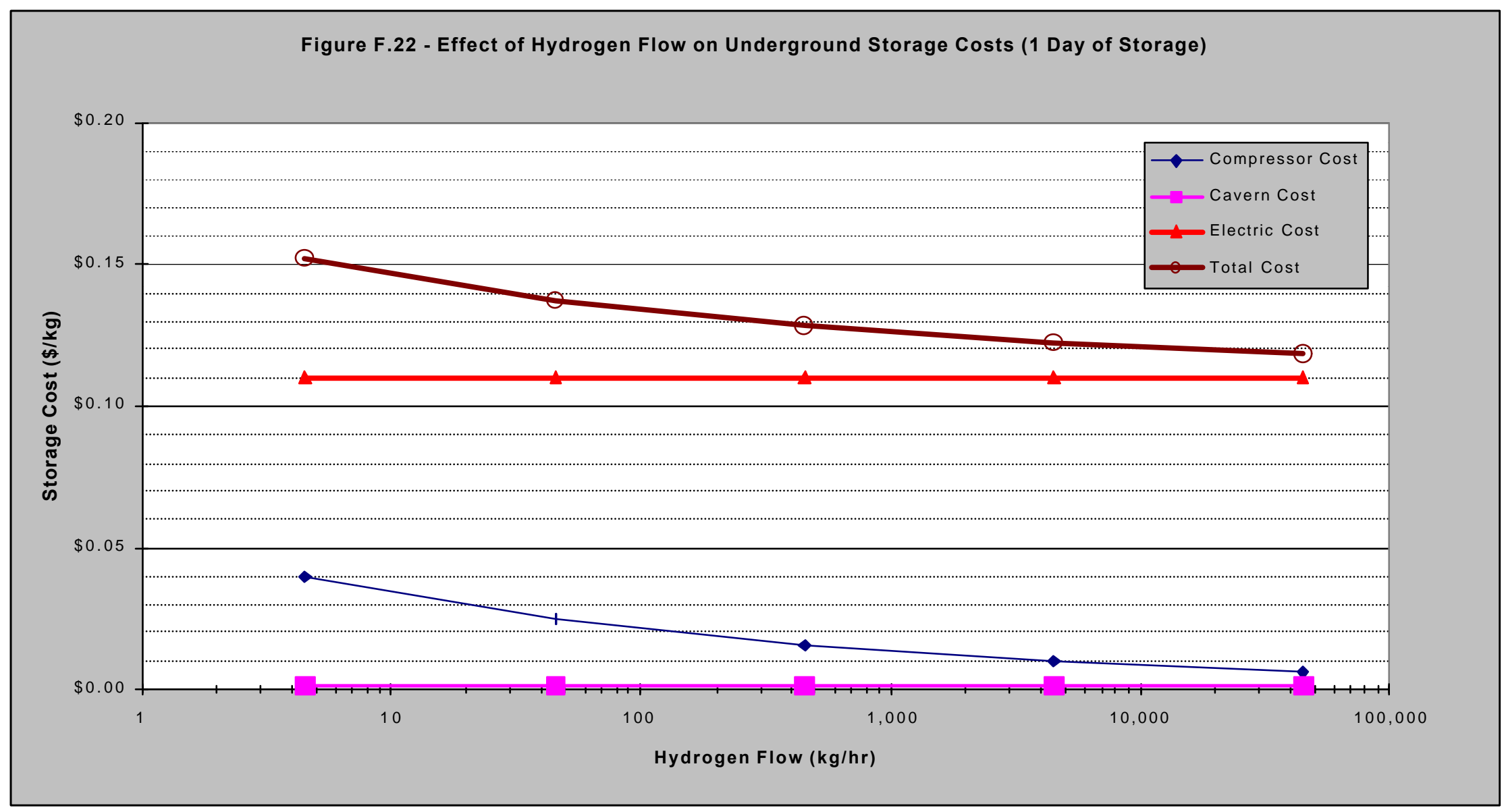

Figure F.22 - Underground storage is the cheapest option with the main cost being compressor electricity. 


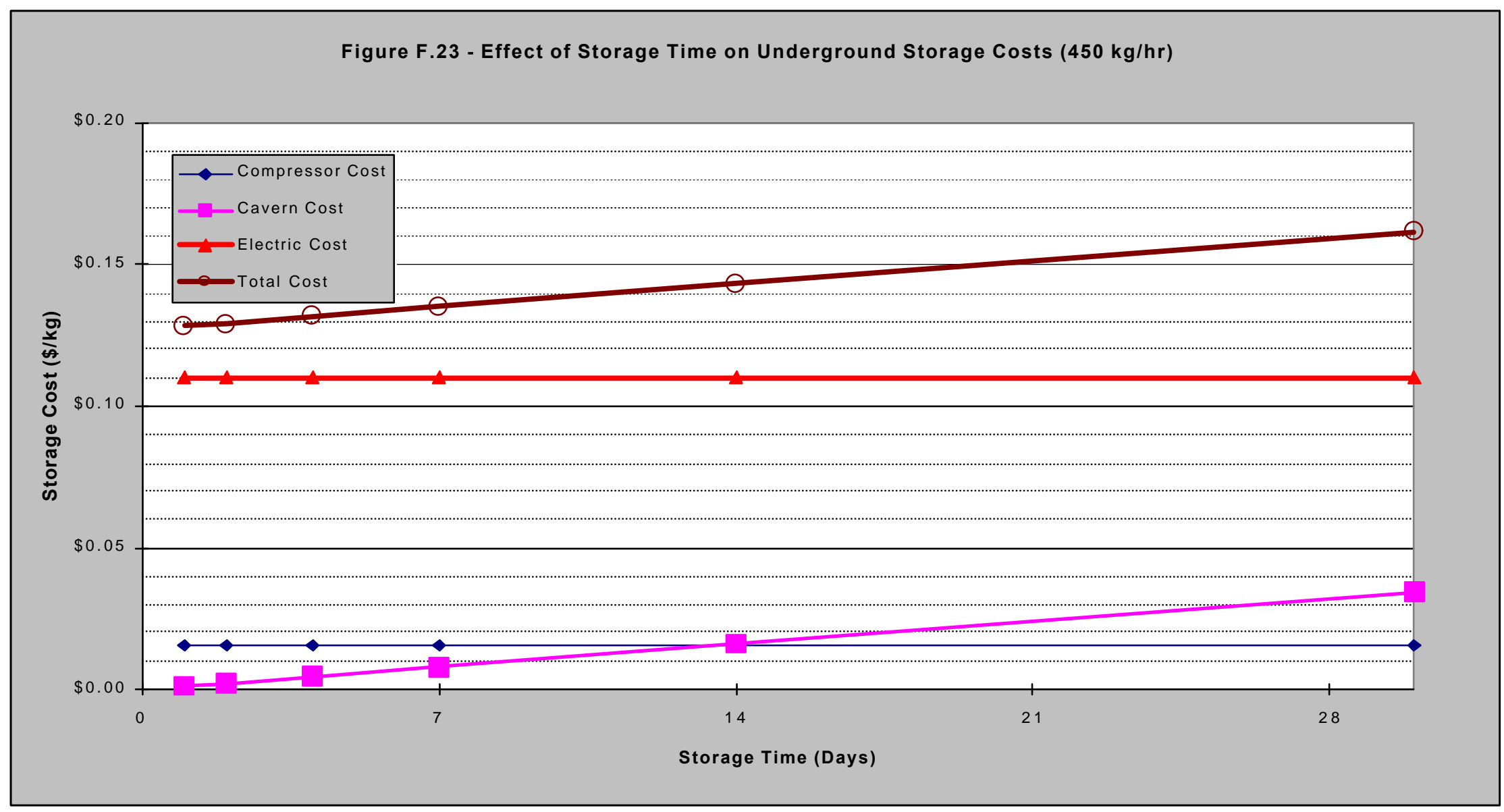

Figure F.23 - There is only a minor increase in storage costs with longer storage times because of low cavern cost. 


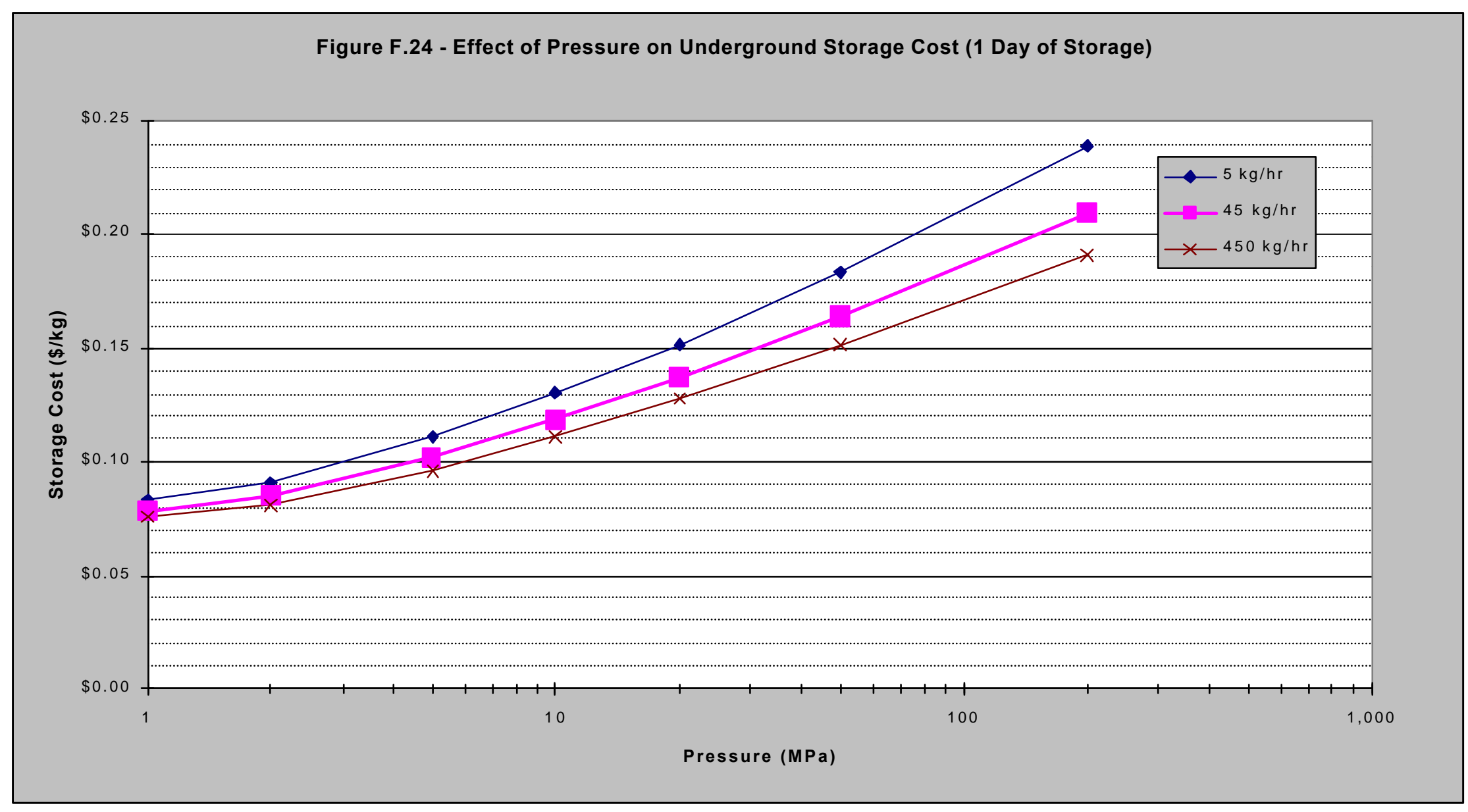

Figure F.24 - For short storage times, the lowest cost is at low pressures where electricity costs are the lowest. 


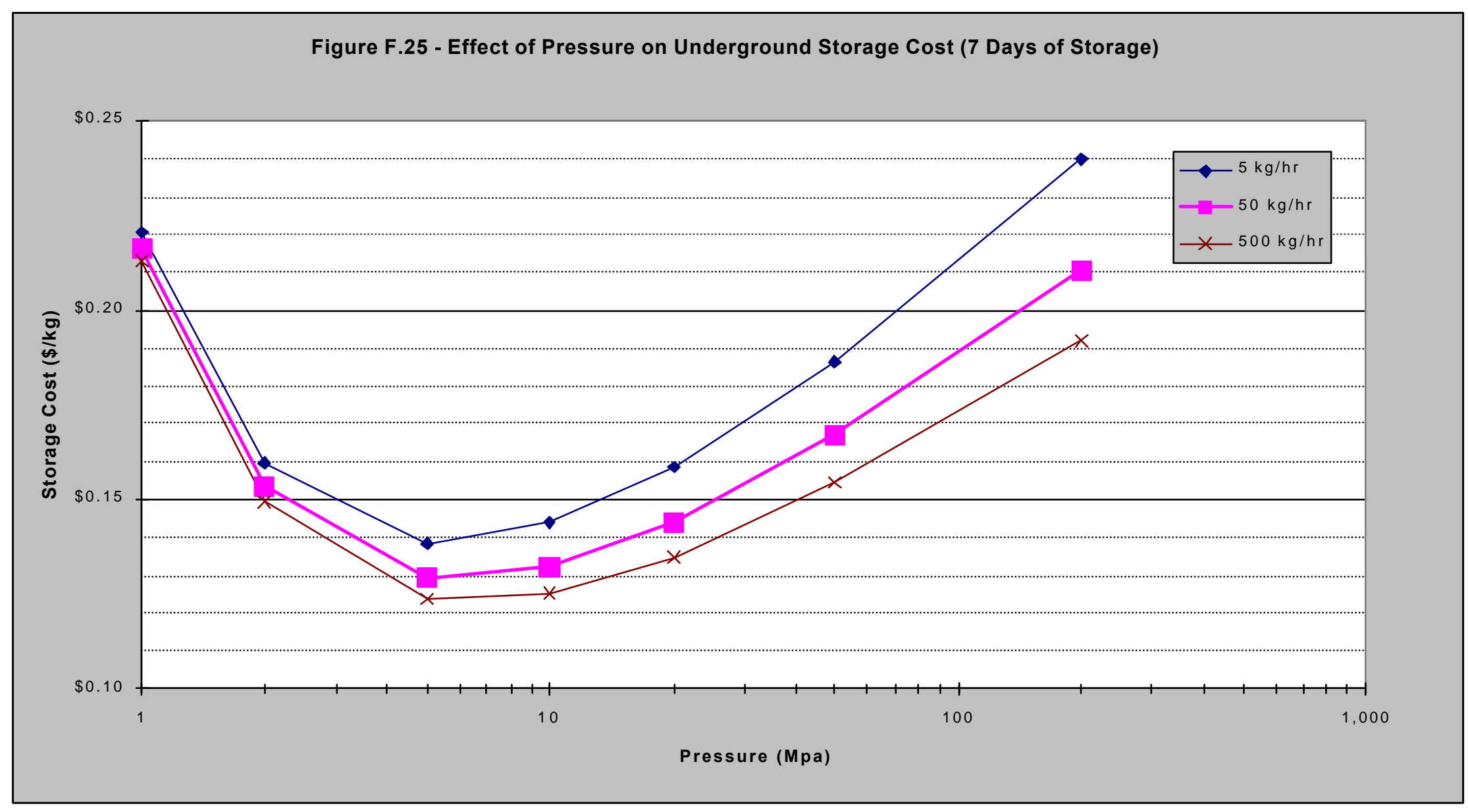

Figure F.25 - For longer storage times, an optimum forms as cavern capital costs increase. 


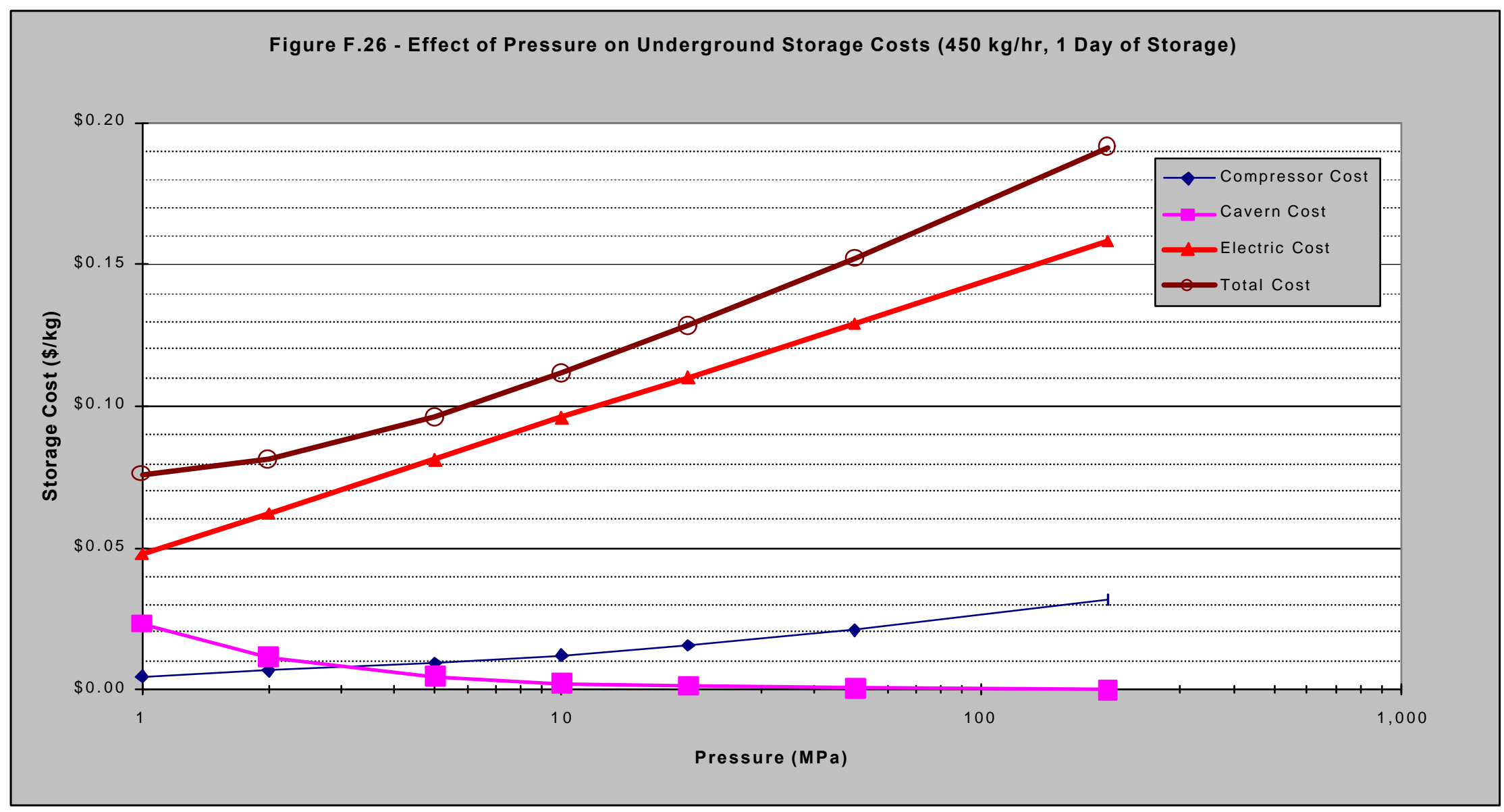

Figure F.26 - For short storage times, the optimum is at low pressures where compressor electricity is minimized. 


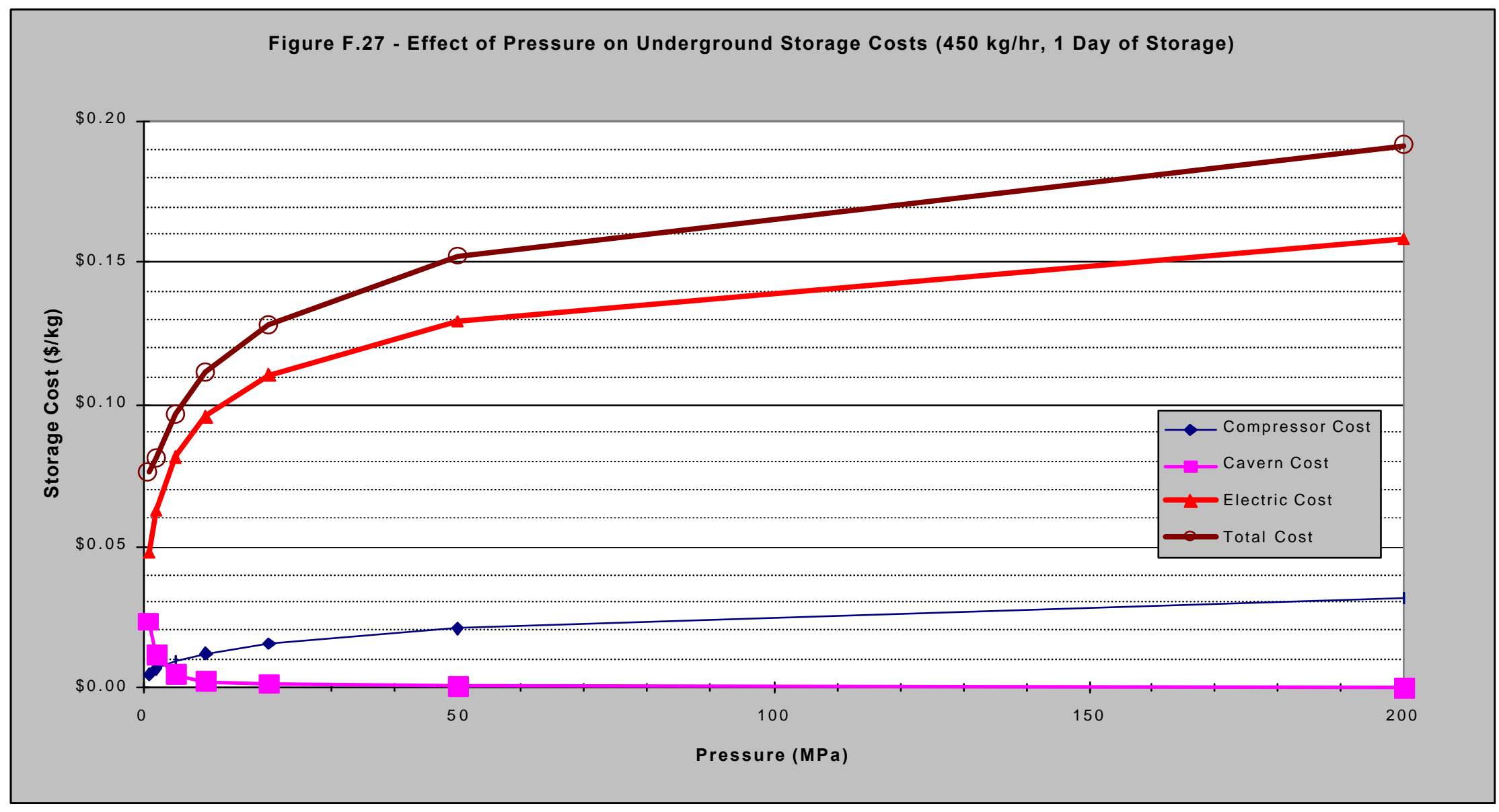

Figure F.27 - One a linear scale, it can be seen the highest energy requirement is for the initial compression at low pressures. 


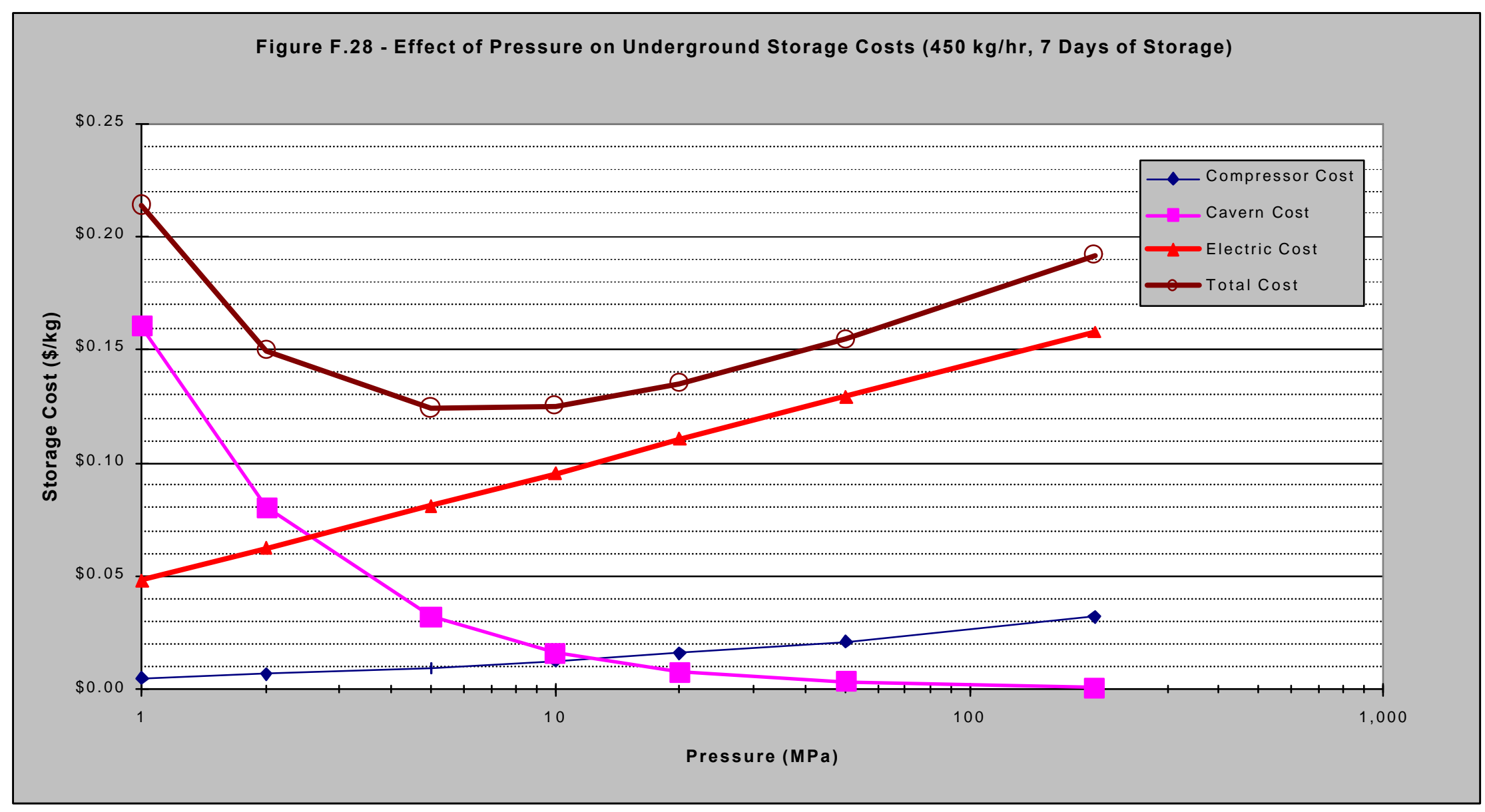

Figure F.28 - For longer storage times, an optimum occurs where lower capital costs offset higher electricity costs. 


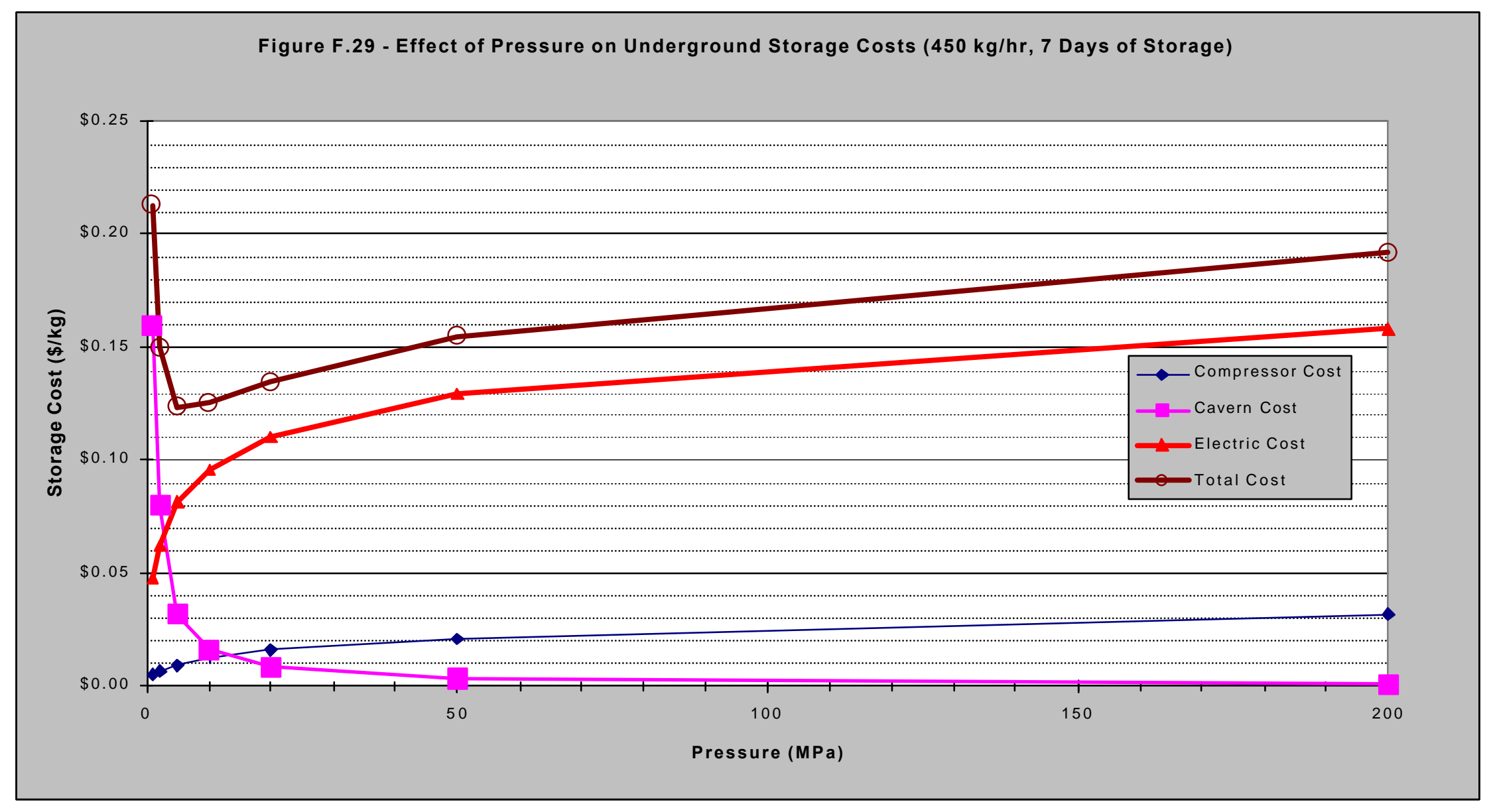

Figure F.29 - On a linear graph, the pressure effects are more pronounced at low pressures. 


\section{APPENDIX G - HYDROGEN TRANSPORTATION FIGURES}

Appendix $\mathrm{G}$ contains figures showing important trends and sensitivity analyses for the transport of hydrogen. An index for the figures is included to help find specific information quickly. Most of the graphs either compare the different transport methods, or show a cost breakdown of the cost contributions for one method of delivery. 


\begin{tabular}{|c|c|c|c|c|c|c|c|c|c|}
\hline \multicolumn{10}{|c|}{ G.0 INDEX TO HYDROGEN TRANSPORT FIGURES } \\
\hline Figure & Method & $y$-axis & $\mathrm{x}$-axis & Dep. Var. & Ind. Var. & Flow & Time & Distance & Lines \\
\hline & & & & $(y)$ & $(x)$ & (lb/hr) & (days) & (miles) & \\
\hline & & & & & & & & & \\
\hline 1 & All & $\log$ & $\log$ & Cost $(\$ / \mathrm{kg})$ & Flow (kg/hr) & & & 16 & Comp \\
\hline 2 & All & $\log$ & $\log$ & Cost $(\$ / \mathrm{kg})$ & Flow (kg/hr) & & & 160 & Comp \\
\hline 3 & All & $\log$ & $\log$ & Cost $(\$ / \mathrm{kg})$ & Flow (kg/hr) & & & 800 & Comp \\
\hline 4 & All & $\log$ & $\log$ & Cost $(\$ / \mathrm{kg})$ & Distance $(\mathrm{km})$ & 450 & & & Comp \\
\hline 5 & All & Norm & Norm & Cost $(\$ / \mathrm{kg})$ & Fuel Cost (\$/gal) & 450 & & 160 & Comp \\
\hline 6 & All + Rail & $\log$ & $\log$ & Cost $(\$ / \mathrm{kg})$ & Flow (kg/hr) & & & 16 & Comp \\
\hline 7 & All + Rail & $\log$ & $\log$ & Cost $(\$ / \mathrm{kg})$ & Flow (kg/hr) & & & 160 & Comp \\
\hline 8 & All + Rail & $\log$ & $\log$ & Cost $(\$ / \mathrm{kg})$ & Distance $(\mathrm{km})$ & 450 & & & Comp \\
\hline 9 & All + Rail & Norm & Log & Cost $(\$ / \mathrm{kg})$ & Distance $(\mathrm{km})$ & 450 & & & Comp \\
\hline 10 & $\mathrm{GH} 2$ & Norm & Norm & Cost $(\$ / \mathrm{kg})$ & Capacity (kg/truck) & & & 160 & Flow (kg/hr) \\
\hline 11 & $\mathrm{GH} 2$ & Norm & $\log$ & Cost $(\$ / \mathrm{kg})$ & Flow (kg/hr) & & & 160 & Costs \\
\hline 12 & $\mathrm{GH} 2$ & Norm & $\log$ & Cost $(\$ / \mathrm{kg})$ & Distance $(\mathrm{km})$ & 450 & & & Costs \\
\hline 13 & LH2 & Norm & Norm & Cost $(\$ / \mathrm{kg})$ & Capacity (kg/truck) & & & 160 & Flow (kg/hr) \\
\hline 14 & LH2 & Norm & $\log$ & Cost $(\$ / \mathrm{kg})$ & Flow (kg/hr) & & & 160 & Costs \\
\hline 15 & LH2 & Norm & Norm & Cost $(\$ / \mathrm{kg})$ & Distance $(\mathrm{km})$ & 5 & & & Costs \\
\hline 16 & LH2 & Norm & Norm & Cost $(\$ / \mathrm{kg})$ & Distance $(\mathrm{km})$ & 450 & & & Costs \\
\hline 17 & LH2 & Log & $\log$ & Cost $(\$ / \mathrm{kg})$ & Capacity (kg/truck) & 5 & & 160 & Costs \\
\hline 18 & LH2 & Norm & Norm & Cost $(\$ / \mathrm{kg})$ & Capacity (kg/truck) & 5 & & 160 & Costs \\
\hline 19 & LH2 & Log & Log & Cost $(\$ / \mathrm{kg})$ & Capacity (kg/truck) & 450 & & 160 & Costs \\
\hline 20 & LH2 & Norm & Norm & Cost $(\$ / \mathrm{kg})$ & Capacity (kg/truck) & 450 & & 160 & Costs \\
\hline 21 & $\mathrm{MH} 2$ & Norm & $\log$ & Cost $(\$ / \mathrm{kg})$ & Flow (kg/hr) & & & 160 & Costs \\
\hline 22 & $\mathrm{MH} 2$ & Norm & Norm & Cost $(\$ / \mathrm{kg})$ & Distance $(\mathrm{km})$ & 450 & & & Costs \\
\hline 23 & Pipeline & Norm & Log & Cost $(\$ / \mathrm{kg})$ & Flow (kg/hr) & & & 16 & Costs \\
\hline 24 & Pipeline & Norm & Norm & Cost $(\$ / \mathrm{kg})$ & Distance $(\mathrm{km})$ & 450 & & & Costs \\
\hline 25 & All + Rail & Norm & Bar & Cost $(\$ / \mathrm{kg})$ & & 450 & & 160 & Costs \\
\hline
\end{tabular}




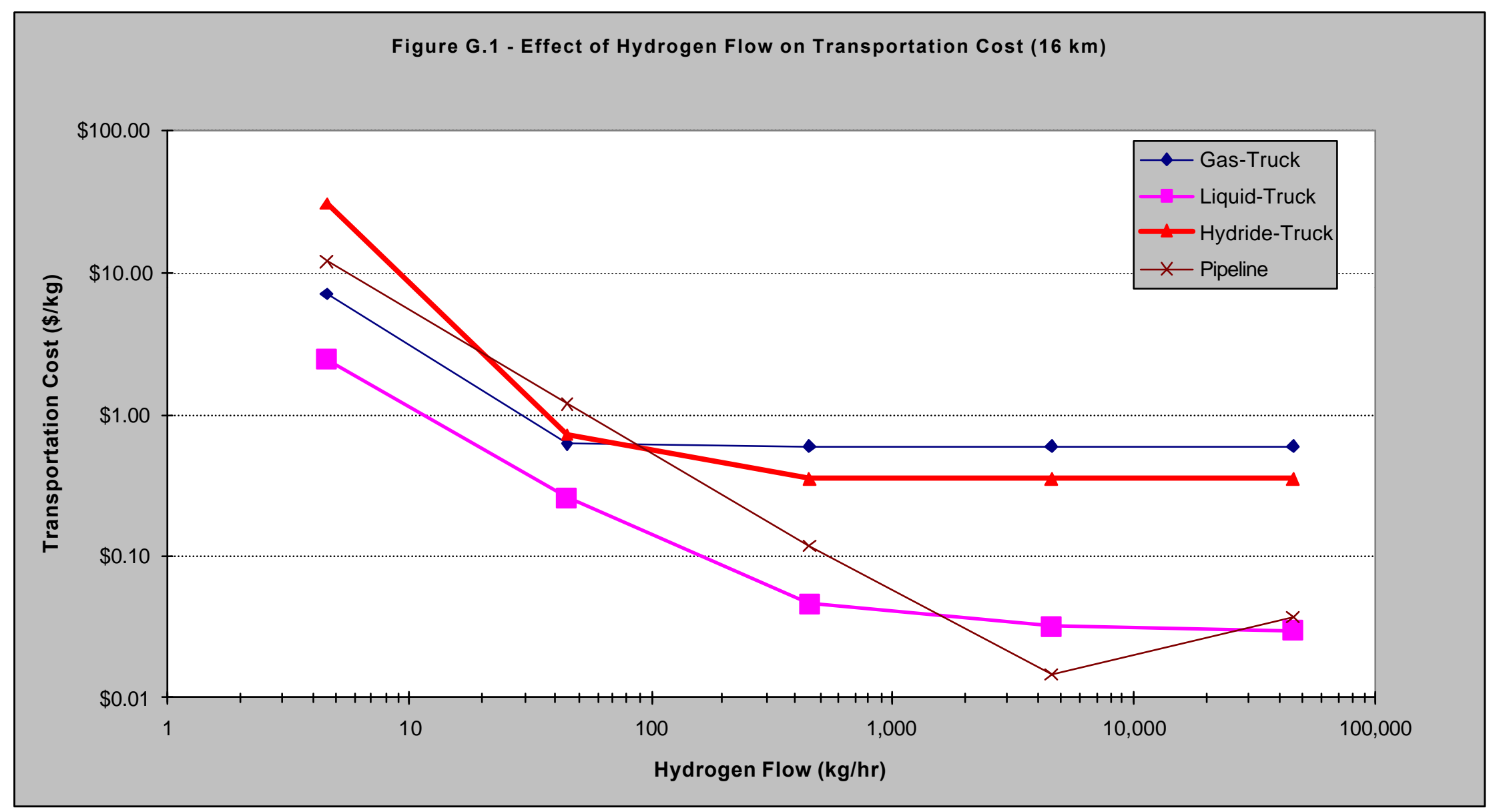

Figure G.1 - At high production rates, the cost of truck transportation bottoms out and levels off. 


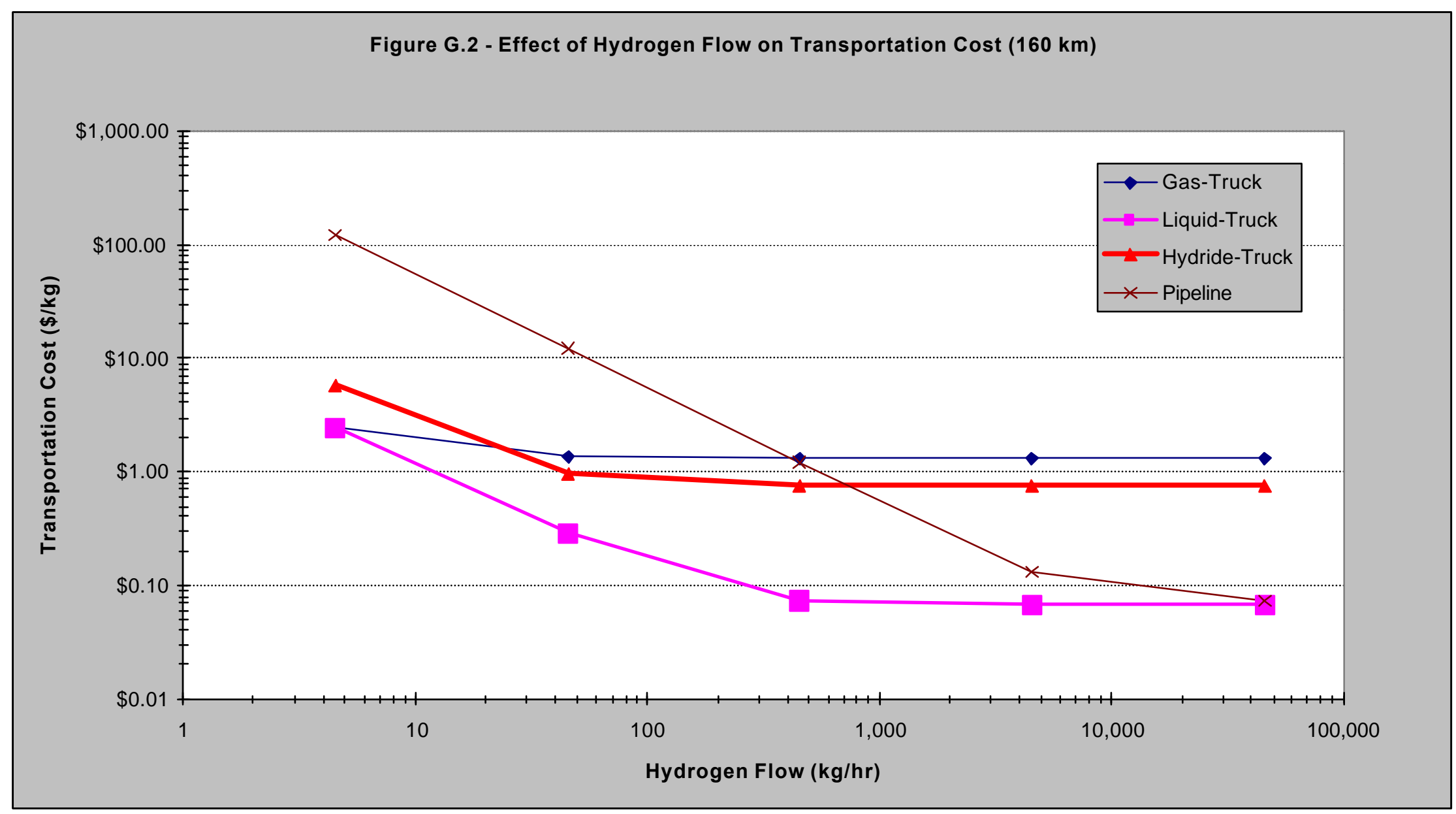

Figure G.2 - At high flows, pipeline costs start leveling off as compressor electricity costs increase. 


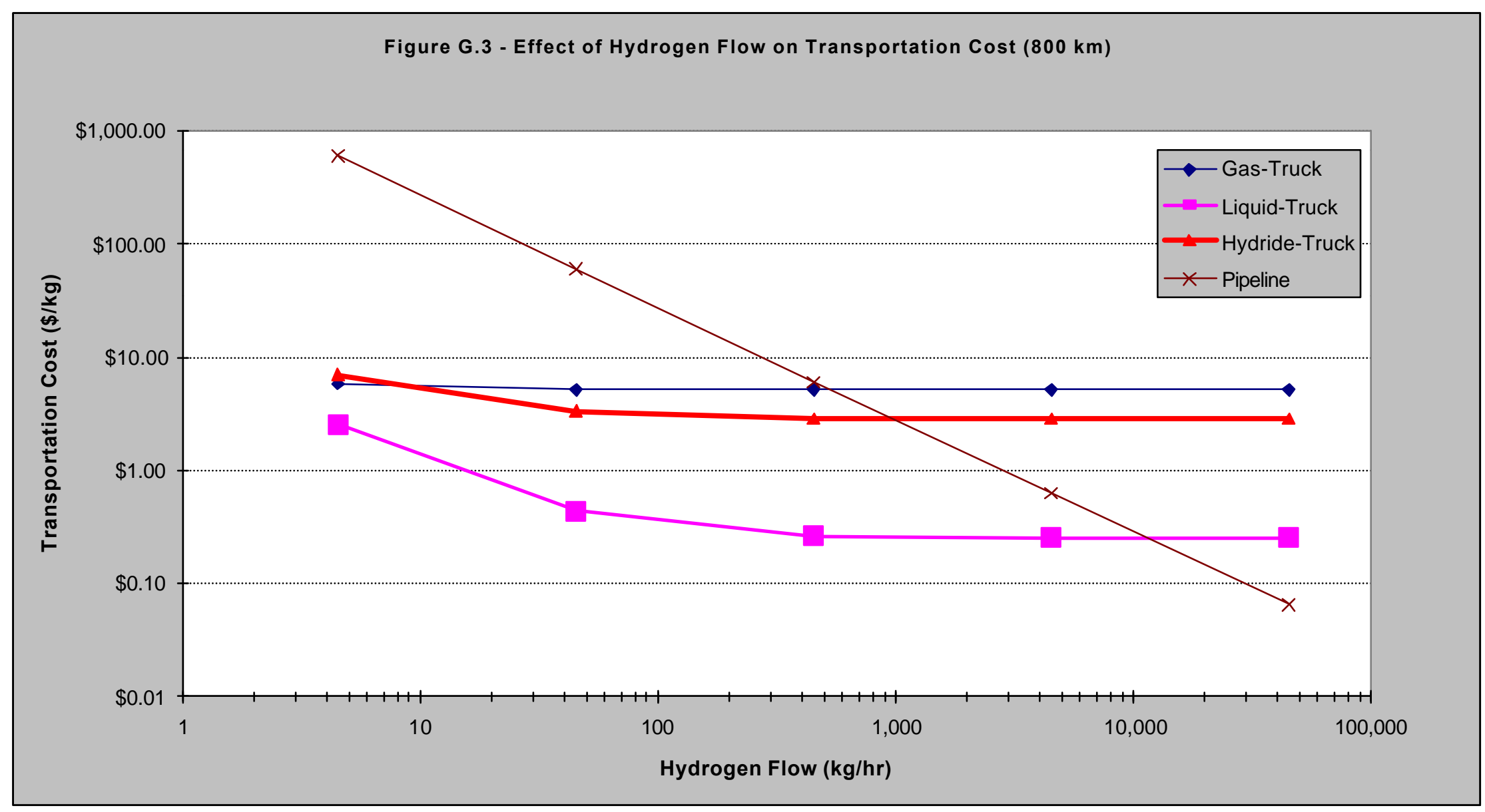

Figure G.3 - Trucking costs level out sooner at longer delivery distances. 


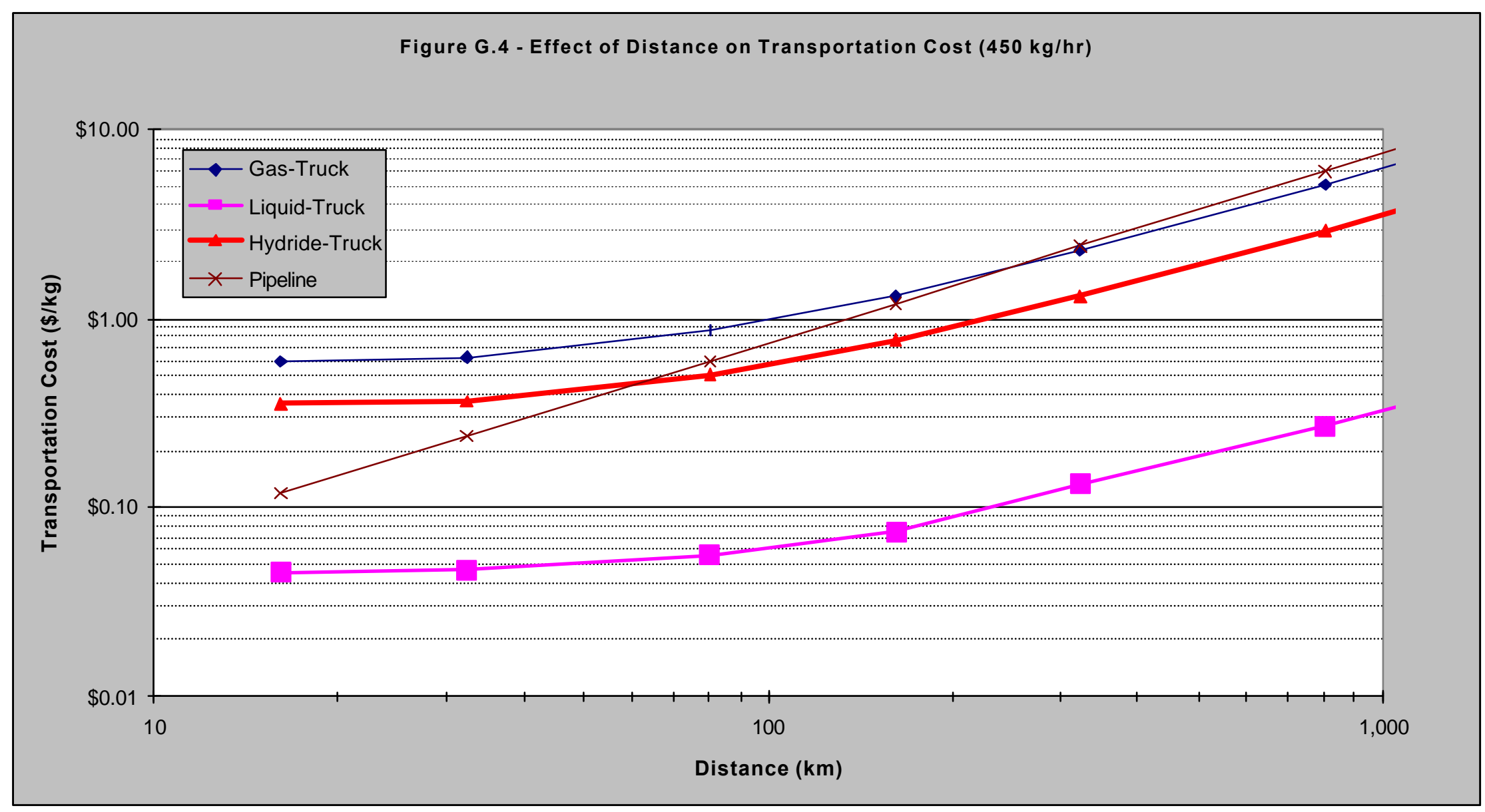

Figure G.4 - Trucking costs quickly increase for delivery distances over $100 \mathrm{~km}$. 


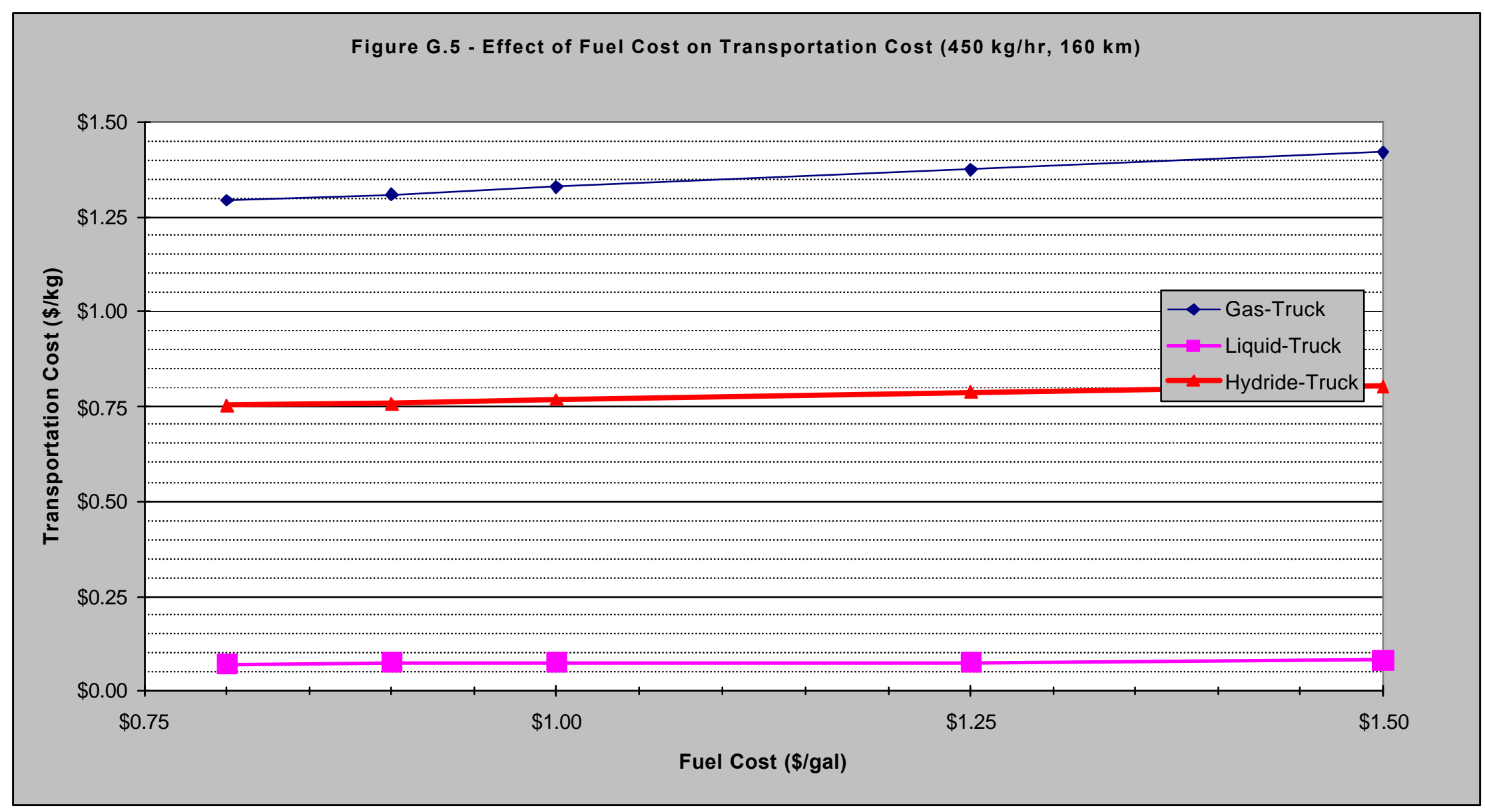

Figure G.5 - Compressed gas delivery is affected the most by fuel cost since the low truck capacity requires more trips. 


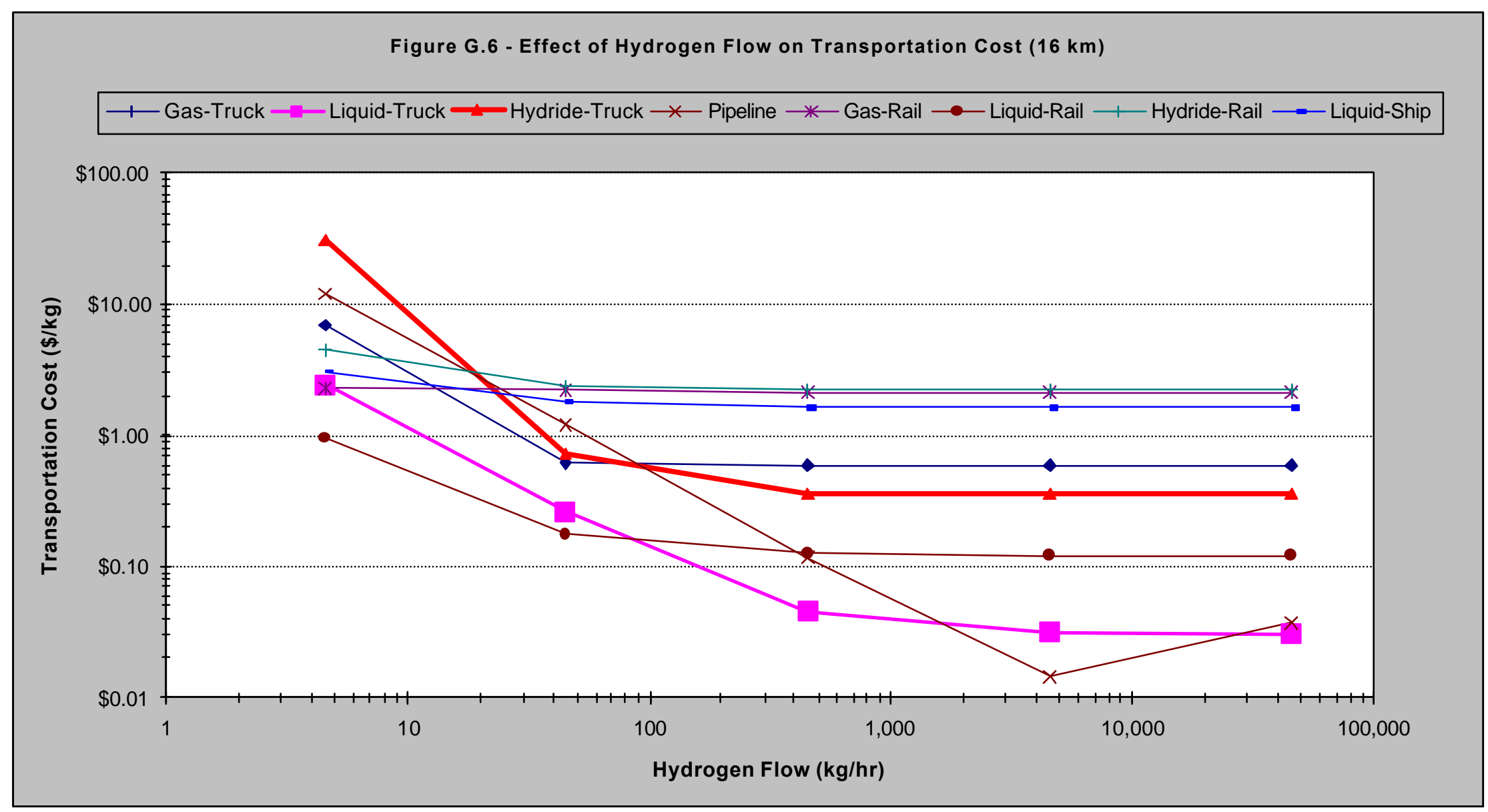

Figure G.6 - Liquid hydrogen delivery by rail has the potential to compete with truck delivery. 


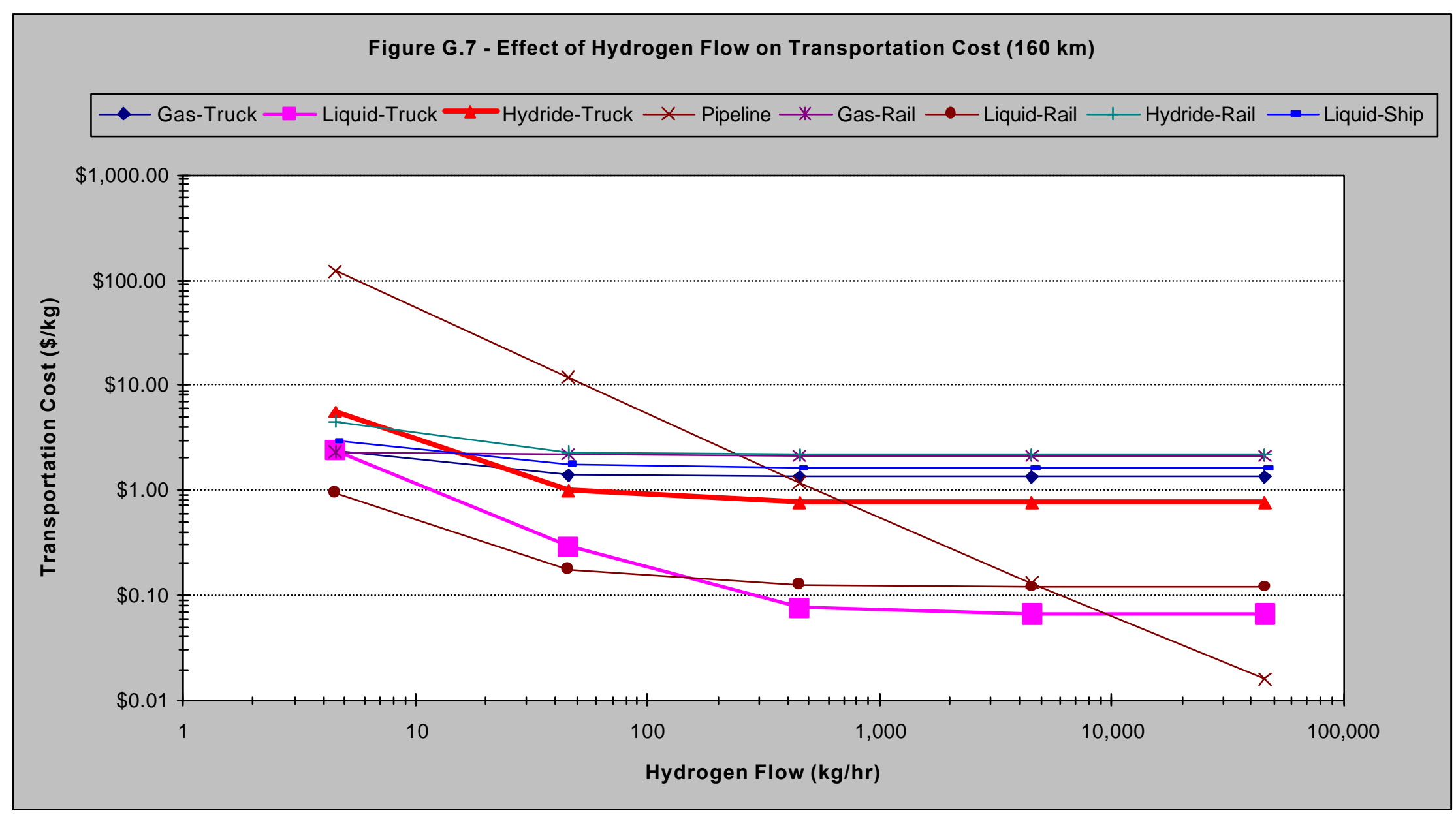

Figure G.7 - At high flows, pipeline delivery becomes the cheapest option. 


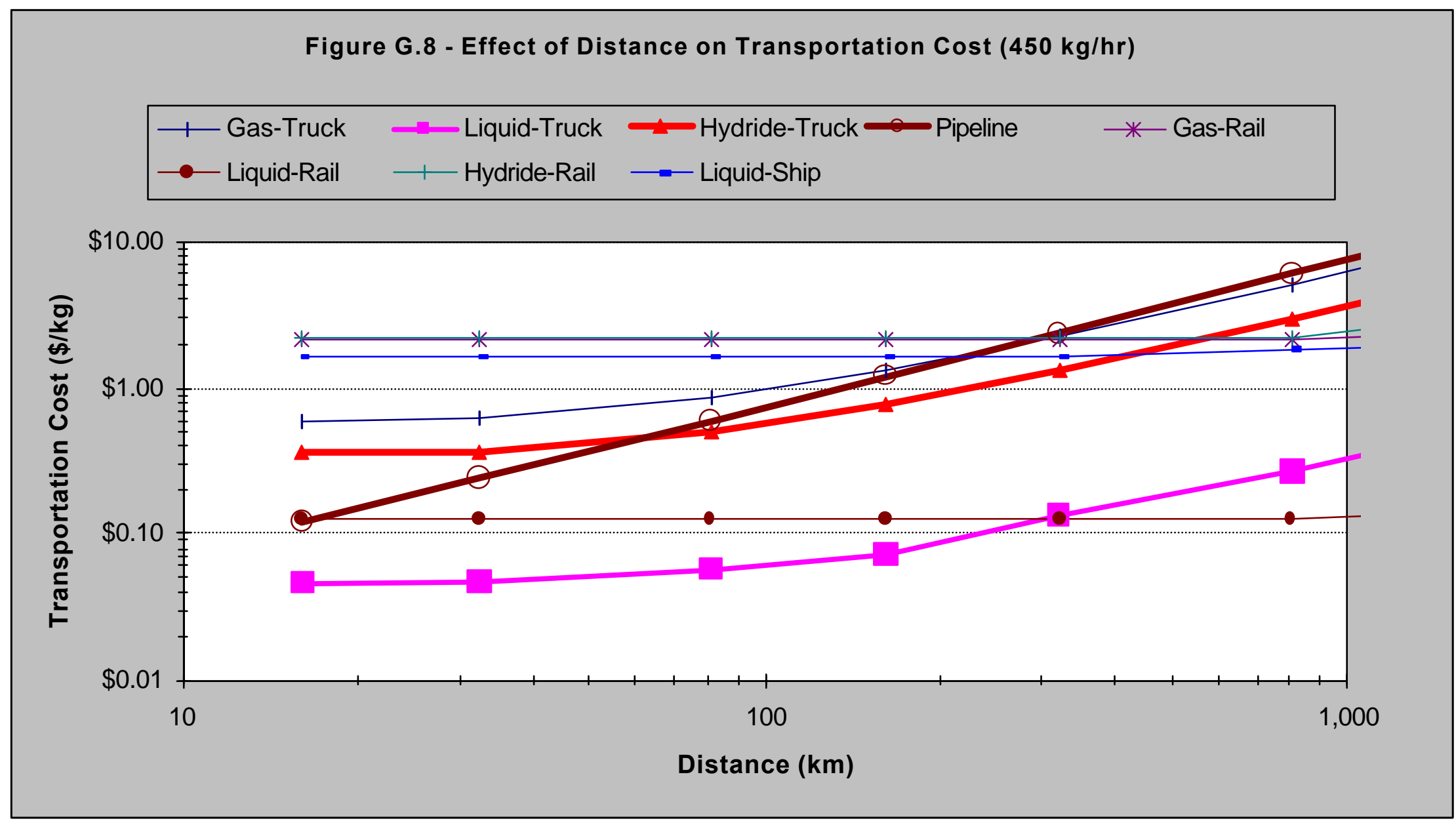

Figure G.8 - Rail transport has an advantage over trucking at long delivery distances because of flat-rate freight charges. 


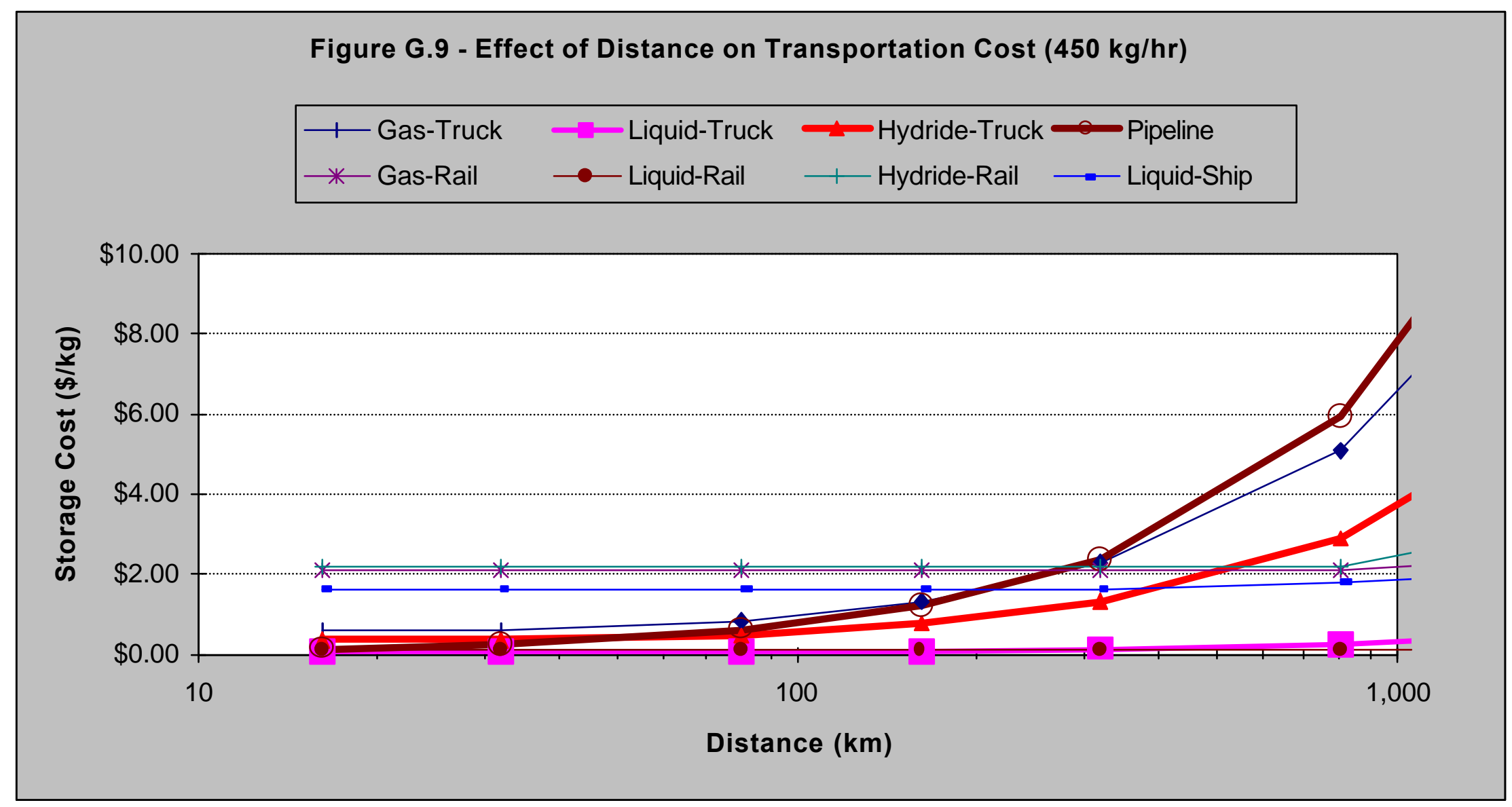

Figure G.9 - Pipeline costs quickly increase with distance compared to liquid hydrogen delivery. 


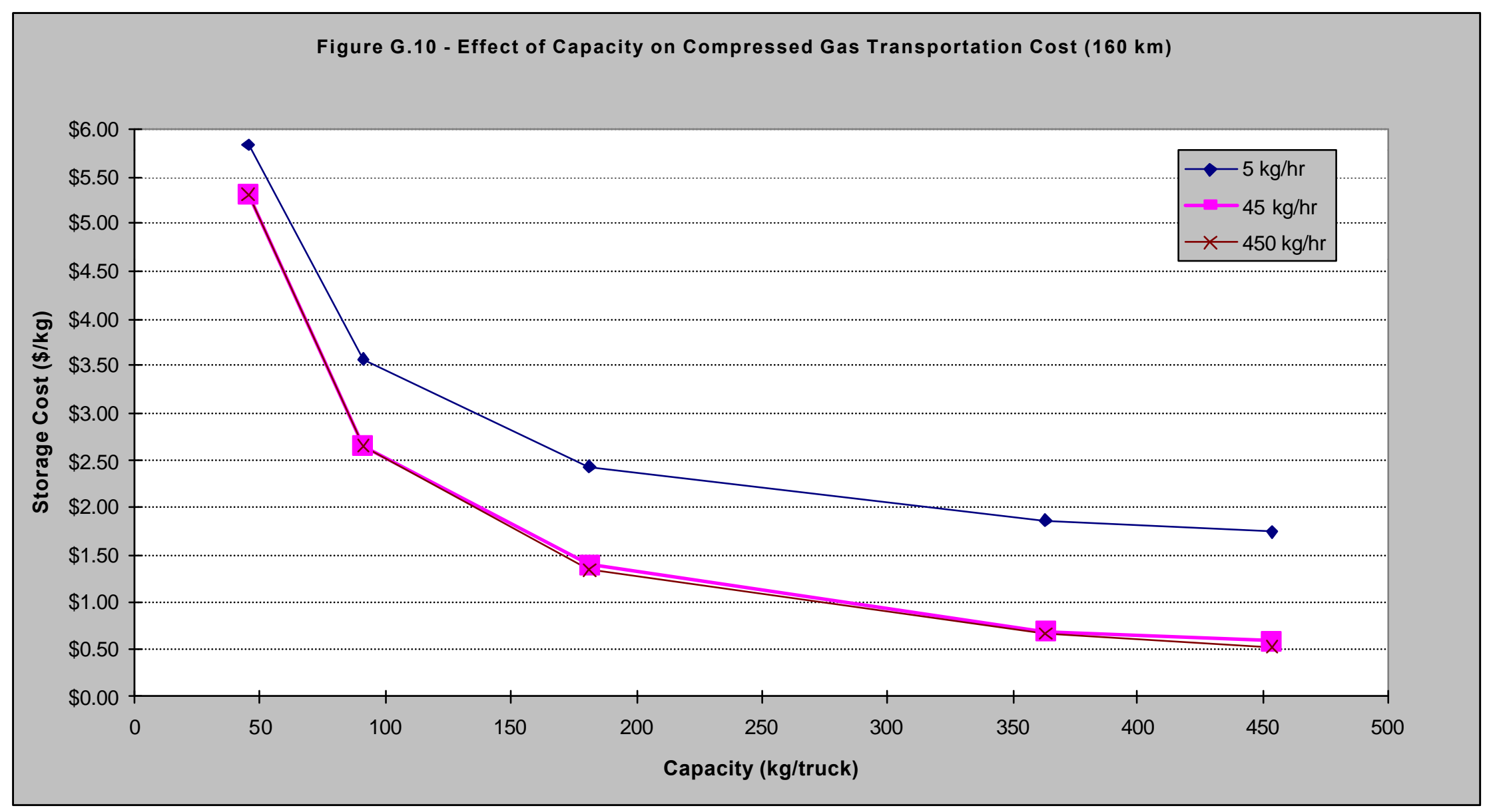

Figure G.10 - Compressed gas transport is very expensive for low capacity (i. e., low pressure) trucks. 


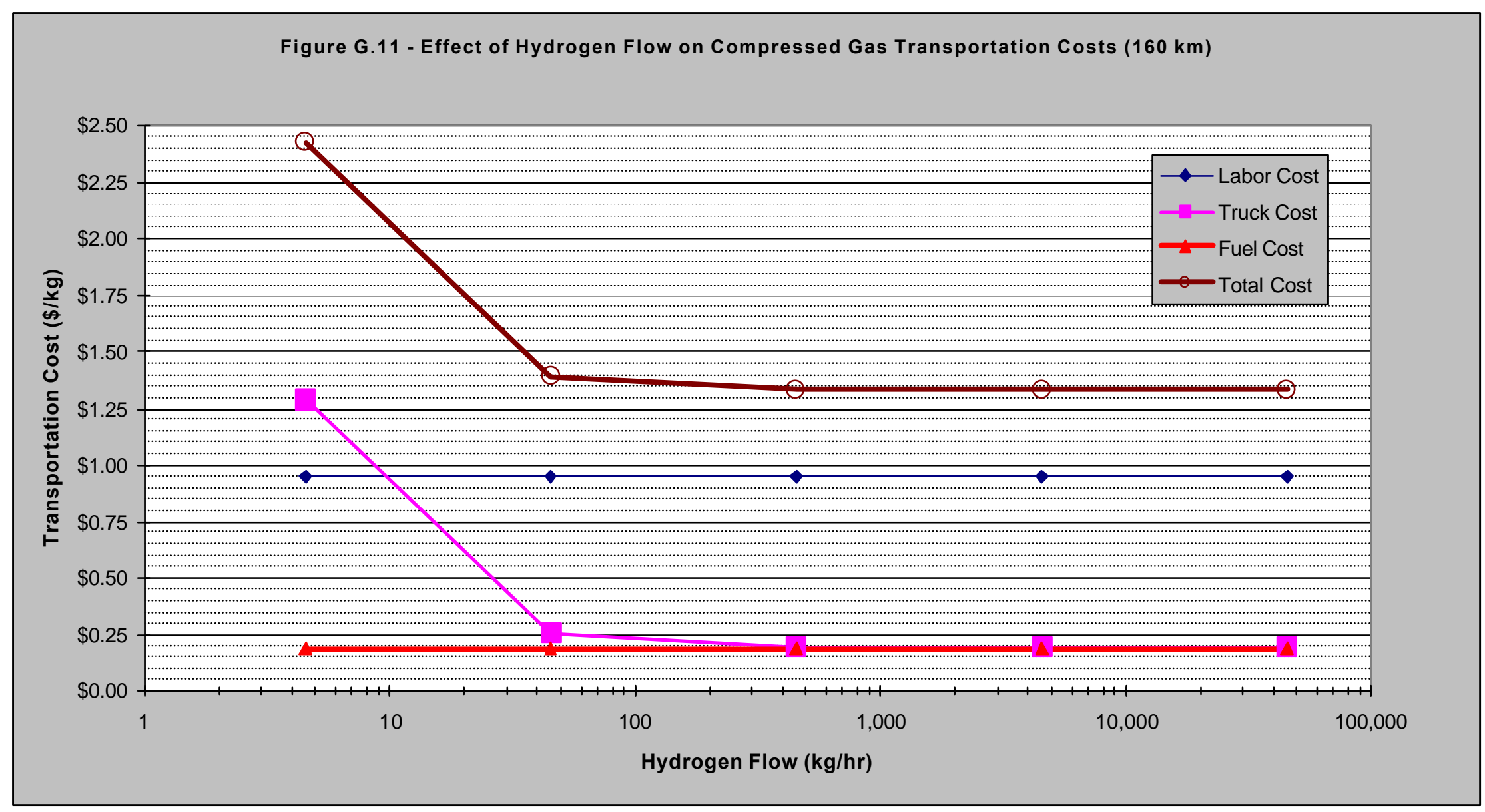

Figure G.11 - At low production rates, the truck is underutilized and represents a large expense. 


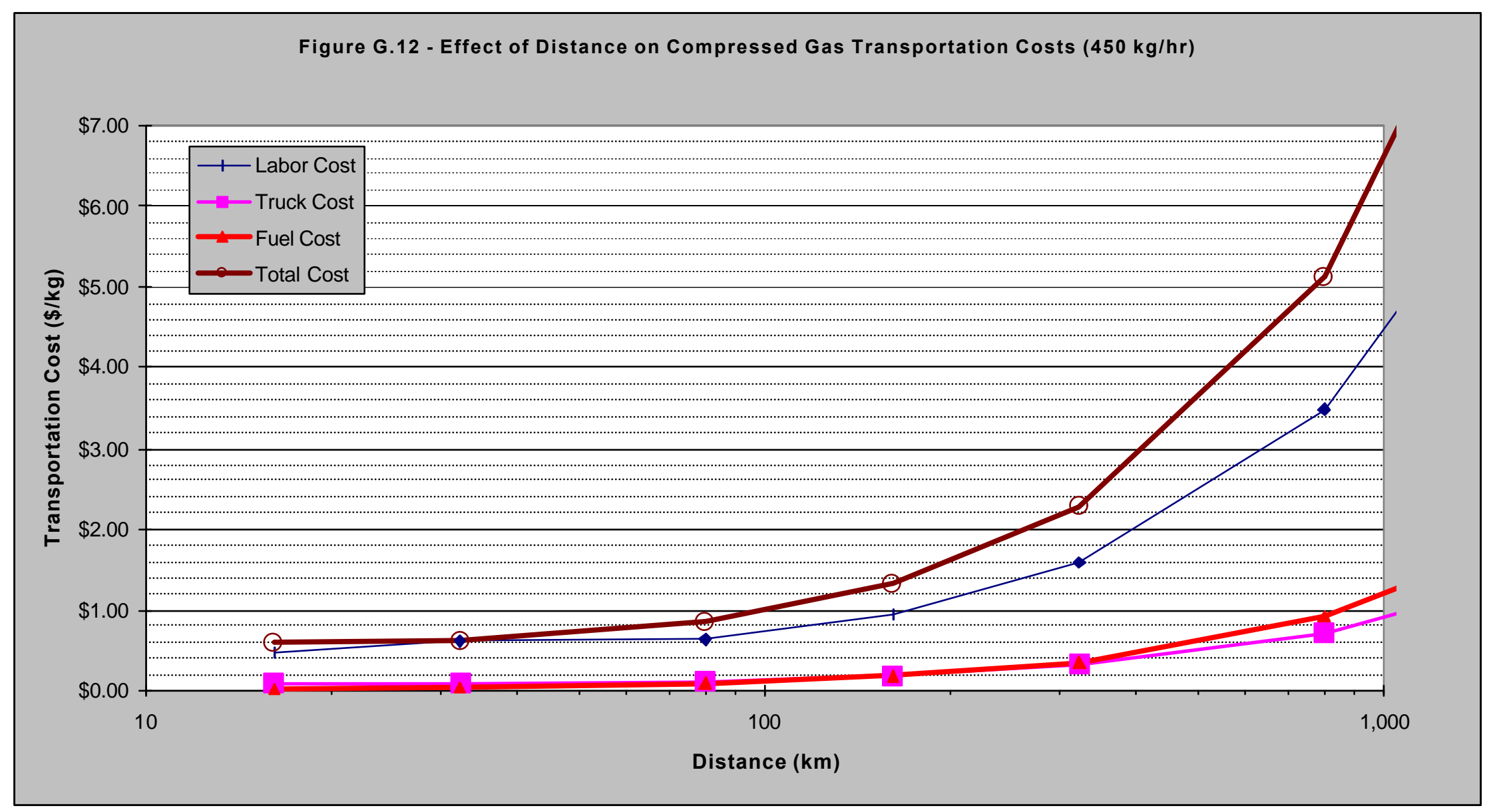

Figure G.12 - Labor costs quickly increase with distance. 


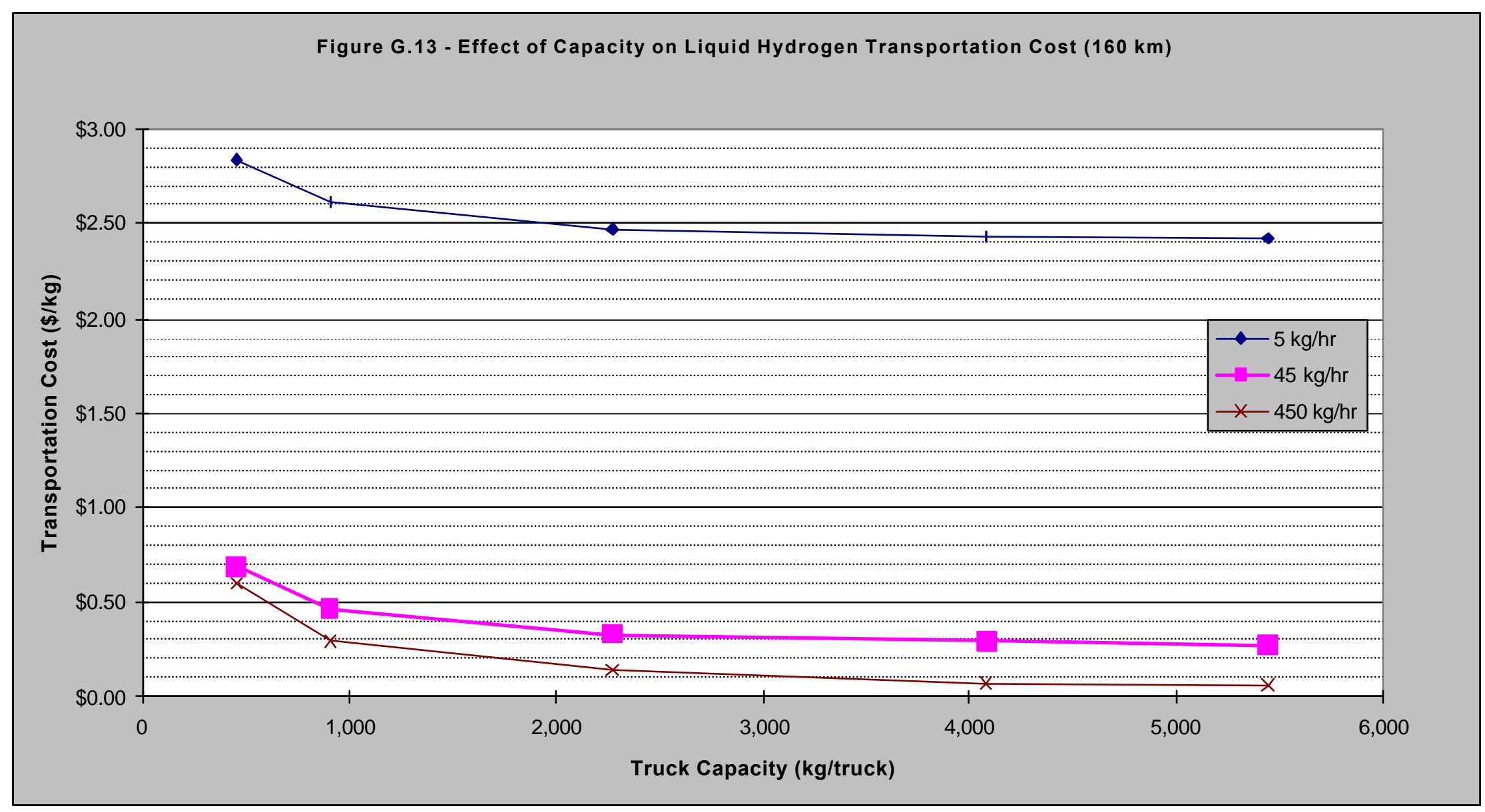

Figure G.13 - Truck capacity is less important with liquid hydrogen transport since a large amount of hydrogen is carried, even at low capacities. 


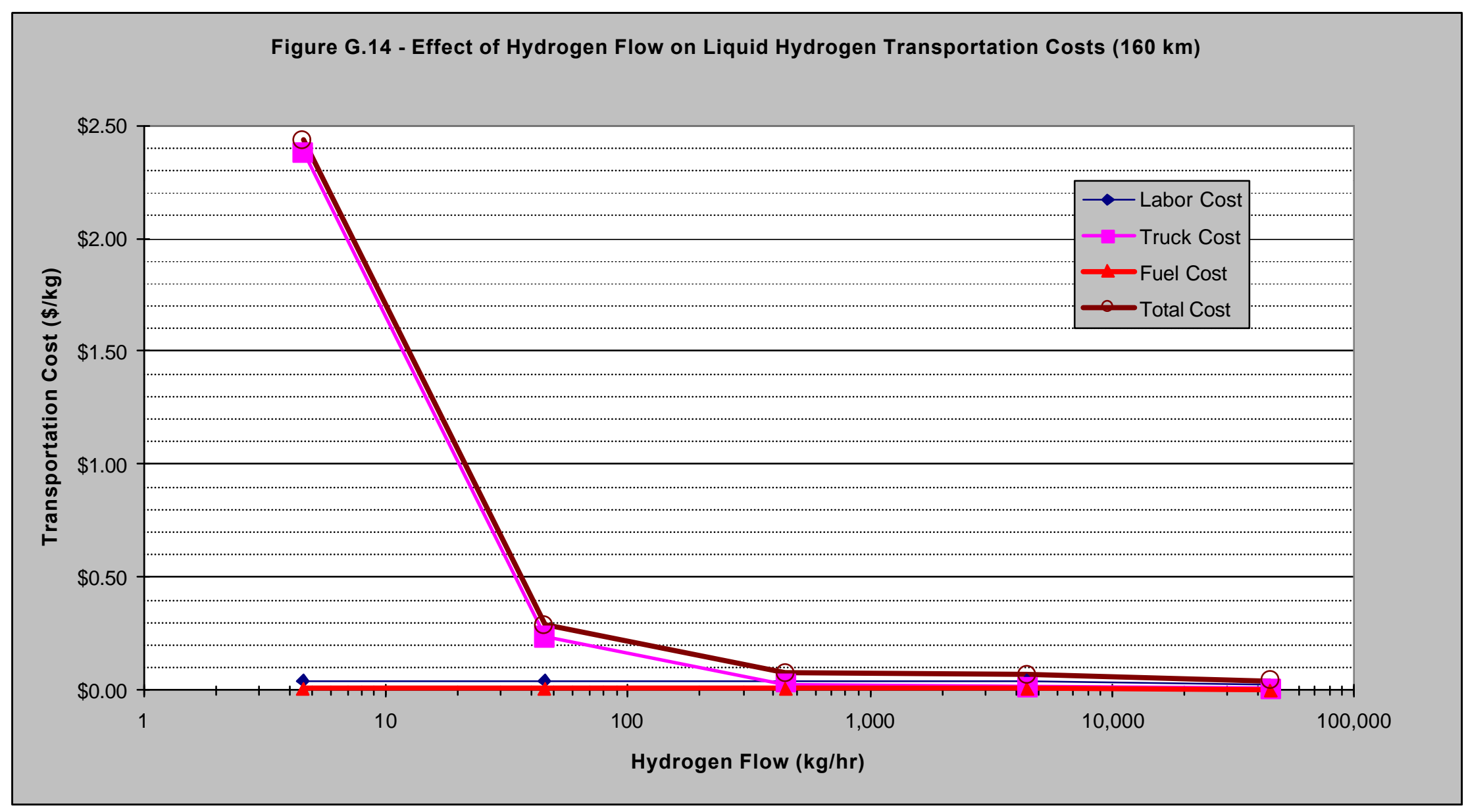

Figure G.14 - At low production rates, truck capital costs are high, but drop as more hydrogen is transported. 


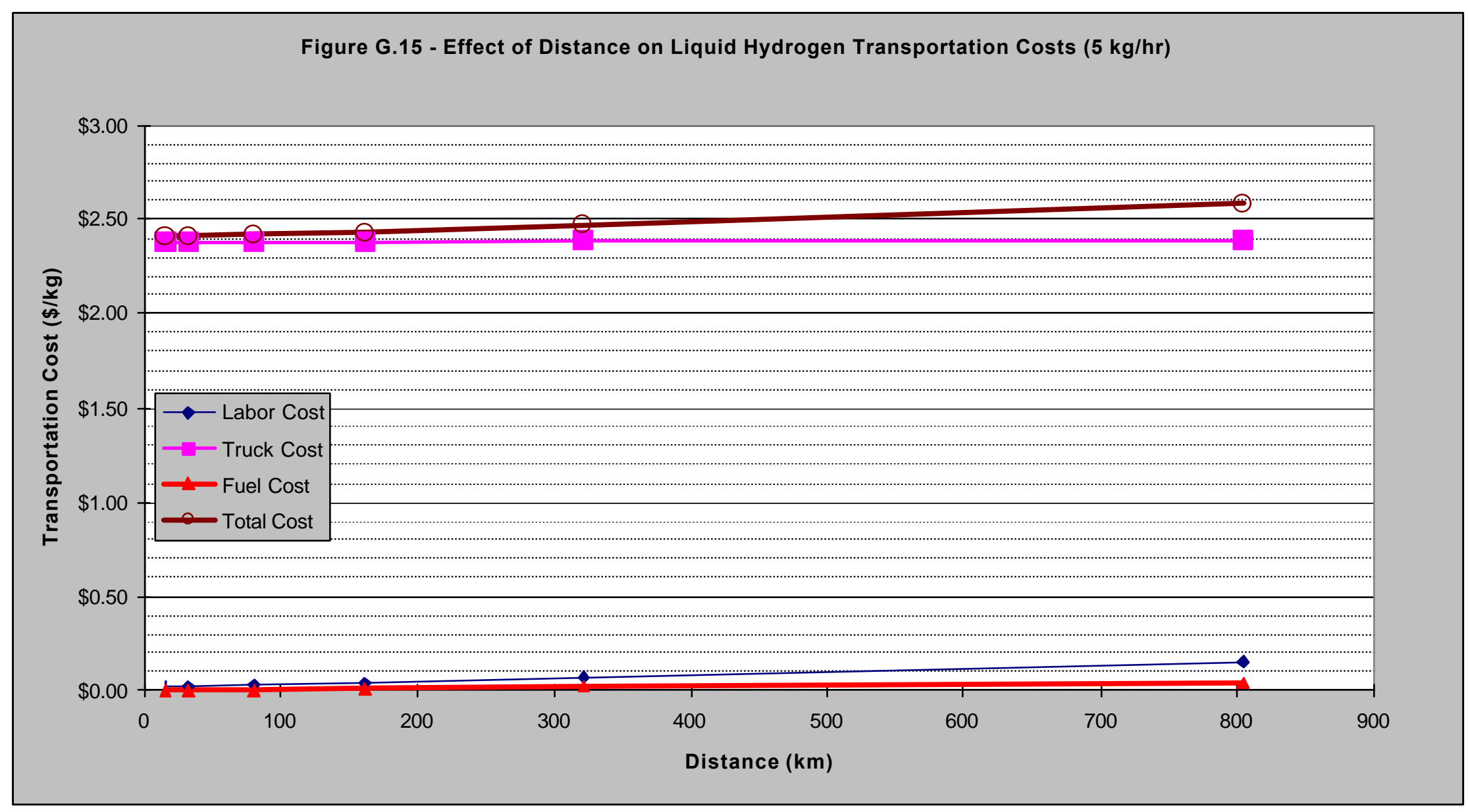

Figure G.15 - At low flows, distance has little effect since trips are infrequent. 


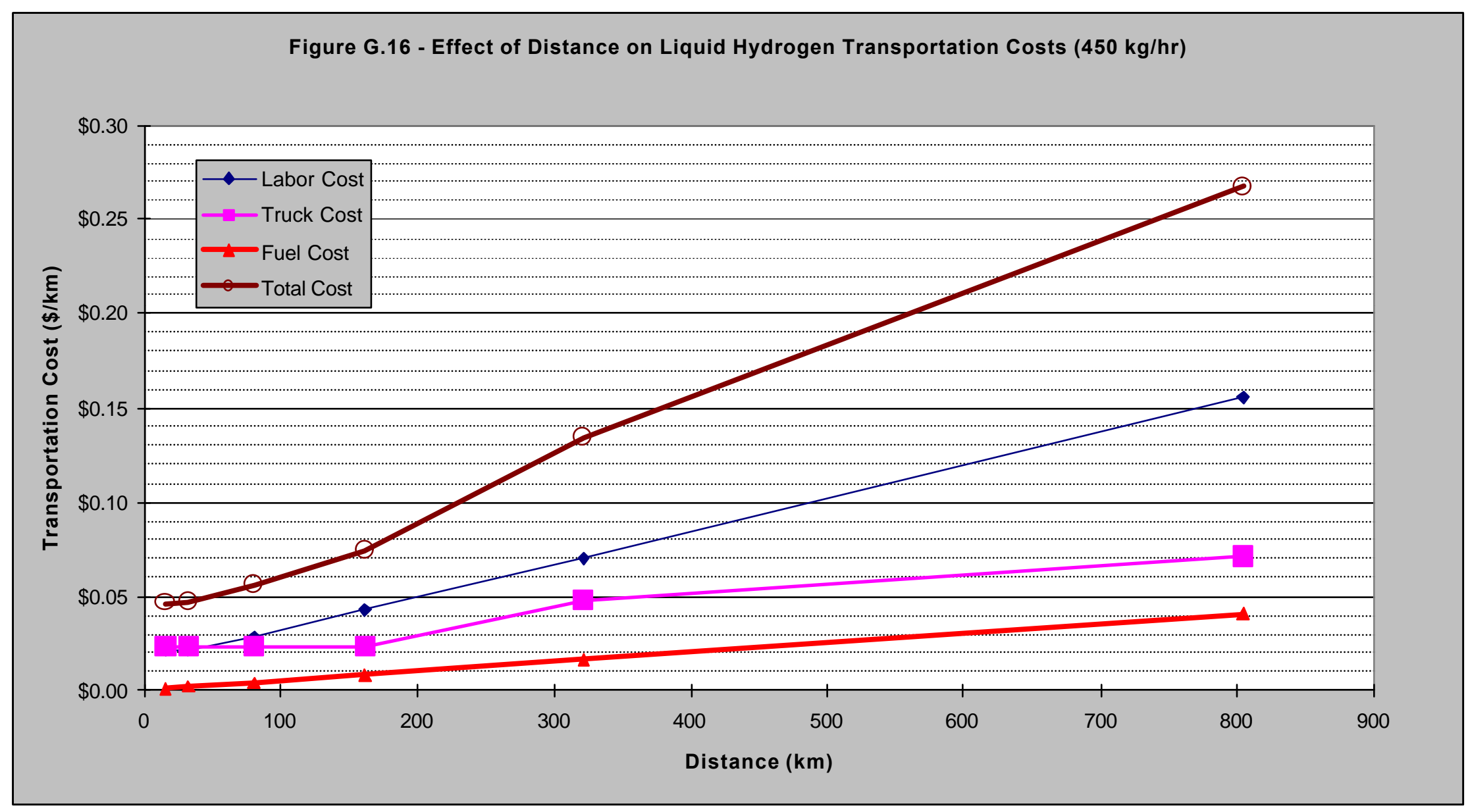

Figure G.16 - At higher flows, labor costs dominate transport costs. 


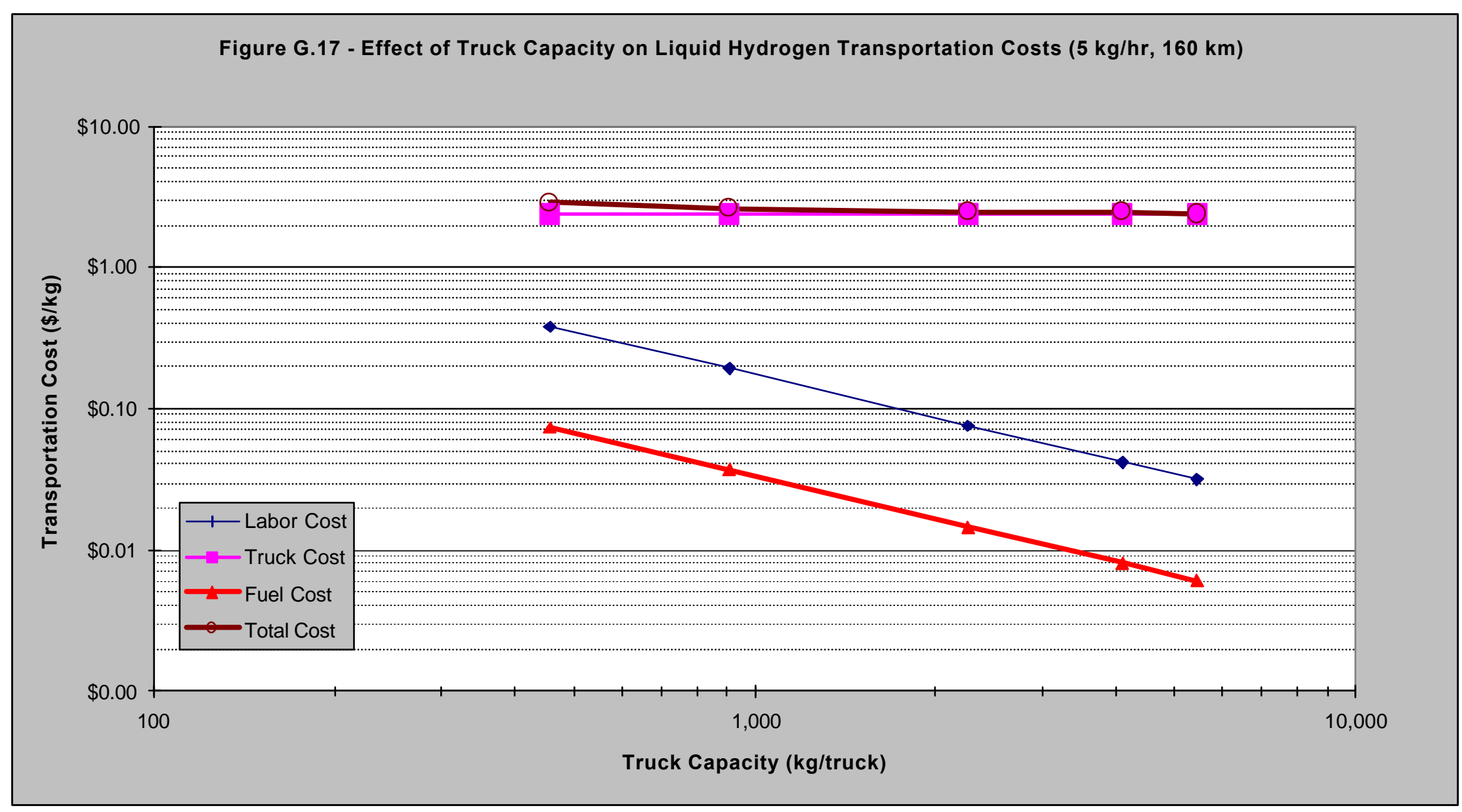

Figure G.17 - Liquid hydrogen truck capital costs dominate at low production rates. 


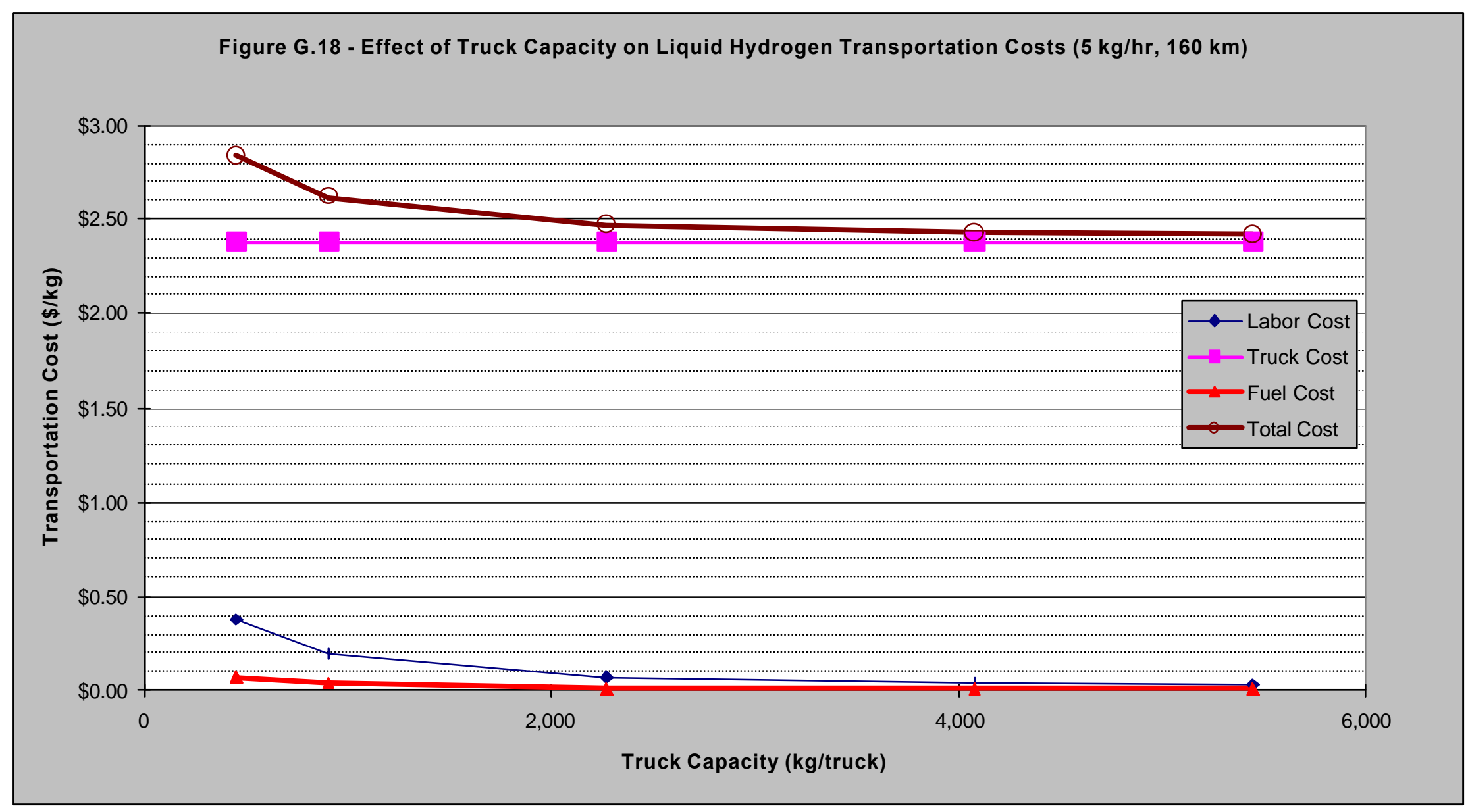

Figure G.18 - Truck capacity has little effect at low production rates. 


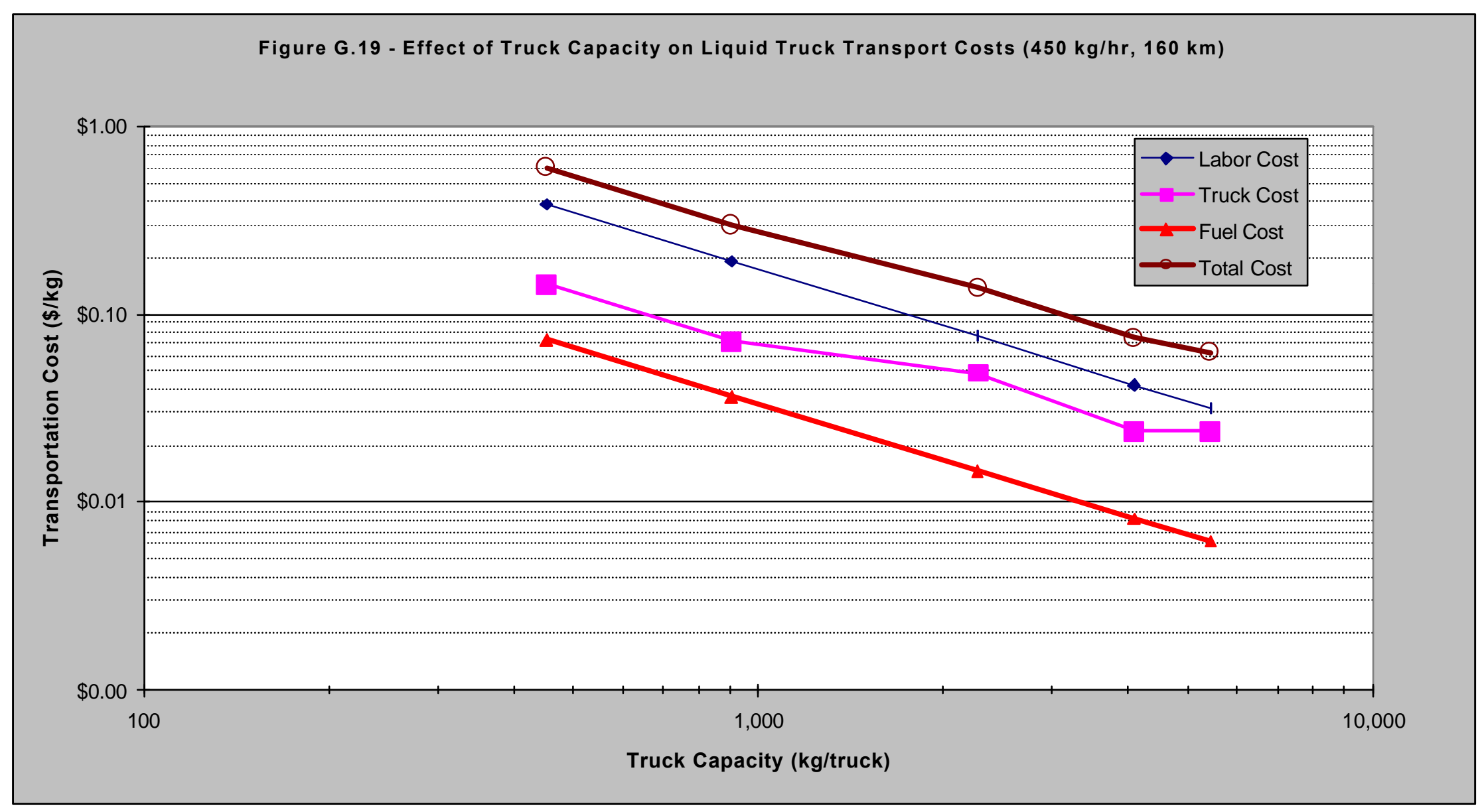

Figure G.19 - Truck capital costs are not linear--discontinuities occur when the number of trucks increases. 


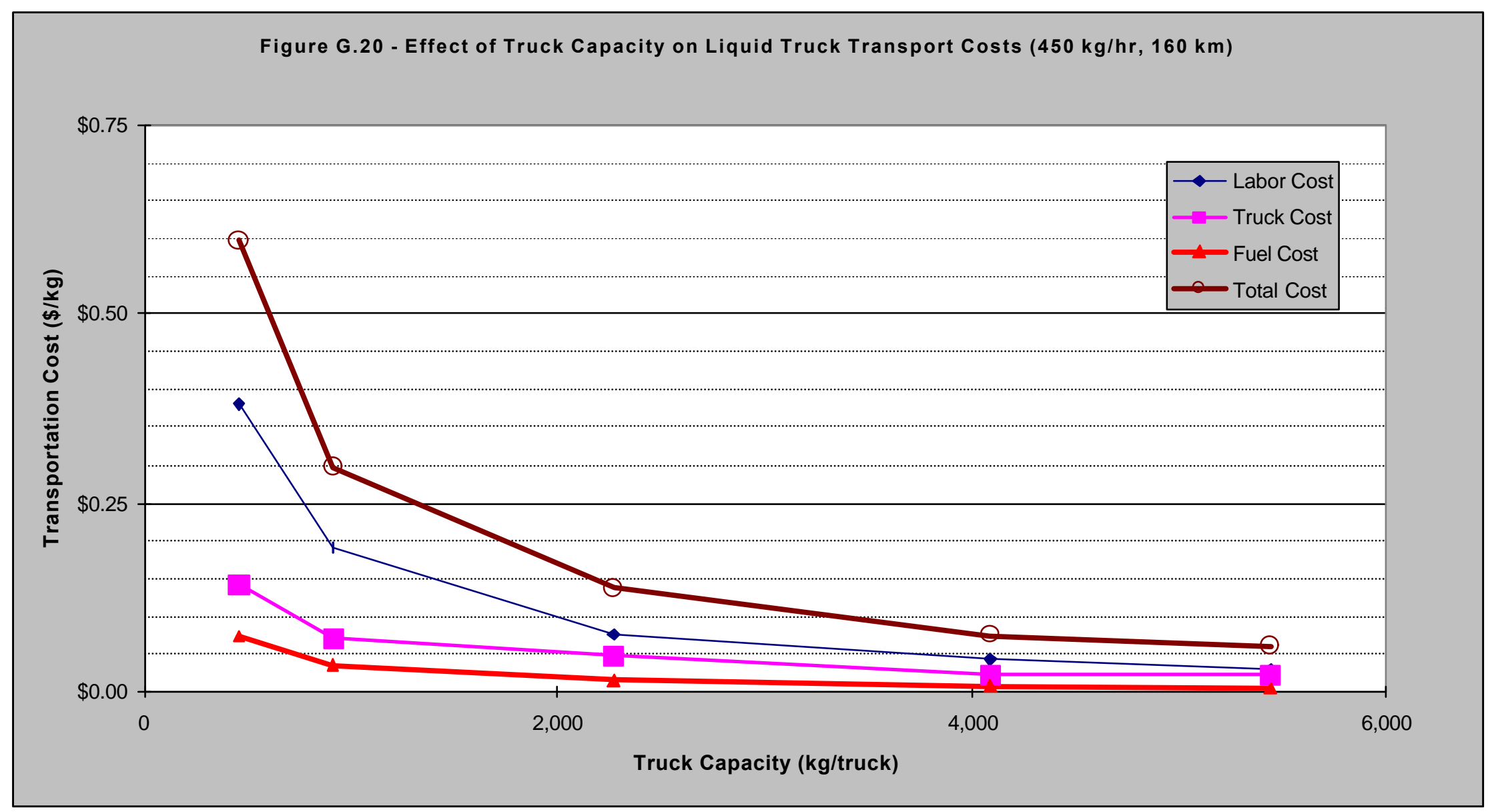

Figure G.20 - Increased truck capacities produce savings in all cost areas. 


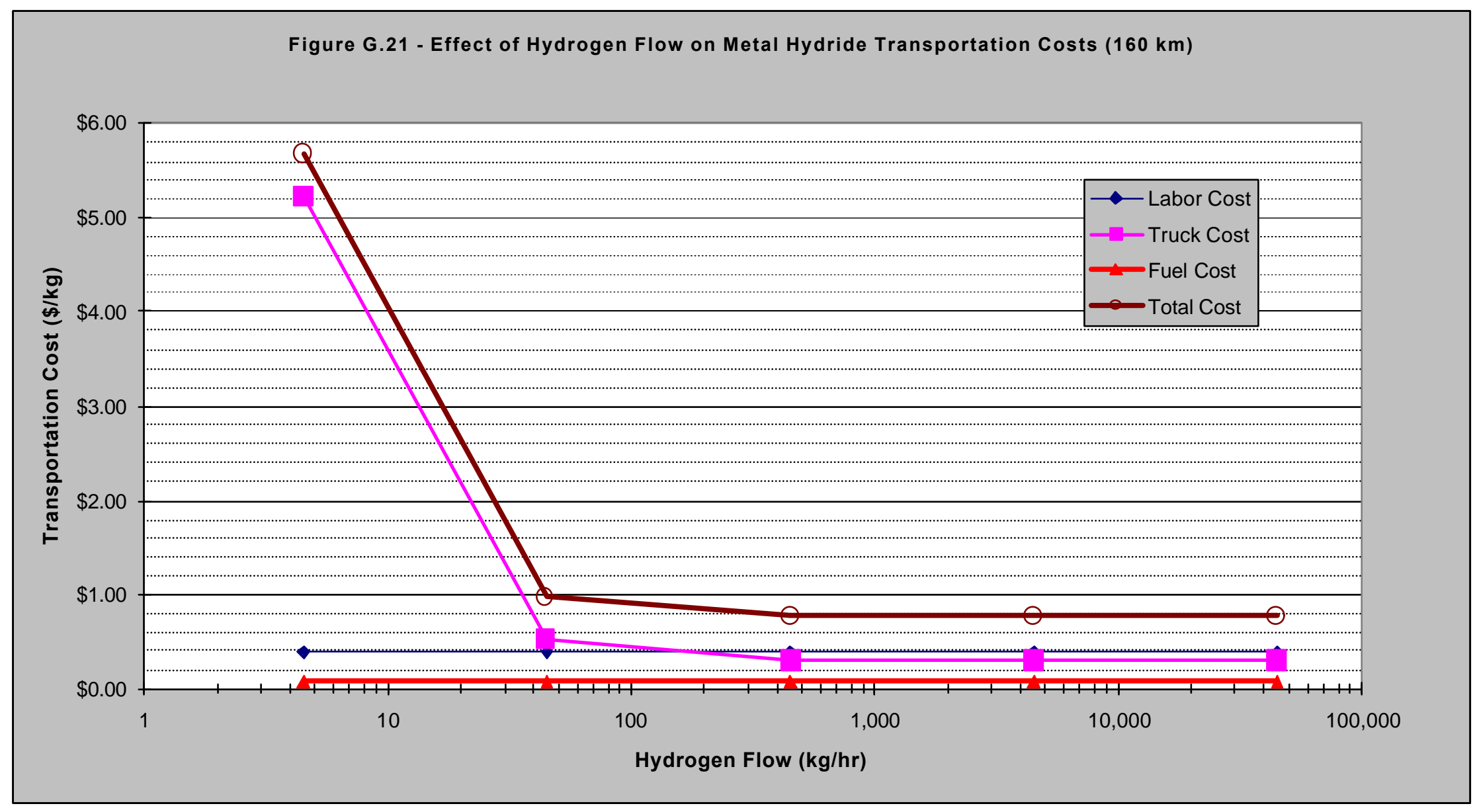

Figure G.21 - Hydride truck capital costs dominate at low production rates. 


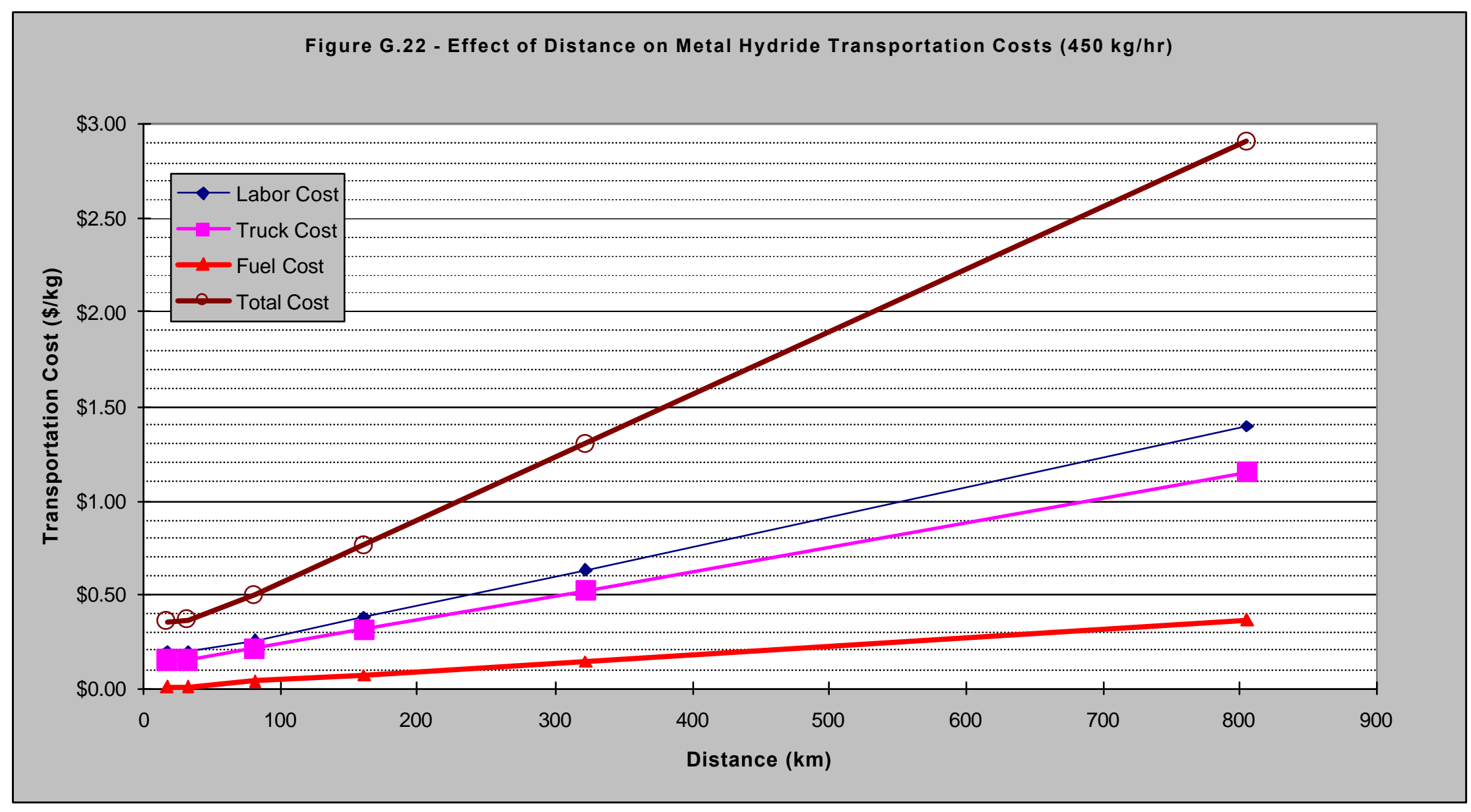

Figure G.22 - At medium production rates, labor is the highest cost of delivery. 


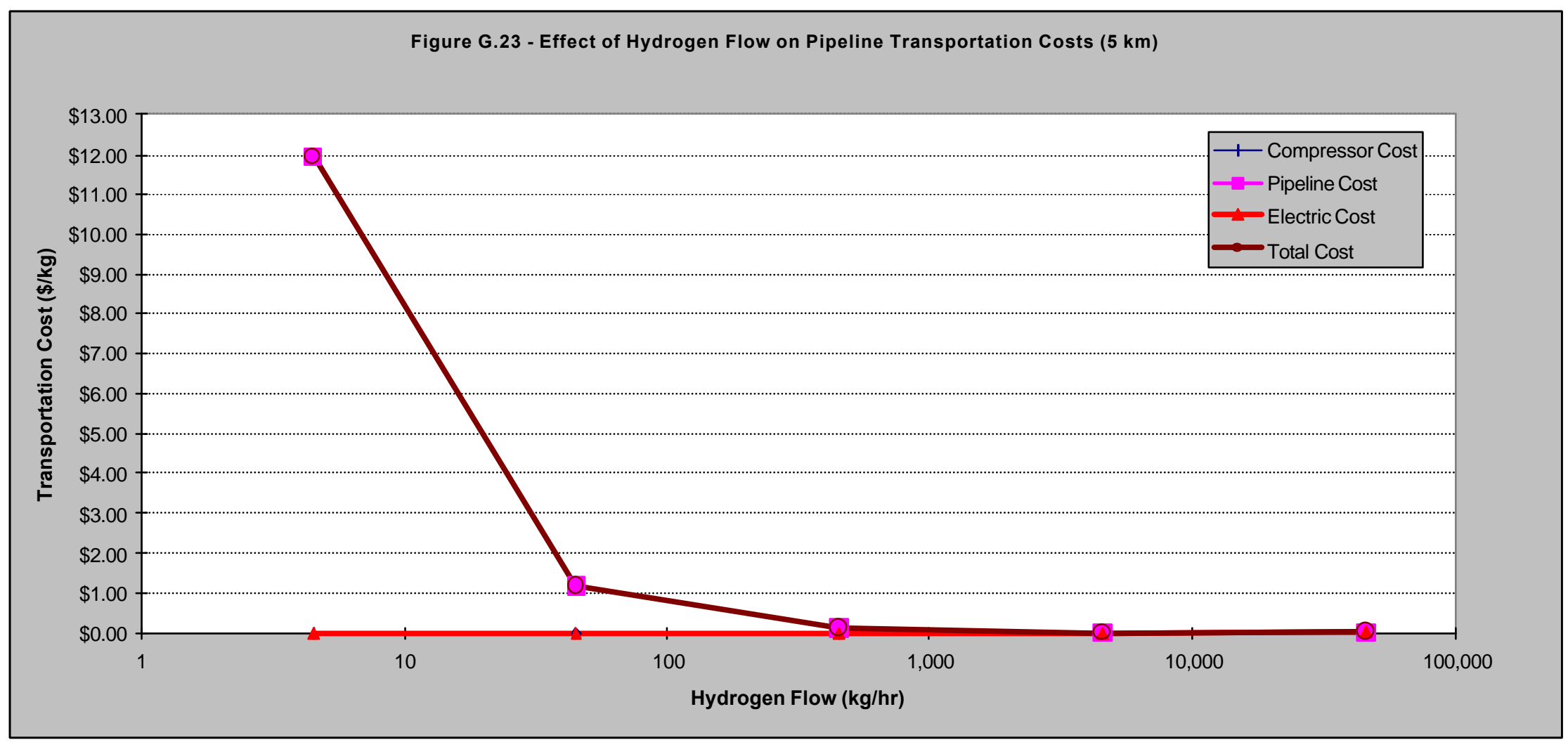

Figure G.23 - At low flows, pipeline costs are high, even for short distances, but drop with increased flows. 


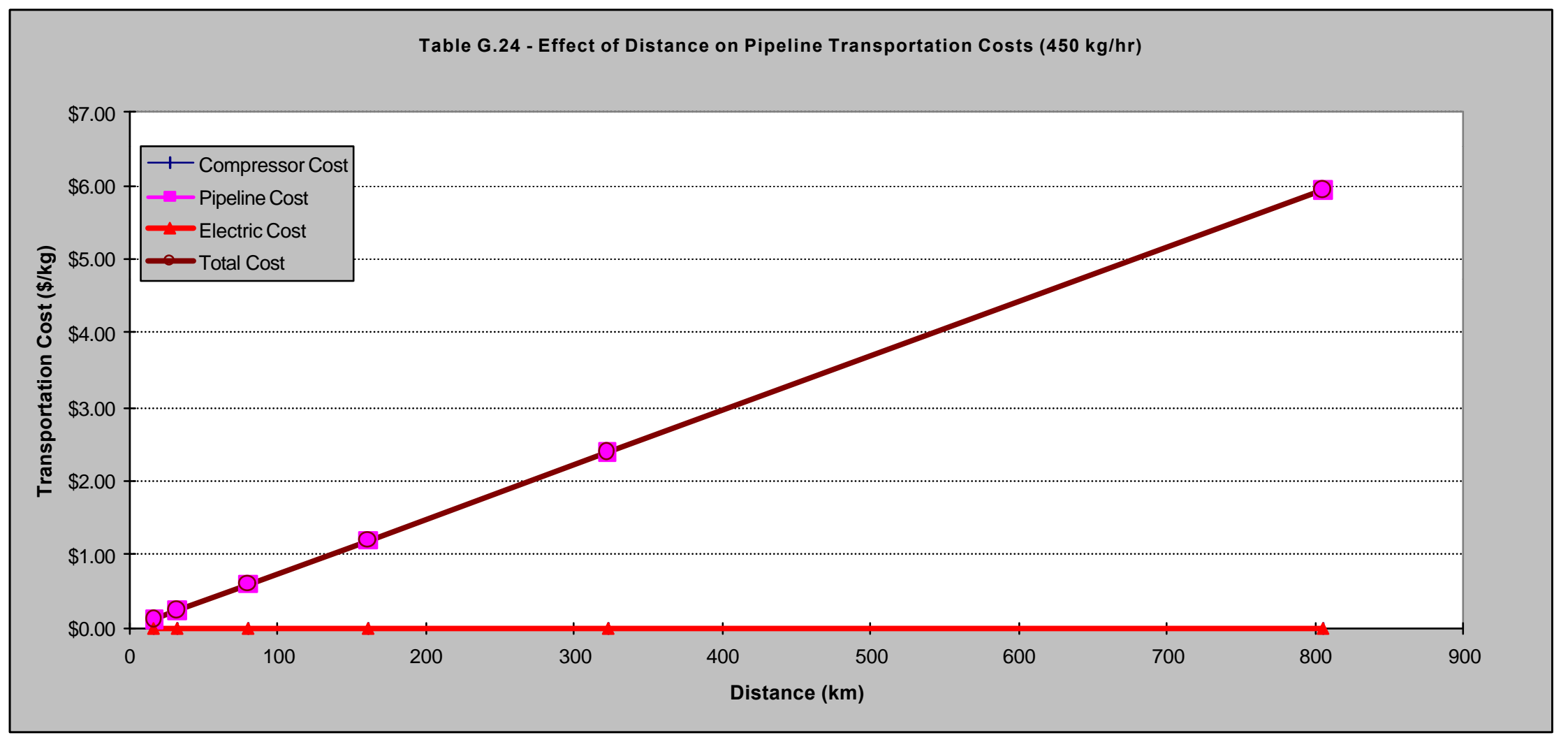

Figure G.24 - Pipeline delivery costs are directly related to the pipeline installation and construction costs. 


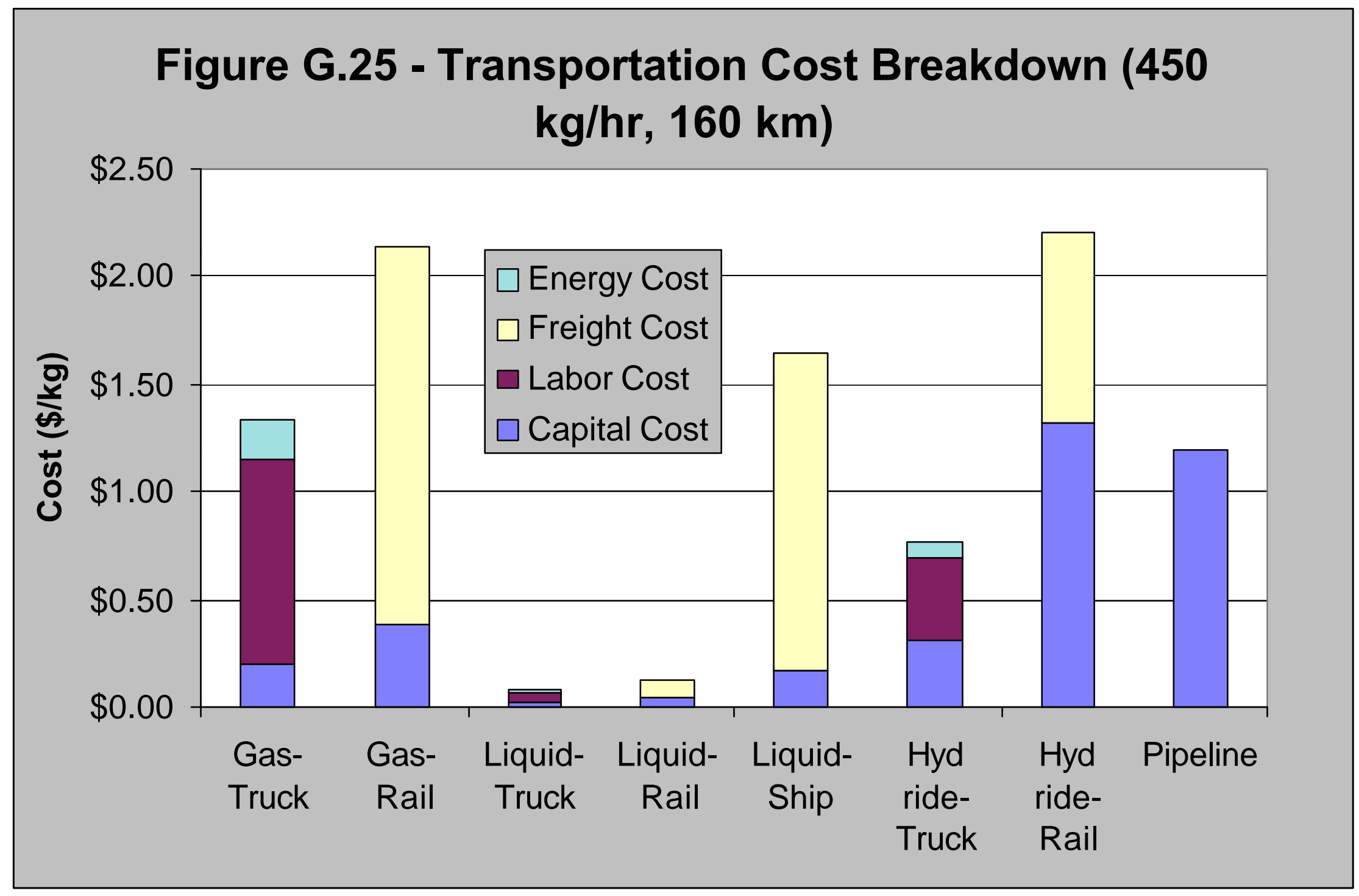

Figure G.25 - Liquid hydrogen delivery by truck or rail is the cheapest delivery option for a medium sized hydrogen facility. 


\section{APPENDIX H - COMBINED STORAGE AND TRANSPORT COSTS}

H.1 Low production rate \& short delivery distance.

H.2 Low production rate \& long delivery distance.

H.3 High production rate \& short delivery distance.

H.4 High production rate \& long delivery distance.

Appendix $\mathrm{H}$ contains figures showing the contributions of both the hydrogen storage and the hydrogen transportation costs for the four cases shown above. Costs for eleven combinations of storage and transport options were examined, plus the option of using a pipeline without any storage. For the low production rate, $45 \mathrm{~kg} / \mathrm{h}(100 \mathrm{lb} / \mathrm{h})$ was used. The high production rate was $4,500 \mathrm{~kg} / \mathrm{h}(10,000 \mathrm{lb} / \mathrm{h})$. The two delivery distances used were $16 \mathrm{~km}(10 \mathrm{mi})$ and $800 \mathrm{~km}(500$ $\mathrm{mi})$. 


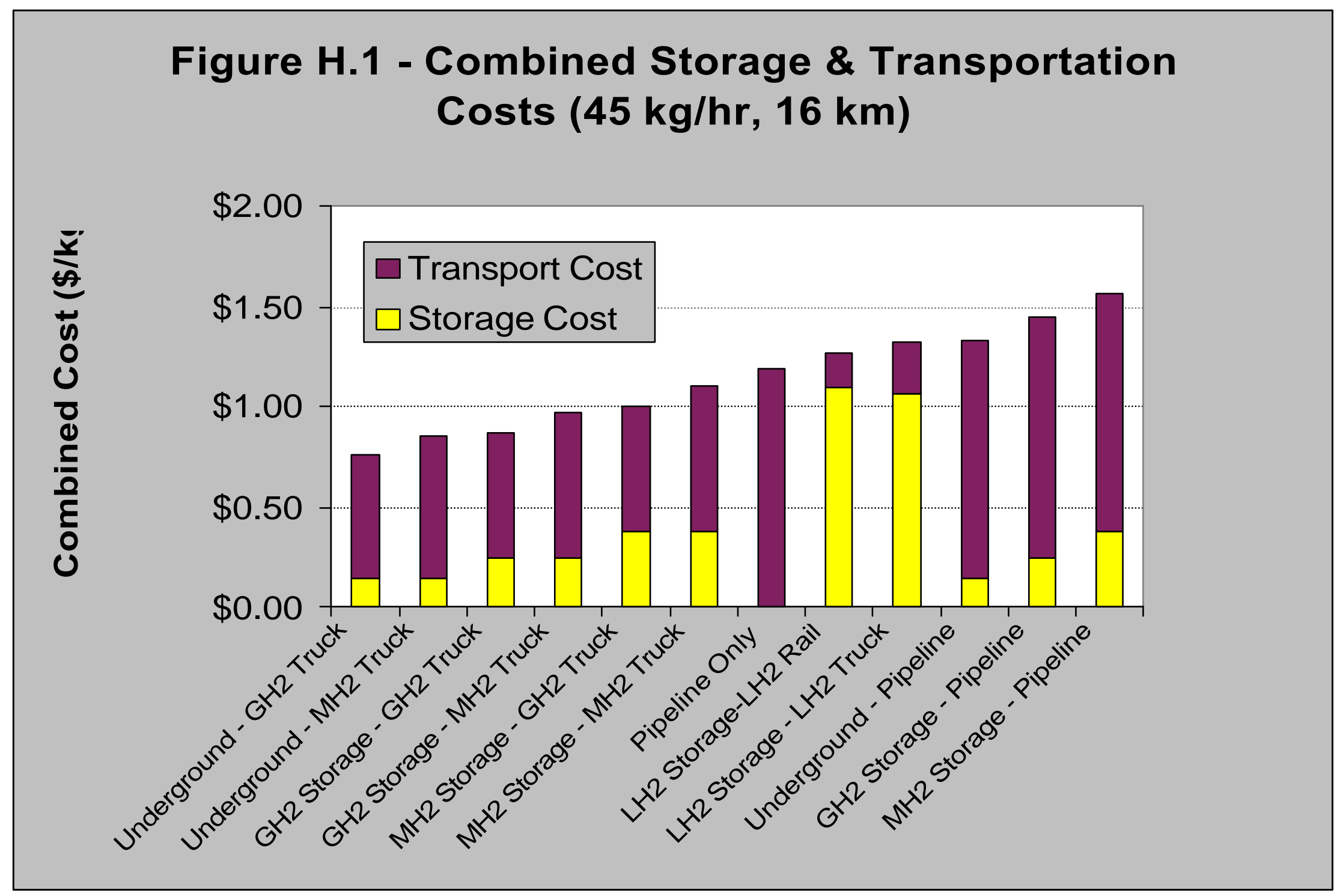

Figure H.1 - For low hydrogen production rates and short delivery distances, compressed gas is the cheapest, but there are several options. 


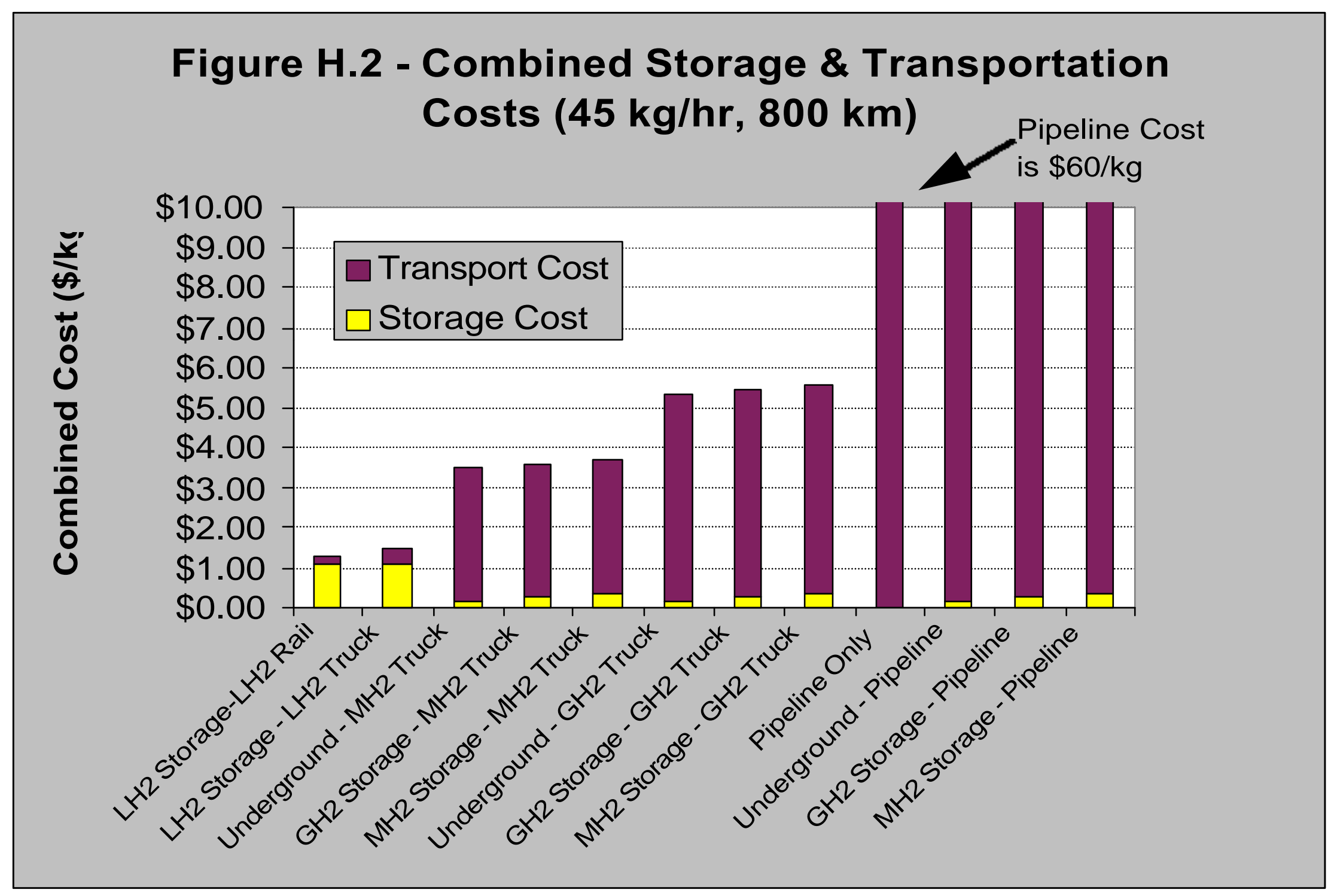

Figure H.2 - For low production rates and long distances, liquid hydrogen is the clear winner. 


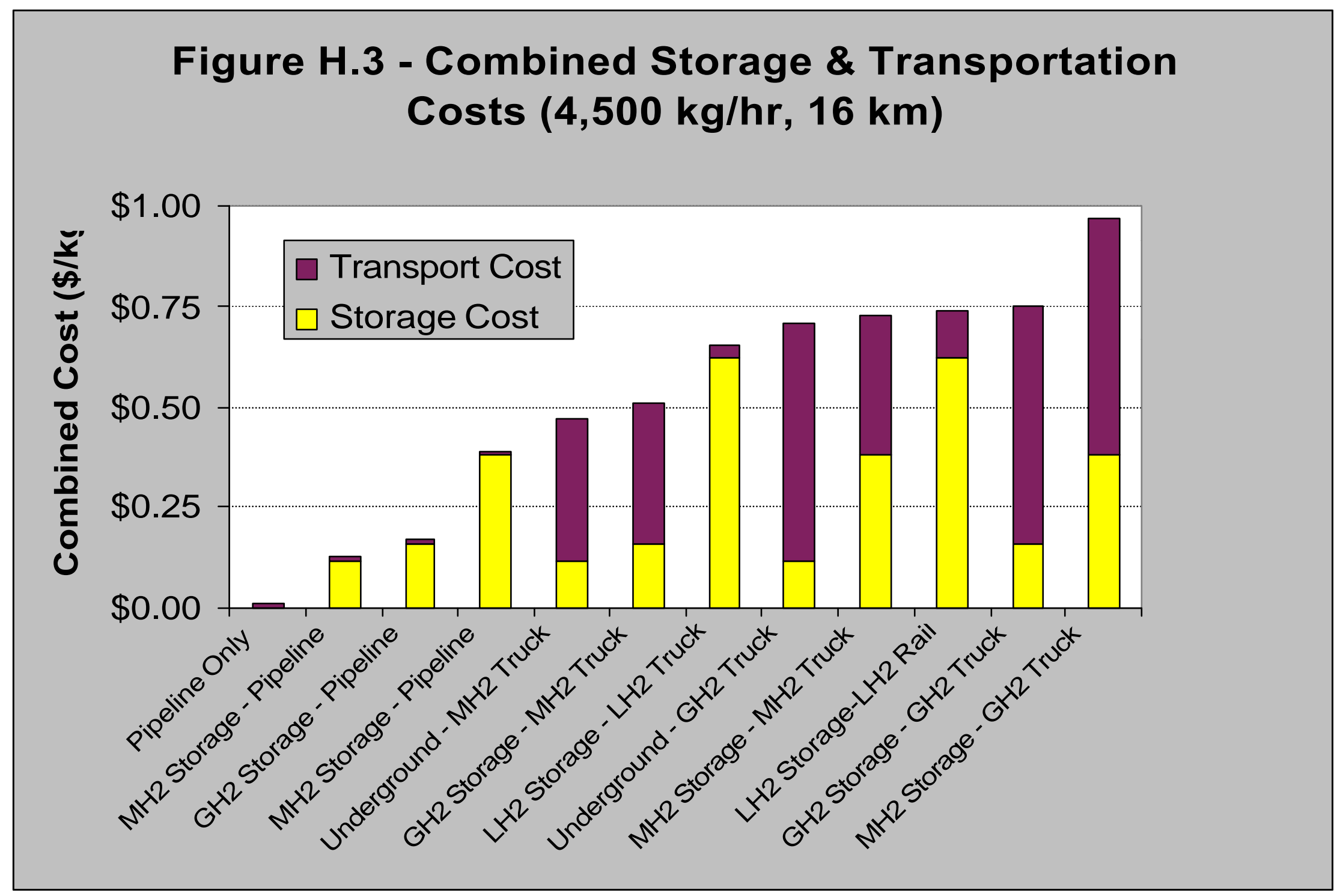

Figure H.3 - For high production rates and short distances, pipeline delivery is very inexpensive. 


\section{Figure H.4 - Combined Storage \& Transportation Costs $(4,500 \mathrm{~kg} / \mathrm{hr}, 800 \mathrm{~km})$}

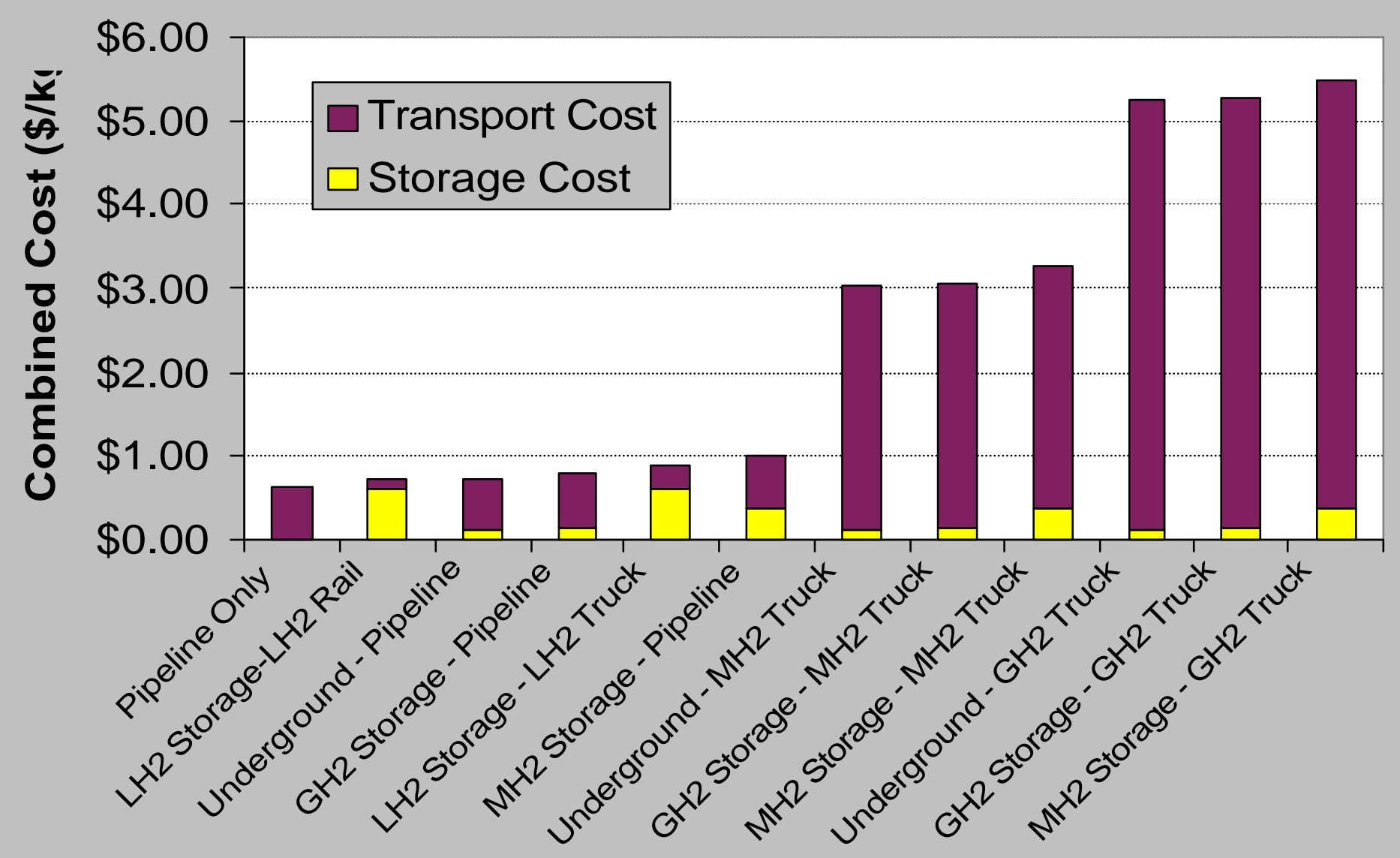

Figure H.4 - For large production rates and long distances, pipeline delivery and liquid hydrogen are the main options. 
Public reporting burden for this collection of information is estimated to average 1 hour per response, including the time for reviewing instructions, searching existing data sources, gathering and maintaining the data needed, and completing and reviewing the collection of information. Send comments regarding this burden estimate or any other aspect of this Davis Highway, Suite 1204, Arlington, VA 22202-4302, and to the Office of Management and Budget, Paperwork Reduction Project (0704-0188), Washington, DC 20503.
1. AGENCY USE ONLY (Leave blank)

2. REPORT DATE
3. REPORT TYPE AND DATES COVERED
November 1998
Technical Report

\section{TITLE AND SUBTITLE}

Costs of Storing and Transporting Hydrogen

5. FUNDING NUMBERS

HY914041

\section{6. $\operatorname{AUTHOR}(S)$}

W.A. Amos

7. PERFORMING ORGANIZATION NAME(S) AND ADDRESS(ES)

National Renewable Energy Laboratory

1617 Cole Boulevard

Golden, CO 80401-3393

9. SPONSORING/MONITORING AGENCY NAME(S) AND ADDRESS(ES)

National Renewable Energy Laboratory

1617 Cole Boulevard

Golden, CO 80401-3393

8. PERFORMING ORGANIZATION REPORT NUMBER

10. SPONSORING/MONITORING AGENCY REPORT NUMBER

NREL/TP-570-25106

\section{SUPPLEMENTARY NOTES}

\section{2a. DISTRIBUTION/AVAILABILITY STATEMENT}

National Technical Information Service

U.S. Department of Commerce

5285 Port Royal Road

Springfield, VA 22161

13. ABSTRACT (Maximum 200 words) An analysis was performed to estimate the costs associated with storing and transporting hydrogen. These costs can be added to a hydrogen production cost to determine the total delivered cost of hydrogen. Storage methods analyzed included compressed gas, liquid hydrogen, metal hydride, and underground storage. Major capital and operating costs were considered over a range of production rates and storage times.
14. SUBJECT TERMS
15. NUMBER OF PAGES
219

hydrogen, compressed gas, liquid hydrogen, metal hydride, underground storage

18. SECURITY CLASSIFICATION OF THIS PAGE
19. SECURITY CLASSIFICATION OF ABSTRACT
16. PRICE CODE
17. SECURITY CLASSIFICATION OF REPORT 